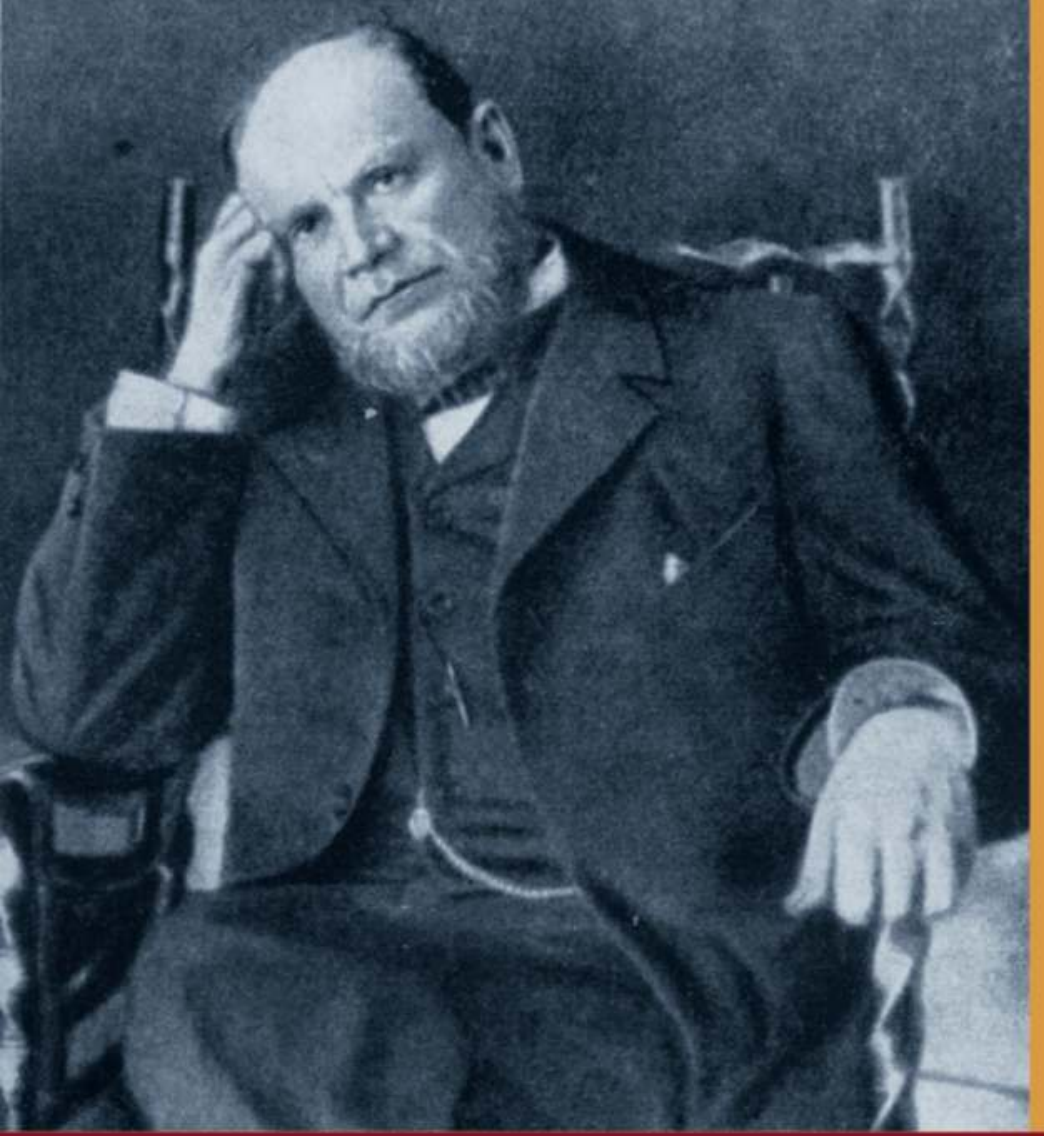

\title{
ANATOLIJ F. KONI (1844-1927) ZWISCHEN HERRSCHER UND VOLK
}

Ein liberaler Jurist und seine autobiografische Praxis in Zarenreich und Sowjetunion 


\title{
IMPERIAL SUBJECTS
}

Autobiographik und Biographik

in imperialen Kontexten

\author{
Herausgegeben von \\ Martin Aust, Robert Luft, Maurus Reinkowski, \\ Frithjof Benjamin Schenk
}

Band 2 
Carla Cordin

\section{ANATOLIJ F. KONI \\ (1844-1927) \\ ZWISCHEN HERRSCHER UND VOLK}

Ein liberaler Jurist und seine autobiografische Praxis in Zarenreich und Sowjetunion 
Publiziert mit Unterstützung des Schweizerischen Nationalfonds zur Förderung der wissenschaftlichen Forschung

Die Druckvorstufe dieser Publikation wurde vom Schweizerischen Nationalfonds zur Förderung der wissenschaftlichen Forschung unterstützt.

Bibliografische Information der Deutschen Nationalbibliothek : Die Deutsche Nationalbibliothek verzeichnet diese Publikation in der Deutschen Nationalbibliografie ; detaillierte bibliografische Daten sind im Internet über http://dnb.d-nb.de abrufbar.

(C 2019 by Böhlau Verlag GmbH \& Cie, Lindenstraße 14, D-50674 Köln This work is licensed under the Creative Commons Attribution-NonCommercial 4.0 International License. To view a copy of this license, visit http://creativecommons.org/licenses/by-nc/4.0/.

Umschlagabbildung:

Автор : unknown ; photo retake by George Shuklin; re-photo by Victor Vizu Государственный музей политической истории России, Общественное достояние, https://commons. wikimedia.org/w/index.php?curid=6636457

Korrektorat : Claudia Holtermann, Bonn

Einbandgestaltung : Michael Haderer, Wien Satz : büro mn, Bielefeld

Vandenhoeck \& Ruprecht Verlage | www.vandenhoeck-ruprecht-verlage.com

ISBN (Print) 978-3-412-51372-6

ISBN (OA) 978-3-412-51374-0

https://doi.org/10.7788/9783412513740 


\section{Inhalt}

Schreibweisen und Datierungen $\ldots \ldots \ldots \ldots$

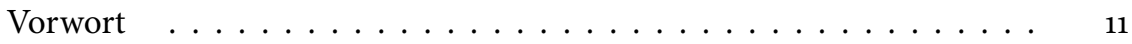

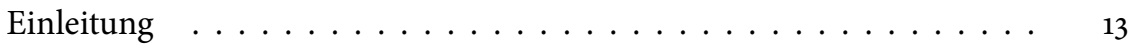

Historischer Hintergrund, Erkenntnisinteresse und Methodik . 13

Forschungskontext, Konis biografische Koordinaten und Aufbau

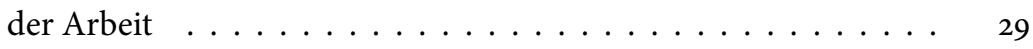

\section{TEIL EINS}

Der Fall Vera Zasulič - ein Mahnbeispiel für mangelnde Kollegialität . . $\quad 51$

1.1 50 Jahre Gerichtsreform 1914: biografische Jubiläumsschriften und autobiografische Erfolgsgeschichten für ein verunsichertes

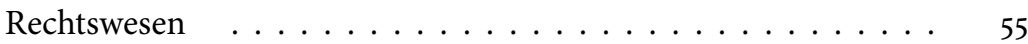

1.1.1 Eine Generation „edler"Juristen _.............. 71

Professionalisierung der Rechtsberufe in Russland nach 1864 . . 82

1.1.2 Die Juristen als "gesellschaftliche Akteure“ . . . . . . . . . . 92

Vernetzung in der Obščestvo . . . . . . . . . . . . . . . . . . . . . . . . . 97

1.1.3 Koni als "edler" Jurist . . . . . . . . . . . . . . . . 110

Charismatisierung des Biografen ................... 115

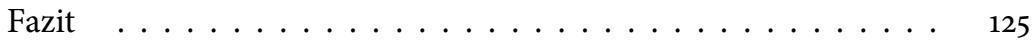

\section{TEIL ZWEI}

Der Fall Vera Zasulič - ein politisches Lehrstück . . . . . . . . . . . 133

2.1 Memoiristische Rückschau auf ein Berufsleben unter autokratischer Herrschaft . . . . . . . . . . . . . . . . . . . 139

2.1.1 Konis „Wahrheit" für den Zaren . . . . . . . . . . . . . . . 146

Einordnung in das liberale Umfeld . . . . . . . . . . . . . . . 163

2.1.2 Gnadengesuche: Autokratie und Justiz . . . . . . . . . . . . . . . . . . 174

Fazit .......................... 181

2.2 Autobiografisches Ringen im Zeichen der ersten Russischen Revolution . . . . . . . . . . . . . . 184 
2.2.1 Konis politische Ambitionen . . . . . . . . . . . . . 190

Polarisierung in Justiz und Politik um 1905 . . . . . . . . . . . . 192

2.2.2 Gewandeltes Selbstverständnis: das „Zasulič-Narrativ“ . . . . . . 206

2.2.3 Biografien von Peers als Probeläufe $\ldots \ldots \ldots \ldots . \ldots . \ldots 211$

Fazit ......................... 217

2.3 Politische Erinnerung an das Zarenreich in der Sowjetunion _ . $\quad 222$

2.3.1 Plädoyer für die Berücksichtigung der „Bedingungen von Ort und Zeit" . . . . . . . . . . . . . . . . . . 232

„Pro“ und „Contra“: Konis Entscheid für die Erinnerungsmission 244

Mission mit Hindernissen: (Selbst-)Zensur . . . . . . . . . . 256

2.3.2 Erinnerte politische Haltungen in einer unklaren

Kommunikationssituation . . . . . . . . . . . . 261

Zwischen Emigranten und Bolschewiki . . . . . . . . . . . 267

Fazit ............................. 279

\section{TEIL DREI}

Der Fall Vera Zasulič - ein Schlaglicht auf die Gesellschaft des späten Zarenreichs ...................... 285

3.1 Puschkins Ehrung 1880: Legitimationssuche in Gesellschaft und Literatur . . . . . . . . . . . . . . . . . . 288

3.1.1 Aneignung der Literaten für die Sache der Justiz . . . . . . . . . . . 298

Transfers zwischen Justiz und Literatur . . . . . . . . . . . 307

3.1.2 Dörfliche „Eigenart“ als Spiegel für die „sogenannte,Gesellschaft“ 312

3.1.3 Fremdversicherung auf Reisen .............. 320

Horizont Schriftsteller: von Tagebüchern und frühen Entwürfen 330

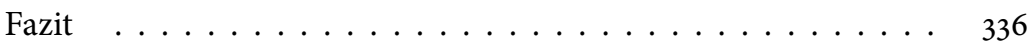

3.2 Öffentliche Literatenporträts und private Überlegungen $\mathrm{zu}$,Volk“ und Intelligencija vor dem Lebensende $\quad \ldots . . . .338$

3.2.1 Verherrlichte Literaten der vorrevolutionären Welt . . . . . . . 347

Künstlerische und wissenschaftliche Vereinigungen in der frühen Sowjetunion . . . . . . . . . . . . . 353

Die „Zuhörer“ erreichen: Koni als Schriftsteller und Vortragender 369

Das Archiv „Puschkinhaus“: Fokus auf die Nachwelt . . . . . . 373

3.2.2 „Volk“ und Intelligencija: Notizen der Enttäuschung . . . . . . . 381

Fazit ............................ 388 
Anatolij Konis autobiografische Praktiken:

Zusammenfassung und Ausblick

Quellen-, Literatur- und Abkürzungsverzeichnis _ . . . . . . . . . 415

Allgemeine Abkürzungen $\ldots \ldots \ldots \ldots \ldots$. . . . . . . 415

Periodika (Abkürzungen) … . . . . . . . . . . . 415

Nachschlagewerke (Abkürzungen) $\ldots \ldots \ldots \ldots \ldots \ldots$

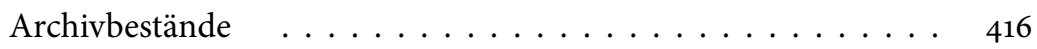

Gedruckte Quellen/Quelleneditionen . . . . . . . . 416

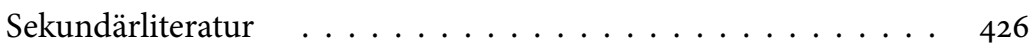

Register $\ldots \ldots \ldots \ldots \ldots \ldots \ldots \ldots \ldots \ldots \ldots \ldots \ldots \ldots$ 



\section{Schreibweisen und Datierungen}

Sofern nicht anders gekennzeichnet, sind alle Übersetzungen aus dem Russischen meine eigenen. Für alle Umschriften aus dem kyrillischen Alphabet wurde die übliche wissenschaftliche Transliteration verwendet. Davon ausgenommen sind Eigennamen und geografische Bezeichnungen, die im Deutschen eingebürgert sind, wie beispielsweise Graf „Pahlen“, „Puschkin“ oder „Charkow“. Wo immer der exakte russische Begriff wichtig scheint, wird er in eckigen Klammern sowohl im Fließtext als auch in Zitaten direkt hinter der deutschen Übersetzung angefügt. Vereinzelt werden in kursiver Form spezifische russische Begrifflichkeiten verwendet, wie beispielsweise Intelligencija oder Duma.

Datierungen erfolgen nach dem jeweils gültigen Kalender. Für Ereignisse von vor 1918 entspricht dies dem julianischen Kalender, der für das 19. Jahrhundert zwölf Tage und für das beginnende 20. Jahrhundert 13 Tage hinter dem gregorianischen Kalender liegt.

Auf dem Umschlag ist eine Porträtaufnahme von Anatolij F. Koni abgebildet. Die Fotografie wurde 1914 in Konis eindrückliche Zusammenstellung seiner biografischen Juristenskizzen integriert, die er zum 50. Jubiläum der Gerichtsreform veröffentlichte. Vgl. ausführlicher zu dieser Publikation, dem fotografischen Porträt und dessen Funktion das Unterkapitel „Charismatisierung des Biografen“. 



\section{Vorwort}

Die Arbeit an der Dissertation über Anatolij Koni war für mich verbunden mit zahlreichen Reisen, Konferenzbesuchen und persönlichen Gesprächen. Vielen Menschen bin ich deshalb zu Dank verpflichtet. Ein besonders großes Dankeschön geht an Benjamin Schenk, den Erstbetreuer meiner Dissertation. Er hat mich auf den Juristen A. F. Koni aufmerksam gemacht, mir ermöglicht, an der Universität Basel im Rahmen des Forschungsprojektes „Imperial Subjects“, das von 2013 bis 2016 vom Schweizerischen Nationalfonds und der Deutschen Forschungsgemeinschaft gefördert wurde, zu doktorieren und meine Arbeit schließlich über die ganze Zeit hinweg mit seinen Kommentaren und Hinweisen in ihrer Entwicklung unterstützt. Hier folgt gleich anschließend der Dank an die Kolleginnen und Kollegen sowie die externen Projektbeteiligten, die sich rund um das Forschungsvorhaben der „Imperial Subjects“ zusammengefunden haben. Gerne denke ich an all die spannenden Workshops und die beiden großen Konferenzen zurück, an denen wir uns über unsere verschiedenen Projekte ausgetauscht haben. Speziell nennen möchte ich Alexis Hofmeister, Murat Kaja, Nora Mengel, Stephan Rindlisbacher und Marion Wullschleger sowie Martin Aust (Bonn), Volker Depkat (Regensburg), Victoria Frede (Berkeley), Jochen Hellbeck (Rutgers), Peter Holquist (Pennsylvania) und Maurus Reinkowski (Basel), die mir alle mit ihren Inputs weitergeholfen haben.

Als Nächstes möchte ich den weiteren Mitgliedern meines Doktoratskomitees danken. Heiko Haumann, mein Zweitbetreuer, hat sich immer wieder die Zeit genommen, meine Entwürfe zu kommentieren und mit mir über die Analyseformen autobiografischen Schreibens zu diskutieren. Claudia Verhoeven, die externe Expertin in meinem Komitee ist, hat mich mit viel Herzlichkeit und großem Zeiteinsatz bei sich an der Cornell University in Ithaca, NY empfangen, wo ich ein halbes Jahr amerikanische Uni-Luft schnuppern durfte, was in jeder Hinsicht eine spannende Erfahrung und für meine Arbeit eine große Bereicherung war. Ein Dankeschön geht auch an die Mitdoktoranden des Departments of History, Nick Bujalski, Kate Horning und Josh Savala sowie an die Leiterinnen des History Colloquiums Durba Ghosh und Rachel Judith Weil.

Von einer Reihe weiterer Gespräche über meine Arbeit durfte ich im Rahmen von Kolloquien, Konferenzen und persönlichen Treffen in der Schweiz, Deutschland, den USA und Russland profitieren. Ich danke Julia Richers (Bern) für die anregende Diskussion im Kreise des Forschungskolloquiums zur Geschichte nach 1800; Jörg Baberowski (Berlin) für die Einladung in sein Kolloquium und das geteilte Interesse für Koni; Richard Wortman (New York) für die Diskussion auf 
der ASEEES-Konferenz; Sandra Dahlke (Moskau) für das Gespräch am dortigen Deutschen Historischen Institut; Andrej A. Isėrov von der Higher School of Economics in Moskau für seine administrative Hilfe und Svetlana A. Domanova, ebenfalls aus Moskau, für ihre Bereitschaft, mir die Zusammenfassung ihrer Dissertation zu Konis Briefwechseln unkompliziert zuzusenden, und natürlich den zahlreichen Mitarbeiterinnen und Mitarbeitern in den russischen Archiven und Bibliotheken für ihre Hilfeleistungen.

Dann sei auch den Kolleginnen und Kollegen in Basel gedankt, die Kapitel meiner Arbeit gegengelesen haben. Neben den schon genannten sind dies insbesondere Flavia Grossmann, Jörn Happel, Charlotte Henze und Bianca Hoenig sowie das ganze Team des Fachbereichs Osteuropa. Doris Tranter und Nina Wiener bin ich sehr dankbar für die äußerst kompetente Unterstützung bei der Korrektur- und Übersetzungsarbeit.

Für den moralischen Support möchte ich mich abschließend bei meinen Freundinnen und Mitdoktorandinnen Davina Benkert, Lenka Fehrenbach und Sandrine Mayoraz bedanken und am meisten natürlich bei meinem Mann Christian, dem ich diese Arbeit widme.

Als Postskriptum in diesem Dankesreigen vielleicht noch ein Wort zu Anatolij Koni selber, dessen schriftliche Hinterlassenschaft ich analytisch zu betrachten hatte. Bei aller geforderten Distanz und Nüchternheit muss in der Untersuchung auch die Anziehungskraft seiner Texte mitberücksichtigt werden. Selbstverständlich haben Konis Erzählungen aus seinem Leben auch mich nicht unberührt gelassen und mir manche Stunden spannender Quellenlektüre beschert. 


\section{Einleitung}

\section{Historischer Hintergrund, Erkenntnisinteresse und Methodik}

Zweierlei geschah an einem Tag im Januar 1878 in der Hauptstadt des russischen Zarenreiches. Der Jurist Anatolij Fëdorovič Koni (1844-1927) trat sein Amt als Vorsitzender des St. Petersburger Bezirksgerichtes an. Und eine junge Frau mit losen Kontakten zur oppositionellen revolutionären Bewegung, Vera Ivanovna Zasulič (1849-1919), schoss auf Fëdor Fëdorovič Trepov (1809/12-1889), den Stadthauptmann [gradonačal'nik] von St. Petersburg, um sich für dessen brutales Verhalten zu rächen. ${ }^{1}$

Anatolij Koni blickte im Moment der Beförderung an das Bezirksgericht bereits auf eine über zehnjährige Karriere im russischen Gerichtswesen zurück, das 1864 mit einer umfassenden Reform von Zar Alexander II. (1818-1881) implementiert worden war. Er wurde 1844 in St. Petersburg als Sohn von Eltern aus dem Theatermilieu geboren. ${ }^{2}$ Nach dem Besuch der deutschen „Annenschule“ und dem

1 Vasilij I. Smoljarčuk: Anatolij Fëdorovič Koni (1844-1927). Moskva 1981, S. 81-82 und Richard PIPes: The Trial of Vera Z. In: Russian History 37 (2010), S. 40-41 zum Zusammenfallen dieser beiden Ereignisse am 24. Januar 1878.

2 Konis Vater Fëdor Alekseevič Koni (1809-1879) war ein erfolgreicher Dramenautor und Kritiker des russischen Theaters. Als Sohn eines Kaufmannes studierte er an der Moskauer Universität und stieg in die intellektuelle Elite auf. Neben dem Verfassen von Vaudevilles Lustspielen mit Gesang - unterrichtete er Geschichte, vgl. Monika Katz: F. A. Koni und das russische Vaudeville. Zur Geschichte des Unterhaltungstheaters in St. Petersburg 1830-1855. München 2012, S. 11-13. Zu den verschiedenen Theorien über die ursprüngliche Herkunft des Geschlechts vgl. Sergej A. VysockiJ: Koni. Moskva 1988, S. 5-7. Konis Mutter Irina Semënovna Koni (geborene Jur'eva, auch Sandunova) (1811-1891) entstammte einer Gutsbesitzerfamilie und startete in den 183oer-Jahren, parallel zu eigenen literarischen Versuchen, eine Karriere als Schauspielerin, vgl. ebd., S. 10-11. Aus ihrer Ehe mit Fëdor Koni gingen zwei Kinder hervor, neben Anatolij der ein Jahr ältere Bruder Evgenij, vgl. Vladimir N. SAšonko: A. F. Koni v Peterburge - Petrograde - Leningrade. Leningrad 1991, S. 13 und 148-55 zu den illegalen Aktivitäten, aufgrund derer Evgenij zu Beginn des Jahres 1880 verurteilt und mitsamt seiner Familie verbannt wurde. Neben der Sorge um seinen Bruder und dessen Familie trug Koni auch Verantwortung für seine beiden Halbschwestern, die aus einer späteren Verbindung seines Vaters hervorgegangen waren, dessen Ehe mit Irina Semënovna nicht lange glücklich war. Zur Liaison von Fëdor Koni mit der 36 Jahre jüngeren Journalistin Anastasija Vasilevna Kairova (1844-1888) vgl. Mary F. ZIRIN: Meeting the Challenge. Russian Women Reporters and the Balkan Crises of the Late 1870s. In: Barbara T. Norton/Jehanne M. Gheith (Hrsg.): An Improper Profession. Women, Gender, and Journalism in Late Imperial Russia. Durham North Carolina u. a. 2001, S. $148 \mathrm{ff}$. 
zweiten St. Petersburger Gymnasium hatte er den Großteil seines Studiums der Rechtswissenschaften an der Moskauer Universität absolviert. 1865 schloss er mit einer Arbeit zum „Recht auf notwendige Verteidigung“ ab und wurde bald darauf als einer der ersten Juristen an den reformierten Gerichten tätig. ${ }^{3}$ Als stellvertretender Staatsanwalt wurde er zuerst unter anderem in Charkow eingesetzt, bevor er sich 1871 endgültig in der Hauptstadt niederließ. Dort arbeitete er als Staatsanwalt und ab 1875 im Justizministerium, bevor er schließlich den Posten als Vorsitzender des lokalen Bezirksgerichtes annahm. ${ }^{4}$

Vera Zasulič ihrerseits befand sich in den Monaten vor ihrer Tat am 24. Januar 1878 in einer krisenhaften Lebenssituation. Als Tochter aus gutem Hause hatte die junge Frau früh Kontakte zu jenen Kreisen aufgenommen, die mit den $\mathrm{Zu}$ ständen im Russischen Reich unzufrieden waren und den Sturz des Zaren und seiner Alleinherrschaft anstrebten. ${ }^{5}$ Ihr revolutionärer Zirkel hatte sich aufgrund interner Konflikte allerdings zerschlagen, weshalb sich der Mordversuch am Stadthauptmann wie die verzweifelte Tat einer wütenden jungen Frau ausnahm. ${ }^{6}$ Der

3 Koni wurde zuerst zuhause unterrichtet, bevor er 1855 in die „Annenschule“ eintrat und ab 14 Jahren schließlich das Gymnasium besuchte, vgl. VysockiJ: Koni, S. 35-36. 1861 schrieb sich Koni an der St. Petersburger Universität ein, wo er aber nur kurz blieb, da die Universität im Zuge der Studentenproteste im gleichen Jahr geschlossen wurde, vgl. dazu unten, S. 168. Daraufhin immatrikulierte sich Koni an der juristischen Fakultät in Moskau. Seine Abschlussarbeit stieß aufgrund ihres als subversiv verstandenen Themas der Selbstverteidigung aufseiten der Behörden auf Unmut, vgl. Elizabeth BALLANTINE: Koni and the Russian Judiciary, 1864-1917. Yale University 1986 (unveröffentlichte Dissertation), S. 13-15 ff sowie unten, S. 326.

4 Vgl. für eine Übersicht zu Konis Anstellungen Vysockij: Koni, S. 427-28. In den Anfangsjahren seiner Karriere war Koni kurzzeitig auch in Kasan und Moskau an verschiedenen Gerichten tätig.

5 Stephan Rindlisbacher: Leben für die Sache. Vera Figner, Vera Zasulič und das radikale Milieu im späten Zarenreich. Wiesbaden 2014, S. 43 ff zu Zasuličs Herkunft. Ihre Mutter stammte aus einer Großgrundbesitzerfamilie und die Zasuličs gehörten deshalb dem Landadel an, ohne aber besonders reich zu sein. Nach dem frühen Tod des Vaters erhielt Vera Zasulič durch die Unterstützung von Verwandten eine standesgemäße Erziehung und machte schließlich eine Ausbildung zur Gouvernante, vgl. ebd., S. 76 und $79 \mathrm{ff}$ zur Annäherung Zasuličs an das radikale Milieu, ihre Abscheu gegenüber der Tradition und die Lektüre radikaler Texte. Anfang der 187oer-Jahre wurde Zasulič wegen der Verwicklung in gewaltsame Aktionen zu einer Gefängnisstrafe verurteilt.

61875 hatte sich Zasulič in Kiew einer radikalen Gruppierung angeschlossen, die sich unter anderem aufgrund eines Mordversuchs an einem Mitglied der Gruppe, das des Verrats bezichtigt wurde, selber auflöste. Im Herbst 1877 begann Zasulič darüber nachzudenken, wie sie auf eigene Art und Weise ihre politischen Ziele befördern könnte. Obwohl nach wie vor in Kontakt mit anderen Revolutionären, war Zasulič doch relativ isoliert, vgl. Rindlisbacher: Leben für die Sache, S. 93 ff und S. 103-04 und 133. Wolfgang Geierhos: Vera Zasulič und die russische revolutionäre Bewegung. München 1977, S. $41 \mathrm{ff}$ mit dem 
Stadthauptmann Fëdor Trepov, der sich von seinen Verletzungen ohne bleibende Schäden erholen würde, hatte den Zorn von Zasulič auf sich gezogen, als er ein halbes Jahr zuvor bei der Besichtigung des städtischen Untersuchungsgefängnisses die Auspeitschung eines Häftlings befohlen hatte. Der Betroffene, ein gewisser Bogoljubov, war ein klassischer politischer Gefangener, der aufgrund seiner Teilnahme an regierungskritischen Aktivitäten inhaftiert worden war und Trepov wohl nur dadurch verärgert hatte, dass er seine Mütze vor der Autoritätsperson nicht schnell genug vom Kopf genommen hatte. ${ }^{7}$ Die Einsetzung der Körperstrafe gegen einen solchen Aktivisten hatte neben Zasulič auch breite Kreise der Petersburger Bevölkerung empört, die für den als korrupten sozialen Aufsteiger verschrienen Stadthauptmann grundsätzlich wenig Sympathie empfand. Quer durch alle Schichten herrschte eine gewisse Faszination für die weibliche „Rächerin" Bogoljubovs. ${ }^{8}$ Zwei Monate nach ihrer Tat wurde Vera Zasulič in einem Geschworenenprozess, an dem ihre Vergangenheit im radikalen Umfeld kein Thema war, trotz zweifelsfreier Schuld durch die Geschworenen vollumfänglich freigesprochen. ${ }^{9}$ Nun aber meldeten sich jene lautstark zu Wort, die sich als Verteidiger von Zar und Staatsmacht sahen und im ungestraften Angriff auf einen Offiziellen den Anfang vom Ende der Selbstherrschaft befürchteten. Der bekannte und einflussreiche Herausgeber der „Moskauer Nachrichten“ [Moskovskij Vedomosti], Michail Nikiforovič Katkov (1818-1887), wandte sich in gehässigen

Versuch einer Rekonstruktion der komplizierten Vorgeschichte der Tat im Kontext der revolutionären Bewegung.

7 Rindlisbacher: Leben für die Sache, S. $135 \mathrm{ff}$.

8 Ana Siljak: Angel of Vengeance. The Girl Assassin, the Governor of St. Petersburg and Russia's Revolutionary World. New York 2008, S. 218-19 und 256. Rindlisbacher spricht von der elegant gekleideten „Rächerin“, die die Hauptstadt durch die Kombination von Gewalt und Weiblichkeit erschütterte und faszinierte, vgl. RindLisbacher: Leben für die Sache, S. 143 ff und Lynn PАт к: Dressed to Kill and Die. Russian Revolutionary Terrorism, Gender, and Dress. In: Jahrbücher für Geschichte Osteuropas 2 (2010), S. 197 ff zum Spiel mit den Geschlechterrollen.

9 Zasulič war nach ihrem Attentatsversuch sofort überwältigt und festgenommen worden, vgl. Rindlisbacher: Leben für die Sache, S. 141. Es ist bis heute unklar, warum die politischen Hintergründe der Tat nicht in die Untersuchung einbezogen wurden. Der Justizminister Graf Pahlen beharrte auf einem öffentlichen Geschworenenprozess, der auf Vera Zasuličs Attentat als isolierten persönlichen Racheakt fokussieren sollte, vgl. SILJAK: Angel of Vengeance, S. $220 \mathrm{ff}$. Möglicherweise erhoffte sich der Minister durch einen von einem Geschworenengericht getroffenen Schuldspruch ein starkes Signal für die Ablehnung von Terrorismus durch die russische Gesellschaft. Im russischen Geschworenenprozess war es aber im Gegensatz beispielsweise zum amerikanischen System möglich, aufgrund der Begleitumstände einer Tat auch bei erwiesener Schuld einen Freispruch zu verfügen, vgl. PIPES: The Trial of Vera Z., S. 44-45. 
Kommentaren gegen das, was in seinen Augen die blinde Verherrlichung einer Attentäterin durch große Teile der hauptstädtischen Gesellschaft war. Im Gerichtswesen und insbesondere in der Institution des Geschworenengerichtes, das die Beteiligung der Bevölkerung an der Rechtsprechung möglich machte, sah der überzeugte Anhänger der Autokratie die Ursache allen Übels. ${ }^{10}$ Der Justizminister Graf Konstantin Ivanovič Pahlen (1833-1912) musste als Folge der Affäre wenig später zurücktreten, und mehrere Staatsanwälte verloren ihre Anstellung. Zasulič entging ihrer erneuten Verhaftung durch die Flucht nach Genf. ${ }^{11}$

Im Auge dieses Sturms öffentlicher Erregung befand sich Anatolij Koni. Er hatte als Gerichtsvorsitzender den Prozess gegen die Attentäterin leiten müssen. Schnell stand für die Regierung fest, dass es sein Verhalten beim Prozess gewesen sei, das die Geschworenen zu einem Freispruch veranlasst habe. Koni wurde der Parteilichkeit für die revolutionäre Bewegung bezichtigt und schließlich zum Rücktritt aufgefordert. ${ }^{12}$ Verunsichert hielt er sich aber vorerst auf seinem Posten, vom dem er nicht abberufen werden konnte. Einige Zeit später stimmte Koni dann dem Wechsel an das Zivildepartement der St. Petersburger Gerichtskammer zu, wo er, der eigentlich Strafrechtsexperte war, sich in einem politisch weniger verfänglichen Feld wiederfand. ${ }^{13}$

10 Pipes: The Trial of Vera Z., S. 69 ff, Rindlisbacher: Leben für die Sache, S. 152 und SILJAK: Angel of Vengeance, S. 26o. Siljak auch zu Katkov, der sich erst in den vorangegangenen Jahren zu einem so kompromisslosen Unterstützer der Autokratie gewandelt hatte.

11 Rindlisbacher: Leben für die Sache, S. 151-53 ff. Unmittelbar nach ihrer Freilassung versuchte man, Zasulič erneut festzunehmen und den Prozess nochmals aufzurollen. Zasulič war aber bereits untergetaucht und floh über Berlin in die Schweiz. SiLJAK: Angel of Vengeance, S. 224 und 258 zu den beiden Staatsanwälten, die aufgrund ihrer Verweigerung, die Anklage im Fall zu übernehmen, den Unmut des Justizministers auf sich gezogen hatten. Beide hatten Bedenken gehabt, im Prozess eine Verurteilung durchsetzen zu können. Nach dem Freispruch blieb ihnen nur der Rücktritt. Bei einem der beiden Männer handelte es sich um Sergej Andreevskij, der später noch ausführlich Thema sein wird.

12 Siljak: Angel of Vengeance, S. 257 und Rindlisbacher: Leben für die Sache, S. 151-52.

13 Rindlisbacher: Leben für die Sache, S. 152 zur gesetzlichen Grundlage, die den Richtern in Russland Unabsetzbarkeit garantierte, so dass Koni nicht einfach entlassen werden konnte. Zwischenzeitlich hatte Koni der Rücktrittsforderung nachgegeben und einen entsprechenden Brief an den Justizminister verfasst, was aber ohne Folgen blieb, vgl. Pipes: The Trial of Vera Z., S. 71. Vgl. SmoljarčUk: Anatolij Fëdorovič Koni (1844-1927), S. 111-12 zu Konis anfänglicher Enttäuschung, dass er bei der Versetzung Ende 1881 das Zivil- und nicht das Kriminaldepartement zugesprochen bekam. Die Gerichtskammern erstreckten sich über mehrere Gouvernements und dienten u. a. als Appellationsgerichte zweiter Instanz in Zivil- und Strafverfahren ohne Geschworene, die an den Bezirksgerichten behandelt worden waren, vgl. BABEROwSKi: Autokratie und Justiz, S. 64-65. 
Für Koni war der Gerichtsprozess gegen Vera Zasulič und die ganzen Umstände, die ihn begleiteten, von außerordentlicher Bedeutung. Vom Moment des skandalträchtigen Freispruchs bis zu seinem Tode fast ein halbes Jahrhundert später ließen ihn diese Geschehnisse nie mehr los. Der Zasulič-Prozess wurde für Koni zu einem „Ereignis“ im Sinne des französischen Philosophen Alain Badiou. In seiner „Ethik der Wahrheiten“ spricht Badiou davon, dass es in der Biografie eines Menschen Erlebnisse geben kann, die den Betreffenden dazu bringen, fortan jede Situation in Relation zu diesem Ereignis zu denken. Mit der Entscheidung, einen Prozess der grenzenlosen „Treue“ zum Erlebten einzuleiten, entwickelt sich eine eigene „Wahrheit“. ${ }^{14}$ Diese enorme Bedeutung des Gerichtsfalles von Vera Zasulič für Koni erklärt sich nicht nur aus den persönlichen Unannehmlichkeiten, die er in Form von Anfeindungen und karrieretechnischen Einschränkungen zu ertragen hatte. Vielmehr kristallisiert sich im Fall Vera Zasulič besonders deutlich die Konfliktsituation heraus, die Konis Leben und Werdegang in seiner Gesamtheit prägen sollte.

Die Gerichtsreform von 1864 hatte der russischen Justiz erstmals moderne Züge verliehen. Zusammen mit der Aufhebung der Leibeigenschaft für die Bauern gehörte die Umstrukturierung des Justizsystems zu einem Paket von „Großen Reformen“, die Zar Alexander II. in der ersten Hälfte der 186oer-Jahre in Russland mit der Unterstützung von aufgeklärten, einem westlichen Vorbild verpflichteten Reformbürokraten vorantrieb. ${ }^{15}$ Die Neuorganisation des Gerichtswesens war fundamental. Im vorreformierten System, das sich an den verschiedenen Ständen orientierte, hatten Untersuchung und Gerichtsspruch einen stark formalisierten Charakter. Die Anhörung des Angeklagten vor Gericht war nicht vorgesehen, und je nach Beweismittel wurden automatisch Urteile gesprochen - so beispielsweise im Falle eines Geständnisses zwingend ein Schuldspruch. Die Richter hatten in einem solchen System kaum Ermessensspielraum. Polizei, Gerichtskanzlei und Gouverneure verfügten dafür über umso mehr Gewicht. ${ }^{16}$ Mit dem Erlass vom 20. November 1864 wurde nun die Basis für eine mündliche und öffentliche Prozessordnung gelegt. Die neuen Gerichtsstatuten hielten fest, dass Verteidiger und

14 Alain BAdiou: Ethik. Versuch über das Bewusstsein des Bösen. Wien 2003, S. 61-65ff.

15 Richard Wortman: The Development of a Russian Legal Consciousness. Chicago 1976, S. 2-6 und Heiko Haumann: Geschichte Russlands. Zürich 2003, S. 256-58 mit einer Übersicht zu den Reformen und S. $251 \mathrm{ff}$ speziell zur Bauernbefreiung, durch die im Februar 1861 die Bauern persönlich frei wurden.

16 Jörg BABerowski: Autokratie und Justiz. Zum Verhältnis von Rechtsstaatlichkeit und Rückständigkeit im ausgehenden Zarenreich 1864-1914. Frankfurt am Main 1996, S. 11-37, S. $15 \mathrm{zu}$ den verschiedenen Ständen, insb. Adel, Stadtbewohner und Bauern mit jeweils eigenen Gerichtstypen. 
Ankläger in Zukunft vor Publikum um ein Urteil zu ringen hatten, teilweise installierte man Geschworenengerichte. Als untere Instanzen dienten Friedensrichter, die von der lokalen Selbstverwaltung, den Zemstva - ihrerseits auch ein Kind der „Großen Reformen“ - gewählt wurden. ${ }^{17}$ Nach wie vor beließ man allerdings als Überbleibsel der ständischen Rechtsprechung die Gerichtsbarkeit über die Bauern in einem separaten System, den sogenannten Volost'-Gerichten. ${ }^{18}$ Grundsätzlich galt, dass im reformierten Justizwesen dank der Gewaltentrennung der Einfluss von Polizeibehörden, Gouverneuren und Ministerien auf den Vollzug der Rechtsprechung eingeschränkt werden konnte. Mit den Kassationsgerichten verfügten die Juristen gar über gewisse rechtsschöpfende Kompetenzen. Richter und Staatsanwälte sahen sich also einem gänzlich gewandelten Berufsbild gegenüber, und erstmals entwickelte sich in Russland quasi aus dem Stand die Berufsgruppe der Anwälte. ${ }^{19}$

Vom reformierten Gerichtssystem ging eine große Faszination aus. Verhandlungen, die nun öffentlich und mündlich stattfanden, wurden von der Öffentlich-

17 Baberowski: Autokratie und Justiz, S. 57 und zu dem 1864 erlassenen Gesetz über die Landschaften [zemstva] Haumann: Geschichte Russlands, S. 256-57. Die Versammlungen wurden durch ein kompliziertes System gewählt, das dem Adel ein Übergewicht verschaffte. Die Zemstva sollten sich um Steuerfragen, Armen- und Krankenfürsorge sowie die örtliche Infrastruktur wie Schulen oder Gefängnisse kümmern. Dies waren völlig neue Möglichkeiten des Engagements, die großen Zuspruch fanden. 1870 kam es dann auch zu einer Stadtreform, die die Wahl eines städtischen Parlaments ermöglichte, das allerdings mit einem sehr hohen Zensus behaftet war.

18 Ein Volost' entsprach der kleinsten rechtlich-administrativen Einteilung des Landes. Nach 1864 war die Zuständigkeit der Volost'-Gerichte, die als Teil der Bauernbefreiung 1861 eingeführt worden waren, ziemlich begrenzt. Laienrichter aus der Bauernschaft sprachen Recht nach Gewissen und Gewohnheitsrecht, allerdings nur bei Fällen mit relativ kleinem Streitwert und entsprechend geringen Strafen, darunter allerdings auch Körperstrafen. Für die höheren Instanzen kamen dann wieder die reformierten Gerichte zum Zuge, so konnte man an das örtliche Friedensgericht gelangen. 1889 wurde die Zuständigkeit der Volost'-Gerichte allerdings deutlich ausgedehnt, vgl. Anna D. Popova: Femida v èpochu preobrazovanij. Sudebnye reformy $1864 \mathrm{~g}$. i rubeža XX-XXI vv. v kontekste modernizacii. Moskva 2009, S. 235-36, Heike Kathrin Litzinger: Juristen und die Bauernfrage. Die Diskussion um das bäuerliche Grundeigentum in Russland von 188o bis 1914. Frankfurt am Main 2007, S. 183 ff und Cathy A. Frierson: Peasant Icons. Representations of Rural People in Late Nineteenth-Century Russia. New York u. a. 1993, S. 55 und 62-63. Ganze 80 \% der Bevölkerung Russlands gehörte nun in den Zuständigkeitsbereich dieses Gerichtstyps, der nicht zum reformierten Justizsystem zählte, vgl. Jane BURBANK: Legal Culture, Citizenship, and Peasant Jurisprudence. Perspectives from the Early Twentieth Century. In: Peter H. Solomon (Hrsg.): Reforming Justice in Russia, 1864-1996. Power, Culture, and the Limits of Legal Order. Armonk New York 1997, S. 91.

19 Baberowski: Autokratie und Justiz, S. 57, 61-62 und 490. 
keit neugierig verfolgt, die neuen Richter regelrecht belagert. Eine Aufbruchsstimmung machte sich breit, die insbesondere Persönlichkeiten für die Arbeit an den neuen Gerichten begeisterte, die der uneingeschränkten Macht des Zaren kritisch gegenüberstanden. Unabhängig und frei von staatlicher Bevormundung im neuen Justizsystem tätig zu sein, war eine unverhofft attraktive Perspektive. ${ }^{20}$ Binnen kürzester Frist stieg die Zahl der Studenten an den Juristischen Fakultäten, bis sie gegen Ende der 186oer-Jahre die Hälfte aller Immatrikulierten überhaupt ausmachten. ${ }^{21}$ Ziel eines großen Teils der juristischen Gemeinschaft, die sich nun bildete, war die Etablierung eines Rechtsstaates. Dieser sollte zwar von den politischen Akteuren konstruiert und mit Macht versehen sein, gleichzeitig den Staat aber auch auf Distanz zu seinen Bürgern halten, denen ermöglicht werden sollte, selber Verantwortung zu übernehmen. ${ }^{22}$ Mit dem Transfer von westlichen juristischen Technologien wollte man eine Kultur etablieren, die den Fokus auf individuelle Rechte legte. ${ }^{23}$ Dazu gehörte die Propagierung von Grundsätzen wie

20 Ebd., S. 256 und 620.

21 Wortman: The Development of a Russian Legal Consciousness, S. 253-54. Wortman führt aus, wie bereits vor der Reform von 1864, ja als Basis für diese, ein Wandel innerhalb der Bürokratie stattgefunden hatte, der eine Gruppe von qualifizierten Rechtsexperten hervorgebracht hatte, ebd., S. 3. Durch Ministeriumsreformen und fortschreitende Spezialisierung und Zentralisierung der Machtstrukturen veränderte sich in der ersten Hälfte des 19. Jahrhunderts das Bewusstsein der Beamten im Rechtsdienst. Während Richterposten bisher als Belohnung beispielsweise für militärische Dienste an unerfahrene und wenig interessierte Adelige vergeben worden waren, entwickelte sich nun eine immer stärkere Professionalisierung, so dass bis zur Jahrhundertmitte eine Gruppe von Rechtsbeamten entstand, die sich über Ausbildung und Erfahrung definierte, ebd., S. 52-53. Immer deutlicher verfügten die Angestellten im Justizministerium über einen „Rechtsethos“, betonten die Wichtigkeit des Rechts an sich und sahen sich auf einer Mission für diese Grundsätze, ebd., S. 198. Bereits zwischen 1835 und 1841 hatte man die juristischen Fakultäten an den Universitäten unter anderem in St. Petersburg, Moskau und Charkow neu organisiert, mithilfe von Professoren, die man zuvor zum Studium nach Westeuropa geschickt hatte. Die Qualität des Rechtsunterrichts stieg nun deutlich an. Ebenfalls in diesem Zeitraum wurde die Kaiserliche Rechtsschule [Imperatorskoe učilišče pravovedenija] gegründet, die insbesondere junge Adelige zu fähigen Beamten des Justizministeriums machen sollte, vgl. Anton D. Rudokvas/Alexei S. Kartsov: Der Rechtsunterricht und die juristische Ausbildung im kaiserlichen Russland. In: Zoran Pokrovac (Hrsg.): Juristenausbildung in Osteuropa bis zum Ersten Weltkrieg. Frankfurt am Main 2007, S. 279-81 und 284.

22 Laura Engelstein: The Dream of Civil Society in Tsarist Russia. Law, State, and Religion. In: Nancy Bermeo/Philip Nord (Hrsg.): Civil Society Before Democracy. Lessons from Nineteenth-Century Europe. Boston 2000, S. 31.

23 Brian L. Levin-Stankevich: The Transfer of Legal Technology and Culture: Law Professionals in Tsarist Russia. In: Harley D. Balzer (Hrsg.): Russia’s Missing Middle Class. The Professions in Russian History. Armonk New York u. a. 1996, S. 236. 
Rede- und Versammlungsfreiheit und weiteren Bürgerrechten und -pflichten, die in der Regel als „liberal“ bezeichnet werden. ${ }^{24}$

Diese liberale Justizreform und die Ideale und Konzepte, auf denen sie aufbaute und die sie in Russland fördern wollte, gerieten nun aber - und das zeigt der Fall Vera Zasulič exemplarisch - sehr schnell von verschiedenen Seiten unter Druck. Die Entfaltungsphase des neuen Systems fiel mit dem Erstarken der radikalen Intelligencija im Lande zusammen. Der Begriff der Intelligencija wurde Mitte des 19. Jahrhunderts in Russland geläufig und bezeichnet in seiner unspezifischen Form die Gruppe derer, „die sich schon ihrer Bildung nach vom,Volk' abhoben und die auf Grund ihrer aufgeklärten, westeuropäisch-orientierten Geisteshaltung der Monarchie und dem bürokratischen Apparat entfremdet" waren. ${ }^{25}$ Als gebildete Persönlichkeit sah man sich in der Pflicht, Verantwortung für Russland und die Welt zu übernehmen und an einer besseren Zukunft zu arbeiten. ${ }^{26}$ Die Zeit der "Großen Reformen“ in den 186oer-Jahren brachte ihre eigene IntelligencijaGeneration hervor, die sogenannten „Männer der Sechziger", die sich in einer Epoche der „Befreiung“ und der „spirituellen Erneuerung“, ja in einem „neuen Zeitalter" wähnten. ${ }^{27}$ Im Gegensatz zu den Intellektuellen-Zirkeln in den beiden Jahrzehnten davor gehörten nun deutlich mehr nicht adelige Personen heterogenen Hintergrunds dieser sozialen Gruppe an, die durch eine alles beherrschende Abneigung gegen die existierende Ordnung vereint wurde. Bestärkt durch die Reformbemühungen von Zar Alexander II. diskutierten die gebildeten Kreise in ihren Journalen weitergehende Pläne für die befreiten Bauern, die Frage des

24 Frances Nethercott: Russian Legal Culture Before and After Communism. Criminal Justice, Politics and the Public Sphere. London 2007, S. 5. Baberowski meint gar: „Die Justizreform verkörperte das Ungestüm und die Aufbruchsstimmung der sechziger Jahre. Sie stand nicht bloß für den Versuch, die Rechtsverhältnisse umzuwälzen und zu europäisieren. Der Rechtsstaat war ein Wechsel auf den liberalen Verfassungsstaat und ein Wegbereiter der modernen Demokratie. So sahen es die Reformer und ihre Adepten inner- und außerhalb der Staatsbürokratie.“, vgl. BABERowski: Autokratie und Justiz, S. 788. Litzinger konstatiert etwas vorsichtiger, dass die russischen Juristen im Nachgang zur Reform zwar meist als Liberale bezeichnet werden und in den von ihr untersuchten Quellen der Leitgedanke des Rechtsstaates tatsächlich zentral sei. Allerdings ohne dass eine Definition davon gegeben würde, was genau man darunter verstanden habe, LITZINGER: Juristen und die Bauernfrage, S. 35.

25 Richard Pipes: Die historische Entwicklung der russischen Intelligentsia. In: ders. (Hrsg.): Die russische Intelligentsia. Stuttgart 1962, S. 66.

26 Victoria Frede: Doubt, Atheism, and the Nineteenth-Century Russian Intelligentsia. Madison 2011, S. 14.

27 Irina Paperno: Chernyshevsky and the Age of Realism. A Study in the Semiotics of Behavior. Stanford California 1988, S. 4-5. 
Landbesitzes, die Pressefreiheit oder die Beseitigung von sozialer und politischer Ungleichheit für Frauen. ${ }^{28}$

Bereits in der zweiten Hälfte der 186oer-Jahre kam es aber zu einer neuen Welle staatlicher Repression, die einen solchen Ausbau der Reformen in den Hintergrund treten ließ. Irina Paperno schreibt: „Die Sechziger endeten 1866, als alle Aktivitäten, die mit Befreiung assoziiert werden, zu einem abrupten Halt kamen [...].“ 1866 beging Dmitrij Vladimirovič Karakozov (1840-1866) ein missglücktes Attentat auf den Zaren, das die konservativen Kräfte in der Regierung stärkte. ${ }^{29}$ Die fortschreitende Neuordnung der Zustände im Zarenreich durch die Regierungsseite schien in Frage gestellt. Grundsätzlich wurde der Reformweg aber nur von einer Minderheit der Intelligencija wirklich als Basis für eine gesetzliche Ordnung verstanden, die mit der Zeit zu politischen Freiheiten führen würde. Für eine Mehrheit überwog die Enttäuschung über die Resultate und die Überzeugung, dass die soziale Ungerechtigkeit nur durch eine revolutionäre Umwälzung endgültig zu beseitigen sei. ${ }^{30}$ Beseelt von solchen Gedanken unternahm im Sommer 1874 eine große Zahl junger Menschen den sogenannten „Gang ins Volk“. Das Narodničestvo [Volkstümlertum] beziehungsweise die Narodniki [Volkstümler] sahen die Bauern und deren Lebensweise in der Dorfgemeinschaft als Schlüssel zu einem neuen Russland. Dank Aufklärung und Bildung unter den Landbewohnern sollte der Zar gestürzt und ein friedlicher Übergang direkt zu einer sozialistischen gerechten Gesellschaftsordnung gelingen. Doch ob Gymnasiasten, Studenten, liberale Bürger oder anarchistische Adelige - die Narodniki blieben den Bauern fremd, und diese übergaben ab und zu die Aufwiegler gleich selber der Polizei. ${ }^{31}$ Hunderte von Narodniki wurden verhaftet und in den darauffolgenden Jahren im Rahmen verschiedener Massenprozesse den Gerichten vorgeführt. Sehr deutlich wurde der Wunsch von Zar und konservativer Elite, dass die Aufständischen in diesen Prozessen öffentlich und exemplarisch bestraft werden sollten. Der Frei-

28 Ebd., S. 5-6.

29 Larissa Zakharova: The Reign of Alexandr II. A Watershed? In: Dominic Lieven (Hrsg.): The Cambridge History of Russia. Volume II: Imperial Russia, 1689-1917. Cambridge u. a. 2006, S. 610 und Paperno: Chernyshevsky and the Age of Realism, S. 6 für das Zitat. Vgl. zum Attentat des ersten Revolutionärs, der den Zaren zu ermorden versuchte: Claudia Verhoeven: The Odd Man Karakozov. Imperial Russia, Modernity, and the Birth of Terrorism. Ithaca 2009.

30 Leonard SCHAPIRO: Die vorrevolutionäre Intelligentsia und die gesetzliche Ordnung. In: Richard Pipes (Hrsg.): Die russische Intelligentsia. Stuttgart 1962, S. 36-37 und 40.

31 Haumann: Geschichte Russlands, S. 273-74 und Rindlisbacher: Leben für die Sache, S. 9o. Genau in diesen Kreisen bewegte sich auch Vera Zasulič, wobei sie zuvor bereits in den Fall um Sergej Nečaev verwickelt war, der schon früh auf Gewalt anstelle von Überzeugung setzte, vgl. detailliert ebd., S. 8o-87. 
spruch von Vera Zasulič war dabei aber nur der Höhepunkt in einer ganzen Reihe an Fällen, bei denen das Strafmaß gegen die Revolutionäre keineswegs in der von der Obrigkeit gewünschten Härte ausfiel. ${ }^{32}$

Vielen waren die neuen Gerichte schon von Anfang an ein Dorn im Auge gewesen, und so wurde nun die Gegenwehr von konservativer Seite umso stärker. Das juristische Reformprojekt fand sich mitten in einem beständigen politischen

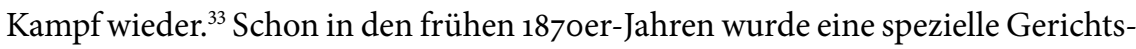
barkeit für politische Fälle eingeführt und die Transparenz an den Verhandlungen eingeschränkt. ${ }^{34}$ Nach dem Zasulič-Debakel gaben die Gesetzgeber nun den „Anschein von Rechtsstaatlichkeit“ auf, den sie bisher im Umgang mit der revolutionären Bewegung aufrechterhalten hatten. ${ }^{35}$ Zuerst wurde die Zuständigkeit der Geschworenengerichte eingeschränkt, dann entschieden, dass Attentate auf Staatsbeamte immer vor Militärgerichten zu verhandeln seien, und schließlich die Befugnisse von politischer Polizei und Generalgouverneuren entscheidend erweitert. ${ }^{36} \mathrm{Im}$ August 1881 wurde diese Entwicklung in einer Ausnahmeregelung festgeschrieben, die bis zum Ende des Zarenreichs gelten sollte. Faktisch hieß dies, dass auf administrativem Wege durch Polizei, Innenministerium und Gouverneure politisch unliebsame Zeitungen geschlossen und Personen festgenommen oder verbannt werden konnten. ${ }^{37}$

Dies hinderte allerdings die revolutionäre Bewegung vorerst nicht daran, ihren Kampf zu intensivieren. Im Gegenteil, ihre verstärkten Aktivitäten im Nachgang zum Prozess gegen Vera Zasulič waren Anlass für die immer neuen Verschärfungen. Der durch ein Geschworenengericht erfolgte Freispruch der Attentäterin wurde von Teilen der revolutionären Intelligencija als Signal verstanden, dass die Gesellschaft bereit war, Terror als Mittel zur Umgestaltung des Landes zu akzeptieren. Radikale Kräfte schlossen sich zur Organisation der Narodnaja Volja [Volksfreiheit/Volkswille] zusammen und versuchten mit allen Kräften, den

32 Siljak: Angel of Vengeance, S. 196-201 ff. Zu den verschiedenen Prozessen Nikolaj A. TroickiJ: Advokatura v Rossii i političeskie processy 1866-1904 gg. Tula 2000, S. $246 \mathrm{ff}$.

33 Die konservativen Kräfte versuchten schon nach dem Attentat von Karakozov einen Kausalzusammenhang zwischen der Redefreiheit vor Gericht und der zunehmenden Stärke der revolutionären Bewegung zu behaupten. Pausenlos verwies gerade der Innenminister auf die angeblich schlimmen Auswirkungen der Justizreform, vgl. BABErowski: Autokratie und Justiz, S. 632.

34 TroickiJ: Advokatura v Rossii i političeskie processy 1866-1904 gg., S. 164.

35 Wortman: The Development of a Russian Legal Consciousness, S. 283-84.

36 Baberowski: Autokratie und Justiz, S. 690 und 696-97 sowie Troickij: Advokatura v Rossii i političeskie processy 1866-1904 gg., S. 164-65.

37 Richard Wortman: Scenarios of Power, Bd. 2. Myth and Ceremony in Russian Monarchy: from Alexander II to the Abdication of Nicholas II. Princeton 2000, S. 263. 
Zaren selber und damit das Zentrum der Macht tödlich zu treffen. ${ }^{38}$ Es kam zu einer regelrechten „Jagd auf den Zaren“, die schließlich insofern erfolgreich war, als dass Alexander II. im März 1881 einem Anschlag zum Opfer fiel. ${ }^{39}$ Entgegen der Hoffnungen von Narodnaja Volja blieb eine Erhebung der Bevölkerung nach der gewaltsamen Beseitigung des Monarchen aber aus. Trotz des Beweises der Verletzbarkeit des Zaren kam es nicht zu einem Aufstand und mithilfe der Ausnahmegesetze wurde die gewaltbereite Bewegung schnell zerschlagen. Endgültig endete diese „Hochphase des politischen Terrorismus" mit einem gescheiterten Attentat auf den nachgefolgten Zaren Alexander III. im Jahre 1887. ${ }^{40}$

Der neue Zar ließ keinen Zweifel daran aufkommen, dass er vom Reformkurs seines Vorgängers wenig hielt. Ein „allumfassendes Programm von Gegenreformen" wurde initiiert, das die Kompetenzen der Zemstva und der Stadtregierungen beschnitt und so die nur kurz zuvor eingeführten Partizipationsmöglichkeiten und Gestaltungsfreiheiten der Bevölkerung wieder einschränkte. ${ }^{41}$ Dabei wurden auch systematisch in mehreren Etappen jene Elemente der Gerichtsreform tangiert, die Eigenständigkeit und Unabhängigkeit von Gericht und Richtern garantieren sollten. Obwohl so die Aufsichtsmacht der Politik über das Gerichtswesen deutlich verstärkt wurde, konnte die Justiz ihre Autonomie aber grundsätzlich aufrechterhalten. ${ }^{42}$ Tatsächlich gab es sogar Korrekturen am Justizsystem, die aufgrund praktischer Unzulänglichkeiten der herrschenden Verfahren initiiert wurden und willkürbeschränkende Auswirkungen hatten. ${ }^{43}$ Insgesamt aber überwog eindeutig der rückwärtsgewandte Aspekt. ${ }^{44}$

Dieses Setting eines ganz neu zu entwickelnden Justizsystems mit liberalen Vorstellungen von einem Rechtsstaat, das sich in konstanter Auseinandersetzung

38 Haumann: Geschichte Russlands, S. 274-75.

39 Julija Safronova: Russkoe obščestvo v zerkale revoljucionnogo terrora. 1879-1881 gody. Moskva 2014, S. 254.

40 Haumann: Geschichte Russlands, S. 275.

41 Wortman: Scenarios of Power, Bd. 2, S. 262 und Zakharova: The Reign of Alexandr II., S. 613 .

42 Marina V. Nemytina: Sud v Rossii. Vtoraja polovina XIX-načalo XX vv. Saratov 1999, S. 247-48 und Wortman: Scenarios of Power, Bd. 2, S. 262.

43 Nemytina: Sud v Rossii, S. 248 und Baberowski: Autokratie und Justiz, S. 662. Baberowski argumentiert hier am Beispiel einer Gesetzesnovelle, die entgegen der Wahrnehmung zahlreicher Juristen aus der Zeit nicht einfach einer Erweiterung administrativer Befugnisse, sondern auch einer Begrenzung von Willkür gleichgekommen sei. Baberowski plädiert in seiner Arbeit „Autokratie und Justiz“ dafür, die Veränderungen im Justizsystem nicht unmittelbar auf die politischen Konflikte zurückzuführen. Er sieht in ihnen auch eine Anpassung an personelle, institutionelle und strukturelle Gegebenheiten im Russland des späten 19. und des frühen 20. Jahrhunderts, vgl. ebd., S. 430-31 und 767-76.

44 Nemytina: Sud v Rossii, S. 248. 
mit dem selbstherrlich regierenden Zaren und seiner Entourage befand und sich gleichzeitig mit Stimmungen der Unzufriedenheit bis hin zu gewaltsamen revolutionären Protestbewegungen in der Bevölkerung konfrontiert sah, erklärt den Charakter eines „Ereignisses“, welchen der Gerichtsprozess gegen Vera Zasulič für Koni annahm. In diesem einen Prozess verdichteten sich die Bedingungen, unter denen er sein Leben und seine Karriere auszugestalten hatte. Seine „Treue“ zum Zasulič-Fall zeigte sich schon wenige Jahre nach 1878 . Koni begann, auf Hunderten von Seiten seine Erinnerungen an den Prozess und die ihm vorangegangenen und nachfolgenden Entwicklungen auszuformulieren. Bei diesem Erinnerungstext sollte es nicht bleiben. Im Verlauf seines Lebens verfasste Koni eine kaum zu überblickende Anzahl an Selbstzeugnissen, in denen er über verschiedenste Aspekte seiner Biografie nachdachte.

Diese Arbeit stellt Anatolij Konis autobiografische Reflexion ins Zentrum. Die Analyse seiner Selbstverortung soll aufzeigen, aufgrund welcher Einstellungen, Zukunftsvisionen und Zugehörigkeiten es für ihn als Pionier im liberalen Gerichtswesen möglich war, sowohl im autokratischen Imperium als auch in der frühen Sowjetunion eine aktive Rolle zu spielen und bis heute in Russland eine Identifikationsfigur zu bleiben. Sein Umgang mit dem Spannungsfeld, das sich im Zasulič-Fall verdichtet dargestellt hat, steht im Zentrum des Interesses. Dabei wird sich zeigen, wie Koni in seinen Selbstzeugnissen erfolgreich an verschiedensten Identifikationsangeboten, Diskursen und Konzepten seiner Zeit anknüpfte, um für sich einen Platz sowohl im späten Zarenreich als auch in der frühen Sowjetunion zu erringen und diese Kontexte in seinem Sinne mitzuprägen. Politische, rechtliche und soziale Entwicklungen im imperialen Russland des 19. Jahrhunderts bis in die sowjetischen 1920er-Jahre manifestieren sich in seiner Auseinandersetzung mit seinem Leben. Die Ausgestaltung eines Rechtswesens im autokratischen Umfeld, die Funktionen von politischen Akteuren im Justiz- und Staatsaufbau, die Wandlungen der Vorstellungen von „Volk“ und intellektueller Elite und deren moralischer Grundlagen oder die veränderten Handlungsspielräume angesichts politischer Polarisierungen und Verhärtungen rücken in den Fokus. In diesen Entwicklungen spiegeln sich Kontinuitäten und Brüche, die nicht nur auf die radikale Wende des Revolutionsjahres 1917 zu beziehen sind. An Koni lässt sich zeigen, dass gerade die Hinterfragung der eigenen Position im Machtgefüge ein Prozess war, der nicht erst durch den Sturz des Zaren und die totalen Umwälzungen unter bolschewistischer Herrschaft ausgelöst worden sein musste.

Omnipräsent im Hintergrund steht in der gesamten Arbeit die Frage, welche Funktion das autobiografische Schreiben nicht nur für Koni als Individuum hatte, sondern inwiefern eine solche Selbstreflexion selber ein Zeichen der Zeit war und wie genau sie mit den genannten Entwicklungen zusammenhing. 
Konis umfangreiche Selbstzeugnisse werden dazu als Teil einer „autobiografischen Praxis" interpretiert, die der Produktion und Repräsentation von Selbstbildern diente. Jochen Hellbeck versteht unter einer solchen „Praxis“ der Selbstdarstellung nicht nur schriftlich notierte Erinnerungen, sondern auch visuelle Darstellungen und Aufführungen wie Reden, mündliche Befragungen oder Bilder. ${ }^{45}$ Diese verschiedenartige Auseinandersetzung mit sich selber, so drückt es Heiko Haumann aus, „prägt das Selbstverständnis des Menschen und steuert Handelı“46 Produkte autobiografischer Praxis sind also nicht nur mit dem Interesse für die darin enthaltenen Hinweise auf die persönliche Vergangenheit zu lesen, sondern mit dem Fokus auf Selbstverständnis und Selbstdarstellung, die sich darin finden und die ihrerseits wiederum zu Handlung führen können. Dazu soll die ,textuelle Dimension“ der Erinnerungsschrift ernst genommen werden. Das „literarische Gebilde" der autobiografischen Schrift besitzt einen Eigenwert, der sich nicht in

45 Vgl. zum Begriff der „autobiografischen Praxis“ die Einführung von Jochen Hellbeck in: Jochen Hellbeck/Klaus Heller (Hrsg.): Autobiographical Practices in Russia. Göttingen 2004, S. 12-13. Vgl. auch die kurze Übersicht zu den Begrifflichkeiten „Selbstzeugnis“, "Ego-Dokument“ und „Autobiografik“ bei Julia Herzberg: Autobiographik als historische Quelle in „Ost“ und „West“. In: dies./Christoph Schmidt (Hrsg.): Vom Wir zum Ich. Individuum und Autobiographik im Zarenreich. Köln u. a. 2007, S. 16-18 mit Berufung auf u.a. Winfried Schulze: Ego-Dokumente: Annäherung an den Menschen in der Geschichte? Vorüberlegungen für die Tagung „Ego-Dokumente“. In: ders. (Hrsg.): EgoDokumente. Annäherung an den Menschen in der Geschichte. Berlin 1996, S. 11-30 sowie Benigna von Krusenstjern: Was sind Selbstzeugnisse? Begriffskritische und quellenkundliche Überlegungen anhand von Beispielen aus dem 17. Jahrhundert. In: Historische Anthropologie 2 (1994), S. 462-71 und Georg Misch: Begriff und Ursprung der Autobiographie [1907]. In: ders. (Hrsg.): Geschichte der Autobiographie, Bd. 1: Das Altertum. Bern 1949, S. 3-21. Sowohl die Begriffe „Selbstzeugnis“ als auch „Ego-Dokument“ fassen ähnlich wie das Konzept der „autobiografischen Praxis“ die Artikulationsformen breiter als die „Autobiografik“, die einzig schriftliche und in Anlehnung an Misch deutlich als Lebensschilderung eines Einzelnen durch ihn selber erkennbare Quellen meint. In einem "Selbstzeugnis“ oder einem „Ego-Dokument“ können auch andere, allerdings ebenfalls textbasierte, Formen der Thematisierung des „Selbst“ auftreten. Vgl. Anke STEPHAN: Erinnertes Leben. Autobiographien, Memoiren und Oral-History-Interviews als historische Quellen. In: Virtuelle Fachbibliothek Osteuropa. Digitales Handbuch zur Geschichte und Kultur Russlands und Osteuropas, zuletzt angepasst 2005, elektronisch verfügbar unter www.osmikon.de/metaopac/singleHit.do?methodToCall=showHit\&curPos=2\&identifier= 2dıbe49b, Zugriff vom 20.10. 2018, S. 6-7 zu den verschiedenen Begriffen für Lebensbeschreibungen im Russischen, die ohne trennscharfe Unterscheidung verwendet werden. So ist die Rede von „Erinnerungen“ [Vospominanija], „Memoiren“ [Memuary] oder „Aufzeichnungen“" [Zapiski].

46 Heiko Haumann: Geschichte, Lebenswelt, Sinn. Über die Interpretation von Selbstzeugnissen. In: ders. (Hrsg.): Lebenswelten und Geschichte. Zur Theorie und Praxis der Forschung. Wien u. a. 2012, S. 87. 
der Summe der aufgelisteten Details erschöpft. Anstatt den Text in Einzelteile zu zerlegen, geht es darum, die spezifischen narrativen Strukturen des Gesamtwerks zu berücksichtigen und so die Schrift als „Sinnganzes“ zu analysieren. So öffnet sich auch der Blick für die Schreibziele und -funktionen hinter der Autobiografie. Diese ist immer auch ein „Kampfinstrument“ im Selbstverständigungsprozess, bei dem Erfahrungen nicht nur reflektiert, sondern im Schreiben erst mit hervorgebracht werden. ${ }^{47}$ Das Erinnern selber wird also als „historisches Ereignis“ verstanden, als im Schreibmoment wirkungsvolles Agieren, das in einem Zusammenhang von Ursachen und Folgen steht und so etwas über Situation, Werte und Überzeugungen nicht nur in der beschriebenen Vergangenheit, sondern vielmehr in der Gegenwart der Reflexion verrät. ${ }^{48}$

Mit diesem Verständnis von autobiografischer Praxis rücken die Momente intensivierten autobiografischen Schreibens, Überarbeitens und Publizierens im Verlauf von Konis Leben in den Fokus. Von diesen autobiografischen Konjunkturen ausgehend, soll nach der inhaltlichen Selbstreflexion Konis in diesen Momenten gefragt werden und die Narrative der Sinnbildung, die sich in der autobiografischen Praxis zeigen, herausgearbeitet werden. Schreibzusammenhang, Funktionsweise und Wirkung dieser Selbstverortung bilden danach jeweils die Brücke zum zeitgenössischen Kontext des Schreibmoments. Julia Herzberg spricht in ihrer Studie zum Erinnerungsschreiben von russischen Bauern treffend davon, dass eine Autobiografie immer das „Ergebnis einer komplexen Kommunikationssituation“ sei. ${ }^{49}$ Als „kommunikative Akte“ sind die autobiografischen Selbstverortungen eine Art „Schnittstelle“ von Individuum und System und somit untrennbar vom Umfeld, in dem sich der Verfasser bewegt und in dem er sich mit seinem Erinnern

47 Volker Depkat: Nicht die Materialien sind das Problem, sondern die Fragen, die man stellt. Zum Quellenwert von Autobiographien für die historische Forschung. In: Thomas Rathmann/Nikolaus Wegmann (Hrsg.): Quelle. Zwischen Ursprung und Konstrukt. Ein Leitbegriff in der Diskussion. Berlin 2004, S. 116-17 und Volker DepKAT: Autobiographie und die soziale Konstruktion von Wirklichkeit. In: Geschichte und Gesellschaft 1 (2003), S. 445-46, 463 und 476. Im Gegensatz zu Hellbeck bezieht sich Volker Depkat in seinen theoretischen Ausführungen einzig auf schriftliche Autobiografien, in denen der Autobiograf „am Leitfaden des eigenen Lebens“ die eigene Zeit interpretiert, vgl. ebd., S. 453. Deркат: Nicht die Materialien sind das Problem, sondern die Fragen, die man stellt, S. $116-17$.

49 Julia Herzberg: Gegenarchive. Bäuerliche Autobiographik zwischen Zarenreich und Sowjetunion. Bielefeld 2013, S. 8-9. Herzberg führt aus, dass Autobiografien immer Teil einer „Interaktion“ sind, bei der ein „Rufender“ und ein „Angerufener“ auszumachen sind. Dass es zu diesem Austausch kommt, kann zum Beispiel durch persönliche Sehnsüchte, Institutionen oder Lektüren ausgelöst werden. 
positioniert. ${ }^{50}$ Geleitet vom Erinnerungsschreiben Konis werden die verschiedenen Elemente dieser „komplexen Kommunikationssituation“ in den Blick genommen. Das Wechselspiel von intrinsischer Motivation und externen Schreibanlässen wie Publikationsangeboten von Zeitungen und Zeitschriften, provokanten Memoiren von Zeitgenossen oder das Einwirken von am Schreibprozess beteiligten Helfern wird ebenso thematisiert wie übergeordnete Wechselwirkungen zwischen Konis Selbstdarstellung und der Fremdwahrnehmung, die über seine Person kursierte und auf die er in seinem Schreiben wiederum reagierte. Unmittelbar miteinander verbunden ist all dies mit der persönlichen biografischen und der allgemeinen historischen Situation zum Schreibzeitpunkt.

Das russische Imperium befand sich durch territoriale Expansionen, innenpolitische Reformen und revolutionäre Umstürze, aber auch durch voranschreitende Industrialisierung, Urbanisierung und Globalisierung auf dem Gebiet von Wissenschaft, Wirtschaft und Kommunikation in der zweiten Hälfte des 19. und zu Beginn des 20. Jahrhunderts in einer Phase ausgeprägten historischen Wandels.

Diese rapiden Veränderungen dürften ihrerseits einen Einfluss auf die intensivierte autobiografische Selbstverortung gehabt haben, der sich nicht nur Koni in diesen Jahren widmete. ${ }^{51}$ Tatsächlich bediente sich der Jurist mit seinem exzessiven autobiografischen Schreiben eines Mittels zur „Tat“, das für seine Zeit typisch war. ${ }^{52}$ Seit der Mitte des 19. Jahrhunderts kam es in Russland zu einem regelrechten Boom beim Schreiben autobiografischer Texte. Dabei spielten verschiedene Faktoren eine Rolle. Für Westeuropa, so führt Ulrich Schmid aus, wird in der Regel von einem sich ab der Mitte des 17. Jahrhunderts herausbildenden „Individualitätsbewusstsein“ gesprochen. Im Zuge der Reformation vergrößerte

50 Depкат: Nicht die Materialien sind das Problem, sondern die Fragen, die man stellt, S. 116-17 zu den „kommunikativen Akten“. Haumann betont, dass Selbstzeugnisse eine wichtige Quelle seien, um mehr über die Lebenswelt eines Menschen zu erfahren, die gleichsam die "Schnittstelle“ von Individuum und System darstelle, vgl. Haumann: Geschichte, Lebenswelt, Sinn, S. 89 und Heiko Haumann: Lebensweltlich orientierte Geschichtsschreibung in den Jüdischen Studien. Das Basler Beispiel. In: ders. (Hrsg.): Lebenswelten und Geschichte. Zur Theorie und Praxis der Forschung. Wien u. a. 2012, S. $80-81$.

51 Vgl. zu dieser Leitfrage des Forschungsprojektes „Imperial Subjects“ Martin Aust/Frithjof Benjamin Schenk: Einleitung. Autobiographische Praxis und Imperienforschung. In: dies. (Hrsg.): Imperial Subjects. Autobiographische Praxis in den Vielvölkerreichen der Habsburger, Romanovs und Osmanen im 19. und frühen 20. Jahrhundert. Köln 2015, S. 14-15 bzw. die hier gleich nachfolgenden Ausführungen.

52 Smith und Watson sprechen mit Verweis auf Thomas G. Couser davon, dass man eine Autobiografie danach lesen solle, was sie tue, und nicht dafür, was sie sei, vgl. Sidonie Sмith/Julia Watson: Reading Autobiography. A Guide for Interpreting Life Narratives. Minneapolis Minnesota u. a. 2010, S. 19. 
sich die Distanz zwischen Mensch und Gott und es wurde immer wesentlicher, das individuelle Schicksal - und nicht länger nur das Walten Gottes in der Welt zu beschreiben. Russland erlebte diese „philosophische Grundlegung eines autonomen Ich" im ausgehenden Mittelalter nicht. ${ }^{53}$ Gleichwohl konnte überzeugend dargelegt werden, dass es ein Fehlschluss wäre zu meinen, in Russland existiere kaum autobiografisches Schreiben und das Selbst spiele in den vorhandenen Erinnerungstexten keine Rolle. ${ }^{54}$ Dass autobiografisches Schreiben auch in Russland ab der zweiten Hälfte des 19. Jahrhunderts in großem Stil sichtbar wird, hängt mit dem ansteigenden Bildungsniveau zusammen, das schriftliche Zeugnisse beförderte, und mit der sich entwickelnden Publikationslandschaft. Seit den „Großen Reformen" mit ihrer ansatzweisen Stärkung der autonomen Gesellschaft stiegen sowohl das Interesse als auch das Verfassen und Publizieren von Zeugnissen einzelner Individuen an. Die neu entstandenen historischen Zeitschriften veröffentlichten nun Autobiografien und Tagebücher von Menschen aus allen Schichten. Gerade die Individualität der Lebensgeschichten ließ sie den Zensoren oftmals harmlos erscheinen und ermöglichte so die öffentliche Thematisierung von Erlebnissen wie die Bauernunruhen nach dem Befreiungsmanifest 1861, über die sonst kaum berichtet wurde. Der Markt für solche Lebenserinnerungen erfreute sich einer großen Nachfrage, die wiederum die Wissenschaft ins Spiel brachte.

In den frühen 187oer-Jahren wurde der quellenkritische Umgang mit Selbstzeugnissen an den historischen Fakultäten der Universitäten von Moskau und St. Petersburg zum Thema gemacht. Immer mehr Bibliografien versuchten den Überblick über die publizierten Schriften zu ermöglichen. Eine weiterführende Auseinandersetzung blieb allerdings aus. Die zeitgenössische russische Geschichtswissenschaft beurteilte Selbstzeugnisse als nur mit großer Vorsicht zu verwendende Quellen, da sie zu wenig zuverlässig seien. ${ }^{55}$ Dies änderte jedoch nichts am anhaltenden Strom von publizierten Erinnerungsschriften, der allein schon die Bedeutung, die autobiografische Praktiken in dieser Zeit besaßen, deutlich macht.

53 Ulrich Schmid: Ichentwürfe. Die russische Autobiographie zwischen Avvakum und Gercen. Zürich 2000, S. 36-37.

54 Herzberg: Autobiographik als historische Quelle in „Ost“ und „West“, S. $29 \mathrm{ff}$.

55 Barbara Walker: On Reading Soviet Memoirs. A History of the „Contemporaries“ Genre as an Institution of Russian Intelligentsia Culture from the 1790 os to the 197os. In: Russian Review 3 (2000), S. 337-39; SCHмID: Ichentwürfe, S. 38 inkl. einer Auflistung der historischen Zeitschriften, die Erinnerungstexte publizierten; Herzberg: Autobiographik als historische Quelle in „Ost“ und „West“, S. 33-46 ausführlich zur russischen Geschichtswissenschaft und der „Aufwertung der Gesellschaft“, die zu einer „Wertschätzung des Individuums" führte, hier insb. 33-34 und 46 sowie zur Zensur S. 35. 


\section{Forschungskontext, Konis biografische Koordinaten und Aufbau der Arbeit}

Die Betrachtung autobiografischer Praktiken in ihrer zeitgeschichtlichen Relevanz ist ein Grundanliegen dieser Arbeit und des Forschungsprojektes „Imperial Subjects", in dessen Rahmen sie verfasst wurde. Damit soll an die SelbstzeugnisForschung der letzten Jahre angeknüpft werden, die einen neuen Umgang mit autobiografischen Dokumenten erprobt. Die Nutzung von Selbstzeugnissen als Quellen für die Geschichtswissenschaft erfreut sich seit geraumer Zeit großer Beliebtheit. Seit dem Ende der 1970er-Jahre verstärkte sich das „Interesse für die Rolle des Subjekts in der Geschichte ${ }^{\text {“ }}{ }^{56} \mathrm{Im}$ Nachgang an die auf Prozesse und Strukturen fokussierte Sozialgeschichte erhielten Ego-Dokumente mit der kulturwissenschaftlichen Wende der 1990er-Jahre endgültig einen zentralen Stellenwert innerhalb der historischen Forschung. Zu diesem Zeitpunkt - nach dem Zerfall der Sowjetunion, in der die Individualität in Selbstzeugnissen vornehmlich als Bedrohung für eine marxistische Geschichtsinterpretation verstanden wurde wuchsen die „verschiedenen Welten“ von „Ost“ und „West“ hinsichtlich der wissenschaftlichen Diskussionen um das Erinnerungsschreiben zusammen. ${ }^{57}$ Nach wie

56 Stephan: Erinnertes Leben, S. 2.

57 Volker Depкат: Zum Stand und zu den Perspektiven der Autobiographieforschung in der Geschichtswissenschaft. In: Bios: Zeitschrift für Biographieforschung, oral history und Lebensverlaufsanalysen 2 (2011), S. 174 und HerzberG: Autobiographik als historische Quelle in „Ost“ und „West“, S. 55 zu den „verschiedenen Welten“ bzw. ebd., S. 47-55 mit einem Überblick zum Umgang mit Selbstzeugnissen in der marxistischen Geschichtswissenschaft. Während autobiografische Texte von vor 1917 diffamiert und moralisch abgewertet wurden, organisierte man in der frühen Sowjetunion in großem Stil das Verfassen neuer Selbstzeugnisse. Diese wurden oftmals durch entsprechende Schreibanleitungen in eine Form gebracht, die zur gewünschten Interpretation passte. Das Ziel, Gesetzmäßigkeiten in der Geschichtsentwicklung herauszuarbeiten, wurde durch die Individualität in Selbstzeugnissen in Frage gestellt, und so zeigten die sowjetischen Historiker lange Zeit großes Misstrauen gegen diesen Quellentyp und seine „Subjektivität“. Die Arbeiten von Petr Zajončkovskij und Andrej Tartakovskij in den 1970er-Jahren und später, die autobiografische Texte in den Mittelpunkt stellten, deutete schließlich eine Trendwende an, die sich in der Perestroika fortsetzte, als man Selbstzeugnisse als besonders wertvolle Quellen für die Aufarbeitung der sowjetischen Geschichte entdeckte. Vgl. auch Aust/Schenk: Einleitung, S. 20. Vgl. Tartakovskijs Analysen zum Zusammenhang vom „Vaterländischen Krieg" gegen Napoleon und autobiografischem Schreiben zu Beginn des 19. Jahrhunderts: Andrej G. TARTAKovskiJ: 1812 god i russkaja memuaristika. Opyt istočnikovedčeskogo izučenija. Moskva 1980 oder Zajončkovskijs Sammlung von Tagebüchern und Erinnerungen, die die Geschichte des vorrevolutionären Russlands beleuchten sollten: Petr Andreevič ZAjONČKovskij (Hrsg.): Istorija dorevoljucionnoj Rossii v dnevnikach i vospominanijach. Annotirovannyj ukazatel' knig i publikacij v žurnalach. 5 Bände. Moskva 1976-1989. 
vor ist die Auseinandersetzung mit autobiografischen Zeugnissen weit verbreitet und wird intensiv betrieben. Allerdings, so konstatiert Volker Depkat, bleibt die "Quellenkunde“ in diesem Bereich „ein Forschungsproblem“. ${ }^{58}$ Problematisch erscheint insbesondere, dass nach wie vor autobiografische Texte in erster Linie als „Steinbruch“ für Informationen verwendet werden, die anders nicht zu erhalten sind. Daneben werden auch Charakter oder Identität des Autors meist als „historische Wirklichkeit" interpretiert, ohne dass die autobiografische Praxis selber und ihr Kontext näher beleuchtet würden..$^{59}$ Oder, um es in Dagmar Günthers Worten auszudrücken: $\mathrm{Zu}$ oft begnügen sich die Historikerinnen und Historiker mit „naiver" Lektüre. ${ }^{60}$

Nichtsdestoweniger sind verschiedene spannende Ansätze entstanden, die sich den Autobiografien „als Texte“ nähern, um sie „auf neue Art und Weise als Quellen" nutzen zu können. ${ }^{61}$ So rückte der Fokus auf die Narrativität von Selbstzeugnissen „literarische Muster“ oder „eigengesetzliche Organisationsformen“ von Schriften ins Blickfeld. ${ }^{62}$ Selbstzeugnisse wurden als Kristallisationsorte von Erinnerungsvorgängen interpretiert, über die Einblicke in Deutungsmuster und die Formung von „kollektiver Identität“ möglich werden. ${ }^{63}$ Durch das Verständ-

58 Depкat: Zum Stand und zu den Perspektiven der Autobiographieforschung in der Geschichtswissenschaft, S. 171 und 174.

59 Depкat: Nicht die Materialien sind das Problem, sondern die Fragen, die man stellt, S. 109 und Dеркат: Zum Stand und zu den Perspektiven der Autobiographieforschung in der Geschichtswissenschaft, S. 174-75.

60 Dagmar Günther: „And now for something completely different.“ Prolegomena zur Autobiographie als Quelle der Geschichtswissenschaft. In: Historische Zeitschrift 272 (2001), S. 26.

61 Dеркат: Zum Stand und zu den Perspektiven der Autobiographieforschung in der Geschichtswissenschaft, S. 175.

62 Vgl. z.B. Stephan: Erinnertes Leben, S. 13 bzw. Anke Stephan: Von der Küche auf den Roten Platz. Lebenswege sowjetischer Dissidentinnen. Zürich 2005. Günther zitiert Oliver Sill (Zerbrochene Spiegel. Studien zur Theorie und Praxis modernen autobiographischen Erzählens. Berlin, New York 1991): „Vielmehr gilt es auch bei einer Beschäftigung mit autobiographischer Literatur [...] die eigengesetzliche Organisationsform aller literarischer Texte anzuerkennen.“, vgl. GüNTHER: „And now for something completely different“, S. 46.

63 Haumann: Geschichte, Lebenswelt, Sinn, S. 88-89. Haumann konstatiert, „dass wir über Erinnerungen sowie die damit verbundenen Lebenswelten unschätzbare Einblicke in die geschichtlich-gesellschaftliche Entwicklung, in Handlungsspielräume und Deutungsmuster, in Strategien, Netzwerke, Mechanismen und den ,Eigen-Sinn' der Akteure erhalten. $\mathrm{Zu}$ diesem Zweck müssen wir die erwähnten Wechselwirkungen der individuellen Erinnerung mit kollektiven Erinnerungen untersuchen." Vgl. die weiteren Arbeiten von Haumann, im vorliegenden Band insb. den Aufsatz Heiko Haumann: Erinnern und erzählen. Historisch-sozialwissenschaftliche Zugänge zu lebensgeschichtlichen Inter- 
nis von Schreiben als Selbstdarstellung, die von kulturellen Gepflogenheiten mitbestimmt ist und als „soziale Praxis“ etwas über einen spezifischen historischen Kontext aussagt, wurde schließlich das kommunikative Element der Autobiografie als Handlung betont. ${ }^{64}$ Hier schließt das Forschungsprojekt „Imperial Subjects. Autobiographische Praktiken und historischer Wandel in den Kontinentalreichen der Romanovs, Habsburger und Osmanen (Mitte des 19. bis frühes 20. Jahrhundert)“ an. ${ }^{65}$ Gefragt wird nach dem Verhältnis von historischen Veränderungen und autobiografischem Schreiben, nach der Art und Weise, wie im Schreiben "das eigene Leben und die eigene Zeit" zu Geschichte wird, und inwiefern solche Deutungen wiederum Wirkung entfalten - für den Autor und darüber hinaus. ${ }^{66}$ Den Bezugsrahmen bildet dabei das „Imperium“ - im Falle von Anatolij Koni das russische -, in dem er als Teil der Elite, aber immer auch als Untertan [engl. subject] lebte und sich in seinen autobiografischen Praktiken mit dieser Herrschaftsform auseinandersetzte. ${ }^{67}$

views (zusammen mit Ueli Mäder). In: ders. (Hrsg.): Lebenswelten und Geschichte. Zur Theorie und Praxis der Forschung. Wien u. a. 2012, S. 96-105. Vgl. beispielsweise auch den Sammelband Claudia Ulbrich/Hans Medick/Angelika Schaser (Hrsg.): Selbstzeugnis und Person. Transkulturelle Perspektiven. Köln u. a. 2012, insb. in der Einleitung S. $10 \mathrm{ff}$ zu „Schreiben und Erinnern“. Depкat: Zum Stand und zu den Perspektiven der Autobiographieforschung in der Geschichtswissenschaft, S. 173 für weitere Arbeiten aus der Erinnerungsforschung.

64 Einführung von Jochen Hellbeck in: Hellbeck/Heller (Hrsg.): Autobiographical Practices in Russia, S. 13 und Depкat: Zum Stand und zu den Perspektiven der Autobiographieforschung in der Geschichtswissenschaft, S. 176, der an dieser Stelle seine eigene Monografie (Volker Deркат: Lebenswenden und Zeitenwenden. Deutsche Politiker und die Erfahrungen des 20. Jahrhunderts. München 2007) aufzählt sowie weitere Autoren nennt.

65 Das internationale Forschungsprojekt der beiden Universitäten Basel (Schweiz) und LMU München (Deutschland) wurde vom Schweizerischen Nationalfonds und der Deutschen Forschungsgemeinschaft über eine Laufzeit von drei Jahren (ab Frühjahr 2013) gefördert. Neben zwei internationalen Tagungen, deren Ergebnisse im Sammelband Martin Aust/Frithjof Benjamin Schenk (Hrsg.): Imperial Subjects. Autobiographische Praxis in den Vielvölkerreichen der Habsburger, Romanovs und Osmanen im 19. und frühen 20. Jahrhundert. Köln 2015 festgehalten wurden, werden im Rahmen des Projektes mehrere Qualifikationsschriften zu den drei Kontinentalreichen verfasst.

66 Deркат: Nicht die Materialien sind das Problem, sondern die Fragen, die man stellt, S. 116-17 und Dеркат: Autobiographie und die soziale Konstruktion von Wirklichkeit, S. 476 sowie Aust/Schenk: Einleitung, insb. S. 14-18.

67 Mit dem englischen Begriff „subject“, so führen Aust/Schenk aus, ist sowohl der imperiale „Untertan“ gemeint, der im Gegensatz zum „Bürger“ eines idealtypischen Nationalstaates nur begrenzte Rechte hat. Daneben aber auch der Mensch, der sich seines „Ichs“, quasi seines Subjekt-Seins, bewusst ist bzw. dieses im Schreiben mit entwirft, vgl. Aust/SCHEnK: Einleitung, S. 18. 
Den Zugang zu den dynastischen Großreichen über ein Individuum zu suchen, ist in den vergangenen Jahren ein immer beliebteres Vorgehen geworden. Die Rede ist vom „biographical turn“ in der Imperienforschung. ${ }^{68}$ Zahlreiche biografische Studien beschäftigen sich auf verschiedene Art und Weise mit Persönlichkeiten aus dem Zarenreich und weiteren Imperien und hauchen damit dem „Bastard der Geisteswissenschaften" neues Leben ein. Die Biografie, so konstatieren Christian Klein und Simone Lässig, steht zwischen der Geschichts-, der Literatur- sowie der Sozialwissenschaft und hinterlässt nicht selten den faden Beigeschmack eines „antiquierten“ und „unreflektierten“ Umgangs mit Geschichte. ${ }^{69}$ Dieser Eindruck hat in den vergangenen drei Jahrzehnten eine entschiedene Korrektur erfahren. Die Biografie „erobert" sich ihren Platz unter den verschiedenen wissenschaftlichen Darstellungsformen, indem sie die „Person nicht mehr aus den gesellschaftlichen Strukturen, in denen sie lebte, die sie prägten und auf die sie andererseits selbst einwirkte", herauslöst. ${ }^{70}$

Für den russischen Kontext lässt sich eine große Zahl an biografischen Arbeiten ausmachen, die nicht selten mit neuen Formen experimentieren. ${ }^{71}$ Dabei sind die Erkenntnisinteressen unterschiedlich. So geht es Michael Khodarkovsky mit seiner Rekonstruktion des Lebens von Semën Semënovič Atarščikov (1807-1845) darum, die Geschichte eines Mannes zu erzählen, der ein „typisches Produkt der russischen imperialen Grenze war". Der russische Offizier mit tschetschenischen

68 Ebd., S. 13 zitieren Jürgen Osterhammel: Imperien. In: Gunnilla Budde u. a. (Hrsg.): Transnationale Geschichte. Göttingen 2006, S. 62. Zentral ist dabei das Interesse für die Wechselwirkung zwischen Individuum und Imperium. So lässt sich beispielsweise danach fragen, wie über Lebensgeschichten - oder besser „Lebensgeographien“ - Verbindungen innerhalb der Großreiche entstanden sind, die die Imperien in ihrer Räumlichkeit mitbestimmten und so den Zusammenhalt dieser „distanzierten kulturellen Strukturen“ erst möglich machten. LAMBERT: Introduction: Imperial Spaces, Imperial Subjects, S. 1-3, 10 und 13 .

69 Christian Klein: Einleitung: Biographik zwischen Theorie und Praxis. Versuch einer Bestandsaufnahme. In: ders. (Hrsg.): Grundlagen der Biographik. Theorie und Praxis des biographischen Schreibens. Stuttgart u. a. 2002, S. 1 für das Zitat vom „Bastard“ und Simone LÄssıg: Die historische Biographie auf neuen Wegen? In: Geschichte in Wissenschaft und Unterricht 10 (2009), S. 540-41. Lässig spricht weiter von einer „Theorieresistenz" und „fehlender Innovationsfreude“, die das Feld der Biografie lange auszeichnete.

70 Hans Erich BöDEkER: Biographie. Annäherungen an den gegenwärtigen Forschungs- und Diskussionsstand. In: ders. (Hrsg.): Biographie schreiben. Göttingen 2003, S. 11 und 19. Vgl. die Aufsätze von Bödeker, Lässig und Klein für eine Übersicht zur Entwicklung der biografischen Forschung.

71 Lässıg: Die historische Biographie auf neuen Wegen?, S. 46-47 betont, dass eine Biografie schreiben häufig auch heiße, zu experimentieren und Grenzen zu überschreiten, sowohl hinsichtlich Konzept und Umgang mit Theorien und Quellen als auch, was die Form der Darstellung anbelange. 
Wurzeln sah sich zeitlebens mit Fragen der Loyalität zwischen seiner Heimat und dem Imperium konfrontiert. ${ }^{72}$ Ausgehend von einer "prinzipiellen Heterogenität“ im imperialen Staat können so die „shifting identities“ von Menschen sichtbar gemacht werden, die Akteure in verschiedensten Gemeinschaften waren. ${ }^{73}$ Atarščikovs Leben dient Khodarkovsky als Vehikel für die Geschichte des Nordkaukasus - er füllt die Lücken in seiner Rekonstruktion gar eigenständig mit Vermutungen zu wahrscheinlichen Szenarien. ${ }^{74}$ Persönliche Heterogenität und die Vielfalt imperialer Orte sind auch in Willard Sunderlands „The Baron's Cloak" zentrale Themen. Anhand des im habsburgischen Graz geborenen Baron Roman Fëdorovič von Ungern-Sternberg (1885-1921), der als baltendeutscher Aristokrat im russischen Militär Karriere machte und schließlich im Kampf gegen die Bolschewiki exekutiert wurde, wird über die Person eine „Mikrogeschichte“ des imperialen Kontextes geschrieben. Dabei lässt Sunderland die Leser an seinen Recherchebemühungen und Überlegungen teilhaben, indem er diese offen anspricht. $^{75}$

Ein ganz anderes Themenfeld steht im Fokus der Arbeiten von Claudia Verhoeven oder Stephan Rindlisbacher, die das radikale Milieu im späten Zarenreich mit einem personenzentrierten Fokus beleuchten. Das missglückte Attentat auf den russischen Zaren durch Karakozov 1866 und die Bedeutung dieses Moments für die „Geburt des Terrorismus“ im Kontext der Moderne beziehungsweise die Lebensläufe der beiden Frauen Vera Zasulič und Vera Figner (1852-1942) in den

72 Michael Khodarkovsky: Bitter Choices. Loyalty and Betrayal in the Russian Conquest of the North Caucasus. Ithaca 2011, S. 5-6 und 170.

73 Für die „shifting identities“vgl.: Alexander P. Kaplunovskiy: Die Politisierung der Angestellten im späten Zarenreich. In: Walter Sperling (Hrsg.): Jenseits der Zarenmacht. Dimensionen des Politischen im Russischen Reich 1800-1917. Frankfurt am Main u. a. 2008, S. 313. Für die „prinzipielle Heterogenität“, vgl. Ilya V. Gerasımov: Modernism and Public Reform in Late Imperial Russia. Rural Professionals and Self-Organization, 1905-30. Basingstoke 2009, S. 140. Weiter schreibt Gerasimov an dieser Stelle von der Biografie als Möglichkeit, die verschiedenen Zugehörigkeiten, die ein Bewohner des Imperiums aufweisen kann, an einer Person exemplarisch aufzuzeigen. Vgl. auch die Überlegungen zum Einfluss der Mobilität in den Karrieren der Staatsangestellten auf deren Imperienund Raumwahrnehmung: Malte RoLF: Einführung: Imperiale Biographien. Lebenswege imperialer Akteure in Groß- und Kolonialreichen (1850-1918). In: Geschichte und Gesellschaft 1 (2014), S. 5-21.

74 Khodarkovsky: Bitter Choices, S. 6 und Lässig: Die historische Biographie auf neuen Wegen?, S. 49-50 zu fiktionalen oder spekulativen Elementen in Biografien, deren reflektierte Einbettung in der Geschichtswissenschaft neben Kritik durchaus auch Zustimmung findet.

75 Willard Sunderland: The Baron's Cloak. A History of the Russian Empire in War and Revolution. Ithaca 2014, S. 1-11, insb. 8-9 zur Mikrogeschichte. 
revolutionären Netzwerken des späten Zarenreichs stehen im Zentrum. Dabei ist, wie Rindlisbacher es zusammenfasst, „die Interaktion zwischen Individuen, Strukturen und Praktiken" von vorrangigem Interesse. ${ }^{76}$ Bei vielen dieser und ähnlicher Arbeiten spielen Selbstzeugnisse allerdings nur eine Nebenrolle. $\mathrm{Zu}$ oft fehlen entsprechende Quellen. Ohne eine Antwort darauf zu haben, sinniert Sunderland deshalb am Schluss seiner Arbeit zu Baron von Ungern-Sternberg rhetorisch: „Was dachte er wohl über sich selbst?" ${ }^{\text {"77 }}$ Diese Frage nach der autobiografischen Selbstverortung und der Bedeutung, die diese für das Leben des Individuums hatte, soll in der Arbeit über Anatolij Koni maßgeblich sein.

Das „Ereignis“ des Zasulič-Falles brachte Koni dazu, einen Prozess der autobiografischen Verarbeitung in Gang zu setzen, der bezogen auf dieses Erlebnis wesentliche Züge seines Selbstverständnisses und seiner grundsätzlichen Überzeugungen in den Bereichen Recht, Politik und Gesellschaft offenlegt. Wie prägend diese Grundzüge waren, zeigt sich an der Textgeschichte. Während Koni wohl 1885 eine erste schriftliche Form seiner Erlebnisse verfasste, arbeitete er daran zu verschiedenen Zeitpunkten in seinem Leben weiter. Um 1904 erstellte er eine vorläufige Endversion der „Zasulič-Erinnerungen“, aber noch kurz vor seinem Tod im mittlerweile sowjetischen Russland widmete er sich erneut der Rückschau auf den Prozess. ${ }^{78}$ Gewissen Elementen blieb er dabei über all die Jahrzehnte hinweg ",reu“. Kristallisiert am Zasulič-Prozess werden drei Themenbereiche sichtbar, die für Koni zeitlebens relevant blieben. Der Aufbau der Arbeit folgt diesen Grundzügen. Ein erster Teil widmet sich Konis Auseinandersetzung mit den Rechtsberufen und seinen Kollegen, ein zweiter Teil verfolgt seine Einstellung zu Macht und Politik und ein dritter Teil orientiert sich an seinen Legitimationsstrategien zwischen „Volk“ und literarischer Intelligencija. Zu Beginn der drei Teile wird jeweils Konis Auseinandersetzung mit dem jeweiligen Thema in seiner Erinnerungsschrift an den Zasulič-Prozess herausgearbeitet. Anhand spezifischer „Momente“, in denen Koni besonders intensiv in Form von weiteren Texten und anderen Formen der Selbstdarstellung über sein Leben nachdachte, werden die entsprechenden Themen in den drei Teilen danach über die Zeit hinweg in ihrer Veränderung erfasst. Die Selbstzeugnisse, die Koni im Verlauf seines Lebens anfertigte, werden so in den Mittelpunkt der Analyse gerückt und dienen als Hauptquellen der Arbeit. Besonders wichtig sind dabei nicht nur die veröffentlichten Schriften, sondern auch Konis Nachlass mit den entsprechenden Manuskripten. ${ }^{79}$

76 Rindlisbacher: Leben für die Sache, S. 8.

77 Sunderland: The Baron's Cloak, S. 233.

$78 \mathrm{Vgl}$. detailliert zu den verschiedenen Manuskripten unten, Fußnote 21 in TEIL ZWEI.

79 Beim Versuch, eine Übersicht über Konis Selbstzeugnisse zu erhalten, war neben der allerdings keineswegs vollständigen Gesamtausgabe seiner Werke aus den 196oer-Jahren 
$\mathrm{Zu}$ Beginn der verschiedenen „Momente“ werden in einem Überblickskapitel jeweils die konkreten Erinnerungstexte beleuchtet, die zu diesem Zeitpunkt aus einem spezifischen Entstehungszusammenhang heraus verschriftlicht wurden, und es wird eine knappe Übersicht über die entsprechenden Inhalte gegeben. Die nachfolgenden Kapitel widmen sich dem Selbstverständnis, das sich in diesen autobiografischen Praktiken ausmachen lässt, und dessen Bedeutung für Konis Verortung in diesem Moment. Die Interpretation von Funktionsweise und Wirkung der Selbstreflexion wird durch Unterkapitel ermöglicht, die sich weg von den konkreten Inhalten von Konis Texten und hin zum Kontext bewegen. Neben Biografie und Zeitgeschichte werden hier insbesondere Wechselwirkungen und Vergleiche mit anderen Akteuren relevant.

Für Koni war der Zasulič-Prozess als Kristallisationspunkt der Spannungen zwischen Justiz, Regierung und Opposition ein Erlebnis persönlicher Enttäuschung. Mangelnde Kollegialität und Loyalität innerhalb der Berufsgruppe trafen ihn tief. Dieser erste Grundzug seiner Interpretation des Ereignisses sensibilisierte ihn fortan für Fragen von Professionalisierung und Berufsethik. Die Auseinandersetzung mit seiner Berufsgruppe zeigt sich im Rahmen von Konis Erinnerungsschreiben am deutlichsten im letzten Jahrzehnt des Zarenreiches, als er eine schier endlose Zahl an biografischen Skizzen - eine spezielle Spielart autobiografischer Praxis - über seine Berufskollegen publizierte. Im Kontext eines immer noch mehr schlecht als recht funktionierenden Rechtswesens setzte er sich darin mit Grundwerten der Profession, der Rolle von Expertise im gesellschaftlichen Gefüge und seiner eigenen Position in der Juristenschaft auseinander. Diese Porträts veröffentlichte er nicht nur in Zeitschriften und Rechtspublikationen, sondern auch in eigenen Sammelbänden. Während er 1888 erstmals seine Gerichtsreden in einem solchen Band bündelte, kamen bald weitere Sammelbände hinzu, in

(vgl. Angaben in Fußnote 98) vor allem eine Bibliografie sehr hilfreich, die 1924/25 in einem Jubiläumsband für Koni erschien (vgl. Angaben in Fußnote 386 in TEIL DREI). Dank des Nachlasses von Koni, der heute in den beiden Archiven IRLI in St. Petersburg und GARF in Moskau lagert, konnte die Entstehung der Texte teilweise nachverfolgt, verschiedene Versionen miteinander abgeglichen und unveröffentlichtes Material gesichtet werden. Allerdings ist das persönliche Archiv außerordentlich groß (vgl. dazu ausführlich unten, S. $373 \mathrm{ff}$ ) und gerade dem Abgleich der Versionen wurde durch den enormen Umfang des Materials, das nicht immer gut lesbar ist, gewisse Grenzen gesetzt. Trotz intensiver Bemühungen waren auch die Datierung und die Einordnung von Überarbeitungsphasen nicht immer eindeutig zu bewerkstelligen. Nach bestem Wissen und Gewissen wurde vor diesem Hintergrund versucht, einen möglichst umfassenden Überblick über Konis autobiografisches Schaffen zu erhalten, auch wenn die unterschiedlichen Titel und die immer neuen Kombinationen, in denen Koni seine Erinnerungsbruchstücke anordnete und ergänzte, eine Herausforderung bleiben. 
denen er sowohl seine Fach- und Gerichtstexte als auch seine bereits in Periodika publizierten autobiografischen und biografischen Werke abdruckte.

Koni selber sah zu diesem Zeitpunkt auf eine lange und durchaus erfolgreiche Karriere zurück (tabellarische Übersicht inkl. Schwerpunkte der autobiografischen Praxis nach der Einleitung). Aus dem Zasulič-Fall hatte keineswegs nachhaltige Ächtung resultiert. Schon 1885, sieben Jahre nach dem Prozess, wurde Koni als Oberstaatsanwalt an das Kriminalkassationsdepartement berufen. Dieses war als Teil des Dirigierenden Senats die oberste Gerichtsbehörde im Zarenreich, die großen Einfluss auf die Rechtsprechung hatte. ${ }^{80}$ Zusammen mit einem Gremium aus Senatoren musste der Oberstaatsanwalt Urteile niederer Instanzen begutachten. ${ }^{81}$ 1891 wurde Koni gar selber zum Senator ernannt und amtete für einige Jahre in dieser Doppelfunktion. In der Mitte der 189oer-Jahre begann dann allerdings sein gradueller Rückzug aus dem aktiven Justizdienst. Koni demissionierte von seinem Posten als Oberstaatsanwalt, blieb zwar bis zur Auflösung des Gremiums gut zwei Jahrzehnte später Senator, ab 1900 allerdings lediglich in der „Ersten Allgemeinen Versammlung “. ${ }^{82}$ Neu übernahm er am Alexanderlyzeum eine Vor-

80 Peter Liessem: Verwaltungsgerichtsbarkeit im späten Zarenreich. Der Dirigierende Senat und seine Entscheidungen zur russischen Selbstverwaltung (1864-1917). Frankfurt am Main 1996, S. 23-24. 1866 wurden im Rahmen der Gerichtsreform das Kriminal- und das Zivilkassationsdepartement als neue Kammern eingerichtet und sorgten für Übergewicht der judikativen Belange innerhalb der Aufgaben des Senats. Vgl. ebd., S. 21 ff zur Vorgeschichte des Dirigierenden Senates, der 1711 von Zar Peter dem Großen zur Aufsicht über die Verwaltung sowie als „Zentrum der Staatsmaschinerie“ institutionalisiert worden war.

81 Baberowski: Autokratie und Justiz, S. 92-93. Am Kriminalkassationsdepartement wurde über Urteile und Prozesse niederer Instanzen verhandelt, von denen Strafverteidiger oder Staatsanwaltschaft der Meinung waren, dass es bei der Einhaltung der Verfahrensnormen, der Interpretation des Gehalts der Gesetze oder der Zumessung des Strafmaßes zu Fehlern gekommen war. Der Oberstaatsanwalt hatte jeweils ein Gutachten zur Gesetzesauslegung vorzubringen, während ein Gremium aus Senatoren schließlich entschied, ob das Urteil aufgehoben und an die erste Instanz zurückverwiesen werden sollte.

82 Vysockij: Koni, S. 427-28, Brian L. Levin-Stankevich: Koni, Anatolii Fedorovich (1844-1927). In: The Modern Encyclopedia of Russian and Soviet History, Bd. 3, 1980, S. 153-55 und Konis eigene Aussage in Anatolij F. KonI: Triumviry. In: ders.: Sobranie sočinenij, 8 Bände, Bd. 2, hrsg. v. V. G. Bazanov/L. N. Smirnov/K. I. Čukovskij. Moskva 1966-1969, S. 302-03. Der Ernennung zum Senator im Kriminalkassationsdepartement war der Rücktritt Konis als Oberstaatsanwalt vorangegangen. Bald darauf übernahm er die alte Funktion aber erneut unter Beibehaltung des Senatorenamtes. 1896 folgte dann der endgültige Rücktritt als Oberstaatsanwalt. Noch vier Jahre lang blieb Koni Senator im Strafrechtsbereich, bevor er in die „Erste Allgemeine Versammlung“ [Pervoe obščee sobranie] wechselte. Dieses Gremium setzte sich aus Senatoren verschiedener Departemente des Dirigierenden Senats zusammen. Zudem gehörten Senatoren dazu, die wie Koni nur in dieser Versammlung tätig waren, vgl. Liessem: Verwaltungsgerichtsbarkeit 
lesung zum Strafgerichtsverfahren, insgesamt war seine Arbeitsbelastung durch den Wechsel in die Allgemeine Versammlung des Senats nun deutlich reduziert. ${ }^{83}$

$\mathrm{Zu}$ diesem Zeitpunkt wird der zweite prägende Grundzug in Konis Reaktion auf das „Ereignis“ Zasulič besonders relevant für ihn. Der Prozess von 1878 hatte ihn in engen Kontakt mit politischen Führungspersönlichkeiten und deren Überlegungen zur Funktion der Justiz im autokratischen Staat gebracht. Dies verdeutlichte für Koni die Relevanz seiner eigenen Analysen der politischen Situation im Zarenreich der zweiten Hälfte des 19. Jahrhunderts und die Notwendigkeit, diese im Kontakt mit Entscheidungsträgern aus der Machtelite einzubringen. Als er nun gegen Jahrhundertende von seiner Tätigkeit als Oberstaatsanwalt zurücktrat, blickte er in einer kleinen Zahl an sehr umfangreichen Erinnerungsschriften auf seine Karriere und die wichtigen Fälle darin zurück. Auch dabei verhandelte Koni insbesondere den politischen Aspekt seiner Tätigkeit und seine eigene Position im Verhältnis zu Zar und Staatsmacht. Das Manuskript von Konis Erinnerungen an den Zasulič-Prozess lässt sich hier selber als Teil dieser Schriften analysieren, weil er es nach der Jahrhundertwende ergänzte, überarbeitete und für beendet erklärte. Daneben steht eine memoiristische Aufarbeitung von Konis Zeit am Kriminalkassationsdepartement und den dortigen rechtlichen Konflikten sowie eine Erinnerungsschrift zu seiner Handhabung der Untersuchung zur Entgleisung des Zarenzuges im Jahre 1888.

Diese gänzlich im privaten Bereich verbliebene Auseinandersetzung mit seinem Berufsleben, seinen eigenen politischen Lösungsvorschlägen und seiner Be-

im späten Zarenreich, S. 96. Die „Erste Allgemeine Versammlung“ hatte sich um Fälle zu kümmern, bei denen es in den Departementen nicht zu einer Einigung gekommen war, vgl. detailliert für weitere Gründe ebd., S. 87 ff. Es handelte sich bei diesen Departementen und folglich auch bei der Versammlung also nicht länger um eine rein juristische Instanz, wie es das Kassationsdepartement war. Vielmehr vermischten sich administrative und judikative Vollmachten, insbesondere im 1. Departement. Beschwerden von Privatleuten beispielsweise gegen die Einziehung zum Militärdienst wurden ebenso behandelt wie die Bestätigung von Friedensrichtern oder die Behandlung abstrakter Rechtsfragen von Ministerien, vgl. ebd., S. 26-27.

83 Die Sitzungen der „Ersten Allgemeinen Versammlung“ des Senats fanden relativ selten statt, und es gab eine geringere Menge an zu lesenden Akten. Gerade jene Senatoren, die einzig für diese Versammlung ernannt wurden, waren denn teilweise auch nur unzureichend juristisch ausgebildet. Oftmals wurden die Ernennungen auch mit dem Ziel vorgenommen, älteren Gouverneuren, Generälen oder Ministern mit einem solchen Posten ein geruhsames Alter zu ermöglichen oder sie elegant abzuschieben, vgl. Liessem: Verwaltungsgerichtsbarkeit im späten Zarenreich, S. 97. Koni unterrichtete von 1901 bis 1910 an der Eliteschule des Alexanderlyzeums im Raum Petersburg, vgl. Slovar' členov Obščestva ljubitelej Rossijskoj slovesnosti: Koni, Anatolij Fëdorovič. In: SČOLRS, 1911, S. $145-46$. 
zugnahme zum Zaren als Alleinherrscher veränderte sich im Moment der ersten Revolution in Russland zwischen 1905 und 1907. Nach Jahren der Unterdrückung setzten sich nach der Jahrhundertwende die liberalen und sozialistischen Kräfte insofern durch, als dass in Russland mit dem „Oktobermanifest“ erstmals der Weg zu Parlamentswahlen freigemacht wurde, die 1906 stattfanden. Zar Nikolaus II. (1868-1918), der 1894 auf den verstorbenen Alexander III. (1845-1894) gefolgt war, sorgte aber schnell wieder dafür, dass diese Duma seine Macht nicht wesentlich einschränken konnte. ${ }^{84}$ Koni begrüßte grundsätzlich die breiteren Beteiligungsmöglichkeiten. Bereits in den 1870/8oer-Jahren hatte er sich selber als Ehrenfriedensrichter zur Wahl gestellt, und 1904 war er für kurze Zeit als Politiker auf lokaler Ebene im Stadtparlament von St. Petersburg tätig. ${ }^{85} 1907$ wurde er schließlich Mitglied im Staatsrat, der zweiten Parlamentskammer, wo er bis zu deren Auflösung ein Jahrzehnt später an diversen Gesetzgebungsprojekten zum Justizsystem, den Rechten für Frauen oder der Alkoholproblematik mitarbeitete. ${ }^{86}$ Unter dem Eindruck der gewaltsamen revolutionären Ereignisse von 1905 verfasste Koni einige kurze, zu Lebzeiten nie veröffentlichte autobiografische Texte, die deutlich sein eigenes Ringen hinsichtlich der Interpretation seiner Karriere und seiner Kontakte in der Machtsphäre deutlich machen. Sein Rückblick auf das Berufsleben veränderte sich graduell, weil Koni angesichts der aufgeheizten

84 Unruhen und Streiks überzogen nach dem sogenannten Blutsonntag im Januar 1905, als eine friedliche Arbeiterdemonstration in St. Petersburg von Elitetruppen in ein Blutbad verwandelt worden war, das Land. Ein breit abgestütztes Bündnis zwischen Arbeiterschaft, Opposition in den lokalen Selbstverwaltungsorganen und weiteren liberalen und sozialistischen Kräften prägte zu Beginn die Bewegung. Mit dem „Manifest“ vom 17. Oktober 1905 wollte der Zar die moderateren Kräfte darunter vom revolutionären Kurs abbringen, und tatsächlich kämpften die radikaleren Gruppierungen um die Arbeiterräte fortan auf verlorenem Posten. Das im Frühjahr 1906 eröffnete Parlament, das im „Oktobermanifest“ zugestanden worden war, wurde vom Zar aber schon nach wenigen Monaten aufgelöst und später auch das Wahlrecht nach dem Gusto der Regierung angepasst, vgl. Andreas KAPPELER: Russische Geschichte. München 2014, S. 31 und Haumann: Geschichte Russlands, S. 301-05.

85 SAšonko: A. F. Koni v Peterburge - Petrograde - Leningrade, S. 189-9o zu Konis Ämtern als gewählter Friedensrichter und Ehrenfriedensrichter und dem wertlosen Boden, den er extra kaufen musste, um die Bedingungen für die Kandidatur zu erfüllen. Vgl. zur Funktion des Ehrenfriedensrichters Anna D. Popova: Femida v èpochu preobrazovanij. Sudebnye reformy 1864 g. i rubeža XX-XXI vv. v kontekste modernizacii. Moskva 2009, S. $186 \mathrm{ff}$. Ehrenfriedensrichter hatten zwar die gleichen Rechte wie Friedensrichter, wurden aber nicht entlohnt. Sie agierten als Vertretungen, was aber nicht immer zuverlässig funktionierte. B. B. Dubencov u. a. (Hrsg.): Peterburgskaja gorodskaja duma, 1846-1918. Sankt-Peterburg 2005, S. 150-54 zum Stadtparlament.

86 SAšonko: A. F. Koni v Peterburge - Petrograde - Leningrade, S. 224-25. 
Stimmung Ambitionen im Staatsdienst und eigene liberale Grundwerte miteinander zu verrechnen hatte.

Selbst der Prozess gegen Vera Zasulič erhielt in diesem Kontext plötzlich eine neue Funktion in Konis Selbstdarstellung. Entgegen gängiger Lesart deutet sich an, dass die Auseinandersetzung mit der eigenen Rolle in Staat und Gesellschaft nicht zwingend erst mit dem in der Forschung oftmals als totalen Bruch interpretierten Moment der Oktoberrevolution von 1917 verbunden werden muss, sondern zumindest im Falle von Koni schon wesentlich früher begann. ${ }^{87}$ Als die Machtübernahme der Bolschewiki im Oktober 1917 tatsächlich erfolgte, traf sie Koni in vollem Aktivismus. Wenige Monate zuvor hatten Unruhen und Streiks von Arbeitern und Soldaten der zarischen Selbstherrschaft ein Ende bereitet. Die Provisorische Regierung, die zwischenzeitlich die Macht übernahm, verstand Russland als demokratische Republik und liberalen Rechtsstaat mit bürgerlichen Grundrechten. ${ }^{88}$ Koni wurde wieder an das Kriminalkassationsdepartement berufen und diskutierte über große Fragen der Weiterentwicklung des Gerichtswesens, als der Oktoberumsturz ihn sowohl seines juristischen als auch seines politischen Amtes im Staatsrat beraubte. ${ }^{89}$ Die vollständige Neukonzeption von Recht und Rechtsprechung im frühen Sowjetrussland, als die Anwälte und Gerichte aus der Zarenzeit auf verdammenswerte Instrumente der damals herrschenden Klasse reduziert wurden, ließ ihn aber nicht völlig verstummen. ${ }^{90}$ Er versuchte in stark

87 Vgl. z. B. Wolfgang Stephan Kissel: Der Kult des toten Dichters und die russische Moderne. Puškin, Blok, Majakovskij. Köln 2004, S. 269-72. Kissel spricht vom „Epochenbruch“, der es nötig habe werden lassen, die Geschichte einer ganzen Generation an Intellektuellen der russischen Moderne neu zu schreiben. Eine spezifische Art von Erinnerungstexten dieser Personen fokussierte in den 1920er-/3oer-Jahren auf Polemik und Rechenschaft.

88 Kappeler: Russische Geschichte, S. 33-34 und Eugene Huskey: Russian Lawyers and the Soviet State. The Origins and Development of the Soviet Bar, 1917-1939. Princeton New Jersey 1986, S. 27-29.

89 Nikolaj P. KARABČEvsKIJ: Čto glaza moi videli. II. Revoljucija i Rossija. Berlin 1921, S. $124 \mathrm{ff}$ und SmoljarčUk: Anatolij Fëdorovič Koni (1844-1927), S. 135. Koni übernahm das Amt des Vorsitzenden. Nachdem aufgrund nach wie vor ungelöster Probleme im Verlauf des Sommers die Anhängerschaft der kleinen, gut organisierten sozialistischen Partei der Bolschewiki angewachsen war, übernahmen diese in der Nacht vom 25. auf den 25. Oktober mit der Hilfe bewaffneter Arbeitereinheiten die Macht. Wider verbreiteten Erwartungen gelang es ihnen, ihre Stellung zu konsolidieren, vgl. KAPpeler: Russische Geschichte, S. 34-35 und Haumann: Geschichte Russlands, S. 328-34. Es folgte die sofortige Auflösung aller politischen und gerichtlichen Strukturen aus der Zarenzeit und den Monaten unter der Provisorischen Regierung, vgl. Robert Sharlet: Pashukanis and the Withering Away of Law in the USSR. In: Sheila Fitzpatrick (Hrsg.): Cultural Revolution in Russia 1928-1931. Bloomington Indiana 1978, S. 169.

9o Huskey: Russian Lawyers and the Soviet State, S. 35-37 zum marxistischen Rechtsverständnis. 
reduzierter Form auch in den 1920er-Jahren gewisse rechtliche Impulse zu geben. Vor allem aber bemühte er sich im Moment dieser fundamentalen bolschewistischen Neukonzeption von Staatswesen und gesellschaftlichen Strukturen so intensiv wie nie zuvor um publizistische Präsenz. Koni wollte seine schon um die Jahrhundertwende fertiggestellten Erinnerungen an sein Berufsleben und zahlreiche dazu passende, neu skizzierte biografische Skizzen über die Politiker seiner Aktivzeit wie den Finanzminister Sergei Witte veröffentlichen und so insbesondere seine politischen Einschätzungen zum Zarenreich in die öffentliche Diskussion einbringen.

Bis zu seinem Tod 1927 blieb Koni ein gebrechlicher, aber äußerst engagierter Einwohner St. Petersburgs, das mittlerweile Leningrad genannt wurde. Er, der nie geheiratet hatte, wurde im Alter gleich von mehreren Frauen umsorgt - darunter Elena Vasil'evna Ponomareva, eine wohlhabende Dame aus Charkow -, die sich nicht nur um sein Wohlbefinden bemühten, sondern auch zahlreiche seiner autobiografischen Texte für ihn niederschrieben. ${ }^{91}$ Seine Hauptbeschäftigung in den letzten Lebensjahren war neben der Arbeit an den Erinnerungstexten und entsprechenden Publikationsbemühungen das Vortragen vor Publikum in verschiedenen Organisationen wie dem „Haus der Literaten“ oder dem „Haus der Wissenschaftler".92

Diese öffentlichen Auftritte widmete Koni dabei mehrheitlich einer weiteren Spielart seiner autobiografischen Praxis: Literatenporträts und Literaturanalysen. Der dritte prägende Grundzug, der in Konis Verarbeitung des Prozesses gegen Vera Zasulič auszumachen ist, weist bereits auf dieses Engagement hin. Der Gerichtsfall von 1878 funktionierte für Koni nicht zuletzt auch wie eine Lupe, unter der sich die Gesellschaftsstruktur des späten Zarenreichs besonders deutlich abbildete. Die Gerichtsverhandlung und insbesondere ihre Folgen warfen für Koni dabei ein äu-

91 Vasilij I. SMOLJARČU K: A. F. Koni i ego okruženie. Moskva 1990, S. 357-6o und SAšonko: A. F. Koni v Peterburge - Petrograde - Leningrade, S. 280-82. Elena V. Ponomareva ist laut Smoljarčuk 1868 geboren und überlebte Koni. Die beiden lernten sich in den 189oerJahren kennen, ein intensiver Briefwechsel setzte ein und einige Jahre vor seinem Tod zog Ponomareva, nach der Oktoberrevolution ihres Vermögens beraubt, schließlich bei Koni ein. Vgl. zum Briefwechsel insb. Domanova, die aufzeigt, dass sich Koni und Ponomareva bis in die 1920er-Jahre brieflich austauschten, Svetlana A. Domanova: Perepiska A. F. Koni. Problemy sravnitel’nogo izučenija. In: N. I. Basovskaja u. a. (Hrsg.): Istočnikovedenie i komparativnyj metod v gumanitarnom znanii. Tezicy dokladov i soobščenij naučnoj konferencii. Moskva 1996, S. 242-44.

92 Das „Haus der Literaten“ und das „Haus der Wissenschaftler“ waren nach der Oktoberrevolution wichtige Treffpunkte für Hunderte von Literaturschaffenden und Wissenschaftler, vgl. Karl Schlögel: Petersburg. Das Laboratorium der Moderne 1909-1921. München 2002, S. $577 \mathrm{ff}$ und $593 \mathrm{ff}$. 
Berst schlechtes Licht auf die "gebildete"Schicht seiner Mitmenschen, was sich in seinem Schreiben in einer vertieften Suche nach Legitimation im einfachen „Volk“ niederschlug. Schon früh nutzte Koni seine autobiografischen Reflexionen, um eine Beziehung mit der Bevölkerung herzustellen. Dabei spielten Schriftsteller und die klassische künstlerische Intelligencija, die sich in besonders engem Verhältnis zu diesen Menschen sah, für Koni eine wichtige Rolle. Schon in den 188oer-Jahren begann er damit, über Literaturkritik juristische Fragen und künstlerische Adaptionen in Bezug zueinander zu setzen. Bald lernte er berühmte Schriftsteller wie Fëdor Dostojewski (1821-1881) oder Lew Tolstoi (1828-1910) persönlich kennen und hielt seine Erinnerungen an diese Treffen wiederum in Texten fest, die er in den ersten beiden Jahrzehnten des 20. Jahrhunderts breit publizierte. ${ }^{93}$ Es folgten eigene literarisch-autobiografische Versuche wie die Schriften über seine Ausbildung, seine Reisen oder Kuraufenthalte. Schon seit 1896 war Koni Mitglied der renommierten Akademie der Wissenschaften und wurde neben Schriftstellern wie Tolstoi oder dem Novellisten Anton Pavlovič Čechov (1860-1904) in die „Abteilung für Belletristik" der Wissenschaftsinstitution aufgenommen. ${ }^{94}$

Nach dem Oktoberumsturz wurde nun dieses Feld zum Hauptbetätigungsbereich von Koni. Seine Erinnerungen an die Literaten und seine Auftritte vor den verschiedensten Kunst-, Literatur- und Wissenschaftsorganisationen der frühen Sowjetunion waren dabei immer der Beschäftigung mit den Menschen und ihren Werten und Haltungen gewidmet, die Koni auf diese Art mit zu prägen versuchte. Die Fragen nach den ethischen Grundlagen des Zusammenlebens und der Zukunft Russlands beschäftigten Koni in den Jahren vor seinem Tod schließlich auch in privaten Notizen, die nicht für die Öffentlichkeit gedacht waren. Diese blieben im Archiv des "Puschkinhauses" erhalten, wohin Koni seinen Nachlass, um dessen Erstellung und Ordnung er sich schon frühzeitig zu kümmern begonnen hatte, in Obhut gab. ${ }^{95}$

93 Mit Tolstoi traf Koni 1887 das erste Mal persönlich zusammen, als er auf Einladung eines Freundes hin auf das Landgut des Schriftstellers fuhr. Dostojewski lernte er in Zusammenhang mit einer gerichtlichen Angelegenheit kennen, in die der Schriftsteller 1873 involviert war. Beide traf Koni mehrfach und zahlreiche Briefe sind überliefert, vgl. mit einer Zusammenfassung der persönlichen Beziehung Smoljarčuk: A. F. Koni i ego okruženie, S. $146 \mathrm{ff}$ und 16off. Oftmals war Konis Tätigkeit im Justizwesen Anlass für seine persönliche Bekanntschaft mit Literaten, so beispielsweise auch im Falle von Ivan Sergeevič Turgenev (1818-1883), der aus Neugier 1874 beim St. Petersburger Bezirksgericht vorbeischaute und dort auf Koni traf, vgl. ebd., S. 126-27.

94 SMOlJarčuk: Anatolij Fëdorovič Koni (1844-1927), S. 139-41ff.

95 Das heutige „Institut für russische Literatur - Puschkinhaus“ gehört der Abteilung für Literatur und Sprache der Akademie der Wissenschaften an, vgl. Wolfgang KASACK: Die Akademie der Wissenschaften der UdSSR. Überblick über Geschichte und Struktur: 
Indem Konis autobiografisches Schreiben in seiner textuellen Dimension als „Sinnganzes“ verstanden wird, soll der Umgang eines Individuums mit den Spannungsfeldern und Identifikationsangeboten seiner Zeit beleuchtet werden. Konis verschiedene Verortungen und seine Auseinandersetzung mit der eigenen Berufsgruppe, der höchsten Machtsphäre und der künstlerischen Intelligencija helfen zu verstehen, wie es ihm gelang, ein selbstbewusstes Verständnis seiner Person und seiner Rolle vom autokratischen Zarenreich in die Sowjetunion und posthum gar darüber hinaus zu transportieren. Die Bedeutung von Gesellschaft, Literatur und Intelligencija und deren vielfältige Bezüge zu "Zar" und „Volk“, aber auch Konis Interpretation von „liberal“ werden in seinen Reflexionen greifbar und zeigen auf, wie individualisiert und mannigfaltig solche Konzepte für die eigenen Interessen und Zukunftsvisionen genutzt werden konnten. Da die autobiografische Praxis in ihrem Entstehungszusammenhang und als Teil einer „komplexen Kommunikationssituation" interpretiert wird, wird der Fokus auf die verschiedenen Ziele und die Handlung gelegt, die durch das Erinnern erfolgte. Die Analyse in „Momenten“ betont dabei die Verbindung zwischen Erinnerungsschreiben und Zeitgeschehen und will das Wirkungspotential dieser autobiografischen Praktiken, die in Russland zu dieser Zeit so intensiv betrieben wurden, für das Individuum ausloten. Mit diesem Vorgehen werden zwei grundlegende Erkenntnisinteressen miteinander verschränkt. Die Ergebnisse aus der Analyse der autobiografischen Praxis sollen gleichzeitig Aufschluss über Funktionsweise und Stellenwert von Selbstreflexion für den einzelnen Menschen und sein größeres Umfeld geben. Dies erlaubt gleichsam als Brücke die intensivierte Betrachtung von Koni in seinem Kontext und im Zusammenspiel mit weiteren Akteuren. Professionalisierung und Entwicklung der Justiz und der juristischen Berufsgruppe im autokratischen Staatswesen, Herausforderungen durch individuelle Ambitionen vor dem Hintergrund von Verschärfungen und Polarisierungen im politischen Klima oder die Veränderungen im Zeit- und Geschichtsverständnis durch die radikalen Umwälzungen nach 1917 sowie die neuen Bruchlinien zwischen Emigranten und Zurückgebliebenen rücken in den Mittelpunkt.

Nicht zuletzt ermöglicht der Fokus auf Konis Selbstdarstellung Erklärungen für seine prominente Position im heutigen Russland. Seine autobiografischen Schriften und biografischen Porträts von Berufskollegen und Literaten boten nach dem Zerfall der Sowjetunion optimale Anknüpfungspunkte für eine Gesellschaft,

Verzeichnis der Institute. Boppard 1978, S. 108-09. Es wurde 1905 gegründet und ist ein Archiv für Handschriften und Erinnerungen an den großen russischen Dichter Alexander Puschkin (1799-1837) und die ihm nachfolgenden Schriftsteller, vgl. A. B. Muratov: A. F. Koni i Puškinskij Dom. In: V. N. Baskakov (Hrsg.): Puškinskij Dom. Stat'i. Dokumenty. Bibliografija. Leningrad 1982, S. 37-38. 
die auf der Suche nach Anleitungen und Vorbildern gerade aus dem imperialen Russland war. Die von Koni in seinem Schreiben geprägten Narrative erwiesen sich bisweilen als derart erfolgreich, dass sie auch in der populärwissenschaftlichen und wissenschaftlichen Literatur über ihn und die russische Justiz ungefiltert Eingang fanden, worauf im Ausblick der Arbeit näher eingegangen wird.

Ungeachtet der wichtigen Stellung Konis sowohl im Zarenreich als auch im Russland des 21. Jahrhunderts ist die Beschäftigung mit ihm in der Forschung relativ bescheiden. Wohl nicht zuletzt aufgrund der größtenteils fehlenden Übersetzung seiner juristischen Fachtexte und autobiografischen Schriften existieren außerhalb des russischsprachigen Raums nur sehr wenige wissenschaftliche Arbeiten, die sich näher mit seiner Person beschäftigen. ${ }^{96}$ Etwas umfangreicher ist hingegen die Auseinandersetzung mit Konis Gerichtsreden und ihrer Rhetorik aus einer literaturwissenschaftlichen oder rechtshistorischen Perspektive. ${ }^{97}$ In Russland selber wurde mit der Herausgabe einer achtbändigen Zusammenstellung von Konis fachlichen und autobiografischen Texten sowie zahlreichen Briefen in den 1960er-Jahren der Grundstein für die weitere Beschäftigung mit ihm gelegt. ${ }^{98}$

96 Michael Ginsburg: Koni and His Contemporaries. Authors. Indiana Slavic Studies 1 (1956); Elizabeth Ballantine: Koni and the Russian Judiciary, 1864-1917. Yale University 1986 (unveröffentlichte Dissertation); Mark G. Pomar: Anatoly Fedorovich Koni. Liberal Jurist as Moralist. Pittsburgh 1996.

97 Der Fokus auf Koni und seine Reden ist dabei unterschiedlich stark ausgeprägt, insbesondere in den Arbeiten zum Zusammenhang von Literatur und Recht, der noch mehrmals Thema sein wird, kommt Koni aber prominent vor, vgl. für Monografien dazu v. a. aus dem amerikanischen Raum Harriet Murav: Russia’s Legal Fictions. Ann Arbor Michigan 1998; Anna Schur: Wages of Evil. Dostoevsky and Punishment. Evanston Illinois 2012; Yanina V. ARnold: Writing Justice. Fiction and Literary Lawyers in Late Imperial Russia, 1864-1900. University of Michigan 2014 (Dissertation in Open Access). Vgl. für deutschsprachige Arbeiten zur Gerichtsrhetorik mit Schwerpunkt auf Koni: Regula Spalinger-BichSel: A. F. Koni und die russische Gerichtsrhetorik. Zürich 1993 (unveröffentlichte Dissertation); Elena Kanty penko: Klassische Plädoyers in Strafprozessen der „europäischen Ära“ russischer Rechtsentwicklung nach der Justizreform von 1864. In: Werner Krawietz (Hrsg.): Gewohnheitsrecht, Rechtsprinzipien, Rechtsbewusstsein. Transformationen der Rechtskultur in West- und Osteuropa: interdisziplinäres Symposion 2004 an der Universität Münster. Berlin 2004.

98 Anatolij F. Konı: Sobranie sočinenij, 8 Bände, hrsg. v. V. G. Bazanov/L. N. Smirnov/K. I. Čukovskij. Moskva 1966-1969. In der Folge werden die acht Bände der Gesamtausgabe von Konis Schriften abgekürzt als GA1-8. An dieser Zusammenstellung war mit dem Literaturkritiker und Schriftsteller Kornej Ivanovič Čukovskij (1882-1969) jemand beteiligt, der mit Koni persönlich gut bekannt gewesen war. Die Gesamtausgabe enthält neben dem Abdruck zahlreicher von Koni zu Lebzeiten publizierter Texte aller Art auch einige Erstpublikationen von Manuskripten. Dabei handelt es sich um Erinnerungsschriften, deren Veröffentlichung Koni aus verschiedenen Gründen nicht gelungen war und die in 
Neben einigen schon früher erschienenen Aufsätzen wurde aber erst im Zuge der Öffnung der Sowjetunion in den 1980er-Jahren Konis Persönlichkeit prominent mit mehreren Biografien bedacht. ${ }^{99}$ Diese zeichnen sich oft durch intensive Recherchen in Konis Nachlass aus, allerdings fehlen Belege teilweise fast ganz und es wird in einer Art und Weise aus Konis Selbstzeugnissen zitiert, die oftmals die Trennung zwischen Selbstdarstellung und Analyse des Autors verunmöglicht. ${ }^{100}$ Die Haltung der Biografen, die Koni manchmal auch in einem der Sowjetunion genehmen Licht darzustellen versuchten, schimmert zudem immer wieder durch.

In den 1990er-Jahren und später wurde Koni beziehungsweise seine schriftliche Hinterlassenschaft dann zwar sehr intensiv rezipiert und mit zahlreichen Aufsätzen bedacht, aber die wissenschaftliche Auseinandersetzung wurde nur punktuell weitergeführt. Besonders hervorzuheben ist hier die unveröffentlichte Dissertation von Svetlana Domanova zu Konis außerordentlich umfangreicher brieflicher Hinterlassenschaft. ${ }^{101}$ Im Zusammenhang mit der Restrukturierung der

seinem Nachlass gelagert hatten. Weder haben die Herausgeber aber alle Manuskripte aus dem Archiv publiziert noch haben sie alle veröffentlichten Texte in die Sammlung aufgenommen. Die Kommentare zu den Schriften und ihren verschiedenen Versionen sind in Umfang und Aussagekraft sehr unterschiedlich. Die Gesamtausgabe wird ergänzt um einige kürzere Analysen, die sich verschiedenen Aspekten von Konis Leben und Tätigkeit widmen, vgl. S. VolK/M. Vydrja/A. Muratov: Anatolij Fëdorovič Koni. In: GA1, S. 5-36; M. Vydrja: A. F. Koni kak sudebnyj orator. In: GA3, S. 5-19; I. D. Perlov: Pravovye vozzrenija A. F. Koni. In: GA4, S. 5-32; A. B. Muratov: Literatur'nye vzgljady A. F. Koni. In: GA6, S. 5-23; Kornej ČukovskiJ: Anatolij Fëdorovič Koni. In: GA8, S. 5-25. Schon zuvor erschienen ab und zu kurze Aufsätze zu Koni, meist Würdigungen in juristischen Zeitschriften beispielsweise anlässlich seines 30. Todestages, vgl. L. JACHNič: Anatolij Fëdorovič Koni. K 30-letiju so dnja smerti. In: Sovetskaja justicija 7 (1957), S. 52-56; M. ŠIfMAN: A. F. Koni vydajuščijsja jurist i sudebnyj orator. K 30-letiju so dnja smerti. In: Socialist. zakonnost' 9 (1957), S. 51-56.

99 Vasilij I. Smoljarčuk: Anatolij Fëdorovič Koni (1844-1927). Moskva 1981; Sergej A. Vysockij: Koni. Moskva 1988; Aleksandr M. Larin: A. F. Koni. Sudebnyj dejatel.' Moskva 1988; Vasilij I. SmoljarčuK: A. F. Koni i ego okruženie. Moskva 1990; Vladimir N. SAšonko: A. F. Koni v Peterburge - Petrograde - Leningrade. Leningrad 1991; und schon früher: N. I. Leonov: Obščestvenno-političeskie vzgljady A. F. Koni v 60-70 gody XIX veke. Moskovskij gosudarstvennyj universitet imeni M. V. Lomonosova, Moskva 1974 (unveröffentlichte Dissertation).

100 Dies trifft insbesondere auf Vysockij zu. Er hat auf Basis seiner Recherchen in Konis Nachlass und Textkorpus nach der Biografie gar noch einen historischen Roman über den berühmten Juristen verfasst, in dem Forschung und Fiktion endgültig ineinander übergehen, vgl. Sergej A. Vysockij: Sud'ja i prokuror. Istoričeskij roman. Moskva 1994.

101 Svetlana A. Domanova: Perepiska A. F. Koni kak istoričeskij istočnik. Rossijskij gosudarstvennyj gumanitarnyj universitet, Moskva 1999 (unveröffentlichte Dissertation). Von den zahlreichen kurzen Ehrungen Konis in Zeitschriften, vgl. z. B. I. GRIL'/A. SoKolova: K 150-letiju so dnja roždenija A. F. Koni. Druz’ja i edinomyšlenniki i Poslednie gody žizni. 
Justiz nach 1991 erschienen zudem verschiedentlich Arbeiten zum vorrevolutionären Rechtssystem und den Ansichten und Überzeugungen, die Koni diesbezüglich vertreten hatte. ${ }^{102}$ Wenn Koni in der aktuellen westlichen Forschungsliteratur auftaucht, dann oftmals in Zusammenhang mit der Forschung zur Reform des russischen Justizsystems 1864 und der weiteren Entwicklung des Rechtswesens im imperialen Russland. Sowohl in Grundlagenwerken zur reformierten Justiz als auch in Arbeiten zu rechtlichen Besonderheiten wie beispielsweise der bäu-

In: Rossijskaja justicija 2 (1994), S. 31-34. Zum Teil werden in kurzen Aufsätzen, die leider nicht alle mit Belegen versehen sind, auch spezifische Themenschwerpunkte ausgelotet, wie beispielsweise Konis Jahre in Charkow, seine Haltung zur Sowjetunion oder sein Engagement für eine Presserechtsgesetzgebung nach der Jahrhundertwende, vgl. M. A. BALYŠEv/A. A. ŠAndula: Anatolij Fëdorovič Koni i char'kovčane. O novych faktach iz žizni izvestnogo russkogo jurista. In: Universitates. Nauka i prosveščenie 3 (2007), S. 26-36; Anton BAKUnCEv: Anatolij Fëdorovič Koni, russkaja ėmigracija i sovetskaja vlast'. In: Inye Berega. Žurnal o russkoj kul'ture za rubežom 3 (2011), S. 58-62; Anton V. Lichoмanov: A. F. Koni v osobom soveščanii po sostavleniju novogo Ustava o pečati. In: Cenzura v Rossii: Istorija i sovremennost'. Sankt-Peterburg 2008, S. 125-41. Gerne widmen sich diese kurzen Arbeiten auch Konis Briefwechsel mit berühmten Persönlichkeiten, vgl. z. B. A. Ju. BALAKIn: Neizvestnye stranicy vospominanij A. F. Koni o Gončarove. In: Russkaja Literatura 2 (2012), S. 97-104; V. G. Buchert: Pis'ma S. F. Platonova A. F. Koni. In: Archeografičeskij ežegodnik za 1995 god. Moskva 1997, S. 351-54. Schon deutlich früher z. B.: T. I. Lysenko: O perepiske A. F. Koni s A. A. Šachmatovym. In: Archeografičeskij ežegodnik za 1979 god. Moskva 1981, S. 274-83. Erst kürzlich wurde gar umfangreiches Briefmaterial des Schriftstellers Ivan Aleksandrovič Gončarov (1812-1891) an Koni auf Deutsch übersetzt und publiziert, vgl. Ivan GončArov: Briefe an Anatolij F. Koni und andere Materialien, hrsg. u. kommentiert v. Vera Bischitzky. Köln u. a. 2016.

102 Neben kleineren Studien wie z. B.: A. V. Iljuchin: A. F. Koni o sude prisjažnych. In: Rossijskij sud'ja 8 (2001), S. 40-46 oder B. A. Kaloev: A. F. Koni o Kavkaze. In: Ėtnografičeskoe Obozrenie 3 (1997), S. 149-56 hat sich eine Dissertation gar um den Stand des Wissens der russischen Rechtsstudenten über Koni und dessen ideellen Einfluss auf die Justizreform Ende der 199oer-Jahre gekümmert: Anatolij V. ŠApovalov: Pravovye vzgljady A. F. Koni i ich vlijanie na provodimuju v Rossii sudebno-pravovuju reformu. Kubanskij gosudarstvennyj agrarnyj universitet, Krasnodar 2005 (unveröffentlichte Dissertation). Eine weitere Dissertation widmet sich den philosophischen Grundlagen verschiedener juristischer Denker, vgl. Anatolij N. JAšın: Filosofskie idei russkich myslitelej sudebnoj zaščity II poloviny XIX veka. A. F. Koni, V. D. Spasovič, F. N. Plevako, K. K. Arsen’ev, S. A. Andreevskij. Murmanskij gosudarstvennyj techničeskij universitet, Murmansk 2009 (unveröffentlichte Dissertation). Auch zur Gerichtsrethorik erschienen verschiedene Arbeiten, z. B. jene von Z. Baiševa, u. a. Z. V. BAIšEva: Vyraženie oratorskogo „Ja“ v obvinitel’nych rečach A. F. Koni. In: „Černye dyry“ v Rossijskom zakonodatel'stve 1 (2004), S. 403-05. Daneben erschienen zahlreiche Lesebücher und Sammlungen von Gerichtsreden, wie z. B.: I. РотAPČUK: Russkie sudebnye oratory v izvestnych ugolovnych processach XIX veka. Tula 1997. 
erlichen Gerichtsbarkeit spielt der berühmte Jurist immer wieder eine Rolle. ${ }^{103}$ Besonders wichtig für die Kontextualisierung von Koni und seinem Schaffen sind die Arbeiten, die sich unmittelbar mit der Herausbildung der Juristenschaft oder verwandter staatlicher Elitegruppen auseinandersetzen. ${ }^{104}$ In der Forschung zum imperialen Justizwesen liegt ein Schwerpunkt auch auf der Entwicklung der rechtlichen und administrativen Gesetzgebung oder in jüngster Zeit auf der Rechtsprechung an der imperialen Peripherie sowie der Nutzung der neuen Gerichte durch ethnische und religiöse Minderheiten. ${ }^{105}$ Die verschiedenen Ansätze und

103 Das erste umfassende Werk zu den reformierten Gerichten im Zarenreich legte Jörg Baberowski vor, vgl. Jörg BABERowski: Autokratie und Justiz. Zum Verhältnis von Rechtsstaatlichkeit und Rückständigkeit im ausgehenden Zarenreich 1864-1914. Frankfurt am Main 1996. Koni taucht darin immer wieder auf, da seine Fachtexte und Memoiren wichtige Einblicke in zeitgenössische Diskussionen und Einschätzungen geben. Genau gleich verhält sich das bei weiteren Gesamtdarstellungen zur russischen reformierten Justiz in der zweiten Hälfte des 19. Jahrhunderts, vgl. Marina V. Nemy tina: Sud v Rossii. Vtoraja polovina XIX-načalo XX vv. Saratov 1999. Ausgiebig beforscht wurde in den letzten Jahrzehnten auch die bäuerliche Rechtsprechung in den Volost'-Gerichten, vgl. insbesondere Jane Burbank: Russian Peasants Go to Court. Legal Culture in the Countryside, 1905-1917. Bloomington 2004. Auch hier spielt Koni eine Rolle, nun als Vertreter einer juristischen Elite, die in Burbanks Optik die Situation der Bauernschaft und deren Rechtsbewusstsein verkannte. Vgl. mit einer Einschätzung zur Forschungsliteratur über das reformierte Gerichtswesen und weiteren Titeln zu den Volost'-Gerichten auch Richard Wortman: Russian Monarchy and the Rule of Law. New Considerations of the Court Reform of 1864. In: Kritika: Explorations in Russian and Eurasian History 1 (2005), S. 163-70, v. a. 169.

104 Vgl. u. a. Jane Burbank: Discipline and Punish in the Moscow Bar Association. In: Russian Review 1 (1995), S. 44-64; Edith W. Clowes/Samuel D. Kassow/James L. West (Hrsg.): Between Tsar and People. Educated Society and the Quest for Public Identity in Late Imperial Russia. Princeton 1991; Brian L. Levin-Stankevich: The Transfer of Legal Technology and Culture: Law Professionals in Tsarist Russia. In: Harley D. Balzer (Hrsg.): Russia’s Missing Middle Class. The Professions in Russian History. Armonk New York u. a. 1996, S. 223-43; Peter Liessem: Verwaltungsgerichtsbarkeit im späten Zarenreich. Der Dirigierende Senat und seine Entscheidungen zur russischen Selbstverwaltung (1864-1917). Frankfurt am Main 1996; Dominic Lieven: Russia's Rulers Under the Old Regime. New Haven Connecticut 1989; Heike Kathrin Litzinger: Juristen und die Bauernfrage. Die Diskussion um das bäuerliche Grundeigentum in Russland von 188o bis 1914. Frankfurt am Main 2007; Peter H. Solomon (Hrsg.): Reforming Justice in Russia, 1864-1996. Power, Culture, and the Limits of Legal Order. Armonk New York 1997 und natürlich - auch zu den Juristen, die im Vorfeld der Gerichtsreform aktiv waren: Richard Wortman: The Development of a Russian Legal Consciousness. Chicago 1976.

105 Vgl. zu Letzterem den Sammelband von Stefan B. Kirmse (Hrsg.): One Law for All? Western Models and Local Practices in (Post-)Imperial Contexts. Frankfurt am Main 2011 und insbesondere sein eigener Beitrag: KIRMSE: Dealing with Crime in Late Tsarist Russia. Muslim Tatars and the Imperial Legal System. In: ebd., S. 209-41, darin auf S. 212 eine Übersicht zu Arbeiten aus diesem Themenfeld. Für die Entwicklungen im gesetzli- 
Schwerpunkte, mit denen hier auf das russische Rechtswesen um die Wende vom 19. zum 20. Jahrhundert geblickt wird, sind - so bringt es Richard Wortman auf den Punkt - alle in irgendeiner Form vom gleichen Interesse angetrieben. Es ist dies die Prüfung, ob die Entfaltung eines Rechtsstaates innerhalb des russischen Zarenreiches möglich gewesen ist. ${ }^{106}$ Eine Frage, die auch in der Beschäftigung mit Anatolij Konis autobiografischen Praktiken zweifelsohne eine Rolle spielt.

Selbstverständlich - und hier schließt sich der Kreis - nimmt in der aktuellen Forschung zum russischen Imperium und seinem Rechtswesen auch Vera Zasulič und der Prozess von 1878 eine zentrale Position ein. Bis heute scheint der sensationelle Freispruch nichts von seiner Faszination verloren zu haben. Eine Vielzahl an Studien widmet sich aus verschiedenen Perspektiven dem Gerichtsfall, der für Koni so prägend sein sollte. ${ }^{107}$

\begin{tabular}{l|l|l}
$*$ & Biografische Eckpunkte & Schwerpunkte autobiografischer Praxis \\
\hline 1844 & * St. Petersburg & Notizen, Tagebucheinträge, Textentwürfe \\
1862 & $\begin{array}{l}\text { Studium, Juristische Fakultät } \\
\text { Moskau }\end{array}$ & \\
1865 & $\begin{array}{l}\text { Juristischer Staatsdienst } \\
\text { u. a. in Charkow und Kasan }\end{array}$ \\
1871 & $\begin{array}{l}\text { Staatsanwalt am St. Petersburger } \\
\text { Bezirksgericht }\end{array}$ \\
1875 & $\begin{array}{l}\text { Direktion Justizministerium } \\
1878\end{array}$ & $\begin{array}{l}\text { Vorsitzender St. Petersburger } \\
\text { Bezirksgericht; } \\
\text { Prozess Vera Zasulič }\end{array}$
\end{tabular}

chen Bereich vgl. z. B.: William G. WAGNER: Marriage, Property, and Law in Late Imperial Russia. Oxford u. a. 1994; Johnathan W. DALY: Emergency Legislation in Late Imperial Russia. In: Slavic Review 3 (1995), S. 602-19; E. A. Pravilova: A Public Empire. Property and the Quest for the Common Good in Imperial Russia. Princeton 2014.

106 Wortman 2005, S. 145.

107 Vgl. neueren Datums Ana Siljak: Angel of Vengeance. The Girl Assassin, the Governor of St. Petersburg and Russia’s Revolutionary World. New York 2008; Richard Pipes: The Trial of Vera Z. In: Russian History 37 (2010), S. 1-82; Lynn Patyk: Dressed to Kill and Die. Russian Revolutionary Terrorism, Gender, and Dress. In: Jahrbücher für Geschichte Osteuropas 2 (2010), S. 192-209; Stephan Rindlisbacher: Leben für die Sache. Vera Figner, Vera Zasulič und das radikale Milieu im späten Zarenreich. Wiesbaden 2014; Tat'jana J. Borisova: „Neobchodimaja oborona obščestva“. Jazyk suda nad Zasulič. In: Novoe literaturnoe obozrenie 5 (2015), S. 101-18. 


\begin{tabular}{|c|c|c|}
\hline * & Biografische Eckpunkte & Schwerpunkte autobiografischer Praxis \\
\hline 1881 & $\begin{array}{l}\text { Vorsitzender Zivildepartement } \\
\text { St. Petersburger Gerichtskammer }\end{array}$ & \\
\hline 1885 & $\begin{array}{l}\text { Oberstaatsanwalt am Krimi- } \\
\text { nalkassationsdepartement des } \\
\text { Dirigierenden Senats }\end{array}$ & \\
\hline $1891 / 92$ & $\begin{array}{l}\text { Doppelfunktion als Ober- } \\
\text { staatsanwalt und Senator am } \\
\text { Kriminalkassationsdepartement }\end{array}$ & \\
\hline 1896 & Rücktritt als Oberstaatsanwalt & \\
\hline 1900 & $\begin{array}{l}\text { Als Senator nur noch in der } \\
\text { „Ersten Allgemeinen Versamm- } \\
\text { lung“ tätig; } \\
\text { Aufnahme in die „Abteilung } \\
\text { für Belletristik“ der Akademie } \\
\text { der Wissenschaften }\end{array}$ & $\begin{array}{l}\text { Umfangreiche, vorerst unveröffentlichte } \\
\text { Erinnerungsschriften über die Karriere am } \\
\text { Kriminalkassationsdepartement und wichtige } \\
\text { Fälle wie die Entgleisung des Zarenzugs } 1888 \\
\text { oder den Zasulič-Prozess } 1878\end{array}$ \\
\hline 1905 & Erste Russische Revolution & $\begin{array}{l}\text { Kurze autobiografische Textentwürfe unter } \\
\text { dem Eindruck der revolutionären Ereignisse }\end{array}$ \\
\hline 1907 & $\begin{array}{l}\text { Ernennung zum Staatsrat } \\
\text { (zweite Parlamentskammer) }\end{array}$ & $\begin{array}{l}\text { Reihe „Alltagstreffen“ mit verschiedenen } \\
\text { literarisch-autobiografischen Erzählungen; } \\
\text { Seit Puschkins Ehrung 188o: Literatur- } \\
\text { analysen und (Erinnerungs-)Porträts von } \\
\text { Literaten; }\end{array}$ \\
\hline 1914 & 50 Jahre Gerichtsreform & $\begin{array}{l}\text { Reihe „Aus den Notizen und Erinnerungen } \\
\text { eines Gerichtstätigen“; } \\
\text { Zahlreiche biografische Porträts von den } \\
\text { Gerichtsreformern und ihren Nachfolgern }\end{array}$ \\
\hline 1917 & $\begin{array}{l}\text { Nach der Februarrevolution: } \\
\text { U.a. Vorsitzender des } \\
\text { Kriminalkassationsdepartements } \\
\text { Nach der Oktoberrevolution: } \\
\text { endgültige Auflösung von } \\
\text { Staatsrat und Senat }\end{array}$ & \\
\hline 1918 & $\begin{array}{l}\text { Professor und Vortragender } \\
\text { für diverse Institutionen, u. a. } \\
\text { die Petrograder Universität } \\
\text { oder das „Haus der Literaten“ }\end{array}$ & $\begin{array}{l}\text { Publikationsversuche der Erinnerungsschrif- } \\
\text { ten über die Karriere und wichtige Fälle; } \\
\text { Entwürfe von biografischen Skizzen über } \\
\text { Politiker der Zarenzeit; } \\
\text { Unzählige Auftritte mit Literaturanalysen } \\
\text { und den (Erinnerungs-)Porträts von } \\
\text { Literaten; } \\
\text { Bruchstückhafte Notizen über das eigene } \\
\text { Leben, Russland und dessen Zukunft; } \\
\text { Nachlassplanung }\end{array}$ \\
\hline
\end{tabular}


TEIL EINS 



\section{Der Fall Vera Zasulič - ein Mahnbeispiel für mangelnde Kollegialität}

„Ich will nicht die Verantwortung für Ihre falschen Handlungen übernehmen!“ So zitiert Koni in seiner Erinnerungsschrift an den Fall Vera Zasulič, die er schon wenige Jahre nach dem Prozess begann und schließlich um 1904 in eine vorläufige Endversion brachte, den Justizminister Graf Pahlen. ${ }^{1} \mathrm{Zu}$ diesem war er einige Tage nach dem Freispruch der Attentäterin einbestellt worden. Der Vorwurf der "falschen Handlungen“ bildet den Auftakt für eine Verteidigungsansprache Konis. In direkter Rede dargelegt, folgt der Leser beeindruckt dem angeschuldigten Gerichtsvorsitzenden, der aus dem Stegreif dem Minister in rhetorischer Geschliffenheit alle Vorwürfe zu widerlegen scheint. Punkt für Punkt arbeitet sich Koni vor und verteidigt sein Handeln seitenlang. Alle könnten seine den Prozess beschließende Rede nachlesen, es müsse eine Fehlinterpretation sein, wenn man diese als parteilich für Zasulič interpretiere. Er habe immer gesagt, dass dem Verteidiger ein fähiger Ankläger gegenübergestellt hätte werden sollen. Aleksandrov zu stoppen in seiner Auslegung der Gründe für Vera Zasuličs Tat, hätte lediglich eine kontraproduktive Reaktion der Geschworenen zur Folge gehabt. Diese wären misstrauisch geworden, dass man ihnen etwas vorenthalte. Dabei sei es doch so wichtig, dass die Gesellschaft an ihr Gericht glaube. Die Zeugen habe er genau nach gesetzlichen Vorschriften und der bisher üblichen juristischen Praxis zugelassen. Man könne ihn doch nicht dafür rügen, das Gesetz nicht verletzt zu haben. Schließlich sei Trepov selber schuld, wenn er nicht vor Gericht erscheine und kein Gegengewicht entstehe. Und ja, es sei beim Freispruch lärmig geworden im Gerichtssaal, aber hätte er etwa Ausschreitungen riskieren sollen, um die Ruhe in blutiger Form wiederherstellen zu lassen? Und über die Vorwürfe, „Nihilisten“ mit Eintrittskarten versorgt zu haben, darüber könne er nur die Schultern zucken. Das Publikum habe aus Vertretern der mittleren gebildeten Schicht St. Petersburgs bestanden. ${ }^{2}$

Auf diese umfassende Auflistung reagierte Pahlen - so schildert es Koni in seiner Erinnerungsschrift - mit Worten, die die einzig folgerichtigen zu sein

1 Anatolij F. KonI: Vospominanija o dele Very Zasulič. In: GA2, S. 194. Wenn nicht anders angemerkt, wird jeweils aus der Version zitiert, die in der Gesamtausgabe abgedruckt ist und der im Wesentlichen die Überarbeitung von nach der Jahrhundertwende zugrunde liegt. Auf Unterschiede zwischen den verschiedenen Manuskripten wird im Verlauf der Arbeit näher eingegangen.

2 Ebd., S. 194-201. 
scheinen: „Nun, Anatolij Fëdorovič, es kann sein, dass Sie sogar recht haben und ihre Verhaltensweisen juristisch richtig waren [...]. ${ }^{\text {33 }}$

Sein Handeln als juristisch korrekt zu belegen, ist Koni in seiner gesamten, in gedruckter Form um die 150 Seiten starken Erinnerungsschrift ein offensichtliches Anliegen. Er rechtfertigt und erklärt sein Agieren im Prozess und ordnet es als streng vorschriftsgemäß ein: Er habe juristisch nur seine Pflicht getan und entgegen aller Vorwürfe keine Beeinflussung der Geschworenen in Richtung Freispruch vorgenommen. Inmitten der aufgeheizten Stimmung sei seine Prozessführung so neutral und professionell wie möglich gewesen.

Über den Verweis auf die juristische Korrektheit suchte Koni in seiner Darlegung einen Ausweg aus den politischen Druckversuchen und gesellschaftlichen Erwartungen, mit denen er nach dem aufsehenerregenden Gerichtsfall konfrontiert worden war. Gleichzeitig versuchte er so, das Justizwesen aus der politischen Schusslinie zu nehmen, in die es mit dem Vorwurf der revolutionären Unterwanderung geraten war.

Diese Bemühungen wurden aber - so erinnert sich Koni - von anderen Juristen torpediert. Wie ein Leitmotiv ziehen sich durch die „Erinnerungen an den Fall Vera Zasulič “ Episoden von mangelnder Solidarität seines Umfelds. Etwa ein Drittel der Schrift ist der Zeit nach dem Freispruch gewidmet und davon wiederum beschäftigt sich ein beträchtlicher Teil mit den Reaktionen, die Koni aus seinem Umfeld auf das Zasulič-Ereignis erhalten hatte. Den Anfang nimmt das Ganze im bereits erwähnten Gespräch mit Justizminister Graf Pahlen, als dieser seine Vorwürfe folgendermaßen bekräftigt: „Alle, alle sagen, dass Ihre Verhaltensweisen falsch waren [...].“ „Was sind das schon für Leute?" - zitiert Koni sich daraufhin selber - „Welche ernsthafte Bedeutung können die Meinungen von Leuten haben, die nichts von der Gerichtssache verstehen? Ihre Schreie betrüben mich überhaupt nicht; eine andere Sache sind Missbilligungen von ernsthaften Juristen, aber solche habe ich bis jetzt nicht gehört .... "Woraufhin Pahlen - von Koni weiterhin in Dialogform notiert - dem Petersburger Juristen deutlich macht, dass er sich irre, dass auch erfahrene Juristen dieser Meinung seien, darunter Semën Aleksandrovič Mordvinov. „Er?!“, ruft Koni aus. ${ }^{4}$ Der Verrat scheint total - denn dramaturgisch geschickt hat Koni wenige Seiten vorher einfließen lassen, dass der oberste Vorsitzende der Petersburger Gerichtskammer und Senator Mordvinov (1825-1900) ihm persönlich versichert habe, man hätte den Prozess nicht anders führen können, als Koni dies getan habe. ${ }^{5}$ Diese dramatische Dolchstoß-Inszenierung bildet

3 Ebd., S. 202. In vollständiger Version heißt der Satz: „[...] aber das wird niemals verstanden in den Sphären, in denen man Sie anschuldigt."

4 Ebd., S. 194.

5 Ebd., S. 192. 
den Auftakt für eine lange Reihe von Vorfällen, in denen Koni die unzureichende Kollegialität seiner Berufsgenossen ins Zentrum stellt. Musterhaft erzählt sich dies an den Passagen zu Staatsanwalt Konstantin Ivanovič Kessel' (1843-1918). Bereits im zweiten Teil der Erinnerungsschrift, die die Zeit vor Prozessbeginn beschreibt, berichtet Koni, wie Kessel' den Auftrag zur Anklageführung im Zasulič-Fall erhalten habe und darüber völlig verstört gewesen sei. Koni führt aus, dass er Kessel' schon aus ihrer gemeinsamen Zeit an den Gerichtsbehörden von Kasan Anfang der 1870er-Jahre gekannt und Sympathien für diesen gehabt habe. So habe er ihn in Kasan vor dem Unmut anderer Juristen geschützt und ihn mit Aufgaben betraut, die dieser trotz seiner mangelnden Begabung als Ankläger gut habe bewältigen können. ${ }^{6}$ Gegen Schluss der Zasulič-Erinnerung kommt nun die Rede wieder auf Kessel', und Koni berichtet in einem kurzen Exkurs:

Darüber, wie sich Kessel’ zu seiner Pflicht als Ankläger im Fall Zasulič verhielt, habe ich weiter oben schon gesprochen. Nun kam es so, dass er [...] auch den Kassationsprotest zum Fall aufsetzen musste. Darin hat er sich nicht geschämt zu sagen, indem er auf fiktive Verletzungen verwies [...] dass die Verhaltensweisen des Vorsitzenden des Bezirksgerichts im Fall Zasulič sich deutlich zur Verdunklung der Wahrheit im Interesse eines Freispruchs von Zasulič neigten. Der Protest wurde zur Durchsicht ans Ministerium geschickt und wurde von da mit Billigung zurückgegeben und Kessel' war offenbar außerordentlich erstaunt, dass ich aufhörte, ihm die Hand zu geben, ungeachtet seiner mehrfachen Versuche, sich bei Treffen mir gegenüber zu verhalten, als sei nichts vorgefallen. ${ }^{7}$

Nach einem Absatz fährt die Erinnerung kommentarlos fort mit Ausführungen zu den Reaktionen des Staatsrats auf den Freispruch. Zu Kessel' scheint alles gesagt: Während sich Koni für den Berufskollegen eingesetzt hatte, hat dieser ihn im Fall Zasulič nicht unterstützt, was ihn auf lange Sicht disqualifiziert. Die Reaktion des Juristen auf den Zasulič-Freispruch dient Koni also als Lackmustest für sein Urteil über die entsprechende Person. Dass dies immer auch ein Urteil über deren Professionalität als Jurist war, zeigt ein weiteres Beispiel besonders deutlich: So habe der Justizminister Koni im persönlichen Gespräch gefragt, ob er denn wenigstens die juristische Autorität von Andrej Aleksandrovič Saburov (1837-1916) akzeptieren würde. Saburov war einer der ersten Staatsanwälte am St. Petersburger Bezirksgericht gewesen und hatte auch in hoher Position im Justizministerium gearbeitet. Dieser Saburov, so legt es Koni Pahlen in den Mund, habe nun gesagt,

6 Ebd., S. 84.

7 Ebd., S. 214-15. 
er würde an Konis Stelle aufgrund des Zasulič-Urteils zurückzutreten. Daraufhin zitiert sich Koni selber: „Wenn er tatsächlich in diesem Sinne spricht - antwortete ich, während ich traurig ,et tu quoque!' dachte - dann ist er für mich natürlich keine Autorität, sondern ein Mensch, der im Verwaltungsdienst die besten ge-

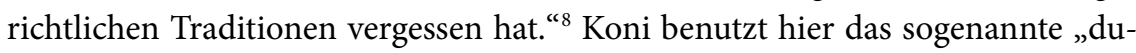
auch“-Argument, mit dem eine Anklage mit dem Verweis auf das Verhalten des Anklägers zurückgewiesen wird. Unwillkürlich ruft das vorangestellte „et“ aber auch das „et tu, Brute!“ in Erinnerung, das Julius Caesar in Shakespeares gleichnamigem Drama ausruft, als der Kaiser im Moment des Verrates begreift, dass sogar sein Vertrauter Brutus in den Komplott involviert war. ${ }^{9}$ Saburov, der einstmals geschätzte Pionier der reformierten Gerichte wird so in Konis Darstellung unmissverständlich zum Verräter der „besten gerichtlichen Traditionen“.

Der Zasulič-Fall bedeutete für Koni die bittere Erfahrung fehlender Rückendeckung durch seine Berufskollegen. Die zahlreichen Episoden à la Kessel' oder Saburov, die sich durch die „Erinnerungen an den Fall Vera Zasulič “ ziehen, verdeutlichen, wie sehr ihn dieses Verhalten getroffen haben musste. Der festen Überzeugung, dass er selber den Fall juristisch einwandfrei geleitet hatte, untergruben die gegenteiligen Aussagen aus den eigenen Reihen den professionellen Anspruch der neuen Gerichte - und damit auch den Ruf von Koni persönlich - in gröbster Weise. Das nachfolgende Kapitel zeigt auf, wie Koni der Gefahr einer unsolidarischen und sich gegenseitig kritisierenden Juristenzunft mit einer Strategie des öffentlichen Lobs entgegentrat. Mit dem exzessiven Verfassen biografischer Porträts seiner Kollegen arbeitete er an einer geschlossenen Berufsgruppe, die sich ihre Handlungsfähigkeit auch unter schwierigen Bedingungen erhalten sollte. Dabei knüpfte er an globalen Professionalisierungstaktiken ebenso an wie an innerrussische Diskussionen um die Rolle der Spezialisten und Experten für die Entwicklung des Landes. Gleichzeitig wurde Koni als Autor einer großen Zahl von biografischen Skizzen zwangsläufig selber mehr und mehr zur makellosen Richtinstanz über den Grad an Professionalität und Kollegialität der beschriebenen Juristen. In einer Wechselwirkung aus Selbst- und Fremddarstellung entwickelte er sich zum Modelljuristen.

8 Ebd., S. 204.

9 Vgl. Jonas Pfister: Werkzeuge des Philosophierens. Stuttgart 2013, S. $126 \mathrm{ff}$ zum „Tu Quoque“-Argument als Teil des Kapitels zu „Fehlschlüssen“ und Amanda MABILlARD: The History and Context of „Et tu, Brute?“. In: Shakespeare Online, 20. 08. 2006, www. shakespeare-online.com/ettubrute.html, Zugriff vom 02. 06. 2016. 


\subsection{Jahre Gerichtsreform 1914: biografische Jubiläumsschriften und autobiografische Erfolgsgeschichten für ein verunsichertes Rechtswesen}

Im August 1888 antwortete Koni dem Literaturwissenschaftler Aleksej Nikolaevič Veselovskij (1843-1918) auf dessen Bitte um seine Mitarbeit für ein biografisches Lexikon:

Ich wiederhole - der allgemeine Verdienst der Schöpfer der Gerichtsstatuten ist sehr groß [...], aber für sich genommen ist keiner von ihnen herausragend - ihnen gebührt ein Platz in der Geschichte der Reform, aber nicht in einzelnen biografischen Skizzen. ${ }^{10}$

Er fügte einige wenige Namen von Gerichtsreformern an, über die man vielleicht etwas Biografisches schreiben könne, schränkte auch dies aber sogleich ein, indem er auf den Mangel an Quellen verwies. Zwei weitere Juristen nannte er unter dem Vorbehalt, dass sie noch lebten und eine Biografie deshalb grundsätzlich wenig sinnvoll sei. ${ }^{11}$ Koni erteilte den Publikationsplänen von Veselovskij damit eine umfassende und unmissverständliche Abfuhr. Umso verblüffender ist es, dass er nur wenige Jahre später seine Meinung radikal änderte. Ab den 189oer-Jahren begann Koni mit zunehmender Regelmäßigkeit biografische Porträts von den Gerichtsreformern und den ihnen nachfolgenden Juristen zu verfassen. Ein Engagement, das 1914 zum 50. Jubiläum der Reform qualitativ wie quantitativ seinen Höhepunkt erreichte. Einer der Gründe für diesen Sinneswandel lag darin, dass mit den Jahren immer mehr Reformer verstarben und sich Anlässe häuften, wo diesen Akteuren mit biografischen Würdigungen gedacht werden sollte. Doch als Erklärung für den regelrechten Boom an Skizzen führt dies nicht weit genug. Omnipräsent als Schreibanlass im Hintergrund lassen sich die mannigfaltigen Probleme im reformierten Rechtswesen ausmachen. Diese nahmen mit der voranschreitenden Etablierung der neuen Berufe und Strukturen nach 1864 keineswegs ab, sondern verschärften sich tendenziell in den letzten Jahrzehnten vor dem Ende des Zarenreiches. ${ }^{12}$ Nachdem die neuen Gerichte schon wenige Jahre nach ihrer

10 GA8, S. 106 (Brief an Aleksej N. Veselovskij vom 29. 04. 1888).

11 GA8, S. 105-07 (Brief an Aleksej N. Veselovskij vom 29. 04.1888).

12 Wortman hält treffend fest: „Die neuen rechtlichen Institutionen und Berufe wurden natürlich mit Problemen konfrontiert, die alle neu gegründeten Organe antreffen würden. Probleme, die mit der Zeit vielleicht hätten überwunden werden können. Aber der Fakt, dass diese Probleme die gleichen blieben oder in den letzten Dekaden des Imperiums gar zunahmen, legt nahe, dass sie eher strukturelle Kontinuitäten anstatt Wachstums- 
Einführung mit zahlreichen Einschränkungen zu kämpfen hatten, wurden in den 189oer- und 190oer-Jahren zwar diverse Projekte zur Weiterentwicklung der Justiz angedacht, beinahe nichts davon aber umgesetzt. Insbesondere die Gesetzbücher verharrten in inkonsistenter und lückenhafter Form. Während die Gerichte sich bemühten, Anpassungen im geltenden Recht vorzunehmen, gelangen maßgebliche gesetzgeberische Maßnahmen aufgrund ideologischer Differenzen und Rivalitäten innerhalb und außerhalb der staatlichen Bürokratie und des politischen Systems nur in sehr bescheidenem Maße. ${ }^{13}$ Ein neues Strafgesetzbuch, an dem jahrelang gearbeitet worden war, wurde nach der Jahrhundertwende lediglich zu einem kleinen Teil in Kraft gesetzt. ${ }^{14}$ Dieser Reformstau führte zum Nebeneinander von verschiedenen Rechtskonzepten und war symptomatisch für die völlig disparate und oftmals miteinander inkompatible Ausgestaltung der Institutionen des späten Zarenreiches. ${ }^{15}$ Die in der Revolution von 1905 erkämpfte Einführung eines Parlaments wurde zudem begleitet vom tiefen Misstrauen des letzten Zaren Nikolaus II., der seine Beziehung zur Bevölkerung nach wie vor einzig in der Kategorie von „Beherrschung und dankbarem Gehorchen“ zu begreifen schien. Unmissverständlich brachte sein Justizminister dies 1914 auf den Punkt, als er im Parlament erklärte, dass in Russland Gesetzlichkeit die „freie Manifestation des höchsten Willens der russischen Autokraten" bedeute. ${ }^{16}$ Diese Haltung aus Regierungskreisen wurde von der politischen Opposition in einer Weise gekontert, die für das Justizwesen ebenfalls nicht unproblematisch war. Einige Anwälte nutzten die Gerichte gerade im Vorfeld und nach der Revolution von 1905 immer ausschließlicher als Arena des politischen Kampfes. Es wurde - beispielsweise mit Streiks - in einer Art und Weise verteidigt, die mit klassischer Rechtsprechung nur noch am Rande etwas zu tun hatte. ${ }^{17}$ Ein Stück weit spiegelte sich in dieser Nutzung des Rechts für die eigenen politischen Zwecke die Einstellung der Auto-

schmerzen waren." Richard Wortman: Russian Monarchy and the Rule of Law: New Considerations of the Court Reform of 1864. In: Kritika: Explorations in Russian and Eurasian History 1 (2005), S. 162.

13 Vgl. William G. Wagner: Marriage, Property, and Law in Late Imperial Russia. Oxford u. a. 1994, S. 56 und 378-82 mit Fokus auf das Zivilrecht.

14 Lothar Schultz: Russische Rechtsgeschichte. Von den Anfängen bis zur Gegenwart einschliesslich des Rechts der Sowjetunion. Lahr 1951, S. 255.

15 Wortman: Russian Monarchy and the Rule of Law, S. 162.

16 Ebd., S. 152 und 156.

17 Jörg BABerowski: Rechtsanwälte in Russland, 1866-1914. In: Charles E. MacClelland/ Stephan Merl/Hannes Siegrist (Hrsg.): Professionen im modernen Osteuropa. Berlin 1995, S. 49-50. Vgl. dazu ausführlicher unten, Kapitel Polarisierung in Justiz und Politik um 1905. 
kratie zur Justiz. ${ }^{18}$ Waren die Anwälte aber nicht politische Aktivisten, wurden sie dafür oftmals mit dem Vorwurf konfrontiert, sich an ihrem Beruf übermäßig $\mathrm{zu}$ bereichern und kein Interesse an moralischen Grundwerten mitzubringen. ${ }^{19}$

In bezeichnender Diskrepanz zu diesem tristen Bild intensivierte sich im letzten Jahrzehnt des 19. Jahrhunderts Konis lobgefüllte Porträtpraxis. Hatte er noch vor Kurzem behauptet, dass die einzelnen Gerichtsreformer und ihre Nachfolger nichts „Herausragendes“ geleistet hätten, klang es nun ganz anders. Als 1889 Aleksandr Dmitrievič Gradovskij (geb. 1841) starb, der zwei Jahrzehnte an der St. Petersburger Universität gelehrt und wesentlich zur Entwicklung des russischen Staatsrechts beigetragen hatte, hielt Koni vor einer Versammlung von Juristen - der „St. Petersburger Juristischen Gesellschaft“ - eine Rede, in der er die Leistung des Pioniers würdigte. Wenig später, an der Jahresversammlung der Gesellschaft Anfang 1892, trat Koni mit einem Vortrag auf, der im Titel durch die Abwandlung der Redewendung vom "alten Wein in neuen Schläuchen“ die Reformzeit und ihre Akteure als in allen Belangen neuartig charakterisiert und zum Thema macht: „Neue Schläuche und neuer Wein“ [Novye mecha i novoe vino]. In dieser Ansprache holte Koni zuerst lange aus, um die Entwicklung der neuen „Schläuche“ des reformierten Gerichts zu rekapitulieren. Ausgehend von der Situation in Frankreich berichtete er, wie sich in Russland das Justizministerium abmühen musste, um anständige Gebäude für das neue Gerichtswesen zu erhalten und so die Reform auch äußerlich umzusetzen. ${ }^{20}$ Den zweiten Teil des Vortrags widmete er dann ganz und gar dem neuen „Wein“, der diese Schläuche füllte. Er blickte auf die vergangenen gut 25 Jahre zurück und berichtete von den Anfangszeiten der Gerichtsreform und ihren besten Exponenten. In raschem Durchgang sprach er über die Bildung erster Kreise von Juristen, die ersten großen Prozessen und die ersten Vorsitzenden der Bezirksgerichte in den Hauptstädten. Auch die Advokatur lobte er in den höchsten Tönen. Und die Geschworenen hätten sich - trotz mancher schwer verständlicher Entscheidungen - als würdig des Vertrauens erwiesen, das die neue Gerichtsordnung in sie gesetzt habe. ${ }^{21}$ Gut zwei Jahre später trat Koni erneut mit einer Rede vor der Juristischen Gesellschaft

18 Brian L. Levin-Stankevich: The Transfer of Legal Technology and Culture: Law Professionals in Tsarist Russia. In: Harley D. Balzer (Hrsg.): Russia’s Missing Middle Class. The Professions in Russian History. Armonk New York u. a. 1996, S. 241.

19 Guido Hausmann: Universität und städtische Gesellschaft in Odessa, 1865-1917. Stuttgart, Köln 1998, S. 364.

20 Anatolij F. Koni: Novye mecha i novoe vino. Iz istorii pervych dnej sudebnoj reformy. In: ders. (Hrsg.): Za poslednie gody. Sudebnye reči (1888-1896), Vospominanija i soobščenija, Juridičeskie zametki. Sankt-Peterburg 1896, S. 461-75.

21 Ebd., S. 475-92, zu den Geschworenengerichten S. 490-91. 
von St. Petersburg auf und sprach nun explizit an, was ihn antrieb: „Es kann sein, dass die vielköpfige Versammlung von mir eine seriöse wissenschaftliche Arbeit erwartet, die streng juristischen Charakter hat [...].“ Aber - so führt er weiter aus - er könne nicht über Themen wie den Strafprozess in Italien und Deutschland reden, ohne auch den Puls in Russland zu fühlen. Und dann sei da eine zweite, rein persönliche Befangenheit. Er habe die letzten eineinhalb Jahre wegen Dienst und Krankheit nicht aktiv an der Tätigkeit der Gesellschaft teilnehmen können. Und jetzt, wo er wieder hier spreche, suche er nach vertrauten Gesichtern, die in der Zwischenzeit verstorben seien:

Die Erinnerung an sie muss Platz in den Sitzungen einer wissenschaftlichen Versammlung haben [...]. Ich denke, dass der Herr Vorsitzende nichts dagegen hat, mir zu erlauben, in kurzen Worten an die seit dem Frühling 1893 verstorbenen Mitglieder der Gesellschaft zu erinnern. ${ }^{22}$

Es folgen zehn Seiten Ehrung für die verschiedenen Juristen, bevor Koni sich schließlich doch noch dem Strafprozess im Ausland zuwendet.

Koni nutzte die Auftritte vor versammelter Juristenschaft also immer deutlicher, um in einer positiven Form an die Zeit der Reform und ihre wichtigsten Aktivisten zu erinnern. Die meisten dieser Reden wurden wenig später veröffentlicht und einem breiteren Publikum zugänglich gemacht. So erschien der Vortrag zum italienischen und deutschen Strafprozess nur einen Monat nach der Versammlung im „Journal des Justizministeriums“ [Žurnal Ministerstva Justicii]..$^{23}$ „Neuer Wein und neue Schläuche“ wurde sofort in der Zeitschrift „Bücher der Woche“ [Knižki Nedeli $]^{24}$ platziert und die Würdigung von Gradovskij erschien Anfang 1891 in der Zeitschrift „Russische Altertümer“ [Russkaja Starina] wie auch schon davor als Teil des Sammelbandes, der von der Juristischen Gesellschaft zum Gedenken an das ehemalige Mitglied herausgegeben worden war. ${ }^{25}$ Ungefähr zur gleichen Zeit publizierte Koni ausführliche Nachrufe auf die Se-

22 Anatolij F. Konı: Juridičeskie pominki i novye tečenija v ugolovnom processe Italii i Germanii. In: ders. (Hrsg.): Za poslednie gody. Sudebnye reči (1888-1896), Vospominanija i soobščenija, Juridičeskie zametki. Sankt-Peterburg 1896, S. 403-04. Konkret spricht Koni über V. A. Arcimovič, A. M. Unkovskij, P. A. Aleksandrov, P. Ja. Levenson, A. V. Belostockij, E. I. Utin, A. A. Markov, wobei er sich dem Letztgenannten am ausführlichsten widmet. Im Sammelband wurde die Rede in zwei gleich aufeinanderfolgende Abschnitte eingeteilt.

25 RS 1 (1891), S. 199-203; Pamjati Gradovskogo, Izd. jurid. Obščestva pri Imperatorskom Sankt-Peterburgskom universitete, Sankt-Peterburg 1890, S. 28-40. Bereits einige Jahre davor hatte Koni einen ausführlichen Nachruf auf den berühmten russischen Historiker 
natoren Viktor Antonovič Arcimovič (1820-1893) und Dmitrij Aleksandrovič Rovinskij (1824-1895). Die Gedenkschrift für Letzteren präsentierte Koni zuerst mündlich sowohl vor der Juristischen Gesellschaft als auch vor der Akademie der Wissenschaften und sprach dabei stolze 3,5 Stunden über den verstorbenen Juristen. ${ }^{26}$ In den nachfolgenden Jahren ehrte Koni mündlich wie schriftlich unter anderem Nikolaj Ivanovič Stojanovskij (1821-1900), der im Justizministerium an der Ausarbeitung der Gerichtsreform gefeilt hatte, seinen ehemaligen Professor an der Universität und berühmten Rechtsphilosophen Boris Nikolaevič Čičerin (1828-1904) sowie den ehemaligen Justizminister Dmitrij Nikolaevič Nabokov (1827-1904). ${ }^{27}$ Bald ging Koni auch dazu über, eigene Sammelbände herauszugeben, in denen die biografischen Würdigungen der Juristen nochmals in kompakter Form abgedruckt wurden. Schon 1888 hatte er mit einer ersten solchen Sammelpublikation große Aufmerksamkeit erregt. Dieses Buch hatte allerdings noch hauptsächlich seine Gerichtsreden enthalten. Auf über 700 Seiten wurden 17 Anklagereden, drei Anleitungen an die Geschworenen und sieben Kassationsentscheidungen abgedruckt. ${ }^{28}$ Solche Reden, in denen offener als irgendwo sonst im von Zensur und mangelnder Partizipation geprägten autokratischen Russland Missstände und die herrschenden Eliten kritisiert werden konnten, wurden zur „begehrten Lektüre der städtischen Intelligenz“.29 Tatsächlich hatte Koni mit der

und Juristen Konstantin Dmitrievič Kavelin (1818-1885) veröffentlicht, vgl. u. a. Anatolij F. Koni: Pamjati Konstantina Dmitrieviča Kavelina. In: RS 6 (1885), S. 649-6o.

26 Anatolij F. Koni: Pamjati V. A. Arcimoviča. In: VE 4 (1893), S. 807-13 sowie Anatolij F. Koni: Dmitrij Aleksandrovič Rovinskij. In: VE 1 (1896), S. 129-75; und VE 2 (1896), S. 607-6o. Ein Teil dieser Veröffentlichung wurde zuvor im Dezember 1895 unter dem Titel „Obščestvennaja i gosudarstvennaja dejatel'nost’ D. A. Rovinskogo “ [Die gesellschaftliche und staatliche Tätigkeit von D. A. Rovinskij] vor der Akademie der Wissenschaften vorgetragen und separat veröffentlicht. Die Angabe zum Umfang seiner Rede macht Koni in einem Brief an eine seiner Halbschwestern, vgl. GA8, S. 132 (Brief an Ljudmila Fëdorovna Gramatčikova vom 01. 01.1896).

27 Anatolij F. Koni: Nikolaj Ivanovič Stojanovskij. In: VP 1 (1901), S. 113-50 sowie in: P 2 (1901), S. 53-88. Dieser Abdruck beruht auf einer Rede vor der Petersburger Juristischen Gesellschaft vom Februar 1900. Fast gleichzeitig auch der Nachruf auf den Mitarbeiter des Kriminalkassationsdepartements Michail Fëdorovič Gubskij (1850-1901), vgl.: Anatolij F. Konı: Gubskij, Michail Fëdorovič. In: P 42 (1901), S. 1862-65. Sowie etwas später: Anatolij F. Koni: Pamjati B. N. Čičerina. In: P 6 (1904), S. 361-66 und Anatolij F. Koni: Pamjati D. N. Nabokova. In: P 12 (1904), S. 713-18. Auch hier ging ein Auftritt vor der Juristischen Gesellschaft voraus.

28 Anatolij F. Koni (Hrsg.): Sudebnye reči, 1868-1888. Sankt-Peterburg 1888. Eingeführt werden die Reden jeweils von knappen Darstellungen des Falls und dem Ausgang des Prozesses.

29 Jörg BAвеRowsкi: Autokratie und Justiz. Zum Verhältnis von Rechtsstaatlichkeit und Rückständigkeit im ausgehenden Zarenreich 1864-1914. Frankfurt am Main 1996, S. 538. 
Entscheidung, einige seiner bis anhin nur verstreut in Zeitungen der Hauptstädte und der Peripheriepresse erschienenen Plädoyers als Sammelband herauszugeben, einen Nerv getroffen. ${ }^{30}$ Das Buch wurde schon zwei Jahre später erneut aufgelegt und erschien auch 1897 und 1905 nochmals. ${ }^{31}$ Prominent an vorderster Stelle nutzte Koni schon diesen Band, um an juristische Akteure zu erinnern. Er widmete ihn nämlich Nikita Ivanovič Krylov (1807-1879), seinem ehemaligen Professor für Römisches Recht an der Moskauer Universität und schrieb dazu: „Für ehemalige Studenten von ihm muss man kaum erklären, warum es zu dieser Widmung kommt. Jenen aber, die Krylov nicht zugehört haben, möge hier eine schwache und entrückte Vorstellung gegeben werden [...]." Auf zweieinhalb Seiten folgt ein Nachruf auf den Professor, in dem er dessen lebendiges Unterrichten, seine Treue und seinen Glauben an die Fähigkeit der Heimat zur „Vervollkommnung über den Weg der rechtlichen Entwicklung " und seine Freude über die Gerichts-

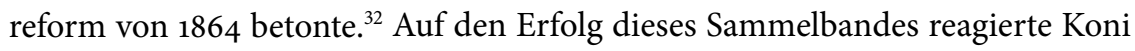
mit der Zusammenstellung eines weiteren, ähnlichen Werkes. Nun spielte die biografische Komponente schon eine deutlich gewichtigere Rolle. „Im Laufe der letzten Jahre" [Za poslednie gody] erschien 1896 und in zweiter Auflage 1898 und enthielt zahlreiche Erinnerungsporträts fast ausschließlich von Juristen. ${ }^{33}$ Wenig

Baberowski spricht gar davon, dass die Anwaltsrede eine „Form des vorparlamentarischen Diskurses" gewesen sei. Koni sprach zwar nicht als Anwalt, seine Reden wurden und werden aber aufgrund von Form und Inhalt ähnlich verortet. Vgl. Nikolaj A. TrогскіJ: Advokatura v Rossii i političeskie processy 1866-1904 gg. Tula 2000, S. 110. Troickij schreibt, dass neben den Advokaten nur noch Koni die Gerichtsreden-Kunst praktiziert hätte. Vasilij I. SmolJarčuk: Anatolij Fëdorovič Koni (1844-1927). Moskva 1981, S. 69 mit der Betonung, dass Konis Reden auch weit weg vom Gerichtsort St. Petersburg in Zeitungen abgedruckt wurden.

31 2. Auflage 189o, 3. Auflage 1897, 4., überarbeitete Auflage: Anatolij F. Koni (Hrsg.): Sudebnye reči. Sankt-Peterburg 1905. In der Auflage von 1905 sind neben klassischen Plädoyers auch einige Fachtexte Konis zu Gerichtsfragen abgedruckt. Weitere Juristen folgten Konis Vorbild und gaben ebenfalls Sammlungen ihrer Plädoyers heraus, vgl. BABEROwski: Autokratie und Justiz, S. 538-39.

32 Koni (Hrsg.): Sudebnye reči, 1868-1888, S. I-IV. Diese Worte, so macht Koni selber transparent, habe er schon beim Tod von Krylov im Dezember 1880 an dessen Grab vorgetragen. Die erweiterte Ausgabe von 1905 widmete er dann Čičerin und führt die bereits erwähnte Erinnerungsschrift an, die er nach dessen Ableben verfasst hatte (S. VII-XIV). Anatolij F. Koni (Hrsg.): Za poslednie gody. Sudebnye reči (1888-1896), Vospominanija i soobščenija, Juridičeskie zametki. Sankt-Peterburg 1896. 2. Auflage 1898. Darin finden sich die schon erwähnten Porträts und Nachrufe auf: D. A. Rovinskij, V. A. Arcimovič, A. D. Gradovskij, K. D. Kavelin. Ebenfalls: Novye mecha i novoe vino; Juridičeskie pominki i novye tečenija v ugolovnom processe Italii i Germanii. Auch ein sehr kurzer, schon 1880 vor der Versammlung des St. Petersburger Bezirksgerichtes vorgetragener Nachruf auf den Juristen Georgij Nikolaevič Motovilov (1834-1880) wurde integriert. Neben den 
später, im Jahre 1906, erschien „Skizzen und Erinnerungen“. Fast der gesamte Band - der über 900 Seiten umfasst - ist gefüllt mit den biografischen Porträts, die Koni in den vergangenen Jahren verfasst hatte; auch hier liegt der Schwerpunkt auf seinen Berufskollegen. ${ }^{34} 1912$ erschienen schließlich die letzten beiden von Koni vor dem Ende des Zarenreiches zusammenstellten Sammelbände. In den schnell schon in mehreren Auflagen veröffentlichten Bänden von „Auf dem Lebensweg" fehlen neben zahlreichen anderen Schriften selbstverständlich auch die Juristenporträts nicht. ${ }^{35}$ Koni fügte dort noch ein, was er zeitlich nach der Veröffentlichung von „Skizzen und Erinnerungen“ verfasst hatte. So das Porträt des

biografischen Juristenporträts erschienen im Sammelband auch wieder einige Gerichtsreden, Entscheidungen des Kassationsgerichtes, diverse Fachtexte zum Rechtswesen und einige wenige biografische Porträts zu anderen Persönlichkeiten. Nicht immer lässt sich die Erstveröffentlichung der Nachrufe - beispielsweise im Falle von Motovilov - eruieren. Oftmals wurden diese nach mündlicher Präsentation in einer Tageszeitung oder Zeitschrift abgedruckt. Nur dank der Sammelbände hielt Koni seine Gedenkschriften auch langfristig fest. Immer wieder kam es dabei vor, dass er für den Wiederabdruck kleinere oder größere Veränderungen, oftmals Ergänzungen, vornahm oder den Wortlaut der Titel leicht anpasste. Der Einfachheit halber wird darauf aber nur dort eingegangen, wo dies in den kommenden Kapiteln noch eine Rolle spielen wird. Umgekehrt bleibt anzumerken, dass nicht ausgeschlossen werden kann, dass Koni weitere Nachrufe und Porträts verfasste, die er ausschließlich in Tageszeitungen oder Zeitschriften veröffentlichte, nicht in seine Sammelbände integrierte und die auch sonst keine weiteren Spuren hinterlassen haben und deshalb nicht aufzufinden sind.

34 Anatolij F. Koni (Hrsg.): Očerki i vospominanija. Publičnye čtenija, reči, stat'i i zametki. Sankt-Peterburg 1906. Darin erneut die bereits erwähnten Namen: K. D. Kavelin, A. D. Gradovskij, V. A. Arcimovič, G. N. Motovilov, D. A. Rovinskij, M. F. Gubskij, N. I. Stojanovskij, B. N. Čičerin, D. N. Nabokov, N. I. Krylov und A. A. Markov sowie einige weitere kurze Nachrufe auf kürzlich verstorbene Juristen und Rechtsgelehrte wie Pavel Osipovič Bobrovskij (1832-1905), Sergej Fëdorovič Moroškin (1844-1900), Aleksandr Michajlovič Bobriščev-Puškin (1851-1903). Eingang in diesen Sammelband fand auch das biografische Porträt des Chefarztes der Gefängnishospitäler und Mitglieds im Gefängnisschutzkomitee Friedrich Joseph Haas (1780-1853), vgl. dazu ausführlicher unten, S. 347. Hinzu kommen eine Rede zum Jubiläum eines juristischen Lehrbuches und seines Verfassers und eine ganze Reihe an Skizzen über Juristen, die im Sammelband zum 40. Jubiläum der Gerichtsreform 1904 erschienen waren. Auf beides wird sogleich noch eingegangen. „Skizzen und Erinnerungen“ enthält auch Porträts von Literaten und anderen wichtigen Akteuren sowie einige weitere Texte.

35 Anatolij F. KonI (Hrsg.): Na žiznennom puti, Bd. 1. Iz zapisok sudebnogo dejatelja, žitejskie vstreči. Sankt-Peterburg 1912, ebenfalls herausgegeben in Moskau 1913, 2. Auflage Moskau 1914. Anatolij F. Koni (Hrsg.): Na žiznennom puti, Bd. 2. Iz zapisok sudebnogo dejatelja, žitejskie vstreči. Sankt-Peterburg 1912, 2. Auflage St. Petersburg 1913 sowie Herausgabe in Moskau 1916. Die sowohl in St. Petersburg beim Verlag Trud als auch in Moskau bei Sytin herausgebrachten Bände wurden für die neuen Auflagen jeweils mit einigen zusätzlichen Texten ergänzt oder um gewisse Beiträge gekürzt. Diese Reihe hat Koni in den 
berühmten Anwalts Aleksandr Ivanovič Urusov (1843-1900), das er 1907 für einen Sammelband zu dessen Ehren geschrieben hatte. Oder eine Skizze über Konstantin Konstantinovič Arsen’ev (1837-1919), der ein Porträt zum 50. Dienstjubiläum des Anwalts und Publizisten aus dem Jahre 1908 zugrunde lag. ${ }^{36}$ Sowohl Urusov als

1920er-Jahren mit weiteren Auflagen und einem 3., 4. und 5. Band fortgesetzt, worauf noch eingegangen wird.

36 Anatolij F. Koni: Vospominanie o knjaze Aleksandre Ivanoviče Urusove. In: Aleksandr I. Urusov/A. A. Andreeva/O. B. Gol'dovskij (Hrsg.): Knjaz' Aleksandr Ivanovič Urusov (1843-190o). Stat'i ego, pis'ma ego, vospominanija o nem, Bd. 2 und 3. Moskva 1907, S. 191-216; leicht angepasst in KoNI (Hrsg.): Na žiznennom puti, Bd. 1 und stärker ergänzt in Konı (Hrsg.): Na žiznennom puti, Bd. 2; zudem darauf aufbauend und erweitert um Erinnerungen an den Anwalt Fëdor Nikiforovič Plevako (1842-1908/o9): Anatolij F. Koni: Dva sudebnych oratora. In: ders. (Hrsg.): Na žiznennom puti, Bd. 2. Iz vospominanij, publičnye čtenija, v verchnej palate. Sankt-Peterburg 1912, S. 416-29. Zu Arsen'ev: Anatolij F. Koni: Konstantin Konstantinovič Arsen'ev. Po povodu 5o-letija ego dejatel'nosti. In: RS 2 (1908), S. 245-55; deutlich erweitert: Anatolij F. KonI: Konstantin Konstantinovič Arsen’ev. Po povodu 50-letija ego dejatel'nosti. In: ders. (Hrsg.): Na žiznennom puti, Bd. 2. Iz vospominanij, publičnye čtenija, v verchnej palate. Sankt-Peterburg 1912, S. 234-60. Die beiden ersten Bände von „Auf dem Lebensweg“ widmete Koni dem 1907 verstorbenen Graf Petr Aleksandrovič Gejden ( $\left.{ }^{*} 1840\right)$, der neben seinem politischen Engagement auch lange an den reformierten Gerichten tätig gewesen war. Zu Beginn des ersten Buches findet sich eine Gedenkschrift für ihn, vgl. Koni (Hrsg.): Na žiznennom puti, Bd. 1, S. 1-7. Vgl. zuvor schon: Anatolij F. Koni: Pamjati grafa Gejdena. In: Slovo 484 (1908) sowie eine abgewandelte Form der Gedenkschrift in: Anatolij F. Koni: Gejden, Petr Aleksandrovič. In: NĖS 12 (1913), Sp. 84 of. Nachrufe u. a. auf den 1912 verstorbenen Senator und Staatsrat Ivan Ivanovič Šamšin (geb. 1835) und den 1910 verstorbenen Kriminalisten Dmitrij Andreevič Dril aus Char'kov (geb. 1846) fanden ebenfalls Eingang in „Auf dem Lebensweg“, vgl.: Anatolij F. KonI: Pamjati D. A. Drilja. In: ders. (Hrsg.): Na žiznennom puti, Bd. 2, S. 284-89 (Erstveröffentlichung unklar) sowie Anatolij F. Koni: Pamjati I. I. Šamšina. In: ders. (Hrsg.): Na žiznennom puti, Bd. 2, S. 783-88, schon zuvor in P 4 (1912). Zudem auch: Anatolij F. Koni: Pamjati Jakova Grigor'eviča Esipoviča. In: ders. (Hrsg.): $\mathrm{Na}$ žiznennom puti, Bd. 2, S. 430-39 (Erstveröffentlichung unklar), Rede von 1906 für Ja. G. Esipovič (1822-1906); sowie ein Doppelporträt der beiden Zivilrechtler Aleksandr L’vovič Borovikovskij (1844-1905) und Nikolaj Nikolaevič Mjasoedov (1839-1908): Anatolij F. Koni: A. L. Borovikovskij i N. N. Mjasoedov. In: ders. (Hrsg.): Na žiznennom puti, Bd. 1, S. 499-510, teilweise zuvor veröffentlicht u. a. in RS 12 (1911). In diesen Kontext gehört auch der bereits 1908 veröffentlichte Artikel „Der Bote Europas“. Er porträtiert das Redaktionskollegium der Zeitung, das zahlreiche Juristen umfasste. Vgl. Anatolij F. Koni: „Vestnik Evropy“. In: ders. (Hrsg.): Na žiznennom puti, Bd. 2. Iz vospominanij, publičnye čtenija, v verchnej palate. Sankt-Peterburg 1912, S. 193-233, dazu ausführlicher in TEIL ZWEI. Auch nach 1912 verfasste Koni noch neue Juristenporträts und Nachrufe für seine verstorbenen Kollegen, diese wurden in die Sammelbände integriert, die Koni in den 1920er-Jahren veröffentlichte. Vgl. insb. Konis Schriften über Saburov, der in den „Erinnerungen an den Fall Vera Zasuličc“ eine wichtige Rolle spielt: Anatolij F. Koni: A. Saburov. In: P 11 (1916), S. 657-68 und P 1 (1917), S. 1-5, dies dann später als: Anatolij 
auch Arsen'ev gehörten wie Koni zu den Pionieren der neuen Gerichte. Zwei bis drei Jahrzehnte vor der Gerichtsreform geboren, absolvierten sie ihre Studien in Moskau - Koni und Urusov fast zeitgleich an der Juristischen Fakultät der Universität - oder St. Petersburg - Arsen'ev an der Kaiserlichen Rechtsschule einige Jahre früher - und traten wenig später in das neue Gerichtswesen ein. Mehrfach kreuzten sich ihre Wege in den nachfolgenden Jahrzehnten, in denen Koni als Staatsanwalt und Richter, Urusov und Arsen'ev hauptsächlich als Anwälte und Letzterer auch als Publizist arbeiteten. ${ }^{37}$

Es mag wenig erstaunlich sein, dass Koni anlässlich von Tod, Geburtstag oder Dienstjubiläum solcher Gefährten seine Erinnerungen aufnotierte. Fast beliebig fand Koni aber auch weitere weniger naheliegende Anlässe, um über Rechtsgelehrte, Reformer, Studienkollegen, Vorgesetzte oder Mitarbeiter zu berichten, und oftmals sorgte er gleich selber dafür, dass er ein breites Publikum erhielt. Beispielhaft zeugt davon die 40. Jährung der Herausgabe von Vladimir Danilovič Spasovičs (1829-1906) juristischem Lehrbuch 1903. Koni hielt an der Jahresversammlung der Juristischen Gesellschaft von St. Petersburg eine Rede zur Feier dieses Buches, in der er auch das Leben des Akademikers und berühmten Anwalts ehrte. ${ }^{38}$ Kurz darauf verfasste er eine Reinschrift dieses Auftritts und fragte an, ob man denn

F. Koni: Pamjati Andreja Aleksandroviča Saburova. In: ders. (Hrsg.): Na žiznennom puti, Bd. 4. Publičnye čtenija i reči. Revel', Berlin 1923, S. 397-411. Auch mehrfach zum Rechtsgelehrten Maksim Maksimovič Kovalevskij (1851-1916), z. B.: Anatolij F. KonI: M. M. Kovalevskij v zakonodatel'noj dejatel'nosti. In: VE 4 (1916), S. XI-XXVII. Für die entsprechende Wiederveröffentlichung in den späteren Sammelbänden und weitere Juristenporträts, die Koni nach der Oktoberrevolution verfasste vgl. unten, Kapitel Politische Erinnerung an das Zarenreich in der Sowjetunion.

37 Von 1849 bis 1855 hatte Arsenev die Kaiserliche Rechtsschule in St. Petersburg besucht und gehörte nach der Gerichtsreform zu den ersten Anwälten Russlands. Ab 1880 konzentrierte er sich auf die juristische Arbeit in Gremien, Kommissionen und Publizistik. Vgl. zu Arsen'ev: Aleksandr A. Simu tenko: K. K. Arsen'ev i rossijskoe liberal'noe dviženie konca XIX-načala XX veka. Sankt-Peterburg 2006 (unveröffentlichte Dissertation). Urusov gehörte mit spektakulären Verteidigungen in politischen Prozessen schnell zu den berühmtesten Anwälten des Landes. 1872 wurde er für einige Jahre ins Gouvernement Livland verbannt, weil man ihn der Unterstützung von verurteilten revolutionären Mandanten bezichtigte. Danach schickte man ihn als Staatsanwalt nach Warschau. Ab 1881 arbeitete er wieder als Anwalt in St. Petersburg und Moskau bis zu seinem Tod 190o. Vgl. Anžela V. Stepanova: A. I. Urusov. Jurist i sudebnyj orator. Saratov 2005 (unveröffentlichte Dissertation).

38 Vgl. die Angabe auf der ersten Seite des Abdrucks in „Skizzen und Erinnerungen“: Anatolij F. KonI: Vladimir Danilovič Spasovič. In: ders. (Hrsg.): Očerki i vospominanija. Publičnye čtenija, reči, stat'i i zametki. Sankt-Peterburg 1906, S. 771-82. Vgl. zu dieser Rede im Zusammenhang mit einer Kampagne zum Presserecht unten, S. 200. 
seine Ansprache nicht veröffentlichen möchte. ${ }^{39}$ Prompt erschien die Skizze über Mann und Buch in der Zeitschrift „Recht“ [Pravo] auf der Titelseite. ${ }^{40}$ Auf solche Art und Weise erinnerte Koni entsprechende Organisationen und Publikationsorgane immer wieder daran, dass sich ein Jahrestag näherte und es dazu einen Artikel zu verfassen oder eine Rede zu halten gelte. ${ }^{41}$ Einen besonderen Stellenwert nahmen dabei natürlich die Jubiläen der Gerichtsreform ein. Gerade um die Jahrhundertwende war nicht nur in Russland, sondern auch in Europa das Feiern von Jubiläen für verschiedene Interessengruppen ein ganz wesentlicher symbolischer Akt. Eine regelrechte „Jubiläumsmanie“ hielt Einzug. ${ }^{42}$ Wie stark insbesondere die Feierlichkeiten zu den Jahrestagen der „Großen Reformen“ in Russland einen politischen Charakter hatten, zeigt die Tatsache, dass sie zu gewissen Zeiten von der Regierung verboten wurden. So machte Zar Alexander III. 1886 mit dem Verbot, den 25. Jahrestag der Bauernbefreiung zu feiern, seine Abkehr von jeglichen

39 GARF F. 564, op. 1, d. 4319. Brief vom 19. März 1903. Leider ist der Adressat des Briefes unklar.

40 Anatolij F. Koni: Po povodu jubileja odnoj knigi. Otryvok iz ličnych vospominanij. In: P 48 (1903), S. 2695-701. Offen ist, warum der Artikel erst in dieser Ausgabe der Zeitschrift - am Sonntag, 23. November - erschien. Koni schlug in seinem Brief den 23. als Veröffentlichungsdatum vor. Ob er damit den 23. November meinte, weil dieser nah beim 20. November - dem Tag des Erlasses zum neuen Gericht 1864 - lag?

41 Svetlana Domanova verweist im Rahmen ihrer Recherche zu Konis Briefwechsel mit dem Herausgeber der Zeitschrift „Bote Europas“ [Vestnik Evropy] darauf, dass Koni diesen in Briefen regelmäßig an sich nähernde Jubiläen erinnert habe. Vgl.: Svetlana A. Domanova: Epistoljarnoe nasledie A. F. Koni v CGAOR SSSR. In: Sovetskie archivy 6 (1990), S. 73. Koni war seit Anfang der 188oer-Jahre ständiger Mitarbeiter der liberalen Zeitschrift und beteiligte sich auch an der Ausarbeitung der Publikationsstrategie, dazu ausführlicher in TEIL ZWEI.

42 Konstantin N. Tsimbaev: Jubilee Mania in Late Nineteenth- and Early Twentieth-Century Russian Society. In: Russian Studies in History 2 (2008), S. 18 ff. 1300 war von päpstlicher Seite erstmals in institutionalisierter Art und Weise ein Jubiläum ausgerufen worden. Seit der Frühen Neuzeit nahmen auch in weltlichen Bereichen wie Universitäten oder Städten solche „Memorialtechniken“ zu. Im Verlauf des 19. Jahrhunderts wurden dann in ganz Europa Nationalfeiertage eingerichtet und eine große Zahl von öffentlichen, konfessionellen, privaten oder halbprivaten Jubiläen gefeiert. Rudolf JAWORSKI: Jubiläen und Gedenktage im östlichen Europa. Versuch einer einordnenden Betrachtung. In: ders./Jan Kusber (Hrsg.): Erinnern mit Hindernissen. Osteuropäische Gedenktage und Jubiläen im 20. und zu Beginn des 21. Jahrhunderts. Münster 2011, S. 14-15. Die „Kulturtechnik Jahrestag" bedient sich eines einfachen Verfahrens. Der Zyklus der Natur macht es unumgänglich, dass ein spezifisches Datum immer wiederkehrt, und durch das feierliche Begehen des entsprechenden Tages wird Wissen erhalten. „Kollektives Wissen“ entsteht, das kollektiv weitergegeben werden kann. Thomas SснміDт: Kalender und Gedächtnis. Erinnern im Rhythmus der Zeit. Göttingen 2000, S. 16 und 19-20. 
weiteren Reformen überdeutlich. ${ }^{43}$ Als 1904 das 40. Jubiläum der Gerichtsreform anstand, ignorierte Zar Nikolaus II. das Werk seines Vor-Vorgängers vollständig und überließ so den Anhängern weiterer Reformen das Feld. Aus den Feierlichkeiten der liberalen Kreise ergab sich die sogenannte Bankettkampagne, die mit zur Revolution beitrug. ${ }^{44}$ Unter der Federführung von Arsen'ev gedachten die Juristen des 40. Jubiläums der Gerichtsreform unter anderem auch mit einem biografischen Sammelband, zu dem Koni sechs der insgesamt ${ }_{13}$ Skizzen beisteuerte. ${ }^{45}$ Die bereits erwähnten Texte über Rovinskij und Stojanovskij wurden ergänzt durch die schon 1899 gehaltene Rede zu Zarudnyj und drei weitere Porträts von Wegbereitern der Gerichtsreform wie Michail Evgrafovič Kovalevskij (1829-1884), Nikolaj Andreevič Buckovskij (1811-1873) und Dmitrij Nikolaevič Zamjatin (1805-1881), der zeitweise das Amt des Justizministers innegehabt hatte. ${ }^{46}$ Das Buch wurde vom Verlag Brokgauz i Efron gedruckt, der vor allem für das „Enzyklopädische Wörterbuch von Brockhaus und Efron“ bekannt war, für das Arsenev schon seit geraumer Zeit in leitender Funktion tätig war. Auch einige von Konis Skizzen erschienen in dieser Universalenzyklopädie, die in Russland nach dem Vorbild des deutschen „Brockhaus“ zwischen 1890 und 1907 in 86 Bänden herausgegeben wurde. ${ }^{47}$

43 Richard Wortman: Scenarios of Power, Bd. 2. Myth and Ceremony in Russian Monarchy: from Alexander II to the Abdication of Nicholas II. Princeton 2000, S. 262. In seinen eigenen Erinnerungen erwähnt Koni auch das inexistente 25. Jubiläum der Gerichtsstatuten 1889, vgl. Anatolij F. Konı: Graf Dmitrij Alekseevič Miljutin. In: ders. (Hrsg.): Na žiznennom puti, Bd. 2. Iz vospominanij, publičnye čtenija, v verchnej palate. Sankt-Peterburg 1912, S. 274.

44 Tsimbaev: Jubilee Mania in Late Nineteenth- and Early Twentieth-Century Russian Society, S. 27. Zur ersten Russischen Revolution ausführlicher in TEIL ZWEI.

45 Arsen’ev äußerte sich einige Jahre später auch schriftlich und explizit zur Notwendigkeit, Jubiläen zu begehen, und forderte programmatisch aktives Erinnern. Vgl. Konstantin K. Arsen'ev: Polveka tomu nazad i teper'. In: VE 2 (1911), S. 315. Vgl. dazu ausführlicher Carla CoRdin: Von Schreibanlässen und Erinnerungsfunktionen. Erkenntnisgewinn aus autobiographischer Praxis von Juristen im späten Zarenreich. In: Martin Aust/Frithjof Benjamin Schenk (Hrsg.): Imperial Subjects. Autobiographische Praxis in den Vielvölkerreichen der Habsburger, Romanovs und Osmanen im 19. und frühen 20. Jahrhundert. Köln 2015, S. 185-86.

46 Konstantin K. ArSen'ev (Hrsg.): Glavnye dějateli i predšestvenniki sudebnoj reformy. Sankt-Peterburg 1904. Ursprünglich hätte Koni sogar die Herausgabe des Buches übernehmen sollen, vgl. GA8, S. 406 (Anmerkungen) und den entsprechenden Brief an den Verleger GA8, S. 196-97 (Brief an Semën Afanas'evič Vengerov vom 20. 12.1903).

47 Der russische Verleger Il’ja Abramovič Efron (1847-1917) gründete gemeinsam mit dem Verlagshaus F. A. Brockhaus in Leipzig eine Aktionärsgesellschaft, die die Herausgabe des monumentalen Werks koordinierte. Vgl. für eine Übersicht Isaak M. KAUf MAN: Russkie ènciklopedii. Obščie ènciklopedii. Bibliografija i kratkie očerki. Moskva 1960, S. 44-54. 
Auch zehn Jahre nach dem von der ersten Russischen Revolution geprägten 40. Jubiläumsfest, als es bereits ein halbes Jahrhundert reformierte Gerichte zu feiern galt, ließ der Justizminister mit seinen Worten vom „höchsten Willen des russischen Autokraten" keinen Zweifel am Stellenwert, den die Justiz in der Herrschaftskonzeption des Zaren einnahm. Gerade in diesem Moment aber produzierte Koni nun als alleiniger Autor und Herausgeber die wohl eindrücklichste Zusammenstellung von Juristenporträts, die in den 50 Jahren reformierter Justiz entstanden war. Bereits der Titel des Sammelbandes „Väter und Söhne der Gerichtsreform" [Otcy i deti sudebnoj reformy] weist darauf hin, dass mit einer solchen Publikation die Funktionalität des Jubiläumsfeierns und Gedenkens an verstorbene Berufskollegen eine neue Dimension erreichte. Rund um den Fluchtpunkt der Gerichtsreform formierte sich jetzt nicht mehr nur die Erinnerung an einen einzelnen, vielmehr bildete eine ganze Gruppe von Juristen eine Einheit. Als „Väter" wurden die Exponenten porträtiert, die in der Ausarbeitung der Gerichtsreform vor 1864 präsent gewesen waren. Als „Söhne“ erschienen zahlreiche Juristen aus Konis eigener Kohorte, die gleich nach der Reform die Pionierarbeit an den neuen Gerichten aufgenommen hatten. In einer kurzen Vorbemerkung heißt es, dass die publizierten biografischen Skizzen von Koni bereits bei früheren Gelegenheiten erschienen seien. Tatsächlich finden sich in dem Werk 20 von Konis Porträts, die teilweise unverändert, teilweise ergänzt den ursprünglich in Zeitschriften und seinen früheren Sammelbänden veröffentlichten Nachrufen oder Reden über seine Berufskollegen entsprachen. ${ }^{48}$ In der aufwendigen, mit zahlreichen Fotografien geschmückten Ausgabe finden sich auch ein Vor- und ein Nachwort, die eine Art Fazit zur Gerichtsreform und den vergangenen 50 Jahren $\mathrm{zu}$ ziehen versuchen. Gemeinsam mit anderen ähnlichen und teilweise identi-

Arsen’ev war ab 1891 zuständig für die Redaktion der geisteswissenschaftlichen Sparte des Nachschlagewerks und übernahm später die Chefredaktion, Simutenko: K. K. Arsen'ev i rossijskoe liberal'noe dviženie konca XIX-načala XX veka, S. 50 und KaUfman: Russkie enciklopedii, S. 49. Von Koni erschienen in der Universalenzyklopädie verschiedene seiner Juristenporträts und biografische Skizzen zu anderen Akteuren. Zudem ist Koni der Autor mehrerer Einträge zu juristischen Themen, wie u. a. dem Geschworenengericht („Sud prisjažnych“), dem Autorenrecht („Avtorskoe pravo“) oder der Glaubenstoleranz („Veroterpimost' v Rossii“).

48 Anatolij F. Koni (Hrsg.): Otcy i deti sudebnoj reformy. K pjatidesjatiletiju Sudebnych Ustavov, 20. nojabrja 1864-1914. Moskva 1914. Darin erschienen folgende Porträts, über allesamt bereits genannte Juristen: Rovinskij, Zarudnyj, Stojanovskij, Zamjatin, Buckovskij, M. E. Kovalevskij, Nabokov, Arcimovič, Motovilov, Šamšin, Bobriščev-Puškin, Gubskij, Markov, Spasovič, Arsen'ev, Borovikovskij, Moroškin, Urusov, Plevako, Esipovič. Zusätzlich hat Koni eine zusammenfassende Skizze zu Juristen verfasst, denen kein eigenes Porträt gewidmet wurde, vgl. Anatolij F. Koni: K portretam. In: ebd., S. 276-84. Ferner integrierte Koni in den Sammelband noch wenige weitere bereits publizierte Texte. 
schen Artikeln, die Koni zum Jubiläum in verschiedenen Publikationsorganen veröffentlichte, zeigt sich auch darin seine Bezogenheit auf alle Juristen vereinende "typische Eigenschaften eines russischen Gerichtstätigen“, die sich eng an die Anfangszeit der Reform und ihre zentralen Elemente angliedern. ${ }^{49}$

Ungeachtet - oder gerade wegen - der unbefriedigenden Situation im russischen Rechtswesen ging Koni beginnend in den 189oer-Jahren dazu über, den Juristen und der Öffentlichkeit Würdigungen für seine Berufskollegen mündlich in Versammlungen oder schriftlich in Zeitschriften oder Sammelbänden zu präsentieren. Ohne schon detaillierter auf den Inhalt der erwähnten Schriften einzugehen, legen es insbesondere Sammelwerke wie jenes von den „Vätern und Söhnen“ nahe, dass hier mit den Mitteln einer „biografischen Praxis" an einer generationenübergreifenden professionellen Identität gearbeitet wurde. Auch wenn zwischen einem biografischen Eintrag für ein Lexikon, einem Nachruf in einem Gedenkband für einen Freund oder einer Festrede auf einer Jubiläumsversammlung gewisse genretypische Unterschiede bestehen - so variiert beispielsweise die Anzahl gemeinsamer persönlicher Erlebnisse -, sind die verbindenden Elemente doch größer als die trennenden. Während Koni allein aufgrund der außerordentlich hohen Zahl an Skizzen zweifelsohne eine Führungsrolle in dieser verbindenden Beschreibung von „typischen Eigenschaften“ einnahm, wurde er in seinen Bemühungen von anderen Juristen unterstützt. Insbesondere Arsenev, der nach seiner Aktivzeit als Anwalt neben der Arbeit für "Brockhaus und Efron“ auch zur gewichtigen Stimme in der liberalen Zeitschrift „Bote Europas“ [Vestnik Evropy] wurde, schrieb in ganz ähnlichem Stile und in ähnlichen Momenten Erinnerungsschriften an die Juristenschaft. ${ }^{50}$ Spannend ist dabei zu sehen, wie die

49 Koni (Hrsg.): Otcy i deti sudebnoj reformy, S. I-IV (Vorwort); Nachwort separat nummeriert in ebd., S. 1-18. Schon im August 1913 verfasste Koni eine Einführung für eine kommentierte Neuauflage der Strafprozessordnung, die große Ähnlichkeit mit dem Nachwort von „Väter und Söhne“ aufweist, vgl. Anatolij F. Konı: Vvedenie k Sistematičeskomu Kommentariju U. U. S. In: Michail N. Gernet (Hrsg.): Ustav ugolovnago sudoproizvodstva, Bd. 1. Moskva 1914-1915, S. 1-30. Schon 1913 auch als separates Büchlein in Moskau publiziert. Ebenfalls sehr ähnlich gehalten ist ein Artikel mit dem Titel „Gerichtsstatuten 1864-1914“, vgl. Anatolij F. Koni: Sudebnye ustavy 1864-1914. In: ŽMJ 11 (1914) sowie als separate Ausgabe im gleichen Jahr in St. Petersburg. Auf diese drei Texte verweist Koni selber in einem vierten, etwas kürzeren Artikel, der den programmatischen Titel „Vor 50 Jahren“ trägt, vgl. Anatolij F. KonI: Pjat'desjat' let nazad. In: RS 1 (1915), S. 5-28. Unter ebendiesem Titel integrierte Koni auch eine Version seiner Gedanken in der Moskauer Ausgabe des zweiten Bandes von „Auf dem Lebensweg“, die 1916 erschien.

50 Schon seit der Gründung des „Boten Europas“ 1866 schrieb Arsen’ev Artikel für die Zeitschrift. Ab ca. 1880 bis 1910 wurde er dann zum festen Mitarbeiter und übernahm die Abschnitte zur Innenpolitik und Wirtschaftslage Russlands und die Rubrik „Aus der gesellschaftlichen Chronik“ [Iz obščestvennoj chroniki], vgl. Simutenko: K. K. Arsen’ev i 
entsprechenden Skizzen miteinander in Dialog gebracht wurden, wenn mehrere Personen zum gleichen Exponenten der Zunft Porträts verfassten oder gegenseitig über den jeweils anderen schrieben. So wurde zum Beispiel Urusov nicht nur von Koni, sondern auch von Arsen'ev mit einem Porträt geehrt, und auch der Anwalt Sergej Arkad'evič Andreevskij (1847-1918) sprach am Grab und veröffentlichte seine Worte ebenso. Die gegenseitigen Porträts dieser vier Juristen werden - neben weiteren biografischen Skizzen sowie autobiografischen Schriften und Fachtexten - im nachfolgenden Kapitel besonders häufig als Quellen benutzt. ${ }^{51}$ Andreevskij war eng mit Urusov befreundet und auch mit Koni gut bekannt. Auch er hatte in den 1860er-Jahren studiert und arbeitete danach zusammen mit Koni in der 1868 reformierten Staatsanwaltschaft in Charkow und später in St. Petersburg. Im Zasulič-Fall hätte er die Rolle des Anklägers übernehmen sollen, was er ablehnte und deshalb nach dem Freispruch entlassen wurde. Koni unterstützte ihn bei der Suche nach einer Anschlussstelle; sehr schnell aber konnte Andreevskij sich eine Reputation als Anwalt erarbeiten und so ein Auskommen finden. ${ }^{52}$ Koni und Andreevskij porträtierten sich gegenseitig. Andreevskij nutzte dazu sein memoiristisch-literarisches Lebenswerk „Das Buch vom Tode“ ${ }^{\text {“53 Und auch }}$

rossijskoe liberal'noe dviženie konca XIX-načala XX veka, S. 35 und 49-50. Einige Nachrufe und biografische Porträts Arsen'evs von Berufskollegen: Konstantin K. Arsen'Ev: A. D. Gradovskij. In: VE 12 (1889); Konstantin K. Arsen'Ev: M. N. Ljuboščinskij. In: VE 8 (1889); Konstantin K. Arsen'Ev: E. I. Utin. In: VE 9 (1894); Konstantin K. Arsen'ev: V. N. Gerard 1839-1903. In: P 51 (1903); Konstantin K. Arsen'Ev: V. D. Spasovič v ego zastol'nych rečach. In: P 11 (1903); Konstantin K. Arsen'ev: Vospominanija o V. D. Spasoviče. In: VE 11 (1906); Konstantin K. Arsen'ev: Pamjati K. D. Kavelina. In: VE 5 (1910); Konstantin K. Arsen'ev: Vospominanija ob A. A. Saburove. In: Vestnik Graždanskago Pravo 1 (1916).

51 Konis Porträts von Urusov sowie Urusov und Plevako wurden bereits genannt. Vgl. für Arsen'ev über Urusov: Konstantin K. Arsen'ev: Kn. A. I. Urusov. In: VE 5 (1900), S. 433-35 (Abschnitt in Rubrik: Iz obščestvennoj chroniki) und Konstantin K. Arsen'ev: Vospominanija o knjaze A. I. Urusove. In: Aleksandr I. Urusov/A. A. Andreeva/O. B. Gol'dovskij (Hrsg.): Knjaz’ Aleksandr Ivanovič Urusov (1843-1900). Stat'i ego, pis'ma ego, vospominanija o nem, Bd. 2 und 3. Moskva 1907, S. 237-39. Vgl. für Andreevskij über Urusov die nachfolgende Fußnote.

Andreevskij studierte in Charkow und lernte den etwas älteren Koni bei dessen Versetzung an die örtlichen Gerichtsbehörden kennen. 1870 war Koni Trauzeuge an Andreevskijs Hochzeit. Trotz gewisser Meinungsverschiedenheiten verblieben beide in einem lebenslangen Briefwechsel, vgl. Diana A. RJAzanova: S. A. Andreevskij. Jurist i obščestvennyj dejatel' (1847-1918 gg.). Saratov 2003, S. 32-45 (unveröffentlichte Dissertation). Vgl. zur Involvierung in den Zasulič-Fall oben, Fußnote 11 in der Einleitung.

53 In den 189oer-Jahren hatte der Anwalt mit diesem umfangreichen Buch begonnen, dessen Entstehung von Koni über Jahrzehnte hinweg eng begleitet wurde. Im Werk vermischen sich memoiristische Prosa mit tagebuchähnlichen Aufzeichnungen zu einem historischen und persönlichen Dokument, das gleichzeitig ein literarisches Werk darstellt, vgl. Sergej A. 
Arsen’ev ließ es sich nicht nehmen, über Andreevskij und dessen Anwaltsreden zu berichten.$^{54}$ Die inhaltliche Analyse solcher Skizzen wird deutlich machen, was die Anlehnung an den berühmten gleichnamigen Roman des russischen Schriftstellers Ivan Sergeevič Turgenev (1818-1883) schon vermuten lässt. In der Kreation von „Vätern und Söhnen“ vermischten sich Professionalisierungsstrategien allgemeiner Art mit spezifisch russischen Diskursen um Rolle und Möglichkeiten der intellektuellen und berufsständischen Eliten im Kontext des späten Zarenreichs. Die „typischen Eigenschaften“, die in den Porträts betont werden, orientieren sich an übergeordneten gesellschaftlichen Idealen vom „edlen“ Kämpfer für Land und Leute.

Die Person Anatolij Koni rückte gerade durch das intensive Porträtieren der Berufskollegen dabei immer stärker in den Fokus. Was auf den ersten Blick wie eine rein „biografische“ Praxis wirkt, in der der Autor völlig im Hintergrund steht, trägt unweigerlich starke „autobiografische“ Züge. Der russische Literaturtheoretiker Michail Bachtin (1895-1975) nannte die Position, die der Verfasser jeder Lebensbeschreibung einnimmt, „Außerhalbbefindlichkeit“ [Vnenachodimost']. Egal ob über das eigene Leben oder das Leben einer anderen Person berichtet wird, immer erfordert diese Reflexion das Vorhandensein zweier Bewusstseinssphären, die das Einnehmen einer Außenperspektive erst ermöglichen. ${ }^{55}$ So vermischen sich die Grenzen zwischen Biografie und Autobiografie. Indem über das Leben

Andreevskij: Kniga o smerti, hrsg. u. mit einem Nachwort versehen v. I. I. Podol'skaja. Moskva 2005, S. 471-553, insb. S. 530; 533-35 (Nachwort von I. I. Podol'skaja). Neben Erinnerungen an Todesfälle von Verwandten und Freunden oder historische Ereignisse wie die Krönung von Zar Nikolaus II. schreibt Andreevskij im Rahmen seiner Erinnerungen und in eigens betitelten Kapiteln auch über seine Berufskollegen, darunter über Koni v. a. in Band 1, S. 136-45 sowie S. 186-87 etc. als auch über Urusov v. a. im nach ihm benannten Abschnitt in Band 2, S. 153-71 etc. Alles in: Sergej A. Andreevskij: Kniga o smerti, Bd. 1 und 2. Revel', Berlin 1922. Das Werk Andreevskijs erschien erst posthum in Estland/ Berlin. Schon zu Lebzeiten äußerte sich Andreevskij aber über Urusov, was er in seinen Sammelbänden festhielt: Sergej A. Andreevskij: Nad mogiloj knjazja A. I. Urusova. In: ders. (Hrsg.): Dramy žizni. Petrograd 1916, S. 621-23. Sowie in: Sergej A. AndreEvskiJ (Hrsg.): Zaščititel'nye reči. Sankt-Peterburg 1909, S. 593. 1924 hatte Koni persönlich zudem dafür gesorgt, dass das „Buch vom Tode“ auch in St. Petersburg herausgegeben wurde, allerdings deutlich zensiert, vgl. Andreevskij: Kniga o smerti, 2005, S. 475 (Nachwort von I. I. Podol'skaja). Für diese Version hatte Koni auch sein Porträt von Andreevskij verfasst, Anatolij F. Koni: S. A. Andreevskij. Po ličnym vospominanijam. In: Sergej A. Andreevskij: Kniga o smerti. Leningrad 1924 bzw. in: Anatolij F. KonI (Hrsg.): Na žiznennom puti, Bd. 5. Leningrad 1929, S. 178-96. Dieses Porträt ist insofern untypisch, als es später als die anderen geschrieben wurde.

54 Konstantin K. Arsen'ev: Novye sborniki sudebnych rečej. In: VE 6 (1891), S. 777-804.

55 Ulrich Schmid: Ichentwürfe. Die russische Autobiographie zwischen Avvakum und Gercen. Zürich 2000, S. $20 \mathrm{ff}$. 
von Berufskollegen nachgedacht wird, gerät das eigene "Selbst“ ebenso ins Bild. Jochen Hellbeck spricht in seiner Definition von „autobiografischer Praxis“ davon, dass damit nicht nur klassische autobiografische Texte gemeint sind, sondern auch visuelle Repräsentationen und Aufführungen wie Reden, mündliche Befragungen oder Bilder. Kurz alles, was als Instrument für eine aktive Darstellung des "Selbst" dient. ${ }^{56}$ Insofern erscheint es plausibel, auch ein biografisches Porträt von Berufskollegen als Teil der Selbstdarstellung des Autors zu verstehen. ${ }^{57}$ Diese autobiografische Komponente in der biografischen Stilisierung zeigt sich im Fall von Koni je länger je deutlicher. Er machte sich selber mehr und mehr zur Ikone, die er in seinen Porträts heraufbeschwor. Diese Darstellung wurde durch eine weitere, nun klassischer „autobiografische“ Textgattung gestützt, mit der Koni ab 1907 die Öffentlichkeit zu erreichen versuchte. In diesem Jahr erhielt er von der Zeitschrift „Russische Altertümer“ [Russkaja Starina] die Möglichkeit, regelmäßig Aufsätze zu publizieren, die als Reihe mit dem Titel „Aus den Notizen und Erinnerungen eines Gerichtstätigen“ bis ins Jahr 1915 erschienen. Die rund 20 zwischen 15 und 40 Seiten umfassenden Erinnerungsschriften drehen sich dabei allesamt um verschiedenste Themen aus Konis beruflicher Laufbahn und sind eigentümliche Mischungen aus Erinnerungen, Fallberichten und Fachtexten. Manche sind direkt nach einzelnen gewichtigen Gerichtsfällen benannt, in die Koni involviert war (zum Beispiel „Der Fall Ovsjannikov“, „Der Fall Gulak-Artemovskoj“), andere tragen als Titel die Namen der Orte, an denen Koni eine Zeitlang gewirkt hatte (zum Beispiel „Aus Kasaner Erinnerungen“, „Aus Charkower Erinnerungen“). Wieder andere sind Elementen der Gerichtspraxis gewidmet (zum Beispiel „Die Geschworenen“; „Angeklagte und Zeugen“).$^{58}$ Zeitlich schauen diese Erinnerungs-

56 Jochen Hellbeck/Klaus Heller (Hrsg.): Autobiographical Practices in Russia. Göttingen 2004, S. 12-13.

57 Vgl. ähnliche konkrete Überlegungen von Hellbeck, der davon schreibt, dass das biografische Werk „zu einer autobiografischen Praxis“ werde, wenn Biografen im Produzieren von „modellhaften historischen Ichs“ auch eine historische Subjektivität für sich selber entwickeln. Jochen Hellbeck: The Diary between Literature and History. A Historian's Critical Response. In: Russian Review 4 (2004), S. 623.

58 Koni: Iz zametok I vospominanij sudebnogo dejatelja. I. Osvidetel'stvovanie duševnobol'nych (1870-1895). In: RS 2 (1907), S. 259-87; II. Iz prokurorskoj služby [Delo Ovsjannikova, Iz kazanskich vospominanij, Iz char'kovskich vospominanij]. In: RS 10 (1907), S. 5-26; III. Iz prokurorskoj služby [Iz prokurorskoj praktiki, Delo Gulak-Artemovskoj, Ivan Dmitrievič Putilin]. In: RS 12 (1907), S. 507-23; IV. Iz prokurorskoj služby [Igumen'ja Mitrofanija, Delo o poddelke serij]. In: RS 3 (1908), S. 491-508; V. Iz prokurorskoj služby [Igornyj dom Kolemina, Iz prokurorskoj praktiki, Temnoe delo]. In: RS 11 (1908), S. 289-302; VI. Iz sudejskoj služby [Landsberg]. In: RS 12 (1908), S. 531-46; VII. Iz sudejskoj služby [Margarita Žjužan]. In: RS 1 (1909), S. 5-27; VIII. [Uniatskie dela]. In: RS 2 (1909), S. 233-55; IX. [Štundisty]. In: RS 10 (1909), S. 3-29; X. [Pastorskie dela]. In: RS 11 
texte - die Koni fast alle auch in seinen ersten Memoirenband „Auf dem Lebensweg" integrierte - in den meisten Fällen Jahrzehnte zurück in die Wirkungsepoche nach 1864 und führen so Leserinnen und Leser in einem Moment, als die Lage des Justizwesens prekärer denn je war, zurück in eine Epoche, in der Koni und seine Kollegen anscheinend meistens sehr erfolgreich und zum Wohle aller die kniffligen Gerichtsfälle lösten, die sich ihnen stellten. ${ }^{59}$

\subsubsection{Eine Generation „edler“Juristen}

In Konis biografischen Porträts, aber immer wieder auch in jenen eines Arsen'evs und weiterer Juristen, wurden die Akteure aus der Anfangszeit der reformierten Gerichte charakterisiert. Ein zentrales vereinendes Element war dabei unmissverständlich der Bezug zu den neuen Statuten von 1864. So schrieb Koni beispielsweise über Urusov und den berühmten Moskauer Anwalt Fëdor Plevako, dass sie der Gerichtsreform immer „treu“ geblieben seien. ${ }^{60}$ „Unvergessliche Jahre“ hätten

(1909), S. 231-47; XI. [Sudebnye sledovateli]. In: RS 11 (1910), S. 231-57; XII. [Obvinjaemye i svideteli]. In: RS 1 (1911), S. 3-40; [XIII scheint zu fehlen]; XIV. [Svedujuščie ljudi i ekspertiza]. In: RS 2 (1911), S. 227-56; XV. [Priemy i zadači obvinenija]. In: RS 11 (1911), S. 231-69; XVI. [Iz prošlovo peterburgskoj prokuratury]. In: RS 12 (1911), S. 461-88; XVII. [Prokuratura I administracija]. In: RS 1 (1912), S. 3-30; XVII. [sic] Graždanskie dela. In: RS 12 (1912), S. 451-81; XIX. [sic] Graždanskie dela - Revizii. In: RS 1 (1913), S. 3-17; XX. Prisjažnye zasedateli. In: RS 1 (1914), S. 5-26 und 2 (1914), S. 243-80. Auch das Resümee zur Gerichtsreform: „Vor 50 Jahren“ wurde in „Russische Altertümer“ [Russkaja Starina] mit dem Übertitel „Aus den Erinnerungen und Notizen eines Gerichtstätigen“ versehen.

59 Vgl. Koni (Hrsg.): Na žiznennom puti, Bd. 1, S. 11 ff. Die Reihenfolge ist nicht ganz identisch und die Titelsetzung nun deutlich anders, alle oben in eckigen Klammern genannten Titel stammen aus dem Wiederabdruck „Auf dem Lebensweg“ I. In der Regel wurden die Texte inhaltlich wenig bis gar nicht verändert, lediglich „Osvidetel'stvovanie duševnobol'nych“ erhielt gleich eine mehrseitige Fortsetzung. Die Texte ab Ende 1912 erschienen erst nach dem Druck von „Auf dem Lebensweg“ I und fehlen dort folglich. Dafür hat Koni noch einige zusätzliche Texte in die Reihe integriert, wie z. B. das Porträt von Urusov oder eine Erinnerungsschrift an Friedensrichter. Diese wurde erstmals abgedruckt als: KonI: Otryvki iz vospominanij. In: VE 1 (1909), S. 42-80. Der Text erschien auch als: Anatolij F. KonI: Mirovye sud'i. Iz vospominanij. In: ders. (Hrsg.): Otcy i deti sudebnoj reformy, S. 192-215 und gekürzt in: Petrogradskij mirovoj sud za pjat'desjat' let. 1866-1916, Bd. 2. Petrograd 1916, S. 1313-339. 1922 erschien der erste Band von „Auf dem Lebensweg“ in einer 4. Auflage. Hier integrierte Koni nun auch noch die Erinnerungen zu den „Graždanskie dela“. Erneut kam es zu geringfügigen Veränderungen und Ergänzungen in den Texten. GA1, S. $513 \mathrm{ff}$ (Anmerkungen) macht auf solche aufmerksam. Vgl. für den Wiederabdruck dieser Schriften in der Sowjetunion unten, S. 232.

6o Koni: Dva sudebnych oratora. In: ders. (Hrsg.): Na žiznennom puti, Bd. 2, S. 427. 
er, Urusov und die gesamte Generation erlebt. ${ }^{61}$ Urusov seinerseits beschrieb in einer Porträtierung des Juristen Vladimir Ivanovič Žukovskij (1838-1899) jenen als „Idealist der 6oer-Jahre“. 62 Eine "helle Epoche“ sei das damals gewesen, betonte Koni in der Beschreibung von Arsenev. ${ }^{63}$ Und Andreevskij charakterisierte diese Epoche, indem er erzählte, wie in den 186oer-Jahren "herausragende Gelehrte“ ins Gerichtswesen geströmt seien und über die „innere Schönheit ihres Talents“ mit „großen geistigen und künstlerischen Kräften“ gewirkt hätten. ${ }^{64}$ „Mit tiefer Achtung“ seien Andreevskij und andere Staatsanwälte „dem buchstäblichen Sinn, aber auch dem Geiste der Gerichtsregeln" begegnet, ${ }^{65}$ betonte Koni und ordnete Andreevskij jenen Menschen zu, die ,den aufkommenden Hauch der ,Epoche der Großen Reformen' spürten“ und „begierig gegenüber der Tätigkeit in den neuen Gerichten " gewesen seien. ${ }^{66}$ Arsen'ev schrieb seinerseits in einem autobiografischen Text von den „hellen Perspektiven“, die sich in der Zeit der Gerichtsreform gezeigt hätten, und betonte die vielen guten Erinnerungen, die er an „die ,Flitterwochen des neuen Gerichts “ habe ${ }^{67}$ In der Porträtierung zu Arsen'evs 50. Dienstjubiläum beschrieb Koni die Gerichtsreform als „Aphrodite“, die sich im Verlauf der Jahrzehnte allerdings beugte, der Haare und Zähne ausfielen, die Runzeln bekam und an Gesichtsfarbe verlor. Arsenev und mit ihm all jene, „die mit dem alten Glauben aber mit schwankender Hoffnung [...] sich schützend in den Wind stellten“, blieben ihr „treu, weil im privaten wie im öffentlichen Leben die erste Liebe, die ins Herz geht, auch die letzte ist, die wieder aus dem Gedächtnis geht“ ${ }^{\text {“68 }}$

Das Bild von der Gerichtsreform als „Aphrodite“ geht auf Spasovič zurück. Koni selber benutzte die Allegorie häufig, nicht nur in biografischen Skizzen, sondern auch in seinen Überblicksdarstellungen zu 50 Jahren reformierter Gerichte. Darin erinnerte er auch an den Urheber der Allegorie:

61 Koni: Vospominanie o knjaze Aleksandre Ivanoviče Urusove. In: Urusov/Andreeva/ Gol'dovskij (Hrsg.): Knjaz' Aleksandr Ivanovič Urusov (1843-1900), Bd. 2 und 3, S. 216.

62 Aleksandr I. Urusov: Pamjati V. I. Žukovskogo. In: Kur'er, 07. 02. 1899. Hier zitiert nach: Aleksandr I. Urusov: Pamjati V. I. Žukovskogo. In: Aleksandr I. Urusov/A. A. Andreeva/O. B. Gol'dovskij (Hrsg.): Knjaz' Aleksandr Ivanovič Urusov (1843-1900). Stat'i ego, pis'ma ego, vospominanija o nem, Bd. 2 und 3. Moskva 1907, S. 40.

63 Koni: Konstantin Konstantinovič Arsen’ev. In: RS 2 (1908), S. 248.

64 Sergej A. Andreevskij: Ob ugolovnoj zaščite. In: ders. (Hrsg.): Dramy žizni. Petrograd 1916, S. 3-38, hier S. 31-32. Diese Rede zum Beruf des Strafverteidigers hielt Andreevskij 1903 auf einer Konferenz von Anwaltsgehilfen. Sie beinhaltet auch Beschreibungen verschiedener Juristen, darunter auch von Urusov oder Koni.

65 Anatolij F. Koni: Iz zametok i vospominanij sudebnogo dejatelja. XVI. [Iz prošlovo peterburgskoj prokuratury]. In: RS 12 (1911), S. 484.

66 Koni: S. A. Andreevskij. In: ders. (Hrsg.): Na žiznennom puti, Bd. 5, S. 179.

67 Konstantin K. Arsen'ev: Iz vospominanij. In: GM 2 (1915), S. 117 und 120.

68 Koni: Konstantin Konstantinovič Arsen’ev. In: RS 2 (1908), S. 254. 
[...] V. D. Spasovič, an die Vergangenheit erinnernd, hat die Statuten in ihrer jungfräulichen Unversehrtheit mit Aphrodite verglichen, die aus der Meeresgischt entsteigt. Bald sind es fünfzig Jahre seit dem 20. November 1864 ... Die harmonischen Züge der Göttin haben sich verändert, ihre Stirn ist von Runzeln überzogen - das Resultat trauriger Verluste und schwerer Prüfungen - aber für jene, die sie vor einem halben Jahrhundert kennengelernt haben, die mit Liebe und Sorge ihren Lebensweg mitverfolgt haben, ist ihre innere Schönheit unverändert geblieben $[\ldots] .^{69}$

Ähnlich wie die Gerichtsreform selber wurden auch die konkreten fachlichen Fähigkeiten der in dieser Pionierzeit aktiven Juristen in allen Skizzen in überschwänglichem Ton gelobt, es war die Rede von „hoher Begabung " ${ }^{\text {“70 }}$, „Geister, die selbständig, künstlerisch, fähig zur Eröffnung des Neuen“ und damit „hell und selten wie Brillanten“ waren. ${ }^{71}$ Die „Atmosphäre von Talentiertheit ${ }^{\text {" } 72}$ umgab sie, und die Plädoyers flogen "glänzend von hellen Funken des Einfallsreichtums ${ }^{\text {“"73 }}$ dahin. Immer wieder wurde auch das romantische Bild des Ritters bemüht, wenn es darum ging, fachliche Fähigkeiten und Professionalität der Juristen zu betonen. Als „Ritter der Wahrheit“ [Rycar' pravdy] beschrieb Arsen’ev Urusov. ${ }^{74}$ Und bezogen auf dieses Recht sollten die Juristen denn auch agieren und die Wahrheitsfindung voranbringen. Koni nannte im Arsenev-Porträt die reformierten Gerichtsstatuten einen „Leuchtturm“, entzündet vom „Feuer der echten Rechtsbarkeit“. In Arsen'evs Gerichtsreden spiegelte sich „die Sonne der ungeheuchelten Wahrheit“, und er erfülle so die „ewigen Forderungen des menschlichen Geistes und der Ge-

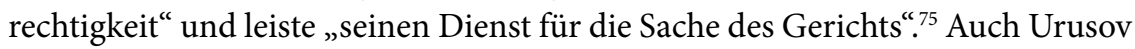
und Plevako verrichteten laut Koni den „Dienst am Wort“ mit Würde. ${ }^{76}$ Koni selber wurde von Andreevskij beschrieben als „Hüter der reinen und furchtlosen Wahrheit". ${ }^{77}$ Und umgekehrt sprach Koni von „großen Kenntnissen“ und „reicher Begabung", „Zurückhaltung im Ausdruck, Durchdachtheit und Gerechtigkeit der Schlüsse“ und einem Redestil, der „ohne künstliche Höhen und Tiefen seiner harmonischen und ebenen Stimme" auskomme. ${ }^{78}$ Urusovs Stil wiederum war in

69 Koni: Vvedenie k Sistematičeskomu Kommentariju U. U. S., S. 30.

70 Koni: Konstantin Konstantinovič Arsen’ev. In: RS 2 (1908), S. 253.

71 Andreevskij: Ob ugolovnoj zaščite, S. 34.

72 Andreevskij: Kniga o smerti, Bd. 1, 1922, S. 186.

73 Koni: Vospominanie o knjaze Aleksandre Ivanoviče Urusove. In: Urusov/Andreeva/ Gol'dovskij (Hrsg.): Knjaz' Aleksandr Ivanovič Urusov (1843-1900), Bd. 2 und 3, S. 192-93.

74 Arsen'ev: Kn. A. I. Urusov, S. 434.

75 Koni: Konstantin Konstantinovič Arsen’ev. In: RS 2 (1908), S. 248-54.

76 Koni: Dva sudebnych oratora. In: ders. (Hrsg.): Na žiznennom puti, Bd. 2, S. 427.

77 Andreevskij: Kniga o smerti, Bd. 1, 1922, S. 137.

78 Koni: S. A. Andreevskij. In: ders. (Hrsg.): Na žiznennom puti, Bd. 5, S. 181-82. 
den Augen Andreevskijs das herausragende „Beispiel lebendiger, menschlicher, allgemeinzugänglicher Verteidigung " 79

Dieses Betonen vom Dienst der Begabten für Recht und Wahrheit wurde begleitet von einem Adjektiv, das mit seinem pathetischen Unterton sehr schön zum Rechtsgelehrten als „Ritter" passte: „edel“ [blagorodnyj]. Ein in der Moskauer Advokatur tätiger Kollege glänze „edel ${ }^{“ 80}$ und „edel in seinen rhetorischen Methoden ${ }^{\text {"81 }}$ sei auch Andreevskij. Spasovič und der Staatsanwalt Valerian Aleksandrovič

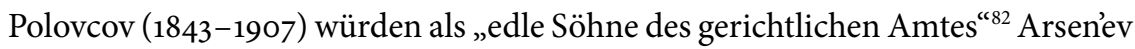
zum Dienstjubiläum gratulieren wollen, wenn sie noch lebten, und Arsen'ev selber zeichne sich in seiner Arbeit als Anwalt durch „tiefen und bedingungslosen Edelmut“ aus. Jeglicher Mangel an solcher „Edelheit“ unter den Juristen stellte in Konis Aufzeichnungen zum Fall Vera Zasulič ein dominantes Thema dar. Kein Wunder deshalb, dass auch in dieser Erinnerungsschrift jene als besonders "edel“ hervortraten, die sich loyal zu Koni verhalten hatten und sich für das Einhalten der Rechtsprinzipien eingesetzt hatten:

Mein verstorbener Kollege, der edle Ritter Otto von Dehn [Otton fon Den], der auch im Gericht gewesen war an der unglücklichen Sitzung [...] stritt mit Pahlen über mich, dass ich doch das Urteil gar nicht gesprochen habe. Worauf Pahlen meinte, ich hätte das Papier mit dem Geschworenenspruch vernichten sollen. Darauf konnte Otto nichts mehr sagen, fuhr aber sofort zu mir und erzählte mir das. ${ }^{83}$

Über eine oftmals poetisch anmutende Sprechweise wurden die Gerichtsreform und ihre Anfangszeit mit einer mythischen Aura umgeben. Kanonische Begriffe tauchten immer wieder auf, ja ganze Allegorien wurden von Porträt zu Porträt weiterverbreitet. Die Gerichtsreform war Aphrodite, Göttin der Liebe oder auch die erste Liebe und die Ehefrau, mit der man Flitterwochen genoss. Grundsätzlich - so die Diktion - war die Zeit der Einführung der Reform allen unvergesslich, besonders hell scheinend, und ihr musste folglich mit tiefer Achtung begegnet werden. Getragen vom Hauch dieser ganz speziellen Epoche entstanden großartige Juristen, die begabt und edel waren, im Dienste von Recht und Wahrheitsfindung standen und der Reform zeitlebens treu blieben.

79 Andreevskij: Nad mogiloj knjazja A. I. Urusova. In: ders. (Hrsg.): Dramy žizni, S. 622.

80 Koni: Vospominanie o knjaze Aleksandre Ivanoviče Urusove. In: Urusov/Andreeva/ Gol'dovskij (Hrsg.): Knjaz' Aleksandr Ivanovič Urusov (1843-1900), Bd. 2 und 3, S. 195.

81 Koni: Iz zametok i vospominanij sudebnogo dejatelja. XVI. [Iz prošlovo peterburgskoj prokuratury], S. 483.

82 Koni: Konstantin Konstantinovič Arsen’ev. In: RS 2 (1908), S. 255.

83 Koni: Vospominanija o dele Very Zasulič. In: GA2, S. 221. 
Durch die starke Betonung der Anfangszeit der reformierten Gerichte als konstituierendes Element dieser edlen Juristen geschah rhetorisch noch implizit eine Aufteilung der Berufsleute in zwei Kohorten. Jene, die unmittelbar nach 1864 gewirkt hatten, standen jenen anderen gegenüber, die erst Jahrzehnte später aus den juristischen Fakultäten des Landes ins Arbeitsleben entlassen wurden. Diese, so macht Koni schon 1892 in seiner Rede vom „neuen Wein“ auch explizit klar, unterschieden sich grundsätzlich von ihren Vorgängern: „In der ersten Zeit hat niemand [...] die Beschäftigung auf den neuen Stellen als einen gewöhnlichen Routinedienst gesehen. Es war eine Tätigkeit, Herausforderung, Berufung. Es war die erste Liebe. [...] Die heutige junge Generation hat diese Gefühle nicht erlebt [...].“84 Diese ,junge Generation“ wurde nun immer offensichtlicher der Adressat, auf den die lobgefüllten Skizzen über die Vorgänger einwirken sollten. Zum 50. Jubiläum der Reform war die Generationenthematik in Konis Texten besonders präsent. Schon der Titel seines monumentalen Skizzenbandes „Väter und Söhne der Gerichtsreform“" zeichnete eine Abfolge von Kohorten an Berufsleuten vor. Die „Väter“, Wegbereiter der Reformstatuten, wurden von den „Söhnen“, Pionieren in der neuen Gerichtswelt, abgelöst. Den Band widmete Koni denn auch offiziell den nun auf die „Söhne“ folgenden „jungen Gerichtstätigen“. An welchen Werten und Vorbildern sich diese Jungen zu orientieren hatten, liegt auf der Hand. In den einleitenden Worten zu „Väter und Söhne der Gerichtsreform“ schreibt Koni unmittelbar, dass der Sammelband ein Mittel zur Stärkung des Zusammenhalts in der Berufsgruppe der Juristen sei und deren Akteure - insbesondere die kommende Generation - auf gemeinsame Werte und Vorbilder einschwören solle. Von elementarer Wichtigkeit sei diese „Belebung der Vorstellung über die Zeit

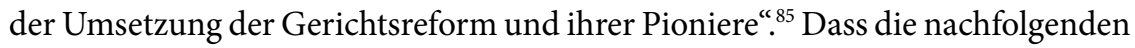
„Enkel“ sich vom „Vermächtnis der Väter" und dem „Vorbild der Söhne“ inspirieren ließen, hofft Koni im Nachwort. ${ }^{86}$ Im Jubiläumsartikel für „Russische Altertümer“ [Russkaja Starina] spricht er davon, dass es nun an den "neuen und jungen Akteuren" liege, die Weiterentwicklung der Gerichte voranzutreiben. ${ }^{87}$ Grundwerte der Profession sollten also, fest gekoppelt an die Anfangszeit des Berufsstandes, an Nachfolger weitergegeben werden, die selber die Zeit der Gerichtsreform nur vom Hörensagen kannten. Koni machte auch offen deutlich, dass sich zu diesem Zweck seine Porträts der „Väter und Söhne“ ganz auf die vorbildhaft „,hellen Seiten“ der Beschriebenen beschränkten. ${ }^{88}$ Offensichtlich wurde die Berufsgruppe

84 Koni: Novye mecha i novoe vino, S. 483.

85 Koni (Hrsg.): Otcy i deti sudebnoj reformy, S. III (Vorwort).

86 Ebd., S. 18 (Nachwort).

87 Koni: Pjat'desjat' let nazad, S. 28.

88 Koni (Hrsg.): Otcy I deti sudebnoj reformy, S. III-IV (Vorwort). 
in ihrer Gesamtheit in den Blick genommen und der Einzelne dabei zum positiven exemplarischen und kaum noch individuellen Teil für das Ganze gemacht.

Dies soll aber nicht heißen, dass in den Skizzen keine Worte der Kritik zu hören wären. Gerade Nachrufe sind in ihrer Funktion als „,instant biography“ zwar in der Regel auf die positiv konnotierten Aspekte im Leben des Verstorbenen fokussiert. ${ }^{89}$ Auch Publikationen zu Dienstjubiläen und Sammelbände zu Ehren der Berufsgruppe spielen vornehmlich mit den von Koni explizit gemachten „hellen Seiten“. Trotzdem funktionierte die Mythisierung der Anfangszeiten und ihrer Akteure in den Porträts häufig vor einer Negativfolie. Ohne Namen zu nennen ist die Rede von Juristen, die sich nicht passend verhalten würden. Als Negativbeispiele unterstrichen sie die Vorbildhaftigkeit der Porträtierten erst recht. Der Abfall von den Anfängen und die Abwendung von den Kernpunkten der Gerichtsreform bildeten dabei meist den Hintergrund für den Niedergang. Das mehrfach verwendete Bild von der Gerichtsreform, die in der Zeit bis zur Jahrhundertwende immer mehr einer gealterten und zerfallenen Liebesgöttin glich, drückt dies drastisch aus. Indem negative Bewertungen manchmal auch spezifisch auf eine jüngere Generation an Juristen bezogen wurden, die nach der Jahrhundertwende aktiv war, zeigte sich einmal mehr die Bedeutung der mythischen Überhöhung der Reform und ihrer Pioniere als einheitsstiftendes Narrativ, das man insbesondere den nachfolgenden Berufsleuten weiterzugeben versuchte. So schrieb Koni, dass Arsen'evs Beispiel zeige, „wie aus Advokaten gesellschaftliche Akteure im besten Sinne entstehen können [...] und nicht Rhetoriker, Sophisten und Schwatzbasen, die die Autorität des gerichtlichen Worts schmälern". Und gerade seine Gerichtsreden wären noch heute sehr wertvoll, „wo Arbeit und rednerische Weiterentwicklung bei uns oft von saloppem Eifer und Selbstverliebtheit abgelöst" würden. ${ }^{90} \mathrm{Zu}$ Urusov und Plevako schrieb Koni: „Beide sind gegangen und hinterlassen hinter sich eine farbige und lebendige Erinnerung in der Geschichte der russischen Anwaltschaft." Sie seien der Gerichtsreform „treu“ geblieben, trotz des „Zwielichts“, das über sie gekommen sei. Zu diesem „Zwielicht“ resümiert Koni: „Wir leben in einer grauen Zeit, graue Leute ohne Originalität wirken überall um uns [...]. ${ }^{\text {“1 }}$ Auch Andreevskij meinte in seiner Rede von 1903, dass heute Verteidigung vorhersehbar und „banal“ sei. Oder habe man je vorausgesehen, was Urusov sagen würde? Früher sei man

89 Nigel Starck: Life After Death. The Art of the Obituary. Carlton Victoria 2006, S. 9.

90 KonI: Konstantin Konstantinovič Arsen’ev. In: ders. (Hrsg.): Na žiznennom puti, Bd. 2, S. 245-46. Dass gerade Anwälte "moderne Sophisten“ seien, die gegen Geld jegliche moralische Prinzipien verraten würden, war ein verbreiteter Vorwurf, vgl. Andrzej WALICKI: Legal Philosophies of Russian Liberalism. Notre Dame, Ind. U. a. 1992, S. 76 . Zu diesem Thema ausführlicher unten, S. 79 .

91 Koni: Dva sudebnych oratora. In: ders. (Hrsg.): Na žiznennom puti, Bd. 2, S. 427-29. 
ohne "Selbstannoncen“ ausgekommen, mit denen die Strafverteidiger - heute „total ordinäre Geister" - für sich Werbung machten..$^{92}$ Ohne überhöhte Ideale von Recht, Wahrheit oder Gerechtigkeit, die der edle Jurist in die Gesellschaft einbringen soll, scheinen diese nie namentlich genannten Anderen ihres Amtes zu walten und daraus für sich persönlich Profit zu schlagen. Das Festschreiben der Juristen auf idealistische Grundwerte und ein zusammenschweißendes Gefühl, einer besonderen Berufung nachzugehen, scheint deshalb umso dringlicher.

Diese Darstellung wurde in den biografischen Skizzen und weiteren Erinnerungsschriften nicht selten mit einem interessanten Schachzug unterstrichen: Die Verbindungen unter den porträtierten Juristen selber wurden zum Thema gemacht und gewisse Namen, Motive, Werke und Erinnerungsschriften immer wieder zitiert und so in ihrer besonderen Bedeutung für die Berufsgruppe gestärkt. Teil der allermeisten biografischen Skizzen war eine oft recht detaillierte Aufzählung der Schriften, die der Porträtierte im Verlauf seiner Tätigkeit verfasst hatte. Sowohl Fachtexte als auch Gerichtsredenbände, Publizistik zu allen möglichen Themen, autobiografische Texte und sogar eigene literarische Versuche wurden aufgelistet, oftmals inklusive Inhaltsangaben und Beurteilungen von Seiten des Porträtierenden. Auch umgekehrt fand sich manchmal in der Skizze die Nennung von Titeln, die der Autor selber verfasst hatte und zu denen die porträtierte Person Stellung bezogen hatte. Ab und zu wurde sogar deutlich gemacht, dass die Erwähnung von Titeln auch deshalb geschah, um vergessene Inhalte zum Schreibzeitpunkt des Porträts wieder präsent zu machen. So beschrieb Koni zum Beispiel in seiner Porträtierung von Arsen'ev von 1908 sehr ausführlich dessen Buch von 1875 „Notizen zur russischen Anwaltschaft“, das die Tätigkeit des St. Petersburger Anwaltsrates in den Jahren 1866 bis 1874 untersucht. ${ }^{93}$ "Ein wertvoller Beitrag zur juristischen Literatur“ sei dieses. „Strenge ethische Forderungen“ würden darin sichtbar, weshalb es „bis heute" von Bedeutung sei und ein "moralischer Kodex“ werden solle. ${ }^{94}$ Nicht selten wurde gar der Prozess des gegenseitigen Lesens und Bewertens von Erinnerungen, publizistischen Artikeln, Gerichtsreden oder gar Gedichten zwischen Porträtiertem und Porträtierendem im Text offen dargelegt. Es entwickelte sich ein Kommunikationsgefüge. So berichtete Andreevskij in seinem Urusov-Porträt, dass dieser viel für Zeitungen schreibe und ihm von all seinen Arbeiten per Brief berichte und Auszüge schicke. Gleich nachfolgend fügte Andreevskij hinzu, dass auch er seinerseits Urusov Teile seiner Erinnerungsschriften und literarischen Aufzeichnungen gebracht habe, die dieser „mit einer Notiz“

92 Andreevskij: Ob ugolovnoj zaščite, S. 33-34.

93 Konstantin K. Arsen'ev: Zametki o russkoj advokature. Obzor dejatel'nosti St. Peterburgskogo soveta prisjažnych poverennych za 1866-74 gg. Sankt-Peterburg 1875.

94 Koni: Konstantin Konstantinovič Arsen’ev. In: RS 2 (1908), S. 247. 
versehen zurückgegeben habe. ${ }^{95}$ Noch mehrschichtiger gestaltet sich Andreevskijs Bericht über die Ansichten anderer Juristen zu seinem Band mit Gerichtsreden, den er 1891 herausgegeben hatte. ${ }^{96}$ Arsen'ev, so Andreevskij, habe ein Exemplar dieses Buches von ihm verlangt und dann einen Artikel darüber geschrieben, in dem er viel Lob für den Autor gefunden habe. Der Band habe daraufhin ein Eigenleben entwickelt, und junge Anwälte würden nun fleißig daraus zitieren und plagiieren, was Andreevskij freue. ${ }^{97}$ In der Koni-Skizze über Urusov erwähnte der Autor selber seinen eigenen Sammelband „Im Laufe der letzten Jahre“. Nach Erscheinen des Buches habe ihm Urusov einen Brief geschickt, in dem er "sich in warmen Worten über die Zeiten unserer Jugend und den gemeinsamen Dienst äußerte“ ${ }^{98}$ Die Offenlegung dieser spezifischen Kommunikation rund um Erinnerungsschriften und Fachtexte deutet an, dass die Inhalte solcher Porträts ein Stück weit im Dialog ausgehandelt wurden. Davon zeugen auch die brieflichen Reaktionen und Diskussionen, die sich darum herum entwickelten. 1909 schrieb Andreevskij an Koni über dessen Urusov-Skizze:

Ich las aufgewühlt und mit Liebe Eure Erinnerungen über Urusov. Wir ergänzen einander: Sie haben die erste Hälfte seines Lebens und die „Advokatur" behandelt; ich habe mich auf seine reifen Jahre konzentriert und versucht, seine „Seele“ herüberzubringen.

Einige Jahre später fragte er Koni per Brief, was dieser denn zu seinem eigenen Urusov-Porträt meine: „Wie gefällt Ihnen MEIN Urusov?“" ${ }^{99}$

Gegenseitiges Zitieren, Bezüge auf die Berufskollegen und ihre Texte, das Porträtieren an sich: All das trug zweifelsohne zu einer „horizontalen Vernetzung“ bei. Inwiefern waren solche „Erinnerungsgemeinschaften“ aber auch „Erinnerungskartelle“, die durch die Verweise auf die einen und Verschweigen der anderen Erinnerungsschriften und Fachtexte die Deutungshoheit über bestimmte Themen erreichten und andere Personen und ihre Darstellungen ausschlossen? ${ }^{100}$

95 Andreevskij: Kniga o smerti, Bd. 2, 1922, S. 168-69.

96 Sergej A. Andreevskij (Hrsg.): Zaščititel’nye reči. Sankt-Peterburg 1891. Weitere Ausgaben 1898 und 1909.

97 Andreevskij: Ob ugolovnoj zaščite, S. $15 \mathrm{ff}$.

98 Konı: Vospominanie o knjaze Aleksandre Ivanoviče Urusove. In: Urusov/Andreeva/ Gol'dovskij (Hrsg.): Knjaz' Aleksandr Ivanovič Urusov (1843-1900), Bd. 2 und 3, S. 210.

99 Sergej A. Andreevskij: Kniga o smerti. Moskva 2005, S. 549-51 (Nachwort von I. I. Podol'skaja).

100 Claudia Ulbrich/Hans Medick/Angelika Schaser: Selbstzeugnis und Person. Transkulturelle Perspektiven. In: dies. (Hrsg.): Selbstzeugnis und Person. Transkulturelle Perspektiven. Köln u. a. 2012, S. 11. Ulbrich et al. Weisen auf Vernetzungen hin, die durch Schriften entstehen, in denen Bezüge nicht nur vertikal in einer Generationenkette, son- 
Sicher ist, dass die vorgefundene kanonische Darstellung der Juristenschaft in der Lage war, auch über Differenzen ideologischer oder politischer Art hinwegzuschreiben, unterschiedliche berufliche Überzeugungen nur am Rande zu erwähnen und persönliche Antipathien gänzlich hintenanzustellen. Die daraus resultierenden „Leerstellen“ lassen sich lediglich aus Andeutungen oder dem Kontext erschließen. ${ }^{101}$ Ganz sachte werden in den Porträts Hinweise darauf angebracht, dass auch gewisse Differenzen zwischen dem Autor und seinem Subjekt vorhanden waren. Dabei handelte es sich meistens um verschiedene Auffassungen, wie die Rolle des Anwalts oder Staatsanwalts im Detail auszuüben sei. Koni sah den Staatsanwalt als „sprechenden Richter" und nicht - wie Urusov in seinen Augen die Funktion umgesetzt habe - als parteiischen Kämpfer für eine Seite. ${ }^{102}$ Sowohl Koni als auch Arsenev kritisierten den ihrer Meinung nach manchmal übertriebenen Hang zur Literatur in Andreevskijs Gerichtsreden, wodurch sich die Beweisführung einzig auf die Psychologisierung des Täters beschränke. ${ }^{103}$ Mit keinem Wort aber wird erwähnt, dass auch den porträtierten Juristen von Öffentlichkeit und Berufskollegen oftmals genau jene Vergehen vorgeworfen wurden, derer man die nur anonym erwähnten, negativen Exponenten der Zunft in den Skizzen bezichtigte. Auch die positiv porträtierten Anwälte Andreevskij, Urusov oder Spasovič waren mehrfach in Fälle verwickelt, die großen Aufruhr zur Folge hatten. ${ }^{104}$ Dies weil Klienten verteidigt und freigesprochen wurden, die

dern auch horizontal auf Freunde und Verwandte, Mentoren, Vorgesetzte, Lehrer etc. gemacht werden. Dabei können auch Erinnerungsgemeinschaften oder -kartelle entstehen.

101 Vgl. zu „Leerstellen“ in Selbstzeugnissen Heiko Haumann: Die Verarbeitung von Gewalt im Stalinismus am Beispiel ausgewählter Selbstzeugnisse. Methodische Bemerkungen und ein Werkstattbericht. In: ders./Jörn Happel/Carmen Scheide (Hrsg.): Das Jahrhundert des Gedächtnisses. Erinnern und Vergessen in der russischen und sowjetischen Geschichte im 20. Jahrhundert. Traben-Trarbach 2010, S. 68-69.

102 Koni: Vospominanie o knjaze Aleksandre Ivanoviče Urusove. In: Urusov/Andreeva/ Gol'dovskij (Hrsg.): Knjaz' Aleksandr Ivanovič Urusov (1843-1900), Bd. 2 und 3, S. 205. Vgl. zum in Russland vorherrschenden Verständnis des Prozesses als Suche nach Konsens: Girish N. Bнат: The Consensual Dimension of Late Imperial Russian Criminal Procedure. The Example of Trial by Jury. In: Peter H. Solomon (Hrsg.): Reforming Justice in Russia, 1864-1996. Power, Culture, and the Limits of Legal Order. Armonk, New York 1997, S. 67-68. Bhat führt aus, wie im russischen Strafprozessrecht die Notwendigkeit nach Konsens über die „Wahrheit“ betont wurde. Sie verortet die Ursprünge dieses Konsensualismus in Petrinischer Zeit, merkt aber an, dass der Fokus aller Prozessbeteiligter auf Kollegialität auch aus dem Misstrauen der Gerichtsreformer gegen die Macht des Richters, der das „imperiale Element“ verkörperte, gespeist wurde.

103 Koni: S. A. Andreevskij. In: ders. (Hrsg.): Na žiznennom puti, Bd. 5, S. 177 und Arsen’Ev: Novye sborniki sudebnych rečej, S. $794 \mathrm{ff}$.

104 Vgl. z. B. die Verteidigung des Kaufmanns Elagin 1900 durch Andreevskij, AndreevskiJ: Kniga o smerti, 2005, S. 496 (Nachwort von I. I. Podol'skaja). Podol'skaja macht selber da- 
mit besonders schlimmen Verbrechen aufgefallen waren. Den verteidigenden Anwälten wurde vorgeworfen, aus Gier jegliche moralischen Prinzipien zu verraten. Der wirtschaftliche Konkurrenzkampf um lukrative Fälle nahm tatsächlich seit den 188oer-Jahren zu. ${ }^{105}$ Gängige Vergleiche mit dem englischen „Barrister“ und dem französischen „Advocat“ überhöhten und idealisierten in der Öffentlichkeit die Erwartungen an die Tätigkeit eines Anwalts, der in Russland, wie beispielsweise auch im amerikanischen Rechtssystem, oftmals wenig spektakulärer Arbeit fern von den Gerichtssälen nachgehen musste und dabei auch so Profanes tat wie Geld zu verdienen. Zur idealisierten Vorstellung vom Verhalten eines Anwaltes passte das wenig. ${ }^{106}$ Während sogenannte Ambulanzenjäger in allen Justizwesen auftauchten und entsprechend kritisiert wurden, verschärfte sich in Russland das Problem und der daraus hervorgehende Imageverlust aber insofern, als dass tatsächlich gewisse Missstände in der Selbstregulierung der Anwälte bestanden. Ethische Grundlagen des Berufs, wie beispielsweise eine Gehälterdeckelung und ein Verbot von Investitionen der Verteidiger bei den eigenen Klienten, waren nicht vorhanden oder wurden nur ungenügend durchgesetzt. ${ }^{107}$ Skandalöse Prozesse, von Gerüchten rund um Korruption und Geldgier begleitet, waren deswegen keineswegs die Ausnahme. So lief beispielsweise 1874 im aufsehenerregenden Prozess gegen die Äbtissin Mitrofanija beim Versuch, ein vorbildlich transparentes und gerechtes Gerichtsverfahren durchzuführen, einiges schief. Zahlreiche Anwälte fielen negativ mit hohen Geldforderungen auf. Zudem wurde gemunkelt, dass Plevako als einer davon heimlich einen Deal mit dem Richter geschlossen hätte. Generell sei der Eindruck bestätigt worden, dass der Wert eines Anwalts nicht auf seinem Können, sondern auf seinen Beziehungen zu den höheren Gerichtsbehörden beruhe. ${ }^{108}$ Zweifel an der Art der

rauf aufmerksam, dass Koni darüber nichts gesagt habe in seinem veröffentlichten Porträt, dies allerdings in den erst posthum publizierten „Erinnerungen an den Fall Vera Zasulič kritisch anspreche, vgl. Koni: Vospominanija o dele Very Zasulič. In: GA2, S. 22o. Ein besonders bekanntes Beispiel ist auch Spasovičs Verteidigungsplädoyer für einen gewalttätigen Vater, gegen das sogar Fjodor Dostojewski öffentlich protestierte, vgl. BABEROWSKI: Autokratie und Justiz, S. 551-52. Vgl. dazu auch unten, S. 300.

105 Hausmann: Universität und städtische Gesellschaft in Odessa, S. 364-65.

106 William Pomeranz: The Practice of Law and the Promise of Rule of Law. The Advokatura and the Civil Process in Tsarist Russia. In: Kritika: Explorations in Russian and Eurasian History 2 (2015), v. a. S. 250-53 und 260 mit Erklärungen zu den unterschiedlichen Arten von Anwälten und den idealisierten Vorstellungen von der Rolle des Anwalts.

107 Pomeranz: The Practice of Law and the Promise of Rule of Law, S. 253-54. Dazu auch ausführlicher das nachfolgende Unterkapitel zur Professionalisierung der Juristen in Russland.

108 Sandra Dahlke: Old Russia in the Dock. The Trial Against Mother Superior Mitrofaniia Before the Moscow District Court (1874). In: Cahiers du monde russe et soviétique 1 (2012), S. 110-11. 
Verteidigung und den Motiven eines Plevako, der aufgrund seiner Erfolge ein äußerst populärer Mann war, waren weit verbreitet und zeigten sich beispielsweise in einer großen Zahl an drastischen Anekdoten, die über seinen zynischen Stil kursierten. ${ }^{109}$ Ohne es öffentlich in seinen Porträts anzubringen, vertrat auch Koni eine ablehnende Haltung gegen viele Entwicklungen in der Advokatur. Unter anderem in seinen „Erinnerungen an den Fall Vera Zasulič “schreibt er, dass er nicht zufrieden sei mit der Ausgestaltung des Anwaltsberufs, der zu sehr „privatem Interesse" diene. ${ }^{110}$ Nichtsdestotrotz beschrieb er auch Plevako im Doppelporträt mit Urusov in der üblichen Weise als edlen Juristen und Getreuen der Gerichtsreform. ${ }^{111}$ Auch im Band „Väter und Söhne der Gerichtsreform“" erhielt Plevako eine gewichtige Stellung. Dies, während Briefe Konis an Freunde und Verwandte zeigen, dass er auch ganz persönlich ein äußerst angespanntes Verhältnis zum berühmten Mann aus Moskau gehabt hatte. ${ }^{112}$ Diese Zurückhaltung mit in der Öffentlichkeit präsentierten kritischen Einschätzungen von wichtigen Juristen fällt auch auf, wenn nochmals ein Blick zurück auf Konis Wahrnehmung des

109 Aleksej A. Demičev hat die Anekdoten untersucht, die man sich über Anwälte erzählte, und kommt dabei zum Schluss, dass sie insbesondere Plevako als Person darstellen würden, die oftmals zynisch, grob und nur auf großen Verdienst aus gewesen sei. Als Beispiel dient ihm eine ins Extreme überzeichnete Anekdote, in der Plevako einen Vergewaltiger der eigenen Tochter damit verteidigt, dem Richter zu sagen, dass es ja noch schlimmer hätte kommen können. Der Angeklagte hätte ja auch die Tochter des Richters schänden können. Aleksej A. Demičev: Sudebnaja reforma 1864 g. v dorevoljucionnom anekdote. Opyt izučenija rossijskoj mental'nosti. Moskva 2012, S. 101-08, Beispiel S. 104. KonI: Vospominanija o dele Very Zasulič. In: GA2, S. 245-46.

111 Vgl. die bereits angeführten Zitate aus diesem Text.

112 Im Gegensatz zu der z. B. von Vladimir Smoljarčuk vertretenen Darstellung, dass Koni freundschaftliche Beziehungen zu Plevako gehabt habe, verweist Sergej Vysockij in seiner Koni-Biografie auf das angespannte Verhältnis und belegt dies mit entsprechenden Briefausschnitten. Vgl.: Sergej A. Vysockij: Koni. Moskva 1988, S. 304-06 und SMOLJARČUk: Anatolij Fëdorovič Koni (1844-1927), S. 54. Die gleiche Diskrepanz im Verhältnis zu Plevako zeigt sich noch augenfälliger am Beispiel des Anwalts Nikolaj Platonovič Karabčevskij (1851-1925). So schrieb dieser 1908 einen Nachruf auf den soeben verstorbenen Plevako und veröffentlichte ihn in der Fachzeitschrift „Recht“ [Pravo]. In diesem vergleicht er Plevako mit niemand Geringerem als dem hochgelobten Dichter Alexander Puschkin und nennt ihn ein „Genie des Wortes“. Gleichzeitig entwarf Karabčevskij aber einen nie publizierten Text, in dem er sehr kritisch der Frage nachgeht, ob Plevako wirklich die herausragende Stellung unter den Advokaten verdient habe. Er kommt darin zum Schluss, dass Plevakos Ruhm zu schnell zu groß geworden sei, so dass dieser nicht länger an sich gearbeitet habe, und so seien seine Reden eben keine Paradebeispiele der Gerichtsrhetorik geworden. Vgl.: Dar'ja N. Kovaleva: Rossijskaja prisjažnaja advokatura. Vzgljad iznutri (N. P. Karabčevskij o F. N. Plevako). In: Vestnik Saratovskogo gosudarstvennogo social'no-èkonomičeskogo universiteta 2 (2009), S. 148-49. 
Zasulič-Ereignisses geworfen wird. Dort hatte er über Saburov noch geschrieben „et tu quoque" - auch dieser stehe nicht zu den Prinzipien der Gesetzgebung und falle Koni in den Rücken. Als Saburov nach langer Tätigkeit in Gerichten, Senat und Staatsrat 1916 starb, verfasste Koni einen Nachruf und trat mit später veröffentlichten Erinnerungsreden an Saburov auch vor der Juristischen Gesellschaft von St. Petersburg und anderen Vereinigungen auf. Kein Wort nun von Saburovs Verhalten im Zasulič-Fall. Koni betonte vielmehr gleich zu Beginn, dass Saburov der Vorstellung von Richter und Gericht als ehrlich, unabhängig und furchtlos „das ganze Leben treu“ gewesen sei. ${ }^{113}$

Zugunsten der stimmigen Darstellung vom begabten und edlen Juristen wurden persönliche Abneigungen überwunden und negative Ereignisse und Tendenzen von einzelnen oder der Berufsgruppe verschwiegen. Gerade eine Figur wie Plevako, die sich großer Bekanntheit erfreute, konnte nicht einfach aus dem Narrativ ausgeschlossen werden. Lieber wurde über zweifelhafte Momente hinweg- beziehungsweise die unabdingbaren Elemente des edlen Juristen herbeigeschrieben.

Professionalisierung der Rechtsberufe in Russland nach 1864

Viele Aspekte der biografischen Porträtpraxis von Koni und seinen Kollegen erinnern an klassische Strategien der Professionalisierung von Berufsgruppen, die gerade dann besonders relevant sind, wenn die Profession sich in der Aufbauphase befindet oder unter verschärftem Druck steht. Mit der umfassenden Gerichtsreform unter Zar Alexander II. erhielt die russische Justiz erstmals moderne rechtsstaatliche Züge. Die Gerichte funktionierten nun im mündlichen und öffentlichen Verfahren, bei dem Verteidiger und Ankläger um ein Urteil rangen. Teilweise wurden Geschworenengerichte installiert. In der Justizlandschaft entstand so eine Vielzahl an neuen oder neu definierten Berufen. Deren Ausformung geschah mitten in einer Zeit, als Professionalisierung in ganz Europa zu den dominanten sozialen Prozessen gehörte. ${ }^{114}$ Klassischerweise wird eine Profession definiert über das Vorhandensein einer gemeinsamen Wissensbasis, die durch formales Training

113 Vgl. die auf den öffentlichen Auftritten und Nachrufen von 1916/1917 beruhende Veröffentlichung: Konı: Pamjati Andreja Aleksandroviča Saburova. In: ders. (Hrsg.): Na žiznennom puti, Bd. 4. Publičnye čtenija i reči. Revel', Berlin 1923, S. 397-98. Trotzdem mag es bezeichnend sein, dass Saburov in „Väter und Söhne“ kein eigenes Porträt erhielt. Er taucht darin zwar ab und an auf, und im Sammelartikel am Schluss des Bandes erwähnt ihn Koni nochmals und verweist auf sein Engagement für die reformierten Gerichtsstatuten. Doch damit hat es sich. Vgl.: KonI: K portretam, S. 284.

114 Harley D. Balzer: Introduction. In: ders. (Hrsg.): Russia’s Missing Middle Class. The Professions in Russian History. Armonk New York u. a. 1996, S. 5. 
erarbeitet wird. Wissenschaftliche Gesellschaften, Universitäten, Zeitschriften und regulierende Organe und Professionsorganisationen sorgen dafür, dass die Berufskollegen gemeinsame Verhaltensstandards festlegen und sich selber kontrollieren, weiterbilden und verwalten. ${ }^{115}$ Über seine biografischen Porträtierungen arbeitete Koni mit an der Erschaffung solcher verbindlicher Standards. Das in den Skizzen präsentierte Bild vom „edlen“ Juristen, der „Dienst “ für „Wahrheit" und „Gerechtigkeit“ leistet und als „Ritter“ für seine „Aphrodite“ kämpft, stärkte die Bedeutung der Rechtsberufe. Immer wieder griffen Professionsgruppen auf solche Überhöhungen der eigenen Aufgaben und Persönlichkeiten zurück. Die „Figur des klassischen Professionellen“ wird dafür gerne als „Prototyp einer charismatischen Persönlichkeit“ inszeniert. ${ }^{116}$ Getreu den Genremerkmalen der „Schilderung großer Männer [...] und ihrer großen Taten“ wird die moralische Integrität des Vorbilds betont. ${ }^{117}$ Dieser Persönlichkeit werden Qualitäten zugesprochen, die übernatürlich anmuten, ja fast schon "gottgesandt", sicher aber vorbildlich sind und dabei einem übergeordneten Lebenszwecke dienen sollen. ${ }^{118}$ In der Terminologie Max Webers führt diese Inszenierung von Menschen im Stile von „Erlöserfiguren“ zu einer „charismatischen Herrschaft“ ${ }^{119}$ Die „Charismatisierung des einzelnen“, an der Koni mit seinen Porträts so stark arbeitete, ermöglichte es, den „Pioniergeist“ ständig neu zu erschaffen, der für das ,alltägliche Professionshandeln" vieler Berufsgruppen zentral ist. ${ }^{120}$ Es erstaunt deshalb nicht, dass auch in anderen Ländern zur gleichen Zeit Anwälte ihre Berufsausübung mit ähnlichen

115 Ebd., S. 4. Die russischen Juristen erfüllten viele dieser Grundlagen, am deutlichsten die systematische Ausbildung, die sie an den Rechtsfakultäten und Rechtsschulen im Zarenreich bekamen. Allerdings wurde darin nicht unbedingt eine einheitliche Rechtskonzeption vermittelt, umso wichtiger für das Berufsethos der Juristen waren deshalb die nach der Ausbildung einsetzende unmittelbare Beschäftigungserfahrung und das entsprechende institutionelle Setting. Vgl.: Wagner: Marriage, Property, and Law in Late Imperial Russia, S. 31. Wortmans Studie zur Entwicklung des Rechtsbewusstseins in Russland geht ausführlich darauf ein, wie sich die Ausbildungssituation im russischen Imperium entwickelte, vgl. Fußnote 21 in der Einleitung und Richard Wortman: The Development of a Russian Legal Consciousness. Chicago 1976, S. 198 ff. Dabei wird deutlich, wie gerade jene Juristen, die aktiv in die Erarbeitung der Gerichtsreform involviert waren, vom Geist ihrer Ausbildung geprägt waren, ebd., S. 265.

116 Doris Schaeffer: Psychotherapie zwischen Mythologisierung und Entzauberung. Therapeutisches Handeln im Anfangsstadium der Professionalisierung. Opladen 1990, S. 42-43.

117 Patrick BüHler/Thomas BüHLer/Fritz Osterwalder: Vorwort. In: dies. (Hrsg.): Zur Inszenierungsgeschichte pädagogischer Erlöserfiguren. Bern 2013, S. 8-9.

118 Schaeffer: Psychotherapie zwischen Mythologisierung und Entzauberung, S. 42-43.

119 Rolf Becker: Grusswort. In: Patrick Bühler/Thomas Bühler/Fritz Osterwalder (Hrsg.): Zur Inszenierungsgeschichte pädagogischer Erlöserfiguren. Bern 2013, S. 14.

120 Schaeffer: Psychotherapie zwischen Mythologisierung und Entzauberung, S. 71. 
Worten beschrieben. So heißt es in dem 1905 publizierten Buch zur „Deutschen Rechtspflege“, dass „dem Rechte dienen“ heiße, „am Reich Gottes zu arbeiten“. Dem Anwaltsberuf wurde ein christlich-religiöses Ethos des „Dienstes“ im stetigen „Kampf mit der Sünde“ zugeschrieben. ${ }^{121}$ Über einen starken „Zentralwertbezug", der sich auf das übergeordnete Gemeinwohl berief, wurde versucht, die zahlreichen heterogenen Interessen der Berufsleute für die Auseinandersetzung mit Öffentlichkeit, Politik und Verwaltung auf einen gemeinsamen Nenner zu bringen. ${ }^{122}$ Für die Formung einer solchen Gruppenidentität wurde und wird gerade auch in Professionalisierungskontexten gerne "selbst-generationalisierend“ vorgegangen. Ein Generationennarrativ wird in einer „diskursiven Konstruktion“ erschaffen, um als mobilisierende Kraft zu wirken. ${ }^{123}$ Gerade das Totengedenken und insbesondere Nachrufreden nehmen hier gemeinhin eine besonders wichtige Funktion ein. Als stark formalisierte Texte widmen sie sich „genealogischen Praktiken" und dirigieren so Normen, die zur Herausbildung, aber auch zur Abwertung oder Überschreibung von Werten beitragen können. ${ }^{124}$ Konis den ,jungen Gerichtstätigen“ gewidmeter Sammelband von den „Vätern und Söhnen der Gerichtsreform“ versucht genau diese "Generationenkontinuität“ zu erschaffen, um das Weiterleben der Profession zu sichern. ${ }^{125}$

Nicht überall allerdings wurde eine solche Überhöhung des Juristenberufes angestrebt; der berühmte amerikanische Rechtswissenschaftler und langjährige Richter am Obersten Gerichtshof der Vereinigten Staaten Oliver Wendell Holmes Jr. (1841-1935) definierte den Juristen als technischen Experten, ohne Elemente wie ein höheres Commitment, Bürgerpflicht, Gerechtigkeit oder humanistische

121 Martin Stein: Zur Problematik von Professionalisierungs- und Substitutionsprozessen neuer Berufsgruppen. Am Beispiel der Absolventen sozialwissenschaftlicher Studiengänge. Bochum 1993, S. 50-51.

122 Ebd., S. 54-55.

123 Ondřej MatĚjka: Uses of a „Generation“. The Case of the Czech „68ers“. In: Hartmut Berghoff/Bernd Weisbrod/Uffa Jensen (Hrsg.): History by Generations. Generational Dynamics in Modern History. Göttingen 2013, S. 263 und Dirk Schumann: Youth Culture, Consumption, and Generational Dispositions in Twentieth-Century Germany. In: ebd., S. 145.

124 Anna Echterhölter: Schattengefechte. Genealogische Praktiken in Nachrufen auf Naturwissenschaftler (1710-1860). Göttingen 2012, S. 44-45.

125 Jane Burbank: Discipline and Punish in the Moscow Bar Association. In: Russian Review 1 (1995), S. 59. In ihrem Aufsatz zu den Disziplinierungspraktiken unter den Moskauer Anwälten spricht Burbank vom „didaktischen Paternalismus“, der bemüht wurde, um eine "Generationenkontinuität“ unter den Juristen zu schaffen. In diesem Zusammenhang erwähnt sie auch Konis Band, vgl. ebd., S. 63-64. 
Werte zu bemühen ${ }^{126}$ Dass solche Begrifflichkeiten zusammen mit der Schaffung von Vorbildern und einem Generationennarrativ aber für die russischen Juristen so wichtig waren, verweist auf Einflüsse der Intelligencija-Traditionen. Vorbildhaftes moralisches Verhalten spielte in diesen Kreisen eine wesentliche Rolle. Das Pflichtgefühl, die eigenen Fähigkeiten für nichts Geringeres als eine bessere Zukunft Russlands und der Welt einzusetzen, zeichnete die Intelligencija-Zirkel aus. ${ }^{127}$ Diese hohen Anforderungen wurden typischerweise über Erinnerungstexte an Zeitgenossen geformt und transportiert. Das Genre der „Erinnerungen der Zeitgenossen" [Vospominanija sovremennikov] fügte sich bestens ein in den Boom an Erinnerungstexten, der in Russland im 19. Jahrhundert zu verzeichnen war. Für die intellektuelle Elite wurden diese Texte geradezu zu einer „Institution“ ihrer Schicht, um Barbara Walker zu zitieren. Über das Erinnern an wichtige Exponenten der eigenen Gruppe sollte deren Zusammenhalt bestärkt werden. ${ }^{128}$ Zeitgenossen verfassten Erinnerungen an einzelne Exponenten ihrer Kreise und legten dabei größte Aufmerksamkeit auf das Individuum und seinen Lebensstil. Jegliche moralischen Verfehlungen oder Abweichungen vom Idealweg wurden stark kritisiert und vorbildhaftes Verhalten umso mehr hervorgehoben. So wurden besonders bekannte Exponenten der Intelligencija, wie etwa der Literaturkritiker und Publizist Vissarion Grigorevič Belinskij (1811-1848) oder der Philosoph und Schriftsteller Aleksandr Ivanovič Gercen (Herzen) (1812-1870) immer wieder in lobpreisender Art und Weise einer jüngeren Generation vorgehalten, damit diese sich ein Vorbild nehme und ihre moralische Mission zur Voranbringung Russlands nicht vernachlässige. ${ }^{129}$ Die aus Westeuropa importierten Ideale der Romantik mit

126 Darauf verweist Anna Schur in ihrem Vortrag „Dostoevsky and the Mythology of the Lawyer-Artist“, Association for Slavic, East European, \& Eurasian Studies, 47th Annual Convention, Philadelphia, November 19-22. Siehe von ihr auch: Anna Schur: Wages of Evil. Dostoevsky and Punishment. Evanston Illinois 2012. Vgl. für Holmes Jr.s Ansichten von einem „businesslike understanding“ vom Rechtswesen z. B.: Oliver Wendell Holmes: The Path of the Law [1897]. In: ders.: The Essential Holmes. Selections from the Letters, Speeches, Judicial Opinions, and Other Writings of Oliver Wendell Holmes Jr., hrsg. u. mit einer Einleitung versehen v. Richard A. Posner. Chicago 1992, S. 160-77, Zitat S. 161 sowie die Einführung zum Kontext von Holmes Ideen: Holmes: The Essential Holmes, z. B. S. XI (Einleitung v. Richard A. Posner).

127 Victoria Frede: Doubt, Atheism, and the Nineteenth-century Russian Intelligentsia. Madison 2011, S. 14.

128 Barbara Walker: On Reading Soviet Memoirs. A History of the „Contemporaries“ Genre as an Institution of Russian Intelligentsia Culture from the 1790 os to the 1970s. In: Russian Review 3 (2000), S. 330.

129 Frede: Doubt, Atheism, and the Nineteenth-century Russian Intelligentsia, S. 137. 
ihren messianisch-erlösenden Elementen kommen zur Geltung. ${ }^{130}$ Gerade diese "hagiografische Komponente“ ermöglichte den Transport von Werten und machte das Individuum wie einen christlichen Märtyrer zum Träger einer „überpersönlichen Identität“. Die Parallelen zu Konis Porträtpraxis sind offensichtlich. ${ }^{131}$ Indem er 1914 seinem monumentalen Skizzenband den Titel „Väter und Söhne“ gab, schuf er gar einen direkten Bezug zu den Intelligencija-Zirkeln. Turgenevs gleichnamiger Roman war im Frühjahr 1862 in der Zeitschrift „Russischer Bote“ [Russkij Vestnik] erschienen und hatte einen der größten öffentlichen Aufruhre hervorgerufen, die es in Russland jemals um einen Roman gegeben hatte. ${ }^{132}$ Die Auseinandersetzung drehte sich dabei insbesondere um die Figur des Nihilisten Bazarov, der als Ver-

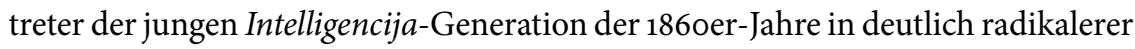
Opposition zur bestehenden Ordnung zu stehen schien als dies bei seinen intellektuellen „Vätern“ der Fall gewesen war. Es entbrannte ein erbitterter Streit über Ausgestaltung und Darstellung der verschiedenen Intelligencija-Generationen. ${ }^{133} \mathrm{Bei}$ allen vorhandenen, interpretierten oder herbeigeschriebenen Unterschieden war aber offensichtlich, dass die „Väter und Söhne“ auch über gemeinsame Elemente verfügten. Dazu gehörte insbesondere ein gewisses „romantisches Bewusstsein“. Auch wenn sich die radikale intellektuelle Bewegung nach 1860 dem Realismus verschrieb und von den oftmals noch adeligen Vorgängern mit ihrer Philosophie von Idealismus und Romantik nichts mehr wissen wollte, lag doch gerade in diesen Vorstellungen eine unterschwellige Kontinuität zwischen den beiden Generationen. Aller vordergründiger Rückweisung zum Trotz waren auch diese Männer von den Zirkeln eines Belinskijs oder Herzens geprägt. ${ }^{134}$ In Konis Darstellung vom „edlen“

130 Laurie Manchester: Holy Fathers, Secular Sons. Clergy, Intelligentsia, and the Modern Self in Revolutionary Russia. DeKalb 2008, S. 179-80.

131 Frances Nethercotт: Russian Legal Culture Before and After Communism. Criminal Justice, Politics and the Public Sphere. London 2007, S. 154-55. Nethercott spricht von der „hagiografischen Komponente“ und dem Transport von Werten, vgl. zu diesen Ausführungen von ihr auch Fußnote 262 in TEIL EINS. Vgl. Benjamin Nathans: Talking Fish. On Soviet Dissident Memoirs. In: Journal of Modern History 87 (2015), S. 606-07 zur ,extrapersonal identity“.

132 Isaiah BERLin: Fathers and Children. Oxford 1972, S. 29. Möglich, dass auch Konis immer wieder erwähnte „erste Liebe“, die für ihn die Gerichtsreform gewesen sei, eine Anspielung auf die gleichnamige Novelle „Pervaja ljubov““ (1860) von Turgenev ist. Vgl. TEIL $D R E I$ für Konis intensive Beschäftigung mit Literaten, darunter insbesondere auch mit Turgenev.

133 Ebd., S. 29-31 zu den verschiedenen diametral entgegengesetzten Einschätzungen von Bazarov, den die einen als zu Unrecht teuflisch dargestellt, die anderen als verheerend heldenhaft gezeichnet sahen.

134 Irina Paperno: Chernyshevsky and the Age of Realism. A Study in the Semiotics of Behavior. Stanford California 1988, S. 6-7. 
Juristen, der sich selber dem „Dienst am Recht“ verschreibt, ist dieses sich über die Generationen hinwegziehende „romantische Bewusstsein“ der Intelligencija unverkennbar. Nicht zuletzt trat so auch das in den kritischen gebildeten Kreisen oftmals skeptisch beäugte technische Element in der Rechtsprechung hinter die „ritterlichen“"Vorstellungen zurück. ${ }^{135}$

Konis Engagement zur Stärkung einer Gruppenidentität unter den Juristen beschränkte sich keineswegs auf seine Veröffentlichungen von biografischen Skizzen und Sammelbänden. Vielmehr war diese Praxis eng verschränkt mit einem anderen wichtigen Element in der Schaffung von einheitlichen Normen innerhalb eines Berufszweiges: dem organisierten Training und der Selbstverwaltung. ${ }^{136}$ Beides fand für die russischen Juristen in unterschiedlichem Ausmaß sowohl in den Juristischen Gesellschaften als auch in den Anwaltsräten statt.

Grundwerte, die für alle Juristen unabhängig der tatsächlichen Berufsausübung gelten sollten, wurden ganz entscheidend in den Juristischen Gesellschaften geformt. Diese Gesellschaften ähnelten als Foren des Austausches und der gegenseitigen Unterstützung den typischen westlichen Berufsorganisationen. Neue Ideen für Gesetzgebungen wurden ausgearbeitet, die rechtliche Sicht auf Probleme in der russischen Gesellschaft erörtert, fortwährende Weiterbildung gewährleistet und Kontakt zu ausländischen Juristenorganisationen aufgenommen. ${ }^{137}$ Die Juristischen Gesellschaften konnten die Einheit zwischen behördlichen, privaten und akademischen Juristen stärken, öffentliche Diskussionen zu Rechtsfragen in Gang bringen und an der Verbreitung des Wissens der Gesellschaft zu Rechtsfragen arbeiten. Je länger, je mehr agierten sie auch als Lobby für die Promotion von Veränderungen im Rechtsbereich und für die berufliche Autorität der Juristen. ${ }^{138}$ Nach Moskau wurden in den $1870 e r-J a h r e n$ auch in weiteren Städten wie St. Petersburg, Kasan, Kiew oder Odessa Juristische Gesellschaften gegründet. Mitgliedschaften und Intensität ihrer Tätigkeit nahmen allerdings im Verlauf der Zeit ab, aber gerade über die Zeitschriften, die sie herausgaben, konnten sie trotzdem das juristische Fachpublikum erreichen. ${ }^{139}$ Spezialisierte Zeitschriften und Fachpublikationen wurden ein wichtiges Forum für die Diskussion von Gerichtsentscheiden, Rechtstheorien, Berufsleben und der Rechts-

135 Vgl. ausführlicher zur Haltung der Intelligencija dem Rechtswesen gegenüber und der Vorstellung von „Recht“ und „Gerechtigkeit“ in TEIL DREI.

136 BALzer: Introduction, S. 4 zu Training und Selbstverwaltung als zentrale Kriterien für die Ausformung einer Profession.

137 Levin-Stankevich: The Transfer of Legal Technology and Culture, S. 241-43.

138 WAGNER: Marriage, Property, and Law in Late Imperial Russia, S. 32.

139 Ebd., S. 32-34 und Levin-Stankevich: The Transfer of Legal Technology and Culture, S. 242. 
praxis in Westeuropa. Ungeachtet von Differenzen war mit dem Fokus auf die Rechtsstaatlichkeit, in dem Gesetze das Verhältnis zwischen Staat und Bürger regeln, ein Stück weit eine gemeinsame Ausgangsposition unter allen Juristen gegeben. ${ }^{140}$ Die Diskussion über konkrete gesetzgeberische Detailfragen und Ärger über Widersprüchlichkeiten in der Rechtsprechung waren somit Elemente, die die Juristen als Fachleute über inhaltliche Differenzen hinweg vereinten. ${ }^{141}$ Dem gemeinsamen Interesse, sich als Experten für die als zentral befundene Rechtsstaatlichkeit zu positionieren, war dieser Fachdiskurs nur förderlich. ${ }^{142}$ Diskussionen und Publikationen trugen so zur Professionalisierung der Juristen bei und halfen ihnen, ein öffentliches Selbstbild zu kreieren und die Autorität ihrer beruflichen Expertise zu behaupten. ${ }^{143}$

Koni engagierte sich sehr in der Juristischen Gesellschaft von St. Petersburg, in deren Führungsgremien er mehrfach vertreten war. ${ }^{144}$ Er nahm intensiv am

140 Heike Kathrin Litzinger: Juristen und die Bauernfrage. Die Diskussion um das bäuerliche Grundeigentum in Russland von 188 o bis 1914. Frankfurt am Main 2007, S. 34-37 und Wortman: The Development of a Russian Legal Consciousness, S. 198.

141 Litzinger: Juristen und die Bauernfrage, S. 262-63.

142 Wagner: Marriage, Property, and Law in Late Imperial Russia, S. 36. Wagner fasst zusammen: „Philosophische und ideologische Differenzen führten zu bitteren Konflikten zwischen den russischen Juristen. Aber paradoxerweise halfen diese Konflikte sogar dabei, die Juristen als eine eigene professionelle Gruppe zu definieren."

143 Ebd., S. 33-34. Ausführlich zur Entwicklung der Juristischen Gesellschaften und der Rechtszeitschriften in Russland der Aufsatz von Peter Liessem: Autonomie in der Autokratie? Die Juristischen Gesellschaften im späten Zarenreich. In: Heiko Haumann (Hrsg.): Aufbruch der Gesellschaft im verordneten Staat. Russland in der Spätphase des Zarenreiches. Frankfurt am Main, Berlin 1994, S. 242-71. Liessem beschreibt darin auch das Eingehen des Fachjournals der Juristischen Gesellschaft von St. Petersburg 1906 in Zusammenhang mit Auseinandersetzungen mit der Regierung. Die Gesellschaft habe danach fast jede Bedeutung verloren, vgl. ebd., S. 261-63 sowie unten, S. 194. Vgl. auch den Aufsatz: Michel Tissier: Les sociétés juridiques dans l'Empire russe au tournant du XXe siècle. Professionnalisation des juristes et culture juridique. In: Cahiers du monde russe et soviétique 1 (2010), S. 5-34. Tissier betont, dass es zwar bemerkenswert sei, dass die Juristischen Gesellschaften über Jahrzehnte bis 1917 existierten, dass ihre Wirkung für die Profession aber nicht überschätzt werden sollte. Sowohl in den hauptstädtischen als auch in den Gesellschaften in der Provinz war die Mehrheit der ,juristes-praticiens" nicht Mitglied der jeweiligen Organisation, vgl. ebd., S. 25.

144 Schon bei der Gründung der St. Petersburger Juristischen Gesellschaft 1876/77 mit Unterstützung der juristischen Fakultät der hauptstädtischen Universität übernahm Koni das Amt des stellvertretenden Vorsitzenden der Strafrechtsabteilung, und in den nachfolgenden Jahrzehnten war er immer wieder engagiert im Redaktionskomitee dieser Abteilung. Ungezählt sind seine Auftritte mit Fachreferaten wie z. B. dem später noch zu thematisierenden Vortrag „Die Gerichtsreform und das Geschworenengericht“ oder „Das Gericht und das Passwesen“, „Über das Arztgeheimnis“ und den bereits erwähnten 
Fachdiskurs zur Austarierung von juristischer und medizinischer Expertise vor Gericht teil ${ }^{145}$ oder besuchte Kongresse mit Juristen aus anderen Ländern. ${ }^{146}$ Während an Sitzungen der Juristischen Gesellschaften fachliche Diskussionen und Training im Vordergrund standen, boten sie Koni oftmals auch eine Bühne, um seine biografischen Juristenporträts an die intendierten Adressaten zu bringen. Zahlreiche der genannten Skizzen in seinen Sammelbänden oder in Zeitschriften beruhten auf mündlichen Reden vor der versammelten Juristenschaft. 1902 sprach Koni diesen Aspekt der Professionsvereinigung in einer programmatischen Rede über "Die Arbeiten und Aufgaben der Juristischen Gesellschaft von St. Petersburg“" auch unmittelbar an. So meinte er unter anderem, dass es bekanntlich eine Weile gebraucht habe, bis sich der Brauch durchgesetzt habe, Erinnerungssitzungen zu Ehren verstorbener Juristen abzuhalten. Diese sollten als Vorbild für die Jungen dienen, und über sie zu sprechen gehöre folglich zu den zentralen Aufgaben der

Text über „die neusten Strömungen im Strafprozess Italiens und Deutschland“. Vgl. Vl. SL.: Koni, Anatolij Fëdorovič. In: ĖSBE 15A/30, 1895, S. 949-51 sowie GA4, S. 497 (Anmerkungen) und für eine Auswahl seiner Erörterungen ebd., S. 497-98 sowie zu den juristischen Gesellschaften und Koni als Gründungsmitglied des Petersburger Ablegers auch Liessem: Autonomie in der Autokratie?, S. 249-50 und Fußnote 28 mit allen Gründungsmitgliedern.

145 Vgl. zur Diskussion über die Rolle von Ärzten bei Gerichtsverhandlungen und Konis Haltung in dieser Auseinandersetzung zwischen zwei aufstrebenden Berufsgruppen, Elisa Marielle Becker: Medicine, Law, and the State in Imperial Russia. Budapest 2011, z. B. S. 252 und 377 sowie Lena Gautam: Agents of Knowledge Transfer. Western Debates and Psychiatric Experts in Late Imperial Russia. In: Stefan B. Kirmse (Hrsg.): One Law for All? Western Models and Local Practices in (Post-)Imperial Contexts. Frankfurt am Main 2011, S. 93-116. Im Herbst 1904 äußerte sich Koni in einem Vortrag vor der Juristischen Gesellschaft von St. Petersburg zum Thema der Bewertung von Zeugenaussagen vor Gericht. Vgl. die Einladung mit der Ankündigung seines viel beachteten Vortrags in Konis Nachlass: IRLI F. 134, op. 4, d. 343, 1. 28. Seine Rede wurde vielfach publiziert, u. a. in seinem Sammelband mit Gerichtsreden: Anatolij F. Konı: Svideteli na sude. Zametki i vospominanija sud'i. In: ders. (Hrsg.): Sudebnye reči. Sankt-Peterburg 1905, S. 36-79 (4., erweitere Auflage). Dieser Text liegt auch der Version zugrunde, die Koni 1911 als „Obvinjaemye i svideteli“ in seine Erinnerungsreihe in „Russische Altertümer“ [Russkaja Starina] integrierte. Vgl. GA4, S. 49o ff (Anmerkungen) mit Hinweisen zu den verschiedenen Varianten und auch generell zum Hintergrund der Kontroverse. Vgl. für eine Zusammenfassung des Inhalts von Konis Rede: I. D. Perlov: Pravovye vozzrenija A. F. Koni. In: GA4, S. 22-26. Koni argumentierte, dass man als Richter unzuverlässigen Zeugenaussagen durch das sorgfältige Studium der Grundlagen der Gerichtspsychologie beikommen könne. Entschieden spricht er sich dagegen aus, die Beurteilung von Zeugenaussagen vollständig psychologischen Experten anstelle der Juristen zu überlassen.

146 Vgl. zur Mitarbeit Konis beispielsweise in der russischen Gruppe des internationalen Bundes der Kriminalisten, Baberowski: Autokratie und Justiz, S. 778. 
Juristischen Gesellschaft. ${ }^{147}$ In dieser Rede macht Koni auch darauf aufmerksam, dass für den Zusammenhalt von Jung und Alt die Weitergabe der Gerichtsstatuten wichtig sei, allerdings nicht nur deren technischen, sondern auch die moralischen Elemente. Die „Gerichtsethik“, die auf das Verhalten der Juristen während ihrer Berufsausübung abzielt, sei diesbezüglich von größter Bedeutung. ${ }^{148}$ Tatsächlich hatte Koni um 1901 einen Kurs mit dem Titel „Gerichtsethik" zusammengestellt. ${ }^{149}$ Nicht alles davon durfte er auch öffentlich vortragen. ${ }^{150}$ Seine wichtigsten Grundsätze fasste er zusammen unter dem Titel „Moralische Grundlagen im Strafprozess". Unter anderem im Rahmen seiner Unterrichtstätigkeit am Alexanderlyzeum, wo Koni im ersten Jahrzehnt des 20. Jahrhunderts beschäftigt war, trug er diese Erkenntnisse als Teil seines Kurses zum Strafgerichtsverfahren vor und veröffentlichte den Text unter verschiedenen Titeln wenig später gleich mehrfach. ${ }^{151}$ Kein Zweifel besteht darin, was Koni mit dieser Vorlesung bezwecken wollte. So schreibt er in einer Einführung, dass die Lehre ethischer Grundlagen im Rahmen von Strafprozessen von "großer Wichtigkeit“ sei und ermutigt all jene, die seine Vorlage aufnehmen wollten, „mit der jungen Generation“ über diese moralischen Grundlagen, die untrennbar seien vom „wahren Rechtswesen“, zu sprechen. ${ }^{152}$ Konkret nennt er im Aufsatz Punkte wie die Persönlichkeit des Richters und das Verhältnis zwischen Richter und den anwesenden weiteren Personen am Pro-

147 Rede vom 23.02.1902 an der Jubiläumsversammlung der Gesellschaft, veröffentlicht u.a. in VP 3 (1902) und P 11 (1902). Hier zitiert nach: Anatolij F. KonI: Trudy i zadači Peterburgskogo Juridičeskogo Obščestva. In: GA4, S. 310.

148 Koni: Trudy i zadači Peterburgskogo Juridičeskogo Obščestva, S. 314-15.

149 Vgl. z. B. den Brief von Koni an Čičerin, in dem er davon spricht, dass er mit viel Freude den Kurs beendet habe und es nicht erwarten könne, diese nützlichen Lektionen auch vorzutragen, GA8, S. 174 (Brief an B. N. Čičerin vom 06. 08.1901).

150 Vgl. den Brief vom Juni 1902 an Čičerins Ehefrau Aleksandra Alekseevna Čičerina (1845-1920), in dem Koni den Justizminister Nikolaj Valerianovič Murav'ev (1850-1908) bezichtigt, aus persönlichen Gründen die Erlaubnis für den Vorlesungszyklus zurückgehalten zu haben, GA8, S. 185-86 (Brief an A. A. Čičerina vom 05. 06. 1902), vgl. auch S. 218 (Brief an A. A. Čičerina vom 10. 05.1905). Zu Konis schwierigem Verhältnis zu Murav’ev vgl. S. 212. Vgl. GA4, S. 489 (Anmerkungen) mit dem Hinweis, dass Koni schließlich 1913 doch noch eine Reihe öffentlicher Lektionen zum Thema der Ethik für Juristen hielt.

151 Veröffentlicht u. a. in ŽMJ 1 (1902) sowie: Anatolij F. KoNI: Nravstvennye načala v ugolovnom processe. Obščie čerty sudebnoj ètiki. In: ders. (Hrsg.): Sudebnye reči. Sankt-Peterburg 1905, S. 3-35 (4., überarbeitete Auflage). Vgl. grundsätzlich die Hinweise zu diesem Text in GA4, S. 487ff (Anmerkungen). Koni unterrichtete zwischen 1901 und 1910 am Alexanderlyzeum. Zwischen 1876 und 1883 hatte er bereits an der Kaiserlichen Rechtsschule einen Kurs zum Strafgerichtsverfahren gehalten, vgl. Slovar’ členov Obščestva ljubitelej Rossijskoj slovesnosti: Koni, Anatolij Fëdorovič. In: SČOLRS, 1911, S. 145-146.

152 Koni (Hrsg.): Sudebnye reči, 1905, S. LXVI-LXVII („Anstelle einer Einleitung“). Hier auch weitere Informationen zur Textentstehung und den Vorträgen. 
zess, wobei er stets die "Achtung der Menschenwürde" als Leitlinie hervorhebt. Er geht auf juristische Prinzipien wie Unabhängigkeit und Unabsetzbarkeit der Richter ein und betont dabei die Notwendigkeit, sich nicht von der öffentlichen Meinung beeinflussen zu lassen. Schließlich äußert er sich auch zu der Rolle von Verteidiger und Ankläger. Letzterer solle nicht überhastet dem westlichen Vorbild folgen, sondern im Gegenteil voller „Ruhe, Abwesenheit von persönlicher Bosheit gegen den Angeklagten, [...] Objektivität und Unparteilichkeit" sein. ${ }^{153}$ Mit seiner „Gerichtsethik“ trieb Koni also genauso wie durch sein Engagement in der Juristischen Gesellschaft und insbesondere der Porträtpraxis, die er so gerne in deren Rahmen ausübte, die Schaffung von einheitlichen Wertgrundlagen seiner Profession voran. Auch weitere Juristen, die ausgiebig öffentlich über ihre Berufskollegen nachdachten, gehörten zu den wichtigsten Exponenten in den Trainings- und Selbstverwaltungsorganen der reformierten Justiz. Koni selber betont in seinem Porträt von Arsen'ev, wie dieser sich um die Einführung von Grundwerten und Regeln in der Anwaltschaft bemüht habe. Der von Arsen'ev geprägte St. Petersburger Anwaltsrat habe die Formierung des „Berufsstandes“ [soslovie] vorangetrieben und sei auch vor dem Ausschluss fehlbarer Mitglieder nicht zurückgeschreckt. ${ }^{154}$ Die Organisation der Anwälte in St. Petersburg war aufgrund der hohen Mitgliederzahl zusammen mit der Schwesterorganisation in Moskau von großer Bedeutung für die Selbstverwaltung der Verteidiger. ${ }^{155}$ Diese Selbstverwaltung entsprach einem bisher ungekannten Grad an Unabhängigkeit, den die Anwälte im reformierten russischen Justizsystem genossen. ${ }^{156}$ Wer vereidigter Anwalt werden wollte, musste ein abgeschlossenes Rechtsstudium und eine fünfjährige Ausbildung bei einem niedergelassenen Advokaten vorweisen können. Der Schwur auf die Gerichtsstatuten und den Zaren hatte danach die Registration bei der zuständigen Gerichtskammer als Rechtsanwalt [prisjažnyj poverennyj] zur Folge. Sobald sich mehr als 20 Anwälte in einem Gerichtskammerbezirk nieder-

153 Vgl. die Zusammenfassung von Perlov: Pravovye vozzrenija A. F. Koni, S. 6-12, Zitate S. 10-11. Vgl. zu dieser Schrift Konis auch Nethercott: Russian Legal Culture Before and After Communism, S. 91-92 sowie ausführlicher zu Konis rechtsphilosophischen Ansichten und deren Hintergründen unten, S. 304.

154 Koni: Konstantin Konstantinovič Arsen’ev. In: RS 2 (1908), S. 247. Vgl. zur Pionierrolle Arsen’evs im Anwaltsrat Simut en Ko: K. K. Arsen'ev i rossijskoe liberal’noe dviženie konca XIX-načala XX veka, S. 40-41.

155 Levin-Stankevich: The Transfer of Legal Technology and Culture, S. 232-33. Von großer Bedeutung waren in Russland v. a. die in Moskau und St. Petersburg beheimateten Anwaltsräte, da hier die überwiegende Mehrheit der Anwälte praktizierte. Zudem setzte die Regierung nach 1875 die Neugründung von Räten für 30 Jahre aus. An vielen Orten übernahmen deshalb die regionalen Bezirksgerichte die Funktionen der Räte.

156 Wortman: Russian Monarchy and the Rule of Law, S. 162. 
gelassen hatten, konnten diese einen „Rat der Rechtsanwälte“ wählen. ${ }^{157}$ Diese Räte waren in der Lage, ohne große Einmischung von administrativer oder gerichtlicher Seite die Selbstverwaltung des Anwaltsstandes umzusetzen. Typische Aufgaben waren die Aufnahme von Bewerbern, das Ernennen von Pflichtverteidigern und die Behandlung von Beschwerden, die von Klienten oder Gerichten eingereicht wurden. Im Rahmen dieser Disziplinaraufsicht konnten die Anwaltsräte Verwarnungen, Verweise, Suspendierungen und gar den Ausschluss aus der Anwaltschaft beschließen. ${ }^{158}$ So sollten ethische Normen und Benehmensformen geschaffen werden und zu einer starken Berufsidentität beitragen. Insbesondere Respekt vor den Älteren, Zurückhaltung in Honorarfragen, Pünktlichkeit und Höflichkeit versuchten die Anwaltsräte unter ihren Mitgliedern durchzusetzen. ${ }^{159}$

Juristen und Rechtspublizisten wie Koni oder Arsen'ev, die zur Elite ihres Berufes zählten und sich - ebenso wie ein Urusov oder Andreevskij - großer Bekanntheit erfreuten, kombinierten den expliziten Einsatz für eine Professionsidentität in Juristischen Gesellschaften oder Anwaltsräten mit dem exzessiven biografischen Porträtieren von Kollegen und verliehen dieser Praxis so noch deutlicher den Charakter einer Professionalisierungsstrategie.

\subsubsection{Die Juristen als "gesellschaftliche Akteure“}

Nation und Menschheit zu dienen und sie in eine bessere Zukunft zu führen, lässt sich als Kern des Selbstverständnisses der Intelligencija festmachen. Daran knüpfte Koni direkt an, wenn er in seinen biografischen Beschreibungen und in seinen Reden vor der Juristischen Gesellschaft immer wieder davon sprach, dass es die Aufgabe der Juristen und ihrer Berufsorganisationen sei, in der Gesellschaft das „richtige Rechtsbewusstsein“ zu wecken. Diese schwierige Arbeit sei geprägt vom „Vertrauen in die geistige Stärke des russischen Volkes“ ${ }^{460}$ Dieses Vertrauen wurde für Koni versinnbildlicht in der Institution des Geschworenengerichtes. Besonderes Lob erhielten deshalb in den Skizzen jeweils jene Juristen, die sich dafür einsetzten. So schrieb Koni in dem Porträt zu Arsen'evs Dienstjubiläum: „Arsen’ev war $[. .$.$] ein leidenschaftlicher Vertreter der, alten' Rechtsartikel, vor allem des$ Geschworenengerichts. “161 Und zu Andreevskij betonte er: „Vor der Institution

157 Baberowski: Autokratie und Justiz, S. 490-93.

158 Ebd., S. 493-94. Vgl. als Übersicht zur Professionalisierung der Anwälte in Russland auch: BABEROWsKi: Rechtsanwälte in Russland, S. 29-59.

159 Burbank: Discipline and Punish in the Moscow Bar Association, S. 48-49 und 51-55.

160 Koni: Trudy i zadači Peterburgskogo Juridičeskogo Obščestva, S. 293 und 299.

161 KonI: Konstantin Konstantinovič Arsen'ev. In: RS 2 (1908), S. 247-48. 


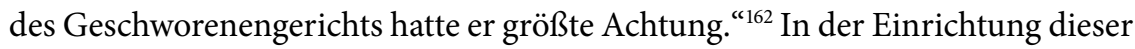
Gerichtsform, in denen einfache Menschen an der Rechtsprechung partizipierten, sah Koni gar den Hauptgrund, die Gerichtsreformer „in eine Reihe“ mit den Bauernbefreiern zu stellen. ${ }^{163}$ Die enorme Bedeutung, die dem GeschworenenModell beigemessen wurde, erläutert er beispielhaft in seinen Jubiläumsartikeln zu 50 Jahren reformierter Gerichte. Ausführlich berichtet er darin von der Ausarbeitung der Gerichtsreform vor 1864 und der kontroversen Diskussion, die es damals um das Geschworenengericht gegeben habe. Zahlreiche Gegner hätten ein Gerichtssystem mit Geschworenen als diametralen Widerspruch zur absoluten Monarchie verstanden und eine pessimistische Einstellung zum Funktionieren einer solchen Volksjustiz gehabt. ${ }^{164}$ Dagegen hätten sich andere Juristen gewehrt, die überzeugt waren, dass das „Volk“ [narod] gerade durch die Übung im Geschworenengericht „die Wahrheit erlernen“ würde [naučitsja pravde]. Diese Stimmen hätten sich schließlich durchgesetzt, schreibt Koni weiter und hält fest:

Ein Historiker der Gerichtsreform muss sich mit tiefer Achtung an diesen Kampf der Meinungen erinnern, deren Grundlage der bewusste und feste Glaube bildete, dass der eben erst aus der Sklaverei hervorgegangene russische Mensch, der in die Funktion eines Geschworenen berufen wird, sowohl seine Rolle als auch die großherzig in ihn gelegten Hoffnungen versteht. ${ }^{165}$

Die erst 1861 aus der Leibeigenschaft befreiten Menschen sollten also dank der Tätigkeit als Geschworene ein Bewusstsein für Rechtsstaatlichkeit ausbilden und so die Entwicklung von Land und Bevölkerung vorantreiben. ${ }^{166}$ Diese unmittel-

162 Koni: S. A. Andreevskij. In: ders. (Hrsg.): Na žiznennom puti, Bd. 5, S. 188.

163 A. F. Koni: Sudebnaja reforma i sud prisjažnych. In: ders.: GA4, S. 214. Vgl. zu diesem Vortrag auch unten, S. 128.

164 Koni: Vvedenie k Sistematičeskomu Kommentariju U. U. S., S. 11. Ebenso in den sehr ähnlichen Texten, die er zeitgleich publizierte, vgl. oben, S. 66.

165 Ebd., S. 12-13.

166 Litzinger fasst zusammen, wie viele Juristen, darunter im Speziellen Koni, davon ausgingen, dass die Geschworenengerichte eine „pädagogische Wirkung“ entfalten würden und gleichzeitig die gesamte Bevölkerung über ihre Teilhabe am Rechtsprechungsprozess eigene Rechtsvorstellungen mit einbringen könne, vgl. LitzINGER: Juristen und die Bauernfrage, S. 227-28. Vgl. auch Jane Burbank: Legal Culture, Citizenship, and Peasant Jurisprudence. Perspectives from the Early Twentieth Century. In: Peter H. Solomon (Hrsg.): Reforming Justice in Russia, 1864-1996. Power, Culture, and the Limits of Legal Order. Armonk New York 1997, z. B. S. 84 ff die kritisiert, dass mit fixen Vorstellungen vom „richtigen Rechtsbewusstsein“, das die Menschen zu erlernen hätten, führende Juristen wie Koni den Blick auf die tatsächlichen Entwicklungen in der vielfältigeren Rechtskultur des Russischen Reiches verstellt hätten. 
bare Auswirkung der juristischen Tätigkeit wurde in den biografischen Porträts gerne unterstrichen, indem das "Lebendige“ an der Tätigkeit von Juristen und ihren Auftritten vor Gericht betont wurde. Es kam zu oft sehr ausführlichen Beschreibungen der Art und Weise, wie die entsprechenden Juristen ihre Gerichtsreden hielten, wobei exzessiv Gebrauch gemacht wurde von Variationen rund um „Sprache“ und „Leben“. Dass die Juristen nun im mündlichen Verfahren um ein Urteil rangen, gehörte zu den entscheidenden Neuerungen der reformierten Gerichte. Ähnlich wie das Geschworenengericht wurde auch die „Sprechkultur“ als "mächtiges Werkzeug der individuellen und gesellschaftlichen Bildung" verstanden. ${ }^{167}$ Über das Sprechen, so suggerieren es die Juristenporträts, bewiesen die Anwälte und Richter ihre Nähe und ihren Einfluss auf das „Leben“.168 So berichtete Andreevskij über Koni:

Er sprach mit gleichmäßiger, natürlicher Diktion, mit nicht starker aber deutlicher Stimme, manchmal scherzte er mit derselben weichen Stimme. Er gab lebendige Beispiele und zeichnete sich dadurch aus, dass er poetisch moralisieren konnte, fast ohne vom offiziellen Ton abzuweichen. ${ }^{169}$

Seinerseits beschrieb Koni Andreevskij als: „Weich und menschlich, Literat und Poet in der Seele [...] war er auf der Anklägerbühne einer der sprechenden Rich-

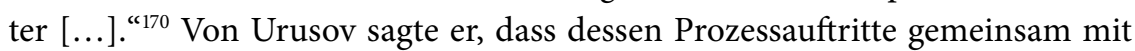
Plevako wie ein „Kampf der Giganten des Wortes“ gewesen seien. ${ }^{171}$ Und Arsen’ev berichtete in einer Erinnerung an Urusov vom „Triumph des, lebendigen Wor-

167 Die Gerichtssphäre war in der Folge prädestinierter Ort für begabte Redner. Vgl.: Peter BRANG: Das Land der sprachlosen Ebenen zum Sprechen bringen. Über öffentlichen und privaten Vortrag von Dichtung in Russland. In: Nada Boškovska u. a. (Hrsg.): Wege der Kommunikation in der Geschichte Osteuropas. Köln 2002, S. 439-40. Brang behauptet gar, manche talentierten Rhetoriker seien nur deshalb Juristen geworden, um ihre Redefähigkeiten zu nutzen. Ansonsten habe es im autokratischen Russland an entsprechenden Foren gemangelt. Für die Aussage zur Sprechkultur als Bildungswerkzeug verweist Brang insbesondere auf die Arbeiten des Philologen Vasilij Il'ič Černyšev (1866/67-1949).

168 „Lebendig“ gehörte auch zu den typischen Adjektiven, die in den „Erinnerungen der Zeitgenossen“ auftauchten. Besonders gerne wurde dabei betont, wie „lebendig“ [živoj] sich die Erinnerung und damit auch die Verbindung zur Vergangenheit mit ihren großen Vorbildern ausgestaltete. Vgl. dazu und zu Konis Gebrauch von „lebendig“ ausführlicher Cordin: Von Schreibanlässen und Erinnerungsfunktionen, S. 188-89 sowie WALKER: On Reading Soviet Memoirs, S. 335.

169 Andreevskij: Kniga o smerti, Bd. 1, 1922, S. 137.

170 Koni: Iz zametok i vospominanij sudebnogo dejatelja. XVI. [Iz prošlovo peterburgskoj prokuratury], S. 483.

171 Koni: Dva sudebnych oratora, S. 424. 
tes““172 Andreevskij führte im Rahmen seiner Rede „Über die Strafverteidigung“ aus, dass es nun nicht mehr genug sei, Kenntnisse des Gesetzes zu haben, um ein guter Jurist zu sein. „Neu gilt das Gericht des Lebens und nicht die tote Formalität.“ Leute, die das nicht so sähen, würden nie „zu Gerichtsrednern in der echten und ritterlichen Bedeutung des Wortes ${ }^{\text {“ }}{ }^{173}$ Besonders prägnant kombiniert hat all dies Spasovič, der von den Juristen, die sich im Strafprozess mit ihren Reden maßen, als „Ritter des lebendigen Wortes" sprach. ${ }^{174}$

Die Wirkungsmächtigkeit der Juristen und ihrer Taten wurde von Koni schließlich auch mit einem weiteren Schlagwort betont, das mit verblüffender Regelmäßigkeit in seinen biografischen Skizzen und Vorträgen auftaucht. Die Rede ist von der Obščestvo [Gesellschaft]. So ist es Koni besonders wichtig zu unterstreichen, dass durch die auf die Justiz bezogene Tätigkeit der Anwälte und Richter immer auch „Gesuche des gesellschaftlichen Lebens und der Lebensbedingungen “ [zaprosy obščestvennoj žizni i uslovija byta] behandelt würden. ${ }^{175}$ Die Mitglieder der juristischen Gesellschaft trügen mit dem Sammeln von ethnografischem oder statistischem Material dazu bei, die leider oft in „Bildungsferne, Schutzlosigkeit, Ignoranz und Armut" lebende Bevölkerung besser zu verstehen und die entsprechenden Probleme anzugehen. ${ }^{176}$ Im Vorwort zum Sammelband "Väter und Söhne der Gerichtsreform“" schreibt er weitere erläuternde Worte. So wolle er in seinen Porträts die Juristen inklusive ihrer „Arbeiten in Wissenschaft, Literatur und Kunst“ darstellen, um einen „ganzheitlicheren Begriff“ von ihrer Vielseitigkeit zu generieren. ${ }^{177}$ Diese „Ganzheitlichkeit“ schien das Engagement der Juristen für jegliche „Fragen des gesellschaftlichen Lebens und der Lebensbedingungen“"zu meinen. Über Urusov schrieb Koni passend, dass dieser seine Tätigkeit als Staatsanwalt in Warschau in den 1870er-Jahren nicht wie eine Arbeitsstelle, sondern wie einen „Dienst an die Öffentlichkeit“ bestritten habe. ${ }^{178}$ In seinem Alltag habe er sich für ernste Fragen des „öffentlichen Lebens“ interessiert, und rund um ihn sei ein Kreis von Schauspielern, Schriftstellern und Kunstinteressierte entstanden. ${ }^{179}$ Auch Arsen'ev, so Koni, habe sich immer für das ,allgemeine Wohl“ eingesetzt. So sei er auch Landschaftsabgeordneter und Friedensrichter

\footnotetext{
172 Arsen'ev: Vospominanija o knjaze A. I. Urusove, S. 239.

173 Andreevskij: Ob ugolovnoj zaščite, S. 11.

174 Baberowski: Rechtsanwälte in Russland, S. 45.

175 Koni: Trudy i zadači Peterburgskogo Juridičeskogo Obščestva, S. 307.

176 Ebd., S. 308.

177 Koni: Otcy i deti sudebnoj reformy, S. IV (Vorwort).

178 Koni: Vospominanie o knjaze Aleksandre Ivanoviče Urusove. In: Urusov/Andreeva/ Gol'dovskij (Hrsg.): Knjaz' Aleksandr Ivanovič Urusov (1843-1900), Bd. 2 und 3, S. 199.

179 Ebd., S. 206.
} 
gewesen und habe sich im St. Petersburger Stadtparlament engagiert. ${ }^{180} \mathrm{Zu}$ all dem habe er auch noch Literaturabende veranstaltet, an denen auch religiöse und moralphilosophische Fragestellungen angegangen worden seien. ${ }^{181}$ Seine Stimme, so schließt Koni die Ausführungen, sei „das Echo des russischen Volkes“ gewesen. ${ }^{182}$ In der ausführlicheren Version des Porträts heißt es weiter, dass Arsen’ev zeigen würde, wie aus Advokaten ,gesellschaftliche Akteure [obščestvennye dejateli] im besten Sinne dieses Wortes" entstehen könnten. ${ }^{183}$ Arsen'ev selber beendet einen Artikel über Andreevskij und dessen Anwaltsreden mit den Worten, dass Andreevskij ein großes Vorbild für die Jugend sei. Ein Anwalt solle nämlich nicht in erster Linie unbedingt seinen Klienten frei bekommen wollen, sondern - gerade in Russland - vor allem auch ein "gesellschaftlicher Akteur" sein. ${ }^{184}$ Über Urusov schreibt Arsen’ev, dass dieser „der russischen Gesellschaft“ ehrlich gedient habe. So habe er neben der Juristerei auch die französische Literatur geliebt und Texte zum Theaterwesen verfasst. ${ }^{185}$ Die integrierende Kraft des Konzepts der Obščestvennost' zeigt sich besonders augenfällig am Beispiel des polnischstämmigen Juristen Vladimir Spasovič (Włodzimierz Spasowicz). Koni beschreibt den berühmten Advokaten in seinem biografischen Porträt als würdigen Fachmann und treuen Verfechter der neuen Gerichtsstatuten. ${ }^{186}$ Doch das letzte Fünftel des Textes ist ganz dem polnischen Selbstverständnis des Juristen gewidmet. Nach ausführlichen Kommentaren zum Polentum Spasovičs, in denen auch Schmähungen aufgrund seiner Herkunft und Haltung zitiert wer-

180 KonI: Konstantin Konstantinovič Arsen’ev. In: RS 2 (1908), S. 249.

181 Ebd., S. 250.

182 Ebd., S. 255.

183 KonI: Konstantin Konstantinovič Arsen’ev. In: ders. (Hrsg.): Na žiznennom puti, Bd. 2, S. 244-45.

184 Arsen'ev: Novye sborniki sudebnych rečej, S. 804.

185 Arsen'ev: Kn. A. I. Urusov, S. 433-35.

186 Vgl. für diese Ausführungen auch Cordin: Von Schreibanlässen und Erinnerungsfunktionen, S. 192. Vgl. zu Spasovič Jens Herlth: „Verengung des Handlungsfelds“. Tadeusz Bobrowski, ein polnischer Adeliger in der ukrainischen Provinz. In: Martin Aust/Frithjof Benjamin Schenk (Hrsg.): Imperial Subjects. Autobiographische Praxis in den Vielvölkerreichen der Habsburger, Romanovs und Osmanen im 19. und frühen 20. Jahrhundert. Köln 2015, v. a. S. 39o. Spasovič war eine wichtige Persönlichkeit in der polnischen Öffentlichkeit im russischen Teilungsgebiet. Er war ein prominenter Befürworter der Politik des Ausgleichs mit der Zarenherrschaft. Vgl. Haumann: Geschichte Russlands, S. $186 \mathrm{ff}$ und 284: Polen gehörte in Teilen seit dem 18. Jahrhundert zum Zarenreich, hatte aber in Aufständen 1830 und 1863 versucht, wieder selbständig zu werden. Dies hatte dazu geführt, dass die zarische Regierung die Autonomierechte für Polen aufhob und das Gebiet noch stärker in das autokratische System eingliederte. 
den, holt Koni zum Gegenangriff aus. ${ }^{187}$ Er nennt den Anwalt einen „Proteus“ und will mit dem Bild des wandelbaren Meeresgottes einmal mehr die Vielfalt der Felder, Interessen und Aktivitäten des Juristen betonen. Von Theater, Kunst oder öffentlichen Lesungen und Disputen ist die Rede. ${ }^{188}$ Und schließlich weist Koni jegliche weitere Kritik an der Person Spasovičs mit dem Schlüsselbegriff der Obščestvennost' zurück, wenn er im abschließenden Satz schreibt, dass der Advokat die Vorstellung vom Menschen als „Diener an der gesellschaftlichen Entwicklung" zur Maxime hatte. ${ }^{189}$

Breit literarisch, künstlerisch und wissenschaftlich interessiert zu sein, Zirkel von Gleichgesinnten zu bilden, Einsitz in Gremien und Organisationen zu nehmen und bei der Berufsausübung immer das „allgemeine Wohl“ im Blick zu haben, scheinen die Kriterien gewesen zu sein, die für das Prädikat des „gesellschaftlichen Akteurs" maßgebend waren. Dabei mischt sich in die klassische Rhetorik des in allen Künsten gebildeten Intelligent das Element des Experten, der auch mit seinem Fachwissen und einem hohen Organisationsgrad zur Zukunft der "Gesellschaft" und deren Wohlergehen beitragen kann.

\section{Vernetzung in der Ob̌̌čestvo}

Das Bild, das in der öffentlichen Wahrnehmung von den Intelligenty dominierte, wurde stark von den radikalen, politisierten Gruppierungen geprägt. Gebildete Landvermesser, Ärzte, Eisenbahntechniker oder Ingenieure, die durchaus von ähnlichen Überzeugungen von „Dienst“ beseelt waren, blieben hingegen im Hintergrund..$^{190}$ Nichtsdestotrotz setzte sich gegen Ende des 19. Jahrhunderts immer

187 Anatolij F. Koni: Vladimir Danilovič Spasovič (1829-1907). In: ders. (Hrsg.): Otcy i deti sudebnoj reformy. K pjatidesjatiletiju Sudebnych Ustavov, 20. nojabrja 1864-1914. Moskva 1914, S. 234.

188 Koni: Vladimir Danilovič Spasovič (1829-1907). In: ders. (Hrsg.): Otcy i deti sudebnoj reformy, S. 234-35. Auch Arsen’ev schreibt sehr ähnlich, dass Spasovič sich nicht auf „Fragen des Rechts“ eingeschränkt habe, sondern sich z. B. auch für Literatur oder Kunst interessiert habe, vgl. Arsen'ev: Vospominanija o V. D. Spasoviče, S. 459-6o.

189 Koni: Vladimir Danilovič Spasovič (1829-1907). In: ders. (Hrsg.): Otcy i deti sudebnoj reformy, S. 235. Es passt ins Bild, dass Koni ähnlich wie im Falle von Plevako auch zu Spasovič privat ein komplizierteres Verhältnis hatte. Kritische Aussagen zu dessen Person und gerade auch seiner Haltung zu Polen finden sich in Briefen Konis, vgl. GA8, S. 95 (Brief an Jakov Grigor'evič Gurevič vom o1. 08. 1887) und 156 (Brief an K. K. Arsen'ev vom 21. 11. 1899). Deutlich positiver dann ebd., S. 191 (Brief an Varvara Dmitrievna Komarova vom 09. 03.1903) im Jahre 1903, als Koni die erste Version des Porträts verfasste.

190 Nikolaj A. Berdjaev u. a. (Hrsg.): Vechi. Wegzeichen: zur Krise der russischen Intelligenz, hrsg. u. mit einer Einleitung versehen v. Karl Schlögel, Original Moskau 1909. Frankfurt am Main 1990, S. 13-14 (Einleitung v. Karl Schlögel) und Samuel D. KAssow/James L. 
stärker die Erkenntnis durch, dass zum Dienen und Führen nicht nur moralische Komponenten, sondern auch konkrete berufliche Fähigkeiten und Fertigkeiten von großer Wichtigkeit waren ${ }^{191}$ Jene Gruppierungen, die in ihrer Gesamtheit gemeinhin als Intelligencija definiert wurden, gerieten als zu faul, zu wenig patriotisch, persönlich wenig moralisch und politisch unreif in Kritik. Fachleute aller Art sahen in ihrer professionellen Arbeit gleichfalls einen Beitrag zur Zukunft des Landes. Als Experten wollten sie mit Disziplin, Kompetenz und Effizienz ihre Tätigkeit ausüben und so im eigenen Fachgebiet der Gesellschaft wenig spektakulär, aber konkret Schritt für Schritt voranhelfen. ${ }^{192}$ Der Führungsanspruch, der im Begriff der Intelligencija inhärent war, wurde also nicht zurückgewiesen, sondern vielmehr auf die eigene Berufsausübung angewandt. Der den Intellektuellen in Russland anhaftende Beigeschmack der abgehobenen, weit vom realen Leben entfernten Theoretiker wurde dadurch vollständig negiert. ${ }^{193}$ Die praktischen Berufsleute wollten aber gleichzeitig, auch wenn sie teilweise selber im Staatsdienst standen, auf keinen Fall Teil des „Beamtentums“ [činovničestvo] sein, das gemeinhin als Gegenstück zur Intelligencija gesehen wurde. ${ }^{194}$ Beamte galten als Menschen, die Weisungen ohne weiteres Nachdenken umsetzten und so viele Ränge und Orden wie möglich zu sammeln versuchten, um damit den „Dienst an ihrem Herrn“ auch nach außen zu demonstrieren. Der „Dienst an der Sache“ stand dabei nicht im Vordergrund. ${ }^{195}$ Das Ansehen von Beamten war ausgesprochen niedrig, gerade auch weil Amtsmissbrauch in Russland kaum je Konsequenzen nach sich zog. ${ }^{196}$ Wenn Koni und seine Kollegen bemüht waren, sich gegenseitig ihrer „Lebendigkeit“ zu versichern, dann geschah dies also nicht zuletzt im Bestreben, sich vom Vorwurf der „Schreibstubengelehrtheit“ und dem Vorurteil vom „lebensfernen

West/Edith W. Clowes: Introduction. The Problem oft the Middle Class in Late Imperial Russian Society. In: dies. (Hrsg.): Between Tsar and People. Educated Society and the Quest for Public Identity in Late Imperial Russia. Princeton 1991, S. 7.

191 Kassow/West/Clowes: Introduction, S. 7.

192 Ebd., S. 7-8.

193 Trude Maurer: Hochschullehrer im Zarenreich. Ein Beitrag zur russischen Sozial- und Bildungsgeschichte. Köln 1998, S. 862-64.

194 Denis A. SDvižKov: Das Zeitalter der Intelligenz. Zur vergleichenden Geschichte der Gebildeten in Europa bis zum Ersten Weltkrieg. Göttingen 2006, S. 156 und MAURER: Hochschullehrer im Zarenreich, S. 832.

195 Maurer: Hochschullehrer im Zarenreich, S. 864 und Susanne Schattenberg: Die korrupte Provinz? Russische Beamte im 19. Jahrhundert. Frankfurt am Main 2008, S. 107.

196 Wortman: Russian Monarchy and the Rule of Law, S. 168-69 zu den stark eingeschränkten Möglichkeiten der Justiz, gegen Verbrechen von Offiziellen vorzugehen. Wortman zitiert auch einen moderaten Liberalen aus der Zeit, der festhielt: „Der Begriff, činovnik ‘ [...] kann in keine Fremdsprache übersetzt werden, weil der Beigeschmack der Beleidigung, der darin - wie bei einem Fluchwort - enthalten ist, nicht übersetzbar ist.“ 
Petersburger Kanzleiangestellten“ zu distanzieren. ${ }^{197}$ Vom „typischen Beamtentum“ unterschied sich die „Intelligencija der Professionen ${ }^{\text {“198 }}$ durch das Leistungsprinzip, nach dem die berufliche Karriere funktionierte, und durch den Stellenwert, den selbstverwaltete Korporationen, Gesellschaften und Zusammenschlüsse der Berufstätigen einnahmen, besonders augenfällig aber auch durch ihr Berufsethos. ${ }^{199}$ Diesen „Dienst an der Sache“ sahen zahlreiche Professionen wie zum Beispiel die Universitätsgelehrten als wichtiges Element ihrer Tätigkeit. Sie wollten als Bürger mittels Bildung und sozialen Reformen Russland zu einem Rechtsstaat mit funktionierender Zivilgesellschaft formen ${ }^{200} \mathrm{Im}$ Zentrum dieser ,erzieherischen Aufgabe" sahen sie ihr persönliches Engagement für Verbreitung von Wissen im „Volk“, aber auch die Ausübung von wohltätigen Aktivitäten für die „Gesellschaft“. ${ }^{201}$

Der Begriff der Obščestvo [Gesellschaft] wurde im Verlauf der zweiten Hälfte des 19. Jahrhunderts immer stärker zu jenem der Obščestvennost' [Gesellschaftlichkeit/Öffentlichkeit] erweitert. Dieser abstraktere Terminus spiegelte die „Bedeutungsbreite“ und die „Suggestivkraft", die die Rede von der „Gesellschaft“ mehr und mehr besaß, besser wider. ${ }^{202}$ Beginnend mit den Reformen in den 1860er-Jahren, die beispielsweise der lokalen Selbstverwaltung eine aktivere Rolle zugestanden, steigerte sich in Russland der Grad des sozialen Engagements in der Gesellschaft, die immer deutlicher den Staat und sein „Monopol, für das öffentliche Wohl zu sorgen" herausforderte. ${ }^{203}$ Weiter förderten die Prozesse der

197 Litzinger schreibt, dass die russischen Juristen sich gegen solche Anwürfe zu wehren versuchten, und sie nennt als Beispiel Konis Nachruf auf Kavelin, in dem dieser verkündet: „nichts Lebendiges war ihm fremd“, vgl. Litzinger: Juristen und die Bauernfrage, S. 295.

198 Renner: Russischer Nationalismus und Öffentlichkeit, S. 154.

199 MaUrer: Hochschullehrer im Zarenreich, S. 858 und 861.

200 Ebd., S. 864.

201 Ebd., S. 832 und 862. Allerdings waren nicht unbedingt alle Berufstätigen von einer solchen Kombination „professioneller Pflichten“ und „öffentlicher Agenda“ begeistert. Wer sich aber in den 19ooer-Jahren bewusst gegen den Staatsdienst und für eine Tätigkeit z. B. als Agrarfachmann entschied, tat dies in der Mehrheit aus ideologischen Gründen und verzichtete so auf reines Karrierestreben, vgl. Ilya V. Gerasimov: Modernism and Public Reform in Late Imperial Russia. Rural Professionals and Self-Organization, 1905-30. Basingstoke 2009, S. 63. Vgl. zu den Agrarexperten auch Katja BRuisch: Als das Dorf noch Zukunft war. Agrarismus und Expertise zwischen Zarenreich und Sowjetunion. Köln u. a. 2014.

202 Andreas RenNer: Russischer Nationalismus und Öffentlichkeit im Zarenreich 1855-1875. Köln 2000, S. 148-51. Renner sieht im Ausmaß dieser „Suggestivkraft“ allerdings auch Grenzen, wie die nachfolgenden Ausführungen zeigen werden.

203 Ebd., S. 146. Ausführlicher zu der lokalen Selbstverwaltung durch die „Landschaften“ [Zemstva] mit ihren Wahl- und Beschlussversammlungen und der entsprechenden Reform von 1864 vgl. Heiko Haumann: Geschichte Russlands. Zürich 2003, S. 256 ff. 
Urbanisierung und Industrialisierung und das verstärkte Interesse an der eigenen Kultur das Zusammenfinden von gut ausgebildeten Personen und deren Angehen eigener Projekte. ${ }^{204}$ Bis zum frühen 20. Jahrhundert hatte sich etwas herausgebildet, das mit dem Begriff der Obščestvennost' bezeichnet wurde. Dies umfasste - wie Joseph Bradley es definiert - eine „öffentliche Sphäre“ [public sphere], in der gewisse Gruppen ein Gefühl für „öffentliche Pflicht“ [public duty] und „Bürgersinn“ [civic spirit] entwickelten. Daraus bildete sich eine „Civil Society“, die unabhängig vom Staat agierte. ${ }^{205}$ Die Konturen dieser „Civil Society“ oder „Zivilgesellschaft" bleiben allerdings eher unscharf. ${ }^{206}$ Diese bewegt sich irgendwo zwischen dem "Gesinnungsverband“ der Intelligencija und der "Sozialformation und politischen Zielutopie bürgerlicher Schichten", die sie nie ganz zu erreichen vermochte. Wichtig waren dabei „meinungsbildende und freie: weder staatliche noch primär wirtschaftliche Zusammenschlüsse“, aus denen sich „soziale und kommunikative Netzwerke" ergaben. ${ }^{207}$ Solche zivilen Organisationen prägten das Gefühl von Obščestvennost’ oder "Öffentlichkeit“, in der praktisch veranlagte Bürger sich für das allgemeine Wohl einsetzten. ${ }^{208}$

Dass dabei der Begriff der Ob̌šcestvennost' auch als Kategorie der Selbstbeschreibung genutzt wurde, war weit verbreitet. ${ }^{209}$ Die Juristenporträts mit ihrer Betonung des "gesellschaftlichen Akteurs" reihen sich nahtlos ein und ordneten die Rechtsberufe der „Intelligencija der Professionen“ zu. Die „Gesellschaft“ erforderte von ihren "Akteuren" aber nicht nur in solchen biografischen Skizzen,

204 Joseph Bradley: Voluntary Associations, Civic Culture, and Obshchestvennost' in Moscow. In: Edith W. Clowes/Samuel D. Kassow/James L. West (Hrsg.): Between Tsar and People. Educated Society and the Quest for Public Identity in Late Imperial Russia. Princeton 1991, S. 140-41.

205 Ebd., S. 131.

206 Andreas Renner: Russland und die Civil Society. Neue Wege zur Erforschung des Liberalismus im Zarenreich. In: H. G. Fleck u. a. (Hrsg.): Jahrbuch zur Liberalismus-Forschung. Baden-Baden 1996, S. 233 spricht von „schemenhaften“ Konturen. Hausmann: Universität und städtische Gesellschaft in Odessa, S. $12 \mathrm{ff}$ macht darauf aufmerksam, dass die Begriffe der "Civil Society“ und der "Zivilgesellschaft“ oftmals austauschbar verwendet werden. Beide beziehen sich auf den sich in Westeuropa seit dem 18. Jahrhundert entwickelnden Gesellschaftstyp der „Bürgergesellschaft“. Im Fokus standen dabei die Durchsetzung von Bürgerrechten, Versammlungs- und Vereinigungsfreiheit und die Stärkung einer alternativen Öffentlichkeit und sozialer Bewegungen.

207 Renner: Russland und die Civil Society, S. 233.

208 Bradley: Voluntary Associations, Civic Culture, and Obshchestvennost' in Moscow, S. 131 Vgl. auch Hausmann: Universität und städtische Gesellschaft in Odessa, S. 14-16 zu Jürgen Habermas und seiner Definition der „zivilen Gesellschaft“ als „Selbstkonstituierung der Gesellschaft in einer reflektierenden Öffentlichkeit“.

209 Gerasimov: Modernism and Public Reform in Late Imperial Russia, S. 23. 
sondern auch bei unzähligen anderen Gelegenheiten, sich zu ihr zu bekennen. Ein typischer "coaxer" - eine Person oder Institution, die jemandem eine Geschichte entlocken kann - stellte oftmals die Aufnahme in eine der zivilgesellschaftlichen Organisationen und Vereine dar. ${ }^{210}$ Diese „freien [...] Zusammenschlüsse“, die für das Gefühl der Obščestvennost’ so wichtig waren, erlebten ab den 189oer-Jahren in Russland einen regelrechten Boom. Als konkreter Anstoß für ihre Herausbildung wird oftmals die Hungersnot genannt, die Russland in den Jahren 1891/92 erfasst hatte. ${ }^{211}$ Die Regierung war mit dem Ausmaß der Krise überfordert und sah sich gezwungen, die Bürger um Eigeninitiative zu bitten. ${ }^{212}$ Innerhalb kürzester Zeit gründeten diese Hunderte von Komitees, und Tausende zogen aus, um an Hilfsaktionen für die Bevölkerung teilzunehmen. Genau zu diesem Zeitpunkt begann auch Koni, mit öffentlichen Vorlesungen Spenden zu sammeln. Er lud ein zu Vorträgen „zugunsten der Hungerleidenden“ und beteiligte sich an dem 1892 veröffentlichten Buch „Brot für die Hungernden. Album mit Autogrammen von Schriftstellern, Künstlern, Schauspielern und gesellschaftlichen Akteuren. Herausgabe zugunsten der Hungernden“. ${ }^{213}$ Insbesondere im Vergleich mit der

210 Sidonie Smith und Julia Watson führen in ihrem Standardwerk „Reading Autobiography“ den Begriff des „coaxers“ ein, vgl. Sidonie Smith/Julia WAtson: Reading Autobiography. A Guide for Interpreting Life Narratives. Minneapolis Minnesota u. a. 2010, S. 64.

211 Anton A. Fedyashin: Liberals under Autocracy. Modernization and Civil Society in Russia, 1866-1904. Madison Wisconsin 2012, S. 146. Aufgrund von Wetterkatastrophen kam es im Sommer 1891 im Südosten des Russischen Reiches zu einer Hungersnot. Im Verlauf der nächsten Monate breitete sich diese vom Ural bis zur Ukraine aus und umfasste bald eine riesige Fläche, auf der 36 Millionen Menschen wohnten. Die hungernden Bauern wurden zusätzlich von Cholera und Typhus heimgesucht, woran bis Ende 1892 eine halbe Million Menschen starben. Die Regierung versuchte, die Tragödie herunterzuspielen, indem sie z. B. den Zeitungen verbot, den Begriff der „Hungersnot“ zu benutzen. In den Augen Vieler gestand sie so nur ein, dass sie mit ihrer Wirtschaftspolitik Schuld an der Not hatte. Einerseits waren die Steuern auf Konsumgüter erhöht worden, um die Bauern zum Verkauf von Getreide zu zwingen, andererseits sah die Regierung lange davon ab, zugunsten der Hungerleidenden auf den Getreideexport ins Ausland zu verzichten, vgl. Orlando Figes: Hundert Jahre Revolution. Russland und das 20. Jahrhundert. München 2015, S. 15-16.

212 FIgEs: Hundert Jahre Revolution, S. 15-16.

213 Vgl. Werbeflyer von 1892 für einen entsprechenden Vortrag in GARF F. 564, op. 1, d. 745, 1. 24; Russkaja žizn': Golodnomu na chleb. Al'bom avtografov pisatelej, chudožnikov, artistov i obščestvennych dejatelej: izd. v pol'zu golodajuščich. Sankt-Peterburg 1892. Das Buch wurde von der Zeitung „Russisches Leben“ herausgegeben und enthält pro Seite zwei bis acht kurze Beiträge von einer bekannten Persönlichkeit aus dem In- oder Ausland in alphabetischer Reihenfolge. Neben der handschriftlichen Unterschrift sind dies z. B. Bilder, Gedichte, Briefe, Musiknoten oder kurze Texte. Von Koni befindet sich darin ein ca. 20 Zeilen langer Ausschnitt aus einer Rede, in dem es um den von ihm nicht als 
ersten Hälfte des 19. Jahrhunderts, als unter Zar Nikolaus I. noch alles verboten war, das nach privater Initiative aussah, hätte der Kontrast dieses „Geistes der Freiwilligkeit" nicht stärker ausfallen können. ${ }^{214}$ Noch in der zweiten Jahrhunderthälfte wurden Freiwilligenverbände - und auch berufliche Organisationen wie zum Beispiel die Juristischen Gesellschaften - nur widerwillig toleriert. Es herrschte in Regierungskreisen nach wie vor eine große Angst vor solch eigenständiger Aktionsbereitschaft. ${ }^{215}$ Die Assoziationen wurden als Quelle von Subversion verstanden und entsprechend oftmals unterdrückt. ${ }^{216}$ Doch der gesteigerte Organisationsgrad konnte von der Regierung nicht mehr vollständig kontrolliert werden. ${ }^{217}$ Gegen Ende des 19. Jahrhunderts gab es in Russland bereits eine große Zahl an wohltätigen Assoziationen, die sich spezifischen gesellschaftlichen Problembereichen widmeten und zum Beispiel nicht russische Ethnien oder arme Studenten unterstützten oder sich um medizinische Versorgung und Hygiene kümmerten. ${ }^{218}$ Gleichzeitig wurden insbesondere in den beiden Hauptstädten des Imperiums laufend neue zivile Vereine und Organisationen aller Art gegründet. Es kam zu einer regelrechten „Vereinseuphorie“, die sich durchaus in einem europäischen Kontext verstehen lässt. Auch dort erlebten Organisationen aller Art im Rahmen einer „Manie“ für Aktivitäten der Bürgerinnen und Bürger seit den 186oer-/7oer-Jahre einen starken Aufschwung. ${ }^{219}$ Um die Jahrhundertwende hatte sich in den russischen Städten schließlich eine neue „soziale und kommunikative Infrastruktur" etabliert, die nach 1905 nochmals weiter gestärkt wurde. Vereine und Organisationen gründeten Museen, Bibliotheken oder Theater. ${ }^{220} \mathrm{Um}$

zwingend angesehenen Zusammenhang von geistiger Begabung und guten Taten geht, vgl. ebd., S. 12. Neben Koni gab es weitere Juristen, die sich beteiligten, darunter z. B. Spasovič.

214 Adele Lindenmeyr: The Rise of Voluntary Associations during the Great Reforms. The Case of Charity. In: Ben Eklof/John Bushnell/Larissa Zakharova (Hrsg.): Russia's Great Reforms, 1855-1881. Bloomington 1994, S. 264.

215 Philip Nord: Introduction. In: Nancy Bermeo/Philip Nord (Hrsg.): Civil Society before Democracy. Lessons from Nineteenth-Century Europe. Boston 2000, S. XIX.

216 Bradley: Voluntary Associations, Civic Culture, and Obshchestvennost' in Moscow, S. 135.

217 Figes: Hundert Jahre Revolution, S. 16.

218 BRadley: Voluntary Associations, Civic Culture, and Obshchestvennost' in Moscow, S. $136-37$.

219 NorD: Introduction, S. XVI-XVII. Nord spricht mit Verweis auf die Arbeit von Klaus Tenfelde von „Vereinseuphorie“. Vgl., Klaus Tenfelde: Die Entfaltung des Vereinswesens während der Industriellen Revolution in Deutschland (1850-1873). In: Otto Dann (Hrsg.): Vereinswesen und bürgerliche Gesellschaft in Deutschland. München 1984.

220 Renner: Russischer Nationalismus und Öffentlichkeit im Zarenreich 1855-1875, S. 155 und Berdjaev u.a. (Hrsg.): Vechi, S. 15 (Einleitung v. Karl Schlögel). Schlögel schreibt, dass nach 1905 neue Vereinigungen Tag für Tag „aus dem Boden“ geschossen seien. 
1912 zählte man in Moskau bereits über 60o Vereinigungen, die sich neben der Wohlfahrt vor allem für Technik, Literatur, Sport, Kunst, Bildung oder Kultur stark machten. ${ }^{221}$ Neben diesen freiwilligen Verbänden, die als autonome Institutionen ihre eigenen Statuten gestalteten und nicht direkt einer höheren politischen Einheit unterstellt waren, kam in diesem Zusammenhang auch den politischen Assoziationen eine wichtige Funktion zu, wie beispielsweise den lokalen Organisationen der Selbstverwaltung oder den städtischen Korporationen. ${ }^{222}$

Immer wieder galt es im Moment des Eintritts in diese „soziale und kommunikative Infrastruktur", in Form eines Kurzlebenslaufes Rechenschaft über seine bisherigen Tätigkeiten abzulegen. Diese „entlockten Geschichten“ passten sich oftmals dem institutionellen Setting der entsprechenden Organisation an oder wurden unmittelbar über standardisierte Formulare in die gewünschten Bahnen gelenkt. ${ }^{223}$ Dabei kam es zu einer verstärkenden Wechselwirkung, bei der sich der "gesellschaftliche Akteur" mit dem Verweis auf möglichst umfangreiches persönliches Engagement für seinen Beitritt zu weiteren zivilgesellschaftlichen Organisationen empfehlen wollte. Kurzautobiografien, die Koni aus Anlass seiner Berufung in diverse Verbände und Organisationen literarischer, künstlerischer, wohltätiger, wissenschaftlicher oder juristischer Natur verfasste, finden sich in seinem Nachlass gleich mehrfach. Bereits im Jahre 1878 umfasste sein Curriculum Vitae mehrere Seiten. ${ }^{224}$ Fein säuberlich nach Rubriken geordnet, fasste er darin zusammen, was er mit seinen 35 Jahren alles erreicht hatte. Nach Personalien und Angaben zur Ausbildung folgen die Anstellungen an den verschiedenen Gerichtsbehörden. Diese Rubrik „Dienst“ hat eine zweite Komponente, den „gesellschaftlichen Dienst“ [obščestvennaja služba]. Hier schreibt Koni unter anderem von seiner mehrfachen Wahl zum Friedensrichter und Ehrenfriedensrichter. Ergänzt wird dies von der Rubrik der "gesellschaftlichen Tätigkeit“ [obščestvennaja dejatel'nost'], wo Koni unter anderem auf seinen Einsitz in einer Gesellschaft verweist, die sich um minderjährige Straftätige kümmern will. Auch die „wissenschaftliche und lehrende Tätigkeit" und entsprechende Mitgliedschaften zum Beispiel

221 Bradley: Voluntary Associations, Civic Culture, and Obshchestvennost' in Moscow, S. 136-37. 1897 zählte man in St. Petersburg ebenfalls bereits etwa 400 Gesellschaften. Keine anderen Städte im Russischen Reich kamen diesen Zahlen nahe.

222 Joseph Bradley: Voluntary Associations in Tsarist Russia. Science, Patriotism, and Civil Society. Cambridge Massachusetts 2009, S. 5-6. Bradley definiert hier seinen Gebrauch der „voluntary“ oder "civil“ „associations“ und verweist auch auf die „political associations“, um die es in seiner Untersuchung aber nicht geht.

223 Smith und Watson verweisen darauf, dass persönliche Narrative in solchen Settings der Situation entsprechend angepasst werden, vgl. SMITH/WATSON: Reading Autobiography, S. $65-66$.

224 IRLI F. 134, op. 4, d. 93, 1. 34-37. 
in der "Société de législation comparée à Paris“ sowie die "literarische Tätigkeit“ dürfen nicht fehlen. ${ }^{225}$ Einige Jahre später wurde eine Kurzform dieser umfangreichen Auflistung von Konis Werdegang veröffentlicht. ${ }^{226}$ Datiert vom März 1884 konzentriert sich dieser Abschnitt mehrheitlich auf die beruflichen Stationen Konis; allerdings werden zum Schluss auch wieder die Unterrichtstätigkeit und sein Engagement als Friedensrichter erwähnt. Diese gesellschaftliche, wissenschaftliche und lehrende Tätigkeit beziehungsweise dieser Dienst erhält in den nachfolgenden Jahren ein immer stärkeres Gewicht in Konis Curriculum. Als das zweite St. Petersburger Gymnasium, in das Koni mit 14 Jahren eingetreten war, zum Jubiläum der Schule im Jahre 1905 in Zeitungen einen Schreibaufruf an Ehemalige veröffentlicht, schickt Koni sogleich eine umfassende Auflistung seines Werdegangs ein. ${ }^{227}$ Zusammen mit 13 weiteren solchen Curricula wurde diese veröffentlicht und nimmt weitaus am meisten Platz ein. ${ }^{228}$ Diese Avtobiografija liest sich wie eine Aufzählung aller Vereine und Organisationen, die es im imperialen Russland gegeben haben mag. Zuerst verweist Koni noch auf seinen Besuch des zweiten St. Petersburger Gymnasiums und das nachfolgende Studium und seine Gerichtskarriere, auch die verschiedenen Ämter als Friedensrichter werden genannt. Mit besonderem Stolz erwähnt er, dass er bei der Wahl in das Stadtparlament von St. Petersburg mit 832 von 952 Stimmen in seinem Wahlkreis gewählt worden sei. Danach folgen die Mitgliedschaften: 1898 sei er zum Mitglied in der von der Zarin persönlich präsidierten Wohlfahrtsstiftung „Vormundschaft über die Arbeitshäuser und die Zwangsarbeitsanstalten" ernannt worden, schon Jahrzehnte engagiere er sich im St. Petersburger Hilfswerk „Vormundschaftskomitee für Gefängnisse", daneben betätige er sich für wissenschaftliche Wettbewerbe und gesetzgebende Kommissionen, die Akademie der Wissenschaften, medizinische Kommissionen, die „Gesellschaft der Liebhaber der Russischen Sprache“, die Juristischen Gesellschaften der Universitäten von Moskau und St. Petersburg, aber auch von Charkow, Kiew oder Kasan, die wohltätigen Organisationen an den Gerichten oder für die ehemaligen Moskauer Studenten in St. Petersburg, die „Gesellschaft für Selbsthilfe der St. Petersburger Ärzte“ sowie die „Psychologische

225 Ebd., 1. 34-37. Zum Schluss wird noch die Rubrik „Erinnerungen“ genannt, die aber keine Einträge enthält. 1878 hatte Koni auch noch keine entsprechenden Texte publiziert.

226 Michail Semevskij (Hrsg.):Znakomye. Al'bom M. I. Semevskogo. Kniga avtobiografičeskich sobstvennoručnych zametok 850 lic. Vospominanija. Stichotvorenija. Epigramy. Šutki. Podpisi. 1867-1888. Sankt-Peterburg 1888, S. 208.

227 Auf diesen Schreibaufruf wird in der Jubiläumsschrift selber verwiesen. Vgl. zu Konis Gymnasiumsbesuch Vysockij: Koni, S. $36 \mathrm{ff}$.

228 Anatolij F. Koni: Avtobiografija. In: P. K. Tichomirov (Hrsg.): Istoričeskaja zapiska vtoroj S.-Peterburgskoj gimnazii, Bd. 3. Sankt-Peterburg 1905, S. 378-80. 
Gesellschaft der Moskauer Universität“. Ergänzt wird diese beeindruckende Auflistung erneut um Konis Unterrichtstätigkeit im Bereich von Recht und Gerichtsethik. Den letzten Abschnitt des Lebenslaufs bilden die "gedruckten Werke“.229 Neben den Mitgliedschaften nehmen in Konis Curricula diese publizistischen Arbeiten eine immer wichtigere Stellung ein. Dass dabei der "coaxer" beziehungsweise der Schreibanlass dies vorstrukturierte, zeigt sich besonders deutlich am Kurzlebenslauf von Koni, der 1911 im „Lexikon der Mitglieder der Gesellschaft der Liebhaber der Russischen Sprache" erschien. ${ }^{230}$ Vermutlich in Vorbereitung für dieses Lexikon hatte Koni ein Formular der Gesellschaft ausgefüllt, das eine Art Mitgliederkartei zu sein scheint. Neben den Personalien und den Angaben zur Ausbildung wird hier in der Rubrik 5 auch nach den Eltern gefragt. Und in Rubrik 6 nach der „gesellschaftlichen Situation“ [obščestvennoe položenie], was Koni erneut die Aufzählung von Mitgliedschaften zuerst in beruflich-politischen und schließlich in wissenschaftlich-literarischen Organisationen „entlockt“. Die nachfolgende Rubrik erfragt die Publikationen Konis, die nun bereits zahlreiche Erinnerungsbände und -artikel wie den Sammelband „Skizzen und Erinnerungen“ oder die Reihe „Aus den Erinnerungen eines Gerichtstätigen“ in „Russische Altertümer“ [Russkaja Starina] umfassen. Als letzte Rubrik vor der Unterschrift und Adressangabe wird den Mitgliedern der Gesellschaft die Möglichkeit gegeben, allgemeine Anmerkungen zu machen beziehungsweise jene Erfolge zu unterstreichen, die in ihrer wissenschaftlichen und literarischen Tätigkeit von besonderer Relevanz seien. Dies nutzt Koni, um erneut von seiner Unterrichtstätigkeit unter anderem am Alexanderlyzeum zu berichten, speziell betont er die Gerichtsethik. Neu unterstreicht Koni nun aber auch seine öffentlichen Vorlesungen zu verschiedensten Themen, mit denen er zwischen 1892 und 1910 Geld für wohltätige Zwecke gesammelt habe. Er nennt sogar die Summe, die dabei zusammengekommen sei. Zum Schluss verweist Koni noch auf seine Reden vor der Akademie der Wissenschaften beispielsweise zu Rovinskij. ${ }^{231}$ Bis ins Detail wird seine Darstellung im Lexikon übernommen, sogar die 22.00o Rubel Spendensumme durch seine Vorlesungen schaffen es in die Zusammenstellung. ${ }^{232}$

229 Ebd., S. 378-80.

230 Slovar' členov Obščestva ljubitelej Rossijskoj slovesnosti: Koni, Anatolij Fëdorovič. In: SČOLRS, 1911, S. 145-46.

231 GARF F. 564, op. 1, d. 4318, 1. 1-2ob. Detaillierter zu Konis Reden vor der Akademie der Wissenschaften, die oftmals auch berühmten Schriftstellern gewidmet waren, in TEIL DREI.

232 Slovar' členov Obščestva ljubitelej Rossijskoj slovesnosti: Koni, Anatolij Fëdorovič. In: SČOLRS, 1911, S. 145-46. 
Koni verfasste also im Verlauf seines Lebens immer wieder kurze Curricula Vitae. ${ }^{233}$ Oftmals scheinen berufliche Veränderungen, die Aufnahme in Organisationen oder der Schreibaufruf eines Lexikons das Verfassen solcher Texte nicht nur ausgelöst, sondern auch inhaltlich vorstrukturiert zu haben. ${ }^{234}$ In einer Art verdichteten Autobiografie präsentierte Koni in den Lebensläufen jene Elemente aus seinem Werdegang, die es aufgrund des Settings und seiner persönlichen Überzeugungen besonders hervorzuheben galt. Sein thematischer Fokus weist darauf hin, dass mit zunehmenden Jahren und im Kontext der verbreiteten „Vereinseuphorie“ seine "gesellschaftlichen“ Tätigkeiten für Koni immer wichtiger wurden. Laufend zahlreicher wurden seine Mitgliedschaften in wissenschaftlichen, literarischen, beruflichen oder wohltätigen Organisationen und immer stärker betonte er dies in seinen entsprechenden Curricula. Das vorrangige Ziel dieser Organisationen - als Vermittler von aufklärerischen Ideen und Bildung für die gemeine Bevölkerung tätig zu sein - betont Koni dabei unentwegt. ${ }^{235}$ Er unterstreicht immer wieder seine Unterrichtstätigkeiten. Er betont gerne, dass er von Organisationen oder gar von der Bevölkerung selber in Ämter gewählt worden sei. Besonders ausführlich zählt er auch all jene Städte außerhalb der Zentren

233 Es sind in Konis Nachlass noch weitere solche Lebensläufe erhalten, in einem grünen Heft in IRLI F. 134, op. 4, d. 93 gar einer mit elf Doppelseiten, vermutlich 1898 verfasst. Auch nach 1917 hat Koni erneut Curricula Vitae geschrieben, vgl. dazu unten, S. 371.

$234 \mathrm{Zu}$ Lebzeiten Konis erschien eine ganze Reihe an Lexika, die ihm einen Eintrag widmeten. Im Falle der „Gesellschaft der Liebhaber der Russischen Sprache“ ist es offensichtlich geworden, dass Koni selber die entsprechende Darstellung verfasste, da seine Angaben im Formular wortwörtlich in gedruckte Form übertragen wurden. Es ist deshalb davon auszugehen, dass dies auch für weitere Nachschlagewerke zutraf. So schickte Koni auch für das nie vollendete Monumentalwerk von Semën Afanas'evič Vengerov (1855-1920) „Kritiko-biografičeskij slovar’ russkich pisatelej i učenych“ dem Verfasser zwischen 1890 und 1913 mehrfach aktualisierte Versionen seines Curriculums zu bzw. ergänzte die bereits eingereichten, vgl. Elena D. Konusova: Russkaja intelligencija. Avtobiografii i biobibliografičeskie dokumenty v sobranii S. A. Vengerova, Bd. 1. Sankt-Peterburg 2001, S. 514-15. Neben den bereits genannten biografischen Nachschlagewerken finden sich auch Einträge zu Koni in: German A. Gol'dberg (Hrsg.): Al'manach sovremennych russkich gosudarstvennych dejatelej. Sankt-Peterburg 1897; Gallereja russkich pisatelej. Moskva 1901; N. I. Afanas'ev: Sovremenniki. Al’bom biografij, 2 Bände. Sankt-Peterburg 1909-1910; M. L. Levenson: Pravitel'stvujuščij Senat. Sankt-Peterburg 1912; ders.: Gosudarstvennyj Sovet. Petrograd 1915.

235 Bradley weist darauf hin, dass diese Art von „civic activity“ auch in den viktorianischen Städten in Europa und Amerika zu finden ist, in denen z. B. das „Museum Movement“ ebenfalls die Nützlichkeit von Museen für Bildung betonte und mit den Freiwilligenverbänden Selbstverbesserung, kulturelle Bereicherung, soziale Einheit oder nationale Ziele verfolgt wurden. BRADLEY: Voluntary Associations, Civic Culture, and Obshchestvennost' in Moscow, S. 146. 
des Reiches auf, in denen er zum Ehrenmitglied der jeweiligen Juristischen Gesellschaft ernannt worden war. Ob Kasan, Charkow oder Kiew, zumindest in der autobiografischen Darstellung verbinden sich diese Orte über die „Lebensgeografie" Konis. ${ }^{236}$ All diese Aufzählungen erscheinen fast wie eine Art Rapport, den Koni vor der „Gesellschaft“ ablegte. Denn es ist offensichtlich, dass er mit dem Verweis auf die enorme Breite seiner Interessen und Involvierungen und dem großen Engagement für Erziehung und Wohlergehen der Bevölkerung in allen Reichsteilen ein Musterexemplar des "gesellschaftlichen Akteurs“ sein wollte.

Sein Beispiel macht auch deutlich, dass diese Berufung keineswegs mit radikaler Opposition gegen das politische Establishment einhergehen musste. Gerne wird die „Emanzipation von obrigkeitlicher Bevormundung" als sine qua non der "Civil Society“ verstanden. Phänomene wie die „Vereinseuphorie“, die Verstärkung der Professionalisierungsbestrebungen oder die zunehmende Autonomie der Selbstverwaltung werden als Gegenbewegungen zur offiziellen Struktur interpretiert, so dass eine absolute Dichotomie zwischen Bürgern und Offiziellen, zwischen zivilgesellschaftlichen Organisationsformen und dem Staat zu bestehen scheint. ${ }^{237}$ Die „kompromisslose Ablehnung der Autokratie“ und der Kampf gegen sie werden als moralische Basis des Engagements von revolutionären Parteien aber auch liberalen Freiberuflern und weiteren Mitgliedern der Intelligencija angesehen ${ }^{238}$ Dadurch scheint der „Dienst an der Gesellschaft“ unmöglich mit einem allfälligen „Dienst für den Staat" vereinbar zu sein. ${ }^{239}$ Gerade die „Spezialisten-

236 David Lambert/Alan Lester: Introduction. Imperial Spaces, Imperial Subjects. In: dies. (Hrsg.): Colonial Lives across the British Empire. Imperial Careering in the Long Nineteenth Century. Cambridge, New York 2006, S. 2 sprechen von „life geographies“ in Anlehnung an S. DAniel/C. NASH: Life Paths. Geography and Biography. In: Journal of Historical Geography 30 (2004), S. 450. Sie meinen damit die „bedeutsamen Verbindungen“ im Großreich, die durch die mobilen Werdegänge der „imperial careerists“ entstanden. Tatsächlich herrschte zwischen den unterschiedlichen juristischen Professionsverbindungen verschiedener Städte ein sporadischer gegenseitiger Austausch von Zeitschriften und Publikationen, vgl. Levin-StAnkevich: The Transfer of Legal Technology and Culture, S. 242-43. Koni hat beispielsweise 1889 den Gerichtsbehörden in Charkow ein siebenbändiges Werk der Kommission zur Überarbeitung des Volost'-Gerichts zugeschickt, wofür man sich schriftlich bedankte. 1901 bedankte sich das St. Petersburger Friedensgericht bei Koni für die Zustellung von Material über ein früheres Mitglied, vgl. beides GARF F. 564, op. 1, d. 749.

237 Renner: Russland und die Civil Society, S. 233 kritisiert dies.

238 Figes: Hundert Jahre Revolution, S. 28.

239 Samuel D. Kassow: Students, Professors, and the State in Tsarist Russia. Berkeley u. a. 1989, S. 388 argumentiert, warum eine Vereinigung dieser beiden Ideale für Russland nicht wie z. B. in Preußen denkbar gewesen sei. Er führt an, dass der Staat beispielsweise die Professorenschaft immer unter Generalverdacht gestellt habe und es in Russland anstelle eines 
autorität" von Berufsgruppen wie den Juristen schien nicht zu der autokratischen Ordnung zu passen. Technische Kenntnisse kombiniert mit einem eigenen Ethos, eigener Verantwortlichkeit und eigener Mission der Verbreitung von Recht in der Gesellschaft schienen sich nur ungut in das hierarchische System des Imperiums einzuordnen. ${ }^{240}$ Vereine und ihre Mitglieder dienen so als quantitatives Argument, um die "Vergesellschaftung als Schulung gegen den autokratischen Staat" zu erfassen. ${ }^{241}$ Wenn nun Koni aber als Senator und ab 1907 gar Staatsrat Mitglied in eigenständigen Berufsorganisationen, privaten wohltätigen Komitees zugunsten Hungerleidender oder Gremien der lokalen Selbstverwaltung wurde, verbanden sich die angeblich diametral verschiedenen Welten. Der Übergang zwischen staatlicher Administration und einer Öffentlichkeit, die als „Ausgleich für die Ambitionen der Mächtigen“ fungieren sollte, konnte also durchaus fließend sein. ${ }^{242}$ Die Zivilgesellschaft musste nicht der absolute Antipode des Staates sein. ${ }^{243}$ Auch in neuen Vereinsstrukturen konnten alte Vorstellungen weiterleben, die nicht zwingend die Selbstherrschaft an sich in Frage stellten. ${ }^{244}$ Zahlreiche „Teilnehmer“ dieser Strukturen sahen sich als Teil einer gesellschaftlichen Bewegung und nicht als Teil eines politischen Dauerkonflikts mit der Autokratie. ${ }^{245}$ Und tatsächlich gehörte zu den klassischen Forderungen der Organisationen, die sich um den Kampf gegen Armut und Hunger kümmerten, eine stärkere regulative Initiative von staatlicher Seite. ${ }^{246}$ Neben der Bemühung, sich von Autokratie und willkürlicher Beamtenherrschaft zu emanzipieren, wurde also auch ein Plädoyer für eine

„Rechtsstaates“ vielmehr einen „Polizeistaat“ gegeben habe, der mittels Notverordnungen regierte.

240 Wortman: The Development of a Russian Legal Consciousness, S. 269-70.

241 Walter Sperling: Jenseits von Autokratie und Gesellschaft. Zur Einleitung. In: ders. (Hrsg.): Jenseits der Zarenmacht. Dimensionen des Politischen im Russischen Reich 1800-1917. Frankfurt am Main u. a. 2008, S. 15-16 plädiert für einen anderen Fokus, vgl. nachfolgendes Argument.

242 NorD: Introduction, S. XIV.

243 N. V. Andrianov: Graždanskoe obščestvo kak sreda institucionalizacii advokatury. Moskva 2011, S. 48-49. Andrianov betont, dass Hegels Vorstellung von einer Dichotomie zwischen Zivilgesellschaft und Staat immer noch von Bedeutung sei, dass es aber wissenschaftlich nicht haltbar sei, von einem totalen Gegensatz zwischen administrativem Apparat und den Bürgerinnen und Bürgern zu sprechen. Er argumentiert, dass im Gegenteil gerade dort Konflikte zwischen Individuum und Staat besonders folgenschwer seien, wo keine Bürgergesellschaft mit hohem Organisationsgrad existiere, die für die soziale Integration des Einzelnen sorge.

244 Sperling: Jenseits von Autokratie und Gesellschaft, S. 15-16.

245 Renner: Russland und die Civil Society, S. 234.

246 Sperling: Jenseits von Autokratie und Gesellschaft, S. 16. 
engere Partnerschaft zwischen Staat und Gesellschaft angebracht. ${ }^{247}$ Gerade im Bereich der Armutsbekämpfung fanden sich denn auch große Teile der Elite bestehend aus der hohen Adels- und Beamtenschaft ein. ${ }^{248}$ Konis Mitgliedschaft in der Wohlfahrtsstiftung der Zarin zu den „Arbeitshäusern“, auf die er auch im Curriculum für sein ehemaliges Gymnasium verweist, dient hier als Paradebeispiel. ${ }^{249}$

Obwohl, oder gerade weil die Rede vom "gesellschaftlichen Akteur" omnipräsent war, dürfte die reale Involvierung Konis in die unzähligen Organisationen, Gesellschaften und Gremien der Selbstverwaltung, die er wieder und wieder nennt, nicht immer sehr konkret gewesen sein. Während die Juristische Gesellschaft aus Kasan Koni 1900 in einem feierlichen Brief mitteilt, dass sie ihn zum Ehrenmitglied ernannt habe, ${ }^{250}$ erhält er von einer Tolstoi-Gruppierung zusammen mit dem Ernennungsbescheid gleich noch eine Geldbitte. Faktisch informiert die Organisation, die sich dem Studium und der Verbreitung des Werks des berühmten Schriftstellers widmen will, Koni über die bereits erfolgte Wahl zum Ehrenmitglied und bittet ihn erst danach um sein Einverständnis, das er mit der Überweisung von ca. 100 Rubel belegen solle. ${ }^{251}$ Zahlreiche weitere Schreiben von Gesellschaften machen klar, dass diese oftmals genauso interessiert daran waren, Koni in ihren Reihen zu wissen oder einen Vortrag von ihm ankündigen zu dürfen, wie er umgekehrt seine demokratisch legitimierte Zugehörigkeit zu diesen Vereinigungen

247 Bradley: Voluntary Associations in Tsarist Russia, S. 1. Gerasimov führt aus, wie die „anti-staatliche“ Haltung in der russischen Obščestvennost' besonders stark in der Krisenzeit während des Ersten Weltkrieges überdacht wurde. Gerade die neue IntelligencijaGeneration aus der Zeit nach 1905 arbeitete immer enger mit ähnlich denkenden Staatsbeamten zusammen, vgl. Gerasimov: Modernism and Public Reform in Late Imperial Russia, S. 155.

248 Sperling: Jenseits von Autokratie und Gesellschaft, S. 16. Vgl. auch Joseph Bradley: Subjects into Citizens. Societies, Civil Society, and Autocracy in Tsarist Russia. In: The American Historical Review 4 (2002), S. 1121.

249 Vgl. dazu auch unten, S. 149. Dies war längst nicht die einzige von der erweiterten Zarenfamilie geführte Wohlfahrtsgesellschaft, an der sich Koni beteiligte, vgl. z. B. GARF F. 564, op. 1, d. 746, 1. 57-58 oder GARF F. 564, op. 1, d. 250, l. 1. Koni äußerte sich auch schriftlich in einem Artikel zu seiner Mitgliedschaft in der Stiftung und nannte sich dabei einen „Juristen-Praktiker“, der nicht nur „mechanisch“ „Formeln des Gesetzes“ aufsage, sondern auch die „dunklen und traurigen Seiten des Lebens“ kenne. Gerade deshalb sei er sich über die Wichtigkeit von wohltätigem Engagement im Klaren. Vgl. Anatolij F. KonI: Zadači trudovoj pomišči. Pis’mo k redaktoru žurnala „Trudovaja pomošč'“. In: Trudovaja pomošč 1 (1897), hier zitiert nach: ders. (Hrsg.): Očerki i vospominanija. Publičnye čtenija, reči, stat'i i zametki. Sankt-Peterburg 1906, S. 824-25.

250 GARF F. 564, op. 1, d. 20, 1. 79.

251 GARF F. 564, op. 1, d. 752, 1. 41. 
in seinen Lebensläufen als symbolisches Kapital einsetzte. ${ }^{252}$ Manchmal schien der Fakt der Wahl oder Ernennung in eine Organisation wesentlicher zu sein als das tatsächliche Engagement. Gerade die Aktivität in der lokalen Selbstverwaltung gehörte quasi zum russischen liberalen „Life-Styl “.253 Wie Koni in seinen eigenen Erinnerungen anführt, hat er zum Beispiel das Amt des Ehrenfriedensrichters nicht in allen Kreisen gleich intensiv ausfüllen können und sich vor allem auf die Hauptstadt beschränkt, bevor er 1885 nach acht Jahren die Tätigkeit wieder aufgab. ${ }^{254}$ Auch der Einsitz im Stadtparlament, den er in einem Brief an Čičerin als seine „Bürgerpflicht“ bezeichnete, beendete er sehr schnell wieder. ${ }^{255}$ Dies änderte aber nichts daran, dass Koni in seinen Kurzlebensläufen auf immer mehr Mitgliedschaften verweisen konnte. Wie um seinen Vernetzungserfolg zu belegen, bewahrte er zahlreiche solcher Ernennungen zum Ehrenmitglied auf. Auch eine sehr umfangreiche Sammlung von Bittbriefen und Dankesschreiben wohltätiger, literarischer, wissenschaftlicher oder berufsständischer Organisationen an Koni findet sich in seinen Unterlagen. Diese fragten nach Bücherspenden, dem Verfassen von Grußworten und Ehrungen oder bedankten sich für seine finanzielle Unterstützung oder seinen politischen Einsatz für ihre Anliegen. ${ }^{256}$ Dieses Zelebrieren des gesellschaftlichen Engagements in Kurzlebensläufen, den gegenseitigen biografischen Porträts oder dem Aufbewahren von Anschreiben verschiedenster Organisationen war unverzichtbarer Bestandteil der Ob̌šcestvennost’, konstruierte es doch den „gesellschaftlichen Akteur" ganz wesentlich mit.

\subsubsection{Koni als „edler“ Jurist}

Vom Autor der Biografien anderer wurde Koni ab 1907 dank seiner in der Zeitschrift „Russische Altertümer“ [Russkaja Starina] veröffentlichten Reihe „Aus den Erinnerungen eines Gerichtstätigen“ immer mehr zum Helden seiner eigenen Geschichten. Den Auftakt machte die Erinnerungsschrift „Die Begutachtung

252 Hinter den Bemühungen der Zusammenschlüsse und Vereine standen sowohl Hoffnungen, an Prestige zu gewinnen, als auch handfeste finanzielle Aspekte. Vgl. z. B. GARF F. 564, op. 1, d. 250, l. 1 wo eine Gesellschaft zum Schutz von Kindern Koni 1901 inständig bittet, einen Vortrag zu irgendeinem Thema zu halten und so Geld zu sammeln. Oder ebd., d. 250, 1. 18, wo ein kunstinteressierter Anwaltskreis in St. Petersburg Koni 1912 einen Brief schreibt, in dem die Genugtuung darüber ausgedrückt wird, dass Koni vor dem Kreis auftreten wolle und so seine „hohe moralische Autorität" und sein „herausragendes Talent" mit ihnen teile.

253 Fedyashin: Liberals under Autocracy, S. 201. Dazu ausführlicher in TEIL ZWEI.

254 Koni: Mirovye sud'i. In: ders. (Hrsg.): Otcy i deti sudebnoj reformy, S. $208-09$ und 212.

255 GA8, S. 200 (Brief an B. N. Čičerin vom 30. 12. 1903). Vgl. dazu ausführlicher unten, S. 195.

256 Vgl. z. B. GARF F. 564, op. 1, d. 250, 251, 745, 749 oder 752. 
von psychisch Kranken“, in der Koni unter anderem einen kniffligen Fall um eine fälschlicherweise als geisteskrank abgeschriebene Person bravourös zu lösen weiß. So führt er lange aus, wie eine 25-jährige Frau, die selber jegliche Aussage verweigert habe, von den Ärzten in der Begutachtungskommission, der auch Koni zugeteilt war, zur psychisch Kranken erklärt worden sei. Koni aber habe sich davon nicht überzeugen lassen und auf weiteren Nachforschungen bestanden. Zum Schluss habe sich herausgestellt, dass die junge Frau schon seit Jahren herumgeschoben worden sei und gemeinsam mit ihrem Bruder in großer Armut lebte, aber keineswegs psychisch krank gewesen sei. Diese entlastenden Erklärungen lässt Koni in seiner Nacherzählung die junge Frau selber dem Staatsanwalt der St. Petersburger Gerichtskammer vortragen. Nachdem dieser auf Konis Drängen zuerst etwas mürrisch reagiert habe, habe sich der Staatsanwalt dann zu einem Besuch im Krankenhaus bei der schweigenden jungen Frau entschlossen, und diese habe ihm schließlich ihre Geschichte erzählt. Koni beendet diese Episode in der Erinnerungsschrift nach fast acht Seiten mit dem erneuten Zusammentreten der Kommission:

Und tatsächlich, nach einer halben Stunde habe ich mit fröhlichem Gefühl das Protokoll unterschrieben, auf dem nun durch die gleiche ärztliche Hand, die so lange unter dem Namen von B. die verhängnisvollen Worte „düstere Melancholie“ hingesetzt hatte, hingeschrieben wurde "gesund“. Das arme Mädchen wurde von der Witwe des Geheimrats Pejker aus dem Spital zu sich genommen. ${ }^{257}$

Ähnlich erfolgreich zeigt Koni sich im Fall der Frau „Gulak-Artemovskoj“. Diese Dame - wie sich zeigen sollte, selber in unredliche Machenschaften verstrickt habe Koni um rechtliche Unterstützung gebeten für eine schwangere junge Frau. Da der Kindsvater jegliche Unterstützung verweigere, sei die Frau in größter Not. Koni löste die Situation - so berichtet er in seiner Erinnerungsschrift - mit einer simplen Vorladung der zukünftigen Eltern. Im Moment der persönlichen Konfrontation hätten diese sich nämlich sofort versöhnt und würden nun gemeinsam dem Nachwuchs Sorge tragen. ${ }^{258}$ Von aufsehenerregenderen Fällen berichtete Koni gerne auch sehr detailliert. So erzählt er zum Beispiel die Hintergründe bis zur Verurteilung des zwölffachen Millionärs „Ovsjannikov“ nach. Koni, 1874 Staatsanwalt am St. Petersburger Bezirksgericht, leitete Ermittlungen ein, die schließlich im vielbeachteten Schuldspruch gegen einen einflussreichen und wohlhabenden

257 Anatolij F. Koni: Iz zametok i vospominanij sudebnogo dejatelja. I. Osvidetel'stvovanie duševno-bol'nych (1870-1895). In: RS 2 (1907), S. 272.

258 Anatolij F. Koni: Delo Gulak-Artemovskoj. In: ders. (Hrsg.): Na žiznennom puti, Bd. 1. Iz zapisok sudebnogo dejatelja, žitejskie vstreči. Sankt-Peterburg 1912, S. 250-59. 
Bürger endeten. In diesem Fall, wie beispielsweise auch bei den Geschehnissen rund um das „Spielhaus von Kolemin“, ergibt sich der Erfolg der Erzählung aus der Verurteilung von Gesellschaftsschichten, die unter dem vorreformierten Gericht als unantastbar gegolten hatten. Während es bei „Ovsjannikov“ ein Reicher ist, ist es im Fall des illegalen Glückspiels ein hoher Militär. Mit Stolz merkt Koni an, dass dieses harte Durchgreifen große Aufregung verursacht habe. ${ }^{259}$ Und über den Prozess gegen den Millionär, der ein „,echtes Fest für das neue Gericht“ gewesen sei, sei sogar - mit ungläubigem Unterton ob der erfolgreichen Verurteilung - in einer deutschen Zeitung berichtet worden. ${ }^{260}$

Die neuen Gerichte wollten mit solchen Fällen eine „Lektion“ gegen die „Ungerechtigkeit der alten Ordnung " erteilen ${ }^{261}$ Indem Koni diese Prozesse aus den 1870-er Jahren Jahrzehnte später wieder aufleben ließ, erinnerte er an seine persönlichen gleichsam wie die grundlegenden Erfolge des neuen Gerichtswesens. Es liegt auf der Hand, dass damit nicht nur die eigene Berufsgruppe auf Grundwerte der Profession eingeschworen werden sollte, sondern als Adressat eine möglichst breite Öffentlichkeit gesucht wurde, deren Vertrauen in die Rechtsprechung und deren Akteure aller Missstände im Justizwesen zum Trotz gewonnen werden wollte. Einem sonst wenig zugänglichen Publikum sollten Ideale von Justiz und Humanismus vermittelt werden. ${ }^{262}$ Diese Intentionen zeigten sich nicht zuletzt daran, dass Koni seine Erinnerungsreihe an wichtige Fälle und Ereignisse in seinem Berufsleben nicht in einer juristischen Fachpublikation veröffentlichte, sondern in der historischen Zeitschrift "Russische Altertümer" [Russkaja Starina]. Die juristischen Fachzeitschriften kämpften seit den 189oer-Jahren mit tiefen Abonnentenzahlen und wurden zum Teil eingestellt. Neue Projekte wie die Monats-

259 Anatolij F. Koni: Igornyj dom Kolemina. In: ders. (Hrsg.): Na žiznennom puti, Bd. 1. Iz zapisok sudebnogo dejatelja, žitejskie vstreči. Sankt-Peterburg 1912, S. 70-71.

260 Anatolij F. Koni: Delo Ovsjannikova. In: ders. (Hrsg.): Na žiznennom puti, Bd. 1. Iz zapisok sudebnogo dejatelja, žitejskie vstreči. Sankt-Peterburg 1912, S. 20.

261 Dahlke: Old Russia in the Dock, S. 106. Dahlke nennt auch direkt Koni, der u. a. diese Meinung vertreten habe. Sie bezieht sich in ihrer Analyse v. a. auf den Prozess gegen Äbtissin Mitrofanija, über den auch Koni einen kurzen Erinnerungstext in seiner Reihe verfasst hatte. Koni war allerdings nur zu Beginn am Fall beteiligt, bevor dieser weg von St. Petersburg nach Moskau verlegt wurde. In seiner Erinnerung zeigt er sich sehr zurückhaltend in der Beurteilung der Art und Weise, wie der Prozess von den Moskauer Kollegen geführt wurde. Wie Dahlke schreibt, war Koni später in die heimliche Begnadigung der verurteilten Äbtissin involviert, vgl. dazu ausführlicher unten, S. 180.

262 Nethercott: Russian Legal Culture Before and After Communism, S. 154-55 erwähnt spezifisch die Nachrufe und Jubiläumsausgaben der russischen Juristen, mit denen über eine „hagiografische Komponente“ Werte von Recht, Justiz und Humanismus anerzogen werden sollten. Sie sieht die Adressaten dieser Praxis dabei im breiten russischen Publikum, das solchen Ideen vorsichtig und wenig aufgeschlossen gegenübergestanden habe. 
schrift „Juristische Chronik“, die sich nicht nur an professionelle Juristen, sondern an gebildete Bürger generell wandte, konnte unter den 30.000 Angestellten der Gerichtsbehörden nur gerade 700 Abonnenten finden und scheiterte so an mangelnden Einnahmen. Kurz vor der Jahrhundertwende gab es zwar eine Wiederbelebung auf dem Markt, und zumindest die neue Zeitschrift „Recht“ [Pravo] konnte großen Erfolg und hohe Auflagen verbuchen. ${ }^{263}$ Doch Zeitschriften wie die „Russischen Altertümer“ waren auf noch größere Lesergruppen ausgerichtet. Das bedeutende historische Journal erschien seit 1870 und enthielt neben Arbeiten geschichtswissenschaftlicher und literaturhistorischer Art auch zahlreiche Publikationen von literarischen Texten, Memoiren und Dokumenten. Während die juristischen Zeitschriften wie „Juristische Chronik““ oder „Recht“ [Pravo] unmittelbar zum Ziel hatten, Rechtsbelange auch unter breiteren Schichten der gebildeten Bevölkerung populär zu machen, trug Koni mit seinen „Erinnerungen eines Gerichtstätigen“ in den „Russischen Altertümern“ auf seine Art und Weise gleichsam zu diesem Begehren bei.

Dabei gewann er als Hauptperson in seinen Erinnerungen an die Erfolge des reformierten Gerichtswesens nicht nur durch das gekonnte Agieren in den Geschichten alleine, sondern auch durch die wohlwollenden Beurteilungen Dritter an Gewicht. Gerne ließ Koni nämlich in seinen Erinnerungen Personen zu Wort kommen, die sich lobend über ihn äußerten, oder er nutzte sein eigenes Lob für einen Berufskollegen, um sich auch selber mit zu meinen. So schreibt er beispielsweise im Jubiläumsporträt über Konstantin Arsen'ev 1908 von einem Abend zu Ehren des 10. Geburtstages der Gerichtsreform, zu dem „neben den Verfassern der Reform nur zwei junge Juristen eingeladen waren, in denen die edlen Teilnehmer der „Großen Reformen“ Geistesgenossen und praktische Fortsetzer ihrer Tätigkeit sahen: es sind dies Arsen’ev und der Verfasser dieser Strophen“. ${ }^{\text {“264 In }}$ der Erinnerung an den Prozess gegen die französische Gouvernante „Margarita Žjužan“, die der Vergiftung ihres Zöglings beschuldigt wurde, fügt Koni zum Schluss des Textes ein Briefzitat ein, in dem er selber für seine Prozessführung in den höchsten Tönen gelobt wird. ${ }^{265}$ Im Artikel zu den „Zivilen Fällen“ erwähnt er einen langjährigen Juristenkollegen und Studiengenossen, der nach der Lektüre

263 Liessem: Autonomie in der Autokratie?, S. 261-62. In „Recht“ [Pravo] kamen neben dem Establishment auch oppositionelle Gruppen wie Marxisten oder Narodniki zu Wort, so dass die Zeitung immer wieder in Konflikt mit der Zensur lag, sich dafür aber großer Beliebtheit erfreute. Koni veröffentlichte darin zahlreiche seiner Nachrufe auf Juristen.

264 Koni: Konstantin Konstantinovič Arsen’ev. In: RS 2 (1908), S. 252-53.

265 Anatolij F. Konı: Margarita Žjužan. Iz predsedatel'skoj praktiki. In: ders. (Hrsg.): Na žiznennom puti, Bd. 1. Iz zapisok sudebnogo dejatelja, žitejskie vstreči. Sankt-Peterburg 1912, S. 305 . 
einer umfangreichen Fallbeurteilung von Koni vollends überzeugt von dessen Fähigkeiten auch im zivilrechtlichen Bereich zu sein scheint. ${ }^{266}$ Und im Fall des Offiziers „Karl Landsberg“, der sich des Mordes schuldig gemacht hatte, berichtet Koni davon, wie ein Zeuge sich ausgesprochen wohlwollend und voll „aufrichtigem Respekt für das Gericht“ gezeigt habe aufgrund von Konis Führung des Falles. Dabei handelte es sich um niemand Geringeres als den „sich temporär in St. Petersburg aufhaltenden Generalgouverneur von Turkestan, General-Adjutant Konstantin Petrovič fon-Kaufman“ ${ }^{267}$ Koni versuchte offensichtlich mit solchen Zitaten aus Dokumenten und Aussagen von Dritten ein Stück weit Objektivität zu generieren. So, als sei die Information neutral und nicht durch seine Einfügung in der eigenen Erinnerung gefiltert. Durch diese „,autobiografische Lücke“ lassen sich auch Sachen glaubhaft versichern, die man als Autobiograf lieber nicht in der Ich-Form formulieren möchte. ${ }^{268}$

Nichts aber trug so stark zu einer Hervorhebung von Koni bei, wie seine Angewohnheit, auch in der Erinnerungsreihe für die Zeitschrift „Russische Altertümer" [Russkaja Starina] andere Juristen zu porträtieren. Wie schon in den klassischen biografischen Porträts übte er sich unentwegt in der Rolle des Richters über den Grad an „Edlem“, den seine Berufskollegen besaßen. So wird beispielsweise der Staatsanwalt, der sich mit der fälschlicherweise für geisteskrank befundenen Frau auseinandersetzen muss, von Koni im Erinnerungstext auf über einer Seite als „einer der edelsten Vertreter der Gerichtsbehörde“ geschildert. ${ }^{269}$ In den CharkowErinnerungen wird der Gerichtsmediziner Dušan Fëdorovič Ljambl’ als „lieber, äußerst gelehrter und origineller Freund“ porträtiert. ${ }^{270}$ In den „Zivilen Fällen“ sind es die „Zivilisten-Praktiker“, an die sich Koni „mit dem Gefühl aufrichtigen

266 Anatolij F. Koni: Graždanskie dela. In: ders. (Hrsg.): Na žiznennom puti, Bd. 1. Iz zapisok sudebnogo dejatelja. Revel', Berlin 192(2/4?), S. 465-66 (4., überarbeitete Auflage).

267 Anatolij F. Koni: Landsberg. Iz predsedatel'skoj praktiki. In: ders. (Hrsg.): Na žiznennom puti, Bd. 1. Iz zapisok sudebnogo dejatelja, žitejskie vstreči. Sankt-Peterburg 1912, S. 278 und 266.

268 Hülya Adak hat den Begriff „autobiographical void“ in Ergänzung zu Philippe Lejeunes „autobiografischem Pakt“ geprägt und meint damit die Lücke, die entsteht, wenn die zwischen Autorschaft und Erzähler vorhandene Ineinssetzung ignoriert wird, vgl.: Hülya ADAK: Identifying the „Internal Tumors“ of World War I. Talat Paşa's Memoirs, or the Travels of a Unionist Apologia into „History“. In: Andreas Bähr/Peter Burschel/Gabriele Jancke (Hrsg.): Räume des Selbst. Selbstzeugnisforschung transkulturell. Köln u. a. 2007, S. $153 \mathrm{ff}$.

269 KonI: Iz zametok i vospominanij sudebnogo dejatelja. I. Osvidetel'stvovanie duševnobol'nych (1870-1895). In: RS 2 (1907), S. 270-71.

270 Anatolij F. Koni: Iz char'kovskich vospominanij. In: ders. (Hrsg.): Na žiznennom puti, Bd. 1. Iz zapisok sudebnogo dejatelja, žitejskie vstreči. Sankt-Peterburg 1912, S. 32. 
Respekts" erinnert und die er den Lesern in der Folge vorstellt. ${ }^{271}$ Es liegt nahe, dass dieses omnipräsente Biografieren und Bewerten den Autor selber in die Rolle des tadellosen Vorzeigeexemplars des „edlen“ Juristen beförderte, von dem er so gerne schrieb. Wie stark Koni selber aus dem Selbstverständnis heraus agierte, nicht nur ein vorbildhafter Jurist zu sein, sondern auch das Ausmaß des Engagements seiner Kollegen bewerten zu dürfen, zeigt eine kleine Anekdote, die er selber anführt. In einer Diskussion am Kriminalkassationsgericht sei er mit den Ansichten der anderen Senatoren nicht einverstanden gewesen und habe deshalb betont, „dass es in Russland noch Gerichtsstatuten gebe“. Daraufhin sei einer seiner Kollegen - in der Optik Konis unerklärlicherweise - beleidigt gewesen und habe gemeint, er achte schließlich diese Gerichtsstatuten „nicht weniger als Senator Koni “ ${ }^{272}$ Offensichtlich enthielt Konis Rhetorik Elemente, die geradezu für eine Monopolisierung der „Treue“ zur Gerichtsreform sorgten. Seine eigene Person als eine Art Idealvertreter seiner Zunft zu positionieren, war aber keineswegs ein Prozess, der nur von Koni ausgegangen wäre. Vielmehr zeigt der Blick auf den Schreibkontext und die Rezeption von Konis autobiografischen und biografischen Werken, dass eine Wechselwirkung aus Selbstdarstellung und Fremdwahrnehmung ihn mehr und mehr zum Paradebeispiel des „edlen“ Juristen und zur charismatischen Führungspersönlichkeit für seine Berufskollegen machte.

\section{Charismatisierung des Biografen}

Der Titel von den „Vätern und Söhnen der Gerichtsreform“ macht es einfach, von der biografischen Zuschreibung an die Porträtierten auf die Rolle des Autors zu schließen. Es war aber der Verlag, der diesen Link gleich zu Beginn von Konis Skizzenband zum 50. Jubiläum der Gerichtsreform offensiv propagierte. So schrieb der Herausgeber in einer Vorbemerkung, er habe es für richtig gehalten, in den Jubiläumsband neben den Fotografien der skizzierten Juristen auch das Fotoporträt des Autors zu integrieren. ${ }^{273}$ Tatsächlich enthält das Buch über 25 großformatige schwarz-weiße Fotografien der beschriebenen Personen, die jeweils mit einem Deckblatt geschützt sind. Und nach dem letzten biografischen Porträt des Bandes ziert eine ganzseitige Fotografie von Anatolij Koni das Werk. Dieser sitzt auf einem Stuhl und hält den Kopf nachdenklich auf seine Hand ge-

271 KonI: Graždanskie dela. In: ders. (Hrsg.): Na žiznennom puti, Bd. 1, 1922, S. 466 ff (4., überarbeitete Auflage).

272 Anatolij F. Koni: Triumviry. In: GA2, S. 305. Zu diesem autobiografischen Text ausführlich in TEIL ZWEI.

273 Koni (Hrsg.): Otcy i deti sudebnoj reformy („Ot izdatelja“). 
stützt. ${ }^{274}$ Koni greift so textuell zu Beginn und visuell zum Schluss als Klammer um all die dazwischenliegenden „Väter und Söhne der Gerichtsreform“. Verlag hatte wohl nicht zuletzt selber ein Interesse daran, ihn im Werk als eine Art „Übervater" seiner Zunft zu positionieren. Der Jubiläumsband erschien bei der äußerst erfolgreichen Sytin'schen Verlagsgenossenschaft, die 1914 für etwa einen Viertel der gesamten russischsprachigen Buchproduktion zuständig war. ${ }^{276} \mathrm{Koni}$ hatte schon in den Jahren vor dem 50. Jubiläum der Reform mit Sytin im Rahmen seiner Memoirenbände "Auf dem Lebensweg“ zusammengearbeitet, deren großer Erfolg den Verleger dazu bewogen hatte, weitere Auflagen zu initiieren. ${ }^{277}$ Auch zahlreiche Artikel von Koni erschienen in Zeitschriften, die im Besitz des Verlagshauses waren. Neben der Promotion dieses gewichtigen Autors gehörten für Sytin Werke wie der Jubiläumsband zur Gerichtsreform grundsätzlich zur zentralen Werbestrategie seines Unternehmens. Gleich mehrfach hatte er Prachtausgaben zu wichtigen historischen Jubiläen produziert, wie zum Beispiel 1912 ein Werk zur Erinnerung an den napoleonischen Feldzug gegen Russland von vor 100 Jahren oder 1911 das sechsbändige Werk „Die Große Reform“, mit der die Aufhebung der Leibeigenschaft ein halbes Jahrhundert zuvor gefeiert werden sollte und schließlich 1913 ein weiteres sechsbändiges Monument zum 300-JahrJubiläum der Romanov-Zarendynastie. ${ }^{278}$

274 Koni (Hrsg.): Otcy i deti sudebnoj reformy, zwischen S. 18 und 19 des Nachwortes. Vgl. die Abbildung auf dem Umschlag dieses Buches.

275 Zusätzlich erscheint Koni auch auf einer Gruppenaufnahme, die das Aufgebot des Charkower Bezirksgerichtes 1867 zeigt, ebd., zwischen S. 282 und 283 sowie auf einer Gruppenaufnahme der Staatsanwälte am St. Petersburger Bezirksgericht zu Beginn der 187oer-Jahre, ebd., zwischen S. 276 und 277.

276 Karl SChlö GeL: Petersburg. Das Laboratorium der Moderne 1909-1921. München 2002, S. 272. Vgl. zu Sytin und seinem Verlag Charles Ruud: Russian Entrepreneur Publisher Ivan Sytin of Moscow, 1851-1934. Montreal Quebec 1990.

277 T. I. Lysenko: O perepiske A. F. Koni s A. A. Šachmatovym. In: Archeografičeskij ežegodnik za 1979 god. Moskva 1981, S. 281. 1913 berichtete Koni in einem Brief vom großen Erfolg der beiden Bände, der Herausgabe des ersten Bandes in einer 2. Auflage und dem Vorschlag von Sytin, noch eine weitere Ausgabe, wohl für den zweiten Band, vorzubereiten. Vgl. auch A. Izmajlov: Rezension über Anatolij F. Koni, Na žiznennom puti, Bd. 2 (1912). In: $\mathrm{PkN}_{3}$ September - Dezember (1912), S. 681-84. Izmajlov schreibt in seiner Rezension, dass der erste „Auf dem Lebensweg“-Band mit einer Auflage von 6.0oo Exemplaren innerhalb weniger Monate ausverkauft gewesen sei.

278 Schlögel: Petersburg, S. 271 und Wortman: Scenarios of Power, Bd. 2, S. 421. Vgl. A. K. Dživelegov/S. P. Mel'Gunov/V. I. Pičet (Hrsg.): Otečestvennaja vojna i russkoe obščestvo. 1812-1912, 7 Bände. Moskva 1912; dies. (Hrsg.): Velikaja Reforma. Russkoe obščestvo i krest囚janskij vopros v prošlom i nastojaščem, 6 Bände. Moskva 1911; Vladimir V. Kallaš (Hrsg.): Tri veka. Rossija ot smuty do našego vremeni, 6 Bände. Moskva 1912/13. 
Während die Regierung versuchte, mit solchen historischen Jubiläumsfeierlichkeiten die Verbindung zwischen dem amtierenden Zaren Nikolaus II. und der Bevölkerung zu stärken, standen für Sytin die Zurschaustellung der technischen Fertigkeiten seiner Druckereien im Vordergrund. ${ }^{279}$ Nichts konnte diese so gut unter Beweis stellen, wie die aufwendigen Jubiläumsproduktionen, in denen die feinsten Materialien verarbeitet waren, Papier von bester Qualität, farbige, von Hand eingeklebte Lithografien und zahlreiche Fotografien. ${ }^{280}$

Der auffällige Fokus Sytins auf Bilder - seien es Fotografien oder Lithografien - diente allerdings nicht nur dem Zweck, die moderne Technik seiner Verlagsgenossenschaft zu belegen. Schon früh hatte Sytin erkannt, wie zentral Produktion und Verkauf von Bildern waren. Günstige lithografische Drucke gehörten in den 1870ern und 188oern zu seiner ersten Handelsware und bald verkaufte er Bilderbögen [Lubki] oder Kalender in großer Zahl. ${ }^{281}$ Während sich später von Heiligenlegenden über Traumbücher bis zu zahlreichen Zeitschriften, Zeitungen und Schulmaterialien diverse Produkte zu seinem Portfolio hinzugesellten, blieb das Bild immer von herausragender Bedeutung in Sytins Publikationsstrategie. ${ }^{282}$ Diese besagte, gleichzeitig billigere und niveauvollere Bücher für die große Masse zu produzieren. Bilder, beispielsweise in Form von Kalendern, übernahmen im Rahmen dieser Strategie eine „Kulturfunktion“, die das Sytin'sche Verlagswesen in eine „umfassende Alphabetisierungs- und Aufklärungskampagne“ verwandelte. ${ }^{283}$ Der demokratische Aspekt der Ausbreitung von Buch und Bildung war für Sytin - eng verbunden mit finanziellen Erwägungen - ein gewichtiger Motor seines Tuns. ${ }^{284}$ Dass in einem Land, in welchem zwar der Markt für Druckerzeugnisse

279 Vgl. zur Strategie der Regierung hinsichtlich solcher Jubiläen Wortman: Scenarios of Power, Bd. 2, S. 421.

280 RuUd: Russian Entrepreneur Publisher Ivan Sytin of Moscow, 1851-1934, S. 158 bezogen auf die Spezialausgabe „Ein halbes Jahrhundert für das Buch“ von 1916, mit der Sytin sein eigenes Jubiläum feierte. Schlögel: Petersburg, S. 259 beschreibt, wie an Sytins 50. Verlagsjubiläum jeder Schriftsteller oder Publizist, der etwas auf sich hielt, mit dem so erfolgreichen Verleger mitfeiern wollte. Auch Koni scheint zu dieser Gelegenheit einen Artikel verfasst zu haben, vgl. die Abschrift davon in IRLI F. 134, op. 15, d. 17, 1. 320b-1. 34. Vgl. für Briefe zwischen Koni und Sytin GARF F. 564, op. 1, d. 3360.

281 RuUd: Russian Entrepreneur Publisher Ivan Sytin of Moscow, 1851-1934, S. 24, 26 und 29. Vgl. zur Entwicklung der Drucktechniken von Fotografien Marina P. MochnačEva/Anna KASK (Hrsg.): Russkij illjustrirovannyj žurnal. 1703-1941. Moskva 2006, S. 16-34.

282 SChlÖgel: Petersburg, S. 270 und 272-73 und RuUd: Russian Entrepreneur Publisher Ivan Sytin of Moscow, 1851-1934, S. 29.

283 Ruud: Russian Entrepreneur Publisher Ivan Sytin of Moscow, 1851-1934, S. 106 und SCHLÖGEL: Petersburg, S. 266, 268 und 283.

284 RuUd: Russian Entrepreneur Publisher Ivan Sytin of Moscow, 1851-1934, S. 10 und SCHLÖGEL: Petersburg, ausführlich S. $267 \mathrm{ff}$. 
um die Jahrhundertwende explodierte, aber immer noch nur $34 \%$ der Männer und $14 \%$ der Frauen lesen und schreiben konnten, Bilder einen speziell wichtigen Stellenwert hatten, liegt auf der Hand. ${ }^{285}$ Wie sehr „das Bild das Buch trug ${ }^{\prime 286}$ und damit eine eingängigere Botschaft vermitteln konnte als es bei reinem Text der Fall wäre, schien auch Koni schon früh bewusst gewesen zu sein. Bereits Ende der 186oer-Jahre hat er damit begonnen, Porträtabbildungen von wichtigen Juristen zu sammeln. Manche davon wurden ihm mit einer persönlichen Widmung versehen geschenkt. Koni hat diese Sammlung mit den Worten „Wahrhaftige Väter und Söhne der Gerichtsreform " [Podlinnye otcy i deti sudebnoj reformy] beschriftet. ${ }^{287}$ Genau diese Bilder waren es auch, die Sytin schließlich im fast gleichnamigen Sammelband abdruckte. Obwohl die Sammlung bereits Jahrzehnte alt war, eignete sie sich auch 1914 noch ausgezeichnet zur Bebilderung der biografischen Skizzen. Die „Physiognomie des Bürgers“, die sich in den Porträtaufnahmen von Rovinskij, Spasovič oder Urusov zeigte, war nicht nur in Pose und Dekoration untereinander identisch. ${ }^{28}$ Auch fehlten solchen Studioporträts jegliche Merkmale von Ort und Zeit. ${ }^{289}$ Sich porträtieren zu lassen oder Visitbilder von Berühmtheiten aus allen Sparten zu sammeln, erfreute sich nicht nur in Russland seit der zweiten Hälfte des 19. Jahrhunderts großer Beliebtheit. Die vereinfachte Herstellung und der günstigere Preis solcher Bilder mündeten in Paris schon um 1860 in ersten Steckalben. ${ }^{290}$ In Russland waren Bildersammlungen der kultisch verehrten Helden der radikalen oppositionellen Bewegungen besonders begehrt unter der Intelligencija. Im Genfer Exil erschien gar ein „Kalender“ mit Bildern

285 SCHLÖGEL: Petersburg, S. 266.

286 Ruud: Russian Entrepreneur Publisher Ivan Sytin of Moscow, 1851-1934, S. 29.

287 Vgl.: IRLI F. 134, Op. 15, d. 47. Die hochwertigen Abzüge in Konis Sammlung sind mit der Firmenaufschrift des Fotografen versehen und oft auch datiert. Der Sammelzeitraum erstreckt sich über mehrere Jahrzehnte.

288 Timm Starl: Im Prisma des Fortschritts. Zur Fotografie des 19. Jahrhunderts. Marburg 1991, S. 26-27.

289 Christopher Stolarski: Another Way of Telling the News. The Rise of Photojournalism in Russia, 1900-1914. In: Kritika: Explorations in Russian and Eurasian History 3 (2011), S. 573. Es ist der Verlag selber, der im Falle von Konis Sammelband darauf hinweist, dass die Bilder fast ausschließlich in der zweiten Hälfte der 186oer- und der ersten Hälfte der 1870er-Jahre aufgenommen worden seien, vgl. KonI (Hrsg.): Otcy i deti sudebnoj reformy („Ot izdatelja").

290 Starl: Im Prisma des Fortschritts, S. 26 und 45. Dabei konnte sich zu dieser Zeit nach wie vor der überwiegende Teil der Bevölkerung solche Porträts nicht leisten. Aber neben wirklich mächtigen Finanzaristokraten, Prominenten oder Repräsentanten der regierenden Häuser ließen sich doch immer mehr Bürger zu Atelierbesuchen verführen, wo die vermeintliche Zugehörigkeit zur tonangebenden Klasse mit einem Bild, das „symbolische Gleichheit“ verkündete, unterstrichen werden konnte. Vgl. ebd., S. 29. 
von Revolutionären - auch Vera Zasulič fehlte nicht. ${ }^{291}$ Das Porträtbild konnte nun als physisches Artefakt und Beweis eigener Loyalität und Überzeugung gesammelt und gruppiert werden. Umgekehrt war nach der Aufkündigung solcher Loyalität auch die Zerstörung des Fotos oder Drucks ein möglicher symbolischer Akt. So berichtet Turgenev, dass er im Aufruhr nach seinem Roman über die „Väter und Söhne" Berichte von jungen Menschen erhalten habe, die sein Foto unter Gelächter verbrennen würden. ${ }^{292}$ Während es in revolutionären Kreisen also Mode war, Fotoporträts von Attentätern, Terroristen oder Schriftstellern zu sammeln, schuf Koni eine bildliche Zusammenstellung von Juristen, die die „wahrhaftigen“ Grundwerte der Profession besonders gut transportieren sollten. Diese Bilder dienten denn folglich im Wortsinne als „Vor"bilder. Die Abzüge sollten weniger ein „Nachbild“ der konkreten Person in ihrer individuellen Eigenheit darstellen. Vielmehr stellten die „Bilder“ eine Zukunft „vor“ - immer auf der Suche nach dem Ideal. ${ }^{293}$ Überzeugt von der visuellen Wirkungskraft nutzte Koni seine Bildersammlung denn nicht nur für den Sammelband zum Justizjubiläum, sondern stellte sie auch für diverse andere Publikationen zur Verfügung. ${ }^{294}$

In Sytins Band wurde mit dem Fotoporträt des nachdenklichen Anatolij Koni dem Reigen der „Väter und Söhne der Gerichtsreform“ ein bildlicher Höhepunkt aufgesetzt. Endgültig selber zum besonders wertvollen Element in dieser Generationenkette wurde Koni aber schließlich in der sprachlichen Übernahme des Motivs durch andere Akteure aus dem Justizwesen. Ein anonym bleibender Jurist, der von sich selber lediglich schreibt, dass er aus der Provinz stamme, verfasste ein in mehreren Auflagen veröffentlichtes Büchlein mit dem Titel: „Zum fünfzigsten

291 Stephan Rindisbacher: Leben für die Sache. Vera Figner, Vera Zasulič und das radikale Milieu im späten Zarenreich. Wiesbaden 2014, S. 210-11, mit Abbildungen. Rindlisbacher schreibt, dass mit diesem „Kalender von Narodnaja Volja“ [Kalendar’ Narodnoj Voli] die „kanonischen Märtyrer der Radikalen“ festgehalten und das „Verlangen vieler Sympathisanten nach Bildern ihrer ,Helden“" gestillt werden konnte.

292 BERLin: Fathers and Children, S. 31.

293 Vgl. die Gedanken zu „Nachbilder oder Vorbilder“ bei Thomas Масно: Vorbilder. Paderborn 2011, S. 82 und in der Rezension dazu von Patrick Merziger: Rezension über Thomas Macho, Vorbilder (Paderborn 2011). In: H-Soz-Kult, 22.10. 2013, www.hsozkult. de/publicationreview/id/rezbuecher-17121, Zugriff vom 24.10. 2016.

294 Vgl. den Brief von Koni an Arsen'ev bezüglich dessen Sammelband zum 40. Jubiläum der Gerichtsreform, für den Koni nicht nur biografische Skizzen verfasste, sondern auch seine Abbildungen von Rovinskij, Zarudnyj und Stojanovskij anbot. Im Brief unterstrich er, dass diese sehr sorgfältig zu behandeln und schnellstmöglich wieder zu retournieren seien, da vor allem das Porträt von Rovinskij eine für Koni sehr wertvolle Unterschrift enthalte, vgl. GA8, S. 203-04 (Brief an K. K. Arsen'ev vom 04. 02.1904). Vgl. auch die Aussage von Konis alter Freundin Ponomareva, dass er die Sammlung seiner Porträts und Gravuren allen zur Verfügung gestellt habe, GARF F. 564, op. 1, d. 4208, 1. 2. 
Jubiläum des Geschworenengerichts. Aus Anlass des Buches von A. F. Koni, Väter und Söhne der Gerichtsreform“". Gleich zu Beginn nennt er seine Beweggründe für diese Publikation. Er wolle einerseits durch das Spenden der Einnahmen aus dem Verkauf einen Beitrag für die Familien der Kriegsopfer sammeln. Andererseits wolle er unbedingt empfehlen, dass „Anfänger im Gerichtswesen“ sich sehr eingänglich mit allen gedruckten Werken von A. F. Koni beschäftigten, die „Quelle des Wissens, der Stärke und des Lebensmuts" auf dem "Gerichtsweg“ seien. ${ }^{295}$ Das Büchlein ist denn folglich auch den „Anfängern im Gerichtswesen“ gewidmet und besteht aus gedichteter Beschreibung der Gerichtsreform, wichtiger Juristen und eigener Erlebnisse des Autors mit dem Geschworenengericht. Zudem sind einige Fotografien abgedruckt - auch eine Aufnahme von Koni. Zuerst kommt die Rede aber auf die Reformer, zu denen es heißt: „O nich jurist mastity - Koni; nedavno knigu padaril; i siloj razuma i voli; ich dlja potomstva voskresil“ [Ihnen hat der gestandene Jurist - Koni; vor Kurzem ein Buch gewidmet; und mit der Kraft von Geist und Willen; sie für die Nachkommenschaft auferweckt]. ${ }^{296}$ Konkret verweist der Autor in der Folge auf die Vorbildhaftigkeit der von Koni Porträtierten, sie würden einem die Kraft zum Leben und Arbeiten und Antworten auf viele Probleme geben. Weiter hält er die jungen Juristen dazu an, „die Ratschläge Konis zu befolgen; aus den Prozessen zu lernen; und [...] in den Fällen nur die Wahrheit zu suchen ${ }^{\text {“ }}{ }^{297}$ In ganz ähnlicher Manier nimmt ein weiterer Jurist Konis Werk auf und macht ihn zum Beispiel für die Berufskollegen. In einer Broschüre zum 50. Geburtstag der Reform mit dem Titel „Die Gerichtsreform dargestellt durch ihre Akteure“ werden die „Persönlichkeiten der Väter wie Zarudnyj, Stojanovskij, Arcimovič“ beschrieben und Konis „Väter und Söhne“ erwähnt. ${ }^{298}$ Es ist die Rede von der „Pflicht“, sich an diese Kämpfer für die Reform zu erinnern. Und schließlich werden - basierend auf Konis Sammelband - ausführlich die Charakteristiken dieser Personen dargelegt. ${ }^{299}$ Dann folgt ein Hinweis, dass zum Schluss des Jubiläumsbandes das fotografische „Porträt des Erstellers“ zu sehen sei, und ebendies wird zum Anlass genommen, nun über Konis Leben zu berichten. Seine „Virtuosität“, sein Wissen, sein Charakter werden gelobt und ihm wird eine zentrale historische Rolle im „Schicksal unserer Justiz“ zugeschrieben. Koni

295 F. S.: K pjatidesjatiletiju suda prisjažnych. Po povodu knigi A. F. Koni „Otcy i deti sudebnoj reformy“. Moskva 1915 (Vorwort).

296 F. S.: K pjatidesjatiletiju suda prisjažnych, S. 9.

297 Ebd., S. 16-17.

298 I. A. Chmel'nicкij: Sudebnaja Reforma v eë dejateljach. K 50-letiju „Sudebnych Ustavov“. Odessa 1915, S. 8 ff. Diese Arbeit war von Chmel'nickij laut eigenen Angaben zuerst mündlich an verschiedenen Orten vorgetragen worden.

299 Ebd., S. 9 ff. 
habe jede Gelegenheit genutzt, um seine „autoritätsvolle Stimme zur Verteidigung der Immunität der Gerichtsreform " zu erheben. ${ }^{300}$ Und schließlich werden Konis Sammelbände mit seinen Erinnerungen und Porträts „heiß zur Beachtung“ empfohlen. Konis Werk und er selber seien „Synonym für Licht, Schönheit und Streben zum Großen“. Der Wunsch an die „junge, wachsende Generation von Gerichtstätigen“ sei deshalb: „Seid wie Anatolij Fëdorovič Koni!“‘301

In Selbst- und Fremddarstellung wird so das Bild der generationellen Weitergabe der Grundlagen der Profession insbesondere zum 50. Jubiläum der Reform festgeschrieben und Koni eine Hauptrolle darin zugedacht. Das Redaktionskomitee des Journals „Rechtswissenschaft“ schrieb Koni 1914 gar, dass er „jedem Juristen und vor allem den jungen Gerichtstätigen“ teuer sei, und bittet darum, ihn pro forma unter den Mitarbeitern der Zeitschrift aufzählen zu dürfen, weil man ohne seinen Namen nur schwer auskommen könne. Dies, obwohl Koni der Zeitschrift hinsichtlich seiner Mitarbeit bereits eine abschlägige Antwort erteilt hatte. ${ }^{302}$ Wie erfolgreich Koni nach der Jahrhundertwende mehr und mehr zur „charismatischen“ Figur wurde, die er selber in seinen Porträts so oft skizzierte, zeigt weiter auch der Blick auf die Glückwunschtelegramme, die er sowohl zum 50. Jubiläum der Gerichtsreform 1914 als auch zum 50. Jubiläum seiner persönlichen Dienstkarriere 1915 bekam. Darin wird er nicht zuletzt dadurch zur Ikone stilisiert, dass die gleichen Begriffe, die er für die Beschreibung des professionellen, "edlen" Juristen etabliert hatte, auf ihn selber angewandt werden. Was indirekt also in Konis Porträtpraxis immer mitschwang - die Selbstdarstellung in der Biografik -, wird so explizit. Es ist die Rede von der „edlen Sache“ und von Koni als „Kämpfer für die Reinheit [...] der Gerichtsstatuten“; als „heiligem Ritter“ wird ihm alles Gute gewünscht; ihm wird als „Vater der Gerichtsreform ${ }^{\text {“303 }}$ von einem "Stiefsohn der Advokatur" gratuliert; bezogen auf die Gerichtsstatuten nennt man ihn „deren lebendige Verkörperung “. ${ }^{\text {"304 }}$ In Reden und Zeitungsartikeln heißt es,

\footnotetext{
300 Ebd., S. 28-31.

301 Ebd., S. 33-34.

302 GARF F. 564, op. 1, d. 246, 1. 14.

303 Wenn Koni hier selber als „Vater der Gerichtsreform“ bezeichnet wird, entspricht dies nicht seiner eigenen Definition der Generationenfolge, vgl. oben, S. 75. Da er den Dienst bereits in den reformierten Gerichten begonnen hatte, wäre Koni eigentlich ein „Sohn“. Die Metapher ist also instabil, allerdings macht es aus Sicht der um die Jahrhundertwende nachfolgenden deutlich jüngeren Juristen durchaus Sinn, Koni als ihren „Vater“ zu sehen.

304 Vgl. dazu die gesammelten Telegramme zum 50. Jubiläum der Gerichtsreform an Koni, die er in seinem Nachlass aufbewahrte, zusammengebunden von einem blauen Band mit dem Aufdruck: „Heil dem Beschützer der Statuten von Alexander II.“. GARF F. 564, op. 1, d. 5. In der Reihenfolge der Zitate: 1. 1-2; 1. 4; 1. 26; 1. 37; 1. 38 .
} 
er sei der „unvoreingenommene Richter“ und „Diener der Justiz“305 und habe 50 Jahre wie „ein alter Ritter“ gedient. ${ }^{306}$ In einer Wechselwirkung rückt nun in den Beschreibungen von Koni auch seine eigene Porträtpraxis als wesentlicher Beitrag zur Formung von professionellen Werten immer mehr in den Vordergrund. Seine Position in der Berufsgruppe und der Beweggrund, ihn als Vorbild zu empfehlen, werden direkt mit seinem biografischen Engagement verknüpft. 1889 waren zur Charakterisierung des Juristen noch fast ausschließlich wissenschaftliche Kriterien von Relevanz gewesen. Die Universität Charkow verlieh Koni damals einen Ehrendoktortitel anlässlich der Herausgabe seiner gesammelten Gerichtsreden. ${ }^{307}$ In einer Würdigung an der juristischen Fakultät der Universität sprach man von den „wissenschaftlichen Erkenntnissen und Überlegungen“, die in den Reden Konis verarbeitet seien. Die „objektive Anleitung der Geschworenen“ in seiner Funktion als Gerichtsvorsitzender wurde lobend erwähnt. Wann immer der Redner auf publizistisches Schaffen Konis verwies, das nicht direkt mit seiner Berufsausübung zusammenhing, verwies er auch dort auf die „tiefen wissenschaftlichen Überlegungen“ ${ }^{308}$ Ein gutes Jahrzehnt später ehrte der Anwalt und Publizist Michail Ignat'evič Kulišer (1847-1919) auf einer „Konferenz der Anwaltsgehilfen“ Koni mit einem bald auch veröffentlichten Vortrag „35 Jahre Tätigkeit von A. F. Koni“. Bereits ganz zu Beginn nennt er nun offensiv als Feld dieser Tätigkeit nicht mehr nur das „Gericht“, sondern auch die „Biografie“. Wenn man die Kassationsentscheide und einige juristischen Texte weglasse, dann sei alles, was Koni schreibe, Biografie. Natürlich widmete auch Kulišer sich ausführlich Konis „nie einseitigen“ Anklagereden und betont seine „Objektivität“. Aber auch wenn es sich um Gerichtsreden handle, seien diese biografischer Natur. Koni sei immer an der Verbundenheit zwischen Persönlichkeit und gesellschaftlichen Bedingungen interessiert, ja er sei ein „Biograf aus Berufung“. ${ }^{309}$ Dann folgt ein ausführlicher Absatz unmittelbar zu Konis biografischen Skizzen. Kulišer weist darauf hin, dass vor allem in den letzten zehn Jahren zahlreiche Porträts von Koni über Juristen erschienen seien, wie jene über Rovinskij oder Stojanovskij, so dass mittlerweile

305 P. Voronov: Anatolij Fëdorovič Koni. K 5o-letiju ego literaturnoj i obščestvennoj dejatel'nosti, 30 sentjabrja 1865-1915 gg. Petrograd 1915, S. II. Ebenfalls veröffentlicht in RS 1915.

306 Aus einer Rede, die 1915 gehalten wurde. Zitiert nach: N. N. Poljanskij: A. F. Koni. In: ders./B. I. Syromjatnikov (Hrsg.): Na službe pravu. a. F. Koni. Moskva 1928, S. 23.

307 M. A. BAlYšev/A. A. Šandula: Anatolij Fëdorovič Koni i char'kovčane. O novych faktach iz žizni izvestnogo russkogo jurista. In: Universitates. Nauka i prosveščenie 3 (2007), S. 33 .

308 L. E. Vladimirov: Russkij sudebnyj orator A. F. Koni. Char'kov 1889. Hier zitiert nach: GARF F. 564, op. 1, d. 4196, 1. 3, 3ob ff, 8 ob.

309 M. I. KulišER: 35-letie dejatel'nosti A. F. Koni. In: VP 10 (1901), S. 172-76. 
die „ganze Zeit der Reformen“ von Koni abgedeckt sei. ${ }^{310}$ Nochmals ein Jahrzehnt später reagierte der Belletrist und Literaturkritiker Aleksandr Alekseevič Izmajlov (1873-1921) auf Konis Herausgabe seines zweiten „Auf dem Lebensweg“-Bandes mit einer Rezension und lobte darin Konis gesammelte Werke in den höchsten Tönen. Er unterstrich die hohen Verkaufszahlen des ersten Bandes und zeigte sich auch vom zweiten Band mit seinen literarischen Porträts von Schriftstellern und Juristen sehr angetan. ${ }^{311}$ Auf das gleiche Buch antwortete auch der KriegsHistoriker und Geschäftsmann Aleksandr Nikolaevič Vitmer (1839-1916) mit einem Artikel im „Historischen Boten“. „Flüchtige Notizen und skizzenhafte Erinnerungen, hervorgerufen durch den zweiten Band ,Auf dem Lebensweg von A. F. Koni“ nennt er seinen Beitrag, in dem er das "große künstlerische Talent“ von Koni lobt und daraus folgert:

So ist die warme Rezeption völlig selbstverständlich, die der Autor der Gerichtsreden bekam, als er mit der Öffentlichkeit teilen wollte, was er gesehen, gehört hat und mit wem er in Kontakt war im Verlauf seines interessanten „Lebenswegs“. 312

Zum Schluss führt Vitmer eine kleine Anekdote an und berichtet, wie er einmal mit der Bitte um Korrekturen an einem seiner Manuskripte beim Verlag der „Russischen Altertümer"vorsprach. Dort habe man ihm gesagt, das sei kein Problem, er solle die Korrekturen sehen, die Koni jeweils an seinen Manuskripten vor deren Druck noch vornehme. Dieses Arbeiten an der Sprache, die künstlerische Form, die Koni sogar für seine beruflichen Reden benutze, all dies sei ein seltenes Beispiel, das „Nachahmung" verdiene. ${ }^{313}$

Das Erinnern von Erfolgsgeschichten aus früher Reformzeit und das Biografieren von Anwälten und Richtern wurden zu konstituierenden Merkmalen des Juristen Koni. Präsenz und Beliebtheit von seinen (auto-)biografischen Schriften zogen dabei immer neue Möglichkeiten für Publikationen nach sich. So finden sich in Konis Nachlass zahlreiche Briefe mit Anfragen verschiedenster Zeitungen, Zeitschriften und Verlage. Klassisch ist in dieser Hinsicht der Brief des Verlags „Sovremennye Problemy“ vom Dezember 1912. Man habe in der Zeitung „Russisches Wort“ Erinnerungsschriften von Koni gelesen und habe nun die Ehre zu fragen, ob Koni diese nach dem Abdruck in der Zeitung nicht vielleicht dem Verlag zur

\footnotetext{
310 Ebd., S. $177 \mathrm{ff}$.

311 Izmajlov: Rezension über Anatolij F. Koni, Na žiznennom puti, Bd. 2, S. 681-84.

312 A. Vitmer: Chudožnik slova i pera. Beglye zametki i otryvočnye vospominanija, vyzvannye vtorym tomom na „Žiznennom puti“ A. F. Koni. In: IV 8 (1913), S. 567.

313 Ebd., S. 577-79.
} 
Einzelherausgabe übergeben möchte? ${ }^{314} \mathrm{Gar}$ „zu einem beliebigen Thema“ solle Koni doch bitte einen Artikel schreiben - begehrte die Tageszeitung „Börsenanzeiger" im Oktober 1915 per Brief. Als Koni auf diesen Wunsch offensichtlich nicht reagierte, schickte das wirtschaftlich-literarische Blatt zwei Monate später erneut eine Anfrage um einen publizistischen Beitrag. Und wenig später wandte es sich mit der "riskanten Bitte" an Koni, trotz seiner Trauer einige Zeilen zum verstorbenen Rechtsgelehrten und Politiker Maksim Maksimovič Kovalevskij (1851-1916) zu verfassen. ${ }^{315}$ Eigentlich schon längst nicht mehr im aktiven Gerichtsdienst, beließ Koni sein Engagement für die Belange der Justiz nicht bei seinem Einsitz in Senat und Staatsrat. Rund um das 50. Jubiläum der Gerichtsreform wurde es zu seiner Hauptaufgabe, als Biograf eines juristischen Idealbildes und Mahner an Grundwerte des Rechtswesens zu agieren. In seiner Einleitung für die 1914/15 neu aufgelegte und kommentierte Strafprozessordnung nahm Koni diese Rolle par excellence ein. Während er eingestand, dass die Gerichtsreform von 1864 in der Praxis auf Umsetzungsprobleme gestoßen sei, was einige Anpassungen nötig gemacht habe, appellierte er gleichzeitig daran, Änderungen an den reformierten Gerichtsartikeln nur ,unter Berücksichtigung von Achtung und Aufmerksamkeit gegenüber den Arbeiten und Ratschlägen der Verfasser der Gerichtsstatuten“vorzunehmen, um die „wahrhaftige Rechtsprechung“ zu erhalten. ${ }^{316}$ Fast zeitgleich gab er nicht nur seinen eigenen Sammelband von den „Vätern und Söhnen“ heraus und wurde von der Juristischen Gesellschaft von St. Petersburg als einer der „herausragendsten“ Vertreter der Jurisprudenz zu einer möglichst „autoritätsvollen" Rede seiner Wahl an der Festsitzung aufgefordert, sondern beteiligte sich auch an weiteren Projekten zum Gedenken an Justiz und Reform. ${ }^{317}$ So arbeitete er mit an einem umfassenden, fünfbändigen Werk zur Neustrukturierung der Justiz nach 1864, dessen erster Band 1915 erschien. Darin wird schon im Vorwort auf Koni und seine Beschreibung der reformierten Gerichte Bezug genommen, und zudem darauf verwiesen, dass dieser als Autor für einen Artikel über die Prokuratur im projektierten dritten Band sowie als Verfasser von Biografien und Memoiren im geplanten fünften Band vorgesehen sei. ${ }^{318}$ Für das mehrbändige

314 GARF F. 564, op. 1, d. 246, 1. 12.

315 Ebd., 1. 22, 26, 31. Ob Koni schließlich doch noch einen Artikel eingesandt hat, bleibt offen. Sicher ist, dass er zu M. M. Kovalevskij 1916 u. a. einen Artikel im „Boten Europas“ veröffentlicht hat. Vgl. Angaben in Fußnote 36 in TEIL EINS.

316 Koni: Vvedenie k Sistematičeskomu Kommentariju U. U. S., S. 21 ff. Wie auf S. 92 bereits ausgeführt, verteidigte Koni insbesondere die Institution des Geschworenengerichts, an der man „ohne jeglichen realen Grund“ regelmäßig zweifeln würde, vgl. ebd., S. 25.

317 GARF F. 564, op. 1, d. 250, 1. 23-23ob.

318 N. V. Davydov/N. N. Poljanskij (Hrsg.): Sudebnaja reforma, Bd. 1. Moskva 1915, S. V und Schluss des Buches. Die Bände mit Konis Beiträgen wurden allerdings nicht realisiert. 
Werk „Geschichte der russischen Advokatur“, das die Moskauer und St. Petersburger Anwaltsräte zum Jubiläum planten, war auch ein Band mit Biografien der Advokaten vorgesehen. Einen Teil davon hätte - wie könnte es anders sein Koni verfassen sollen, doch die Arbeit wurde 1917 mit dem politischen Umsturz eingestellt. ${ }^{319}$ Wie Koni nun gemeinhin als eine Art Chronist der Gerichtsreform und ihrer Akteure wahrgenommen wurde, wird an den Plänen für die Feier des 100. Geburtstags des Reformzaren Alexander II. besonders deutlich. 1918 hätte dieser, wäre nicht ebenfalls das Revolutionsjahr in die Quere gekommen, festlich begangen werden sollen. Zwei Jahre vor dem projektierten Anlass traf sich die Historische Gesellschaft, um Pläne zu schmieden. Eingeladen wurde an die Sitzung - quasi als Experte für die Reformzeit - auch Anatolij Koni. Er schlug vor, zu Ehren des Zaren eine Prämie einzurichten für die besten wissenschaftlichen Arbeiten zu seiner Regierungszeit. ${ }^{320}$ Gleichzeitig stellte er sich zur Verfügung, um die allgemeinen Richtlinien für eine Reihe an historischen Skizzen zusammenzustellen, die in einem populärwissenschaftlichen Band zur Reformära herausgegeben werden sollten. Er selber wollte den Beitrag zur Gerichtsreform verschriftlichen. ${ }^{321}$ All dies lässt es nur als folgerichtig erscheinen, wenn Koni in einer Würdigung zu seinem 8o. Geburtstag 1924 „Historiker unseres Gerichts“ genannt wurde und eine aktuelle Monografie zu einem Juristen aus dem Zarenreich von ihm als „Historiker der Gerichtsreform“ spricht. ${ }^{322}$

\section{Fazit}

Die im Prozess gegen Vera Zasulič so traumatisch erfahrene mangelnde Einheit der Berufsgruppe wurde von Koni in seinen biografischen Porträts mit einer idealisierten Darstellung seiner Kollegen gekontert. Immer wieder war die Rede vom „Dienst“ für das Gesetz, von der großen Begabung im Umgang mit dem „lebendigen“ Wort, vom uneigennützigen, „edlen“ Einsatz für die Wahrheitsfindung, für

319 Troickij: Advokatura v Rossii i političeskie processy 1866-1904 gg., S. 11.

320 GARF F. 564, op. 1, d. 248, 1. 1ob. Einen solchen „Schreibanlass“ schuf Koni auch über sein Testament. 1916 hielt er fest, dass er der Juristischen Gesellschaft von St. Petersburg die Finanzen zukommen lassen wolle, damit diese eine Prämie für die beste Arbeit zur Geschichte der Gerichtsreform ausschreiben könne. Vgl. VysockiJ: Koni, S. 420-21. Da Koni aber erst über zehn Jahre später starb, hatte dieses Testament keine Bedeutung mehr. 321 GARF F. 564, op. 1, d. 248, 1. 10b-2ob.

322 Aleksandr A. Žıžılenko: A. F. Koni, kak kriminalist. In: Sergej F. Platonov/Sergej F. Ol'denburg u. a. (Hrsg.): Anatolij Fëdorovič Koni 1844-1924. Jubilejnyj sbornik. Leningrad 1925, S. 37 sowie Dmitrij M. LegkiJ: Dmitrij Vasil'evič Stasov. Sudebnaja reforma 1864 g. i formirovanie prisjažnoj advokatury v Rossijskoj Imperii. Sankt-Peterburg 2011, S. 246. 
die Gerechtigkeit, ja für die ganze „Gesellschaft“. Konstant wurde dazu der Bezug zur Gerichtsreform von 1864 und den darin involvierten Persönlichkeiten betont. Immer wieder drehten sich die biografischen Skizzen und Nachrufe um die Gerichtsstatuten, die in geradezu mythischer Art und Weise verklärt wurden. Das Verhältnis zur Reform wurde mit Begriffen wie „Treue“ und „Liebe“ umschrieben und die gemeinsame „Verteidigung" ihrer Grundzüge somit zur zentralen Aufgabe gemacht. Mit dieser Porträtierungspraxis, begleitet von der Veröffentlichung autobiografischer „Erfolgsgeschichten“ aus der Anfangszeit der Gerichte wurde Koni selber in einer Wechselwirkung aus Fremd- und Selbstzuschreibung zum Vorbild für zukünftige Juristen. In dieser „Charismatisierung“, der Etablierung eines "Generationennarrativs" und der Überhöhung des eigenen (Erziehungs-) Auftrags lassen sich gleichermaßen globale Elemente eines Professionalisierungsprozesses als auch spezifisch russische Anlehnungen an das Führungs- und Sendungsbewusstsein der Intelligencija und der "gesellschaftlichen Akteure“ erkennen. Der hohe Grad an Selbstreflexivität ist an sich ein typisches Charakteristikum professionellen Handelns. ${ }^{323}$ Abgestützt gleichsam durch die Tradition der „Erinnerungen der Zeitgenossen" in den russischen Intelligencija-Zirkeln wird das biografische und autobiografische Schreiben zu einem mächtigen Artikulator der Interessen der Berufsgruppe.

Gerade der hohe Grad an Idealisierung und Verherrlichung gewisser Elemente und Eigenschaften der neuen Gerichte und ihrer Akteure können allerdings auch als Schönreden wider besseres Wissen interpretiert werden. ${ }^{324}$ Tatsächlich ist die Stilisierung einzelner Führungspersönlichkeiten, um Zusammenhalt und Wirkungskraft zu propagieren, stetig mit der Gefahr konfrontiert, der professionellen Tätigkeit als „Typus hochgradig rationalen Handelns“ diametral entgegenzulaufen. ${ }^{325}$ Es gilt eine Balance zu finden zwischen der Entwicklung des Berufs zu einer

323 Margret Kraul/Winfried Marotzki/Cornelia Schweppe: Biographie und Profession. Eine Einleitung. In: dies. (Hrsg.): Biographie und Profession. Bad Heilbrunn Oberbayern 2002, S. 9 und Sabine Reh/Carla Schelle u. a.: Biographie und Professionalität. Die Reflexivität Berufsbiographischer Erzählungen. In: Johannes Bastian u. a. (Hrsg.): Professionalisierung im Lehrerberuf. Von der Kritik der Lehrerrolle zur pädagogischen Professionalität. Opladen 2000, S. 108.

324 Mit Erstaunen hält Wagner fest, dass auch noch zum 50. Jubiläum der Reform diese von progressiven Juristen wie Koni als Ideal angepriesen würde, obwohl sich die Erwartungen in sie keineswegs erfüllt hätten, vgl. WAGNER: Marriage, Property, and Law in Late Imperial Russia, S. 1.

325 Schaeffer: Psychotherapie zwischen Mythologisierung und Entzauberung, S. 72. Baberowski kritisiert, wie Koni und weitere liberale Juristen jede Veränderung am Geschworenengericht als Angriff auf den Rechtsstaat und Parteinahme für Despotie abgetan hätten. Weil man das Geschworenengericht für eine Art „konstitutionelles Verfassungsorgan in 
"bloßen Erwerbstätigkeit“ und dem Beibehalten einer übergeordneten „Berufung“, die die ethischen Grundregeln, die sich für Berufsbilder wie jenes der Ärzte oder Anwälte besonders aufdrängten, garantierten. Dies führt im besten Falle zu einer Art „Veralltäglichung der Prophetie“ “ ${ }^{326}$ Im Moment, als Koni und seine Kollegen immer stärker an ihrem Idealbild dieser „Prophetie“ bastelten, konnte man wohl ein Stück weit davon sprechen, dass sich auch die Justizberufe in Russland einige Jahrzehnte nach ihrer Schaffung nun in einer Phase der Konsolidierung hin zur etablierten „bloßen Erwerbstätigkeit“ befänden, die eine gewisse Rückbesinnung auf gloriose Anfänge und herausragende Exponenten der Zunft nötig machen würde. ${ }^{327} \mathrm{Zu}$ groß waren gleichzeitig aber immer noch die Unsicherheiten und strukturellen Disfunktionalitäten, denen das Rechtswesen und ihre Akteure ausgesetzt waren. Die Strategie, derart ausgeprägt an einer "Charismatisierung “ von Exponenten aus dem Justizwesen zu arbeiten und den Bezug auf das Gemeinwohl und die Ob̌̌čestvo so zu betonen, mag deshalb auch eine Möglichkeit gewesen sein, mangelhafte Wirkungskraft des eigentlichen Professionshandelns auszugleichen. Der Fokus auf übergeordnete Vorstellungen von „Wahrheit“, „Gerechtigkeit“ und dem „Dienst“ für die Justiz war wohl gerade im Kontext einer im Realen unvollständigen und mangelhaften Rechtsprechung umso relevanter. Die Befürchtung, dass über Institutionen und Gesetze im Kontext der zarischen Autokratie keine wesentlichen Veränderungen möglich seien, legte das Argumentieren in großen Kategorien von absolutem Recht und Moral nahe. ${ }^{328}$ Die Bezüge zu sakralen Begrifflichkeiten weisen deshalb auch auf ein faktisches "Defizit an Technologie“ im Rahmen der Berufsausübung hin. ${ }^{329}$ Wo angestrebte Reformen politisch nicht $\mathrm{zu}$ erreichen waren, war die übersteigerte Signifikanz einzelner Individuen, die

embryonalen Zustand“ gehalten habe, habe man allen Korrekturversuchen ablehnend gegenübergestanden, vgl. BABerowski: Autokratie und Justiz, S. 95 ff. Auf ebd., S. 200-01 verweist Baberowski aber auch auf eigene Vorschläge Konis zur Anpassung des Gesetzes in diesem Bereich.

326 Schaeffer: Psychotherapie zwischen Mythologisierung und Entzauberung, S. 43 und 72.

327 Baberowski argumentiert, dass ,angesichts des täglichen Einerlei und der gerichtlichen Routine“ die „Aura“ verblasst sei, die die „Juristen der ersten Stunde“ noch umgeben habe. Er sieht einen wesentlichen Grund dafür in der Einrichtung eines Parlaments nach der Revolution von 1905. Dorthin habe sich nun die Opposition verlagert und die Justizbehörden, insbesondere die Berufe des Richters und des Staatsanwalts „,vom Ruf befreit, ein Forum des politischen Widerspruchs zu sein“, vgl. BABERowski: Autokratie und Justiz, S. 778 .

328 Eric Lohr: The Ideal Citizen and Real Subject in Late Imperial Russia. In: Kritika: Explorations in Russian and Eurasian History 2 (2006), S. 194 argumentiert, dass diese Einsicht unter vielen Liberalen geherrscht habe.

329 P. BühleR/Th. BüHLeR/F. Osterwalder: Vorwort, S. 8. 
als „Lebensführer“ dienen sollten, ein möglicher Weg, um eine handlungsfähige Position zu behaupten. ${ }^{330}$ Dass in den biografischen Porträts und Darstellungen zur Reform blinde Flecken in Kauf genommen, über Differenzen hinweggeschrieben wurde und angebrachte Kritik beispielsweise am Geschworenengericht nur sehr zurückhaltend ausfiel, entbehrt deshalb nicht einer gewissen Situationslogik. Koni selber berichtet, wie ihn der Vorsitzende der Juristischen Gesellschaft von St. Petersburg 1880 zuhause besuchte und ihn bat, bei seinem bevorstehenden Fachreferat vor der Gesellschaft mit dem Thema „Die Gerichtsreform und das Geschworenengericht" von deutlicher Kritik abzusehen, da sonst nur den Gegnern der neuen Justiz mit ihren demokratisch-liberalen Elementen Munition verschafft werde. Koni verweist danach zwar trotzdem auf einige kritische Punkte, beschränkt diese aber auf den letzten Teil des Vortrags und verzichtet auf konkrete Verbesserungsvorschläge. ${ }^{331}$ Angesichts des starken Gefühls einer omnipräsenten Bedrohung des gesamten Justizwesens durch konservative Teile der Elite war die Idealisierung von Richtern und Anwälten und das Festhalten an den Reformstatuten von 1864 nicht nur Panegyrik und „realitätsferner Dogmatismus“, ${ }^{332}$ sondern lässt sich irgendwo zwischen Professionalisierungsbestrebungen und Zuflucht zu einem ideellen Überbau im ablehnend gesinnten politischen Umfeld situieren.

Vor diesem Hintergrund lag es auch auf der Hand, dass Koni seine Enttäuschungen und harten Urteile über das Verhalten vieler Berufskollegen und

330 Nathans: Talking Fish, S. 606 argumentiert, dass im 19. Jahrhundert Oppositionelle in Russland aufgrund ihres fehlenden Einflusses auf Politik und Bevölkerung solche „Lebensführer“ - eine Wortschöpfung des Revolutionärs und Schriftstellers Nikolaj Gavrilovič Černyševskij (1828-1889) - kreierten. Zumindest jene zu Beginn des Kapitels kurz erwähnten Anwälte, die in der ersten Russischen Revolution ihr Handwerk ganz aufgaben, um in Streiks als Sprachrohr der Aufbegehrenden zu dienen, schienen die eigentliche Verteidigungsarbeit im Kontext der Autokratie für völlig sinnlos zu halten.

331 Dies führte Koni 30 Jahre später aus, als er erneut einen Artikel zum Geschworenengericht verfasste, der im Rahmen seiner Reihe „Aus den Erinnerungen eines Gerichtstätigen“ publiziert wurde, vgl. der hier und in der Folge zitierte Abdruck aus der Gesamtausgabe: Anatolij F. Koni: Iz zametok i vospominanij sudebnogo dejatelja. Prisjažnye zasedateli. In: GA1, S. 322. Sein Vortrag aus dem Jahr 188o war wenig später auch publiziert worden, vgl. VE 1 (1881), S. 199-235 und wurde danach in mehrere von Konis Sammelbänden integriert. Vgl. auch Berdjaev u. a. (Hrsg.): Vechi, S. 7 (Einleitung v. Karl Schlögel) zu der verbreiteten Überzeugung, dass Kritik innerhalb der Intelligencija nur den ideologischen Gegnern helfen würde und deshalb lang Tabu gewesen war.

Puttkamer spricht von „realitätsfernem Dogmatismus“ im Strafrecht als im Kern nicht umstrittenes Ergebnis der Arbeit Baberowskis, stellt aber in Frage, ob es deswegen wirklich zur Untergrabung der eigenen Ziele durch die liberalen Juristen gekommen sei, vgl. Joachim von Puttkamer: Die russische Justizreform von 1864. Eine Kontroverse. In: Jahrbücher für Geschichte Osteuropas 3 (1999), S. 406 und 408-09. 
Freunde im Nachgang zum Zasulič-Prozess nicht an die breite Öffentlichkeit brachte. In dieser fokussierte er auf Werke im Stile seines Sammelbandes von den „Vätern und Söhnen“. Noch 1918 erhielt er für dieses Buch eine Auszeichnung von der Akademie der Wissenschaften. In seinem Dankesschreiben betont er, wie wichtig dieses „Zeichen der Aufmerksamkeit“ gerade zur jetzigen Zeit sei, wo

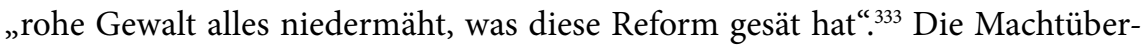
nahme der Bolschewiki hatte wenige Monate zuvor mit dem Zarenreich auch das Justizsystem von 1864 vollständig aufgelöst. Dennoch engagierte sich Koni auch im frühen Sowjetrussland noch in allerdings stark eingeschränktem Ausmaß für die Belange der Justiz und hielt teilweise gar an der Verbreitung seiner „Erfolgsgeschichten“ und biografischen Juristenporträts fest. ${ }^{334}$ Doch zeigt Konis autobiografische Praxis, wie nun andere Elemente in seinem Selbstverständnis stärker zum Tragen kamen. Darunter seine politische Analysefähigkeit und die eigene Positionierung im Verhältnis zur Staatsmacht, die Koni im Verlauf seines Lebens, herausgefordert von den politischen und gesellschaftlichen Entwicklungen, mehrfach überdachte.

333 Zitiert nach: VysockiJ: Koni, S. 391.

334 Vgl. dazu das Kapitel Politische Erinnerung an das Zarenreich in der Sowjetunion. 

TEIL ZWEI 



\section{Der Fall Vera Zasulič - ein politisches Lehrstück}

Bogoljubov steht am Anfang von Konis umfangreicher Erinnerungsschrift zum „Fall Vera Zasulič“. Dem jungen Narodnik, den Zasulič mit ihrer Attacke auf den Petersburger Stadthauptmann rächen wollte, widmete er die ersten sechs Seiten des Textes. Darin beschreibt er, wie im Dezember 1876 am helllichten Tag revolutionäre Aktivisten im Zentrum von St. Petersburg vor der Kasaner Kathedrale demonstrierten und allesamt verhaftet und zu langen Jahren der Zwangsarbeit verurteilt worden seien - unter ihnen auch besagter Bogoljubov. ${ }^{1}$

Nicht nur die Ausführlichkeit des Berichts und die prominente Position gleich zu Beginn des Textes machen deutlich, welch zentrale Bedeutung Koni der Verhaftung und Verurteilung dieses Mannes zuwies. Auch im weiteren Verlauf der Schrift kommt er immer wieder auf die Art und Weise zu sprechen, wie der Staat mit Oppositionellen wie Bogoljubov umgegangen sei. So ist der ganze erste Teil der „Erinnerungen an den Fall Vera Zasulič“ den Jahren vor Zasuličs Schuss auf den Stadthauptmann gewidmet. Neben der Demonstration vor der Kathedrale, der Verhaftung von Bogoljubov und der gegen ihn verhängten Körperstrafe sind auch die großen Gerichtsprozesse der 1870er-Jahre gegen Heerscharen angeblicher Revolutionäre Thema. ${ }^{2}$ Koni stellt dabei einen ausführlich dargelegten Kausalzusammenhang zwischen dem repressiven Vorgehen der Behörden und den Taten von Vera Zasulič und ihresgleichen her. Gleichzeitig zeigt er auf, wie er versuchte, seinen Vorgesetzten von diesen Einsichten und den Konsequenzen daraus zu berichten.

Er verweist mit Nachdruck darauf, wie er bereits im Frühling 1877 in einem Gespräch mit Justizminister Graf Pahlen die gefährlichen Folgen der harten Haltung des Staates gegenüber jungen Oppositionellen angesprochen habe. ${ }^{3}$ Graf

1 Koni: Vospominanija o dele Very Zasulič. In: GA2, S. 26-31. Koni nennt den Namen Bogoljubovs erst am Schluss dieser Einführungsepisode. Beim Namen Bogoljubov handelt es sich um ein Pseudonym, vgl. Rindlisbacher: Leben für die Sache, S. 135.

2 KonI: Vospominanija o dele Very Zasulič. In: GA2, S. 26-62.

3 Seit Mitte 1875 arbeitete Koni als Vizedirektor im Justizdepartement, bevor er Ende 1877 zum Vorsitzenden des St. Petersburger Bezirksgerichtes ernannt wurde, wo er sich dann in der Folge um den Zasulič-Fall kümmern musste, vgl. die Einleitung und SMOLJARČUK: Anatolij Fëdorovič Koni (1844-1927), S. 73 und 81-82.

Der Grund für diese Besprechung lag darin, dass der Zar beunruhigt von den andauernden Agitationsaktivitäten radikaler Gruppierungen in Russland eine außerordentliche Versammlung verschiedener Ministerien ins Leben gerufen hatte, die Vorschläge für erweiterte Maßnahmen gegen dieses Phänomen entwickeln sollte. In Vorbereitung auf diese Zusammenkunft berief der Justizminister einige Berater zu sich, die ihre Meinungen einbringen sollten. Die 
Pahlen aber galt als Verfechter drastischer Maßnahmen. Er war der festen Überzeugung, dass die harte gerichtliche Bestrafung von Gedankengut, das sich gegen die Selbstherrschaft richtete, die Revolutionäre stigmatisieren und ihre Appelle neutralisieren würde. ${ }^{4}$ Bereits 1872 hatte man eine spezielle Instanz für politische Aktionen eingeführt, das sogenannte „Außerordentliche Kollegium des Regierenden Senates“. Als in den darauffolgenden Jahren junge Menschen den „Gang ins Volk" unternahmen, kam es zu Gerichtsprozessen gegen Hunderte von Radikalen. Vergeblich hatten sie versucht, die breite Bevölkerung mit dem Verteilen von Broschüren und in direkten Gesprächen davon zu überzeugen, dass die $\mathrm{Zu}$ kunft Russlands nicht in der autoritären Herrschaft durch den Monarchen liege. ${ }^{6}$ In den Massenprozessen sollte der Öffentlichkeit gezeigt werden, dass die Ideen der Narodniki vom Aufbrechen der Familie, der Neuverteilung von Eigentum oder der freien Liebe negative Konsequenzen für ganz Russland haben würden. ${ }^{7}$

In den „Erinnerungen an den Fall Vera Zasulič“ zitiert Koni seine eigene, dem Justizminister vorgetragene Analyse zu dieser Thematik:

Als ich an der Reihe war, verwies ich darauf, dass die revolutionäre Partei die Taktik geändert hat [...], neue Kräfte unter der Jugend anwirbt und sie „ins Volk“ schickt, indem sie in ihnen das edle Mitgefühl mit der Armut des Volkes und den Wunsch ihm zu helfen weckt. ${ }^{8}$

Was könne man also gerade in den Schulen tun, um die Jugend davon abzubringen, dem „falschen und gefährlichen Weg der Doktrin des ,Ganges ins Volk““ zu

erste Sitzung der Sonderkonferenz [Osoboe Soveščanie] fand schließlich im Frühjahr 1877 statt, gefolgt von Treffen in losen Abständen bei außerordentlichen Geschehnissen. Petr A. ZAjONČKovsKiJ: Krizis samoderžavija na rubeže 1870-188o godov. Moskva 1964, S. $59 \mathrm{ff}$. Zitiert nach: GA2, S. 445 (Anmerkungen).

4 Wortman: The Development of a Russian Legal Consciousness, S. 278-79.

5 TroickiJ: Advokatura v Rossii i političeskie processy 1866-1904 gg., S. 164, „Osoboe prisutstvie Pravitel'stvujuščego senata“', kurz OPPS.

6 Vgl. die Einleitung und Haumann: Geschichte Russlands, S. 273-74.

7 Ana Siljak: Angel of Vengeance. The Girl Assassin, the Governor of St. Petersburg and Russia’s Revolutionary World. New York 2008, S. 196-97. Allein in den Jahren 1877/78 kam es zum Prozess gegen die Demonstranten vor der Kasaner Kathedrale in St. Petersburg, unter denen sich auch Bogoljubov befand sowie zum sogenannten „Prozess der 50 “ und dem „Prozess der 193“, die nach der Anzahl Angeklagter benannt wurden. Beim „Prozess der 193“ saßen von den Tausenden verhafteten Aktivisten des „Ganges ins Volk“ von 1874 die knapp 200 als am gefährlichsten eingeschätzten Personen auf der Anklagebank. Vgl. für die Prozesse Troickij: Advokatura v Rossii i političeskie processy 1866-1904 gg., S. $246 \mathrm{ff}, 250 \mathrm{ff}$ und $256 \mathrm{ff}$.

8 KonI: Vospominanija o dele Very Zasulič. In: GA2, S. 39. 
folgen? - fragt Koni in seiner Erinnerungsschrift rhetorisch. Darauf gibt er sofort Antwort. An den Lehrplänen der Gymnasien gelte es anzusetzen. Die Naturwissenschaften - die man sträflicherweise aus der Schule verbannt habe - könnten der Jugend beibringen, dass sich das Staatsleben „organisch“ zu entwickeln habe und „Sprünge“ weder der „physischen“ noch der "politischen Natur" des Landes bekömmlich seien. Gleichzeitig - so empfiehlt Koni weiter - solle man auf die "gesetzgeberische Tätigkeit des Staates“ setzen, die einen „legalen und ruhigen Ausweg" biete, um die Bedürfnisse des Landes und seiner Bewohner zu befriedigen. ${ }^{9}$ Seinen Vorschlägen lässt Koni deutliche Kritik an der vorherrschenden Situation im Russischen Reich folgen. Er spricht von den Problemen, mit denen die Landbevölkerung tatsächlich konfrontiert sei, wenn sie auf ihren kleinen Bodenparzellen kein Auskommen mehr finden könne. Er spricht die zu langsame „Maschine“ der Gesetzgebung an, die in ihrer Schwerfälligkeit die Jungen weg von den „Worten“ und hin zur „Tat" treibe. Schließlich fasst er seine Kernbotschaft nochmals zusammen: die Überarbeitung des Bildungssystems und die Beschleunigung der Gesetzgebung seien unabdingbar. Was aber die Menschen anbelange, die bereits wegen aufrührerischer „Propaganda“ festgenommen und angeklagt worden seien, so sei ihnen gegenüber "große Milde " angebracht. ${ }^{10}$ Koni endet mit den Worten: „Das heutige System der häufig nicht durchdachten und brutalen Verfolgung rottet das Böse nicht nur nicht aus, sondern treibt auch noch die Verbitterung und Verzweiflung der Verfolgten bis an ihre Grenzen." ${ }^{\text {"1 }}$

Auf diese Erläuterungen habe der Justizminister, wie Koni weiter berichtet, mit grundsätzlicher Zustimmung reagiert. Allerdings habe er auch angemerkt, dass man dazu das Gesetzbuch anpassen müsse, was momentan nicht angebracht sei. Auf Konis Einwand, dass geringere Strafen auch „im Laufe der zarischen Barmherzigkeit" erreicht werden könnten, habe der Minister nur noch ein abwinkendes „nicht sofort" in die Runde geworfen. Die Sitzung sei danach mit einem gemeinsamen „kalten Abendmahl“ beendet worden. ${ }^{12}$ Passend dazu scheinen auch Konis Vorschläge kaltgestellt worden zu sein. Er berichtet nämlich, wie er Pahlen ohne Erfolg darum gebeten habe, wenigstens die Resultate der internen Besprechung in einem kratkij žurnal schriftlich festzuhalten. ${ }^{13}$

9 Ebd., S. 39-40.

10 Ebd., S. 40-41.

11 Ebd., S. 42.

12 Ebd., S. 42-43.

13 Ebd., S. 44. Die Strategie der groß angelegten gerichtlichen Verurteilung Andersdenkender sollte grandios scheitern. Die Anklage hatte in der Regel kaum etwas gegen die Beschuldigten vorzuweisen. Diese entsprachen mit ihrem Auftreten auch vielmehr naiven Jugendlichen als den erwarteten, Angst und Schrecken verbreitenden Fanatikern. Als 
Konis Analyse der gesellschaftlichen Spannungen und seine Kritik an der repressiven Vorgehensweise gegen die kritischen Stimmen im Land wurde von ihm im nachfolgenden Teil der Erinnerungsschrift ausgebaut und weiter konkretisiert. In diesem zweiten Abschnitt stehen die Attacke von Vera Zasulič auf den Stadthauptmann und die Vorbereitungen rund um den Prozess gegen sie im Zentrum. ${ }^{14}$ Erneut führt Koni in Dialogform ein Gespräch zwischen sich und dem Justizminister an. Er erinnert sich daran, wie er Pahlen zu verstehen gegeben habe, dass er als Gerichtsvorsitzender in einem Geschworenenprozess den Schuldspruch gegen die Attentäterin nicht garantieren könne, auch wenn der Justizminister dies gerne gehabt hätte. ${ }^{15}$ Dieser Episode folgen auf fast sechs Seiten Überlegungen Konis $\mathrm{zu}$ den Gründen, warum es durchaus möglich sei, dass Vera Zasulič trotz ihres unbestrittenen Angriffs auf Trepov freigesprochen werden könnte. Koni verfasste den Erinnerungstext, als der Ausgang des Prozesses bereits bekannt war, trotzdem bemühte er sich stets, seine Erzählung zum Fall chronologisch aufzubauen. Er zeichnet deshalb das Bild des Gerichtsvorsitzenden A. F. Koni, der sich kurz vor Prozessbeginn besorgt über die angespannte Atmosphäre in St. Petersburg gab. So argumentiert er mit dem Stadthauptmann und meint, dass in jedem anderen Land dessen brutales Vorgehen gegenüber Gefangenen Konsequenzen gehabt hätte. Er berichtet von der Stimmung in der Gesellschaft St. Petersburgs, die Anfang 1878 vom schwierigen Verlauf des Kriegs auf dem Balkan bestimmt werde. Vertrauensverlust in die russische Armee, Kritik an der Regierung und Trauer um die Opfer würden zu einer unruhigen Gefühlslage in der Hauptstadt beitragen, die auch auf die Geschworenen am Prozess nicht ohne Einfluss bleiben dürfte. ${ }^{16}$ Im Anschluss an diese außenpolitischen Schwierigkeiten zählt Koni innenpolitische Missstände auf. Wirtschaftliche Probleme und mangelnde Freiheiten, wohin man blicke. Weder von ökonomischem Wohlstand noch von „Glaubenstoleranz “ [veroterpimost'] oder Selbstverwaltung könne auch nur die Rede sein. Schließlich kommt er wieder auf das „klassische Bildungssystem“ zu sprechen, das keinerlei „lebendiges Wissen über die Heimat, die Sprache und die Natur" beinhalte. ${ }^{17}$ Diesen Reigen

Mittel der Propaganda waren die Prozesse untauglich, weil ihre Dynamik zu wenig kontrolliert werden konnte. Tatsächlich kam es zu zahlreichen Freisprüchen und viel milderen Urteilen, als von den politischen Instanzen kalkuliert. Wortman: The Development of a Russian Legal Consciousness, S. 279 und SiLJAK: Angel of Vengeance, S. 198-99ff.

14 KonI: Vospominanija o dele Very Zasulič. In: GA2, S. 62-90.

15 Ebd., S. 72-74.

16 Ebd., S. 74-76. Vgl. zum Russisch-Osmanischen Krieg als zeitgeschichtlichem Hintergrund zum Zasulič-Prozess auch Richard Pipes: The Trial of Vera Z. In: Russian History 37 (2010), S. 53. Etwas lapidar meint Pipes: „The Russian people will forgive their leaders any cruelties but never defeat on the battlefield.“

17 KonI: Vospominanija o dele Very Zasulič. In: GA2, S. 77-78. 
an Missständen beendet Koni mit dem Verweis auf die kontraproduktive Wirkung der großen Gerichtsprozesse gegen die Narodniki. Zwar habe man von den fast tausend Angeklagten nur einen verschwindend kleinen Teil verurteilt. Aber die Freigelassenen seien in St. Petersburg geblieben und hätten von ihren Erlebnissen im Gefängnis berichtet. Gerüchte von Selbstmord und Wahnsinn hätten die Runde gemacht. Die Bevölkerung habe den offiziellen Beteuerungen nicht geglaubt, dass diese Leute alle „ehrlos, eigennützig“ und „lasterhaft“ seien. „Alles kam zusammen, zerrte von verschiedenen Seiten an den Nerven, und die Mittelschicht St. Petersburgs, aus der die zukünftigen Richter im Fall Zasulič kommen sollten, war angespannt, zerrüttet und ungesund empfindsam. ${ }^{\text {"18 }}$

In Konis Interpretation der Geschehnisse steht Bogoljubovs Verhaftung - stellvertretend für den harschen Umgang mit politisch Andersdenkenden - am Anfang einer Ereigniskette, an deren Ende eine aufgewühlte hauptstädtische Gesellschaft und eine freigesprochene Attentäterin zu finden sind. Der Angriff auf Trepov wurde von Koni in seiner Erinnerungsschrift als „Lehrstück“ für die verheerenden Folgen repressiver Politik beschrieben. Ob er dieses Lehrstück möglicherweise sogar selber bewusst in seinen Implikationen verschärfte, indem er am Prozess dem brutalen Verhalten Trepovs viel Platz ließ, so die Hintergründe von Zasuličs Tat ins Bewusstsein der Geschworenen rückte und damit dem Freispruch Vorschub leistete, sei dahingestellt. ${ }^{19}$ Sicher ist, dass Koni den Fall in seiner Erinnerungsschrift ausdrücklich in den gesellschaftlichen und politischen Kontext einordnete,

18 Ebd., S. 78-80.

19 Borisova argumentiert, dass Koni die Umstände während des Prozesses bewusst ins Zentrum gerückt und so das brutale Vorgehen Trepovs, das den Anlass für Zasuličs Tat gewesen war, öffentlich verurteilt habe. Sie führt dies auf Konis Überzeugung von einem erweiterten Recht auf Selbstverteidigung zurück, zu dem dieser 1865/66 seine Dissertation verfasst hatte, Tat'jana J. Borisova: „Neobchodimaja oborona obščestva“. Jazyk suda nad Zasulič. In: Novoe literaturnoe obozrenie 5 (2015), S. 103 ff. Vgl. zu Konis wissenschaftlichen Arbeit zum Abschluss seiner Universitätszeit „Über das Recht auf notwendige Verteidigung" [O prave neobchodimoj oborony] ebd., S. 104 ff. Koni untersuchte darin erstmals für Russland die Frage nach der gewaltsamen Verteidigung von Rechten im Fall von Bedrohung derselben unter anderem auch durch Staatsbeamte. Vgl. SMoljarčuk: Anatolij Fëdorovič Koni (1844-1927), S. $29 \mathrm{ff}$ zu den Umständen und S. 33 ff zum Inhalt der Arbeit. Für Konis eigene Erinnerungen an das Werk und die Folgen, die es für ihn hatte, vgl. unten, S. 326. In der Regel wird Konis den Prozess gegen Zasulič abschließende Erklärung als ausgewogen und einem extremen Urteil der Geschworenen - also sowohl Freispruch als auch harten Schuldspruch - entgegenwirkend interpretiert, vgl. in diesem Sinne z. B. Siljak: Angel of Vengeance, S. 243-45 oder Regula Spalinger-Bichsel: A. F. Koni und die russische Gerichtsrhetorik. Zürich 1993 (unveröffentlichte Dissertation), S. $72 \mathrm{ff}$. Spalinger-Bichsel verweist darauf, wie Koni den Geschworenen Optionen für einen Schuldspruch mit mildernden Umständen erklärte. 
und so nicht zuletzt seine eigene Fähigkeit betonte, die größeren soziopolitischen Zusammenhänge zu erkennen und alternative Ideen zu entfalten.

Sein Fokus auf Ursache und Wirkung, sein Plädoyer für ein Bildungssystem, das einen realistischeren Zugang zum Russischen Reich und seiner Gesellschaft vermitteln sollte, seine Forderung nach mehr Selbstbestimmung und persönlichen Freiheiten, nach dem entschiedenen, aber nie von "Sprüngen“ gekennzeichneten Angehen von Problemen mit den Mitteln der Gesetzgebung, und insbesondere seine Aufforderung zur Milde gegenüber Oppositionellen, all dies zeigt deutlich Konis gesellschaftspolitische Positionen auf. Im nachfolgenden ersten Kapitel werden diese zu gängigen liberalen Ansichten in Beziehung gesetzt. Der Schwerpunkt liegt dabei nicht nur auf dem Inhalt der politischen Analyse, sondern auch auf Konis Selbstdarstellung als Jurist, der behauptete, diese Zusammenhänge und ihre Konsequenzen nicht nur zu verstehen, sondern auch andere davon zu überzeugen. In den „Erinnerungen an den Fall Vera Zasulič“ ist der Justizminister Adressat von Konis Zukunftsvisionen und Vorschlägen zum justizpolitischen Umgang mit den Narodniki. In anderen autobiografischen Schriften, in denen Koni um die Jahrhundertwende auf seine Karriere zurückblickte, rückte gar der Zar persönlich ins Zentrum seiner Bemühungen. Auch in diesen Selbstzeugnissen zeichnete Koni von sich das Bild eines Menschen, der stets politisch und in großen Zusammenhängen dachte und den Zugang zu Entscheidungsträgern offensiv nutzte, um seine eigenen Vorschläge einzubringen. Im Zuge der Radikalisierung der liberalen Bewegung rund um die Zeit der ersten Russischen Revolution von 1905 hinterfragte Koni seine Involvierung in den Kreis dieser Entscheidungsträger allerdings grundsätzlich und fand zu einer neuen Selbstdarstellung, die im zweiten Kapitel thematisiert wird. Darin positionierte er sich weit weg von politischen Einflussmöglichkeiten. Bezeichnenderweise nahm in dieser Erzählung der Gerichtsprozess gegen Vera Zasulič eine Schlüsselrolle ein. Diese Auseinandersetzung und die darin inhärente Distanzierung von zu viel Machtnähe wurde von Koni in der frühen Sowjetzeit - ausgeführt im dritten Kapitel - nahtlos weitergeführt und manifestierte sich in einer Vielzahl an autobiografischen Praktiken, mit denen er in den 1920er-Jahren Rechtfertigung und Kontextualisierung seiner eigenen Handlungen in der Zarenzeit betrieb. Gleichzeitig zeigt sich dabei aber, dass er durch das Schreiben neuer Erinnerungstexte oder das Veröffentlichen älterer autobiografischer Schriften auch in Zeiten ideologischen Wandels das „Lehrstück“ der Causa Zasulič nicht vergaß, sondern an seinen politischen Analysefähigkeiten festhielt und sich erneut aktiv für die Verbreitung seiner eigenen Interpretationen von Geschichte und Gesellschaft einsetzte. 


\title{
2.1 Memoiristische Rückschau auf ein Berufsleben unter autokratischer Herrschaft
}

\begin{abstract}
Als Koni in den Jahren 1904 bis 1907 Erinnerungstexte zu zentralen Ereignissen in seinem Berufsleben verfasste, befand er sich bereits seit einiger Zeit in einem Prozess des schrittweisen Rücktritts von seinen Ämtern. 1896 hatte er den Posten des Oberstaatsanwalts am Kriminalkassationsdepartement aufgegeben und lediglich seine Tätigkeit als Senator am entsprechenden Departement beibehalten. 1900 tauschte er auch diese Aufgabe gegen den deutlich weniger aufwendigen Einsitz in der Allgemeinen Versammlung des Senats. Die geringere Arbeitsbelastung setzte Ressourcen für andere Tätigkeiten frei. So erreichte Konis autobiografische Reflexion mit der Jahrhundertwende quantitativ eine bisher ungekannte Dimension. Dabei unterschieden sich diese Rückblicke auf seine berufliche Tätigkeit stark von den kurzen autobiografischen „Erinnerungen eines Gerichtstätigen“ über seine Arbeit an den reformierten Gerichtsbehörden, die er wenige Jahre später in verschiedenen Zeitschriften veröffentlichen sollte. ${ }^{20}$ Erstere widmeten sich viel ausführlicher und detailgenauer den bedeutendsten und auch politisch brisantesten Ereignissen seiner Karriere und waren nur mittelfristig für die Öffentlichkeit gedacht. Ein dominantes Element in diesen Schriften ist Konis Zusammenarbeit und Unterstützung, aber auch Zurückweisung durch hohe Politiker wie Senatoren, Minister und Zaren. Es handelt sich dabei neben den bereits vielfach thematisierten „Erinnerungen an den Fall Vera Zasulič“ um die beiden Texte „Die Entgleisung des Zarenzuges im Jahre 1888“ und „Die Triumvirn“, in dem Koni auf seine Zeit als Oberstaatsanwalt am Kriminalkassationsdepartement zurückblickt. Den Zasulič-Prozess thematisiert Koni inklusive dessen Vorgeschichte sowie langfristigen Folgen des Freispruchs für ihn, das Gerichtswesen und die Justizpolitik in der vorläufigen, auf 1904 datierten Endversion auf über 150 Seiten. ${ }^{21}$ Ebenfalls
\end{abstract}

20 Vgl. dazu ausführlich TEIL EINS.

21 Gegen Ende des Erinnerungstextes geht Koni auch auf Episoden ein, die zwar noch in losem Zusammenhang mit dem Ereignis von 1878 stehen, aber erst Jahrzehnte später stattfanden. Koni datierte das überarbeitete und aktualisierte Manuskript seiner eigenen Version zum Fall mit „15. August 1904“, vgl. GARF F. 564, op. 1, d. 200, 1. 1-154, Datierung auf 1. 154. Teile der Erinnerungsschrift hat Koni wohl schon früher verfasst, in IRLI F. 134, op. 1, d. 110, 1. 31-132ob gibt es ein Teilmanuskript des Textes, das mit „Die Geschichte des Falls Zasulič, 1884-1885“ beschriftet ist, vgl. Datierung auf 1. 31. Ein weiteres Manuskript der gesamten Erinnerungsschrift gibt es im gleichen Archivgut auf 1. 138-3130b. Auf der letzten Seite ist dieses nun aber datiert mit „Sommer 1904-06“. Es ist unklar, ob Koni tatsächlich 1906 eine veränderte Version seiner Erinnerungsschrift verfasste oder ob dieses Dokument nicht erst in einer erneuten Bearbeitungsphase in den 1920er-Jahren entstand. Aus dieser Zeit scheint auch die bearbeitete Teilversion in GARF F. 564, op. 1, 
datiert vom August 1904 ist Konis Erinnerungsschrift an die Entgleisung des Zarenzugs. Auf gut 30 rückseitig maschinengetippten Blättern berichtet Koni davon, wie im Oktober 1888 in der Nähe von Borki bei Charkow der Hofzug des Zaren Alexanders III. entgleist war. ${ }^{22}$ Während über 20 Menschen ums Leben kamen, entstiegen der Zar und seine gesamte Familie wie durch ein Wunder dem stark zerstörten Zug ohne nennenswerte Verletzungen. ${ }^{23} \mathrm{Zu}$ diesem Zeitpunkt war Koni schon seit einigen Jahren Oberstaatsanwalt am Kriminalkassationsdepartement in St. Petersburg. Er wurde zum Leiter der Untersuchungskommission ernannt, die sich um die Entgleisung kümmern sollte. Mit diesem Auftrag beginnt Koni auch seine Erinnerungsschrift und bringt gleich als Erstes den Zaren ins Spiel, indem er betont, dass dieser persönlich seine Einwilligung zur Leitungsfunktion Konis gegeben habe. ${ }^{24}$ In der Folge führt er aus, wie er zur Unfallstelle gefahren sei und umfassende Untersuchungen eingeleitet habe. Er beschreibt seinen Arbeitsalltag vor Ort und die Zusammenarbeit mit den lokalen Gerichtsbehörden und technischen Experten. Ein großer Teil des Textes umfasst schließlich die Erläuterung der Untersuchungsergebnisse und deren Präsentation vor dem Zaren persönlich. Es folgen einige Biografien von Zeugen und involvierten öffentlichen Persönlichkeiten, darunter auch prominente Personen wie der spätere Finanzminister Sergei Witte (1849-1915). Zum Schluss widmet sich die Schrift den politischen Diskussionen und Streitereien um die Ursachen und die Konsequenzen des Unfalls, die von Zar, Staatsräten und Ministern geführt wurden und schließlich die Beilegung des Falls zur Folge hatten. ${ }^{25}$ Um Persönlichkeiten, die in Konis Optik entscheidenden

d. $199 \mathrm{zu}$ stammen. Auf einige der Unterschiede und die Überarbeitungsphase wird noch eingegangen. Wenn nicht anders angemerkt, wird jeweils die in der Gesamtausgabe veröffentlichte Version zitiert.

22 IRLI F. 134, op. 1. d. 188, 1. 38-69. Datierung auf 1. 69. Vgl. auch die später bearbeiteten Abschriften in: GARF F. 564, op. 1, d. 203, 1. 1-97, d. 204, 1. 1-810b. Zudem gibt es eine Teilabschrift in IRLI F. 134, op. 1, d. 134. Koni sagte aus, dass er die Erinnerungsschrift bereits 1890 begonnen habe, vgl. Anatolij F. Koni: Sergej Julevič Vitte. Otryvočnye vospominanija. In: GA5, S. 243. Das Archivgut GARF F. 564, op. 1, d. 198 gibt einen guten Eindruck davon, wie Koni den Text vorbereitete. Auf Agendablättchen hat er in sehr kleiner Schrift Notizen gemacht und diverse Namen, Stichworte, Gesetzesartikel etc. festgehalten, die wohl später als Grundlage für den ausformulierten Bericht dienten. Auf einige der Unterschiede in den verschiedenen Versionen und eine neue Fassung in den 1920er-Jahren wird noch eingegangen. Wenn nicht anders angemerkt, wird jeweils die in der Gesamtausgabe veröffentlichte Variante zitiert. Wortman: Scenarios of Power Bd. 2, S. 289. Anatolij F. KonI: Krušenie carskogo poezda v 1888 godu. Borki-Taranovka. In: GA1, S. 420. Teil des Anfangs ebenfalls datiert mit 16. August 1904. Dieser Textteil fehlt in der Version der „Erinne- 
Einfluss auf „die Schicksale Russlands“26 hatten, dreht sich auch der dritte Erinnerungstext, der sich nicht einem einzelnen Ereignis, sondern Konis langjähriger Tätigkeit in der Kassation als Oberstaatsanwalt und Senator nach 1885 widmet. Dieser umfasst mehrere kleinformatige Notizbüchlein, die datiert von 1907 dicht beschrieben sind mit den Erinnerungen Konis. ${ }^{27}$ Dabei geht es insbesondere um die Zusammenarbeit mit dem Oberprokuror des Heiligen Synods und bekannten Juristen Konstantin Petrovič Pobedonoscev (1827-1907), dem Justizminister Nikolaj Valerianovič Murav'ev (1850-1908) und dem einflussreichen Kollegen am Kriminalkassationsdepartement, Nikolaj Stepanovič Tagancev $(1843-1923){ }^{28}$ Koni rollt seine persönlichen Begegnungen mit den drei Persönlichkeiten Stück für Stück auf. Er beginnt mit dem ersten Treffen zwischen sich und Pobedonoscev, als dieser noch Professor für Zivilrecht an der Moskauer Universität war und Koni dessen Vorlesungen besuchte. ${ }^{29}$ Danach rücken die (religions-)politischen Tätigkeiten Pobedonoscevs in den Vordergrund, und Koni beschreibt dessen Handeln als Oberprokuror des Heiligen Synods. Seit 1721 war der „Heiligste Regierende Synod" für die Belange der Russisch-Orthodoxen Kirche zuständig und wurde dabei jeweils von einem weltlichen Beamten - dem Oberprokuroren - beauf-

rungen an die Entgleisung“, die in der Gesamtausgabe abgedruckt ist. Dies, weil Koni in den frühen 1920er-Jahren einen separaten Text über Witte verfasste und diese Elemente deshalb nicht mehr direkt mit seiner Erinnerung an den Zugunfall in Zusammenhang gebracht wurden.

26 Koni: Triumviry. In: GA2, S. 253.

27 IRLI F. 134, op. 1, d. 143. Neben dieser handschriftlichen Version gibt es auch ein maschinengetipptes Manuskript, das insgesamt 54 Blätter umfasst und wohl aus einer späteren Bearbeitungsphase stammt: GARF F. 564, op. 1, d. 207. Gleich mehrfach ist die Schrift mit Daten aus Frühling und Sommer 1907 versehen, vgl. z. B. GARF F. 564, op. 1, d. 207, 1. 31 und 45. Auf einige der Unterschiede zwischen den beiden Versionen und die spätere Bearbeitungsphase wird noch eingegangen. Wenn nicht anders angemerkt, wird jeweils die in der Gesamtausgabe veröffentlichte Variante zitiert.

28 In einem Brief vom Juli 1907 bezeichnet Koni die Erinnerung als Teil seiner Reihe „Aus den Erinnerungen eines Gerichtstätigen“, von der lediglich ein Teil in den Druck gehen könne. Dabei behauptet er auch, beim „Triumvirat“ handle es sich um Pobedonoscev, Murav'ev und den Innenminister Vjačeslav Konstantinovič fon Pleve (1846-1904). Pleve spielt in der Schrift schlussendlich aber keine Rolle, vgl. GA8, S. 246 (Brief an V. D. Komarova vom 12.07.1907).

29 Pobedonoscev schloss 1846 die Kaiserliche Rechtsschule ab und unterrichtete von 1859 bis 1865 an der Universität. Sein Kurs zum Zivilrecht erschien in fünf Auflagen und entwickelte sich zu einem viel beachteten Handbuch für Juristen. Pobedonoscev beteiligte sich an der Ausarbeitung der Gerichtsreform. Nach 1865 trat er in den Staatsdienst über, wurde Senator und Staatsrat. Vgl. zu Pobedonoscev Aleksandr Ju. Polunov: K. P. Pobedonoscev v obščestvenno-političeskoj i duchovnoj žizni Rossii. Moskva 2010. 
sichtigt. ${ }^{30}$ Zwischen 1880 und 1905 hatte Pobedonoscev durch dieses Amt großen Einfluss auf Politik und Geistesleben des Russischen Reiches. ${ }^{31}$ In „Triumvirn“ berichtet Koni detailliert von ihren unterschiedlichen Ansichten über die Auslegung des Gesetzes, die Glaubensfreiheit und die Rolle der Orthodoxen Kirche im Staat. Ein großer Teil des Textes handelt konkret von den diversen Fällen von „Religionsverbrechen“ [prestuplenie protiv very] durch Altgläubige oder sonstige Glaubenskollektive, die nicht der Orthodoxen Kirche angehörten. Der Umgang mit solchen Fällen führte zu zahlreichen Auseinandersetzungen zwischen Koni im Kassationsdepartement und dem mächtigen Pobedonoscev, der einen streng konservativen Kurs verfocht und auf der privilegierten Stellung der Orthodoxen Kirche beharrte. ${ }^{32}$ Im Zusammenhang mit den Widerständen, auf die Koni bei diesen Glaubensfällen traf, wird auch Senator Tagancev zum Thema, der wie Koni in den 186oer-Jahren studiert hatte und sich zu einer Kapazität im Bereich des Strafrechts entwickelt hatte. ${ }^{33}$ Koni beschuldigt ihn, im Fahrwasser mit den

30 Haumann: Geschichte Russlands, S. 172.

31 Peter Waldron: Religious Toleration in Late Imperial Russia. In: Olga Crisp/Linda Edmondson (Hrsg.): Civil Rights in Imperial Russia. Oxford 1989, S. 107. Pobedonoscevs einst reformorientierten Ansichten wandelten sich Ende der 1870er-Jahre stark. Er wurde zum Vertreter der Reaktion, kritisierte nun die Reformen von Zar Alexander II. und engagierte sich insbesondere nach der Ermordung des Zaren 1881 stark im Kampf gegen die revolutionären Kräfte, vgl. Polunov: K. P. Pobedonoscev v obščestvenno-političeskoj i duchovnoj žizni Rossii.

32 Die Gleichberechtigung verschiedener Glaubensrichtungen blieb so kategorisch ausgeschlossen. Neben der Orthodoxen Kirche, der etwa 70 \% der Bevölkerung des Imperiums angehörten, existierte eine Vielzahl an Gruppierungen, die ihre Wurzeln in der Kirche hatten, aber nicht länger Teil davon waren. Die umfangreichste davon waren die Altgläubigen, die um 1900 auf 11 Millionen beziffert wurden. Unter Alexander II. gab es einige vorsichtige Schritte hin zu einer Ausweitung der Gewissensfreiheit [svoboda sovesti]. Diese Konzessionen an religiöse Minderheiten wurden aber von Alexander III. wenig geschätzt, vgl. WALDRon: Religious Toleration in Late Imperial Russia, S. 103 und 110-11. Neben Altgläubigen waren auch weitere religiöse Minderheiten wie zum Beispiel die freikirchliche Bewegung der Stundisten [štundisty] betroffen vom harten Vorgehen, das gerade Pobedonoscev gegen Ende der 188oer-Jahre gegen sie durchzusetzen versuchte. Vgl. zur Auseinandersetzung zwischen Pobedonoscev und dem Senat bzw. Koni in diesen Fragen: Polunov: K. P. Pobedonoscev v obščestvenno-političeskoj i duchovnoj žizni Rossii, S. 262-65. Koni selber widmete diesem Thema auch drei seiner Texte in der Reihe „Aus den Erinnerungen eines Gerichtstätigen“. In „Russische Altertümer“ [Russkaja Starina] erschienen 1909 „Uniatenfälle“ [Uniatskie dela], „Stundisten“ [Štundisty] und „Pastorenfälle" [Pastorskie dela], vgl. Angaben in Fußnote 58 in TEIL EINS.

33 Tagancev arbeitete nach seinem Rechtsstudium für verschiedene juristische Journale und unterrichtete Kriminalrecht an der Kaiserlichen Rechtsschule und der St. Petersburger Universität. Zusammen mit Koni gehörte er zu den Gründungsmitgliedern der St. Petersburger Juristischen Gesellschaft, vgl. Liessem: Autonomie in der Autokratie?, S. 250. 
mächtigen Akteuren Pobedonoscev und Murav'ev mitgeschwommen zu sein und Druck auf Koni und seine Arbeitsweise ausgeübt zu haben. ${ }^{34}$ Dies sei aus dem „irgendwann mal liberalen Professor" geworden. ${ }^{35}$ Der in den 189oer-Jahren als Justizminister amtierende Murav'ev kommt am ausführlichsten im letzten Teil des Textes zur Sprache. Auch hier dominiert die Beschreibung des „hartnäckigen Kampfes", den Koni gegen den Minister ausgefochten hat, der in seinen Augen mit Umstrukturierungsmaßnahmen im Justizsystem eine Gefahr für das Gerichtswesen darstellte. ${ }^{36}$

Den drei umfangreichen Erinnerungstexten mit ihrer Rekapitulation von Konis Interaktionen auf höchster politischer Ebene ist gemeinsam, dass sie in sommerlichen Kuraufenthalten in ihre endgültige Form gebracht wurden. Dies vermerkte Koni jeweils auf den Manuskripten neben der Datierung. ${ }^{37}$ Sei es im italienischen Stresa, in Finnland oder unweit von St. Petersburg am Finnischen Meerbusen im 1900 neu gegründeten Kurort Sestrorezk - Koni nutzte solche Zeit der Erholung nun für die autobiografische Auseinandersetzung mit seiner persönlichen Laufbahn. Dass für ihn diese Rückschau den Charakter einer abschließenden Bewertung seines Berufslebens nach seinem Rücktritt hatte, zeigt sich beispielhaft in der Titelwahl für die Erinnerungsschrift an die Entgleisung des Zarenzugs. Im Gegensatz zu vielen anderen autobiografischen Schriften Konis, die er „Erinnerungen“ [Vospominanija] nannte, wählte er hier die Bezeichnung „Memoiren“ [Memuary]..$^{38}$ Das kann Zufall sein, vor allem da dies weder im Deutschen noch im Russischen trennscharfe Begriffe sind. ${ }^{39}$ Dennoch mag

Ab 1881 war er im Staatsdienst tätig, sowohl im Justizministerium als auch wie Koni als Senator am Kriminalkassationsdepartement.

34 Koni: Triumviry. In: GA2, S. 301-02.

35 Ebd., S. 321.

36 Ebd., S. 321-23. Murav'ev hatte 1894 nur wenige Wochen nach seiner Amtseinführung dem Zaren ein Reformprogramm für das Gerichtswesen unterbreitet. Anstelle von Einzelmaßnahmen zur Ausbesserung der Gerichtsstatuten von 1864 sollte eine Reformkommission eine grundsätzliche Überarbeitung initiieren, vgl. BABEROWski: Autokratie und Justiz, S. 441-42. Vgl. dazu auch das Kapitel Biografien von Peers als Probeläufe.

37 Vgl. für „Zasulič“: GARF F. 564, op. 1, d. 200, 1. 154, für „Zarenzug“: IRLI F. 134, op. 1. d. 188, 1.69 und für „Triumvirn“: z. B. GARF F. 564, op. 1, d. 207, 1. 31 und 45.

38 IRLI F. 134, op. 1. d. 188, 1. 38. Der volle Titel dieses Manuskriptes heißt: „Memuary A. F. Koni. Krušenie carskogo poezda v 1888 godu (Borki - Taranovka).“

39 Anke Stephan: Erinnertes Leben. Autobiographien, Memoiren und Oral-History-Interviews als historische Quellen. In: Virtuelle Fachbibliothek Osteuropa. Digitales Handbuch zur Geschichte und Kultur Russlands und Osteuropas, zuletzt angepasst 2005, S. 6-7. Erinnerungstexte lassen sich oftmals nur schwerlich in eine der beiden Kategorien einordnen. In der Literaturwissenschaft gilt aber die Gattungsunterscheidung, die Memoiren als Texte bezeichnet, die den Werdegang einer Person in ihrer gesellschaftlichen Rolle 
für einen in westeuropäischer Literatur äußerst belesenen Mann wie Koni der Begriff der „Memoiren“ den Fokus auf Berufslaufbahn und Werdegang verdeutlicht haben, über welche in der Regel nach Ende der aktiven Amtszeit und gegen Lebensende hin berichtet wurde. ${ }^{40}$ Neben diesem in Konis Biografie begründeten Schreibanlass dürften auch die veränderten Publikationsmöglichkeiten und die verstärkte öffentliche Diskussion über Gerichtsprozesse und politische Akteure der letzten Jahrzehnte ein wesentlicher Faktor gewesen sein für seine intensivierte Schreibtätigkeit. Mit der Aufhebung der Zensur nach der Revolution von 1905 waren im Zarenreich plötzlich ganz andere Publikationsmöglichkeiten vorhanden. ${ }^{41}$ Erstmals wurde auch die Geschichte der radikalen Bewegung in legalem Rahmen aufgearbeitet. Die Akten zu den Gerichtsprozessen gegen die Narodniki in den 1870er-Jahren wurden abgedruckt, und sogar die Protokolle zum ZasuličProzess erblickten das Licht der Öffentlichkeit. ${ }^{42}$ Im Vorwort zum Buch „Der Prozess Vera Zasuličc" von 1906 betonte der Herausgeber, dass es bis anhin in Russland kaum möglich gewesen sei, Informationen zu diesem „ersten Terrorakt“ in der russischen Geschichte zu erhalten. Dies sollte nun behoben werden. ${ }^{43}$ Auch Koni schreibt schon zu Beginn von „Triumvirn“, dass die „Befreiungsbewegung“ die Möglichkeit geschaffen habe, „frei“ über die ehemaligen „Steuermänner des russischen Staatsschiffs“ zu urteilen, und auch er deshalb nun sein „Material für die Geschichte“ hier präsentieren möchte. ${ }^{44}$ Bemerkungen und Erklärungen in den Manuskripten machen denn auch unmissverständlich deutlich, dass Koni grundsätzlich alle drei Erinnerungsschriften über seine Berufstätigkeit für ein breites Lesepublikum konzipiert hatte. Immer wieder adressiert er im Fließtext

zum Inhalt haben. Themen sind dadurch oftmals die Berufslaufbahn oder die politische Karriere. Autobiografien hingegen widmen sich eher der Entwicklung der individuellen Persönlichkeit. Im Russischen allerdings werden Autobiografien oftmals sowohl „Erinnerungen“ [Vospominanija] als auch „Memoiren“ [Memuary] oder „Aufzeichnungen“ [Zapiski] genannt. Das russische Wort Avtobiografija hingegen meint den deutschen „Lebenslauf“.

40 Ungeachtet der tatsächlichen Lebensdauer zeigte sich Konis Zeithorizont des nahenden Todes beispielhaft in einer brieflichen Bemerkung aus dem Jahre 1906. Darin schreibt er, dass er nun angesichts des ,wie es scheint nahen Endes“ seine Erinnerungen festhalten wolle, vgl. GA8, S. 244 (Brief an Aleksej Sergeevič Suvorin vom 04.10. 1906).

41 Vgl. ausführlicher sowohl zur Revolution als auch zum Thema Zensur das Kapitel Autobiografisches Ringen im Zeichen der ersten Russischen Revolution.

42 Rindlisbacher: Leben für die Sache, S. 22.

43 V F. A. Gallanin: Process Very Zasulič. Sud i posle suda. Sankt Peterburg 1906, S. 3-4. Koni selber wird im Kapitel „Gerichtsprozess“ als Vorsitzender genannt (ebd., S. 12), ohne dass die Sammlung der Gerichtsreden um eine erweiterte Einschätzung der Rolle Konis ergänzt würde.

44 Koni: Triumviry. In: GA2, S. 253. 
die potentiellen Leser und verweist auf Dokumente und Informationen, die er den Erinnerungsschriften noch beilegen werde..$^{45}$ Doch ungeachtet der gewandelten Publikationsbedingungen und der intensivierten öffentlichen Diskussion publizierte Koni seine Erinnerungsschriften nicht. Dies mag zum Teil daran gelegen haben, dass nach wie vor nicht alle Aussagen im Text hätten gedruckt werden dürfen. So erwähnt Koni in einem Brief vom Juli 1907, dass diese Erinnerungsschriften noch nicht ,ans Licht“ könnten. ${ }^{46}$ Gleichzeitig sind seine Erinnerungen aber nicht nur „Material für die Geschichte“, das er mit Dokumenten versehen der Öffentlichkeit zugänglich machen möchte. Die Retrospektive auf seinen Werdegang eröffnet auch sehr persönliche Momente von Hoffnung und Faszination in den Kreisen von Senatoren, Ministern und Zarenfamilie, in denen sich Koni im Verlauf seiner Karriere bewegt hatte, und die ihm immer noch wichtig zu sein schienen. Seine Idealvorstellungen von der (justiz-)politischen Ausgestaltung des Russischen Reiches und die eigene Rolle, die er dabei zu spielen gedachte, deuten sich ebenso an wie die Verbitterung und Enttäuschung ob all der Kämpfe und der persönlichen Rückweisungen und Missstände, mit denen er in seinem Berufsalltag konfrontiert worden war. Diese Einsichten und persönlichen Auseinandersetzungen wollte Koni wohl nicht zu Lebzeiten vieler seiner Protagonisten - und seiner eigenen Person - veröffentlicht sehen. ${ }^{47}$ So las er die Manuskripte in den Jahren nach ihrer Fertigstellung denn lediglich im kleinen Kreis von Freunden und Bekannten vor. ${ }^{48}$

45 Vgl. z. B. Koni: Krušenie carskogo poezda v 1888 godu, S. 430-31, wo Koni seinen Lesern erklärt, dass er in einem späteren Kapitel der Erinnerungsschrift die Entwürfe für die offiziellen Untersuchungsresultate einfügen werde und deshalb jetzt vorläufig nicht auf die Details eingehe, oder KonI: Triumviry. In: GA2, S. 262, wo Koni darauf verweist, dass er am Schluss des Textes eine Notiz als Anhang anfügen werde.

46 Vgl. die Aussage in der Skizze über Koni: Lev S. UtevskiJ: Poslednij ètap žiznennogo puti. In: Trudy Puškinskogo Doma Akademii Nauk SSSR (Hrsg.): Pamjati Anatolija Fëdoroviča Koni. Leningrad u. a. 1929, S. 97 sowie Konis Brief GA8, S. 246 (Brief an V. D. Komarova vom 12.07. 1907). Vgl. auch den Brief ebd., S. 295 (Brief an A. A. Izmajlov vom 11. 11. 1915).

47 So heißt es in einer Vorbemerkung des Herausgebers einer der posthumen Veröffentlichungen des Zasulič-Textes, dass Koni die Erinnerungen zwar auch aufgrund der Zensurbedingungen nicht schon im Zarenreich publiziert habe, aber hauptsächlich, weil er nicht Leid bei noch lebenden Personen habe auslösen wollen, vgl. Anatolij F. Konı: Vospominanija o dele Very Zasulič, hrsg. u. mit einer Einleitung versehen v. M. F. Teodorovič und Iv. Teodorovič. Moskva u. a. 1933, S. XXXVIII und XXXVIV (Einleitung von Iv. Teodorovič).

48 Schon Ende 1904 spricht Koni in einem Brief an den bekannten Sprachwissenschaftler Aleksej Aleksandrovič Šachmatov (1864-1920) vom Vorlesen der Erinnerung an den Entgleisungsfall, vgl. GA8, S. 212 (Brief an A. A. Šachmatov vom 05. 11. 1904). Der Schriftsteller und Literaturkritiker Kornej Čukovskij berichtet zudem, dass sich 1913 um die 50 Freunde und Juristen aus St. Petersburg versammelt hätten, um Konis Erinnerung an den 


\subsubsection{Konis „Wahrheit“ für den Zaren}

Eine „alte Liebe“ [staraja ljubov'] aus der Kindheit sei Zar Alexander II. Dies merkt Koni in der Zasulič-Erinnerungsschrift an, als er Revue passieren lässt, wie er im März 1878 kurz vor dem Prozess gegen die Attentäterin zum Zaren vorgeladen worden sei. ${ }^{49}$ Er beschreibt das Warten bis zum Beginn der Audienz, für die zahlreiche weitere Persönlichkeiten einbestellt worden seien, und schließlich das Auftauchen des "Selbstherrschers“. Bei dessen Anblick seien in ihm Erinnerungen an das Jahr 1855 hochgekommen. Damals habe er zusammen mit seinem Bruder am Tag der Amtseinsetzung von Alexander II. dessen Büste mit Papierblumen geschmückt. ${ }^{50}$ Aber auch die Bauernbefreiung und die Gerichtsreform seien ihm in den Sinn gekommen. Und schließlich die große Freude, die er und „ohne Ausnahme alle Menschen in St. Petersburg" verspürt hätten, nachdem der Zar im Jahre 1866 den Attentatsversuch von Dmitrij Karakozov überlebt hatte. ${ }^{51}$ Ausführlich und berührt schildert Koni die Audienz und beschreibt Kleidung und Gefühlslage des Zaren und seiner Gattin, die beide bleich und müde gewesen seien. ${ }^{52}$ In ähnlich ergriffenem Stil widmet sich Koni in „Die Entgleisung des Zarenzugs“ dem persönlichen Zusammentreffen mit dem Monarchen. Nun war es Zar Alexander III., dem Koni Rechenschaft ablegte. Dass es für ihn eine ganz spezielle Bedeutung hatte, einen Fall zu bearbeiten, in den der Zar so unmittelbar involviert war, deutet sich schon zu Beginn der Erinnerungsschrift an. Zuerst noch sachlich und kurz angebunden, wird Konis Beschreibung immer ausführlicher und detailreicher, umso näher er selber dem verunfallten Zug kommt. Koni beginnt seine Gefühle zu beschreiben und wechselt in eine blumige und stark stilisierte Sprachform. Die Leser wähnen sich nicht länger in einem faktenbezogenen Bericht zu den damaligen Geschehnissen, sondern entschwinden für einige Absätze in ein romanhaftes Setting, das sofort wieder aufgehoben wird, wenn Koni minutiös die Unfallstelle und seinen Arbeitsalltag als Leiter der Untersuchung beschreibt. Der kurze literarische Einschub dreht sich um den Moment, in dem Koni am Unfallort eintrifft und die Bedeutung der Aufgabe, die man ihm gegeben hat, zu erkennen vermeint. Die Figur des Zaren ist nicht unmittelbar Teil dieses Augenblicks, indirekt aber verflechten sich in Konis Darstellung seine eigene Person eng mit jener des Monarchen im Speziellen und der Geschichte Russlands im Allgemeinen.

Zasulič-Prozess und den Entgleisungsfall zu lauschen, vgl.: Kornej ČukovsкIJ: Anatolij Fëdorovič Koni. In: GA8, S. 8.

Ebd., S. 70.

Ebd., S. 71.

Ebd., S. $70-72$. 
Um ein Uhr nachts am 20. Oktober war ich vor Ort. Als ich, umgeben von [...] Wächtern mit Fackeln und Laternen, eilig den Ort der Entgleisung inspizierte [...], wurde ich von einer großen Befangenheit ergriffen, klar erkennend, dass von mir nun ganz Russland die Lösung dieses verhängnisvollen Rätsels erwartete [...]. Die Größe der Aufgabe, ihre Schwere und die direkte Konfrontation mit den Gründen und Folgen des Ereignisses, welches eine verhängnisvolle historische Bedeutung haben konnte, konnte nicht nicht auf mich wirken. Ich bat Gott aufrichtig und innig, mir zu helfen und mich in jener Prüfung des Geistes und Gewissens, die mir vom Schicksal geschickt worden war, zu erleuchten. Nachdem ich die Begleiter weggeschickt hatte, stand ich lange alleine mit meinen Gedanken am Ort der Entgleisung, unter dem kalten Himmel, der hell mit ukrainischen Sternen glitzerte. Aber wie immer tauchten Ernst und Trivialität des Lebens auf, um meine Stimmung zu zerstören. ${ }^{53}$

Dramatisch inszeniert sich Koni als einsamen Mann unter dem Sternenhimmel, der über sich die Last der Aufgabe spürte, die ihn direkt mit der politischen Führung und der Zukunft des Russischen Reiches zu verbinden schien. Gut 20 Seiten weiter schildert er dann das Treffen mit dem Zaren selber, dem er im Schloss Gatčina außerhalb von St. Petersburg Bericht über die Resultate der Untersuchung erstatten musste. Erneut lehnt sich der Sprachstil in seiner Festlichkeit an Konis damalige Gefühlslage an. Schritt für Schritt wird der Weg hin zum Palast des Zaren aufgezeichnet. Bis schließlich als Höhepunkt nach diversen palästlichen Vorzimmern und Treppen der Monarch persönlich in Sicht gekommen sei: „[...] sah ich den Regenten [vlastelin] über die Geschicke Russlands. “" Ergriffen berichtet Koni, wie für einen Moment seine Stimme gezittert habe, als der Zar im Schloss erschienen sei. Nur „Zwei Schritte“ weg von ihm habe der Mensch ge-

53 KonI: Krušenie carskogo poezda v 1888 godu. In: GA1, S. 421. Da die deutsche Übersetzung kaum einen Eindruck vom Bild zu vermitteln mag, das Koni von sich und seiner Aufgabe zeichnet, sei hier das ungekürzte russische Original angefügt: „V čas noči 20 oktjabrja ja byl na meste. Kogda, soprovoždaemyj upravljajuščim dorogoj i storožami s fakelami i fonorjami, ja beglo osmotrel mesto krušenija i vozvyšavšujusja gromadu vrezavšichsja $\mathrm{v}$ zemlju parovozov i razrušennych, iskalečennych i rasterzannych vagonov, ja prišel v bol'šoe smuščenie, jasno soznav, chto ot menja teper' ždet vsja Rossija razrešenija rokovoj zagadki nad etoj mračnoj, besformennoj gromadoj razvalin. Veličie zadači, trudnost' ee i nachoždenie licom k licu s pričinami i posledstvijami sobytija, kotoroe moglo imet' rokovoe istoričeskoe značenie, ne mogli ne vlijat' na menja. Ja iskrenne i gorjačo molil boga pomoč' mne i prosvetit' menja v tom ispytanii uma i sovesti, kotoroe mne bylo poslano sud'boj. Otpustiv provožatych, ja dolgo stojal odin na meste krušenija so svoimi dumami, pod cholodnym nebom, blistavšim jarkimi ukrainskimi zvezdami. No proza i pošlost' žizni, kak vsegda, javilis', čtoby razrušit' moe nastroenie.“

54 KonI: Krušenie carskogo poezda v 1888 godu. In: GA1, S. 449. 
standen, der mit seinem Willen über „Wohlergehen und Unglück“ eines „Volkes von 100 Millionen“ bestimme. ${ }^{55}$ Doch das aufmerksame Zuhören des Zaren habe ihn sogleich beruhigt:

In diesen Augen, tief und fast berührend, leuchtete eine Seele, erschreckt in ihrem Vertrauen in die Menschen und hilflos gegen die Lügen, zu denen sie selber nicht fähig waren. Sie haben mich tief beeindruckt. ${ }^{56}$

Die Audienz, bei der der Jurist seinen Bericht und seine Vorschläge darlegte, habe für Koni - wie er festhält - mit dem Dank des Zaren für seine Arbeit und einem kräftigen Händedruck geendet. ${ }^{57}$

An der gleichen Stelle im Text fügt Koni einen weiteren Bericht zu einer Audienz beim Zaren ein. Diesmal ist es eine Rückblende in das Jahr 1885, wo Koni anlässlich seiner Ernennung zum Oberstaatsanwalt am Kriminalkassationsdepartement schon einmal von Alexander III. in einer von dessen Residenzen empfangen worden war. Auch hier zeichnet er wieder ein poetisches Bild:

Ich sah vor mir im Empfangssaal des Ančikov-Palastes, beleuchtet mit hellen Strahlen der Februarsonne, Alexander III. in einer langen Garde-Uniform [...] vor mir einen Schritt zurücktreten und mir mit einem unguten Blick seiner irgendwo auf die Seiten ausweichenden Augen mit schneidiger [...] Stimme sagen ...

Weiter führt Koni aus, dass der Zar ihn damals für den Zasulič-Fall gerügt habe und er deswegen von einem Gefühl der „Ungerechtigkeit“ erfasst worden sei..$^{58}$ In einer Teilabschrift des Manuskripts findet sich anstelle von „Ungerechtigkeit“ [nespravedlivost'] sogar der Begriff „Trauma“ [travma]..$^{59}$ Von diesem „Trauma“ scheint aber drei Jahre später nach der erfolgreichen Präsentation des Berichts zum Unfall des Zarenzuges keine Rede mehr zu sein. Auf den Punkt bringt Koni dies indirekt, indem er in seiner Erinnerung den Justizminister zitiert, der ihn zum Rapport vor dem Zaren begleitet hatte. Dieser habe nach der Audienz bemerkt:

Ich habe beobachtet - sagte Manasein, - wie er [der Zar, CC] Ihnen zugehört hat; man kann sicher sein, dass er nicht ein Wort vergessen wird und ich glaube, dass man Sie

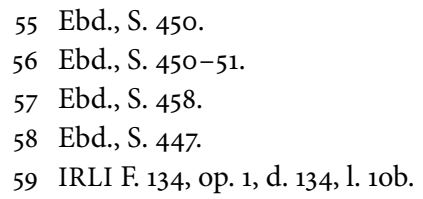


persönlich dazu beglückwünschen kann, dass alles vergessen ist, womit man Sie so lange und ungerechterweise quälte. ${ }^{60}$

Nicht nur Alexander III. hörte Koni seinen Erinnerungen zufolge aufmerksam $\mathrm{zu}$, sondern auch die Gattin des nachfolgenden Zaren Nikolaus II. Aufgrund des inhaltlichen Schwerpunkts von Konis Rückschau auf sein Berufsleben taucht der letzte russische Zar in den drei von 1904 bis 1907 verfassten Erinnerungsschriften kaum auf. ${ }^{61}$ Seine Ehefrau Zarin Alexandra Fjodorowna (1872-1918) wird von Koni aber in der Erinnerung an die Entgleisung des Zarenzugs zum Thema gemacht. Als Mitglied der Wohlfahrtsstiftung für „Arbeitshilf“" begegnete er Alexandra Fjodorowna, die als Vorsitzende amtierte, regelmäßig. Eigentlich kommt Koni nur im Rahmen eines Exkurses auf diese Stiftung zu sprechen, als er einen der wichtigen Akteure im Entgleisungsfall näher beschreibt. Es handelt sich dabei um Sergei Witte, der zur Zeit des Unglücks Generaldirektor der SüdWest-Bahnen war. In Reaktion auf den Unfall wurde Witte 1889 vom Zaren zum Leiter des neu geschaffenen „Departements für Eisenbahnfragen“ ernannt, und einige Jahre später stieg er zum Finanzminister auf und prägte maßgeblich die Industrialisierungspolitik des Landes. ${ }^{62}$ In der Stiftung „Vormundschaft über die Arbeitshäuser und die Zwangsarbeitsanstalten" kreuzten sich nun zu Beginn des 20. Jahrhunderts die Wege von Koni und Witte einmal mehr. Koni erinnert sich in der autobiografischen Schrift ausführlich an die Diskussionen unter den Stiftungsmitgliedern. ${ }^{63}$ Doch zum eigentlichen Thema wird schon bald die Angetraute

60 Koni: Krušenie carskogo poezda v 1888 godu. In: GA1, S. 458.

61 Ende 1894 wurde Nikolaus II. durch den überraschenden Tod seines Vaters plötzlich zum Herrscher über das Russische Reich. Nach der Abdankung des letzten Zaren 1917 schrieb Koni einen separaten kurzen Text über die Persönlichkeit von Nikolaus II. und den Eindruck, den er persönlich in einigen Audienzen Ende der 189oer-Jahre von ihm gewonnen hatte. Bereits 1906 schrieb Koni auch einen Bericht zu Nikolaus' Eröffnung der ersten Duma. Beide Erinnerungsschriften werden später noch Thema sein.

62 Frithjof Benjamin Schenk: Russlands Fahrt in die Moderne. Mobilität und sozialer Raum im Eisenbahnzeitalter. Stuttgart 2014, S. 314 und 317 sowie ausführlicher zu Wittes persönlichem Hintergrund und seiner Finanz- und Wirtschaftspolitik: Stephen Kот KIN: Stalin. Vol 1: Paradoxes of Power, 1878-1928. London u. a. 2014, S. 68-71.

63 Die sogenannte Arbeitshilfe [trudovaja pomošč] entwickelte sich seit Ende der 188oerJahre als eigenständiger Zweig der Wohltätigkeit und nahm sich speziell der Armutsproblematik an. Arbeit wurde dabei als Hilfe zur selbständigen Befreiung aus der Not gesehen. Die Stiftung „Vormundschaft über die Arbeitshäuser und Zwangsarbeitsanstalten“ [Popečitel'stvo o domach trudoljubija i rabotnych domach] war als Wohlfahrtseinrichtung der Zarin seit ihrer Gründung 1895 eine Regierungsrichtung. Sie entwarf Modellstatute und spendete in hohem Umfang für diverse Projekte. Der Finanzminister nahm regelmäßig an den Sitzungen des Zentralkomitees teil und verlieh der Organisation so eine 
von Nikolaus II. Die „Kaiserin“ [imperatrica] - so beschreibt sie Koni - habe er das erste Mal im Herbst 1899 in der Residenz in Carskoe Selo angetroffen. Sie habe ihn vor der Sitzung freundschaftlich empfangen. ${ }^{64}$ Während der eigentlichen Versammlung habe er auch selber das Wort ergriffen, wie er sogleich in direkter Rede nacherzählt: „Erlauben Sie, sagte ich - und die Zarin drehte mir ihren Kopf mit aufmerksamem Ausdruck ihrer tiefgründigen blauen Augen zu -, ,mir scheint $[\ldots] .{ }^{c}{ }^{655}$ Über viele Seiten hinweg schwelgt Koni in seiner Erinnerung an die Stiftung und die Zarin und berichtet mit besonderer Genugtuung darüber, dass Alexandra Fjodorowna in diesen und jenen Punkten mit ihm „vollständig [...] einverstanden" gewesen sei. ${ }^{66}$

Koni lässt die potentiellen Leser seiner Rückschauen an seiner Faszination für die russische Zarendynastie und deren enorme Machtfülle teilhaben. Die poetischen Worte, die er wählt, wenn er Zar und Zarin und sich selbst in deren Gegenwart beschreibt, geben diesen Textstellen einen besonderen Klang und unterstreichen den Stellenwert dieser Momente in Konis Erinnerung. ${ }^{67}$ Noch 1904 bezeichnet er den Augenblick, in dem er vom Zaren wegen des Zasulič-Falles gerügt wurde, als ungerecht und traumatisch. Umso stärker ist sein Stolz spürbar, wenn er den Lesern en détail erläutert, wie Alexander III. mit seiner Arbeit im Fall der Entgleisung zufrieden gewesen sei und Zarin Alexandra Fjodorowna mit ihren „tiefgründigen blauen Augen“ seine Ausführungen mit Zustimmung bedacht habe. Diese Faszination für das Herrscherhaus und der Stellenwert, den er zarischer Wertschätzung gibt, kreieren in Konis autobiografischem Schreiben eine Verbundenheit zwischen seiner Person und der Figur des Monarchen. ${ }^{68}$ Er

besondere Bedeutung, vgl. Annegret BAu tz: Sozialpolitik statt Wohltätigkeit? Der Konzeptionswandel städtischer Fürsorge in Sankt Petersburg von 1892 bis 1914. Wiesbaden 2007, S. 166-67. Koni war nach seinem Zeitschriftenartikel zum Thema der „Arbeitshilfe“ vom November 1897 in dieses Komitee ernannt worden. Vgl. GARF F. 564, op. 1, d. 203, 1. 98. Vgl. für den Artikel auch Fußnote 249 in TEIL EINS.

64 GARF F. 564, op. 1, d. 203, l. 1020b-103.

65 Ebd., 1. 103ob.

66 Ebd., l. 104ob.

67 Vgl. zum minutiösen Aufzählen aller Erlebnisse, die im Zusammenhang mit dem Oberhaupt eines Imperiums stehen, z. B. auch Marion Wullschleger: „Truthfulness and Sincerity“. Habsburg Civil Servants in Trieste and their Autobiographical Practices after the Fall of the Empire. München, Konferenz „Imperial Experts and Their Autobiographical Practices“ Juli 2014 (unveröffentlichter Aufsatz), S. 4-5. Wullschleger berichtet darin von einem Statthalter in der Habsburger Monarchie, der in seinen Memoiren jedes seiner zahlreichen Treffen mit Mitgliedern der Kaiserdynastie aufnotierte. Die Bedeutung des Herrschers manifestiert sich in diesen Repetitionen.

68 Fein säuberlich aufbewahrt, finden sich in Konis persönlichen Unterlagen auch die zahlreichen offiziellen Einladungen in die verschiedenen Zarenpaläste einschließlich eines 
stellt sich selber in seinen Erinnerungen als Beispiel für die notwendige „lebendige Verbindung" zwischen Regierung und Gesellschaft dar, auf die liberale russische Denker so sehr pochten. ${ }^{69}$ Diese Verbindung wurde von den verschiedenen Zaren selber mit vielfältigen Mitteln und in unterschiedlicher Ausprägung hergestellt. So haben sich sowohl Alexander II. als auch seine beiden Nachfolger konstant darum bemüht, ihre Herrschaft durch die enge Beziehung zwischen Monarchen und Bevölkerung zu legitimieren. ${ }^{70}$ Richard Wortman spricht vom „Szenario der Macht" als spezifische Version eines Heldenmythos, den jeder russische Zar ab dem Moment der Thronbesteigung für seine Person zu generieren versuchte. Im „Szenario der Macht“ von Alexander II. wurde dieser Bezug über die Inszenierung von Dankbarkeit und Liebe des "russischen Volkes“ [Russian people beziehungsweise russkij narod] für den „Befreier-Zaren“, der die Leibeigenschaft abgeschafft hatte, hergestellt. ${ }^{71}$ Die liebevolle Verbundenheit des Herrschers zu seinen Subjekten blieb in den auf die Reformzeit der 186o-Jahre nachfolgenden Jahrzehnten für viele die Voraussetzung für die Weiterentwicklung des Russischen Reiches hin zu mehr politischen Freiheiten und größerer Beteiligung der Bevölkerung. ${ }^{72}$ Das „Szenario der Liebe“ zwischen Monarch und Bevölkerung wurde von Alexander II. und den Akteuren in der Zeit der „Großen Reformen“ in einer Art und Weise geprägt, die zu einer enormen Mythisierung der Autorität des Zaren führte. ${ }^{73}$ Dieser zollte Koni Tribut, wenn er in seiner Erinnerungsschrift die

Exemplars der Ordnung, welche Beamten und Ränge zu diesen Empfängen aufgeboten wurden, vgl. IRLI F. 134, op. 4, d. 343, 1. 24 und 74 ff.

69 WALICKI: Legal Philosophies of Russian Liberalism, S. 115. Walicki bezieht sich in seiner Abhandlung zum russischen Liberalismus hier insbesondere auf Boris Čičerin, der vom Ziel eines „living link“ zwischen Regierung und Gesellschaft sprach. Dieser sollte beispielsweise durch mehr gewählte Vertreter in Entscheidungsgremien realisiert werden. Diese Ansichten drückte Čičerin in seiner Schrift an den Zaren Alexander III. aus, auf die noch eingegangen wird. Vgl. für die persönliche Bekanntschaft Konis mit Čičerin und sein Porträt von ihm oben, S. 59 sowie das nachfolgende Unterkapitel. Wortman: Scenarios of Power, Bd. 2, S. $13 \mathrm{ff}$. Ebd., S. 8 und 13 .

WALICKI: Legal Philosophies of Russian Liberalism, S. 115.

Michail Dolbilov: The Political Mythology of Autocracy. Scenarios of Power and the Role of the Autocrat. In: Kritika: Explorations in Russian and Eurasian History 4 (2001), S. 782 und Richard Wortman: Reply to Mikhail Dolbilov. In: Kritika: Explorations in Russian and Eurasian History 4 (2001), S. 797-98. Dolbilov plädiert in seiner Rezension von Wortmans "Scenarios of Power" dafür, den Kreatoren der „Großen Reformen“ selbst eine wichtige Rolle zuzumessen in der Ausprägung dieses Mythos. Er spricht gar von einer „Autorschaft“. Wortman entgegnet dem allerdings, dass die Reformbürokraten lediglich ihre Aktionen und Argumente auf der Basis von Sprache und Narrativ des vorherrschenden Szenarios einbrachten. So haben sie zwar die Kreation des Szenarios mit beeinflusst („reshaping“), aber dieses entspringt nicht ihrer „Autorschaft“. 
Büste von Alexander II. erwähnt, die er und sein Bruder 1855 zur Amtseinsetzung feierlich geschmückt hatten. Eine solche „Einführung in die imperiale Ideologie“ in der Kindheitserinnerung ist ein klassisches Motiv autobiografischer Schriften aus dem Zarenreich. Das imperiale Russland wird in der Rückbesinnung auf die Kindheit über einen Zarenbesuch im Heimatort oder die Trauer der Familie im Moment des Todes eines Monarchen manifest. ${ }^{74}$

Wie genau das „Szenario der Liebe" zwischen Zar und Volk auszusehen habe, davon hatte Koni sehr konkrete Vorstellungen, von denen er die „Selbstherrscher“ aktiv zu überzeugen versuchte. So zumindest stellt er es in seinen Memoiren dar. Er nutzte seinen autobiografischen Rückblick auf das Berufsleben auch, um sich selber als Person abzubilden, die über die gesamte Karriere hinweg die faszinierende Nähe zu den Kreisen der Macht als Gelegenheit begriff, um eigene politische Einsichten und Lösungsvorschläge anzubringen. „Ein Wort der Wahrheit“ - so betont Koni in seiner Erinnerung an den Fall Vera Zasulič - habe er dem russischen Zaren im März 1878 bei der Audienz kurz vor dem Prozess bringen wollen. Ehrlich habe er Alexander II. damals erklären wollen, wie es zur blutigen Selbstjustiz der jungen Attentäterin hatte kommen können. Doch er habe einsehen müssen, dass seine Hoffnungen illusionär gewesen waren, den müde aussehenden Zaren inmitten der anderen zur Audienz geladenen Gäste darauf anzusprechen. ${ }^{75}$ Sowohl in der Erinnerung an den Fall Vera Zasulič als auch in der Erinnerung an die Entgleisung des Zarenzugs verweist Koni aber auch auf Episoden, in denen er sehr wohl erfolgreich wenigstens den Sprösslingen der Zarenfamilie etwas habe beibringen können. Im Zasulič-Text nennt Koni eine Führung durch die Petersburger Gefängnisse, die er dem Großfürsten und Zarensohn Sergej Aleksandrovič (1857-1905) einige Jahre vor dem Gerichtsfall gegeben und die in den „Sphären des Winterpalastes “ für Unmut gesorgt habe. Schließlich habe er ihm die Gefängnisse in ihrer ganzen ,unansehnlichen Nacktheit" gezeigt. $^{76}$ In einer Manuskriptversion

74 Ulrich Scнмid: Die subjektbildende Kraft des Imperiums. Autobiographien in der späten Zarenzeit. In: Martin Aust/Frithjof Benjamin Schenk (Hrsg.): Imperial Subjects. Autobiographische Praxis in den Vielvölkerreichen der Habsburger, Romanovs und Osmanen im 19. und frühen 20. Jahrhundert. Köln 2015, S. 165 ff. Vgl. zum Beispiel auch die Memoiren des Anwalts Nikolaj Platonovič Karabčevskij (1851-1925). Im Band „Kindheit“ erinnert er sich ausführlich an Erlebnisse mit dem Zaren in seinen Kindertagen, vgl.: Nikolaj P. KARABČEvskiJ: Čto glaza moi videli. I. V detstve. Berlin 1921, S. 100 ff. Vgl. ausführlicher zu Karabčevskij und seinen Memoiren unten, S. 277.

75 Koni: Vospominanija o dele Very Zasulič. In: GA2, S. 71.

76 Ebd., S. 71. In seiner Reihe „Aus den Erinnerungen eines Gerichtstätigen“ in „Russische Altertümer“ [Russkaja Starina] fügte Koni diese Episode im Text „Prokuratura i Administracija“ ein, vgl. Anatolij F. KonI: Prokuratura i Administracija. In: ders. (Hrsg.): Na žiznennom puti, Bd. 1. Iz zapisok sudebnogo dejatelja, žitejskie vstreči. Sankt-Peterburg 
des Zarenzug-Textes erwähnt Koni am Rande, dass er zudem Nikolaj Nikolaevič (1856-1929), den Enkel des Zaren Nikolaus I. (1796-1855), in Fragen des Rechts unterrichtet habe..$^{77}$ Erfüllt von solchen Hoffnungen auf pädagogischen Erfolg beschreibt sich Koni auch bei seinem Rapport vor Zar Alexander III. in Sachen Entgleisung. Er habe sich fest vorgenommen, den Zaren während der Audienz auf verschiedene ,abnormale Bedingungen“, Unterschlagungen und Missbräuche in der Eisenbahnwelt anzusprechen. ${ }^{78}$ Koni nutzt diesen Moment, um in seiner Erinnerungsschrift nicht nur ausführlich aufzuzählen, was er dem Zaren zu den Unfallursachen und den Verantwortlichen zu berichten gehabt habe. Vielmehr führt er auch gleich Kritikpunkte allgemeiner Art an, die er als tiefergehende Ursachen betonen wollte. So bemängelt er unter anderem die „bürokratische Beschaffenheit“ der Verwaltung, die ,weit weg von der Realität des Alltags und seinen Anforderungen“ sei. Berichte von Untergebenen, die sich ehrlich einsetzten, würden in St. Petersburg in einer „Karawane von Papieren“ zu einer Nummer unter vielen werden. ${ }^{79}$ Koni rekapituliert über die Nacherzählung des Gesprächs mit dem Zaren seine Ansichten zu den Missständen im Russischen Reich. Dass er diese Analysen auch zum Zeitpunkt der Niederschrift und Bearbeitung der Erinnerung nach der Jahrhundertwende für relevant hielt, deutet sich durch die Ausführlichkeit seiner Ausführungen an. Noch unmissverständlicher wird dies in der Erinnerungsschrift an das Dreigespann, bestehend aus Pobedonoscev, Murav'ev und Tagancev. Darin erinnert sich Koni nicht nur an die Zusammenarbeit mit diesen Politikern und Senatoren, sondern nutzt den autobiografischen Text auch, um seine potentiellen Leser auf politische Aktionen seinerseits aufmerksam zu machen, die nur bedingt mit dem Inhalt der Erinnerungsschrift zusammenhängen. Auf diese Weise konnte er seine eigene gesellschaftspolitische Einschätzung nochmals deutlich machen und aufzeigen, wie intensiv er sich in seinem Berufsleben auch in den höchsten Kreisen um Gehör bemüht hatte. Koni berichtete in „Die Triumvirn“ nicht nur im Fließtext von seinen politischen Einflussversuchen, sondern wollte auch entsprechende Unterlagen im Anhang an die Erinnerungsschrift mitliefern. Als „Material für die Geschichte“ sollte dies getreu seinen eigenen einleitenden Worten dienen.

1912, S. 190 ff. Die Gefängnistour mit Sergej Aleksandrovič habe er genutzt, um den Zarensohn darauf aufmerksam zu machen, was für ungute Folgen das Passsystem in Russland habe. So habe er dem jungen Mann ehrliche Menschen gezeigt, die wegen ungewollten Passvergehen nun neben tatsächlichen Missetätern eingesperrt worden seien.

77 GARF F. 564, op. 1, d. 203, 1. 87ob. Dieser Hinweis wurde durchgestrichen und fehlt in der Version, die in der Gesamtausgabe von Konis Werken abgedruckt ist.

78 Koni: Krušenie carskogo poezda v 1888 godu. In: GA1, S. 447.

79 Ebd., S. 453. 
Bei einem dieser angehängten Dokumente handelt es sich um ein „Memorandum“ [zapiska], das Koni fast drei Jahrzehnte vor seiner Verschriftlichung von „Triumvirn“ verfasst hatte. Thematisch kommt Koni in der Erinnerungsschrift auf dieses Memorandum zu sprechen, weil er es im Jahre 1878 einem der Mitglieder des Dreigespannes, Konstantin Pobedonoscev, übergeben hatte. Ausführlich erklärt er in seiner Rückschau, dass er seinen ehemaligen Universitätsprofessor im Sommer 1878 regelmäßig auf dem Schiff angetroffen habe, mit dem Pobedonoscev von seinem Wohnort zur Arbeit in die Stadt St. Petersburg gependelt sei. ${ }^{80}$ Auf diesen Überfahrten, so Koni, habe er häufig mit dem Mann diskutiert, der mittlerweile als Erzieher und Lehrer der Rechtsgeschichte für den Thronerben Aleksandr Aleksandrovič, den zukünftigen Zaren Alexander III., arbeitete. Dabei habe er ihm auch von seinen Befürchtungen berichtet, dass die Regierung mit dem harten Vorgehen gegen revolutionäres Gedankengut „kurzsichtig, um nicht zu sagen blindlings" agiere. ${ }^{81}$ Natürlich wird in diesen Gesprächen auch der Zasulič-Fall thematisiert, der wenige Wochen vorher mit dem aufsehenerregenden Freispruch geendet hatte. Koni weist die Leser seiner Erinnerungsschrift auf den Fall hin, der eine „Warnung“ [predostereženie] gewesen sei. ${ }^{82}$ Auch Pobedonoscev zeigt sich in Konis Darstellung besorgt darüber, was er ihm berichtet, und habe eines Tages gemeint, dass man diese Fakten unbedingt dem Thronfolger zukommen lassen müsse. Koni erzählt, dass er sich nach dieser Aussage sofort eine ganze Nacht lang hingesetzt und seine Überlegungen verschriftlicht habe. Persönlich sei er schließlich bei Pobedonoscev mit seinem „Memorandum“vorbeigegangen. In „Triumvirn“ merkt Koni an dieser Stelle nun an, dass er die wichtigsten Schlussfolgerungen aus diesem Schreiben hier nochmals nennen möchte und zudem das gesamte Dokument als Anhang seiner Erinnerungsschrift hinzufüge. ${ }^{83}$ Nur wenige

80 Koni: Triumviry. In: GA2, S. 261.

81 Ebd., S. 261.

82 Ebd. Koni verweist auf seine Erinnerung an den Fall Vera Zasulič, obwohl diese, genau wie „Triumvirn“, noch weit weg von einer Publikation war. An seinen Intentionen lässt er so aber keine Zweifel.

83 KonI: Triumviry. In: GA2, S. 261-62. Da sich die posthume Publikation von „Triumvirn“ in der Gesamtausgabe von Konis Werken auf das Manuskript im Archiv IRLI beruft (IRLI F. 134, op. 1, d. 143.), fehlt diese Einfügung der Schlussfolgerungen aus dem „Memorandum“. In dieser Archivversion findet sich lediglich der handschriftliche Vermerk von Koni, dass man an der entsprechenden Stelle eine Seite auslassen solle. Dieser Hinweis wurde von den Herausgebern der Gesamtausgabe kommentarlos übernommen. Die „Triumvirn“-Version im Archiv GARF (GARF F. 564, op. 1, d. 207) enthält hingegen bereits Auszüge aus dem „Memorandum“, vgl. 1. 6ob-1. 9. Diese entsprechen aber nicht exakt dem Original, sondern entstammen wohl einer Überarbeitung aus den 1920er-Jahren, vgl. zu dieser angesichts der neuen politischen Gegebenheiten leicht angepassten Version unten, S. 264. 
Seiten weiter bringt Koni in „Triumvirn“ ein zweites Dokument aus der fernen Vergangenheit ins Spiel. Er geht dazu über, sich an die Ermordung des Zaren Alexanders II. 1881 zu erinnern und an die Folgen, die das für die Rolle Pobedonoscevs gehabt hatte. Dieser war nun als Lehrer und Vertrauter des Zarensohnes in bester Position, um dem so plötzlich an die Spitze des Reiches gelangten Aleksandr Aleksandrovič mit Rat und Tat zur Seite zu stehen. Koni erläutert, dass Pobedonoscev diese Position leider ganz und gar nicht in seinem Sinne genutzt habe. Man hätte dem neuen Zaren klar machen müssen, dass er trotz der Ermordung seines Vaters nicht das ganze Volk für einige „Irre“ [bezumcy] bestrafen sollte. ${ }^{84}$ Dies ergänzt Koni mit dem Hinweis: „Das, was ich damals im ,Porjadok‘ (3. März 1881, Nr. 62) schrieb, am Tag nach dem Ableben des Zaren, ist dieser Schrift in Form von Anhängen beigelegt. ${ }^{\text {"85 }}$ Tatsächlich hatte Koni 1881 einen Zeitungsartikel verfasst, in dem er in anonymer Form dem Zarensohn öffentlich darlegte, was er selber für ein angemessenes politisches Vorgehen in der Epoche nach Alexander II. halten würde. Der Artikel erschien in der politisch-literarischen Zeitung „Ordnung“ [porjadok]. Diese war eine Gründung des mit Koni befreundeten Michail Matveevič Stasjulevič (1826-1911), der schon den „Boten Europas“ herausgab, für den auch Arsen'ev arbeitete. Nun sollte Anfang 1881 eine Zeitung hinzukommen, die es sich zum Ziel setzte, Ideale von Gesetzlichkeit und individuellen Rechten im Bewusstsein ihrer Leser zu stärken. ${ }^{86}$ In den Monaten vor der Ermordung des Zaren im Frühjahr erhielten solche publizistischen Initiativen einen gewissen Freiraum, da der neu ernannte Innenminister Graf Michail Tarielovič Loris-Melikov (1824-1888) Reformpläne schmiedete und kritische Ansichten nicht sofort durch die Zensur zum Verstummen brachte. ${ }^{87}$

Das „Memorandum“ von 1878 und der Zeitungsartikel von 1881, die Koni 1907 als Anhänge in „Die Triumvirn“ einfügen wollte, ergeben zusammen ein deutliches Bild von seiner politischen Haltung. Viele der im Auftakt zu diesem Kapitel angeführten Interpretationen Konis zur gesellschaftspolitischen und rechtlichen Entwicklung des Landes finden sich auch in diesen beiden Schriften wieder. Im „Memorandum“, das Koni unmittelbar für den Thronfolger verfasste, beschreibt er auf vielen Seiten die seiner Ansicht nach gefährliche und kontraproduktive

84 KonI: Triumviry. In: GA2, S. 265-67.

85 Ebd., S. 267.

86 In der zeitgenössischen Ausgabe der „Enzyklopädie Brockhaus-Efron“ heißt es, die Zeitung habe es sich zur Aufgabe gemacht, die Vorstellung von rechtlicher Ordnung im gesellschaftlichen Bewusstsein zu verankern. Jeder Mensch im Zarenreich sollte über seine Rechte und Pflichten Bescheid wissen, vgl. Porjadok. In: ĖSBE 24A/48, 1898, S. 654.

87 Fedyashin: Liberals under Autocracy, S. 99-100, vgl. ausführlicher zu Loris-Melikov und Konis Erinnerungsschrift über ihn unten, S. 228. 
Vorgehensweise der Regierung gegen Oppositionelle in den 1870er-Jahren. Die Auswirkungen der Repressionen gegen die Narodniki werden betont, die durch die Unverhältnismäßigkeit und die Willkür der Maßnahmen nur immer mehr in ihrem Misstrauen gegen die politische Führung bestärkt worden seien. Immer wieder fügt Koni anschauliche Beispiele ein, wie willkürlich und fadenscheinig begründet junge Menschen zum Verhör geladen und für wochenlange Untersuchungen eingesperrt worden seien. „Sympathie für die Revolution“, „schädliche Gedankengänge“ oder „Besitz eines kommunistischen Buches“ - das in Tat und Wahrheit ein antikommunistisches Pamphlet gewesen sei: Solcherlei sei den Anklagen zugrunde gelegt worden. ${ }^{88}$ Minutiös zählt Koni über mehrere Seiten hinweg die Anzahl der angeklagten und verurteilten jungen Kritiker der Regierung im sogenannten „Prozess der 193 “ auf und integriert die Zahlen jener, die im Gefängnis Selbstmord begangen haben oder verrückt geworden seien. ${ }^{89}$ Geschickt gelingt es ihm, die Bedeutung der Analyse zu unterstreichen, indem er die Ausführungen mit solchen statistischen Grundlagen und unzähligen Beispielen belegt. So werden seine Kompetenz und sein umfassender Wissensstand betont und die Tragweite und Bedeutung des vorgefundenen Zustandes in Bezug auf die weitere Ausgestaltung der Regierungspolitik hervorgehoben. ${ }^{90}$ In ihren Überlegungen zum

88 Anatolij F. KonI: Političeskaja zapiska 1878 goda. Zakon 19 maja 1871 g. Iz vospominanij sudebnogo dejatleja. In: GA2, S. 335. In Konis Nachlass befindet sich auch eine inhaltlich sehr ähnliche Erklärung an den Justizminister, die Koni 1876 verfasst hatte. Er selber verweist im Fließtext darauf, als er von der Verhaftung Bogoljubovs und seinesgleichen berichtet, und verspricht auch hier, das Schreiben im Anhang anzufügen, vgl. Koni: Vospominanija o dele Very Zasulič. In: GA2, S. 31. Im Dokument kritisiert er die Mängel im System der Massenanklagen und schlägt entsprechende Änderungen vor. Dieses Schreiben beendet er mit den Worten, dass er „nicht ohne Seelenschmerzen an die abnormale Lage denken könne, in der sich [...] sowohl die gerichtliche Macht als auch die Beschuldigten“ befinden würden, und dass er sich erlaube, diese Überlegung dem Minister darzulegen. Dies allerdings „ohne sich mit Hoffnung zu verführen“, dass sie dessen Entscheidung beeinflussen könnte. Ebd., S. 389-92, Zitate S. 392 (Anhang zur „Erinnerung an Vera Zasulič“). Vgl. auch N. I. Leonov: Obščestvenno-političeskie vzgljady A. F. Koni v 60-70 gody XIX veke. Moskovskij gosudarstvennyj universitet imeni M. V. Lomonosova, Moskva 1974 (unveröffentlichte Dissertation). Leonov verweist auf S. 143 ff auf dieses Schriftstück und setzt es in engen Bezug zum „Memorandum“ (ebd., S. 153).

89 Koni: Političeskaja zapiska 1878 goda. In: GA2, S. 337-39.

90 All diese Beispiele und Zahlenangaben dürfte Koni aus seiner Zeit im Justizdepartement gehabt haben, wo er in die Diskussionen um das Vorgehen gegen die revolutionären Strömungen involviert war, in diesem Zusammenhang ist auch das eben erwähnte Schreiben an den Justizminister zu verstehen. In Konis Unterlagen finden sich denn auch Zusammenstellungen von Übersichten und Statistiken zum Phänomen der politischen Gerichtsfälle in den 1870er-Jahren, die ihm als Grundlage für seine Analysen dienten, vgl. z. B. GARF F. 564, op. 1, d. 624. Diese Übersicht zum Jahr 1876 scheint von Koni selber 
„Politischen als Kommunikationsraum" argumentieren Steinmetz und Haupt, dass Statistiken immer wieder als Mittel verwendet werden, um ein Anliegen in die "politische Sphäre“ zu bringen. ${ }^{91}$ Dabei wird das „Politische“ als spezifische Form der menschlichen Kommunikationsaktivität verstanden, aus der sich eine eigene „Sphäre“ bildet. Diese politische Sphäre grenzt sich von anderen (zum Beispiel der religiösen, rechtlichen, ökonomischen) ab. Ausgehend von dieser Vorstellung kann danach gefragt werden, wie die fließenden Grenzen zwischen diesen Sphären zustandekommen und welche konkreten Dynamiken und Vorgehensweisen in Prozessen der Politisierung und Depolitisierung zu beobachten sind.${ }^{92}$ Neben dem Sammeln von Zahlenmaterial kann eine „Politisierung" beispielsweise auch durch den simplen verbalen Akt, gewisse Themen "politisch“ zu nennen, entstehen. ${ }^{93}$ Tatsächlich sollte Koni sein „Memorandum“ einige Jahre, nachdem er es in „Triumvirn“ erwähnte, umbenennen: in „Politisches Memorandum“.94

Dass Koni die gewaltsame Vorgehensweise gegen Andersdenkende für wenig sinnvoll hielt, machte er auch im Zeitungsartikel für „Ordnung “ klar; hier tastete er sich nun noch deutlicher mit eigenen Lösungsvorschlägen vor. Unmittelbar nach der Ermordung Zar Alexanders II. fragte Koni in diesem Artikel rhetorisch: Wie könne man gegen jene wenigen Menschen vorgehen, die „den organischen Gang der Entwicklung des Landes beschleunigen oder verändern “ möchten? ${ }^{95}$ Was seiner Ansicht nach anstelle der kontraproduktiven Repression die angemessene Vorgehensweise wäre, folgt in einem emotionalen Appell: „Gebe Gott, dass jetzt in

zusammengestellt worden zu sein. Neben der Art des politischen Verbrechens und der Anzahl Verurteilungen gibt es auch eine Einteilung nach Gouvernements. Oder GARF F. 564, op. 1, d. 512 „Statističeskie svedenija o licach, osuždennych i privlečennych k sudebnoj otvetstvennosti po političeskim obvinenijam“. Dieses großformatige, wohl auf das Jahr 1877 bezogene Dokument enthält eine umfangreiche 278 Menschen umfassende Statistik zu Alter, Einkommen, Familienstand, Glauben, Bildungsniveau etc. von Personen, die wegen politischer Vorwürfe vor Gericht kamen.

91 Willibald Steinmetz/Heinz-Gerhard Haup t: The Political as Communicative Space in History. The Bielefeld Approach. In: Willibald Steinmetz/Ingrid Gilcher-Holtey/HeinzGerhard Haupt (Hrsg.): Writing Political History Today. Frankfurt, New York 2013, S. 24. Gerade in Russland wurde in der 2. Hälfte des 19. Jahrhunderts das Erfassen von Datenmaterial in starkem Maß vorangetrieben. So sollte die Bevölkerung besser erfasst und Veränderungen in Ökonomie, Landwirtschaft etc. belegt werden. Durch das Sammeln und Systematisieren von Informationen sollte die Kontrolle über das riesige Reich verbessert werden, vgl. dazu Fedyashin: Liberals under Autocracy, S. 130. Steinmetz/Haupt: The Political as Communicative Space in History, S. 21-23.

93 Ebd., S. 25.

94 Dies geschah im Rahmen der Publikation des „Memorandums“ nach der Oktoberrevolution, vgl. dazu ausführlich unten, S. 263.

95 [Anatolij F. Koni: Ohne Titel] In: Porjadok 61 (03. 03.1881), S. 1. 


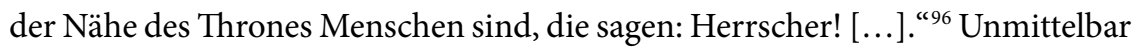
an den Zaren adressiert, folgt eine flammende Rede für einen Zaren, der sich für „Ordnung und gesetzliche Freiheit" einsetzt, ein Plädoyer für eine Herrschaft, die trotz des traurigen Anfangs "mutig“ sei und die "Großen Reformen“ des Vaters weiterführe. ${ }^{97}$ Eine Vision von einem Autokraten also, der die Begehrlichkeiten der Bevölkerung ernst nimmt. So mahnt Koni:

Sie sind auf dem Höhepunkt der Macht, das Buch der Staatsführung liegt schon lange offen vor Ihnen - öffnen Sie nun auch die Seele Ihres Volkes und lassen Sie die Wünsche ans Licht kommen, die schon lange in ihr leben. Sie alle haben das Ziel der Beruhigung und Entwicklung Russlands [...]!98

Konis flammender Appell, den er in seinen Memoiren wiederaufleben lässt, steht in den Schriften neben Momenten bitterer Enttäuschung, in denen er eingestehen muss, dass der Zar seinen „Worten der Wahrheit" nicht folgte. So schreibt Koni gleich nach der Zusammenfassung des Inhalts des „Memorandums“ an den Zarensohn, dass er nie etwas über das Schicksal dieses Dokumentes erfahren habe, das sich wohl als "Stimme eines Predigers in der Wüste" erwiesen habe. ${ }^{99}$ Wann immer nun Konis Bemühungen nicht von Erfolg gekrönt waren, schrieb er in seinen Memoiren die Schuldigen an diesem Versagen eindeutig fest. Exemplarisch zeigt sich dies in der „Erinnerung an die Entgleisung des Zarenzugs“, worin Koni den Autokraten in der persönlichen Audienz so ausführlich über die Missstände in dessen Reich unterrichtete. Konsterniert schreibt er im gleichen Text aber auch, dass dieser ganze Unfall von der Macht nicht richtig genutzt worden sei. Es sei offensichtlich gewesen, dass das Zugunglück im russischen Leben einen erneuten Moment der tiefen Liebe zum Zaren hervorgerufen habe. Alle Schichten der Gesellschaft seien von Rührung ergriffen gewesen, als sie Alexander III. nach der Entgleisung in Charkow begegneten. Diese Rührung, so führt er an, hätte dem Zaren zeigen müssen, wie leicht es sein könnte, „das russische Volk und die Gesellschaft an sich zu binden, wenn man sich ihnen gegenüber nur menschlich und vertrauensvoll verhalten würde“. Solche Momente hätten denn auch lange Zeit die Bedeutung der Zarenmacht zu erhöhen vermocht - nicht aber diesmal. ${ }^{100}$

96 Ebd.

97 Ebd.

98 Ebd. Versöhnlich fügt Koni dem hinzu: „und [...] den Wunsch des friedlichen Ruhmes für Ihre Herrschaft!“

99 Koni: Triumviry. In: GA2, S. 262.

100 Koni: Krušenie carskogo poezda v 1888 godu. In: GA1, S. 472, GARF F. 564, op. 1, d. 203, 1. 1-2 und IRLI F. 134, op. 1. d. 188, 1. 38ob. Vgl. auch die bereits erwähnten Aussagen Ko- 
Worauf Koni damit anspielt, wird im weiteren Verlauf der Erinnerungsschrift deutlich. Bei seiner Untersuchung des Unfalls machte er grobfahrlässiges Verhalten zahlreicher involvierter Personen aus. In seinem Text minutiös ausgeführt, plädierte er für die Anklage von einfachen Inspektoren und Maschinisten, aber auch von hohen Beamten wie Verkehrsminister Konstantin Nikolaevič Pos'et (1819-1899). Schließlich sei auch das Direktorium der Eisenbahngesellschaft selbst mitverantwortlich gewesen, es ginge nicht an, dass der „Herr“ [chozjain] nicht für die Taten seiner „Beauftragten“ [poverennye] geradestehen müsse. Diesen Ausführungen habe der Zar voll und ganz zugestimmt. „Alle“, die schuldig seien, müssten zur Rechenschaft gezogen werden. ${ }^{101}$ Entgegen dieser Aussagen und ungeachtet der Resultate der Untersuchungskommission entschied der Zar schlussendlich aber, den Fall ruhen zu lassen und keinerlei Gerichtsverfahren einzuleiten. ${ }^{102}$ Daraufhin habe er, Koni, versucht, wenigstens über eine Regierungsmitteilung die Öffentlichkeit über die Ursachen des Unfalls und das Fehlverhalten vieler Verantwortlicher zu informieren. Mit großem Arbeitsaufwand habe er eine solche Vorlage - letztlich vergeblich - erstellt. ${ }^{103}$ Konis Bemühungen wurden, so führt er selber in seiner Erinnerung aus, unter anderem von Konstantin Pobedonoscev torpediert, der lyrische Elemente in den eigentlich

nis zur Freude aller Bewohner von St. Petersburg, nachdem Zar Alexander II. 1866 das Attentat von D. Karakozov überlebt hatte, Konı: Vospominanija o dele Very Zasulič. In: GA2, S. 70. Während Koni dies 1904 noch so deutlich an mehreren Stellen in seine Darstellung einbezieht (vgl. die Manuskript-Verweise), sind Teile dieser Textstellen später durchgestrichen oder ganz weggelassen worden. Da eine maschinengetippte Version von 1923 als Vorlage für die Veröffentlichung in der Gesamtausgabe in den 1960ern diente, fehlen diese Elemente im heute verbreiteten Text. Auf Konis Überarbeitungen nach der Oktoberrevolution wird im Kapitel Politische Erinnerung an das Zarenreich in der Sowjetunion eingegangen.

101 Koni: Krušenie carskogo poezda v 1888 godu. In: GA1, S. 456-57. Vgl. zu den Schlussfolgerungen der Untersuchungskommission auch: SCHEnk: Russlands Fahrt in die Moderne, S. 314-15 bzw. RGIA F. 1224, op. 1, ed. Chr. 1, 1. 129ob-130. Die Anklage solch ranghoher Personen konnte Koni aber nicht selber verfügen. Der Staatsrat entschied sich denn im Februar 1889 auch, entgegen Konis Empfehlungen, den Verkehrsminister, der nach dem Unfall von seinem Amt zurückgetreten war, nicht noch gerichtlich zu belangen, vgl. Schenk: Russlands Fahrt in die Moderne, S. 315.

102 Schenk: Russlands Fahrt in die Moderne, S. 315 und Koni: Krušenie carskogo poezda v 1888 godu. In: GA1, S. 485 .

103 Koni: Krušenie carskogo poezda v 1888 godu. In: GA1, S. 486-87 und 489. Was schlussendlich am 15. Mai 1889 veröffentlicht wurde, war lediglich ein kaiserliches Reskript, in dem in allgemeinen Worten von „Unvorsichtigkeit“ die Rede war und die gerichtliche Untersuchung für abgeschlossen erklärt wurde, Schenk: Russlands Fahrt in die Moderne, S. 316 bzw. RGIA F. 1224, op. 1, ed. Chr. 1, 1. 150. 
sachlichen Text eingefügt und sich über die „öffentliche Meinung“ herablassend geäußert habe. ${ }^{104}$

Pobedonoscevs Haltung kommt einer von zwei gänzlich verschiedenen Möglichkeiten des Umgangs mit dem Zugunglück gleich. Benjamin Schenk beschreibt in seiner Monografie "Russlands Fahrt in die Moderne“ die zwei Narrative, in die die Entgleisung des Zarenzugs Eingang fand. Koni und seine Expertenkommission auf der einen Seite wollten eine an rationalen Aspekten orientierte Erzählung über das Ereignis, in der Schuldige genannt und Konsequenzen gezogen werden. Eine andere Strategie verfolgte die Regierung. ${ }^{105}$ Pobednoscev und seine lyrischen Abwandlungen von Konis Bericht stehen sinnbildlich für den Versuch, den Aspekt der wundersamen Rettung stärker zu betonen, anstatt konkrete Verantwortliche $\mathrm{zu}$ benennen. ${ }^{106}$ Der Mythos von Zar und russischem Volk, die von Gott und der Vorsehung auserwählt seien, sollte durch die Tatsache bestärkt werden, dass keinem Mitglied der Zarenfamilie beim Unfall etwas geschehen war. Dieses „Wunder von Borki" sollte sich schlussendlich als das nachhaltigere der beiden Narrative erweisen. ${ }^{107}$ Der Zar selber brachte sein Überleben schon kurz nach dem Unfall in unmittelbaren Zusammenhang mit Volk und Gott, indem er verlauten ließ, das russische Volk bete täglich tausendfach für ihn und habe so die göttliche Intervention im Moment der Entgleisung bewirkt. Diese Betonung des Wunders kam einem fundamentalen Wandel in der Inszenierung des Zaren gleich. Göttliche Interventionen und übernatürliche Elemente standen nun im Zentrum des „Machtszenarios“ Alexanders III. ${ }^{108}$ In diesem Verständnis wurde die russische Monarchie als Ableitung aus natürlichen Glaubensvorstellungen und Traditionen des Volkes dargestellt. ${ }^{109}$ Es entwickelte sich - um nochmals Wortman zu zitieren - ein "nationaler Mythos“. Die Bindung zwischen Zar und Volk war nach wie vor ausschlaggebend. Sie wurde nun aber ethnisch und spirituell definiert. ${ }^{110}$

104 Koni: Krušenie carskogo poezda v 1888 godu. In: GA1, S. 489-9o.

105 Schenk: Russlands Fahrt in die Moderne, S. 312-13.

106 Ebd., S. 316 und KonI: Krušenie carskogo poezda v 1888 godu. In: GA1, S. 489-9o. Später veröffentlichte Briefe von Koni an Pobedonoscev unterstreichen nochmals, wie sehr Transparenz dem Juristen ein Anliegen war. So schreibt er darin, dass es darum gehe, den Willen nach Wissen in der Bevölkerung zu befriedigen, die Sache restlos aufzuklären und in einem objektiven Bericht mit genauen Angaben darzulegen, vgl. Konstantin P. Pobedonoscev: K. P. Pobedonoscev i ego korrespondenty. Pis'ma i zapiski, Bd. 1, mit einer Einleitung versehen v. M. N. Pokrovskij. Moskva u. a. 1923, S. 920. Vgl. auch den Brief auf S. 919.

107 Schenk: Russlands Fahrt in die Moderne, S. 312-13 und nachfolgende Ausführungen.

108 Wortman: Scenarios of Power, Bd. 2, S. 289-91.

109 Dolbilov: The Political Mythology of Autocracy, S. 784.

110 Wortman: Scenarios of Power, Bd. 2, S. 13. 
Von der Konstruktion eines solchen „Wundernarrativs“ und der Überhöhung des Zaren über alle Gesetze der Natur und der Vernunft wollte Koni aber offensichtlich nichts wissen. Vielmehr hätte die Bedeutung der Zarenmacht dadurch gestärkt werden sollen, dass der Monarch das Vertrauen und die Liebe, die das Volk ihm nach dem Unglück habe zukommen lassen, mit verstärktem Vertrauen seinerseits belohnt hätte. Im Gegenzug zu diesem ,vertrauensvollen“ Agieren an höchster Stelle hätte folglich der Missbrauch dieses Vertrauens von Verantwortlichen aller Hierarchiestufen transparent und öffentlich Konsequenzen nach sich ziehen sollen. Doch stattdessen - klagt Koni in seiner Erinnerungsschrift - sei mit Misstrauen und brutalen Maßnahmen gegen Institutionen der Selbstverwaltung und der Gerichte reagiert worden, keinerlei Entwicklung zugelassen und so das Land auf einen revolutionären Weg geführt worden. ${ }^{11}$ Halbherzig versucht Koni noch, den Entscheid des Zaren als verständlich darzustellen. So meint er, dass die Absage an die Eröffnung eines Gerichtsverfahrens als beste Lösung in einer schwierigen Situation interpretiert werden könne. Der Zar habe gar mit Verweis auf Koni für die Beilegung des gesamten Falles plädiert, da sonst das hätte passieren können, was Koni so entschieden nicht wollte: die Bestrafung der Kleinen bei Verschonung der Großen. ${ }^{112}$ Er nennt aber bereits einen Grund für diese Entwicklung: Die „Fiktivität der Selbstherrschaft im Land““ ${ }^{113}$ Was er damit meint, erklärt sich, wenn er zum Ende der Audienz bei Alexander III. Folgendes festhält:

Wenn Alexander III. seinen Ministern so ins Gesicht geschaut hat, ist es mir einfach unbegreiflich, wie einige von ihnen, oft in voller Absicht, ihn in die Irre führen und seinen starken Willen auf enge und ausweglose Pfade lenken konnten. [...] Von ihm - dem Selbstherrscher und Gebieter über die ganze Rus', der mit einem einzigen Federstrich unseren gesamten zivilen [graždanskij] und politischen Alltag auf den Kopf zu stellen vermochte [...] - ging eine solche Hilflosigkeit in Bezug auf Betrug und Hinterhältigkeit seines Umfelds aus [...]. ${ }^{114}$

Im nur wenig später verfassten „Triumvirn“ wird Koni noch deutlicher und bringt die mangelnde Wertschätzung ihm gegenüber im Entgleisungsfall gar in unmittelbaren Zusammenhang mit Rücktrittsgedanken; erneut macht er dafür „Betrug und Hinterhältigkeit" des „Umfelds“ verantwortlich:

111 IRLI F. 134, op. 1. d. 188, 1. 38ob.

112 Koni: Krušenie carskogo poezda v 1888 godu. In: GA1, S. 485.

113 Ebd., S. 485.

114 Ebd., S. 450-51. 
[...] die unsinnige Beilegung des Falles über die Entgleisung in Borki [...], ungeachtet der feierlichen Versprechung des Gegenteils durch den Zaren, wodurch alles, was in meiner aufwendigen Untersuchung aufgedeckt wurde, im Dunkel der Intransparenz belassen wurde, überzeugte mich nochmals und mit besonderer Kraft von der Machtlosigkeit des russischen Selbstherrschers und von seiner Unterwerfung unter die Ansichten der selbstherrschenden Minister, und zeigte mir damit die Richtigkeit des Sprichworts: „Einer im Feld ist kein Kämpfer“.115

Die „Machtlosigkeit“ des Zaren wird von Koni angeführt als Grund für die enttäuschenden Resultate, die er mit seinem Engagement bewirkte. Mit dieser Interpretation konnte er gleichzeitig behaupten, dass seine mangelnden Erfolge, die Herrscher zu beeinflussen oder zu überzeugen, nicht an deren Unbill gelegen hätten. So schreibt er im Rückblick auf die Entgleisung und seinen Rapport bei Alexander III.: „Die ganze Art des Herrschers gab zu verstehen, dass man mit ihm nicht nur mutig und gerade heraus sprechen soll, sondern auch kann [...]. "116 Mutig und offen mit dem Zaren zu sprechen, genau dies versuchte Koni in seiner Darstellung denn auch. Als dies misslingt und Alexander III. den Fall ohne weitere gerichtliche Konsequenzen abschließt und sich sogar einer transparenten Aufarbeitung in der Öffentlichkeit widersetzt, gibt Koni den „selbstherrschenden Ministern“ und insbesondere dem lyrisch veranlagten Pobedonoscev die Schuld. Von der grundsätzlichen Empfänglichkeit des Zaren aber zeigt er sich nach wie vor überzeugt. Dies beweist auch eine ähnliche Episode in „Die Triumvirn“, in der Koni von einem Fall berichtet, bei dem der Justizminister auf sein Bitten hin den Zaren von einer weniger harten Haltung bei „Religionsverbrechen“ zu überzeugen versucht habe. Dies sei gelungen, so Koni in der Erinnerung, und das beweise, dass Alexander III. der „Stimme der Gerechtigkeit“ zugänglich sei und auch Meinungen anderer zustimmen könne. „Leider erschaffen die Kleinmütigkeit und die persönlichen Ziele der Minister rund um ihn ein Ambiente, in dem er nur das diensteifrige Echo seiner eigenen engen Ansichten und selbstherrlichen Wünsche hört. "117 In dem Moment aber, in dem Koni via Justizminister dem Zaren erklärt, wie die Dinge liegen, scheint alles anders zu sein. Im Erinnerungstext ergänzt Koni das Treffen zwischen Justizminister und Zar sogar mit Aussagen im Wortlaut, obwohl er selber gar nicht vor Ort gewesen war. So beschreibt er, wie der

115 KonI: Triumviry. In: GA2, S. 317. In der Erinnerungsschrift bezieht sich Koni hier auf seinen Rücktritt von der Tätigkeit als Oberstaatsanwalt am Kriminalkassationsdepartement im Jahre 1891. Wenig später übernahm er das Amt aber erneut und blieb in dieser Funktion am Kriminalkassationsdepartement bis 1896.

116 KonI: Krušenie carskogo poezda v 1888 godu. In: GA1, S. 450-51.

117 Koni: Triumviry. In: GA2, S. 295. 
Justizminister dem Zaren einen Brief von Koni übergeben habe. In diesem Brief habe er genau erklärt, wie die Gesetzeslage im Bereich der „Religionsverbrechen“ aussehe und welche Haltung daher angebracht sei. Nach Lektüre des Briefes habe der Zar zum Justizminister gesagt: „Nun denn, wenn es das Gesetz so will, wie er [Koni, CC] schreibt, dann soll man so entscheiden. Ihm ist klarer, was man vom Gesetz her zu tun hat, man soll ihm die Karten in die Hände geben. “118

Während die wohlwollende Zustimmung der Zaren oder literarische Passagen über die Audienzen bei diesen Konis Erinnerungstexte prägen, konnte er die Monarchen und deren Umfeld gleichzeitig problemlos scharf kritisieren. Als Koni in der Zasulič-Erinnerung die Einladung im Zarenpalast kurz vor dem Prozess 1878 Revue passieren lässt, merkt er neben vielen positiven Elementen all die "herzlosen Maßnahmen“ an, die in den letzten Jahren unter der Herrschaft von Alexander II. durchgeführt worden seien. ${ }^{119}$ Alexander III. wirft Koni in der „Entgleisung des Zarenzugs" vor, dass er nur wenige Monate nach dem Unfall gegen Friedensrichter und die Organe der lokalen Selbstverwaltung vorgegangen sei. ${ }^{120}$ Und in „Triumvirn“ betont er, wie wenig wohlwollend dieser sich ihm gegenüber insbesondere während seiner zweiten Amtszeit als Oberstaatsanwalt ab 1892 verhalten habe. ${ }^{121}$ Wenn er Alexander III. auch zugesteht, den „Wunsch nach Größe und Glück seines Volkes" gehabt zu haben, ${ }^{122}$ so sei er eben doch auch "grob und kurzsichtig" gewesen. ${ }^{123}$ Die effektive Persönlichkeit des Monarchen schien also weniger im Zentrum von Konis Bewunderung zu stehen als die abstrakte Figur dieses machtvollen Herrschers. Insbesondere dank der Schuldzuweisungen an externe Akteure funktionierte Konis vermittelte Nähe zum faszinierenden Zaren, dem er seine „Wahrheit“ brachte, über alle Enttäuschungen hinweg.

\section{Einordnung in das liberale Umfeld}

Die „Wahrheit“, die Koni in seiner Selbstdarstellung den verschiedenen Zaren unermüdlich zu vermitteln versuchte, lässt sich unmissverständlich in die moderaten liberalen Ansichten einordnen, wie sie die Mitarbeiter des „Boten Europas“ und der Zeitung „Ordnung“ beispielhaft verkörperten. Wenige Jahre nach ihrer Gründung 1866 wurde die Zeitschrift um Stasjulevič zum Sprachrohr der loyalen Opposition, die die „Großen Reformen“ des Jahrzehnts verteidigte. Im Gegensatz

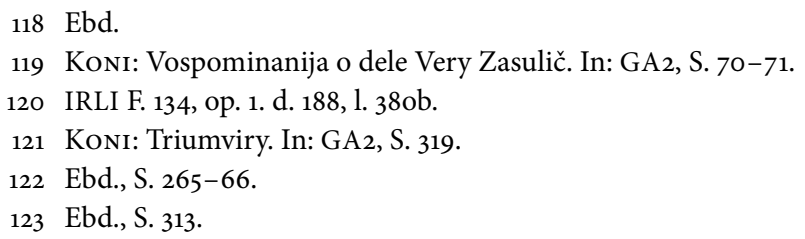


zu radikaleren Teilen der Intelligencija setzten sie - um es in den Worten von Anton Fedyashin auszudrücken - auf ,überzeugen anstatt richten, ermuntern anstatt bedrohen". ${ }^{124}$ Mit der Radikalisierung der populistischen Bewegung entwickelte der „Bote“ in den 187oer-Jahren sein Programm liberaler Werte immer stärker in Opposition zu den Narodniki. ${ }^{125}$ Das Attentat von Vera Zasulič missbilligte der „Bote Europas“ [Vestnik Evropy] zwar bereits, zeigte aber Verständnis für das Urteil der Geschworenen. Als wenig später von einem Mitglied des terroristischen Arms der Narodniki ein Mordanschlag auf den Chef des Gendarmeriecorps erfolgte, verurteilte das Journal dies in aller Deutlichkeit. ${ }^{126}$ Aufgrund der engen Verbindung zwischen Koni und zahlreichen Publizisten im Umfeld dieser Publikationsorgane ist es keine Überraschung, dass sich viele Argumentationsstränge, mit denen Koni die Herrscherdynastie überzeugen wollte, in den Artikeln des „Boten“ wiederfinden. Koni lernte Stasjulevič in den 1870er-Jahren persönlich kennen, und zwischen ihnen entwickelte sich eine enge Freundschaft, die sich nicht zuletzt in Konis zahlreichen Artikeln für den „Boten“ und die Zeitung „Ordnung“ niederschlug. In seiner Erinnerungsschrift „Der Bote Europas“ erzählt Koni selber von seinem engen Verhältnis zum Publizisten und dem Kreis um ihn herum. Dieser bestand neben wichtigen Literaten zu einem großen Teil aus Personen mit einer Verbundenheit zu den reformierten Gerichten, wie neben Arsen’ev zum Beispiel auch Spasovič, Arcimovič oder Kavelin. Sie alle trafen sich immer wieder in der vertrauensvollen Atmosphäre der Redaktionsräume des „Boten“ und seines Chefredakteurs. Kavelin, so erinnert sich Koni, beschrieb dieses Setting als „Artus und die Ritter der Tafelrunde“.127 Mit diesem König der „Tafelrunde“

124 Fedyashin: Liberals under Autocracy, S. 76.

125 Ebd., S. 93.

126 Ebd., S. 102-03. Diese öffentliche Verurteilung des terroristischen Akts von Sergej Michajlovič Kravčinskij (Pseudonym Stepnjak) (1851-1895) in der Zeitschrift hatte zum ersten Mal eine offene Debatte mit einer illegalen Organisation zur Folge. In der Untergrundpublikation „Land und Freiheit“ reagierten die Radikalen auf die Kritik des „Boten Europas“.

127 Anatolij F. Konı: „Vestnik Evropy“. In: ders. (Hrsg.): Na žiznennom puti, Bd. 2. Iz vospominanij, publičnye čtenija, v verchnej palate. Sankt-Peterburg 1912, S. 193-94 und 205-o6. Diese Erinnerungsschrift wurde bereits in TEIL EINS kurz erwähnt. Sie wurde zuerst 1908 in der Zeitschrift „Moskauer Wochenblatt“ [Moskovskij eženedel'nik] verteilt auf vier Ausgaben (Nr. 47-50) veröffentlicht. 1911 publizierte Koni nach dem Tod von Stasjulevič einen Teil davon als „M. M. Stasjulevič kak charakter“ im „Boten Europas“ selbst sowie als „Pamjati Stasjuleviča“ in „Russische Nachrichten“, Nr. 21. Datiert mit „Februar 1911“ erschien dann der umfangreiche Text „Vestnik Evropy“ in Konis Sammelband „Auf dem Lebensweg“ II. Auch in der überarbeiteten Auflage von Moskau 1916 wurde der Text nochmals abgedruckt. Vgl. zur Publikationsgeschichte auch GA7, S. 471-72 (Anmerkungen). $\mathrm{Zu}$ den Literaten, die der Zeitschrift nahestanden, gehörte auch Turgenev. 
führte Koni über Jahrzehnte hinweg auch einen intensiven Briefwechsel. Oftmals tauschten sie sich mehr als einmal pro Woche schriftlich aus. ${ }^{128}$ Stasjulevič und seine Mitstreiter setzten den gewaltsamen Tendenzen in der Intelligencija ein „liberales Programm“ entgegen, das Arsen'ev 1882 im Journal erstmals in solcher Form publizierte. Darin ist die Rede von Presse- und Gewissensfreiheit sowie persönlicher Freiheit und Unverletzlichkeit des Individuums. Fortschritte in der (Aus-)Bildung von Bevölkerung und Professionsgruppen werden verlangt, die Umbildung der lokalen Selbstverwaltung propagiert, in die alle Schichten, auch die Bauern, integriert werden sollen. ${ }^{129}$ In unzähligen Artikeln haben die verschiedenen Autoren des „Boten“ davor und danach diese und weitere Themen aufgegriffen. Themen, wie auch Koni sie im „Memorandum“ und dem „Ordnung“-Artikel in fast identischer Form ansprach. Wenig erstaunlich deshalb, dass sein anonym publizierter Zeitungsartikel nach der Ermordung des Zaren in der Öffentlichkeit lange Arsen’ev zugeschrieben worden war. ${ }^{130}$ Dieser schrieb für den „Boten“ bereits 1871 auch einen Bericht zu den politischen Prozessen gegen die Narodniki. Darin spricht er von der natürlichen Empathie, die diese jungen Menschen gegenüber dem Leiden anderer hätten, und macht klar, dass sich dieses Mitgefühl durch Massenprozesse nicht stoppen lassen würde. Der einzig sinnvolle Weg bestehe darin, die Ursachen zu eliminieren, die zu radikalen Taten führen würden. Dazu müsste der Staat aber legale Wege der Hilfe für Unterdrückte erlauben, anstatt die Jugend, die sich engagieren wolle, per se zu verurteilen. ${ }^{131}$ Die Haltung von Arsen'ev stimmt passgenau mit Konis Argumentation im „Memorandum“ und seinen Ausführungen in den „Zasulič-Erinnerungen“ überein. Auch in zahlreichen weiteren Artikeln bringt Arsen'ev zum Ausdruck, was Koni beispielsweise in seiner Erinnerung an die Entgleisung des Zarenzugs anspricht. So kritisiert der Publizist ebenfalls das Vorgehen der Regierung Alexanders III. in den 188oerJahren gegen die lokalen Selbstverwaltungsinstanzen der Landschaften und der Städte und schreibt erbittert gegen die Einschränkung der Friedensgerichte und die Einführung von Landhauptleuten an, die als Misstrauensvoten gegen mehr

128 Svetlana A. Domanova: Perepiska A. F. Koni kak istoričeskij istočnik. Rossijskij gosudarstvennyj gumanitarnyj universitet, Moskva 1999 (unveröffentlichte Dissertation), S. $107 \mathrm{ff}$ untersucht diesen Briefwechsel. Dass Koni in seinen Schreiben auch immer wieder Hinweise zu Themen für die Zeitschrift einfließen ließ, wurde bereits erwähnt.

129 Fedyashin: Liberals under Autocracy, S. 149.

130 So erinnert sich Koni selber in: Anatolij F. Koni: „Vestnik Evropy“. In: GA7, S. 226-28. Dies - und die näheren Umstände für seinen Artikel - machte er aber erst nach der Oktoberrevolution transparent. Vgl. ausführlich dazu unten, S. 262.

131 Fedyashin: Liberals under Autocracy, S. 87-88. 
Mitsprache der Bevölkerung interpretiert wurden. ${ }^{132}$ Mit diesen Positionen sah sich der „Bote Europas“ [Vestnik Evropy] als Führer eines russischen Liberalismus. ${ }^{133}$ In den Leitartikeln der Zeitschrift findet sich denn auch immer wieder eine Auslegeordnung zum Weg, den Russland aus liberaler Sicht einzuschlagen habe. Oftmals war es der engagierte Literaturhistoriker und Ethnograf Aleksandr Nikolaevič Pypin (1833-1904), der sich intensiv dieser Frage nach der weiteren Entwicklung Russlands widmete. Die Antwort beinhaltete immer eine grundsätzliche Absage an revolutionären Aufstand, wie ihn beispielsweise die Marxisten propagierten. Dieser sei unpassend für den „russischen Nationalcharakter“ und historisch gesehen kontraproduktiv. Hauptziel der Liberalen sei deshalb die Verteidigung des Reformgeistes der 186oer-Jahre. Schritt für Schritt sollten weitere Reformen, größere lokale Autonomie und vor allem auch mehr Freiheiten für Kunst und Wissenschaft folgen. ${ }^{134}$ Immer wieder wurde in liberalen Kreisen ein Kausalzusammenhang zwischen dem mangelhaften Wissenschafts- und Schulsystem in Russland und dem Anwachsen des Terrors betont. ${ }^{135}$ Konis Worte von der nötigen Überarbeitung des Bildungssystems, um das Wesen des russischen Volkes besser zu verstehen, das einen „organischen“ Gang anstelle von „Sprüngen“ präferiere, passen in diesen Diskurs.

Mitgeprägt hat viele dieser Vorstellungen der liberale Denker und ehemalige Professor von Koni, Boris Čičerin. Čičerin war von 1861 bis 1867 an der Moskauer

132 Simutenko: K. K. Arsen'ev i rossijskoe liberal'noe dviženie konca XIX-načala XX veka, S. 90-92 und Fedyashin: Liberals under Autocracy, S. 100. 1889 wurden die Kompetenzen der ständischen Volost'-Gerichte der Bauernschaft stark ausgedehnt. Sie übernahmen nun einen wesentlichen Teil der Aufgaben, denen sich bis anhin die nun aufgelösten Friedensgerichte als Element der Gerichtsreform von 1864 angenommen hatten. Die Volost'-Gerichte und die Landhauptleute wurden von vielen liberalen Kritikern, darunter zahlreiche Juristen, sehr negativ beurteilt. Die Landhauptleute konnten Beschlüsse der Dorfversammlungen kontrollieren oder gar aussetzen. Dies wurde als Übergriff der Verwaltung auf das persönliche und wirtschaftliche Leben und die Selbstbestimmung der Bauern betrachtet. Durch die Volost'-Gerichte als Sonderregelung außerhalb des reformierten Gerichtswesens würden die Bauern zudem bewusst isoliert und in einem $\mathrm{Zu}$ stand der Unkultiviertheit und Unwissenheit gehalten. Vgl. Litzinger: Juristen und die Bauernfrage, S. 18o-87 und Baberowski: Autokratie und Justiz, S. 237-38 und 334-35.

133 Fedyashin: Liberals under Autocracy, S. 121. Eine solche liberale Bewegung, wie sie der „Bote Europas“ [Vestnik Evropy] verkörpern wollte, war zweifelsohne ein Phänomen der „vergleichsweise kleinen hauptstädtischen Elite“. Vgl. dazu die kritische Rezension von Kirsten Bönker: Rezension über Anton A. Fedyashin, Liberals under Autocracy (Madison 2012). In: H-Soz-Kult, 13. 06. 2014, www.hsozkult.de/publicationreview/id/rezbuecher-20583, Zugriff vom 30.10. 2016.

134 Fedyashin: Liberals under Autocracy, S. 122-23.

135 Julija SAFronova: Russkoe obščestvo v zerkale revoljucionnogo terrora. 1879-1881 gody. Moskva 2014, S. 136-37. 
Universität, an der er auch selber studiert hatte, Professor für Staatsrecht und verfasste bis zu seinem Tod 1904 zahlreiche wissenschaftliche Werke wie zum Beispiel die mehrbändige Serie "Geschichte der politischen Theorien“ [Istorija političeskich učenij]. Gemeinhin wird er als eine der herausragendsten Figuren des russischen Liberalismus gesehen. Gleichzeitig wird betont, dass Čičerin ein isolierter Denker gewesen sei, ohne weitreichenden Einfluss. Dies, weil seine konservative Auslegung des Liberalismus nie sehr beliebt, geschweige denn dominant in der russischen liberalen Bewegung geworden sei. ${ }^{136}$ Tatsächlich tut man sich bis heute schwer, Čičerin eindeutig in das Lager der Liberalen einzuordnen. Immer wieder stieß sein Verhalten in konkreten Situationen auf die Kritik der liberalen Presse. ${ }^{137}$ Trotzdem kann sein Werk „Rechtsphilosophie“ [Filosofija prava], das zwischen 1898 und 1900 erschien, als ideologisches Fundament für den moderaten Flügel der konstitutionellen Bewegung in Russland vor 1905 angesehen werden. ${ }^{138}$ Wie wichtig für Koni die Gedanken des Rechtsphilosophen waren, zeigt sich beispielhaft an der von Čičerin anlässlich der Ermordung von Zar Alexander II. verfassten Schrift „Die Aufgaben der neuen Zarenherrschaft“ [Zadači novogo carstvovanija], die sich mit vielen Anzeichnungen am Rande versehen in Konis Unterlagen findet. Datiert auf den 10. März 1881, skizziert Čičerin darin seine Vorstellung von der Entwicklung Russlands. Er propagiert die viel zitierte „lebendige Verbindung "zwischen Regierung und Gesellschaft, in deren Tradition sich auch Koni darstellt, wenn er in seinen Erinnerungsschriften von Wohlwollen und Nähe zu den Monarchen berichtet. ${ }^{139}$

Sowohl Koni als auch Čičerin interpretierten diese Verbindung auf eine sehr aktive Art und Weise. Beide beließen es nicht dabei, ihre Ansichten in Schriften und Artikeln zu äußern. Vielmehr bemühten sie sich darum, diese Verbindung zu nutzen, um die Zaren von ihren eigenen Meinungen zu überzeugen. Koni betonte seine pädagogischen Bemühungen im Rahmen der Gefängnisführung

136 WaLicki: Legal Philosophies of Russian Liberalism, S. 105-06 und 118.

137 Ludmila Thомаs: Georgi Tschitscherin. „Ich hatte die Revolution und Mozart“. Berlin 2012, S. 13-14. Vgl. auch Gary M. Hamburg: Boris Chicherin and Human Dignity in History. In: ders./Randall A. Poole (Hrsg.): A History of Russian Philosophy 1830-1930. Faith, Reason, and the Defense of Human Dignity. Cambridge u. a. 2010, S. 111-30. Hamburg beschreibt die Spannung in Čičerins Werk zwischen dem Ideal menschlicher Freiheit und seiner ideologischen Verwirklichung durch Gehorsamkeit gegenüber historischen Gesetzen.

138 Hamburg: Boris Chicherin and Human Dignity in History, S. 128-30.

139 GARF F. 564, op. 1, d. 308. Neben seinem Porträt von Čičerin hielt Koni Erinnerungen an die Zeit, als Čičerin sein Professor an der Universität in Moskau war, in „Aus Jugend- und Altersjahren“ fest. Diese autobiografische Schrift wird in TEIL DREI noch thematisiert werden. 
und der Rechtslektionen, die er für Sprösslinge der Zarenfamilie machen durfte. In seinen Unterlagen finden sich die Materialien, die er für den Unterricht zusammengestellt hatte. Auf weit über 100 Seiten erläuterte er darin, wie Staaten funktionierten und welche Modelle und Regierungsformen existierten. Einen Schwerpunkt legte er dabei auf die von den russischen Zaren so misstrauisch beäugte Form der konstitutionellen Monarchie. ${ }^{140}$ Auch Čičerin hat sich als bekannter Wissenschaftler Anfang der 186oer-Jahre als Lehrer für den Thronerben Nikolaj Aleksandrovič (1843-1865) betätigt. Zu diesem Engagement war er gekommen, weil sich die Zarenfamilie mit seiner Haltung während der Studentenunruhen von 1861 zufrieden zeigte. Damals setzte sich Čičerin für die Devise von maximalen liberalen Methoden bei gleichzeitig starker Regierung ein und war dagegen, Konzessionen an die protestierenden Studenten zu machen, bevor die Ordnung wiederhergestellt war. ${ }^{141} 1863$ beteiligte er sich jedoch wesentlich daran, dass man sich auf ein neues Universitätsstatut einigen konnte, das die Universitäten für alle Stände öffnete und die Autonomie der Bildungseinrichtungen wieder garantierte. ${ }^{142}$ Čičerin unterrichtete den zukünftigen Monarchen nicht nur, sondern begleitete ihn auch auf seine Reisen ins Ausland. Dort verstarb Nikolaj Aleksandrovič aber 1865. Wenige Jahre später trat Čičerin als Professor zurück, da er wie viele andere Dozenten nicht länger zuschauen wollte, wie das eben erst implementierte neue Universitätsstatut von den Behörden nur mangelhaft res-

140 IRLI F. 134, d. 288. Im Manuskript einer wohl nie veröffentlichten Erinnerungsschrift erklärte Koni, dass er dem jungen Großfürsten zwischen 1872 und 1875 auf Bitten des Vaters Lektionen erteilt habe. Solcher Unterricht sei in einer Zeit, in der auch Großfürsten vielleicht einmal einer bürgerlichen Tätigkeit nachgehen würden, Mode geworden. Den Kurs zu Recht und Rechtsprechung habe er mitten in der Schweiz auf der „Rigi-Scheidek“ zusammengestellt. Mit dem Unterricht habe er dem Großfürsten zeigen wollen, dass auch für ihn die gleichen Gesetze gelten würden wie für alle anderen, vgl. IRLI F. 134, op. 1, d. 148, 1. $50 b$ ff. Dieses autobiografische Manuskript enthält Erinnerungen an mehrere Personen aus dem Umfeld der Zarenfamilie und ähnelt im Stil den anekdotisch-literarischen Texten, auf die in TEIL DREI noch eingegangen wird.

141 Nach dem Tod von Zar Nikolaus I. wurden 1855/56 zahlreiche Restriktionen, die die Universitäten betrafen, aufgehoben. Die Studentenschaft wurde daraufhin vielfältiger und unruhiger. Die Regierung reagierte mit einer Zugangsbeschränkung für arme Studenten und harten Strafen bei Regelverstößen. Daraufhin kam es in Moskau, St. Petersburg und Kasan im Herbst 1861 zu großen Unruhen. Der Ruf nach akademischen Freiheiten fiel zusammen mit der Bauernbefreiung, vgl. Alexander Polunov: Russia in the Nineteenth Century. Autocracy, Reform, and Social Change, 1814-1914. Armonk New York u. a. 2005, S. 141-42.

1421862 hatte man mit Aleksander Golovnin einen aufgeklärten Reformbürokraten zum Volksbildungsminister gemacht. Unter seiner Ägide wurde das neue Universitätsstatut möglich, vgl. Polunov: Russia in the Nineteenth Century, S. 142. 
pektiert wurde. Als nach dem tödlichen Attentat auf den Zaren 1881 der Bruder von Nikolaj Aleksandrovič die Herrschaft übernahm, versuchte Čičerin erneut genau wie Koni, den neuen Selbstherrscher zu beeinflussen, und verfasste dazu die genannte Schrift zu den „Aufgaben der neuen Zarenherrschaft“, die er dem Innenminister Loris-Melikov übergab. Darin spricht er von einer erwünschten schrittweisen Entwicklung hin zu mehr politischen Freiheiten und einer größeren Beteiligung der Bevölkerung. ${ }^{143}$ Deutlich kommen aber auch große Befürchtungen vor der revolutionären Bewegung zum Tragen, die in scharfen Worten gegen die sozialistische Bewegung münden. ${ }^{144}$ Dessen ungeachtet verlor Čičerin nur wenig später endgültig die Gunst der Regierungskreise. 1881 noch zum Bürgermeister von Moskau gewählt, wurde er 1883 zum Rücktritt gezwungen. Man warf ihm vor, in einer Ansprache zur Krönung von Alexander III. für die konstitutionelle Limitierung des bürokratischen Absolutismus geworben zu haben. ${ }^{145}$ Ähnlich erging es Konis Versuch, dem nachfolgenden Zaren mit seinem Zeitungsartikel in "Ordnung" eine eigene Agenda für dessen Herrschaft mitzugeben. Gleich mehrere liberale Blätter veröffentlichten nach dem Attentat unüblich deutliche Artikel, in denen die getroffenen Maßnahmen der Regierung zur Bekämpfung der radikalen Bewegung als unnütz dargestellt wurden. Der terroristische Akt diente in dieser Interpretation als Beweis für die kontraproduktive Wirkung von Repression. Die „Krankheit“ [bolezn'] - wie Koni typischerweise den Terror als Ausdruck des Zustandes der russischen Gesellschaft beschrieb - sollte über mehr individuelle Freiheit und politische Mitsprache geheilt werden ${ }^{146}$ Diese Worte wurden noch im März 1881 ein weiteres Mal bekräftigt, als in „Ordnung“ ein Artikel über die Beerdigung des Zaren erschien, der höchstwahrscheinlich ebenfalls von Koni stammt. Darin werden die „Großen Reformen“ des ermordeten Monarchen feierlich gewürdigt, aber gleichzeitig auch auf deren Unvollständigkeit verwiesen. ${ }^{147}$ Die Rückkehr zu einer härteren Haltung gegen Andersdenkende konnte durch diese Argumentation liberaler Blätter aber nicht verhindert werden, und die ent-

143 WALICKi: Legal Philosophies of Russian Liberalism, S. 114-15.

144 Vasilij I. Smoljarčuk: A. F. Koni i ego okruženie. Moskva 1990, S. 249. Was Smoljarčuk, den Konibiografen aus der Sowjetzeit, dazu veranlasste, die Ansichten Čičerins mit jenen von Pobedonoscev gleichzusetzen und zu konstatieren, dass es doch seltsam sei, dass der Führer der liberalen Wissenschaftler so etwas geschrieben habe.

145 Walicki: Legal Philosophies of Russian Liberalism, S. 115-16.

146 SAfronova: Russkoe obščestvo v zerkale revoljucionnogo terror, S. 139-42. Vgl. S. 141 mit Erläuterungen zur viel verwendeten Chiffre vom „kränklichen“ Zustand Russlands.

147 [Anatolij F. Koni: Ohne Titel] In: Porjadok 73 (15. 03.1881), S. 1 (Abschnitt „Političeskoe obozrenie“). Dieser Artikel kann mit ziemlicher Sicherheit Koni zugewiesen werden, da in seinem Nachlass eine handschriftliche Version davon zu finden ist, vgl. IRLI F. 134, op. 1, d. 257. 
sprechenden Stimmen wurden sehr schnell zum Verstummen gebracht. Da beide Artikel von Koni anonym erschienen waren, hatte die Publikation keine Folgen für ihn. Der Zeitung selber allerdings wurde Ende März verboten, in den Einzelverkauf zu gehen, und Anfang 1882 musste „Ordnung“ schließlich ganz aufgeben. ${ }^{148}$

Wenn Koni vom Zaren gleichzeitig mehr Freiheiten wünschte, sich aber auch fasziniert von dessen Herrschaftskraft zeigte, oder Čičerin dem Monarchen Möglichkeiten zur Partizipation abringen wollte und trotzdem scharf gegen die angebliche Gefahr sozialistischer Ideen aller Art anschrieb, zeigen sich darin Charakteristika, die typisch sind für eine Epoche, in der Liberalismus und Demokratie noch nicht zwingend zusammengingen und eine gewisse Angst vor dem „Despotismus der Masse" in liberalen Kreisen allgegenwärtig war. ${ }^{199}$ Wer sich im Zarenreich für Reformen stark machen wollte, die keinen totalen Umsturz und Systemwechsel mit sich bringen sollten, war in einer paradoxen Situation. Man versuchte - wie Marc Raeff es beschreibt - um die Zustimmung des Zaren zu buhlen und die autokratische Administration effizienter zu machen, umso das Böse zu vertreiben, das ebendiese hervorgebracht hatte..$^{150}$ Die Kadergruppe von Menschen, die sich im Russischen Reich in der Reformzeit der 1850/6oer-Jahre herausgebildet hatte, war zwar bereit und fähig, Verantwortung zu übernehmen. Gleichzeitig war die Weltsicht dieser Reformer nicht frei von einem gewissen utopischen Glauben an die unbegrenzten Möglichkeiten des Staates und des Monarchen. ${ }^{151}$ Diesen galt es von den progressiven Ideen zu überzeugen. ${ }^{152} \mathrm{Die}$,individuelle Audienzpolitik“ in Form von unzähligen persönlichen Treffen mit mächtigen Personen, von denen auch Koni in seinen Erinnerungsschriften so gerne berichtete, gehörte dabei zu den klassischen Formen, wie man im Russischen Reich solche Ideen vorantreiben wollte. Neben der Austragung von Meinungsverschiedenheiten in Gremien wie dem Staatsrat war insbesondere das direkte Gespräch mit dem Zaren ein gern benutztes Mittel, um die Dinge „,im eigenen Sinne“ zu regeln. ${ }^{153}$ Denn die Orga-

148 Vgl. Porjadok. In: ĖSBE 24A/48, 1898, S. 654 sowie S. Volk/M. Vydrja/A. Muratov: Anatolij Fëdorovič Koni. In: GA1, S. 15.

149 WALICKI: Legal Philosophies of Russian Liberalism, S. 157.

150 Marc RaEfF: Political Ideas and Institutions in Imperial Russia. Boulder u. a. 1994, S. 85-86. Ironisch-konsterniert fügt Raeff hinzu, dass es mit dieser Ausgangslage nicht erstaunlich sei, dass die liberale Bewegung eher wenig effektiv gewesen sei. Die echten Konservativen seien wenigstens konsistent gewesen.

151 Larissa Za kharova: The Reign of Alexandr II. A Watershed? In: Dominic Lieven (Hrsg.): The Cambridge History of Russia. Volume II: Imperial Russia, 1689-1917. Cambridge u. a. 2006, S. 608.

152 RaefF: Political Ideas and Institutions in Imperial Russia, S. 85-86.

153 Matthias Stadelmann: Großfürst Konstantin Nikolaevič. Der persönliche Faktor und die Kultur des Wandels in der russischen Autokratie. Wiesbaden 2012, S. 439-40. Stadel- 
nisationsform der Verwaltung, in der vieles von der Willkür der Vorgesetzten abhing, verhinderte systematisch, dass man gegenüber anderslautenden Ansichten für die eigene Meinung einstand. ${ }^{154}$ Tatsächlich kamen richtungsweisende Entscheidungen oftmals als Resultat individueller Beeinflussungen und Fürsprachen zustande. Viel Energie floss deshalb in die Beschäftigung mit dem Hof und der Nähe und dem Vertrauen des Zaren zur eigenen Person. ${ }^{155}$ Konis Rückschau auf sein Berufsleben zeugt von diesen Verhältnissen und hinterlässt dabei einen ambivalenten Eindruck von seinen politischen Einflussmöglichkeiten. Einerseits lässt er keine Gelegenheit aus, auf Momente zu verweisen, in denen er in Beziehung zu den Monarchen getreten sei und deren ungerechtfertigtes Misstrauen oder aber ihm zustehendes Wohlwollen erfahren habe. Aus dieser Nähe schöpft Koni besondere Legitimation, indem er sie mit seinen eigenen rechtlichen und politischen Visionen verbindet, die er über den direkten oder indirekten Kontakt mit dem Herrscher vorangetrieben haben will. Koni wird in seiner Darstellung so vom professionellen Juristen zum rechts- und gesellschaftspolitischen Berater der Regierung. Die in Konis Vorstellung optimale Ausgestaltung dieses Verhältnisses manifestiert sich besonders in der beschriebenen Szene, in der der Zar zugesichert haben soll, ihm „die Karten“ zu übergeben. Eine tiefe Überzeugung von der Stärke des Autokraten und dessen elementarer Rolle für die Entwicklung Russlands hin zu liberalen Freiheiten manifestiert sich in der von Vertrauen geprägten Beziehung des Zaren zur Gesellschaft, wofür Koni selber Beispiel sein will. Gleichzeitig ist Konis Selbstdarstellung durchzogen von gegenläufigen Aussagen. Er relativiert seinen eigenen Einfluss in den Audienzen und über seine Artikel und Memoranden, indem er auf die ausbleibenden Konsequenzen verweist. Immer wieder gibt es Worte der Kritik für die politischen Entscheide der Zaren, die der Idealvorstellung Konis nicht zu genügen scheinen. Der „absolute Glaube“ an ein

mann legt in seiner Monografie über den Bruder von Zar Alexander II. dar, wie dank dessen Durchsetzungswillen gerade in Sachen der „Großen Reformen“ die Diskussionen in kollektiven Gremien wie dem Staatsrat deutlich kontroverser wurden und um die Meinungsfindung härter gerungen wurde.

154 Dominic Lieven: Russian Senior Officialdom under Nicholas II. Careers and Mentalities. In: Jahrbücher für Geschichte Osteuropas 2 (1984), S. 221.

155 Stadelmann: Großfürst Konstantin Nikolaevič, S. 441. Stadelmann verweist auf die „Prominenz individueller Ansichten und menschlicher Leidenschaften“ in der russischen Politik dieser Zeit. Nicht nur Regierungsmitglieder und Zar trafen sich zum vertraulichen Gespräch, auch zwischen den verschiedenen Politikern waren informelle Besprechungen im Arbeitszimmer, beim Abendessen, aber auch auf einem Ball oder beim Zigarrerauchen im Salon wichtiger Bestandteil des politischen Prozesses. Dies führte zu einer „Petersburger Käseglocke“, unter der sich die Regierungsrunde oftmals vom Geschehen im Rest des Landes abkoppelte. 
für Russland nötiges ganz bestimmtes "Szenario“von der Zarenherrschaft lässt Koni an der vorgefundenen Realität verzweifeln. ${ }^{156}$ Diese Widersprüche kann er abschwächen, indem er in seinen Erinnerungsschriften die Schuldigen für die falschen Entscheidungen der Monarchen benennt: die Berater. Mit dieser Taktik sah sich Koni in guter Gesellschaft. Gerade wegen der stark auf persönlichen Beziehungen beruhenden Entscheidungskultur wurde es im 19. Jahrhundert zu einem typischen Zug im Denken der höheren russischen Bürokratie, den Zaren gleichzeitig als außerordentlich willensstark und extrem beeinflussbar wahrzunehmen. ${ }^{157}$ Sobald der Zar nicht der eigenen Meinung folgte, wurde aus dem Autokraten, dem man alles zutraute, eine isolierte, Täuschungen und Missbräuchen hilflos ausgelieferte Person. Betrogen von den engsten Beratern - so lautete das klassische Narrativ - kenne der Zar fern von seinen Untertanen „die ganze Wahrheit" nicht, sonst würde er anders entscheiden. ${ }^{158}$ Wahlweise wurden die Minister und Berater rund um den Monarchen von Zeitgenossen deshalb als „Hände“ und „Ohren“ des Zaren beschrieben, oder aber als „Ketten“ und „Fesseln“, die seinen Willen einschränkten. ${ }^{159}$ Die hohen Offiziellen waren gleichzeitig Untergebene des Monarchen und Mitglieder der herrschenden Elite, die in seinem Namen Macht ausübte. Es ist diese Spannung, die dazu beitrug, dass der Zar nicht als homogene Figur wahrgenommen wurde ${ }^{160}$ Ausschlaggebend ist bei dieser Haltung, dass die Überzeugung von der zentralen Rolle und der Wichtigkeit der Zarenfigur für das weitere Schicksal des Landes aufrechterhalten wurde. Koni selber kann über seine Schuldzuweisungen an die mutlosen und eigennützigen Minister die Figur des Zaren in ihrer herausragenden Stellung belassen. Diese Hoffnung auf den „guten Zaren" erfreute sich in Russland nicht nur in den Kreisen der liberalen Reformbürokraten großer Beliebtheit, sondern findet sich auch in der langen Tradition der sozial-utopischen Volkslegenden. Vom 17. bis in das 19. Jahrhundert lässt sich der Typus der Legende des „Befreier-Zaren“ in verschiedensten Varianten nachweisen. Kern dieser Legende ist das Auftauchen eines Zaren oder Zarensohnes, der den Zustand des Staates und die herrschenden Verhältnisse grundsätzlich

156 Wortman: Reply to Mikhail Dolbilov. S. 798. Wortman beschreibt, wie Alexander II. den Glauben von Mitgliedern seiner Regierung an das Szenario der Liebe zwischen Zar und Volk zerrüttete, indem er dem Narrativ nicht entsprach.

157 Dolbilov: The Political Mythology of Autocracy, S. 793. Seit einer Reform der höheren Administration zu Beginn des 19. Jahrhunderts kamen zumindest die Minister häufig in direkten Kontakt mit dem Zaren, vgl. ebd., S. 792-93.

158 Ebd., S. 793.

159 Ebd., S. 792-93.

160 Wortman: Reply to Mikhail Dolbilov, S. 800. 
veränderte, indem er den regierenden Herrscher als „falschen“ entlarvte. ${ }^{161}$ Der Glaube an die guten Absichten des „echten“ Zaren war so stark, dass es immer wieder zu Fällen kam, bei denen sich die Bevölkerung in gewissen Regionen des Landes überzeugt zeigte, dass auf dem Thron nicht der „wahre“ Herrscher sitze. Klassischerweise spielten in den sich darum herum rankenden Legenden auch böse, selbstsüchtige Personen im Umfeld des Hofes eine Rolle, die die Rückkehr des „Befreiers“ zu verhindern versuchten. ${ }^{162}$

So spürt man denn in Konis Erinnerungsschriften nach der Jahrhundertwende noch die Überzeugung, dass sein Vorgehen nicht chancenlos gewesen war und ist. Nach wie vor und ungeachtet aller Enttäuschungen - so muss Konis Bericht für den zukünftigen Leser wirken - entspricht seine gesellschaftspolitische Analyse der zweiten Hälfte des 19. Jahrhunderts der „Wahrheit“, die es nur endlich an höchster Stelle einzusehen gelte. Gleichzeitig sonnt er sich in der Erinnerung an die kargen Momente, in denen ihm Bestätigung und Wohlwollen der höchsten Macht zuteilgeworden waren. Diese Art, die Figur des Zaren zu interpretieren und sich im Rückblick auf sein Berufsleben in Beziehung mit dieser zu setzen, mag in vielem typisch für den weltanschaulichen Kreis gewesen sein, in dem sich Koni bewegte. Doch betrachtet man beispielsweise die Biografien seiner Gesinnungsgenossen beim „Boten Europas“, so fällt ein gewisser Unterschied auf. Männer wie Stasjulevič oder Pypin hatten auf ihren beruflichen Pfaden aufgrund ihrer politischen Haltung keine Entfaltungsmöglichkeiten. 1866, als der „Bote“ gegründet wurde, waren mehrere seiner wichtigsten Mitarbeiter „intellektuelle Nomaden", die einen neuen Weg abseits ihrer eigentlichen Ausbildungen suchten, um ihre Zukunftsvorstellungen zu artikulieren. ${ }^{163}$ Nicht so Koni. Er stand als Jurist an den Gerichtsbehörden direkter mit den politischen Entscheidungsträgern im

161 Kirill V. Čistov: Der gute Zar und das ferne Land. Russische sozial-utopische Volkslegenden des 17.-19. Jahrhunderts, hrsg. u. mit einer Einleitung versehen v. Dagmar Burkhart. Münster u. a. 1998. S. 5-6, 9 (Einleitung v. Dagmar Burkhart) und 23.

162 Čistov: Der gute Zar und das ferne Land, S. 27-30. Inhaltlich ging es dabei um die Hoffnung der Bauernschaft auf die Befreiung aus der Leibeigenschaft.

163 Fedyashin: Liberals under Autocracy, S. 52 und 67-68. So hatte beispielsweise Stasjulevič bis 1861 als Professor für Geschichte an der St. Petersburger Universität unterrichtet, bevor er zusammen mit anderen Dozenten, u. a. A. N. Pypin, aber auch Kavelin oder Spasovič, im Zuge der Studentenunruhen aus Protest gegen die harte Haltung der Regierung zurücktrat, vgl. ebd., S. 59-6o. Fedyashin zählt auch Arsen'ev zu den „intellektuellen Nomaden“, da er in der Zeit zwischen seinem Studienabschluss an der Kaiserlichen Rechtsschule und dem Anfang seiner Tätigkeit als Anwalt, die erst nach der Gerichtsreform starten konnte, im Justizministerium arbeitete. Da er dort vielfach gebremst und von den bürokratischen Strukturen demotiviert worden war, kann auch seine Hinwendung zur Publizistik, die in diesen Jahren ihren Anfang nahm, als Ausweg interpretiert werden, endlich eigene Überzeugungen voranzubringen, vgl. ebd., S. 63-65. 
Russischen Reich in Kontakt, und der Zar wurde von ihm vielleicht auch deshalb so deutlich ins Bild gerückt. Ganz konkret berichtete Koni in seinen Schriften nämlich nicht nur von sich als juristischem Ratgeber des Herrschers, der „die Karten“ in den Händen hält, sondern auch von unzähligen Gelegenheiten, bei denen er das Wort des Zaren als Teil des Justizwesens benötigte und für seine berufliche Tätigkeit im eigenen Sinne nutzte.

\subsubsection{Gnadengesuche: Autokratie und Justiz}

Wenn Koni in seinen Erinnerungsschriften an seine Zeit an den russischen Gerichten zurückdenkt, fallen eine Vielzahl an Episoden auf, in denen Gnadenbitten im Zentrum stehen. Koni berichtet, wie er solche Bitten an vorgesetzte Personen wie den Justizminister oder gar den Zaren gerichtet habe.

Ein typisches Beispiel findet sich in der Erinnerung an die Entgleisung des Zarenzugs. So betont Koni einerseits, wie deutlich er im persönlichen Rapport bei Zar Alexander III. für die Anklage aller Verantwortlichen plädiert habe. Gleichzeitig führt er aus, dass er den Zaren auch um Milde gebeten habe für einige Beamte, die vor Gericht in Zusammenhang mit dem Unfall zweifelsohne schuldig gesprochen würden. Diese seien aber nicht nur gesundheitlich angeschlagen, sondern hätten grundsätzlich auch engagiert und gut gearbeitet. So bittet Koni den Zaren: „Erlauben Sie mir, Herrscher, zu hoffen, dass ihnen nach dem Gericht die mögliche Barmherzigkeit gezeigt wird. " ${ }^{164}$ Als in der Fortsetzung der Erzählung klar wird, dass Zar und Staatsrat die Anklage von ranghohen Personen in diesem Fall verhindern werden, bringt Koni erneut das Argument der Gnade ein, um doch noch zu einer Lösung zu kommen, die „vom Standpunkt der Gerechtigkeit“ [s točki zrenija spravedlivosti] stimmig sei. „Dort, wo eine gleiche Rechtsprechung für alle nicht möglich ist, kann gleiche Gnade für alle angebracht sein. " ${ }^{165}$ Koni stellt die Barmherzigkeit des Zaren als gerechten Ausweg dar in einer Situation, in der der Autokrat und seine Minister die Untergebenen nicht gleich behandeln wollen. Ähnlich funktioniert dies auch in Bezug auf das Strafmaß der Narodniki, die in den Massenprozessen der 1870er-Jahre verurteilt wurden. Dieses, so argumentiert Koni in den Zasulič-Erinnerungen, könne man unkompliziert über die „Wege der Barmherzigkeit des Zaren“ reduzieren, ohne dafür extra die strikten Gesetze anpassen zu müssen. ${ }^{166}$ Dieses Muster findet sich gleichermaßen in Konis Erinnerungen an das „Dreigespann“. Die vielen Fälle von „Religionsverbrechen“

164 Koni: Krušenie carskogo poezda v 1888 godu. In: GA1, S. 457.

165 Ebd., S. 483. Dem fügt Koni wie bereits erwähnt hinzu, dass man dann aber unbedingt wenigstens schriftlich die gesamten Untersuchungsergebnisse veröffentlichen müsse.

166 Koni: Vospominanija o dele Very Zasulič. In: GA2, S. 42 bzw. oben, S. 135. 
die er in „Triumvirn“ aufzählt, gaben Anlass zu zahlreichen Gnadengesuchen. Pobedonoscev und ab und zu auch Tagancev oder Murav'ev übernehmen dabei den Part der Gegenspieler, die diese Ansinnen Konis zu verhindern versuchen. So rollt er beispielsweise den Fall einer Jüdin auf, die wegen "Gotteslästerung“ [bogochulenie] zu sechs Jahren Zwangsarbeit und anschließender Verbannung nach Sibirien verurteilt worden war. Er betont, wie er sich dafür eingesetzt habe, dass der Fall mit Geschworenen aus der Intelligencija der Gouvernementsstadt nochmals aufgerollt werde. Doch dies sei nicht aufgegangen. Der Fall sei auch beim zweiten Mal in gleicher Manier abgehandelt worden, und die Geschworenen, allesamt christlich-orthodox, hätten das drastische Urteil bestätigt. Zur Kassation habe es nun keinerlei rechtlich stichhaltigen Grund mehr gegeben. Er habe aber, so Koni weiter, den zuständigen Oberstaatsanwalt überreden können, beim Justizminister Murav’ev eine „Milderung der Strafe“ zu beantragen. Gleichzeitig habe er selber einen langen Brief an Murav'ev geschrieben, in dem er diesem die „Absurdität und innere Haltlosigkeit" der Sache erklärt und ihn aufgefordert habe, direkt beim Zaren um die vollständige Begnadigung der Frau zu bitten. In diesem Fall konnte sich Koni durchsetzen, auch wenn er mit dem Widerstand seines Amtskollegen Tagancev rechnen musste. Dieser habe ihn zwar in Fällen, bei denen es um die „Zugehörigkeit zu Häretikern oder Altgläubigen“ ging, meist unterstützt, sei aber trotz seiner ,juristischen Autorität“ in Fällen von „Gotteslästerung“ oft „einseitig“, ja sogar „brutal und seelenlos“ gewesen. ${ }^{167}$ Passend zu dieser Charakterisierung sind denn auch die herablassenden Worte von Tagancev an Koni, mit denen dieser die Episode von der verbannten Frau abschließt: „Nun, wir schwächen das Urteil gegen deine Jüdin [židovka] ab. ${ }^{\text {“168 }}$

„Pravda i milost' da carstvujut v sudach“ - Gerechtigkeit und Barmherzigkeit sollen in den russischen Gerichten herrschen. Mit diesen vielfach zitierten Worten eröffnete Zar Alexander II. 1864 das „Buch der Gerichtsstatuten“ ${ }^{169}$ Im Rechtsverständnis der Reformer war Milde denn auch ein zentraler Aspekt des neuen russischen Gerichtswesens. ${ }^{170}$ Dem Zaren war es dabei vorbehalten, Strafen

167 Koni: Triumviry. In: GA2, S. 275-76. Wie Koni wurde auch Tagancev in den Staatsrat berufen.

168 Ebd., S. 276-77.

169 Schon 1856 war diese Anlehnung an ein Bibelzitat von Alexander II. in einem Manifest festgehalten worden, vgl. GA7, S. 454 (Anmerkungen).

170 Koni führt im Artikel „Geschworene“ in seiner Reihe „Aus den Erinnerungen eines Gerichtstätigen“ in „Russische Altertümer“ [Russkaja Starina] und „Auf dem Lebensweg“ I ausführlich die Möglichkeiten der Geschworenen aus, für mildernde Umstände zu plädieren. Er spricht vom „breiten Horizont der Barmherzigkeit“. So könne Rücksicht auf die Umstände der Tat oder die Persönlichkeit des Angeklagten genommen werden, vgl. KonI: Iz zametok i vospominanij sudebnogo dejatelja. Prisjažnye zasedateli. In: GA1, S. 337 ff. 
nach einem rechtmäßig gefällten Urteil nochmals abzumildern. ${ }^{171}$ Diese Justizkonzeption ging davon aus, dass der Zar als absoluter Monarch ein „göttliches“ Recht zu vergeben - und zu bestrafen - habe. Man kann dies als „,vormodernes“ Rechtsverständnis bezeichnen, allerdings ist es bis heute weit über Russland hinaus verbreitet, dass Könige oder Präsidenten das Privileg zur Vergebung genießen. ${ }^{172}$ Im Zarenreich beförderten die Unklarheiten, die es bezüglich der geltenden Rechtsprechung gab, eine gewisse Willkür, die den Monarchen - „über dem Gesetze" stehend - in seiner Vormachtstellung bestärkten. Er alleine konnte als Teil einer ,autokratischen Gesetzlichkeit“ für Fairness sorgen. ${ }^{173}$ In Russland war im 19. Jahrhundert dieser Glaube an den Zaren als Quelle der unparteilichen Gerechtigkeit tief verankert. ${ }^{174}$ Gleichzeitig wurden Zar und Zarin von aufgeklärten Zeitgenossen als oberste Diener von Recht und Gesetz betrachtet. ${ }^{175}$ Gewaltentrennung in der Autokratie bedeutete also, dass der Monarch sich freiwillig dem Gesetz unterwarf, aber auch regelnd eingriff, wo das nötig schien. Konis Erzählungen zeigen deutlich, dass er mit Stolz Szenen nachzeichnete, in denen der Zar

Im Text zu „Methoden und Aufgaben der Anklage“ aus der gleichen Reihe führt Koni ähnliche Gedanken über das Zusammenspiel von Ankläger und Verteidiger an, vgl. Anatolij F. KonI: Priemy i zadači obvinenija. In: ders. (Hrsg.): Na žiznennom puti, Bd. 1. Iz zapisok sudebnogo dejatelja, žitejskie vstreči. Sankt-Peterburg 1912, S. 102 ff, v. a. S. 106 zu „Barmherzigkeit für den Menschen“ [Milost' k čeloveku].

171 Dahlke: Old Russia in the Dock, S. 116. Vgl. auch ebd., Fußnote 92 zum Privileg des Zaren, Gesetze ohne Zustimmung weiterer Institutionen auszusetzen, und den Auseinandersetzungen, die bis 1906 und latent noch darüber hinaus zwischen einer Regierung, die Rechtsgrundsätze verankern möchte, und einem Zaren, der auf seinen Vorrechten beharrte, stattfanden. Zudem ebd., S. 120 zum Privileg des Zaren, Gnade zu üben, nicht aber Urteile zu widerrufen.

172 Nethercott: Russian Legal Culture Before and After Communism, S. 112-13. Nethercott spricht von einer „vormodernen Justizkonzeption“, während Burbank darauf verweist, dass solche Vorrechte bis in die Gegenwart verbreitet sind. Burbank argumentiert zudem, dass sich gerade auch in der Umsetzung solcher zarischer Gnadenakte durch die lokalen Gerichtsbehörden das „effektive Funktionieren“ des Rechtssystems im späten Zarenreich beweisen lasse, vgl. Jane Burbank: Mercy, Punishment, and Law. The Qualities of Justice at Township Courts. In: Kritika: Explorations in Russian and Eurasian History 1 (2006), S. 47.

173 Tatiana Borisova: The Digest of Laws of the Russian Empire. The Phenomenon of Autocratic Legality. In: Law and History Review 3 (2012), S. $914 \mathrm{ff}$ und 923 zum „Ethos der russischen Autokratie“, wo Widersprüche im Recht ein Stück weit die Macht des Monarchen stützten, und dem Denker Nikolaj Karamzin, der Anfang des 19. Jahrhunderts vom "Monarchen als der Verkörperung des Rechts“ sprach und so eine „autocratic legality“ begründete.

174 Marc Szeftel: Rezension über Michael Cherniavsky, Tsar and People (1961). In: Specu$\operatorname{lum}_{3}$ (1962), S. 424.

175 DAhlke: Old Russia in the Dock, S. 116. 
auf den Rat seines Rechtsexperten hörte und dessen Bitten um Gnade nachkam. Selbstherrschaft und eine unabhängige Justiz scheinen für ihn nicht per se unvereinbar gewesen zu sein, solange der Zar seine Rolle im vorgesehenen Sinne ausfüllte und für Milde und Gerechtigkeit sorgte. Im Gegenteil, die Macht zur Barmherzigkeit, die dem Zaren so zugestanden wurde, wurde von Koni aktiv benutzt, um seine eigenen Vorstellungen von einem funktionierenden Rechtsstaat voranzutreiben. Das Beispiel der Jüdin steht exemplarisch für diese Haltung. In der Erinnerungsschrift widmet sich Koni ausführlich dem Druck, der von Pobedonoscev, dem Heiligen Synod und dem Justizministerium ausgegangen sei, in Glaubensfragen harte Urteile zu sprechen. ${ }^{176}$ Nicht nur diese Politik wird durch die Gnadengesuche beim Zaren ausgebremst. Auch das Verhalten der Geschworenen erhielt die in Konis Augen notwendige Korrektur. Direkt führt er denn in der Erinnerungsschrift auch aus, dass lokale Geschworenengerichte den Schutz der "Glaubenstoleranz“ oftmals erschwert hätten, da sie die „Annahme von der religiösen Toleranz des russischen Volkes “ überhaupt nicht bestätigt hätten. ${ }^{177}$ Wenn es um Gerichtsfälle mit religiösem Hintergrund ging, sah Koni also eine deutliche Diskrepanz zwischen dem, was er aufgrund seiner moralischen und politischen Überzeugungen für richtig hielt, und dem, was unter dem Einfluss der konservativen religionspolitischen Großwetterlage an rechtskräftigen Urteilen gefällt wurden ${ }^{178}$ So kam es zu der paradoxen Situation, dass Koni mittels zarischer Gnade für die Umgehung der eigentlichen Gesetze plädierte, um so einer liberaleren Rechtsprechung Vorschub zu leisten. ${ }^{179}$ Der Zar und seine Macht zur Gnade erscheinen in Konis Darstellung als rettender Ausweg in einem Moment, in dem in Russland noch eine zentralen Freiheitsrechten widersprechende Gesetzgebung herrschte und auch die Geschworenen noch nicht das Rechtsbewusstsein aufwiesen, das er sich wünschte.

Diese Vorgehensweise erfreute sich denn auch in anderen Zusammenhängen außerordentlicher Beliebtheit. So wurde beispielsweise das geltende Familienrecht

176 Koni: Triumviry. In: GA2, S. $268 \mathrm{ff}$.

177 Ebd., S. 274 ff.

178 Vgl. zur sich nochmals verschärfenden Problematik der Lücke zwischen Freiheitsansprüchen und Individualrechten nach der Revolution von 1905 und der tatsächlichen Gesetzeslage: Michel Tissier: Malaise dans la culture juridique libérale en Russie après 1905. „Pédagogie des libertés“ et éducation au droit. In: Cahiers du monde russe et soviétique 2 (2007), S. 185-208.

179 Auch in zahlreichen Gerichtsfällen appellierte Koni an die Geschworenen, Milde walten zu lassen. Besonders prominent erläuterte er im Zasulič-Fall den Geschworenen, wie sie im Falle eines Schuldspruches mildernde Umstände berücksichtigen könnten, vgl. Spalinger-BichSel: A. F. Koni und die russische Gerichtsrhetorik, S. 73 bzw. oben, Fußnote 19 in TEIL ZWEI. 
in Russland im 19. Jahrhundert in großem Stil umgangen, indem sich Frauen mit persönlichen Bittschriften direkt an die „Eigene Kanzlei Seiner Kaiserlichen Majestät" wandten und um die Auflösung der Ehe baten. ${ }^{180}$ Auf gerichtlichem Weg war dies lange kaum möglich, da sich insbesondere die Orthodoxe Kirche jeder Reform der Familiengesetzgebung verweigerte. ${ }^{181}$ Ursprünglich war die „Kanzlei“ als extralegale Einrichtung Teil der „Dritten Abteilung“, die als politische Polizei auch für die Zensur zuständig war und sich grundsätzlich verantwortlich zeichnete für die „moralische Überwachung“ des Imperiums. Die Widersprüche zwischen strengem Gesetz und der „höheren Gerechtigkeit“ sollten hier durch die Gnade des Herrschers ausgeglichen werden. ${ }^{182}$ Diese Art des Umgangs mit Ehestreitigkeiten stieß unter den Juristen aber wegen ihres administrativen, informellen Charakters auf Unmut. Während viele von ihnen an vorderster Front für ein ausgeglicheneres Eherecht kämpften, so drückte der „Bote Europas“ [Vestnik Evropy] und speziell Arsen'ev doch nicht nur einmal Unzufriedenheit mit dem behördlichen und geheimen Vorgehen der „Kanzlei“ aus. Diese Beamten seien schließlich in Gesetzesfragen ungeübt. ${ }^{183}$ Solche Plädoyers für die Vorrangstellung der professionellen Justiz hinderten die gleichen Juristen aber nicht daran,

180 Zahlreich waren in Russland in der zweiten Hälfte des 19. Jahrhunderts die Juristen und Mitglieder der gebildeten Elite, die versuchten, das patriarchische und von der Kirche überwachte Eheregime zu verändern. Eine Reform des Familienrechts sollte die fast absolute Autorität des Mannes über die Frau limitieren. Seit den 186oer-Jahren arbeiteten Juristen daran, das Ehegesetz zu überarbeiten, um Scheidungen zu erleichtern und sie weg von religiösen und hin zu zivilen Gerichten zu bringen, vgl. Barbara Alpern Engel: Breaking the Ties That Bound. The Politics of Marital Strife in Late Imperial Russia. Ithaca 2011, S. 18-19.

181 Die juristischen Mittel in Zusammenhang mit Ehescheidungen waren in Russland auch nach der Gerichtsreform von 1864 beschränkt. Selbst wenn, was immer häufiger geschah, die Richter zugunsten der Frau entschieden, die sich aus der Ehe lösen wollte, konnten sie sich höchstens weigern, der Forderung des Gatten nachzugeben, die Ehefrau wieder in seinen Haushalt einzugliedern. Aber da Richter keine Verfügungsgewalt über die Ausgabe von Pässen hatten - ein verwaltungstechnischer Vorgang -, war dies von begrenztem Nutzen. Erst 1914 änderte sich die Situation grundlegend, da den Frauen nun erlaubt wurde, ohne die Einwilligung des Ehemannes einen eigenen Pass zu erwerben, vgl. ebd. und S. 260.

182 Die Petitionsabteilung trug verschiedene Namen und war im Verlauf der Zeit unterschiedlichen Behörden und Institutionen zugeordnet, vgl. detailliert ebd., S. 19-20. Zwischen 1884 und 1914 gelangten zwischen 30.000 und 40.000 unglücklich verheiratete Frauen an die „Kanzlei“. Und tatsächlich hat die Behörde als Agent des imperialen Willens diesen Frauen überraschend häufig das Recht zugesprochen, selbständig zu leben, vgl. ebd., S. 6 und 11.

183 Ebd., S. 28. 
selber genau wie Koni ausgiebig mit Gnadengesuchen an Justizdepartement und Zar zu gelangen. ${ }^{184}$

Nicht immer waren sich die Anwälte und Staatsanwälte einig darin, ob das Instrument der „Barmherzigkeit“ des Monarchen zu aktivieren sei. Ein bezeichnender Fall, in dem Konis Einschätzung nicht jener anderer Juristen entsprach, findet sich in Form des bereits erwähnten Prozesses gegen die Äbtissin Mitrofanija. ${ }^{185}$ Wie der Titel schon andeutet, handelte es sich um die Anklage und anschließende Verurteilung der Klostervorsteherin Mitrofanija (Baroness Praskov'ja Grigor'evna Rozen, 1825-1899), die mit illegalen Mitteln Geld für ihr Kloster besorgt hatte. Noch nie hatte eine Person von so hohem Rang in einem öffentlichen Prozess auf der Anklagebank gesessen, entsprechend groß war das Interesse. Sandra Dahlke führt in ihrem Aufsatz zum Prozess aus, wie mit diesem die Legitimität der Justizreform bestärkt werden sollte, die weg von Klientelismus und Spezialrechten der Kirche und hin zu Gleichheit vor dem Gesetz und zum staatlichen Monopol über die gesamte Rechtsprechung zu führen versuchte. ${ }^{186}$ Auch Koni wurde in seiner Reihe in „Russische Altertümer" [Russkaja Starina] nicht müde zu betonen, dass nach 1864 das Gesetz weder vor großen Namen noch vor Reichtum Halt gemacht habe ${ }^{187}$ In diese autobiografische Schriftensammlung integrierte Koni aber auch einen Beitrag zum Prozess gegen Mitrofanija, in dem eine gegenläufige Überzeugung angedeutet wird. In diesem Erinnerungstext geht er nicht weiter auf den Schuldspruch ein, sondern betont vielmehr, dass die Frau aus dem Klerus vor Gericht in Moskau die Klage vorgebracht habe, dass man keinerlei Rücksicht auf ihre „Amtswürde, Alter oder Geschlecht“ genommen habe. Dies, so Koni in der Erinnerung, sei wohl ein übertriebener Vorwurf. ${ }^{188}$ Stolz fügt er aber hinzu, dass die Klostervorsteherin sowohl in Moskau vor Gericht als auch in ihren Memoiren erwähnt habe, dass einzig der Staatsanwalt in St. Petersburg - also Koni - sich

184 Vgl. beispielhaft die Aussagen des Anwalts Oskar Osipovič Gruzenberg (1866-1940), der in seinen Memoiren beschreibt, wie er wiederholt beim Justizdepartement darum gebeten habe, sich um Begnadigungen oder zumindest Strafmilderungen für aus politischen Gründen verurteilte Menschen zu kümmern, vgl. O. O. Gruzennberg: Yesterday. Memoirs of a Russian-Jewish Lawyer, hrsg. u. mit einer Einleitung versehen v. Don C. Rawson. Berkeley u. a. 1981, S. 8 o (russisches Original publiziert 1938).

185 Vgl. oben, S. 80 und Fußnote 261 in TEIL EINS.

186 Dahlke: Old Russia in the Dock, S. $105 \mathrm{ff}$.

187 Vgl. oben, S. 110.

188 Anatolij F. Koni: Igumen'ja Mitrofanija. In: ders. (Hrsg.): Na žiznennom puti, Bd. 1. Iz zapisok sudebnogo dejatelja, žitejskie vstreči. Sankt-Peterburg 1912, S. 48. Koni selber war nur zu Beginn in den Prozess involviert, bevor dieser von St. Petersburg nach Moskau transferiert wurde. 
ihr gegenüber „wie ein Mensch mit Herz“ verhalten habe. ${ }^{189}$ Direkter wird Konis Wortwahl in einem Exkurs zum Fall in der Zasulič-Erinnerung. Dort kritisiert er offen das rüde Vorgehen der Moskauer Staatsanwaltschaft. Die Aussage von der mangelnden Rücksicht auf die ältere kirchliche Würdenträgerin lässt er nun unwidersprochen stehen und fügt gar hinzu, dass es zu einer „gerichtlichen Hetzjagd“ [sudebnaja travlja] gekommen sei, wie es sie immer wieder gebe in Fällen, bei denen "die Leidenschaft der Öffentlichkeit auf der Seite der Anklage“ stehe. Und dies sei für ihn „eine der anstößigsten Erscheinungen unserer Justiz“ ${ }^{190}$

Während man also argumentieren kann, dass dieser Prozess durch seine Signalwirkung in alle Schichten und Stände hinaus die Botschaft einer starken und unabhängigen Justiz verbreiten sollte, scheint für Koni das Exempel an der Klostervorsteherin in dieser Härte nicht gerechtfertigt gewesen zu sein. Ohne es in seinen Erinnerungen zu erwähnen, trug er denn dazu bei, auch hier Gnade vor Recht walten zu lassen. So wurde die Strafe der Klostervorsteherin nämlich im Geheimen durch den Zaren reduziert und Mitrofanija in Klöster im Kaukasus und in Südrussland verbannt. Koni war Teil der Kommission des Justizministeriums, die diesen Beschluss ausarbeitete ${ }^{191}$ Entgegen der Ansichten seiner Juristenkollegen setzte er sich also für Gnade gegenüber einer Angeklagten ein, deren „Amtswürde, Alter oder Geschlecht" er höher gewichtete als das Credo der unabhängigen Justiz, die auch vor dem Klerus nicht in Ehrfurcht erstarrte. Indem der Gnadenakt völlig geheim gehalten wurde - was Koni auch noch Jahrzehnte später in seinen veröffentlichten wie unveröffentlichten Erinnerungen berücksichtigte -, wurden die Gerichte in der öffentlichen Wahrnehmung trotzdem in einer starken Position belassen. ${ }^{192}$

Ein ähnlich kompromissbereites Verständnis von Justiz in der Autokratie zeigte Koni auch im Zasulič-Fall. In seiner Erinnerungsschrift berichtet er ungerührt, wie er selber dazu geraten habe, den Fall nicht vor ein Geschworenengericht zu bringen, sondern direkt an die Polizei zu übergeben. Ein Prozess, in dem die Geschworenen nicht frei in ihrem Urteil seien, würde nur eine Gefahr für die Institutionen der Geschworenengerichte an sich darstellen. ${ }^{193} \mathrm{Um}$ die funktionierenden Teile der reformierten Gerichte zu erhalten, schien Koni also zu Zugeständnissen bereit. Dies nicht zuletzt zum großen Missfallen der Herausgeber der Gesamtausgabe seiner Werke, die sich in den 196oer-Jahren genötigt sahen,

189 Ebd., S. 52.

190 Koni: Vospominanija o dele Very Zasulič. In: GA2, S. 226.

191 Dahlke: Old Russia in the Dock, S. 105. Das entsprechende Schreiben Konis dazu auch in seinem Nachlass, vgl. GARF F. 564, op. 1, d. 626, 1. 1-3ob.

192 Dies passt zu seiner bewussten Art der Erinnerung an die Gerichtsreform, vgl. TEIL EINS.

193 Koni: Vospominanija o dele Very Zasulič. In: GA2, S. 72-73. 
diese Haltung mit deutlichen Worten zu kritisieren. Unverständlich schien ihnen, dass Koni sich einerseits beispielsweise im „Memorandum“ darüber empörte, dass die Gesetzgebung in den 187oer-Jahren dazu beigetragen habe, die Rechte der Angeklagten einzuschränken, Willkür in Staatsanwaltschaft und Polizei zu erhöhen und die Öffentlichkeit mit riesigen Prozessen fast ohne Schuldsprüche zu konfrontieren. Andererseits aber kaum darüber spreche, dass in dieser Zeit ungefähr 80 \% aller politischen Fälle auf administrative Weise gelöst wurden, so dass Menschen nach Sibirien verbannt wurden, ohne dass sie überhaupt je vor ein Gericht gestellt worden waren. ${ }^{194}$ Führt man sich aber die Argumentation Konis vor Augen, so wird deutlich, dass in seinem Verständnis der Rechtsstaat dort am unmittelbarsten bedroht war, wo die neuen Gerichte für alle sichtbar zum Spielball des politischen Kampfes der Regierung gegen oppositionelle Strömungen wurden. Seine Priorität jedoch lag auf der Bewahrung der Errungenschaft des transparenten, mündlichen Gerichtsverfahrens am Geschworenengericht. In pragmatischer Manier war er bereit, Fälle, in denen politische Interessen eine Rolle spielten, an administrative Behörden auszulagern, wenn so die Glaubwürdigkeit der Rechtsprechung wenigstens in einem Teilgebiet aufrechterhalten werden konnte.

Dieser flexible Umgang mit Gesetz und Justiz in der Autokratie wurde wesentlich durch Konis Interpretation der Figur des Zaren möglich gemacht. Der allmächtige Monarch war für Koni nicht einfach eine Gegebenheit, mit der man pragmatisch umzugehen hatte. Der Zar wurde von ihm in seinen Erinnerungsschriften - im Gnadenakt beispielhaft versinnbildlicht - als Akteur der Rechtsprechung interpretiert, den es nach eigenem Gutdünken zu beeinflussen galt.

\section{Fazit}

Koni war aufgrund seiner beruflichen Position als Oberstaatsanwalt am Kriminalkassationsdepartement stärker gezwungen, sich mit dem Herrscher über das Russische Reich auseinanderzusetzen, als dies für die in der Selbstverwaltung organisierten Anwälte oder weniger exponierte Mitarbeiter der Gerichtsbehörden galt. In den Erinnerungsschriften zu seiner beruflichen Tätigkeit widmete er sich offensiv dieser Thematik und machte aus der Faszination, die die Figur des Autokraten und dessen Machtfülle auf ihn ausübten, keinen Hehl. In poetischen Worten erinnerte er sich mit Vorliebe an die Momente in der Gegenwart des Zaren, referierte dessen Haltung zu ihm und generierte so für den Leser das Bild einer besonderen Beziehung zwischen sich und dem Monarchen. Aus den Kontakten in

194 Vgl. GA2, S. 459-6o (Anmerkungen). 
die Machtsphäre schöpfte Koni wiederum Handlungsfähigkeit. Die eigene Person wird als aktiver Berater dargestellt, der "die Wahrheit" in die höchsten Entscheidungsgremien des Imperiums trägt und so beharrlich an seinen eigenen liberalen Zukunftsvisionen arbeitet, die aber ohne die Figur des Zaren nicht auskommen können. Das Gnadengesuch fungiert dabei in den Schriften als Prüfstand für das Verhältnis zwischen Zar, Justiz und Koni. Hier zeigte sich, ob der Zar den Rat des Juristen befolgte und seine Aufgabe als Teil der Rechtsprechung in erwarteter Art und Weise erfüllte. Die Justiz im autokratischen Russland wurde in der Forschung oftmals als zum Scheitern verurteilte blinde Nacheiferung westlicher Ideale von Freiheit und Bürgertum inmitten selbstherrschaftlicher Destruktion verstanden ${ }^{195}$ In Konis Erinnerungsschriften zeigt sich allerdings ein Umgang mit Zar und Recht, der beide zu vereinen weiß und aus diesem Setting Spielräume für sich selber generiert.

Indem Koni diese Darstellung in seinem Rückblick so betonte, schien er nicht zuletzt auch die Richtigkeit seiner politischen Analysen und Prognosen der vergangenen Jahrzehnte nochmals zu bekräftigen, mit denen er Jahre zuvor an die Zaren zu gelangen versucht hatte. Eine Prognose kann ein Mittel sein, Situationen $\mathrm{zu}$ verändern, alternative Bedingungen ins Auge zu fassen und Möglichkeiten ins Spiel zu bringen ${ }^{196}$ Konis umfangreiche Erinnerungsschriften zum ZasuličFall, zur Zugentgleisung und zu seiner Arbeit als Oberstaatsanwalt weisen darauf hin, dass er seine Erlebnisse und seine politischen Einflussversuche auch zum Schreibzeitpunkt nach der Jahrhundertwende noch für relevant hielt. Besonders nachhaltig versinnbildlicht am Lehrstück des Zasulič-Prozesses repetierte und aktualisierte Koni seine Interpretation der gesellschaftspolitischen Zustände in diesen Erinnerungen erneut und lehnte sich dabei eng an die Interpretationen und Haltungen seiner Freunde in der liberalen Publizistik wie dem „Boten Europas“ an.

Die Beharrlichkeit, die Koni bei seiner Rekapitulation dieser Überzeugungen auszeichnete, erinnert an ein Zeitverständnis, das demjenigen der revolutionären Bewegung gar nicht so unähnlich zu sein scheint. Die radikalisierten Narodniki sahen sich spätestens seit dem Attentat von Vera Zasulič in einer „Logik der Ereignisse“, die unvermeidbar voranschritten und zum Handeln zwangen. Aus dem Wissen über die Vergangenheit schlossen die Revolutionäre auf die Gegenwart:

195 Sei es, indem man dem autokratischen Staat vorwarf, die moderne Justiz nicht voll zur Entfaltung habe kommen lassen, wie es die vorrevolutionäre Historiografie sah. Oder aber indem man behauptet, „die formalen Prinzipien des Rechtsstaates“ hätten in Russland aufgrund der „sozio-ökonomischen Rückständigkeit“ grundsätzlich schon nur schwerlich institutionalisiert werden können, vgl. BABEROwSKI: Autokratie und Justiz, S. 2 und 6.

196 Reinhart Koselleck: Vergangene Zukunft. Zur Semantik geschichtlicher Zeiten. Frankfurt am Main 1979, S. 359. 
„Bald“ würde die Bosheit der Herrschenden alles zerstört haben, „bald“ würde es keine Zeit mehr geben, um Gegensteuer zu ergreifen. ${ }^{197}$ Beseelt von einer ganz anderen Zukunftsvision vermittelte Koni in seinen Erinnerungen eine ähnliche „Logik der Ereignisse“, in der die Zeit „bald“ ablaufen würde. Die feste Überzeugung der Revolutionäre, zum Handeln gezwungen zu werden, schien er genauso zu spüren, wenn er nach der Jahrhundertwende nochmals zu vermitteln versuchte, was er in den Jahren und Jahrzehnten davor an Analysen und Taten geleistet hatte. Während er sich also wie die Revolutionäre als unermüdlich Insistierenden zeichnete, verkörperten seine politischen Ideen ein Konzept, das eine völlig andere Temporalität aufwies als jenes der radikalen Bewegung. Während für die revolutionären Kräfte „Beschleunigung“ ein zentrales Element des gewaltsamen Kampfes für eine neuartige Zukunft war, ${ }^{198}$ sprachen Koni und mit ihm seine liberalen Gesinnungsgenossen vom „organischen Gang" und von schrittweisen Reformen und „Entwicklung des Landes“.

Wo immer Koni in seinen Erinnerungen eingestehen musste, mit dieser Vision nicht durchgedrungen zu sein, bloß als „Prediger in der Wüste“ geendet zu haben, relativierte das Narrativ von den bösen Beratern die Tragweite seines Scheiterns. Schlussendlich sind seine Memoiren trotz der vielen Stellen voller Enttäuschung und Ärger, trotz all der Kämpfe gegen Pobedonoscev oder der Rückweisungen und falschen Versprechungen durch die Monarchen von der ungebrochenen $\mathrm{Zu}$ versicht geprägt, in der Gunst des ,guten Zaren“ zu stehen und diesen doch noch von den eigenen Rezepten für die Zukunft des Landes überzeugen zu können.

Die verschiedenen Tonlagen, die sich in Konis umfangreicher Rückschau auf sein Berufsleben zeigen, deuten bereits an, dass die Auseinandersetzung mit seiner Rolle ein komplizierter Prozess war. Die drei Erinnerungsschriften, die Koni zwischen 1904 und 1907 in überarbeiteter Form zu Papier brachte, stellen denn auch nur einen Teil seiner autobiografischen Praxis in diesem Zeitraum dar. Praktisch zeitgleich verfasste Koni auch Erinnerungstexte ganz anderer Natur. Die zeitgeschichtlichen Ereignisse mit der Erstarkung der konstitutionellen Bewegung und

197 Claudia Verhoeven: The Odd Man Karakozov. Imperial Russia, Modernity, and the Birth of Terrorism. Ithaca 2009, S. 257-63. Verhoeven führt aus, wie schon das erste Attentat auf den Zaren von D. Karakozov 1866 eine neue „Beziehung zur historischen Zeit“ in die revolutionäre Bewegung einführte. Nun schien es, dass die richtige Zeit gekommen war, um die Revolution zu starten. Ein „zu früh“ wurde undenkbar, es blieb nur das „jetzt“ oder das „zu spät“, vgl. ebd., S. 257-58. Die „Ausführer der historischen Gerechtigkeit“ mussten der „Geschichte“ nun einen „Stoß" geben, damit diese sich endlich voranbewegte, vgl. ebd., S. 262.

198 Verhoeven: The Odd Man Karakozov, S. 264. 
der Revolution von 1905 brachten Koni dazu, seine eigene Position im Verhältnis zu Zar und Macht nochmals grundlegend zu überdenken.

\subsection{Autobiografisches Ringen im Zeichen der ersten Russischen Revolution}

Die Unruhen in den Randgebieten des Russischen Reichs begannen in der Mitte des Jahres 1905 und kreisten das Zentrum immer mehr ein. ${ }^{199}$ Im September kam es in Moskau zu größeren Streiks, im Oktober wurde ein Generalstreik ausgerufen, der schnell die anderen großen Städte und Industriezentren im Kern des Imperiums ergriff. Während zu Beginn ein breit abgestütztes Bündnis zwischen Arbeiterschaft, Opposition in den lokalen Zemstva und weiteren liberalen und sozialistischen Kräften die aufständische Bewegung prägte, war nun die Führung übergegangen an Arbeitergruppierungen und von ihnen gegründete Räte - die Sowjets. Mit dem „Oktobermanifest“ vom 17. Oktober versuchte der Zar, den Revolutionären durch Konzessionen den Wind aus den Segeln zu nehmen. Ein gesetzgebendes Parlament - die Duma - wurde angekündigt, und tatsächlich entschieden sich liberale Teile der Intelligencija, ganz vom konfrontativen Kurs wegzukommen. Sie nutzten die demokratischen Zugeständnisse, um die liberale Partei der Konstitutionellen Demokraten zu gründen, die auf ein starkes Abschneiden bei den Wahlen zum ersten Parlament im Russischen Reich hoffte. ${ }^{200}$ Der Arbeiterrat von St. Petersburg ließ sich vom Entgegenkommen der Regierung aber nicht beeinflussen und fuhr damit fort, sich durch Streiks für weitergehende Forderungen wie zum Beispiel die Aufhebung des Belagerungszustands für Polen oder eine Amnestie für meuternde Soldaten einzusetzen. In Moskau ging der dortige Rat gar zum bewaffneten Aufstand über. Alleine, ohne die Unterstützung

199 Dem war im Januar 1905 der „Blutsonntag“ vorausgegangen. Eine friedliche Arbeiterdemonstration in St. Petersburg hatte sich infolge des harten Durchgreifens von Elitetruppen in ein Blutbad verwandelt, vgl. KAPPELER: Russische Geschichte, S. 31.

200 Haumann: Geschichte Russlands, S. 301-02. Die Zugeständnisse, die der Zar versprach, umfassten neben den Parlamentswahlen die Gewährung bürgerlicher Grundrechte wie Gewissensfreiheit, Versammlungsfreiheit und Pressefreiheit, vgl. Polunov: Russia in the Nineteenth Century, S. 221. Auch von Religionsfreiheit, insbesondere um die unzähligen Einschränkungen für Juden aufzuheben, wurde gesprochen. Die Umsetzung wurde aber nicht zuletzt vom Zaren persönlich stark behindert, vgl. John F. Hutchinson: Late Imperial Russia, 1890-1917. London 1999, S. 68. Die „Konstitutionellen Demokraten“, auch „Kadetten“ genannt, bildeten den linken Flügel im liberalen Parteienspektrum. Ihnen kam eine wichtige Rolle im politischen Leben während und nach der Revolution von $1905 \mathrm{zu}$, vgl. Polunov: Russia in the Nineteenth Century, S. 210. 
der liberalen Opposition, waren die Arbeiterräte allerdings nicht in der Lage, eine starke Front zu bilden. Bis Ende Jahr waren die Sowjetmitglieder in St. Petersburg verhaftet und der Aufstand in Moskau blutig niedergeschlagen. ${ }^{201}$ In diesen letzten Monaten des Jahres 1905 griff schließlich die revolutionäre Stimmung auch verstärkt auf die Bauern über. In den ländlichen Gegenden im Kern des Reiches war es vor Oktober verhältnismäßig ruhig geblieben. Nun aber kam es auch hier zu einer gewaltigen revolutionären Welle. Gutsherren und Landhauptleute waren das Ziel der Kritik. Seit Oktober häuften sich Brandstiftungen und Plünderungen von Gutshöfen, deren Land die Bauern für sich beanspruchten. ${ }^{202}$ Während die Unruhen in den Städten bald darauf zu einem Ende kamen, setzte sich die Erhebung der Bauern auch 1906 fort und wurde erst durch massive Truppeneinsätze und die Einführung von Feldgerichten, die mit Aufständischen kurzen Prozess machten, niedergeschlagen. ${ }^{203}$ Parallel dazu wurden die Vorbereitungen zu den Duma-Wahlen vorangetrieben, die Russland zu einer „eingeschränkten Autokratie" machen sollten. ${ }^{204}$ Am 27. April 1906 eröffnete Zar Nikolaus II. in einer feierlichen Zeremonie schließlich das erste russische Parlament, in dem die in der Opposition zur Autokratie stehenden Konstitutionellen Demokraten die stärkste Kraft bildeten. ${ }^{205}$ Die Duma wurde aber schon nach wenigen Monaten am 8. Juli

201 Haumann: Geschichte Russlands, S. 302-03. Die Räte wurden von spezifischen Arbeitergruppierungen getragen, wie z. B. den Eisenbahnarbeitern oder den Druckern. Die Arbeiterparteien machten sich diese Bewegung erst nach und nach zu eigen. In St. Petersburg wurden die sozialistischen Menschewiki in den Sowjets wichtig, während die Bolschewiki lange hin und her schwankten, dafür in Moskau den Rat im Dezember bei seinem Aufstandsversuch anführten. Die 1898 in Minsk gegründete „Russische Sozialdemokratische Arbeiterpartei“ hatte sich einige Jahre nach ihrer Konstituierung in die Fraktionen der „Menschewiki“ und der „Bolschewiki“ unter der Führung von Lenin getrennt, vgl. dazu ausführlich ebd., S. $277 \mathrm{ff}$.

202 Haumann: Geschichte Russlands, S. 303. Dabei wurden in Verbindung mit der revolutionären Bewegung in den Städten auch politische Forderungen erhoben. Sozialrevolutionäre und Volkssozialisten prägten den Allrussischen Bauernbund, ohne aber die Führung über die Bewegung zu übernehmen, die ihren Ursprung deutlich im Dorf hatte. Die Partei der Sozialrevolutionäre, 1901 gegründet, nahm viele Ideen der Narodniki wieder auf, vgl. ebd., S. 278.

203 Polunov: Russia in the Nineteenth Century, S. 221 und Haumann: Geschichte Russlands, S. 304.

204 Haumann: Geschichte Russlands, S. 301. Kurz vor der Einsetzung des Parlaments erließ der Zar allerdings eigenmächtig Verfassungsbestimmungen, die sogenannten Grundgesetze vom 23. April 1906. So wollte er konstitutionellen Absichten der Duma zuvorkommen. Der Zar gab sich darin das Recht, das Parlament auflösen zu dürfen.

205 Haumann: Geschichte Russlands, S. 304-05. Die revolutionären Parteien konnten dabei nicht gewählt werden oder boykottierten die Wahlen. Trotzdem erlitt die Rechte eine große Niederlage, da die Bauern weniger konservativ stimmten als angenommen. Sie gaben ihre 
1906 wieder aufgelöst. Dies in der Hoffnung, dass erneute Wahlen zu einer der Autokratie gewogeneren Zusammensetzung führen würden. Als dem nicht so war, setzte sich der Zar über die eigenen verfassungsmäßigen Beschränkungen hinweg und erließ im Sommer 1907 ein neues Wahlrecht, das zu dem von ihm angestrebten konservativen Wahlerfolg führte. ${ }^{206}$

Die sich überstürzenden Ereignisse des Jahres 1905/06 waren für Koni Auslöser für drei autobiografische Schriften. Sowohl den ungefähren Schreib- beziehungsweise Überarbeitungszeitpunkt als auch die höchstens mittelfristige Publikationsabsicht haben diese Dokumente mit seinen umfangreichen Memoiren über sein Berufsleben gemeinsam. ${ }^{207}$ Trotzdem handelt es sich um völlig verschiedene Texttypen. Im Gegensatz zu den sehr ausführlichen und teilweise Jahrzehnte zurückblickenden Erinnerungen an seine wichtigsten Gerichtsfälle und die Zeit als Oberstaatsanwalt am Kriminalkassationsdepartement, handelt es sich nun um sehr viel kürzere Texte, die immer eine unmittelbare Verankerung im Zeitgeschehen haben und von ihm zeitnah niedergeschrieben wurden. Besonders eindrücklich steht so die autobiografische Reflexion in direktem Zusammenhang mit den Veränderungen der Revolutionszeit. Die Erfahrung historischen Wandels wird im autobiografischen Text nicht nur widergespiegelt. Vielmehr zeigen Konis Schriften auf, wie historischer Wandel dazu beiträgt, Selbstreflexion zu befördern. ${ }^{208}$ Ganz konkret wird dies in Konis chronologisch frühesten dieser Schriften, die den Titel „Die Vorstellung bei Alexander III. in Gatčina“ trägt. Er beginnt mit der Schilderung des Tages, an dem er schreibt: der 22. Oktober 1905. Morgen - fährt er fort - würden in Petersburg die „feierlichen Begräbnisse der Arbeiter" stattfinden, die in den letzten Tagen bei Zusammenstößen ums Leben gekommen seien. Gleichzeitig würden von überall her Telegramme eintreffen,

Stimmen in großer Zahl den Trudoviki, die politisch zwischen Sozialrevolutionären und Sozialdemokraten standen.

206 Polunov: Russia in the Nineteenth Century, S. 223-27 und Dietmar Neutatz: Träume und Alpträume. Eine Geschichte Russlands im 20. Jahrhundert. München 2013, S. 121-22.

207 Es ist unklar, ob Koni die Veröffentlichung dieser Schriften beabsichtigte. Zumindest für einen der Texte scheint es aber wahrscheinlich, dass er in späteren Jahren eine Publikation anstrebte. Dies ist die Erinnerung „Meine Nacht Gethsemane“ [Moja gefsimanskaja noč]. Im Archiv findet sich die Beschriftung „Für den Druck“. Es ist unklar, von wann diese stammt, vgl. GARF F. 564, op. 1, d. 205B. Koni wollte aber in den 1920er-Jahren zahlreiche Erinnerungen an politische Akteure und Geschehnisse veröffentlichen, dazu gehört auch diese Episode, vgl. IRLI F. 134, op. 1, d. 147, 1. 8ob. Darauf wird im Kapitel Politische Erinnerung an das Zarenreich in der Sowjetunion eingegangen. In der Folge wird jeweils die Version zitiert, die erstmals in der Gesamtausgabe veröffentlicht wurde.

208 Volker De PкAт: Autobiographie und die soziale Konstruktion von Wirklichkeit. In: Geschichte und Gesellschaft 1 (2003), S. 476. 
die von „revolutionären und patriotischen Manifestationen“ berichteten, die in „Blutvergießen und Ausbrüchen von bestialischer Brutalität“ enden würden. ${ }^{209}$ Koni legt so seine Erschütterung offen, und analysiert in der Folge die Gründe für diese Entwicklung, die er in der Politik der letzten 20 Jahre ausmacht. „Deshalb möchte ich mich an meine Vorstellung bei Alexander III. erinnern, zum Anlass meiner zweiten Ernennung zum Oberstaatsanwalt. “" ${ }^{\text {"10 }}$ Nach dieser Ansage führt Koni im Rest des Textes auf insgesamt sieben Seiten seine Erinnerungen an ein ungutes Zusammentreffen mit dem Vorgänger des amtierenden Zaren und dessen Ehefrau an, das 1892 stattgefunden hatte.

Während Koni in dieser Schrift aus Anlass von Tod und Brutalität im Russischen Reich von 1905 den Blick einige Jahre in die Vergangenheit schweifen lässt, sind es bei den beiden anderen Erinnerungen dieser Art nur wenige Tage. In „Die Eröffnung der Duma“ beschreibt Koni aus seiner eigenen Perspektive, wie am 27. April 1906 Zar Nikolaus II. das erste Parlament im Russischen Reich eröffnet hatte. ${ }^{211}$ Zur Eröffnungszeremonie waren zahlreiche Würdenträger geladen, auch Koni gehörte als Senator an der obersten Gerichtsbehörde dazu. Auf fünf Seiten schreibt er durchgehend im Präsens scheinbar noch am Tag der Festlichkeit nieder, wie er diese erlebt hatte. Er berichtet vom Saal, den Anwesenden, dem Zaren und dessen Rede. Auch einige Gespräche mit anwesenden Politikern und Bewertungen von deren Tun lässt er in die Aufzeichnung einfließen. Das Ende der Schrift fällt mit dem Ende der Zeremonie zusammen. Rasch verlasse die Zarenfamilie den Saal und auch er fahre nach Hause, „,oller Unruhe und trauriger Vorahnung“212

Nur wenige Wochen später verfasste Koni erneut einen Text über ein Erlebnis, das nur wenige Tage zurücklag. Datiert vom 22. Juli 1906 erläutert er auf 17 Seiten, wie ihm eine „Nacht Gethsemane“ widerfahren sei. ${ }^{213}$ Am Samstag, 15. Juli - so die

209 Anatolij F. Koni: Predstavlenie Aleksandru III. v Gatčine (v nojabre 1892 goda). In: GA2, S. 348. Zwei Reinschriften, eine handschriftlich, eine mit Maschine, befinden sich in IRLI F. 134, op. 1, d. 133, diese tragen allerdings keinen Titel. Die sie umfassende Archivmappe ist datiert von 1932 und trägt die entsprechende Überschrift, die auch von den Herausgebern der Gesamtausgabe verwendet wurde, deren Erstpublikation der Schrift in der Folge jeweils zitiert wird.

210 Koni: Predstavlenie Aleksandru III. v Gatčine. In: GA2, S. 349.

211 Anatolij F. Konı: Otkrytie I Gosudarstvennoj Dumy. In: GA2, S. 355-59. In der Gesamtausgabe wurde diese Schrift mit dem Titel „Eröffnung der ersten Staatsduma“ versehen. Die Archivversion heißt aber einfach: „Otkrytie dumy“ [Eröffnung der Duma], vgl. GARF F. 564, op. 1, d. 206. In der Folge wird jeweils die Erstpublikation in der Gesamtausgabe zitiert.

212 Koni: Otkrytie I Gosudarstvennoj Dumy. In: GA2, S. 359.

213 Anatolij F. Koni: Moja gefsimanskaja noč. In: GA2, S. 360-76. Die Veröffentlichung bezieht sich auf das Archivgut: GARF F. 564, op. 1, d. 205 B. 
Einleitung der Schrift - habe er während seines Aufenthalts in einem Kurort am Meer Besuch von Graf Petr Aleksandrovič Gejden (1840-1907) erhalten. ${ }^{214}$ Obwohl ursprünglich Militär, kannte und schätzte Koni Gejden insbesondere aufgrund von dessen langjähriger Tätigkeit an verschiedenen Gerichten. Nach seinem Tod 1907 verfasste Koni einen kurzen Nachruf, in dem er Gejdens Engagement für die Reformen von Alexander II. hervorhob, und widmete ihm dann auch die beiden Bände „Auf dem Lebensweg“ I und II. Graf Gejden war Abgeordneter der soeben aufgelösten ersten Duma und Gründungsmitglied der liberal-konservativen Partei „Union des 17. Oktobers“, die die Einrichtung eines Parlaments begrüßte, aber dem Zaren weiterhin gewisse Vorrechte zugestehen wollte. ${ }^{215}$ Der Rest von Konis Erinnerung behandelt die Versuche des Politikers, ihn zum Eintritt in die Regierung zu überreden. Nach dem erzwungenen Auseinandergehen der ersten Duma hatte der neue Ministerpräsident Petr Arkad'evič Stolypin (1862-1911) den Auftrag erhalten, ein Kabinett zusammenzustellen. Dieser wollte - wie man es schon im Vorfeld der ersten Duma-Wahlen versucht hatte - populäre parlamentarische und zivilgesellschaftliche Akteure aus den Reihen jener, die die Einschränkung der Selbstherrschaft unterstützten, von einer Teilnahme an der neuen Regierung überzeugen. ${ }^{216}$ So sollte eine größere Legitimität der Staatsführung in der Gesellschaft erreicht werden. In diesem Zusammenhang ist die Anfrage zu verstehen, mit der sich Koni unverhofft konfrontiert sah. Nach langem Hin und Her endet seine Erinnerungsschrift mit der Rechtfertigung seiner Absage. Erklärend fügte Koni noch hinzu, er habe nun die Ergebnisse der von ihm durchlebten „harten Woche" hier aufgeführt. ${ }^{217}$

214 Koni: Moja gefsimanskaja noč. In: GA2, S. 360.

215 Vgl. unten, S. 196 ausführlicher zur Abspaltung des linken Flügels in die „Partei der friedlichen Erneuerung “ im Sommer 1906. Für Konis Porträt zu Gejden vgl. Angaben in Fußnote 36 in TEIL EINS.

216 D. N. Šıpov: Vospominanija i dumy o perežitom. Moskva 1918, S. 464. Auf S. 464-75ff erinnert sich Dmitrij Nikolaevič Šipov (1851-1920), der ebenfalls hätte Teil dieser Regierung werden sollen, detailliert an die komplizierten Verhandlungen u. a. auch mit Koni. Šipov hatte sich sehr für die Zemstva engagiert und gehörte wie Gejden der „Union des 17. Oktobers" an.

217 Koni: Moja gefsimanskaja noč. In: GA2, S. 375-76. Vgl. zu dieser ganzen Geschichte auch Konis Briefe in GA8, S. $238 \mathrm{ff}$ (z. B. Brief an P. A. Gejden vom 16. 07.1906). Stolypin prägte als Ministerpräsident die Politik der kommenden Jahre. Dabei verband er ein hartes Vorgehen gegen die Opposition mit gewissen Reformen. Insbesondere seine Agrarreform stieß aber bei vielen Adeligen auf Unmut. Die Kirche beargwöhnte zudem seine Pläne, den Altgläubigen entgegenzukommen. In der Öffentlichkeit hingegen entwickelte sich immer größere Unzufriedenheit mit der Art, wie Stolypin die Revolution niederschlagen ließ und Repressionen gegen kritische Organisationen einleitete. 1911 fiel 
Mit dieser Aussage betonte Koni, dass die autobiografische Schrift für ihn in diesem Moment eine „therapeutische“ Funktion erfüllte. ${ }^{218}$ Im Schreiben rekapitulierte Koni das Erlebte, ordnete seine Gedanken und versicherte sich selber der Richtigkeit der getroffenen Entscheidungen. Die Situation, in die Koni durch die rasanten Veränderungen in Politik und Gesellschaft gebracht wurde, hatte etwas Krisenhaftes. Im neuen politischen Klima, das sagbar machte, was lange zensiert geblieben war, und das mit dem Parlament etwas erreicht hatte, was lange für unmöglich gehalten worden war, veränderte sich auch der Maßstab, mit dem die Haltungen und Handlungen der Akteure in der zweiten Hälfte des 19. Jahrhunderts von der Öffentlichkeit bewertet wurden. Gleichzeitig wandelte sich die in die Zukunft gerichtete Anspruchshaltung und es wurde mehr und mehr die Konkretisierung der eigenen Überzeugungen beziehungsweise eine unmissverständliche Stellungnahme gefordert. In diesem Kontext fungierte das autobiografische Schreiben für Koni als Ort der Auseinandersetzung und des Ringens mit sich selber. Das Angebot, Teil der Regierung zu werden, war dabei nur die intensivierte Form einer grundsätzlichen Frage, mit der sich Koni schon seit Jahren konfrontiert sah. Wo war sein Platz beziehungsweise was war seine Rolle im imperialen Machtgefüge? Diese Auseinandersetzung ist denn auch das vereinende Element in den drei Erinnerungstexten, die Koni im Zuge von Revolution und Konstitutionalisierung verfasste. Aber auch in gewissen Abschnitten der ausführlicheren Memoiren über den Zasulič-Prozess, die Entgleisung des Zarenzugs und die Zeit am Kriminalkassationsdepartement lässt sich dieses Ringen ausmachen. Identität wird darin beispielhaft als ,dynamischer Prozess in der Zeit" fassbar, durch den angesichts erfahrenen Wandels neue Kohärenz geschaffen wird. ${ }^{219}$ Voll von widerstreitenden Interpretationen seiner Person lassen die autobiografischen Reflexionen Konis deutlich erkennen, wie er seinen Karriereverlauf und seine beruflichen und politischen Ambitionen angesichts der revolutionären Ereignisse neu einschätzte und dabei die Frage nach seinem tatsächlichen Einfluss, seinem Streben nach solchem und seinen Motiven in Form einer neuen Selbstdarstellung beantwortete.

der von allen Seiten kritisierte Ministerpräsident schließlich einem Mordanschlag zum Opfer, vgl. Haumann: Geschichte Russlands, S. 307.

218 Schmid: Ichentwürfe, S. 377-78 zu Autobiografien, die ihre Entstehung einer Krisensituation zu verdanken haben und so die Funktionen einer „Selbsttherapie“ übernehmen.

219 Volker Dеркат: Nicht die Materialien sind das Problem, sondern die Fragen, die man stellt. Zum Quellenwert von Autobiographien für die historische Forschung. In: Thomas Rathmann/Nikolaus Wegmann (Hrsg.): Quelle. Zwischen Ursprung und Konstrukt. Ein Leitbegriff in der Diskussion. Berlin 2004, S. 113. 


\subsubsection{Konis politische Ambitionen}

Am Ende habe er Nein gesagt. So das Resultat in Konis Bericht über die Anfrage Stolypins, Teil der Regierung zu werden. Dieses Nein relativierte er aber in der Schrift bereits mit der Wahl des Titels: „Eine Nacht Gethsemane“ sei für ihn die Woche Bedenkzeit gewesen, bis er sich zur endgültigen Entscheidung durchgerungen habe. Er zieht eine Parallele zwischen seinem Findungsprozess und jenem des biblischen Jesus, der laut Neuem Testament in der Nacht, in der er sich verraten ließ, im Garten Gethsemane mit seinem Schicksal gehadert haben soll. Konis Ringen manifestiert sich in der Erinnerungsschrift durch das große Gewicht, das er seinen Überlegungen für und gegen die Annahme des Angebots gibt. So erzählt er minutiös seine mehrfachen Meinungswechsel und Verunsicherungen nach und erklärt jeweils detailgenau, was die Argumente gewesen seien, die ihn mal für diese, mal für jene Entscheidung hätten plädieren lassen. Mit dieser Erinnerungsschrift erlaubt Koni einen Blick auf seine Ambitionen, die in diesem Hin und Her deutlich zutage treten. So stellt er denn gleich zu Beginn der Erinnerung klar:

Das Schicksal hat seine böse Ironie mit mir weitergetrieben, indem es mir zu spät all das schickte, von dem ich mir als Mensch und als Bürger das Recht nahm zu träumen. Es hat mich während vieler Jahre zum beinahe fruchtlosen „Protestierer“ [počti besplodnym „protestantom“] gegen die irrsinnige Politik der Regierung gemacht [...]. ${ }^{220}$

„Farblos“ sei die Tätigkeit gewesen, mit der er sich habe herumschlagen müssen. Und jetzt, wo er alt sei, sende ihn das Schicksal an die Front im Kampf mit Revolution und Reaktion. ${ }^{221}$ Konis Traum von einer wirklich einflussreichen Position, in der sein Kampf nicht „farblos“ geblieben wäre, verdeutlicht sich im Verlauf der Erinnerung weiter. So berichtet er, wie Stolypin im Versuch, ihn zu überzeugen, an seinen Patriotismus und an die historische Bedeutung des Moments appelliert habe. ${ }^{222}$ Dies nimmt Koni zum Anlass, in der Schrift über mehrere Seiten hinweg seinen Willen zum „Dienst an den rechtlichen und moralischen Interessen des russischen Volkes“ zu betonen, den er ungeachtet von persönlichen oder karrieretechnischen Interessen ausüben wolle. Gleichzeitig nimmt er sich zurück und behauptet, er sei nun ein alter und kranker Mann, dessen Name niemandem mehr etwas sage. ${ }^{223}$ Plötzlich gibt Koni dem Drängen dann aber trotzdem nach, denn:

\footnotetext{
220 Koni: Moja gefsimanskaja noč. In: GA2, S. 360-61.

221 Ebd., S. 361.

222 Ebd., S. 362.

223 Ebd., S. 361-64.
} 
Die Realisation des liberalen Programmes und der mögliche Ausweg aus der schwierigen Situation, in die die Regierung durch die Auflösung der Duma gekommen war, wurden von meiner Einwilligung abhängig gemacht. ${ }^{224}$

Doch nach Ausführungen zu den politischen und rechtlichen Differenzen zwischen ihm und den weiteren Kandidaten für die Regierung ringt sich Koni zu einer Absage durch. Auch diese zeugt aber von einer selbstbewussten Haltung. So seien er und Graf Gejden gemeinsam zum Schluss gekommen, dass die ganze Idee nicht funktionieren würde. Sie wären alle „kaum länger als eine Woche“ im Amt geblieben aufgrund der „prinzipiellen Meinungsverschiedenheiten“ mit Stolypin und dem Zaren. Ihr Rücktritt hätte dann aber als Anlass für die „radikalen Parteien“ dienen können, zum „bewaffneten Aufstand“ überzugehen. ${ }^{225}$ Vollständig lässt Koni die Möglichkeit zur Einflussnahme jedoch nicht an sich vorbeigehen. Er führt in der Erinnerung nämlich auch an, dass er in einem Brief an Stolypin detailliert seine Meinung zu den wichtigsten Punkten aus dem Programm von Dmitrij Šipov aufgeführt habe. Dieser Mitkandidat für die Regierung vertrat Ansichten, die Koni unterstützte, wie zum Beispiel die Abschaffung der Todesstrafe und eine großangelegte Amnestie. ${ }^{226}$

Konis Liebäugeln mit einem Ministerposten wird in seiner autobiografischen Auseinandersetzung mit Stolypins Angebot in Ansätzen sichtbar. Auch in der Schrift zur Entgleisung des Zarenzugs und in „Triumvirn“ hatte Koni an manchen Stellen seine Ambitionen angedeutet. Nicht nur in den Momenten, in denen er sich in trauter Einheit mit dem Zaren beschreibt, sondern gerade auch dann, wenn die negativen Erlebnisse und Misserfolge thematisiert werden. So erinnert er sich im Kontext des Zugunfalls daran zurück, wie er 1885 vom Zaren Alexander III. für sein Verhalten im Zasulič-Fall gerügt worden war. Daraufhin hätten ihm die Leute schadenfroh geraten, zurückzutreten. Koni entschied sich aber anders und begründet dies in der Erinnerungsschrift damit, dass er doch nicht „die Sache des gesamten Lebens" habe wegwerfen können, nur weil ihm nicht „das Lächeln des Höchsten“ erteilt worden sei. ${ }^{227}$ In „Triumvirn“ spricht er in der abschließenden Schilderung seines Rücktritts aus der Kassation davon, warum für ihn diese „Sache des gesamten Lebens“ nicht von Erfolg gekrönt war: „Karrieristen, Feiglinge und Verräter" hätten ihn übertrumpft. ${ }^{228}$ Die anderen, so macht es hier den Anschein, haben also jene Karriere gemacht, die Koni sich eigentlich

\footnotetext{
224 Ebd., S. 365-66.

225 Ebd., S. 373-74.

226 Ebd., S. 364-65.

227 Ebd., S. 447-48.

228 Ebd., S. 302.
} 
selber erhofft hatte beziehungsweise von der er sich „als Mensch und als Bürger das Recht nahm zu träumen“.

Im revolutionären politischen Klima um 1905 waren solche Ambitionen mehr denn je zuvor dem kritischen Urteil von Berufskollegen und Öffentlichkeit ausgesetzt. Konis Absage an den Ministerposten und seine fast schon qualvolle Aufarbeitung dieser "harten Woche" in der autobiografischen Schrift geschahen unmittelbar unter Eindruck einer intensiven öffentlichen Debatte.

\section{Polarisierung in Justiz und Politik um 1905}

Die Intensivierung der Bewegung für mehr politische Teilhabe nach der Jahrhundertwende, der Zuwachs an gesetzlichen und institutionellen Freiheiten ab 1905 und die nun frei debattierenden politischen Strömungen aller Schattierungen schufen ein Klima der Polarisierung, in dem eine öffentliche Figur wie Koni sich mehr denn je genötigt sah, deutlich Stellung zu beziehen. Verschiedene Lager taten sich auf, und oftmals wurden Forderungen laut, die klar über die moderaten Pläne der Regierung hinausgingen, eine „eingeschränkte Autokratie“ zuzulassen. Gerade unter den russischen Anwälten und Anwaltsgehilfen war es schon seit einigen Jahren zu einer verstärkten Politisierung und Radikalisierung gekommen. Vereint im Kampf gegen die Selbstherrschaft des Zaren bildete sich um 1895/96 in Moskau, aber auch in St. Petersburg eine als ,Junge Advokatur“ [Molodaja advokatura] bezeichnete Gruppe von Anwälten, die gratis Dienstleistungen wie zum Beispiel juristische Unterstützung für Arbeiter oder kollektive Verteidigungen in politisch motivierten Gerichtsfällen anbot. ${ }^{229}$ Dabei rückte das Politische immer stärker in den Vordergrund und schmälerte so die Kategorie des Rechts. ${ }^{230}$ Tatsächlich konzentrierten sich diese „Strafverteidiger neuen Typs“ weniger auf die Anwaltsethik als auf die Nutzung des Gerichts als Medium des Protestes und des

229 Troickij: Advokatura v Rossii i političeskie processy 1866-1904 gg., S. 115-18. Darin waren Angehörige aller oppositionellen und revolutionären Parteien sowie parteilose Juristen vertreten.

230 Anatolij N. JAšIn: Filosofskie idei russkich myslitelej sudebnoj zaščity II poloviny XIX veka. A. F. Koni, V. D. Spasovič, F. N. Plevako, K. K. Arsen’ev, S. A. Andreevskij. Murmanskij gosudarstvennyj techničeskij universitet, Murmansk 2009 (unveröffentlichte Dissertation), S. 148. Jašin geht besonders hart mit der Tätigkeit der politischen Gruppe von Anwälten ins Gericht, nennt sie populistisch und revolutionsverherrlichend. Er kritisiert insbesondere, dass ethische Kriterien der professionellen Berufsausübung dadurch vernachlässigt würden. Gegenbeispiele sieht er in den berühmten Namen von u. a. Spasovič, Arsenev, Andreevskij, Urusov oder Koni - der zwar nicht Anwalt war, aber dessen konzeptuelle Arbeiten zu Fragen des Rechtsschutzes herausragend seien, vgl. ebd., S. 6 und 148-49. 
Befreiungskampfes. ${ }^{231}$ Gleichzeitig meldeten sich aber auch gemäßigtere Kräfte zu Wort, die sich der Vorgehensweise ihrer radikaleren Kollegen entgegenstellten, da durch Mittel wie den Anwaltsstreik die Ideale des Rechtsstaats leiden würden. ${ }^{232}$ Insgesamt war der politisierte Teil der Anwaltschaft, der oftmals zu den am linken liberalen Flügel verorteten „Konstitutionellen Demokraten“ oder den deutlich radikaleren Sozialdemokraten tendierte, nur eine Minderheit unter den Juristen, die das Bild der Advokatur aber stark prägte. ${ }^{233}$ Doch nicht nur in den Organisationen der Anwälte, sondern auch in den Juristischen Gesellschaften wurden nach der Jahrhundertwende mehr und mehr ungeduldige Rufe nach Reformen laut. 1903 erregte ein Vortrag in der St. Petersburger Gesellschaft die Gemüter, in dem Änderungen im Rechtsschutz zugunsten der bäuerlichen Bevölkerung verlangt wurden. ${ }^{234} 1904$ musste sogar eine Sitzung der „administrativen Abteilung" abgesagt werden, die sich mit der Änderung der geltenden Presse-

231 Baberowski: Autokratie und Justiz, S. 577-80. Vgl. dazu auch die Überlegungen oben, S. 56. Die bevorzugte Strategie war der demonstrative Auszug aus dem Gerichtssaal, nachdem die Advokaten unerfüllbare Forderungen an das Gericht gestellt hatten. Der rechtliche Gehalt der Anklage wurde so gar nicht erst erörtert, da man das Gericht an sich als institutionalisierte Form der Klassenjustiz sah, von der keine unvoreingenommenen Urteile zu erwarten waren. Diese sich deutlich als „politische“ Verteidiger kenntlich machenden Anwälte reisten auch in Gouvernements außerhalb der Hauptstädte, wenn es ihnen nötig schien, vgl. Ju V. VARfolomeEv: Nikolaj Konstantinovič Murav’ev. Advokat, politik, čelovek. Saratov 2007, S. 90. Auch in Odessa entwickelte sich so nach 1900 analog zum Moskauer und Petersburger Vorbild eine neue Generation von Rechtsanwaltsgehilfen, die sich in politischen Prozessen engagierten und sich aktiv für politische Freiheiten im Land einsetzten, vgl. Hausmann: Universität und städtische Gesellschaft in Odessa, S. 366-67.

232 Baberowski: Autokratie und Justiz, S. 590. Der Anwalt Nikolaj Karabčevskij, der sich gegen diese starke Politisierung einsetzte, beschreibt die Auseinandersetzung in seinen Memoiren beispielhaft, vgl. Nikolaj P. KARABČEvsKIJ: Čto glaza moi videli. II. Revoljucija i Rossija. Berlin 1921, S. 45 ff. Tatsächlich wurden auch Advokaten, die auf politische Zurückhaltung drängten, um die Stellung der Anwälte nicht zu gefährden, in der Revolutionszeit in wichtige Positionen in den Anwaltsräten gewählt, vgl. LeGKIJ: Dmitrij Vasil'evič Stasov, S. 150-51. Grundsätzlich änderte sich der verstärkte politische Fokus in der Advokatur aber erst mit dem Oktobermanifest und der Einrichtung der Duma. Nun verlagerte sich das politische Engagement mehr und mehr ins Parlament und in die nun von Zensur befreite Presse, vgl. BABerowski: Autokratie und Justiz, S. 602 und Liessem: Autonomie in der Autokratie?, S. 263-64, der ebenfalls schreibt, dass nach 1905 die Duma zum Hauptort der Debatten über die Gesetzgebung wurde.

233 Hausmann: Universität und städtische Gesellschaft in Odessa, S. 369.

234 Liessem: Autonomie in der Autokratie?, S. 247-48. Zu dieser Zeit amtierte Koni sogar als stellvertretender Vorsitzender der St. Petersburger Juristischen Gesellschaft, wie er selber schreibt in KonI: Avtobiografija. In: Tichomirov (Hrsg.): Istoričeskaja zapiska vtoroj S.-Peterburgskoj gimnazii, Bd. 3, S. 378-80. 
gesetzgebung, die durch strenge Zensur gekennzeichnet war, auseinandersetzen wollte. Dies, weil zu viele Leute aus der Bevölkerung an der Versammlung zu so einem brisanten Thema teilnehmen wollten. ${ }^{235}$ Die Gesellschaft verlor dann allerdings in der Revolutionszeit immer mehr an Einfluss. Im Gegensatz zur Juristischen Gesellschaft in Moskau, die 1899 zwangsweise aus nicht ganz klaren Gründen aufgelöst wurde, konnte die Gesellschaft in der nördlichen Hauptstadt dies vermeiden. ${ }^{236}$ Aber sie musste ihr Journal, den „Boten des Rechts“ [Vestnik Prava], der unter verschiedenen Namen seit mehreren Jahrzehnten erschienen war, 1906 einstellen, weil das Justizministerium mit dessen Haltung zu aktuellen Fragen nicht einverstanden war. ${ }^{237} \mathrm{Im}$ Vorfeld und während der revolutionären Ereignisse spielten deshalb insbesondere die Anwaltsräte eine wichtige Rolle. Die Festlichkeiten zum 40. Jahrestag der Gerichtsreform 1904 entwickelten sich als Teil der sogenannten Bankettkampagne geradezu zu einem Wegbereiter der Revolution. ${ }^{238}$ In St. Petersburg und in Moskau verabschiedeten die Anwaltsräte aus Anlass des Jahrestages Resolutionen, die nach bürgerlichen Freiheitsrechten und einem parlamentarischen Regierungssystem verlangten. ${ }^{239}$ Diese politischen Losungen wurden vom in Moskau tagenden Kongress der Zemstva aufgenommen

235 Liessem: Autonomie in der Autokratie?, S. 245-47 und 251-52. In der Juristischen Gesellschaft wurde daraufhin kontrovers diskutiert, wie klar man zwischen Informationsveranstaltungen zur Ausbreitung des juristischen Wissens und internen wissenschaftlichen Fachvorträgen unterscheiden solle. Im März entschied schließlich der Gesamtvorstand, dass alle Sitzungen öffentlich seien. Daraufhin kam es zu einer Verwarnung durch das Bildungsministerium.

236 Ebd., S. 252-53.

237 Tissier: Les sociétés juridiques dans l'Empire russe au tournant du XXe siècle, S. 22-23. Im Januar 1904 hatte sich die Redaktion des „Boten des Rechts“ entschieden, vermehrt auf aktuelle politische Fragen einzugehen und einen Schwerpunkt auf das öffentliche Recht [publičnoe pravo] zu legen, um dringend benötigte größere Leserkreise anzuziehen. Doch dies gelang nicht zuletzt aufgrund der Konkurrenz durch die seit 1898 erscheinende Zeitschrift „Recht“ [Pravo] nur ungenügend. Vgl. ebd., S. 31-33 mit einem Vergleich zwischen den beiden Publikationen sowie oben, Fußnote 143 in TEIL EINS. Nach Auseinandersetzungen der Juristischen Gesellschaft mit den Behörden weigerte sich das Justizministerium schließlich, den „Boten des Rechts“ noch länger finanziell zu unterstützen. Daraufhin blieb dem Blatt nur die Einstellung, was die St. Petersburger Juristische Gesellschaft wesentlich schwächte, vgl. ebd., S. 23.

238 Tsimbaev: Jubilee Mania in Late Nineteenth- and Early Twentieth-Century Russian Society, S. 27. Tsimbaev merkt an, dass es eine Chance für den Staat hätte sein können, sich an dem Jubiläum zu beteiligen und so die reformorientierte Seite der Autokratie wieder stärker ins Bewusstsein zu rücken. Vgl. TEIL EINS zur Bedeutung von Jubiläen für die Professionalisierung der Juristen und Konis Rolle dabei.

239 Baberowski: Autokratie und Justiz, S. 587-88. 
und verbreiteten sich sehr schnell auf weitere Berufsstände und in weitere Städte. ${ }^{240}$ Die Professionsgemeinschaften wurden zu tragenden Organisationen im Kampf um demokratischere Strukturen. ${ }^{241}$ Als „Vertreter der Intelligencija“ forderten die Rechtsanwälte, dass die Advokatur sich an die Spitze dieser revolutionären Bewegung für mehr gesellschaftliche und politische Freiheiten stellen sollte. ${ }^{242}$

Dass auch Koni eine Stärkung dieser gesellschaftlichen und politischen Freiheiten begrüßte, daran lässt sein Engagement in den Kreisen der liberalen Juristen und des „Boten Europas“ keinen Zweifel. Mit seinen eigenen Erinnerungsschriften unterstrich er dies im Moment der Revolution einmal mehr. Wenn er in seinen umfangreichen Memoiren über sein Berufsleben von Artikeln, Memoranden und Gesprächen berichtete, mit denen er über Jahre hinweg die höchsten Kreise von mehr Selbstbestimmung, einer schnelleren Gesetzgebung oder einem realistischeren Bildungswesen zu überzeugen versucht habe, dann bekräftigte er damit nochmals seine Haltung für die entschiedene Weiterführung der „Großen Reformen" der 186oer-Jahre. Doch im Moment der eruptiven Realisierung von mehr politischen Rechten zeigte sich Koni äußerst zurückhaltend und verharrte größtenteils in einer beobachtenden Position. In seinem Archiv liegen die Parteiprogramme der neu entstandenen politischen Gruppierungen. Auch Manifeste, programmatische Artikel und publizistische Schriften aus dieser bewegten Zeit hat Koni fein säuberlich gesammelt. ${ }^{243}$ Selber bekannte er sich aber zu keiner

240 Ebd., S. 589.

241 Polunov: Russia in the Nineteenth Century, S. 210. Die Konferenzen und Kongresse von Lehrern, Agronomen oder Ärzten widmeten sich in dieser Zeit weniger beruflichen Themen als politischen Anliegen. Sie verlangten die Einschränkung der Macht der Bürokratie, die Aufhebung der Verbote gesellschaftlicher Aktivitäten und die Ausweitung des Rechts auf Selbstverwaltung. Als die Revolution begann, gründeten sie eigene „Bünde“, die als Vorformen von Gewerkschaften verstanden werden können. Im Mai 1905 schlossen sie sich zum „Bund der Bünde“ [Sojuz Sojuzov] zusammen, bevor dann diese Organisationsform gegenüber den radikaleren „Räten“ der Arbeiter an Bedeutung verlor, vgl. PoLUNov: Russia in the Nineteenth Century, S. 210 und Haumann: Geschichte Russlands, S. 301.

242 Hausmann: Universität und städtische Gesellschaft in Odessa, S. 368-69 für Odessa. Konkret forderten die Rechtsanwälte Odessas in einer Resolution vom 13. März 1905 Pressefreiheit und Vorgehen gegen die Willkür und Rechtlosigkeit der autokratischen Ordnung sowie Wahlen für eine Volksvertretung auf der Grundlage des freien, geheimen, gleichen und direkten Wahlrechts.

243 Vgl. z. B. IRLI F. 134, op. 4, d. 540, l. 1 und GARF F. 564, op. 1, d. 439 oder IRLI F. 134, op. 4, d. 623-30. Letztere Sammlung ist auch bei den beiden sowjetischen Biografen von Koni, Smoljarčuk und Vysockij, erwähnt. Smoljarčuk nennt zusätzlich d. 534 und 646, vgl. SMOLJArČUK: Anatolij Fëdorovič Koni (1844-1927), S. 125 und VysockiJ: Koni, S. 321. Beide fügen auch hinzu, dass unter den Parteiprogrammen jenes der Bolschewiki gefehlt habe. 
der Parteien und Bewegungen, die die Revolution von 1905 prägten. „Selbständigkeit" und damit parteiliche Unabhängigkeit hatte sich Koni schon 1903 ausbedungen, als erste Anzeichen der Demokratisierung im lokalen St. Petersburg die Mitsprachemöglichkeiten der Bürger erhöhten. Durch ein neues Wahlgesetz wurden in diesem Jahr mehr Personen für das Stadtparlament wahlberechtigt. Es entwickelte sich ein intensiver Wahlkampf mit Versammlungen im großen Stil, die zur allgemeinen Überraschung nicht verboten wurden. Die neuen demokratischen Beteiligungsmöglichkeiten sorgten für eine regelrechte Euphorie, die auch Koni dazu brachte, erfolgreich für das Stadtparlament zu kandidieren. In seinen "Curricula Vitae" verwies er fortan mit Stolz auf die große Zahl an Stimmen, die er damals erreicht hatte. ${ }^{244}$ In einem brieflichen Austausch mit Arsen'ev machte er kurz nach der Wahl aber deutlich, dass er sich „zu keiner Partei zugehörig“ fühle und wünsche, sich die „Unabhängigkeit seiner Ansichten“ zu erhalten. Er erteilte damit Arsen’evs Anfrage um den Beitritt in die „neue Partei“ eine Absage, die dieser aus den Gewählten des reformgesinnten Lagers im Stadtparlament bilden wollte. Koni unterstützte diese zwar, wollte aber nicht als Parteimitglied zählen. ${ }^{245}$ Konis Engagement in der städtischen St. Petersburger Duma blieb eher bescheiden; zusammen mit einer Reihe von weiteren gewählten Vertretern war er von der zeitraubenden Routinearbeit überfordert und trat schnell wieder zurück. Allerdings brachte er sich in den nachfolgenden Jahren ohne offizielles Mandat immer wieder als beratende Stimme in seinem Wahlkreis ein. ${ }^{246}$ Auch nachdem die Revolution von 1905 eine Vielzahl an Parteigründungen möglich gemacht hatte, schrieb Koni einem der Gründer und Anführer der Partei „Union des 17. Oktobers“, dass er unparteilich bleiben werde, selbst wenn er vieles im Programm der „Oktobristen“ als sympathisch empfinde. ${ }^{247}$ Die gemäßigte liberal-konservative Partei wollte mit ihrem Namen an das Oktobermanifest des Zaren erinnern, das sie unterstützte. Verfassung und Duma sollten jedoch ergänzt sein um Vorrechte des Zaren. Eine verfassungsgebende Versammlung und gleiches, direktes Wahlrecht wurden von der Partei kritisch gesehen. Allerdings gab es innerparteilich eine große Spannweite an Meinungen. ${ }^{248}$ So hatte sich um Graf Gejden schon wenige Monate nach der Gründung die „Partei der friedlichen Erneuerung“ abgespalten. Diese bildete in der Duma eine Fraktion aus dem linken Flügel der Union des 17. Oktobers und

244 Vgl. oben, S. 104.

245 GA8, S. 195-96 und 404 (Anmerkungen).

246 B. B. Dubencov u. a. (Hrsg.): Peterburgskaja gorodskaja duma, 1846-1918. Sankt-Peterburg 2005, S. 150-54 und 192.

247 RGIA F. 869, op. 1, d. 1435, 1. 17-17ob. Zitiert nach: Domanova: Perepiska A. F. Koni kak istoričeskij istočnik, S. 116. Der Brief ist an Jurij Nikolaevič Miljutin (1856-1912) gerichtet.

248 Haumann: Geschichte Russlands, S. 313-14. 
dem rechten Flügel der Konstitutionellen Demokraten. ${ }^{249}$ Es war sicherlich dieses Spektrum, mit dem sich Koni verbunden fühlte. ${ }^{250}$ Die Oktobristen waren nicht die einzigen, die sich von Koni gerne eine deutliche Stellungnahme für sie, am besten einen Eintritt in ihre Partei, gewünscht hätten. Auch andere Parteien - so schrieb Koni selber in einem Brief wenige Monate nach dem Oktobermanifest würden ihn als Anführer wollen. Die "Gesellschaft" verlange in dieser „wirren und unruhigen Zeit" sein Wort. Sogar ein „berühmter Historiker" aus Moskau habe in einem persönlichen Schreiben sein Schweigen gerügt. ${ }^{251}$ Der „Weg der liberalen Reformen“, den er als Mittelweg zwischen Revolution und bisherigem Regime präferiere, sei aber nur durch eine Konstitution - also eine „Einschränkung der Selbstherrschaft durch eine Rechtsordnung“ - zu haben. ${ }^{252}$ Doch er sei sich ja nicht einmal sicher, ob es so eine Verfassung in Russland je geben werde. Viele der vagen Versprechungen im Oktobermanifest seien zu „widersprüchlich“, „verlogen“ und „leichtsinnig“. 253

Koni zeigt sich unsicher angesichts der realen Entwicklungen im Revolutionsjahr, geht einer deutlichen Stellungnahme aus dem Weg und bleibt immer darauf bedacht, nicht selber Teil der parteilichen Polarisierung zu werden. Im Hintergrund allerdings bemühte er sich durchaus zu konkretisieren, was ihn beunruhigte und wie man seinen „Weg der liberalen Reformen“ denn umsetzen könnte, ohne dabei in Widersprüchen, Verlogenheit oder Leichtsinn zu enden. Dass Koni mit diesen Ideen und Haltungen aber nicht groß an die Öffentlichkeit trat, wie es Parteien oder der „berühmte Historiker“ wünschten, lag maßgeblich daran, dass diese in einer Zeit der sich überbietenden Forderungen nach rascher Veränderung nur schwer kommunizierbar waren und zwischen allen Fronten standen. Die atemlos niedergeschriebenen Erinnerungen Konis an die Parlamentseröffnung oder die

249 Max Weber: Zur Russischen Revolution von 1905. Schriften und Reden 1905-1912, Gesamtausgabe, Bd. 10, hrsg. u. mit einer Einleitung versehen v. Wolfgang J. Mommsen. Tübingen 1989, S. 64 (Einleitung v. Wolfgang J. Mommsen).

250 Mark G. Pomar: Anatoly Fedorovich Koni. Liberal Jurist as Moralist. Pittsburgh 1996, S. 35 behauptet gar, Koni habe Gejdens Partei der friedlichen Erneuerung angehört.

251 GA8, S. 235 (Brief an E. A. Naryškina vom 05. 01. 1906). In diesem ausführlichen Brief an die adelige Elizaveta Alekseevna Naryškina (1838-1928), die Koni seit drei Jahrzehnten aus dem gemeinsamen Einsitz in wohltätigen Komitees kannte (vgl. z. B. GA8, S. 374 [Anmerkungen]) rechtfertigt er sich offensichtlich gegen Vorwürfe der Fürstin. Diese scheint die Revolution gänzlich negativ zu sehen und wirft ihm vor, den Veränderungen gegenüber zu positiv eingestellt zu sein.

252 GA8, S. 233-34 (Brief an E. A. Naryškina vom 05. 01. 1906). Diese Konstitution, fügt Koni hinzu, könne zu Beginn auch fehlerhaft sein. Die auf Basis der Verfassung gewählte Duma könne dies dann Schritt für Schritt korrigieren.

253 Ebd., S. 233-35. 
„Nacht Gethsemane“ vermitteln, was ihn verstörte. An Stolypin gerichtet erzählt Koni in seiner Erinnerung an die Anfrage für den Ministerposten, dass in der momentanen „Psychose“ die Geduld erfordernde Umsetzung liberaler Gesetze einen schwierigen Stand habe. ${ }^{254}$ Wie unwohl es ihm bei dieser revolutionären „Psychose“ war, die doch eigentlich in vielem seinen eigenen Visionen Vorschub leistete, wird auch in seiner Beschreibung der Eröffnung der Duma deutlich. Er nennt Zar Nikolaus II. darin einen „bemitleidenswerten, willensschwachen“ Monarchen, der nach einem halben Jahr, das geprägt gewesen sei von ,unerhörten Niederlagen unvergleichbarer Schande“, eine erzwungene Konstitution zugestanden habe, anstatt dieses Blutvergießen zu verhindern und Russland schon viel früher ,auf den Weg der politischen Freiheit“ zu führen. ${ }^{255}$

Ihn zutiefst abstoßende Gewaltakte und „Pöbelei“ sah Koni nach der Jahrhundertwende in Russland immer stärker verbreitet. Allgemeines Chaos und Zerfall von Werten und Sitten schien überall zu sein. So schrieb er schon 1903 an Boris Čičerin, kurz vor dessen Tod:

[...] in der Literatur, in der Gesellschaft und auf der Straße regiert die Pöbelei [...] Das russische Leben erscheint mir bisweilen eingeschlossen in irgendeinen Waggon, in dem sie rauchen, lärmen, betrunkene Lieder grölen, Karten spielen und einander sowohl unverhohlen als auch heimlich bestehlen, und währenddessen ist der Waggon bereits aus den Schienen geraten und braust dahin auf einem sogenannt toten Einbahnweg. ${ }^{256}$

Dass Koni noch vor den revolutionären Streiks und Demonstrationen von „Pöbelei“ nicht nur in der Gesellschaft, sondern auch in der Literatur sprach, weist auf seine krisenhafte Wahrnehmung der Jahre um die Jahrhundertwende hin. Die rasche Modernisierung Russlands seit den 189oer-Jahren hatte zu einer Dynamisierung vieler Gesellschaftsbereiche geführt, was allerdings vom generellen „Bewusstsein einer Kulturkrise“ begleitet wurde. ${ }^{257}$ Im Herbst 1904 sprach Koni an einem

254 Koni: Moja gefsimanskaja noč. In: GA2, S. 362-63. Koni fügt hinzu, dass „unverzügliche Maßnahmen“ im Bereich der „Agrarfrage“ vonnöten seien, um die Bevölkerung von der Wahl der linksliberalen oder sozialistischen Parteien abzuhalten, die in diesen Bereichen Verbesserung versprachen.

255 Koni: Otkrytie I Gosudarstvennoj Dumy. In: GA2, S. 355.

256 GA8, S. 201 (Brief an B. N. Čičerin vom 30.12.1903).

257 Klaus StÄDTKE (Hrsg.): Russische Literaturgeschichte. Stuttgart 2011, S. 290 zitiert für den Begriff der „Kulturkrise“ Gudrun LAnger: Kunst - Wissenschaft - Utopie. Die „Überwindung der Kulturkrise“ bei V. Ivanov, A. Blok, A. Belyj und V. Chlebnikov. Frankfurt am Main 1990. Die Modernisierungsschübe verursachten trotz der gefühlten Krise eine „Steigerung der ästhetischen Produktivität“, die sich z. B. in den vielen neuen literarischen Gruppierungen und Richtungen niederschlug. Stender-Petersen verweist auf die Ver- 
viel beachteten Fachvortrag vor der Juristischen Gesellschaft von St. Petersburg über die damals zwischen Juristen und Medizinern beziehungsweise Psychologen äußerst kontrovers diskutierte Frage des Umgangs mit unzuverlässigen Zeugenaussagen in Gerichtsprozessen. ${ }^{258}$ In seiner Hinführung zum Thema holte er weit aus und begann mit einer Charakterisierung seiner Gegenwart: Diese gelte als „Zeit der Umwertung aller Werte“. Koni spricht mit Nietzsche, um Entwicklungen der „radikalen Umwälzungen moralischer Üblichkeiten“ zu benennen, die er in seiner Zeit gegeben sieht. ${ }^{259}$ So führt er weiter aus, dass man heute das Leben als „frei von jahrhundertealten Zwängen und daraus hervorgehenden Lügen“ verstehe. In der Folge zählt Koni Bereiche aus verschiedenen Wissenschaften, insbesondere Recht und Medizin, auf, in denen sich in der vergangenen Zeit solche totalen „Umwertungen“ ergeben hätten. Während er diese wissenschaftlichen Weiterentwicklungen grundsätzlich begrüßt, warnt er in seiner Rede inständig davor, zu weit zu gehen. Denn in vielem, das als veraltet angesehen werde, sei auch „Kräftiges und Gesundes“ enthalten. ${ }^{260}$ Weder sollten nach Konis Meinung berechtigte politische Freiheiten mit Gewalt erzwungen werden, noch bedeuteten Freiheiten für ihn die völlige „Umwertung“ von allen bisherigen Überzeugungen und das Ende von gesellschaftlichen Regeln und juristischen Gesetzen. Beispielhaft verdeutlichte er dies auch mit seinem Einsitz in der Kommission für Pressefragen.

Angesichts der enormen Unzufriedenheit mit den geltenden Zuständen hatten Zar und Ministerrat unter Leitung von Dmitrij Fomič Kobeko (1837-1918), der als gemäßigter Liberaler galt, noch vor den revolutionären Aktionen zu Beginn des Jahres 1905 eine Kommission einberufen, die ein demokratischeres Zensurwesen ausarbeiten sollte. In dieses Gremium wurde auch Koni als Experte und

wandtschaft zwischen den „Dekadenten“ in Russland und ihren Vorbildern in Paris, vgl. Adolf Stender-Petersen: Geschichte der russischen Literatur. München 1993, S. 508-09. Christa Ebert spricht von einer „kurzen, aber intensiven Zeitspanne voller ästhetischer, philosophischer und sozialer Aufbrüche“, vgl. Sinaida Hıppıus: Petersburger Tagebücher, 1914-1919, hrsg. u. mit einem Nachwort versehen v. Christa Ebert. Berlin 2014, S. 447-48 (Nachwort von Christa Ebert). Koni hielt aber gerade diese Art von neuartiger Literatur für Teil der Krise, dazu ausführlicher in TEIL DREI.

258 Vgl. Angaben in Fußnote 145 in TEIL EINS.

259 Andreas Urs Sommer: Was (er)schafft die Umwertung aller Werte? Zu Nietzsches Kreativitätsmythologemen. In: Oliver Krüger u. a. (Hrsg.): Mythen der Kreativität. Das Schöpferische zwischen Innovation und Hybris. Frankfurt am Main 2003, S. 196-97. Sommer erklärt Nietzsches Rede von der „Umwerthung aller Werthe“. Diese Formel, ab Mitte der 188oer-Jahren als potentieller Titel für ein Buch des Philosophen bekannt, sei von Nietzsche auch allgemein verwendet worden, um in „historischen Erzähl- und philosophischen Argumentationskontexten“"Veränderungen, die alles Geltende hinterfragten, zu bezeichnen.

260 Koni: Svideteli na sude, S. 36-37. 
Senator eingeladen. ${ }^{261}$ Neben den unzufriedenen Publizisten und Schriftstellern wollte auch die vereinte russische Publikationsindustrie, die sich in den vorangegangenen Jahren und Jahrzehnten immer mehr zu einer wirtschaftlichen Macht entwickelt hatte, die Zensur ihrer Erzeugnisse nicht länger akzeptieren. ${ }^{262}$ An vorderster Front hatten sich schon seit Jahren die Juristischen Gesellschaften dafür eingesetzt, dass nicht länger ein administratives Zensurwesen Veröffentlichungen kontrollierte, sondern einzig die Gerichte über mögliche Vergehen im gedruckten Wort befinden sollten. ${ }^{263}$ Im Vorgang zur ersten Russischen Revolution verschärften sich die Forderungen nach einer Lockerung der Zensur. Im Februar 1903 porträtierte Koni vor der St. Petersburger Juristischen Gesellschaft Lehrbuch und Leben von Vladimir Spasovič, der in den 1860er-Jahren zahlreiche Pressefälle geführt hatte. In dieser Ansprache betonte Koni die Notwendigkeit von Gerichten als die einzige Instanz, die Druckerzeugnisse einschränken dürfte. ${ }^{264}$ Zwei Jahre später fand sich Koni in der Kommission unter Kobeko wieder, die nun eine Neugestaltung des Pressewesens angehen sollte. Koni war nicht der einzige Rechtsexperte in diesem Gremium, mit Arsenev war auch ein Anwalt und Publizist vertreten, der sich sehr stark in der revolutionären Bewegung engagierte und 1906 gar eine eigene „Partei der demokratischen Reformen“ gründen sollte. ${ }^{265}$

261 Vysockij: Koni, S. 323-27. Die Kommission hieß offiziell: „Osoboe soveščanie dlja sostavlenija novogo ustava po pečati“ und wurde vom Ministerrat am 12. Dezember 1904 beschlossen. Vgl. auch Anton V. Lichomanov: A. F. Koni v osobom soveščanii po sostavleniju novogo Ustava o pečati. In: Cenzura v Rossii: Istorija i sovremennost'. Sankt-Peterburg 2008, S. 126-27, vgl. auch P. I. ŠLEmin: Dnevnik K. K. Arsen’eva. In: Archeografičeskij ežegodnik za 1977 god. Moskva 1978, S. 320 und Simutenko: K. K. Arsen’ev i rossijskoe liberal'noe dviženie konca XIX-načala XX veka, S. 71.

262 Charles RuUd: Fighting Words. Imperial Censorship and the Russian Press, 1804-1906. Toronto 2009, S. 207.

263 In der Regierung wurde intensiv darüber diskutiert, ob eine verwaltungstechnische oder eine juristische Kontrolle zielführender sei, um die sozialistischen Parteien und sonstig unliebsame Gruppierungen an öffentlichen Wortmeldungen zu hindern. Eine Frage, der im Kern die viel größere Frage nach der Ausgestaltung der Beziehung zwischen Staat und Bürgern zugrunde lag, vgl. RuUd: Fighting Words, S. 208-10.

264 RuUD: Fighting Words, S. 211 erwähnt Konis Rede explizit als Teil einer sich intensivierenden Kampagne aus Kreisen der Juristen und der Akademiker. So habe nur einen Tag nach dem Auftritt Konis die Akademie der Wissenschaften eine Petition eingereicht für die rein juristische Kontrolle über das Pressewesen. Vgl. für Konis Porträt von Spasovič oben, S. 63. Ausführliche Versionen erschienen sowohl in "Skizzen und Erinnerungen“ 1906 (S. 776-77 für die Aussagen zu den Pressefällen) und in „Väter und Söhne“ 1914.

265 In seiner eigenen Wohnung legte Arsen'ev im Januar 1906 zusammen mit einigen Gesinnungsgenossen das Programm der „Partija demokratičeskich reform“ fest. Die Partei wollte sich für weitreichenden Parlamentarismus bei Beibehaltung der Erbmonarchie einsetzen. Polen sollte eine autonome Regierung erhalten und das Gerichtswesen wieder 
In der Kommission wirkte er gemeinsam mit Koni und weiteren Gesinnungsgenossen - darunter auch der Herausgeber des „Boten Europas“ Stasjulevič - auf eine Liberalisierung des Pressegesetzes hin. ${ }^{266}$ Entsprechende Journale zu den Sitzungen der juristischen Unterkommission, deren Vorsitz Koni innehatte, finden sich auch in seinem Nachlass. ${ }^{267}$ Dabei zeigt sich, dass sowohl Arsen'ev als auch Koni differenzierte Ansichten zu den Freiheiten hatten, die die Presse nun genießen sollte. Mit einer solchen Haltung manövrierten sich beide in eine unangenehme Lage. So wurde Arsen'ev allein für seine Teilnahme an dieser Kommission scharf von seinen liberalen Kollegen kritisiert. Koni selber bewahrte ein Exemplar des Journals „Stimme des Lebens“ auf, das im November 1905 Arsen’ev öffentlich rügte. In einer Ausgabe, die die Ehrung der wichtigsten Mitglieder der „Befreiungsbewegung“ zum Thema hatte, erschien sein Porträt zusammen mit jenen von Mitkämpfern wie Graf Gejden oder dem Historiker und Gründungsmitglied der Partei der Konstitutionellen Demokraten Pavel Nikolaevič Miljukov (1859-1943). Zu Arsen'ev fügte das Blatt einen kurzen Kommentar hinzu. Er habe zwar seit den 186oer-Jahren gegen die Reaktion gekämpft und liberal-europäische Werte vertreten, aber seine Handlungen der letzten Zeit hätten seine Popularität geschmälert. Schließlich habe er in der Kommission von Kobeko mitgemacht, obwohl doch alle Literaten erklärt hätten, dass es keinerlei Presserecht mehr brauche, da nur die totale Freiheit in Frage komme. Arsen'ev aber habe manchmal sogar Unmut gegen ungeduldigere Kollegen geäußert. ${ }^{268}$ Genau wie Arsen’ev erschien

an die Zeit der Reform von 1864 angeglichen werden. Gratisbildung für alle und Zugang von Frauen an die Universitäten ergänzten das klassische liberale Programm. Die kleine Partei konnte sich aber in Konkurrenz mit v. a. den Konstitutionellen Demokraten nicht weit über den Kreis ihrer Gründer vergrößern. Allerdings wurden einige Exponenten davon in die Duma gewählt. Zum Bedauern Arsen'evs gelang ihm persönlich dies aber nicht. Vgl. Simu tenko: K. K. Arsen’ev i rossijskoe liberal'noe dviženie konca XIX-načala XX veka, S. 75-78. Zu Arsen'evs Engagement vgl. auch ŠLEMIN: Dnevnik K. K. Arsen'eva, S. 320. Die insgesamt 24 teilnehmenden Personen in der Kommission zum Pressewesen wurden teilweise vom Zaren, teilweise von verschiedenen Behörden und Organisationen ernannt. Neben Koni und Arsen'ev gehört eine ganze Reihe weiterer bekannter Juristen dazu, vgl. Lichomanov: A. F. Koni v osobom soveščanii po sostavleniju novogo Ustava o pečati, S. 126-27.

266 Šlemin: Dnevnik K. K. Arsen'eva, S. 320 und Simutenko: K. K. Arsen'ev i rossijskoe liberal'noe dviženie konca XIX-načala XX veka, S. 71. Vgl. für eine Auflistung der einflussreichen „Liberalen“ in der Kommission auch RuUd: Fighting Words, S. 306, Anmerkung 21.

267 GARF F. 564, op. 1, d. 652 „Žurnal podkomissii po peresmotru zakonopoloženij o sudebnoj otvetstvennosti po delam pečati“. Vgl. auch VysockiJ: Koni, S. 325.

268 Golos Žižni 10-14 (1905), S. 104-05. In: IRLI F. 134, op. 4, d. 623. 
auch Koni nun mitunter als „Konservativer unter Liberalen“. ${ }^{269}$ Eine Presse, die ohne jegliche Auflagen funktionierte, war nicht in seinem Sinne. Er setzte sich lediglich dafür ein, dass ein neues Gesetz den Gerichten und nicht mehr der Administration die Verantwortung in Pressefragen auferlegte und so immer noch gewisse Kontrollmöglichkeiten in Kraft blieben. ${ }^{270}$ Der „überrissene Liberalismus“ mancher Kommissionsmitglieder regte ihn auf, denn er sah beispielsweise im Fall von Druckerzeugnissen mit pornografischem Inhalt gewisse Einschränkungen als unbedingt nötig an. ${ }^{271}$ Ebenso störten ihn aber die „,verräterischen“ Zwecklügen der Konservativen. ${ }^{272}$ Dass schlussendlich die Vorschläge der Kommission vom „Oktobermanifest“, das die totale Freiheit des Wortes versprach, quasi überholt wurden und das Zensursystem für einige Wochen ohne gesetzliche Grundlagen dastand und völlig zusammenbrach, konnte Koni schon recht nicht gutheißen. ${ }^{273}$ Er tat deshalb, was er schon früher versucht hatte, er verfasste im Dezember 1905

269 Vysockis: Koni, S. 323 zitiert eine Bekannte, die Koni in Bezug auf diese Kommission so nannte.

270 Lichomanov: A. F. Koni v osobom soveščanii po sostavleniju novogo Ustava o pečati, S. $132-37$.

271 VysockiJ: Koni, S. 326 und Brief von Koni an die Witwe von Boris Čičerin, vgl. GA8, S. 217-19 (Brief an A. A. Čičerina vom 10.05.1905).

272 GA8, S. 217-19 (Brief an A. A. Čičerina vom 10. 05. 1905). Darauf wird auch verwiesen bei Lichomanov: A. F. Koni v osobom soveščanii po sostavleniju novogo Ustava o pečati, S. 137. Als Vertreter der Konservativen spricht Koni im Brief konkret von Boris Michajlovič Juzefovič (1843-1911), Publizist und Organisator der Monarchistischen Partei in Kiew.

273 Vgl. Vysockij: Koni, S. 324 und Lichomanov: A. F. Koni v osobom soveščanii po sostavleniju novogo Ustava o pečati, S. 137-38 und RuUd: Fighting Words, S. 221. In den Wirren der Oktoberwochen gingen die Empfehlungen der Kommission von Kobeko unter. Diese hatte vorgeschlagen, den Gerichten die Autorität über das Pressewesen zuzusprechen, aber auch gewisse Restriktionen beizubehalten. Koni machte keinen Hehl aus seiner Enttäuschung. In der Zeit nach dem Oktobermanifest versuchte Witte dann allerdings, die Autorität der Regierung wiederherzustellen. In Bezug auf die Presse schrieb er Ende November Regelungen nieder, die die versprochene Freiheit festschreiben, aber gleichzeitig auch limitieren sollten. Dabei, so meinte er, habe er die Materialien der KobekoKommission durchaus teilweise als Grundlage benutzt, vgl. RuUd: Fighting Words, S. 221. Tatsächlich setzte sich nach einer kurzen unkontrollierten Phase die Pressefreiheit in dem Sinne durch, als dass einzig die Gerichte über Einschränkungen verfügen konnten. Dies schlug sich binnen kürzester Frist in einer Vielzahl an Anklagen gegen Presseorgane nieder, die in vielen Fällen zu einer Verurteilung führten, da das russische Strafrecht Presseverbrechen sehr allgemein definierte, vgl. ebd., S. 221-22. Ruud macht auch darauf aufmerksam, dass Russland hier sehr ähnlich handelte wie viele westliche Staaten vor ihm. Die Abschaffung der Zensur wurde vom intensivierten Gebrauch juristischer Mittel gegen unliebsame Publikationsorgane begleitet, vgl. ebd., S. 226. 
ein Schreiben direkt an den Zaren. ${ }^{274}$ Die Presse - klagt er darin - habe nun faktisch alle Freiheiten erhalten und folglich sei sie gefüllt mit Artikeln und Zeichnungen, die auch „in den demokratischsten aller Republiken“ nicht erscheinen würden. ${ }^{275}$ Koni skizziert in dem mehr als zehn Seiten umfassenden Schreiben, wie seiner Ansicht nach die „logische und normale“ Entwicklung eines Umbaus des Staatswesens aussehen sollte. Grundlage müsste eine "Charta" sein, die die „Prärogative“ der Macht des Imperators in Bezug auf die Regierung regelt. Auch Anzahl und Zusammensetzung der Kammern und die Beziehungen der Gewalten untereinander müssten darin festgelegt werden. ${ }^{276}$ In Russland seien aber überall Widersprüche zu sehen. „Freunde der Ordnung" seien durch das Manifest vom 17. Oktober in die Ratlosigkeit gestürzt worden, da es Freiheiten gewähre, ohne diesen eine Grundlage zu geben, die mehr Eindeutigkeit und Unabänderlichkeit garantieren würde. Dem folgt eine Aufzählung zum Misstrauen der Gesellschaft gegenüber dem Zaren, das die Aufrechterhaltung der Ordnung nur schwer möglich mache. ${ }^{277}$ Schließlich endet Koni mit der Versicherung, dass er selber nicht an den Worten des Zaren zweifle, aber dass diese in der momentanen Lage nicht genug seien. Es könne doch nicht sein, dass keiner die Zivilcourage habe, den Monarchen auf das Misstrauen und den Hass gegen ihn aufmerksam zu machen beziehungsweise auf die gefährliche Situation hinzuweisen, dass die Duma sich

274 GARF F. 564, op. 1, d. 163. Das Archiv hat das Dokument beschriftet als „Memorandum von A. F. Koni über die politische Lage in Russland und über die Notwendigkeit der Einführung einer Regierung mit konstitutioneller Form [o neobchodimosti vvedenija konstitucionnogo obraza pravlenija], vom Autor im Dezember 1905 an Nikolaus II. geschickt“. Ob Koni das Dokument aber wirklich direkt an den Zaren richtete und es diesen je erreichte, ist unklar. Während das Schriftstück in einer unbekannten Handschrift verfasst wurde, findet sich auf der ersten Seite oben in Konis Schrift u. a. der Vermerk „Zur Weitergabe an E. I. V.“. Mit E. I. V. dürfte „Ego Imperatorskoe Veličestvo“ gemeint sein - der Zar. Schon im Mai 1905 hatten einige hohe Beamte wie u. a. der ehemalige Justizminister Graf Pahlen ein Schreiben an den Zaren verfasst, das dieser Erklärung ähnlich ist. Ein Abdruck davon hat Koni in seinem Archiv aufbewahrt, vgl. GARF F. 564, op. 1, d. 4293. Darin wird der Zar gedrängt, die Volksbeteiligung so schnell wie möglich umzusetzen, und es werden konkrete Vorschläge zum Wahlprozedere gemacht, vgl. S. 7-8 und 29 ff. Direkt verweisen diese Männer ganz im Sinne Konis darauf, dass das Übel Russlands seinen Anfang nahm, als 1881 die Reformpolitik der 6oer-Jahre aufgegeben worden sei, vgl. ZAKHAROvA: The Reign of Alexandr II., S. 613.

275 GARF F. 564, op. 1, d. 163, 1. 5.

276 Ebd., l. 4ob-5. Weiter ergänzt er dies: Dazu gehöre auch ein breites Wahlgesetz. Derweil könne ein Gesetz über die zentralen Freiheiten wie Gewissens- oder Pressefreiheit ausgearbeitet werden. Die erste Aufgabe der neuen Parlamentskammer wäre dann, die Gesetzesprojekte zu den Freiheiten anzusehen und ihnen eine gesetzliche Grundlage zu geben und danach möglicherweise Teile der Konstitution zu überarbeiten.

277 Ebd., 1. 5obff. 
gleich selber zur verfassungsgebenden Versammlung machen könnte, wenn nicht vorher eine Charta erstellt werde. Zugunsten seines unglücklichen Volkes solle der Zar nun endlich Schritte zur Einschränkung der Selbstherrschaft in die Wege leiten. ${ }^{278}$

Das „Oktobermanifest“, das eben keine Konstitution darstellte und die gewährten Rechte nicht juristisch einwandfrei festhielt - und damit aber auch klarer umfasste und begrenzte, verstieß gegen Konis Ordnungssinn. ${ }^{279}$ Geordnet, friedlich und auf gesetzlicher Grundlage, moderat und unbedingt vom Zaren persönlich in die Wege geleitet, so sah sein Planspiel hin zu mehr politischen Freiheiten aus. Gerade der ambivalente Blick auf den Zaren schimmert auch in seiner Erinnerung an die Parlamentseröffnung durch. Er gesteht, dass ihm im Moment der Zeremonie vor Rührung die Tränen gekommen seien. Er habe sich mit dem zukünftigen Parlamentspräsidenten unterhalten, und gemeinsam hätten sie daran zurückgedacht, was sie alles in Erwartung dieses Tages hatten durchstehen müssen. ${ }^{280}$ Gleichzeitig habe er sich aber gefreut, dass der Zar an diesem Tag der „Beerdigung der Selbstherrschaft“ mit großer Gefasstheit aufgetreten sei. Seine Befürchtung, diesen voller „entwürdigender Angst“ sehen zu müssen, habe sich nicht bewahrheitet. ${ }^{281}$ Koni zeigte sich also emotional bewegt ob der Einführung einer Volksvertretung, die er sich schon viel früher gewünscht hätte, gleichzeitig aber auch entsetzt ob all der Gewalttätigkeit und der Unmöglichkeit, in Ruhe an moderaten Gesetzesprojekten zu arbeiten. Er war froh über die würdevolle Haltung des Zaren, den er mit einem Schreiben auch direkt darum bat, das Zepter wieder stärker in die Hand zu nehmen. In seiner Niederschrift der „Nacht Gethsemane“ verheimlicht er zudem nicht, dass er sich auch im früheren, gänzlich autokratischen Russland die Zusammenarbeit mit diesem Zaren in Form eines Ministerpostens durchaus hätte vorstellen können, wenn er nicht von irgendwelchen „Karrieristen“ übertrumpft worden wäre.

Dass Koni mit einer solchen Haltung als „Konservativer unter Liberalen“ erscheinen musste, ist naheliegend. Die Art und Weise, wie die Arbeit der Presse-

278 Ebd., 1. 6-7.

279 Eine von Koni verlangte klärende „Charta“, die das Verhältnis der verschiedenen Gewalten zueinander im Staat festlegte, wurde von Nikolaus II. in Form der „Grundgesetze“ im April 1906 schließlich doch noch erlassen, vgl. oben, Fußnote 204 in TEIL ZWEI.

280 Koni: Otkrytie I Gosudarstvennoj Dumy. In: GA2, S. 356-57.

281 Ebd., S. 359. Tatsächlich gilt Nikolaus II. als erster russischer Zar, der in den offenen politischen Kampf „herunterstieg“ und so die hier von Koni so stark gewünschte Würde und „epische Distanz“ opferte, die die imperiale Macht emporgehoben hatte. Im Bemühen, seine autokratischen Vorrechte auf diese Weise zu verteidigen, habe er traditionelle Supporter der Monarchie - auch solche, die die neuen Institutionen unterstützten - entfremdet, vgl. Wortman: Scenarios of Power, Bd. 2, S. 15. 
rechtskommission von der "Stimme des Lebens" beurteilt worden war, hat bereits angedeutet, dass gesetzgeberische Differenzierungen im Eifer des Gefechts auf wenig Verständnis stießen. Seine Karriere im Staatsdienst und das Senatorenamt, die Orden und zarischen Auszeichnungen, die er erhalten hatte, waren nun mehr denn zuvor den kritischen Blicken jener ausgesetzt, die vom alten Regime gar nichts mehr wissen wollten. Schon bei Konis Amtseinsetzung als Oberstaatsanwalt in den 188oer-Jahren hatte es Gerede gegeben, er verfolge nur karrieristische Motive. Sogar seine Freunde, so wird in einem Nachruf erinnert, hätten es ihm als Karrierismus ausgelegt, dass er nicht aus Protest das Amt niedergelegt habe, nachdem Zar Alexander III. ihn beim Begrüßungsempfang so unfreundlich behandelt hatte. ${ }^{282}$ Dass Koni sich dieser Vorwürfe bewusst war, zeigt sein Aufgreifen der entsprechenden Ratschläge in der Erinnerung an den Entgleisungsfall. Während er auf das „Trauma“ dieses Moments verweist und betont, dass er nicht die „Sache des gesamten Lebens“ habe opfern können, brandmarkt er gleichzeitig die Rücktrittsforderungen als Schadenfreude. In der gleichen Schrift erwähnt er auch, wie man 1891 auf seine Ernennung zum Senator reagiert habe. So habe ihn ein Bekannter wissen lassen, dass die „Moskauer Intelligencija“ überzeugt sei, dass seine Ernennung mit dem Entgleisungsfall und Konis ,edelmütiger" Beseitigung politischer Motive daraus zusammenhänge. ${ }^{283}$ Andreevskij spricht in seiner Beschreibung des Freundes von „poetischer Ehrliebe“:

Immer leidend brachte Koni dank der empfindlichen Sanftheit seiner einsamen, puritanischen Seele - dank seiner poetischen Ehrliebe [čestoljubie], die auf dem engen Pfad des Staatsdienstes allgemeine Liebe suchte - mit sich eine Atmosphäre von Talentiertheit, anziehender Scherzhaftigkeit und sogar kindlicher Freude, wenn er unwillkürlich $[\ldots]$ seine melancholische Pein vergaß. ${ }^{284}$

282 Rašel' M. Chin-Gol'dovskaja: Pamjati starogo druga. In: Trudy Puškinskogo Doma Akademii Nauk SSSR (Hrsg.): Pamjati Anatolija Fëdoroviča Koni. Leningrad u. a. 1929, S. $62-63$.

283 Koni: Krušenie carskogo poezda v 1888 godu. In: GA1, S. 493.

284 Andreevskij: Kniga o smerti, Bd. 1, 1922, S. 186. Čestoljubie ist ein Begriff, der in Erinnerungen von Beamten an ihre Tätigkeit im Staatsdienst sehr häufig auftaucht. Čest' - Ehre zu erhalten, wurde zum wesentlichen Motiv für den Dienst erkoren. Susanne Schattenberg übersetzt den Begriff in ihrer Monografie zu den russischen Beamten im 19. Jahrhundert nicht mit „Ehrgeiz“, sondern wörtlicher mit „Ehrliebe“. Dies auch um zu betonen, dass viele „Beamten nicht Eifer im Dienst an einer abstrakten Sache entwickelten, sondern in erster Linie davon beseelt waren, möglichst schnell und möglichst viele Würdigungen einzuheimsen“. Ehre und deren Verteidigung sowie Loyalität zu jenen, die diese Ehre vergaben, waren deshalb entgegen anderslautender Forschungsthesen wichtige Elemente im Habitus der russischen Beamten, vgl. Schat tenberg: Die korrupte Provinz?, S. 106-07. 
Dass Koni 1906 nach langem Ringen Stolypins Angebot ausschlug, einen Platz in der Regierung einzunehmen, war denn sicherlich auch ein Stück weit Selbstschutz, sich nicht noch stärker in der Nähe von Zar und Regierung einzufinden und entsprechender Kritik ausgesetzt zu sein. Vor allem aber war es wohl die nun mittels Parteien strukturierte, nach unmissverständlichen Stellungnahmen dürstende öffentliche politische Auseinandersetzung, die ihn von seinen Ambitionen zurücktreten und stumm bleiben ließ. Seine Kritik am ungesetzlichen und gewaltsamen Prozess der Veränderungen, seine Unsicherheit ob des „widersprüchlichen“ eingeschlagenen Wegs, sein Credo der Unparteilichkeit bei gleichzeitigem Hinwirken auf eine langsame, moderate und streng gesetzliche Reformation des Staatsaufbaus passten denkbar schlecht in diesen Moment der „akuten Polarisierung“. Isiah Berlin prägte diesen Ausdruck für Zeiten, in denen „moralisch sensitive, ehrliche und intellektuell verantwortungsvolle Menschen“ in der um sich greifenden Verschärfung der Haltungen in ein Dilemma geraten, weil sie keinen klaren Ausweg anzubieten haben. ${ }^{285}$ Fast schon hilflos klingen Konis Verweise auf sein Alter und seinen Gesundheitszustand, mit denen er vor Stolypin seine Absage rechtfertigte und einige Monate früher auch Gerüchten um seine Ernennung zum Volksbildungsminister entgegengetreten war. ${ }^{286}$

\subsubsection{Gewandeltes Selbstverständnis: das „Zasulič-Narrativ“}

Immer deutlicher ging Koni angesichts der „akuten Polarisierung“ dazu über, die eigene Rolle im Machtgefüge zu justieren. Schließlich entwickelte er eine verblüffende neue Sicht auf seine Karriere und die politischen Ambitionen seiner Vergangenheit. In „Die Vorstellung bei Alexander III. in Gatčina“ macht Koni den Schreibanlass gleich zu Beginn transparent. Er spricht von einem Kausalzusammenhang zwischen den blutigen revolutionären Zusammenstößen der Vortage und der Entwicklung der Selbstherrschaft in den letzten Jahrzehnten

285 BerLin: Fathers and Children, S. 59-60. Berlin zieht dieses Fazit bezeichnenderweise im Rahmen seiner Analyse von Turgen'evs Roman „Väter und Söhne“, vgl. zum Roman auch oben, S. 86.

286 In einem Brief vom Oktober 1905 schreibt Koni, dass gemunkelt werde, man wolle ihm den Posten des Volksbildungsministers anbieten. Er habe sich aber zu einer Absage entschieden. Als Gründe führt Koni auch da u. a. die Gesundheit an, vgl. GA8, S. 227-28 (Brief an Elena Aleksandrovna Liven vom 20.10.1905). In einem Entwurf für ein offizielles Absageschreiben für das Amt listete Koni ebenfalls die Tatsache auf, dass seine Gesundheit angeschlagen sei und er sich zu wenig auskenne, vgl. GARF F. 564, op. 1, d. 16. Das Archiv beschriftet diesen entwurfartigen Text ohne Datierung, Unterschrift oder Adressierung mit: „Zapiska Koni s izloženiem pričin, pobudivšich ego otkazat'sja ot dolžnosti ministra narodnogo prosveščenija“. 
und will deshalb von seiner Audienz im Zarenpalast berichten. Der offengelegte Auslöser für den Erinnerungstext lässt vermuten, dass Koni nun seinen negativen Eindruck vom Zaren und den ihn umgebenden Politikern am Beispiel dieses Treffens begründen möchte. Und tatsächlich beschreibt Koni danach, wie er vor der Audienz im Palast auch mit der Gattin von Alexander III. habe konversieren dürfen. Dabei sei das Thema auf die Ursachen der Cholera-Unruhen auf dem Lande gekommen. ${ }^{287}$ Er habe der Zarin zu erklären versucht, dass die Übergriffe auf Ärzte ein „Resultat der Unwissenheit des Volkes“ seien. Die Menschen würden in ihren Leben „weder durch die Kirche, noch durch die Schule“ angeleitet. Doch die Zarin habe darauf bestanden, dass die „Nihilisten“ die Verantwortung für alle Gewalttaten trügen, dies habe ihr der Innenminister versichert. ${ }^{288}$ Als wenig später Alexander III. zum Empfang gebeten habe, sei der Zar Koni „mit bösem Blick“ begegnet und habe sich nach einigen wenig erbaulichen Worten bereits dem Nachbarn zugewandt. ${ }^{289}$ Dies - so Koni - sei sicherlich auf die Zarin zurückzuführen, die wohl ihren Unmut über Konis Ausführungen kundgetan habe. Das Ziel der Erinnerungsschrift scheint also zu sein, Kurzsichtigkeit und Unverständnis der Herrscherfamilie und ihrer Berater gegenüber den Folgen ihrer Politik und den Zuständen in Russland deutlich zu machen. Gleichzeitig stellt Koni seine eigene Person als Opfer dieser Ignoranz dar. Diese implizierte Distanzierung von der zarischen Politik gelingt aber lediglich unvollständig. Nur in knapp der Hälfte der Erinnerungsschrift geht es wirklich um die politische Unbedarftheit der Zarenfamilie und die Sündenbock-Politik, mit der sich der Innenminister aus der Verantwortung stehlen wollte. Im Rest führt Koni unter anderem auch im Rahmen eines biografischen Exkurses über einen Fürsten, der ihn für die Audienz in Empfang genommen habe, seine eigenen Beziehungen und Zusammentreffen

2871891 hatte in Russland eine große Hungersnot zu Abertausenden von Toten geführt. Im Anschluss daran kam es zu Cholera- und Typhusepidemien. In einem Klima der Unwissenheit über Ursache und Übertragung der Krankheiten kamen zahlreiche Gerüchte auf. So hieß es z. B., die Regierung produziere zur Eindämmung des Bevölkerungswachstums bewusst Epidemien. Ärzte und Offizielle seien die Komplizen. In einigen Landesteilen kam es daraufhin zu tödlichen Übergriffen auf medizinisches Personal durch einen wütenden Mob, vgl. Hutchinson: Late Imperial Russia, 1890-1917, S. 14-16.

288 Koni: Predstavlenie Aleksandru III. v Gatčine. In: GA2, S. 352-53. Tatsächlich reagierte die Regierung mit harter Repression auf die Übergriffe, was die Aufständischen nur noch mehr in ihren Befürchtungen bestärkte. Die Ärzte ihrerseits sahen, dass Bildung und nicht Gewalt der einzige Weg wäre, die Verbreitung solcher Gerüchte zu stoppen. Das Wissen über Entstehen und Verbreiten der Seuchen sollte über sanitäre Kommissionen zur Bevölkerung gebracht werden. Konflikte zwischen wissenschaftlichem Expertentum und den offiziellen Behörden zeichneten sich ab und nahmen in den darauffolgenden Jahren zu, vgl. Hutchinson: Late Imperial Russia, 1890-1917, S. 16.

289 Koni: Predstavlenie Aleksandru III. v Gatčine. In: GA2, S. 354. 
mit wichtigen Figuren im Russischen Reich an. So berichtet er beispielsweise, wie Großfürst Nikolaj Nikolaevič (1831-1891), der dritte Sohn von Zar Nikolaus I., ihn auf einem Fest in den 1870er-Jahren dem damaligen Thronerben und zukünftigen Zaren Alexander III. vorgestellt habe. Er erwähnt die Rechtslektionen, die er dem Sohn des Großfürsten später gegeben habe, und betont, dass sich der Großfürst ihm gegenüber immer sehr sympathisch verhalten habe. ${ }^{290}$

Die in diesem Text nur in Ansätzen deutlich gewordene Distanznahme von den monarchischen Kreisen wird von Koni in „Meine Nacht Gethsemane“ expliziter gemacht. Während er darin zwar seine Ambitionen auf ein einflussreiches Ministeramt offen anspricht, wird im Gegenzug auch die Absage an diesen Karriereweg von unmissverständlichen Worten begleitet. So nimmt er zum Schluss nach dem ganzen Hin und Her um den Ministerposten eine letzte Interpretation und Bewertung der Ereignisse und eine neue Einordnung seiner eigenen Person vor:

[...] ich blicke mit ruhigem Gewissen zurück und freue mich, dass ich mich nicht von der zweifelhaften Rolle eines fiktiven Vaterlandsretters habe verführen lassen, der vermessen träumt, dass sein Name allein in Zeiten der radikalen Entflammung und der rachgierigen, blutigen Instinkte irgendetwas ausrichten könne. ${ }^{291}$

Schon fast vergessen scheint nun das Ringen um diese Entscheidung, das Koni soeben noch ausführlich beschrieben hat.

Die Krise, ausgelöst durch die Frage nach der eigenen Positionierung im imperialen Machtgefüge fungierte als „Hauptmotor des Schreibens “ ${ }^{292}$ Sinnbildlich mündete ihre Bewältigung schließlich im „Erschreiben“ eines neuen Selbstverständnisses, das Koni in weite Ferne von Karrierestreben und höfischen Machtpositionen rückte. Während er sich zu Beginn von „Meine Nacht Gethsemane“ noch darüber ärgert, als Oberstaatsanwalt auf dem Posten eines „fruchtlosen ,Protestierers“" sitzen gelassen worden zu sein, zeigt er sich zum Schluss des gleichen Textes zufrieden damit, sich nicht „verführt“ haben zu lassen. Ähnlich positive Urteile über seine Karriere finden sich auch in „Triumvirn“, wo er so ausführlich seine Kämpfe gegen Pobedonoscev, Murav'ev und Tagancev beschreibt. Ungeachtet dieser Auseinandersetzungen betont Koni nämlich auch, wie zufrieden er mit dem sei, was er habe erreichen können. Eine „innere Stimme“ habe ihn zusammen mit moralischer Unterstützung von außen darin bestätigt, dass er mit seiner Tätigkeit bei der Kassation auf dem richtigen Weg sei. Er habe eingesehen, dass

290 Ebd., S. 351.

291 Koni: Moja gefsimanskaja noč. In: GA2, S. 375.

292 Schmid: Ichentwürfe, S. 377. 
er nicht „noch Besseres wünschen“, sondern bei dieser Tätigkeit bleiben solle. ${ }^{293}$ Dass die hier propagierte Zufriedenheit mit einem Karriereverlauf, der ihn nicht zu etwas „Besserem“ als dem Oberstaatsanwalt am Kassationsdepartement hat werden lassen, auch direkt mit den öffentlichen Diskussionen zum Schreibzeitpunkt zusammenhing, wird durch den Kontext der Aussage Konis verdeutlicht. Ein Schwerpunkt im nachfolgenden Textabschnitt von „Triumvirn“ ist nämlich sein Verhältnis zur Todesstrafe für politische Attentäter. Mit dieser habe er als „prinzipieller Gegner“ mit nur ganz beschränkten Ausnahmen auf keinen Fall etwas zu tun haben wollen. ${ }^{294}$ Auch wenn Koni von den 188 oer- und 189oerJahren spricht, liegt es nahe, dass die brutale Niederschlagung der Unruhen auf dem Lande in den Jahren 1906/o7 hier unmittelbar hineinspielte. In Parlamentskreisen kam es in dieser Zeit zu intensiven Debatten um die exzessiv angewandte Todesstrafe als Mittel zur Wiederherstellung der Ordnung im Staat. ${ }^{295}$ Im letzten Abschnitt von „Triumvirn“ bemüht sich Koni nun zu betonen, dass er nie etwas mit staatlicher Repression zu tun gehabt habe. So führt er aus, dass er einer zweiten Amtszeit als Oberstaatsanwalt nur zugestimmt habe, nachdem er vom Justizminister die Zusicherung erhalten hatte, nie mit politischen Fällen und der Todesstrafe in Kontakt kommen zu müssen. ${ }^{296}$

Am deutlichsten wird Konis „Erschreiben“ eines Selbstverständnisses, das ihn von jeglichen Ambitionen auf Macht distanziert, im allerletzten Abschnitt der Erinnerungen an den Zasulič-Fall.

[...] Wenn ich nun nach 26 Jahren meine Erinnerungen an diesen Fall und seine persönlichen Folgen für mich abschließe, betrachte ich die Vergangenheit gänzlich ohne Erbitterung und mit Dankbarkeit für das Schicksal ... Hätte es diesen Fall nicht gegeben, so hätte ich wahrscheinlich schon lange einen hohen Ministeriumsposten innegehabt.

Alles habe darauf hingewiesen, Graf Pahlen habe ihn schon fast wie seinen Nachfolger behandelt, und unter gewogenen Umständen wäre das wohl eingetreten.

293 Koni: Triumviry. In: GA2, S. 312.

294 Ebd., S. 313.

295 Vgl. dazu den Aufsatz von Lutz HäFner: Die Bombe als „Notwendigkeit“. Terrorismus und die Debatten der Staatsduma um die Legitimität politischer Gewalt. In: Walter Sperling (Hrsg.): Jenseits der Zarenmacht. Dimensionen des Politischen im Russischen Reich 180o-1917. Frankfurt am Main u. a. 2008, S. 433-61.

296 Z. B. Koni: Triumviry. In: GA2, S. 316 und 319. BAberowski: Autokratie und Justiz, S. 709 verweist darauf, dass viele Senatoren des Kriminalkassationsdepartements in andere Departemente wechselten, um nicht Todesstrafen gegen politische Gefangene aussprechen zu müssen. Neben Koni sei u. a. auch Tagancev nur gegen das Versprechen im Amt verblieben, nicht in das Sondergericht für politische Fälle berufen zu werden. 
Das Amt des Justizministers aber, „der als Vollzieher des persönlichen Willens des Monarchen gilt", hätte die „Stimme seines Herzens" zu „verlogenen Stimme der sogenannten Staatsraison“ werden lassen. Er hätte kein „fähiger Beamter“ [sposobnyj činovnik] werden können und wäre gleichzeitig gezwungen gewesen, „die Züge eines gesellschaftlichen Akteurs auf dem Feld der Rechte" zu verzerren. Die ganze „Hetze" rund um den Fall Zasulič habe ihm hingegen die Möglichkeit gegeben, „einige echte Freunde“ kennenzulernen und einige „Minuten der süßen Erholung in den seltenen aber teuren Oasen des Mitgefühls und des Verständnisses“"zu erleben. Obwohl er „seine persönlichen Wünsche“ gezähmt und die Sinnlosigkeit seiner „ehrliebenden Träumen“ [čestoljubivych mečtanij] eingesehen habe, habe er den Glauben an die „guten Kräfte der menschlichen Natur" beibehalten. Die Entwicklungen nach 1881 hätten nahegelegt, dass er „,auf dem breiten staatlichen Feld“ nichts Nachhaltiges hätte erreichen können. Die „nützliche Tätigkeit eines einzelnen Menschen“ wäre schnell „mitsamt der Wurzeln ausgerissen“ worden. Diese Überlegungen hätten ihn auch dazu veranlasst, 1906 das Angebot Stolypins auf den Ministerposten auszuschlagen. „Das Schicksal hat mich dazu ausersehen, ein treuer Diener jener Grundsätze zu bleiben, in deren Dienst ich mit meinem Universitätsstudium eingetreten bin [...].“ ${ }^{\text {297 }}$

Was hier so glatt dargelegt wird, ist nichts weniger als das Eingeständnis, dass die eigenen Wünsche und Träume zu ehrgeizig und selbstbezogen gewesen waren angesichts der realen politischen Verhältnisse. Fast schon dankbar für den skandalträchtigen Gerichtsfall und den damit einhergehenden Unmut der höchsten Kreise sieht sich Koni in diesem „Zasulič-Narrativ“ vor den Versuchungen der Macht bewahrt. Diese versöhnliche Interpretation seiner Laufbahn ist in einer Manuskriptversion sogar mit noch selbstkritischeren Zügen versehen. Darin schreibt Koni zusätzlich in diesem Schlussabschnitt vom „Einfluss der höfischen Sphären“, die ihm seit Mitte der 7oer-Jahre besondere Aufmerksamkeit entgegengebracht hätten. Die ihm eigentümliche „Beeindruckbarkeit/Sensibilität [vpečatlitel'nost'] und Unschlüssigkeit unter dem Einfluss von widersprüchlichen Zweifeln" hätten sich unweigerlich einschränkend auf seine Handlungsfreiheit ausgewirkt. ${ }^{298}$ Nur aufgrund der Verhinderung einer einflussreichen Position

297 KonI: Vospominanija o dele Very Zasulič. In: GA2, S. 251-52.

298 GARF F. 564, op. 1, d. 200, l. 152. Dieser Text scheint dem Original von 1904 zu entsprechen. Wohingegen Koni den Schluss in IRLI F. 134, op. 1, d. 110, 1. 312ob-3130b deutlich veränderte und aufgrund der Einfügung des Verweises auf Stolypins Anfrage von 1906 neu mit 1904 bis 1906 datierte. Auffällig ist, dass hier auch Elemente wie eine Berufung auf Gott als Schlusssatz fehlen. Gut möglich deshalb, dass diese Überarbeitung aus der Zeit nach der Oktoberrevolution von 1917 stammt, vgl. dazu das Kapitel Politische Erinnerung an das Zarenreich in der Sowjetunion sowie Zusammenfassung und Ausblick. Die Heraus- 
habe das Schicksal den Menschen in Koni bewahrt und ihm die Möglichkeit gegeben, angesichts des nicht fernen Grabes ruhig und ohne zu erröten auf seine Vergangenheit zu blicken. ${ }^{299}$

Die in der Zeit des revolutionären Umbruchs mit seinen neuen Werten und radikaleren Ansichten verschärft sich stellende Frage nach der eigenen Rolle in Gegenwart und Vergangenheit brachte Koni dazu, seinen Werdegang nochmals zu überdenken und in seiner autobiografischen Auseinandersetzung eine positive Interpretation seines Berufslebens zu finden. Mit dem „Zasulič-Narrativ“ konnte er sich in seiner Selbstdarstellung von nachgesagtem und tatsächlichem Karrierestreben und Machtnähe distanzieren.

\subsubsection{Biografien von Peers als Probeläufe}

Während eine Autobiografie durch ihre „Textarchitektur“ oftmals die „Schlüssigkeit der gewählten Identität“ untermauern und die „Lebenssituation auf eine Generallinie“ bringen will, gelang dies Koni in Bezug auf das "Zasulič-Narrativ“ nur unvollständig. ${ }^{300}$ Immer wieder tauchen in seinen Erinnerungstexten nach der Jahrhundertwende verschiedene Interpretationen seiner Karriere auf, oftmals sogar in ein und demselben Text. Einmal ist er der zu Unrecht übergangene, eigentlich zu Höherem vorgesehene, ein anderes Mal der mit seiner Stellung höchst zufriedene Jurist. Das Ringen mit sich und seinen Ambitionen führte Koni in seiner autobiografischen Praxis gar auf eine noch komplexere Ebene. Er probierte im Rahmen des Schreibens immer wieder aus, welche anderen Verläufe sein Leben hätte nehmen können, wenn er andere Entscheidungen getroffen hätte. Dies tat Koni mithilfe zahlreicher eingestreuter biografischer Porträts, mit denen er die Lebensgeschichte von Berufskollegen nachverfolgte, die - quasi an seiner statt einen anderen Weg eingeschlagen hatten. Mit so einem „Probelauf“ konnte er im Unterschied zum realen Leben in der Erinnerungsschrift andere Legitimierungen und Zugehörigkeiten ausprobieren beziehungsweise deren Verwerfen bekräftigen. ${ }^{301}$ Pierre Bourdieu spricht von der „biografischen Illusion“, die eine künstlich

geber der Gesamtausgabe haben den Schluss als Mischung aus verschiedenen Versionen veröffentlicht. So erwähnen sie die Ministeranfrage, lassen aber die Berufung auf Gott weg sowie die oben zitierten Sätze. Dafür fügen sie den Teilsatz zu den „,ehrliebenden Träumen“ wie im Original ein sowie einen weiteren Absatz, der im d. 110, 1. 312obff nicht existiert.

299 GARF F. 564, op. 1, d. 200, 1. 154.

300 SCHмid: Ichentwürfe, S. 372-73 zur identitätsstiftenden Funktion einer Autobiografie, die immer die „Konstanz“ der konstruierten Identität plausibel machen muss.

301 Ebd., S. 14 spricht von der Lebensgeschichte, die per se keinen „Probelauf“ zulässt. Vgl. auch S. 393 zu „,negativen Identifikationsfiguren“, die in Erinnerungen auftauchen können. 
geordnete Sinnschöpfung aus jedem Leben macht. Die „Matrix“ der möglichen Wege, die auch hätten eingeschlagen werden können, wird dabei ausgeblendet. ${ }^{302}$ Durch dieses „Probehandeln“ konnte Koni - ohne dies explizit zu machen - genau diese „Matrix“ an Alternativen und Möglichkeiten testen und sich in Situationen und Entscheidungen anderer hineindenken. ${ }^{303}$ Dies allerdings gerade auch, um den schlussendlich von ihm gewählten Pfad zu legitimieren.

Nikolaj Valerianovič Murav'ev war einer der drei Männer des „Triumvirats“, über das Koni 1907 seine Erinnerungen festhielt. In der Rückschau auf seine Zeit am Kriminalkassationsdepartement zeichnet Koni seine Dienstlaufbahn als eng verflochten mit jener von Murav'ev. ${ }^{304}$ Ganz direkt überschnitten sich die Lebensläufe der beiden Juristen 1891. Koni trat vom Amt des Oberstaatsanwaltes zurück und wurde zum Senator ernannt. Murav'ev wurde sein Nachfolger am Kriminalkassationsdepartement. In „Triumvirn“ schreibt Koni, es sei sein ausdrücklicher Wunsch gewesen, dass der Justizminister Murav'ev ernenne, der der „einzig passende Kandidat“ gewesen sei. Und tatsächlich sei dieser dem Amt auch gewachsen gewesen.$^{305}$ Auf über zehn Seiten holt Koni danach aber zu einem vernichtenden Urteil über seinen Nachfolger aus. Dieser sei nämlich mit der Position nicht zufrieden gewesen, die seine „unersättliche Ehrliebe und gierige Herrschsucht" nicht habe stillen können. ${ }^{306}$ Alles, was Koni am Amt gemocht habe: „der moralische Einfluss, das Fehlen obligatorischer Begegnungen mit dem Starken der

302 Pierre Bourdieu: Praktische Vernunft. Zur Theorie des Handelns. Frankfurt am Main 1998, S. 76 und 82.

303 Heiko Haumann: Geschichte, Lebenswelt, Sinn. Über die Interpretation von Selbstzeugnissen. In: ders. (Hrsg.): Lebenswelten und Geschichte. Zur Theorie und Praxis der Forschung. Wien u. a. 2012, S. 93-94. Haumann spricht von „Probehandeln“ auch in Bezug auf Historiker, die mit ihren Interpretationen von Lebensgeschichten selber „Sinn-Konstruktionen“ hervorrufen. Gedankliches „Probehandeln“ ist dabei elementar, um Hintergründe, Ursachen, Handlungsvarianten und mögliche Alternativen mit in den Blick nehmen zu können.

304 Murav'ev hatte seine juristische Ausbildung an der Moskauer und der St. Petersburger Universität aber auch im Ausland erhalten und war ab 1870 im Dienst bei der Moskauer Staatsanwaltschaft. Parallel dazu unterrichtete er an der Universität. Nach Zwischenstationen in anderen Städten wurde er 1879 an die Petersburger Gerichtskammer berufen, wo er bald zum Staatsanwalt aufstieg. Das Abschlussplädoyer im Prozess gegen die Mörder Alexanders II. trug entscheidend zum Ruf Murav'evs als außerordentlich begabter Gerichtsredner bei, vgl. für eine Analyse zu Zielen und Taktik dieser Rede: Claudia Verhoeven: Court Files. In: Miriam Dobson/Benjamin Ziemann (Hrsg.): Reading Primary Sources. The Interpretation of Texts from Nineteenth- and Twentieth-Century History. Milton Park 2009, S. 98-102.

305 KonI: Triumviry. In: GA2, S. 318.

306 Ebd. 
Welt", aber auch die Selbständigkeit der Mitarbeiter, all dies habe Murav’ev nicht gefallen. ${ }^{307}$ In verächtlichem Tonfall berichtet Koni, wie sich Murav'ev bei seinem „Moskauer Beschützer", dem Großfürsten Sergej Aleksandrovič (1857-1905), eingeschmeichelt habe, um nicht einmal ein Jahr später schon weiter die Karriereleiter hinaufbefördert zu werden. ${ }^{308}$ Schließlich habe er sich so beeilt, dass er 1894 auch gleich noch Justizminister geworden sei. ${ }^{309}$ Parallel zu diesem steilen Aufstieg Murav'evs kommt Koni in der Erinnerungsschrift nun wieder auf seinen eigenen Werdegang zu sprechen. Nach Murav'evs Abgang aus der Kassation kehrte Koni erneut in das Amt zurück. ${ }^{310} 1893$, also kurz bevor Murav'ev zum Justizminister befördert wurde, habe dessen Vorgänger beim Zaren um eine Rente [arenda] für Koni gebeten. Dies unter anderem, weil er mit der Übernahme der Prokuratur "große Opfer in Hinblick auf Ruhe und Gesundheit" habe erbringen müssen. ${ }^{311}$ In diesem Jahr habe er aufsehenerregende Fälle zu behandeln gehabt, und seine Schlussfolgerungen seien von ,großer Anteilnahme der Juristen und der Öffentlichkeit" begleitet gewesen. Der Zar aber habe das anders gesehen. Er habe die Bitte abgeschlagen mit der Begründung, dass Koni zwar „eine der fähigsten Personen in Russland" sei, diese Fähigkeiten aber gegen ihn nutze. ${ }^{312}$

Dienstliche Beziehungen waren im Zarenreich für die politische und bürokratische Karriere von herausragender Bedeutung. Persönliche Protektion durch geneigte Vorgesetzte und einflussreiche Individuen, die Auszeichnungen, Beförderungen oder Pensionszahlungen nach sich zog, war für kontinuierlichen Aufstieg und Macht unerlässlich. ${ }^{313}$ Indem Koni in der Erinnerungsschrift Murav'evs Aufstieg mit seiner persönlichen Herabsetzung durch den Zaren kombinierte, zeichnete er ein deutliches Bild. Seine juristische Brillanz alleine, so die Darstellung, reichte nicht aus. Die für sich selber wohl ebenfalls erhoffte Protektion von oben wurde an einen Murav'ev vergeben, dem Koni zwar gewisse Fähigkeiten attestiert, der aber vor allem durch seine politische Linientreue aufzufallen schien. Um diese Darstellung zu bekräftigen, führt Koni denn nun in „Triumvirn“ auch all die in seinen Augen negativen Maßnahmen an, die Murav'ev in der Amtszeit

\footnotetext{
307 Ebd.

308 Ebd., S. 318-19. Zur Beförderung von Murav'ev mit Unterstützung von Großfürst Sergej Aleksandrovič vgl. BABEROWsKi: Autokratie und Justiz, S. 438.

309 Koni: Triumviry. In: GA2, S. 320.

310 Ebd., S. $318 \mathrm{ff}$. Koni beschreibt seine Freude, unter Beibehaltung des Senatorenamtes wieder die Tätigkeit als Oberstaatsanwalt aufzunehmen. Die Aufgaben im Senat hätten ihn nicht ausgefüllt.

311 Ebd., S. 320.

312 Ebd.

313 Stadelmann: Großfürst Konstantin Nikolaevič, S. 310.
} 
als Justizminister bis 1905 vorangetrieben hat. In all seinem Tun sei dieser „ein Verteidiger der Traditionen und Rechtsansichten “von Alexander III. gewesen. ${ }^{314}$ Am schwersten ins Gewicht fällt dabei die sogenannte Murav'ev-Kommission, die sich ab 1894 der Revision der Gerichtsstatuten von 1864 widmen sollte. Zur allgemeinen Überraschung waren in dieser Kommission „ausgewiesene Konservative" in der Minderheit, zahlreiche als liberal geltende Juristen, unter ihnen auch Koni und Tagancev, wurden eingeladen. Die juristischen Zeitschriften und die liberale Öffentlichkeit beobachteten Murav'evs Reformanliegen mit Argwohn. Man befürchtete das baldige Ende der Gerichtsstatuten von $1864 \cdot{ }^{315}$ In einer Rede vor der Juristischen Gesellschaft äußerte sich Koni zu Beginn noch positiv über die Kommission und deren Versuch, Verbesserungen und Adaptionen an den damals eingeführten Spielregeln der Justiz anzubringen. ${ }^{316}$ In „Triumvirn“ aber verurteilt Koni die Kommission und ihren Vorsitzenden in aller Deutlichkeit. Er spricht von "gnadenloser Zerstörung“ anstelle von „unabdingbarer Umgestaltung“. Murav'ev habe gegen die Hauptpfeiler der reformierten Gerichte, wie zum Beispiel das Geschworenensystem, angekämpft. Vier Jahre mit 511 Sitzungen lang habe Koni versucht, Gegensteuer zu geben. Murav'ev habe ihn sogar mit Orden und Geld zu bestechen versucht, und natürlich hätten ob dieser ganzen Auseinandersetzung auch ihre „dienstlichen Beziehungen“ arg gelitten. ${ }^{317}$

Am Beispiel von Murav'ev, dem er fast schon dämonische Züge verlieh, konnte Koni für seine potentiellen Leser und wohl auch für sich selber eindrücklich deutlich machen, was der Preis für die Gunst von Zar und Großfürsten gewesen wäre. Niederträchtig und gegen alle Ideale der Gerichtsreform, die Koni in seinen Porträts der Berufskollegen so betonte, hätte er handeln müssen. Entschieden wies er so zum Schreibzeitpunkt im Jahre 1907 jede Ähnlichkeit mit dem Typus des selbstsüchtigen Karrieristen und reaktionären Hardliners von sich. Die enge Verwobenheit der Dienstwege der beiden Männer, die Koni in seiner Erinnerung selber betonte, lassen hinter seinen harschen Worten aber auch persönliche Bitterkeit dem Mann gegenüber vermuten, der zu jener einflussreichen Position aufstieg,

314 KonI: Triumviry. In: GA2, S. 320-21.

315 Baberowski: Autokratie und Justiz, S. 442 und 447. Baberowski interpretiert die Vorschläge der Kommission, die bis 1899 tagte, in einem umfangreichen Kapitel seiner Monografie „Autokratie und Justiz“ deutlich positiver. Vgl. Kapitel 6, „,... damit endlich eine wirkliche Rechtsprechung in Russland herrscht': N. V. Murav'ev und die Reorganisation der Justiz“. Die politischen Veränderungen im Revolutionsjahr 1905 sorgten dafür, dass die Vorschläge der Reformkommission nicht weiterverfolgt wurden, vgl. ebd., S. 479.

316 Marina V. Nemytina: Sud v Rossii. Vtoraja polovina XIX-načalo XX vv. Saratov 1999, S. $168 \mathrm{ff}$.

317 KonI: Triumviry. In: GA2, S. 321-23. 
die auch für Koni eine Option hätte sein können. ${ }^{318}$ „Feind“ und „Konkurrent“ nannte viele Jahre später der Anwalt Oskar Osipovič Gruzenberg (1866-1940) Murav'ev in einer Erinnerungsschrift über Koni. ${ }^{319}$

Koni beließ es denn auch nicht bei seiner Abrechnung in „Triumvirn“. Er plante offensichtlich zusätzlich ein Porträt alleine über Murav’ev, für das er im Frühling 1907 Stichworte sammelte und schließlich nach 1908 auch einen Fließtext verfasste. ${ }^{320}$ Dieser beginnt bereits mit dem Jahr 1876/77, in dem Koni und Murav'ev sich das erste Mal gesehen haben sollen. „Ziemlich kühl“ habe dieses erste Treffen geendet, da Koni, der damals im Justizministerium arbeitete, eine Versetzungsbitte Murav'evs nicht habe unterstützen wollen. Murav'ev habe darum gebeten, näher an „politische Fälle " heranzurücken. ${ }^{321}$ Zum Schluss des Porträts erwähnt Koni auch seine letzte Begegnung mit Murav'ev, als dieser kurz vor seinem Tod als Botschafter in Italien tätig war. Es sei traurig - schreibt Koni -, dass ein zweifellos reich talentierter Mensch eine Spur der Zerstörung der heiligen Sache, der er hätte dienen sollen, hinterlasse. ${ }^{322}$ Diese nachdenklichen Worte zum Schluss weisen vielleicht auf eine ambivalente Beziehung zwischen den beiden Juristen hin. Interessanterweise ist es ein überschwängliches Lob, das ausgerechnet Murav'ev 1889 für Konis Fähigkeiten als Gerichtsredner aussprach, das besonders oft in Nachrufen und in der Sekundärliteratur über Koni aufgegriffen wird. ${ }^{323}$ Und in

318 Vgl. auch BABerowski: Autokratie und Justiz, S. $454 \mathrm{ff}$ zum persönlichen Kampf zwischen Koni und Murav'ev in der Kommission.

319 O. O. Gruzenberg: Ob A. F. Koni. In: ders. (Hrsg.): Včera. Vospominanija. Paris 1938, S. 198.

320 Stichworte: GARF F. 564, op. 1, d. 93, 1. 24-26. Fließtext: 1. 1-22. Der Fließtext ist nicht datiert, wurde aber sicher nicht vor 1908 ausformuliert, da er den Tod Murav'evs im entsprechenden Jahr behandelt. Auch in den 1920er-Jahren machte Koni nochmals Notizen für ein Porträt von Murav'ev. Darauf wird im Kapitel Politische Erinnerung an das Zarenreich in der Sowjetunion eingegangen.

321 GARF F. 564, op. 1, d. 93, 1. 1-2. Konkret habe Murav'ev Koni darum gebeten, ihn dabei zu unterstützen, Staatsanwalt am Bezirksgericht zu werden. Koni aber fand, dass die Tätigkeit Murav'evs an der Moskauer Universität doch viel wirkungsvoller sei. VysockiJ: Koni, S. 284-85 behauptet, dass Murav'ev fand, Koni habe ihm mit diesem Rat fast die Karriere zerstört. Im Fließtext geht Koni auch ausführlich auf Murav'evs Handhabung der Untersuchung zur Ermordung von Zar Alexander II. 1881 ein. Murav'evs Anklagerede sei sehr lange ausgefallen und von „dramatischen Gesten“ begleitet gewesen, vgl. GARF F. 564, op. 1, d. 93, 1. 4. Danach zählt Koni Ähnliches auf wie in „Triumvirn“.

322 GARF F. 564, op. 1, d. 93, l. 22. Im Januar 1905 war Murav'ev vom Amt des Justizministers zurückgetreten und als Botschafter nach Rom geschickt worden, vgl. BABERowski: Autokratie und Justiz, S. 479-80.

323 N. V. Murav'ev: Prokurorskij nadzor v ego ustrojstve i dejatel'nosti. Moskva 1889, S. 489. Murav'ev schreibt darin zum 1888 erschienenen Sammelband von Konis Reden, es sei ja allgemein bekannt, wie gut dessen Reden seien. Man könnte sie nicht nachahmen, sondern 
Konis Nachlass steht bis heute ein Exemplar der publizierten Rede, die Murav'ev zu den Resultaten seiner Justizkommission 1902 gehalten hatte. Die persönliche Widmung - angesichts der Vorgeschichte vielleicht auch ironisch zu verstehen lautet „zum guten Andenken“.324

Wenn die Parallelen in Murav'evs und Konis Lebenslauf schon unübersehbar sind, so wird dies bei einer weiteren Person noch augenfälliger, deren Karriere Koni in „Triumvirn“ ebenfalls kurz nachzeichnet. Nikolaj Adrianovič Nekljudov (1840-1896) war als Kollege Konis am Kriminalkassationsdepartement tätig. ${ }^{325}$ „Probehalber“ spielt Koni in der Erinnerung anhand von Nekljudov durch, was ihm hätte passieren können, wenn er versucht hätte, sich den Aufstieg ins Ministeramt mit verstärkter Kooperation in Fällen politischer Repression zu erkaufen. So beschreibt er die Figur seines Amtskollegen und berichtet, wie Nekljudov Todesurteile in Fällen politischen Terrors habe sprechen müssen und daran, in der Interpretation Konis, schließlich zerbrochen sei. Die Verdienste Nekljudovs als Fachmann und als populärer Friedensrichter in seinen jungen Jahren stellt Koni neben den „zermalmten“ Nekljudov fortgeschrittenen Alters, der Ende der 188oer-Jahre ,farblose“ Reden gegen angeklagte politische Attentäter hielt und vor sich hin litt. ${ }^{326}$ Koni stellt sich im Text vor, wie er reagiert hätte, wenn der Justizminister ihm solche Fälle übergeben hätte. Zum „großen Skandal“ wäre es dann

nur von ihnen lernen. Darauf wird u. a. verwiesen in: Sergej M. KAZAncev (Hrsg.): Sud prisjažnych v Rossii. Gromkie ugolovnye processy 1874-1917 gg. Leningrad 1991, S. 22-23 oder Gruzenberg: Ob A. F. Koni, S. 198. Seinerseits hat Koni allerdings mehrere Artikel zu Murav'evs Ableben in einem Kuvert aufbewahrt, das er mit „Merzavec Murav'ev“ beschriftet hat - was so viel wie „Mistkerl“ heißt, vgl. GARF F. 564, op. 1, d. 441. Unter den gesammelten Artikeln befinden sich auch solche, die Murav'ev der Korruption beschuldigen. Koni hat zudem in einer anderen Akte eine längere Notiz aufbewahrt mit einer Aufzählung von „Fällen, die das öffentliche Gewissen empören“ und in die Amtszeit von Murav'ev als Justizminister fallen, vgl. GARF F. 564, op. 1, d. 685.

324 GARF F. 564, op. 1, d. 4133. Der Titel lautet: „Erklärung des Justizministers und Staatssekretärs N. V. Murav'ev in der ersten Sitzung der Vereinigten Departemente des Staatsrates zum Fall der Überarbeitung der Gerichtsstatuten, 16. Dezember 1902“. Von Hand hat Murav'ev hinzugeschrieben: „Dem hochverehrten Anatolij Fëdorovič Koni zum guten Andenken. " Das Büchlein enthält in der Folge die Ausführungen des Justizministers vor der Versammlung des Staatsrates über die geplanten Veränderungen im Gerichtswesen, die die Kommission in den 189oer-Jahre ausgearbeitet hatte. Koni hat keinerlei Anmerkungen dazu gemacht.

325 Koni erwähnt Nekljudov auch in seiner Reihe in „Russische Altertümer“ [Russkaja Starina], vgl. „Štundisty“ und „Mirovye sud'i“", Angaben auf S. 70/71.

326 Koni: Triumviry. In: GA2, S. 313-14. Konkret geht es um die Todesurteile gegen u. a. den älteren Bruder von Lenin, Aleksandr Ul'janov (geb. 1866), der als Narodnik 1887 bei den Vorbereitungen zu einem Attentat verhaftet und hingerichtet wurde, vgl. Hans Joachim Torke: Einführung in die Geschichte Russlands. München 1997, S. 178-79. 
wohl gekommen, da er, den man „für rot" halte, solches Vorgehen nicht hätte akzeptieren können ${ }^{327}$ Nekljudov aber sei ganz gut in seine Rolle hineingewachsen, wofür seine „Seele“ hingegen teuer bezahlt habe. „Stolz und selbstverliebt“ habe er versucht, dies zu kaschieren. Aber einmal, da habe Koni ihn zufällig auf einem Bahnhof angetroffen. Nie werde er dessen zitternde Hände und den „schrecklichen Ausdruck“ in seinem Gesicht vergessen. ${ }^{328}$

Konis abschließendes Resümee zum Leben des Berufskollegen liest sich wie ein Schreckensszenario, das auch ihn selber hätte ereilen können: Einen Weg der „unehrenbaren Kompromisse und Konzessionen“ habe Nekljudov zurückgelegt, um in eine Position zu kommen, die ihm Handlungsmöglichkeiten verschafft hätte. Vielleicht nur kurz vor dem Aufstieg ins Ministeramt sei er dann aber verstorben, wodurch die „Träume der Jugend“ nichtig wurden und nur die Sünden des Alters geblieben seien. ${ }^{329}$

Anhand solcher „Lebensläufe von Zeitgenossen“ maß Koni den „Spielraum des Möglichen“ - oder eben des Unmöglichen - in seiner Situation aus. ${ }^{330}$ Murav'ev und Nekljudov werden als Figuren im Rahmen einer „VerAnderung“ („Othering“) von Koni für seine eigene Identitätsfindung geformt. ${ }^{331}$ Sowohl der "Murav’ev’sche“ als auch der „Nekljudov'sche“ Lebensverlauf unterstrichen dabei als Negativbeispiele besonders eindrücklich die Sinnhaftigkeit von Konis "Zasulič-Narrativ“, das ihn weit weg von Machtnähe und politischen Ambitionen positionierte und dafür sein reines Gewissen und die Treue zu den Idealen der Gerichtsreform akzentuierte.

\section{Fazit}

Koni sammelte Parteiprogramme und Diskussionsbeiträge, politische Manifeste und Memoranden aus der Revolutionszeit. Er engagierte sich im Stadtparlament von St. Petersburg und in der Kommission für ein liberaleres Presserecht. Er schrieb eine lange Erklärung an den Zaren, in der er diesen zur raschen Ein-

\footnotetext{
327 Koni: Triumviry. In: GA2, S. 314.

328 Ebd., S. 315.

329 Ebd., S. 315-16.

330 Jens Herlth spricht in Bezug auf den polnischen Adeligen Tadeusz Bobrowski von „Lebensläufen der Zeitgenossen“, anhand derer der „faktische Spielraum des Möglichen“ durchexerziert wird, vgl. Herlth: „Verengung des Handlungsfelds“, S. 394.

331 Julia Reuter: Ordnungen des Anderen. Zum Problem des Eigenen in der Soziologie des Fremden. Bielefeld 2002, S. 20. Reuter definiert „Othering" als Praxis, bei der ein Fremder als „Anderer“ nicht einfach entdeckt oder beschrieben werden kann, sondern eben immer durch den Beschreibenden mit hervorgebracht wird.
} 
setzung einer Konstitution und somit einer gesetzlichen Grundlage für die Freiheiten, die seit dem Oktobermanifest galten, zu bewegen versuchte. Gleichzeitig aber vermied Koni klare Stellungnahmen und verzichtete auf die Hebelwirkung eines Parteibeitritts, wie ihn zahlreiche seiner Kollegen vollzogen. Grundsätzlich waren Anwälte und sonstige Juristen in den politischen Institutionen des Zarenreichs nach 1905 besonders stark vertreten. Sergej Andreevič Muromcev (1850-1910), der Präsident der ersten Duma, war ein bekannter Moskauer Anwalt und ehemaliger Vorsitzender der Moskauer Juristischen Gesellschaft. Als Mitglied der Konstitutionellen Demokraten war er nur einer von insgesamt 36 Anwälten des ersten parlamentarischen Aufgebots. ${ }^{332}$ Dass Koni hier nicht dazugehörte, erklärt sich in seinen von den revolutionären Ereignissen ausgelösten kurzen Erinnerungsschriften nicht zuletzt durch die tiefe Erschütterung über die entfesselte Gewalt und Gegengewalt. Gleichzeitig wird seine Ohnmacht deutlich, keinen klaren Ausweg zu sehen. Selbst die Erinnerung an den Tag der Eröffnung der ersten Duma, über deren Einsetzung ihm vor Rührung die Tränen kamen, beendet Koni mit Worten der Unsicherheit. So fragt er rhetorisch:

Und die Duma, was bringt sie uns? Verstehen ihre besten Leute die auf ihnen lastende Verpflichtung, der russischen Staatlichkeit die neuen Grundlagen der Gerechtigkeit und Ordnung in Fleisch und Blut einzuverleiben [...]? Vor dieser verhängnisvollen Frage ist mein Herz voller Unruhe und trauriger Vorahnung. ${ }^{333}$

Konis Fokus auf „Ordnung“, seine sorgsame, aber langwierige Arbeit an ausgewogenen moderat-liberalen Gesetzesprojekten stoßen genauso auf Kritik und machen ihn zum „Konservativen unter Liberalen“ wie sein nicht versiegender Glaube an den Zaren. Seine Erinnerungsschriften lassen gerade im Moment der

332 Levin-Stankevich: The Transfer of Legal Technology and Culture, S. 243 und Fußnote 87 sowie Baberowski: Autokratie und Justiz, S. 602. Vgl. ebd., Fußnote 415 für eine Auflistung bekannter Anwälte in den verschiedenen Parlamentskonstellationen. Vgl. auch Litzinger: Juristen und die Bauernfrage, S. $41 \mathrm{ff}$ zu Muromcev. Parteipolitik und parlamentarische Arbeit als wichtiges Betätigungsfeld von Juristen, die sich so unmittelbar an der Gesetzgebung beteiligen konnten, war dabei nicht unbedingt ein russischer Sonderfall. So zeichnete sich z. B. auch die Frankfurter Nationalversammlung 1848 durch einen besonders hohen Anteil von Juristen aus. Allein von den 59 Abgesandten der Deutschen in den Böhmischen Ländern für das Frankfurter Parlament waren 34 ausgebildete Juristen, vgl. Helmut SLAPNICKA: Juristen als Wegbereiter des aufsteigenden Bürgertums des 19. Jahrhunderts in den Böhmischen Ländern. In: Österreichische Akademie der Wissenschaften, Philosopisch-historische Klasse (Hrsg.): Anzeiger. 125. Jahrgang 1988, Nr. 1-9. Wien, S. $46 \mathrm{ff}$.

333 Koni: Otkrytie I Gosudarstvennoj Dumy. In: GA2, S. 359. 
Anfrage, Justizminister zu werden, seit vielen Jahrzehnten in ihm schlummernde Träume und Ambitionen für einen Aufstieg an die Schalthebel der Macht durchschimmern. Doch er lehnte dies nicht nur ab, sondern überdachte seine Karriere gleich von Grund auf neu.

Diese Auseinandersetzung spielte sich wesentlich in Konis damals nicht veröffentlichten autobiografischen Schriften ab. Das daraus resultierende „ZasuličNarrativ" wurde von ihm aber mehr und mehr auch proaktiv gegen außen verwendet. Exemplarisch zeigt sich das in der Ansprache, die Koni zu seinem 40. Dienstjubiläum 1905 im Kreis rund um den „Boten Europas“ hielt. Darin blickt Koni auf die Zeit zurück, in der er entgegen der offiziellen Erwartungen versucht habe zu zeigen, dass ein russischer Richter nicht ein „Lakai“, sondern ein „Diener“ der Justiz sei. Der Zasulič-Fall habe ihn dann zu einem „nur noch geduldeten“ Juristen gemacht. Neben materiellen Einbußen habe sich das auch an der Ernennung zum Mitglied in der Kommission für alte Gerichtsakten gezeigt. Aber darüber könne er sich heute in der Rückschau nur freuen. Er danke dem Schicksal, dass er auf 40 Jahre Dienst an der Gesellschaft zurückblicken dürfe, ohne sich für seine Vergangenheit schämen zu müssen. ${ }^{334}$ In seiner Erinnerungsschrift „Der Bote Europas“, die unter anderem einige Jahre später auch in einer ausführlichen Fassung im Memoirenband „Auf dem Lebensweg“"II publiziert wurde, findet Koni beinahe identische Worte, um das "Zasulič-Narrativ" auch in der Öffentlichkeit zu vertreten. ${ }^{335}$ So könnte man sagen, dass Koni herausgefordert von einer Zeit, der er vorwarf, zu überhastet alte „Werte“ umzuwerten, doch auch selber eine solche „Umwertung“ seiner Karriere für sich angebracht sah. Zumindest wecken die Gedanken, die er in seiner Rede von 1904 zur Frage der Zeugenaussage vor Gericht äußerte, solche Assoziationen. Darin spricht er nämlich nicht nur von den „Umwertungen“ in Gesellschaft und Wissenschaft, sondern geht auch auf ähnliche Prozesse in der menschlichen Biografie ein. Beim Zuendegehen des Lebens, so Koni in der Rede, würde man bekanntlich besonders „konturenstark“ sehen und vieles in sich und anderen neu beurteilen.

Gesegnet sei der, der aus dieser inneren Arbeit herausgeht, ohne den Glauben an die Menschen zu verlieren und ohne vor sich selbst zu erröten. Auch mitten im Leben [...] kann es zu solchen Umwertungen kommen. Manchmal scheint es, dass die Zeit der unerfüllten Träume und Hoffnungen, die Zeit verhängnisvoller Leidenschaft und sturen Existenzkampfes für immer vorbei ist, und nur der schmale Weg persön-

334 GARF F. 564, op. 2, d. 4, 1. 1.

335 Koni: „Vestnik Evropy“. In: ders. (Hrsg.): Na žiznennom puti, Bd. 2, S. 231-33. Vgl. zum Erinnerungstext oben, S. 164 . 
licher Zufriedenheit zieht unter dem grauen Himmel dahin, in der Ferne mit der nichts versprechenden, aber auch nichts vortäuschenden Weite verschmelzend. Und dann, plötzlich, erhebt sich aus einem vergessenen oder flüchtig übergangenen Winkel des Lebens eine Frage, die alles zu verändern droht und den Umbau des gesamten Seelenhaushaltes erzwingt. ${ }^{336}$

Es liegt nahe, diese Worte nicht zuletzt auf Konis eigenes Ringen um eine kohärente Interpretation seiner bisherigen Laufbahn zu beziehen, die ihn nicht „erröten" ließ.

Dank des „Zasulič-Narrativs“ und der entsprechenden Interpretation seines Werdegangs und seiner Rolle im zarischen Russland konnte Koni ein für alle Mal auf die Frage nach seinem tatsächlichen Einfluss, seinem Streben nach solchem und seinen Motiven hierfür antworten. Er gab sich dankbar für den misslungenen Aufstieg in die Regierungskreise und fokussierte sich ganz auf die Justiz und die Bewahrung der Reform als Kernaufgaben. Als „treuer Diener“ des Rechtswesens machte denn Koni in den Folgejahren seine autobiografische Reihe mit Erfolgsgeschichten aus der Anfangszeit der reformierten Gerichte einem breiten Publikum zugänglich. ${ }^{337}$ Diese auch nach außen propagierte Zufriedenheit mit dem Verlauf seiner Karriere bot für Koni einen Ausweg aus einer Situation der Handlungsunfähigkeit, in die er aufgrund seiner vorsichtig-gemäßigten politischen Ansichten geraten war, die ihn 1905 im Moment der „akuten Polarisierung“ zurückhaltend bleiben ließen. Durch die Selbstdarstellung des nur „Geduldeten“, aber unermüdlich für die Sache der Justiz Kämpfenden war es für Koni möglich, Glaubwürdigkeit als moralische Instanz fern von „lakaienhaften“ höfischen Kreisen, reaktionärer Repression und politischen Todesurteilen zu wahren. Dabei nahmen ihm nicht alle die in den späten Jahren propagierte Zufriedenheit mit seinem Berufsleben ab. In einer Ehrung für Koni zu dessen Dienstjubiläum 1915 wurde seine Darstellung von einem der Gratulanten offen angezweifelt. Im Nachhinein würden einem Knicke in der Karriereleiter eben oft weniger schlimm erscheinen als im Moment, wo man mit ihnen konfrontiert sei. ${ }^{338}$ Wenn hier also gewisse Glättungen in Konis

336 Koni: Svideteli na sude, S. 36-37.

337 Vgl. TEIL EINS.

338 M. P. Čubinskij: Anatolij Fëdorovič Koni. In: VE 10 (1915), S. 237. Konkret geht es hier um die Versetzung des Kriminalisten Konis an das Zivildepartement der St. Petersburger Gerichtskammer 1881. Dies, so interpretiert der Autor, müsse eine Strafe für den Freispruch von Vera Zasulič gewesen sein. Er führt weiter an, dass Koni selber nun zwar behaupte, dass ihm diese Aufgabe damals viel gebracht habe. Im Nachhinein - so sieht sich der Autor genötigt anzufügen - erscheine einem solches allerdings bekanntlich immer weniger schlimm. 
Lebensnarrativ angesprochen werden, so werden diese Widersprüche noch viel deutlicher, wenn man sich vor Augen hält, dass Koni im 20. Jahrhundert keineswegs getreu dem "Zasulič-Narrativ“ den völligen Rückzug von den Kreisen, die ihn zum nur noch ,geduldeten“ Richter gemacht hatten, antrat.

In seiner Erinnerung an die „Nacht Gethsemane“ deutete Koni schon an, dass Zar und Stolypin ihn für einen Posten in der zweiten Parlamentskammer vorgesehen hatten. In den „Grundgesetzen“ wurde das Gremium des Staatsrates, auch Reichsrat genannt, als obere Kammer der Duma institutionalisiert. Der Zar und gesellschaftliche Institutionen ernannten je die Hälfte der Mitglieder. ${ }^{339}$ Stolypin, so erinnert sich Koni, habe ihn im persönlichen Gespräch aufgefordert, doch wenigstens Staatsrat zu werden, wenn er schon nicht Justizminister sein wolle. Da habe er ihm geantwortet, dass er sich immer dazu verpflichtet fühle, ,mit allen seine Wissensbestände und Erfahrungen zu teilen", und das gelte insbesondere für diese schwierige Zeit. Aber seine Tätigkeit als Senator mache die Mitgliedschaft im Staatsrat nicht unbedingt nötig. ${ }^{340}$ Nur wenig später, im Januar 1907 ließ sich Koni aber trotzdem zum Beitritt überreden. In einem Brief an Graf Gejden beklagte er allerdings seine Berufung in das Gremium, das wenig sympathisch zusammengesetzt sei. Getreu dem „Zasulič-Narrativ“ verwies er darauf, dass er doch Jurist und Moralist, aber sicher kein Politiker sei. ${ }^{341}$ Dies hinderte ihn aber nicht daran, bis zur Auflösung des Gremiums im Zuge des Revolutionsjahres 1917 ein aktiver Parlamentarier zu sein. Immer noch unparteilich, schloss Koni sich mit einigen anderen Staatsräten ohne Parteizugehörigkeit zusammen. Obwohl inhaltlich keine Übereinstimmungen bestanden, war ihm so der Einsitz in Kommissionen möglich. Bei den Abstimmungen schlossen sich die Mitglieder dieser Gruppe jeweils den ihnen am naheliegendsten Positionen an. ${ }^{342}$ Koni schreibt im Herbst 1907 davon, dass er an einer Sitzung der „Gruppe Zentrum“ [Gruppa centra] teilnehme. ${ }^{343}$ Diese größte aller Fraktionen war allerdings sehr heterogen und konnte sich trotz der zahlenmäßigen Überlegenheit vor der „Gruppe der Rechten“ oftmals nicht durchsetzen. ${ }^{344}$ Später trat Koni dem „Progressiven Block“

339 Haumann: Geschichte Russlands, S. 304.

340 KonI: Moja gefsimanskaja noč. In: GA2, S. 371.

341 RO IRLI F. 134, op. 2, d. 9, 1. 176. 6ob, zitiert nach: Domanova: Perepiska A. F. Koni kak istoričeskij istočnik, S. 116.

342 Evgenija A. Jurtaeva: Gosudarstvennyj sovet v Rossii (1906-1917 gg.). Moskva 2001, S. 66-67. Jurtaeva verweist darauf, dass in dieser unparteilichen Gruppe „Kružok vnepartijnogo ob’edinenija“, die sich ab Dezember 1910 zusammentat, sehr unterschiedliche Personen vereint waren. So neben Koni auch adelige Reaktionäre. Die Gruppe umfasste nicht mehr als ein Dutzend Mitglieder und blieb so im Rat ohne Einfluss.

343 GA8, S. 248 (Brief an E. A. Liven vom 29.10.1907).

344 Jurtaeva: Gosudarstvennyj sovet v Rossii (1906-1917 gg.), S. 66. 
bei, der ab August 1915 alle oppositionellen Kräfte außerhalb der Sozialisten umfasste, die von der Regierung - gerade auch unter Eindruck der militärischen Niederlagen im Weltkrieg - eine personelle Erneuerung und verstärkte liberale Reformen forderten. ${ }^{345}$ Die Gestaltungsmöglichkeiten von Duma und Staatsrat waren eingeschränkt, nicht nur durch die entsprechende Wahlordnung und Ernennungspolitik, sondern auch weil der Zar mit den Entscheiden der beiden Parlamentskammern einverstanden sein musste und ein Teil der Gesetzgebung gerade nach Kriegsausbruch völlig am Parlament vorbei organisiert wurde. ${ }^{346}$ Doch Koni ließ sich nicht davon abhalten, im Staatsrat zu diversen Themen das Wort zu ergreifen: Von der rechtlichen Stellung der Frauen über das Problem des Alkoholismus bis zur Überarbeitung der lokalen Gerichtsinstanzen nahm er zu einer Vielzahl an Gesetzesprojekten Stellung. ${ }^{347}$ Seine Ansprachen veröffentlichte er zeitnah im zweiten Band von „Auf dem Lebensweg“. ${ }^{348}$

Fast kann man sagen, dass Koni sich dank des "Zasulič-Narrativs" gewisse Freiheiten „erschrieben“ hat. Es erlaubte ihm, seine Rolle als aktiver Analyst der gesellschaftlichen und politischen Entwicklungen im Russischen Reich, die er in der Rückschau auf sein Berufsleben nach der Jahrhundertwende so betont hatte, weiterhin in seinen Ämtern als Senator und Staatsrat auszufüllen, ohne dabei zu sehr durch die Nähe zur Macht kompromittiert zu werden.

\subsection{Politische Erinnerung an das Zarenreich in der Sowjetunion}

Nach dem Ende des Zarenreiches 1917 veränderte sich Konis Haltung zu Sinn und Zweck seiner Erinnerungen an Berufsleben, Zar und Politik grundlegend.

345 Haumann: Geschichte Russlands, S. 322. In einem Album in Konis Nachlass findet sich, allerdings mit der Jahreszahl 1911 versehen, diese Angabe zum „Progressiven Block“, vgl. IRLI F. 134, op. 4, d. 391. Vgl. zu diesem Album auch unten, S. 378.

346 JuRtaeva: Gosudarstvennyj sovet v Rossii (1906-1917 gg.), S. 83 ff, v. a. auch S. 96-97.

347 Vladimir N. SAšonko: A. F. Koni v Peterburge - Petrograde - Leningrade. Leningrad 1991, S. 224-25 mit einer Übersicht. Gerade die 1912 begonnene Eingliederung der bäuerlichen Rechtsprechung in den Volost'-Gerichten in die wieder gestärkten Friedensgerichte war ein von Koni und vielen Juristen schon Jahrzehnte gewünschtes Projekt, vgl. Konis Äußerung dazu in: Koni: Mirovye sud'i. In: ders. (Hrsg.): Otcy i deti sudebnoj reformy, S. 214-15. Er arbeitete denn auch in der entsprechenden Kommission im Staatsrat daran mit, vgl. Jurtaeva: Gosudarstvennyj sovet v Rossii (1906-1917 gg.), S. 28. Vgl. zu diesem Projekt Ju A. ŠEsTA Kov: Sudebnaja Reforma načala XX veka i frakcii III gosudarstevnnoj dumy. Šachty 2010, S. 4-5 und 58-59 sowie BA BERowski: Autokratie und Justiz, S. 780.

348 Vgl. zu den genannten Themen z. B. „Uravnenie nasledstvennych prav ženščin“, „Mestnyj sud“, „Popečitel'stva o narodnoj trezvosti“ alle in KonI (Hrsg.): Na žiznennom puti, Bd. 2. 
Als er zwischen 1904 und 1907 die Rückschau auf den Zasulič-Fall, den Unfall des Zarenzugs und seine Amtskollegen und Vorgesetzten am Kriminalkassationsdepartement neu verfasste oder vervollständigte und gleichzeitig die revolutionären Ereignisse in kurzen, zeitnahen autobiografischen Niederschriften festhielt, stand eine unmittelbare Publikation dieser Schriften nicht im Vordergrund. Keiner der Texte wurde in dieser Zeit veröffentlicht, und für Koni war völlig klar, dass diese Inhalte noch nicht „ans Licht“ konnten. Im frühen Sowjetrussland intensivierte Koni aber plötzlich seine Bemühungen um die Herausgabe zahlreicher dieser Erinnerungen. Einen starken Anlass hierfür spricht er in einem Brief aus dieser Zeit indirekt an:

In diesen Tagen habe ich [...] viel gelesen [...]. Was für eine Desorganisation, Zersetzung und Verwesung geht von der Zarenherrschaft unter Nikolaus II. aus! Was für einen Ekel ruft das Tagebuch von Kuropatkin hervor [...], von was für einem Geist der Denunziationen sind die Briefe von Pobedonoscev durchdrungen und wie schrecklich sind die Aussagen der Wache Rasputins über sein Betragen! Das ist alles aus dem „Roten Archiv“ und dem „Roten Neuland“. ${ }^{349}$

Die veröffentlichten Tagebücher, Briefe und Dokumente in den beiden literarischhistorischen Zeitschriften aus der Gründungszeit des sowjetischen Russlands konfrontierten Koni und mit ihm die gesamte lesende Öffentlichkeit mit bislang unbekannten Hintergründen zur politischen Führung im Zarenreich. ${ }^{350}$ Dabei

349 RGALI F. 1018, op. 1, d. 127, 1. 66-66ob. Zitiert nach: Domanova: Perepiska A. F. Koni kak istoričeskij istočnik, S. 128. Aleksej Nikolaevič Kuropatkin (1848-1925) war ein hoher russischer Militär, der in diverse Feldzüge Ende des 19. und Anfang des 20. Jahrhunderts involviert war. Für seine Führung im Russisch-Japanischen Krieg 1904/05 geriet er stark in Kritik, vgl. Anatolij P. ŠIKMAN: Kto est kto v rossijskoj istorii. Biobibliografičeskij slovar'. Moskva 2003, S. 317-18. Sein Tagebuch aus dieser Zeit erschien ab 1922 in mehreren Bänden.

Grigorij E. Rasputin (1871-1916) genoss als angeblicher „Wundertäter“ engste Verbindung zur letzten Zarin Alexandra Fjodorowna, da er die Heilung einer Blutkrankheit ihres Sohnes und Thronfolgers versprach. Höfische Intrigen spitzten sich zu, und während des Ersten Weltkriegs ging das Gerücht um, die Zarin, die deutscher Herkunft war, strebe unter dem Einfluss von Rasputin ein Arrangement mit dem Deutschen Reich an. Tatsächlich hat Rasputin versucht, politisch Einfluss zu nehmen und den Zaren in der Ernennung von Ministern anzuleiten. 1916 wurde Rasputin, der als „Schandfleck“ für die Monarchie angesehen wurde, von Konservativen ermordet, vgl. Haumann: Geschichte Russlands, S. 307 und 322.

350 Die wissenschaftliche Zeitschrift „Rotes Archiv“ [Krasnyj archiv] wurde in Moskau von den Archivorganen der RSFSR und der UdSSR herausgegeben und publizierte zwischen 1922 und 1941 Dokumente zur Geschichte Russlands. Die Zeitschrift „Rotes Neuland“ [Krasnaja nov'] erschien im gleichen Zeitraum. 
offenbarten solche nach dem Revolutionsjahr 1917 in großer Zahl veröffentlichte Dokumente ab und zu sogar unmittelbar auf Koni und seine Karriere bezogene Details. So enthalten beispielsweise die 1923 posthum veröffentlichten Briefe und Notizen Pobedonoscevs Aussagen über Konis Ernennung zum Oberstaatsanwalt 1885. In einem Brief vom 6. Februar erwähnt Pobedonoscev, dass er gegen diese Personalentscheidung protestiert habe, aber der Justizminister ihn beruhigt habe. Koni, dessen Ernennung den Zasulič-Fall wieder in Erinnerung rufe, könne als Oberstaatsanwalt schließlich problemlos beim ersten Ungeschick von seinem Platz entfernt werden. ${ }^{351}$ Fein säuberlich abgeschrieben findet sich diese Textstelle in Konis persönlichem Nachlass. ${ }^{352}$ Während er durch solche Veröffentlichungen neue Detailinformationen über die politischen Intrigen während seines Berufslebens bekam, spielte die Publikation dieser historischen Quellen auch im größeren Kontext eine wichtige Rolle. Mit der Veröffentlichung von Unterlagen aus der Zarenzeit ging eine öffentliche Neubeurteilung von Akteuren und Politikern des imperialen Russlands einher. Deren ideologischen Hintergrund tragen die beiden historischen Zeitschriften mit dem Adjektiv „rot“, das an die sozialistische Überzeugung der neuen Machthaber erinnert, schon im Titel. Auch die Herausgeber der Sammlung von Pobedonoscevs Dokumenten ließen keinen Zweifel daran, wie sie diese Schriftstücke interpretiert haben wollten. In einem Vorwort schrieb der wichtige bolschewistische Geschichtswissenschaftler Michail Nikolaevič Pokrovskij (1868-1932), dass man mit den neuen Erkenntnissen aus den Briefen und Notizen Pobedonoscevs gleich noch ein weiteres Buch schreiben könne, eines über Russland zur Zeit von Zar Alexander III. ${ }^{353}$ Ein beträchtlicher Teil seiner einleitenden Worte widmet Pokrovskij dem abgedruckten Austausch zwischen Pobedonoscev und Boris Čičerin und nutzt dies gekonnt für einen Angriff auf die liberale, nicht sozialistische Opposition im Zarenreich. So kommt er prominent zum Schluss, dass „Liberalismus“ und „Reaktion“ nur mit großer Naivität als Gegensätze verstanden werden könnten. Vielmehr zeige der Sammelband auf, wie eng die beiden beieinanderliegen würden. ${ }^{354}$

351 Pobedonoscev: K. P. Pobedonoscev i ego korrespondenty, Bd. 1, S. 496-97.

352 GARF F. 564, op. 1, d. 221, 1. 59.

353 Pobedonoscev: K. P. Pobedonoscev i ego korrespondenty, Bd. 1, S. V (Einleitung von M. N. Pokrovskij).

354 Ebd., S. XI. Konkret zeigt sich Pokrovskij entsetzt darüber, dass das bereits bekannte Schreiben Čičerins vom März 1881, kurz nach der Ermordung von Zar Alexander II., direkt an den Thronfolger gerichtet war und dass Pobedonoscev dabei als Mittler gedient hatte, vgl. ebd., S. VII. Ausführlich zitiert Pokrovskij die Abschnitte aus dem Schreiben, in denen es um den „Kampf gegen den Sozialismus“ geht, vgl. ebd., S. IX. Vgl. zu diesem Schreiben und Konis ähnlichem Vorhaben auch das Kapitel Memoiristische Rückschau auf ein Berufsleben unter autokratischer Herrschaft. 
Die Februar- und Oktoberrevolution führten 1917 in Russland zu völlig neuen politischen Verhältnissen. Die aus der letzten Duma hervorgegangene Provisorische Regierung übernahm nach der Abdankung von Zar Nikolaus II. im März die Führung des Landes. Angeführt von gemäßigt-liberalen Kräften verstand sie Russland als demokratische Republik und proklamierte bürgerliche Grundrechte und die Gleichberechtigung von Religionen und Nationen im ehemaligen Zarenreich. ${ }^{355}$ In einer Art „Doppelherrschaft“ stand sie neben dem mächtigen „Petrograder Sowjet“. Die Mitglieder dieses Arbeiter- und Soldatenrates waren die treibenden Kräfte hinter den massenhaften Unruhen und Streiks, die der zarischen Selbstherrschaft in den Wochen zuvor ein Ende bereitet hatten. ${ }^{356} \mathrm{Nach}$ wie vor ungelöste Probleme wie die prekäre Versorgungssituation, die Rechte der Arbeiter, der andauernde Weltkrieg und das Bedürfnis weiter Bevölkerungsteile nach unmittelbaren Reformen in den Bereichen Landbesitz und nationale Selbstbestimmung unterminierten aber die Autorität der Doppelherrschaft und insbesondere der Provisorischen Regierung schnell wieder. ${ }^{357}$ Vor allem in den Industriezentren wuchs im Frühjahr und Sommer 1917 die Anhängerschaft der kleinen, gut organisierten Partei der Bolschewiki, die sich in den Augen der Bevölkerung nicht wie viele andere linke Gruppierungen durch die Unterstützung der Übergangsregierung kompromittiert hatte. ${ }^{358}$ In der Nacht vom 24. auf den 25. Oktober besetzten Truppenteile und den Bolschewiki nahestehende bewaffnete Arbeitereinheiten schließlich die wichtigsten Gebäude in Petrograd und verhafteten die Mitglieder der Provisorischen Regierung. ${ }^{359}$ Wider verbreiteten Erwartungen gelang es der Partei, ihren Einfluss zu behaupten und nach gescheiterten Koalitionsverhandlungen mit anderen linken Gruppierungen schließlich als dominierende Kraft die Regierung zu übernehmen. Sofort nach der Machtübernahme der Bolschewiki wurden nicht nur alle politischen und verwaltungstechnischen Behörden und Gremien, sondern auch die gesamten gerichtlichen Strukturen aus der Zarenzeit und den wenigen Monaten unter der Provisorischen Regierung aufgelöst. ${ }^{360}$ Auch Koni wurde so seiner Ämter als Senator und Staats-

355 Kappeler: Russische Geschichte, S. 33-34.

356 Haumann: Geschichte Russlands, S. 325-27. Seit Mitte 1914 hieß St. Petersburg „Petrograd“. Nikolaus II. wollte mit diesem slavischer klingenden Namen jede Verbindung der Stadt zu Deutschland ablegen, mit dem man sich im Krieg befand, vgl. Solomon Volkov: St. Petersburg. A Cultural History. New York u. a. 2010. S. 337.

357 Kappeler: Russische Geschichte, S. 34 und Haumann: Geschichte Russlands, S. 328-30.

358 Haumann: Geschichte Russlands, S. 331.

359 Ebd., S. 334 und Kappeler, S. 34-35.

360 Robert Sharlet: Pashukanis and the Withering Away of Law in the USSR. In: Sheila Fitzpatrick (Hrsg.): Cultural Revolution in Russia 1928-1931. Bloomington Indiana 1978, S. 169. 
rat enthoben. Der neue Staat erhielt im Januar 1918 die Bezeichnung „Russische Sozialistische Föderative Sowjetrepublik“ (RSFSR) und erklärte sich zur „freien sozialistischen Gemeinschaft aller Werktätigen Russlands“. Direkte Rätedemokratie unter Ausschluss der im untergegangenen Zarenreich herrschenden Klassen war das erklärte Ziel. ${ }^{361}$

Die veränderte politische Ausrichtung des Landes führte zu einer intensiven Auseinandersetzung mit der Vergangenheit, die sich unter anderem in der Neuveröffentlichung unzähliger Tagebücher und Dokumente aus der Zarenzeit manifestierte. Wie die Worte des Historikers Pokrovskij schon angedeutet haben, wurden nun nicht nur die Vertrauten des Selbstherrschers, sondern auch die liberalen Intelligencija-Mitglieder kritisch beurteilt. Neben Persönlichkeiten wurden auch Berufsgruppen, wie zum Beispiel die Juristen, und politische Handlungen und Strategien der ehemaligen Regierungen unter den veränderten politischen und weltanschaulichen Vorzeichen neu bewertet. Diese ihn unmittelbar betreffenden Diskussionen verfolgte Koni intensiv. Er las und kopierte aber nicht nur die Trouvaillen an vorrevolutionären Quellentexten, die in „Rotes Neuland“, „Rotes Archiv“ oder den Bänden Pobedonoscevs zu finden waren. Für Koni kam die breit geführte Auseinandersetzung mit der Vergangenheit auch einem erstrangigen Schreibanlass gleich. So bemühte er sich in den 1920er-Jahren inständig, seine eigenen Erinnerungen an Eindrücke und Erlebnisse in den juristischen und politischen Institutionen im Zarenreich in die Diskussion einzubringen und dadurch seine Ansichten und Interpretationen dieser Zeit festzuhalten.

Neben den umfangreichen Erinnerungen an den Fall Vera Zasulič und an die Entgleisung des Zarenzugs wollte Koni nun auch das schon 1878 zuhanden des zukünftigen Zaren verfasste „Memorandum“, von dem er in „Triumvirn“ berichtet, in der Originalversion publizieren. Gut möglich, dass Koni auch die Erinnerung an die Anfrage zur Regierungsteilnahme in der „Nacht Gethsemane“ zu veröffentlichen versuchte. ${ }^{362}$ Daneben nahm er Ergänzungen an seinen bereits

361 Haumann: Geschichte Russlands, S. 334-38. Im Juli 1918 erhielt die RSFSR ihre erste Verfassung. Erst einige Jahre später, im Dezember 1922, erfolgte die Gründung der Sowjetunion. Dabei schloss sich Sowjetrussland mit Weissrussland, der Ukraine sowie Armenien, Georgien und Aserbaidschan formell zur „Union der Sozialistischen Sowjetrepubliken“ zusammen, vgl. Helmut Altrichter: Kleine Geschichte der Sowjetunion 1917-1991. München 1993, S. 37 und 55-56.

362 Auf die konkreten Vertragsentwürfe aus den frühen 1920er-Jahren wird im Verlauf des Kapitels eingegangen. Für „Nacht Gethsemane“ vgl. Fußnote 207 in TEIL ZWEI, wo die Vermutung aufgestellt wurde, dass Koni dieses Dokument in Druck geben wollte. Schlussendlich gelang von den erwähnten Texten lediglich die Publikation des „Memorandums“: Anatolij F. KonI: Iz vospominanij sudebnogo dejatelja. Zakon 19 maja 1871 g. In: DD 1 (1920), S. 175-88. 
publizierten Erinnerungstexten vor, so erweiterte er die Schrift über den „Boten Europas" und dessen Herausgeber Stasjulevič um ausführliche Erklärungen zu seinem 1881 anonym in der Zeitung „Ordnung“ veröffentlichten Artikel über die Ermordung von Alexander II. und seine Empfehlungen zur einzuschlagenden Richtung der zarischen Politik. ${ }^{363}$ In all diesen Texten - auch wenn schließlich in den meisten Fällen die Publikation trotz intensivster Bemühungen nicht gelang bezieht Koni besonders deutlich Stellung, was Einschätzung und Bewertung von justizbezogenen, politischen und gesellschaftlichen Entwicklungen im Russischen Reich in der zweiten Hälfte des 19. und zu Beginn des 20. Jahrhunderts anbelangt. Sein ausgeprägter Wille, diese Erinnerungen nun doch noch zu veröffentlichen, erscheint deshalb wie ein Versuch, im frühen Sowjetrussland mit der geballten Kraft seiner viele Hundert Seiten umfassenden Aufzeichnungen aus den letzten beiden Jahrzehnten vor dem Ende des Zarenreiches an den Beurteilungen und Analysen der vergangenen imperialen Politik teilzunehmen. Dabei rücken die Persönlichkeiten in den Vordergrund, die diese Politik gestaltet hatten und mit denen Koni im Verlauf seiner Karriere oftmals selber in Kontakt gekommen war. Nach der Oktoberrevolution begann Koni damit, über die Politiker aus der Zarenzeit eine große Zahl an Erinnerungsskizzen zu verfassen, in denen er seine Urteile über diese Menschen und ihre Haltungen mit denen abglich, die in genannten Zeitschriften und der öffentlichen Diskussion vorherrschten. Seine Bemühung um eine differenzierte Darstellung, die den Kontext der zarischen Autokratie als Handlungsrahmen dieser Politiker bei der Beurteilung ihrer Aktionen berücksichtigt, wird darin augenfällig. Schon im Juni 1917, also noch vor der Oktoberrevolution, schrieb Koni ein Porträt von Nikolaus II., in dem er auf gut zehn Seiten seine Eindrücke von Persönlichkeit und Regierungsführung des letzten Zaren und dessen Umfeld festhielt und sich dabei auch auf seine persönlichen Audienzen berief. ${ }^{364}$ Während dieser Text nie veröffentlicht wurde, findet sich zwei Jahre später in der Zeitschrift „Stimme der Vergangenheit“ [Golos Minuvščego] eine Erinnerungs-

363 Vgl. für die bibliografischen Angaben zu dieser Erinnerungsschrift S. 164 und den weiteren Verlauf des Kapitels.

364 Anatolij F. Koni: Nikolaj II. Vospominanie. In: GA2, S. 377-88. Ob Koni diese Erinnerungsschrift wirklich veröffentlichen wollte, ist ungeklärt. $\mathrm{Zu}$ seinen Lebzeiten blieb es bei der Manuskriptversion, vgl.: IRLI F. 134, op. 1, d. 138, auf die sich auch der in der Folge zitierte Abdruck in der Gesamtausgabe beruft. Dieses Porträt ist besonders interessant, weil es zu den wenigen Zeitzeugnissen gehört, die nach der Februar- aber noch vor der Oktoberrevolution verfasst wurden und somit die Ereignisse nicht im Wissen um die Machtübernahme durch die Bolschewiki beurteilt werden. Vgl. dazu auch die nach vielen Jahren der Suche nun veröffentlichten Interviews mit Akteuren der Februarrevolution, die im Frühsommer 1917 aufgezeichnet wurden: Semion Lyandres: The Fall of Tsarism. Untold Stories of the February 1917 Revolution. Oxford 2013. 
schrift Konis über seine Begegnungen mit dem konservativen Staatsmann und Gegner der Bauernbefreiung Pëtr Andreevič Šuvalov (1827-1889). ${ }^{365}$ Und wenig später publizierte Koni nach dem Ableben der beiden Juristen und Staatsräte Ivan Jakovlevič Golubev (1841-1918) und Sergej Sergeevič Manuchin (1856-1922) Erinnerungen von jeweils ungefähr zehn Seiten Umfang. ${ }^{366}$ Ausführlicher und bedeutender sind schließlich die zwischen 1922 und 1925 veröffentlichten Porträts der beiden Staatsmänner der obersten Führungsriege, des ehemaligen Innenministers Graf Michail Loris-Melikov und des ehemaligen Finanzministers Sergei Witte. In diesen mit autobiografischen Elementen gespickten Analysen der beiden Politiker wird Konis Strategie besonders deutlich, den Lesern im frühen Sowjetrussland die Handlungsbedingungen von Führungspersönlichkeiten aus dem Zarenreich zu erklären, mit deren Abwertung im aktuellen Diskurs er sich nicht vollständig einverstanden erklären konnte. Der Text über Loris-Melikov stellt insofern eine Ausnahme dar, als dass Koni die Erinnerungsschrift in einer früheren Fassung schon kurz vor dem Ende des Zarenreiches publiziert hatte. ${ }^{367}$ Über Politiker, die während seiner eigenen Zeit aktiv waren, hatte sich Koni ansonsten kaum öffentlich geäußert. ${ }^{368}$ Mit einem angepassten Vorwort versehen und um einige Episoden

365 Šuvalov war zeitweise Leiter der „Dritten Abteilung“ - der politischen Polizei - und wurde wegen seines starken Charakters gerne „Petr IV.“ genannt, vgl. Šikman: Kto est kto v rossijskoj istorii, S. 629. Konis Porträt bediente sich denn auch dieses Übernamens, vgl. Anatolij F. Koni: Žitejskie vstreči. Petr IV. In: GM 5-12 (1919), S. 163-70.

366 Anatolij F. Koni: Iz nedavnego prošlogo. Ivan Jakovlevič Golubev (1841-1918). In: Prošloe i nastojašče 1 (1924), S. 3-11 und ders.: S. S. Manuchin. In: PŽ Juli (1922), S. 84-9o. Das Porträt zu Manuchin zudem auch in „Auf dem Lebensweg“ V, vgl. zu diesem Band die nachfolgenden Ausführungen.

367 Anatolij F. Konı: Graf M. P. Loris-Melikov. Otryvočnye vospominanija. In: GM 1 (1914), S. 181-202. Den autobiografischen Bericht über seine Treffen mit Loris-Melikov konzipierte Koni bereits 1906 auf der Basis von Notizen aus den 1880er-Jahren, als er LorisMelikov bei Kuraufenthalten in Europa antraf. Koni publizierte dann den Text ein erstes Mal 1914. Kritische Aussagen zu Zar und Selbstherrschaft ließ er darin weg und nahm sie auch später nicht wieder in den Text auf, vgl. die Manuskriptversion in IRLI F. 134, op. 1, d. 52, Datierung auf 1. $460 \mathrm{ob}$.

368 Koni publizierte noch über den ehemaligen Kriegsminister Graf Dmitrij Alekseevič Miljutin (1816-1912). Dieses Erinnerungsporträt verfasste er aus Anlass des Todes von Miljutin. Es erschien zuerst in der Literaturbeilage zu „Saatfeld“ [Niva], vgl. Anatolij F. KonI: Žitejskie vstreči. Graf Dmitrij Alekseevič Miljutin († 25 janvarja 1912g). In: PkN 6 (1912), S. 287-314 und danach in „Auf dem Lebensweg“ II. Im Weiteren schrieb Koni ab und zu im Rahmen seiner Gerichtserinnerungen etc. Exkurse zu einzelnen Staatsmännern. Gewisse biografische Porträts von Berufskollegen enthalten ebenfalls politische Aspekte, so z. B. die Erinnerung an den Rechtsgelehrten Maksim Maksimovič Kovalevskij (1851-1916), der auch wie Koni im Staatsrat saß, Graf Gejden oder die beiden Justizminister D. N. Nabokov und D. N. Zamjatin, vgl. Angaben oben, S. 59. Das Porträt Kovalevskijs erschien auch in „Auf 
erweitert, brachte Koni die Erinnerung an den ehemaligen Innenminister nach der Oktoberrevolution erneut heraus. Dies im Rahmen von Band III seiner Sammelbände „Auf dem Lebensweg“, der 1922 erschien und dem bald noch ein vierter und ein fünfter Band sowie eine vierte Ausgabe des ersten Bandes nachfolgte. ${ }^{369}$ Indem Koni erläutert, wie der Reformator 1880 in der Bevölkerung den Glauben an die Fortsetzung der Reformen der 186oer-Jahre wiederaufleben ließ, konnte Koni auch seine eigenen Ansichten zu diesen Projekten nochmals aufrollen. ${ }^{370}$ Gleichzeitig

dem Lebensweg“" III, vgl. zu diesem Band die nachfolgenden Ausführungen. Vgl. auch den kurzen Nachruf über Golovnin (1821-1886), der in den 186oer-Jahren Volksbildungsminister war. Anatolij F. KonI: Aleksandr Vasil’evič Golovnin. In: RS 2 (1887), S. 788-89. Eine weiter Art Politikerporträts, die Koni verfasste, sind Auftragswerke für biografische Sammelbände oder Lexika. Dabei handelte es sich aber um Persönlichkeiten, die in der Mitte des 19. Jahrhunderts gewirkt hatten. So schrieb Koni historische Skizzen über die Akteure der Bauernbefreiung, wie z. B. die Großfürstin Elena Pavlovna (1806-1873), vgl. Anatolij F. Koni: Vel. kn. Elena Pavlovna. In: Glavnye dejateli osvoboždenija krest'jan. Sankt-Peterburg 1903, S. 11-23 sowie in diversen weiteren Lexika und Jubiläumspublikationen und in KoNI (Hrsg.): Očerki i vospominanija; sowie in „Auf dem Lebensweg“ IV, vgl. zu diesem Band die nachfolgenden Ausführungen. Auf diese wissenschaftlich-historische Seite von Konis Porträtierungen wird auf S. 292 eingegangen.

369 Anatolij F. Konı: Graf M. T. Loris-Melikov. In: ders. (Hrsg.): Na žiznennom puti, Bd. 3. Vospominanija, žitejskie dramy, žitejskie vstreči, pamjati ušedšich, kritičeskie očerki. Revel', Berlin 1922, S. 3-40. In der Folge wird die darauf beruhende Version aus der Gesamtausgabe zitiert. Band III und IV von „Auf dem Lebensweg“ erschienen im Verlag Bibliofil, der im Ausland angesiedelt war, vgl. ders. (Hrsg.): Na žiznennom puti, Bd. 3. Vospominanija, žitejskie dramy, žitejskie vstreči, pamjati ušedšich, kritičeskie očerki. Revel', Berlin 1922 bzw. ders. (Hrsg.): Na žiznennom puti, Bd. 4. Publičnye čtenija i reči. Revel', Berlin 1923. Posthum zudem: ders. (Hrsg.): Na žiznennom puti, Bd. 5. Leningrad 1929. Im Vertrag mit dem Verlag Bibliofil heißt es, dass dieser das Recht habe, Band I und II von „Auf dem Lebensweg“ in ergänzter Form neu aufzulegen, vgl. IRLI F. 134, op. 4, d. 89, l. 1. Für den ersten Band gelang dies auch tatsächlich, vgl. Anatolij F. KonI (Hrsg.): Na žiznennom puti, Bd. 1. Iz zapisok sudebnogo dejatelja. Revel', Berlin 192(2/4?) (4., überarbeitete Auflage). Die erneute Herausgabe des zweiten Bandes kam aber nicht zustande. In die neuen Bände integrierte Koni einerseits - wie im Fall der Skizze über Loris-Melikov - vieles von dem, was er in den Jahren seit dem Erscheinen der beiden ersten Bände noch verfasst hatte. Andererseits und mehrheitlich druckte er darin aber zahlreiche Literatenporträts nochmals ab, vgl. dazu, auch zum Verlag Bibliofil, TEIL DREI.

370 Loris-Melikov war ein General und Kriegsheld aus dem Russisch-Osmanischen Krieg von $1877 / 78$. Er wurde 1880 an die Spitze der Höchsten Exekutivkommission gestellt und wenig später Innenminister. Er sollte die Gewalttaten durch Revolutionäre, die soeben mit einer Explosion im Winterpalast einen erneuten Coup gelandet hatten, mit konzentrierter Macht bekämpfen. Loris-Melikov wollte dabei nicht mehr nur repressive Maßnahmen anwenden, sondern auch Konzessionen an die moderaten Kräfte machen. Presse und Selbstverwaltungsorgane wurden gestärkt und Loris-Melikov hatte gar vor, Kommissionen einzurichten, in denen auch gewählte Exponenten aus den Landschaften und den großen 
beschreibt er anhand von zufälligen persönlichen Begegnungen in europäischen Kurorten in den die Absetzung Melikovs nachfolgenden Jahren die ihm sympathischen persönlichen Seiten des Mannes, der zu Unrecht oftmals als „listiger und verschlagener Höfling “ charakterisiert werde ${ }^{371}$ Konis Erinnerungsporträt vom Eisenbahnbeauftragten, Minister und schließlich Staatsrat Witte gleicht im Aufbau der Skizze über Loris-Melikov. Bereits um die Jahrhundertwende hatte Koni eine erste Version dieses Textes entworfen ${ }^{372}$ In der Endfassung weist er fast 40 Seiten auf und besteht aus einer Aneinanderreihung von Konis Treffen mit Witte zwischen 1876 und dessen Tod $1915 .{ }^{373}$ Auch hier greift Koni Themen auf, die ihm selber wichtig waren, wie die Untersuchungen zur Entgleisung des Zarenzuges, in deren Rahmen Koni Witte als Zeugen befragen musste. Die Beschreibung von Wittes politischen Visionen und die Ungnade, in die der Minister nach der Revolution von 1905 und dem von ihm ausgearbeiteten Oktobermanifest fiel, erlauben ihm schließlich eine eigene Bewertung dieser Entwicklungen und eine Einordnung Wittes in die Politikerriege seiner Zeit.

Gegen die Mitte der 1920er-Jahre hin schien Koni den Entschluss zu fassen, dass er noch zu einer ganzen Reihe an weiteren hohen Politikern des Zarenreichs seine Erinnerungen festschreiben wollte. Ein von 1924 datierendes entsprechendes Heft in Konis Nachlass enthält Stichworte für diverse geplante Skizzen über ehemalige zarische Minister, Senatoren und Staatsräte, die er im Verlauf seiner langjährigen Tätigkeit in Gerichtsbehörden und im Parlament kennengelernt hatte. ${ }^{374}$ Darunter sind Notizen zum Vorsitzenden des Staatsrates Anatolij Nikolaevič Ku-

Städten teilnehmen sollten und die Empfehlungen für die Regierung ausarbeiten sollten. Diese Kommissionen hätten als Schritt hin zu einem echten Parlament dienen können, doch im Frühling 1881, kurz nach der Ermordung von Zar Alexander II., wurde LorisMelikov entlassen und seine Projekte hinfällig, vgl. Polunov: Russia in the Nineteenth Century, S. 152-55.

371 Anatolij F. Koni: Graf M. T. Loris-Melikov. In: GA5, S. 190.

372 GARF F. 564, op. 1, d. 203, 1. 98-120ob. Dieser Entwurf steht in Zusammenhang mit Konis Erinnerungsschrift an die Entgleisung des Zarenzugs, vgl. dazu Fußnote 25 in TEIL ZWEI.

373 Koni: Sergej Jul'evič Vitte. Otryvočnye vospominanija. Moskva 1925. Zudem Anatolij F. Koni: S. Ju. Vitte. Otryvočnye vospominanija. In: ders. (Hrsg.): Na žiznennom puti, Bd. 5. Leningrad 1929, S. 245-90. Für den Abdruck in seinem Sammelband verfasste Koni einen zusätzlichen Abschnitt zu einem Brief Wittes vom Oktober 1914 an den Präsidenten der Akademie der Wissenschaften, in dem er sich zum Ersten Weltkrieg äußerte, vgl. ebd., S. 287-88. Die in der Folge zitierte Version aus der Gesamtausgabe beruft sich auf diesen Abdruck, vgl. genauer dazu GA5, S. 464 (Anmerkungen).

374 IRLI F. 134, op. 1, d. 147. Datierung auf 1. 2. Neben den Politikern hat Koni in diesem Heft auch zum Anwalt Aleksandr Jakovlevič Passover (geb. 1840), der bereits 1910 gestorben war, sowie zum 1906 verstorbenen Arzt Veniamin Michajlovič Tarnovskij (geb. 1837) Stichworte aufnotiert, vgl. ebd., 1. 2-3ob. 
lomzin (1838-1923), zum Ministerialbeamten und Staatsrat Aleksandr Alekseevič Naryškin (1839-1916), zum Innenminister Vjačeslav Konstantinovič fon Pleve (1846-1904) sowie zu N. V. Murav’ev und Graf Pahlen. ${ }^{375}$ Unter dem Titel „Obere Parlamentskammer" hat Koni in diesem Heft zudem für eine Gesamtdarstellung seiner Erlebnisse in Senat und Staatsrat Halbsätze aufnotiert sowie eine detaillierte Auflistung zu den politischen Gruppierungen und ihren Mitgliedern entworfen. ${ }^{376}$ Wie schon in den Porträts von Nikolaus II., Witte oder Loris-Melikov erwähnt Koni in den Einzelporträts jeweils den historischen und biografischen Kontext der Skizzierten, schätzt ihre politische Ansichten ebenso wie ihre Haltung zu diversen gesellschaftlichen Fragen ein und erwähnt seine persönlichen Zusammentreffen mit diesen politischen Akteuren. Auch wenn die Stichworte oftmals nur ganz knapp sind, wie zum Beispiel zu Pleve „Warschau und politische Angelegenheiten", kann man das Narrativ doch einigermaßen nachverfolgen. Immer wieder lässt Koni keine Zweifel an seiner eigenen politischen Positionierung im Verhältnis zu den Porträtierten. So lautet ein Stichwort zu Naryškin „bösartige Rede über die Juden, durchdrungen von persönlicher Wut" oder zu Pleve: „strategische Bescheidenheit wie beim Mistkerl Murav'ev“. ${ }^{377}$ Dass Koni diese Skripts für eine geplante Veröffentlichung konzipierte, zeigt sich an entsprechenden Verträgen. Die schriftlichen Abmachungen mit Verlagen nennen sogar noch weitere geplante Erinnerungsporträts von Koni zu Stolypin, Pobedonoscev und dem konservativen ehemaligen Minister für Volksbildung Graf Ivan Davydovič Deljanov (1818-1897). ${ }^{378}$

Wenn Koni in der frühen Sowjetunion den Entscheid fällte, eine so große Zahl an Politikerporträts zu verfassen und die Memoiren zu seinem Werdegang in den Justizbehörden zu veröffentlichen, dann reagierte er damit direkt auf die großangelegten Diskussionen in der Gesellschaft rund um die umfassende Neuorientierung bezüglich der zarischen Vergangenheit. In seinen politischen Erinnerungsschriften nahm er über die Einschätzung seiner Porträtobjekte unmittelbar Stellung und warb öffentlich für seine Interpretation - die nicht zuletzt auch seine eigene Karriere im Zarenreich rechtfertigen sollte. Indem er mit bisher

$375 \mathrm{Zu}$ einem Teil dieser Personen hatte Koni bereits um 1900 Notizen für Erinnerungsschriften angelegt. Vgl. zu Pleve Konis Stichworte von 1907 in GARF F. 564, op. 1, d. 220, 1. 24-24ob. Zu Murav'ev neben „Triumvirn“ auch die Stichworte und den Fließtext datiert von 1907 , vgl. oben, S. 215.

376 IRLI F. 134, op. 1, d. 147, 1. 8 ff.

377 Ebd., 1. 4.

378 Vgl. insbesondere den Vertrag mit dem Verlag Vremja von 1923 über ein Buch mit Ministerskizzen (Pleve, Stolypin, Pobedonoscev, Witte, Murav'ev, Loris-Melikov und Deljanov): GARF F. 134, op. 4, d. 89., 1. 4. Eventuell war als Grundlage hiervon die Schrift „Triumvirn“ gemeint, in der sowohl Pobedonoscev als auch Murav'ev ausführlich vorkommen. 
ungekannter Intensität versuchte, seine persönlichen politischen Analysen und Urteile über die maßgeblichen Akteure der Zarenzeit an ein Publikum zu vermitteln, knüpfte er ein Stück weit an die in seinen autobiografischen Schriften immer wieder präsente Selbstdarstellung des stets politisch und in großen Zusammenhängen denkenden Menschen an, der immer auch andere von seinen Erkenntnissen zu überzeugen versuchte. Neben den politischen Erinnerungen versuchte Koni deshalb auch eine ganze Reihe an Arbeiten aus dem juristischen Umfeld in der Sowjetunion nochmals zu publizieren - darunter Fachtexte wie seinen Vortrag von 1904 zum Umgang mit unzuverlässigen Zeugenaussagen in Gerichtsprozessen oder seine „Erinnerungen eines Gerichtstätigen“. Er ließ es sich auch nicht nehmen, Nachrufe und Porträts auf einige Juristenkollegen zu verfassen, die in diesen Jahren verstarben. ${ }^{379}$ Die Art und Weise, wie und woran Koni sich nun öffentlichkeitswirksam erinnern wollte, gibt dabei nicht nur Aufschluss über seinen persönlichen Umgang mit dem Revolutionsjahr 1917 und den nachfolgenden Entwicklungen. Gerade die Gründe dafür, dass Koni die angestrebten Veröffentlichungen nur sehr unvollständig gelangen, zeigen zusammen mit den öffentlichen Reaktionen auf die erfolgten Publikationen auch die Komplexität der Kommunikationssituation auf, die sich Koni und seinen Zeitgenossen in den frühen 1920er-Jahren präsentierte.

\subsubsection{Plädoyer für die Berücksichtigung der „Bedingungen von Ort und Zeit“}

„Vor dem Krieg hat der Untergang der ,Titanic ‘ aufgrund der Vielzahl der Opfer allgemeines Entsetzen hervorgerufen [...] aber dann, während des Krieges, wuchsen uns seelische Schwielen [...]. “380 Als Koni 1922 wohl zum ersten Mal mit einem Verlag darüber diskutierte, ein Buch mit dem Titel „Erinnerungen an den Prozess von Vera Zasulič“ herauszugeben, fühlte er sich genötigt, seiner Erinnerungsschrift ein neues Vorwort hinzuzufügen. ${ }^{381}$ Auf fast drei Seiten erläutert er die Entstehungsgeschichte des Textes und versucht seinen Lesern klarzu-

379 Vgl. Fußnote 145 in TEIL EINS für Konis vielbeachteten Vortrag zu den „Zeugen vor Gericht" und GA4, S. 490-93 (Anmerkungen) zur Publikationsgeschichte dieses Auftritts. In Sowjetrussland erschien er als: Anatolij F. KonI: Pamjat' i vnimanie. Iz vospominanij sudebnogo dejatelja. Petrograd 1922. In der Folge wird der darauf basierende Abdruck in der Gesamtausgabe zitiert. Vgl. im weiteren Verlauf des Kapitels einige zusätzliche Angaben zu veröffentlichten juristischen Fachtexten und Nachrufen auf Kollegen aus dieser Zeit. Koni konnte in der 4. Auflage des ersten Bandes von „Auf dem Lebensweg“ nochmals die gesamte Reihe „Aus den Erinnerungen eines Gerichtstätigen“ herausgeben.

380 KonI: Vospominanija o dele Very Zasulič. In: GA2, S. 25.

381 Vgl. für den Vertrag mit dem Verlag Poljarnaja zvezda, GARF F. 564, op. 1, d. 245, 10. Dokument. Im maschinengeschriebenen Vertragsentwurf vom 30. April 1922 ist der Ab- 
machen, dass Umstände und Erfahrungen einen großen Einfluss auf Haltungen, Einschätzungen und Taten eines Menschen haben. Am Beispiel des Untergangs der „Titanic" sollte klar werden, dass Opferzahlen genauso relativ sein können wie die Taten vergangener Regime. So erscheine Zar Peter der Große (1672-1725) vom heutigen Standpunkt aus gesehen als brutaler Mensch, doch in seiner Epoche sei dieses Verhalten nichts Außergewöhnliches gewesen. Wer die ZasuličErinnerungen lese, müsse deshalb den Blickwinkel der damaligen Zeit einnehmen und die Ansichten der vergangenen Epoche verstehen. ${ }^{382}$ Dieses Plädoyer für die Berücksichtigung der zeitgenössischen Gegebenheiten ergänzte Koni im Vorwort um damit zusammenhängende grundlegende Gedanken zum Individuum und der Beurteilung seiner Taten.

Ganze Lebensjahrzehnte gewisser Zeitgenossen sind vor den Augen vorbeigegangen, aber nur in der Gesamtheit zeichnen Morgen, Mittag und Abend ihrer Leben ein korrektes Bild [vernyj obraz] eines jeden von ihnen. ${ }^{383}$

Er selber, so betont Koni, könne dieses „korrekte Bild“ besonders gut erfassen, da sich sein Horizont im hohen Alter "verbreitert" habe und er auch das sehe, was bisher „im Schatten“ verblieben sei. ${ }^{384}$ Fast identisch klingen die einleitenden Worte für das Porträt von Loris-Melikov:

Ich teile den von irgendeinem der großen Schriftsteller ausgesprochenen Gedanken darüber, dass die wahre Gestalt eines Menschen [nastojaščij obraz čeloveka], ähnlich wie die Sonne beim Auf- und Untergang, mit besonderer Klarheit zu Beginn und am Ende seiner Tätigkeit sichtbar wird. ${ }^{385}$

An andere Biografen richtete er den Vorwurf des „fehlenden Verständnisses der Bedingungen von Ort und Zeit“. Diese fehlende Einordnung in den historischen Kontext müsse bei den meisten Skizzen über Loris-Melikov bemängelt werden. ${ }^{386}$ Auch für seine 1925 publizierten Erinnerungen an den ehemaligen Minister Sergei Witte schrieb Koni eine ähnliche Einleitung. Die ersten beiden Seiten bilden eine Art theoretische Auseinandersetzung mit der Frage, welche Quellen am zuver-

schnitt zur Zasulič-Erinnerung von Hand durchgestrichen worden, offensichtlich wurde das Projekt also aufgegeben.

382 Koni: Vospominanija o dele Very Zasulič. In: GA2, S. 24-25.

383 Ebd., S. 24.

384 Ebd.

385 Koni: Graf M. T. Loris-Melikov. In: GA5, S. 185.

386 Ebd., S. 184. 
lässigsten die Beurteilung eines Menschen erlaubten. So warnt Koni davor, sich zu sehr auf Memoiren der entsprechenden Person zu verlassen, in die sich möglicherweise "phantastische Lügen“ [mečtatel'naja lož] eingeschlichen hätten. ${ }^{387}$ Aber auch zu persönliche Erinnerungen von Verwandten und Freunden oder aber reine Geschäftsnotizen und Publikationen der entsprechenden Person hätten ihre Schwächen. Umso wichtiger seien deshalb die Erinnerungen von Drittpersonen, die als „objektive Beobachter“ fungieren könnten. ${ }^{388}$

Indem Koni sich selber auf diese Art und Weise anpries, versuchte er das $\mathrm{Pu}$ blikum von der Neutralität seiner Position zu überzeugen. So konnte er einerseits allfällige Zweifel an seiner analytischen Stärke und Glaubwürdigkeit ausräumen. Andererseits schuf er implizit ein Alleinstellungsmerkmal, das die Lektüre seiner Erinnerungen so lesenswert zu machen versprach. Mit seinen über 70 Jahren konnte er im Gegensatz zu manchen anderen Publizisten guten Gewissens behaupten, tatsächlich „Morgen, Mittag und Abend“ im Leben der porträtierten Persönlichkeiten gesehen zu haben. Das wichtigste Element in seinen Begleitworten war aber der Verweis auf die verschiedenen Blickwinkel, die die Leser angesichts der sich stetig wandelnden Zeiten einnehmen sollten. Indem Koni explizit darauf hinwies, dass sich die Erinnerten nur im Kontext der Zeit verstehen ließen und Beurteilungen diese Gegebenheiten entsprechend zu berücksichtigen hatten, versuchte er die Leser den nachfolgend beschriebenen Ereignissen und Akteuren gewogen zu stimmen. Es scheint, als wollte er ihnen eine unmissverständliche Leseanweisung mitgeben, um eine Urteilsbildung in seinem Sinne zu befördern.

Koni orientierte sich beim Verweis auf die Relativität aller Handlung an der seit dem 19. Jahrhundert verbreiteten Selbstkonzeption, bei der die eigene Einzigartigkeit als Produkt einer persönlichen Entwicklung in Wechselwirkung mit den äußeren Umständen verstanden wurde. Der damalige Boom an autobiografischem (und biografischem) Schreiben hing unmittelbar mit dieser Überzeugung zusammen. Weil davon ausgegangen wurde, dass man selber oder das beschriebene Subjekt ein anderer wäre, wäre er zehn Jahre früher oder später geboren, erschien die Auseinandersetzung mit der Schnittstelle von sich und Außenwelt besonders spannend. Zachary Schiffman stellt diese Vorstellung in seiner Monografie „The Birth of the Past" einer früheren gegenüber, bei der man sich den Menschen mit einer spezifischen „Natur" vorstellte, die nicht prozessual angelegt war. Die frühneuzeitliche moderne Philologie und die Altertumswissenschaften beförderten schließlich im 18. und 19. Jahrhundert das historische Schreiben, mit dem

387 Koni: Sergej Jul'evič Vitte. In: GA5, S. 238. Hier spielt wieder Konis fachliche Auseinandersetzung mit der Zuverlässigkeit von Zeugenaussagen vor Gericht mit hinein.

388 Ebd., S. 239. 
"die Geschichte" erfasst wurde. Eine noch zentralere Rolle spielte laut Schiffman die Aufklärungshistoriografie, in der Kontextualisierung von großer Bedeutung war. ${ }^{389}$ Gleichzeitig stieg das Bewusstsein dafür, dass sich historische Subjekte „nur als dem Wandel unterworfene Subjekte“ denken ließen. (Auto-)Biografien präsentierten deshalb lediglich „verzeitlichte Identitätsentwürfe“. ${ }^{390}$ Als „fragil“ und „flüchtig" begriffen, ließen sich diese nur mehr retrospektiv konstruieren und erzählen. ${ }^{391}$ Der Einfluss späterer Erfahrungen, neuer Überzeugungen oder externer Entwicklungen auf den Erinnerungsvorgang zählen heute zu den zentralen Erkenntnissen der Neuropsychologie und der Erinnerungsforschung. ${ }^{392}$ Vieles in Konis Überlegungen zu Individuum und Erinnerung, Autobiografik und Biografik scheint sich darin zu spiegeln. Folgerichtig lehnte er schon 1913 ein Angebot ab, über sich selber eine Biografie verfassen zu lassen. In einem Brief erklärte er, dass man „richtig und vollumfänglich“ nur dann über einen Menschen richten könne, wenn dieser endgültig von der „Lebensbühne“ gegangen sei und nichts Unerwartetes mehr das Bild des Biografen verändern könne. ${ }^{393}$ Zudem sei es wünschenswert, „unter Einhaltung der historischen Perspektive“ zu schreiben und genügend Abstand vom Leben dessen, den man porträtiere, zu haben ${ }^{394}$ Koni wollte bei sich und anderen also darauf warten, bis nach dem persönlichen „Sonnenuntergang" das Menschenleben in seiner Gesamtheit vor dem zeitgenössischen historischen Hintergrund endgültig beurteilt werden konnte. Dass er in seinen eigenen Porträts allerdings auch dann noch eine Darstellung davon präsentierte, was ihm zum Schreibzeitpunkt relevant erschien, wäre der nächste Schritt in der Fortsetzung dieser Überlegungen.

Das für Koni „korrekte Bild“, das die „Bedingungen von Ort und Zeit“ berücksichtigte, erschien ihm mit der ideologischen Neubeurteilung des Zarenreichs nach Februar- und Oktoberrevolution bedrohter denn je. In den 1920er-Jahren wurde von der sowjetischen Propaganda ein ausnahmslos düsteres Bild von der autokratischen Vergangenheit des Landes gezeichnet. Einzig Unterdrückung, Ausbeutung und Brutalität prägten in dieser Optik das Leben der von Armut gebeutelten Bevölkerung im imperialen Russland. ${ }^{395}$ Diese Sichtweise entbehrte all der relativierenden Aspekte, die Koni mit seinem Titanic-Vergleich zu betonen

389 Zachary Schiffman: The Birth of the Past. Baltimore 2011, S. 271-72 und 274-75.

39o Depкat: Nicht die Materialien sind das Problem, sondern die Fragen, die man stellt, S. 112.

391 Ebd., S. 113.

392 Haumann: Geschichte, Lebenswelt, Sinn, S. 85 und insb. Fußnote 4.

393 GA8, S. 279 (Brief an Anna Iosifovna Čičagova vom 29. 08.1913).

394 Ebd.

395 Herman Ermolaev: Censorship in Soviet Literature, 1917-1991. Lanham u. a. 1997, S. 36-37. 
versuchte. „Falsch“ - ruft er in seiner Darstellung von Nikolaus II. aus - sei ein Großteil der nun präsentierten Einschätzungen über den letzten Zaren. ${ }^{396}$ Nur noch auf Schwächen und Fehler - so klagt er bitterlich in einem Brief vom Juli 1922 - seien heutige Personenporträts ausgerichtet. Er aber habe immer über das tief Menschliche schreiben wollen. ${ }^{397}$

Konis Überlegungen zu Erinnerung und Biografik und seine Leseanweisungen und Kritiken an der Darstellung anderer lassen den inhaltlichen Tenor seiner Porträts und Schriften, die er in der frühen Sowjetunion mit Nachdruck zu veröffentlichen versuchte, bereits erahnen. Indem er auf wohlwollende Ausgewogenheit pochte und gleichzeitig die Skizzierten als Menschen ihrer Zeit verstanden haben wollte, konnte er an einem Großteil seiner Interpretationen von Akteuren, Politik und Gesellschaft der Zarenzeit festhalten. Relativierende oder differenzierende Aspekte sind denn auch typische Elemente in Konis Porträts ehemaliger Minister und hoher Staatsbeamter.

Ausführlich beurteilt er beispielsweise Wittes Handlungen in verschiedenen Feldern. Er attestiert ihm große Leistungen im Bereich der Industrialisierung, verweist auf die Eisenbahn oder die Einrichtung von technischen Hochschulen. ${ }^{398}$ Gleichzeitig beschreibt er Wittes konservative politische Haltung. Dessen Idealvorstellung von einer selbstherrlichen Regierung, die auf der Basis einer fähigen Bürokratie agierte, seien für ihn sogar mit den Projekten von Graf Loris-Melikov oder der Stärkung der Zemstva unvereinbar gewesen. ${ }^{399}$ Auch nach dem von Witte geprägten Oktobermanifest, auf das er „mit gerechtem Stolz“ verweisen konnte, habe er sich noch bemüht, die Macht des Monarchen möglichst groß zu halten. Er habe sogar die Unabsetzbarkeit der Richter als Gefahr bezeichnet. ${ }^{400}$ Koni bemängelt, dass Witte es verpasst habe, , anständige Leute“ [porjadočnye ljudi] auf seine Seite zu ziehen und sich gegenüber dem Innenminister Pleve, der „schamlos und verantwortungslos" gehandelt habe, in eine würdige Position zu bringen. ${ }^{401}$ Diese auf Abwägen bedachte Analyse wird begleitet vom konstanten Vergleich Wittes mit seiner Umgebung. So sei der Politiker in seiner Zeit gemessen an seinem „Horizont“ der einzige wirkliche Staatsmann ,in einer fruchtlosen und

396 Koni: Nikolaj II. In: GA2, S. 377.a

397 GA8, S. 314 (Brief an Aleksandr I. Sadov vom 25. 07.1922). Vgl. zu Sadov unten, S. 275. Ähnliche Klagen finden sich auch in Konis Einleitung zur Skizze über Witte. Dort regt er sich darüber auf, dass viele Porträts zu sehr auf die „persönlichen Seiten“ [intimnye storony] der Beschriebenen fokussieren würden, vgl. Koni: Sergej Jul'evič Vitte. In: GA5, S. 239.

398 KonI: Sergej Jul'evič Vitte. In: GA5, S. 255.

399 Ebd., S. 253.

400 Ebd., S. 256-57.

401 Ebd., S. 255-56. 
verhängnisvollen Regierungsepoche“ [v bescvetnoe i rokovoe carstvovanie] gewesen. ${ }^{402}$ Als er schließlich im Verlauf der ersten Russischen Revolution endgültig in Ungnade fiel, habe Ivan Logginovič Goremykin (1839-1917) 1906 an Wittes Stelle die erste Duma eröffnet, „ein Politiker von sehr viel kleinerem Kaliber““403

Trotz deutlicher Unterschiede in der politischen und weltanschaulichen Überzeugung und zahlreicher Kritikpunkte, die Koni anbringt, steht er dem Format der Persönlichkeit Wittes und seinen Leistungen angesichts der damaligen Situation mit einem gewissen Respekt gegenüber. Aufgrund der inhaltlichen Differenzen noch augenfälliger ist diese Haltung in Konis Einschätzung von Pobedonoscev, zu dem Koni in der Mitte der 1920er-Jahre zwar eine Publikation geplant, aber nicht mehr realisiert hatte. In der Beurteilung des mächtigen Mannes, die Koni in „Triumvirn“ schon 1907 entworfen hatte, kommt er nach Dutzenden von Seiten Kritik an der Kirchenpolitik Pobedonoscevs in versöhnlichen Worten auf dessen Tod zu sprechen. Er verweist auf die Tragik von Pobedonoscevs letzten Jahren nach der Jahrhundertwende, als so viele ihn hassten und er wohl nicht habe übersehen können, dass er mit seiner Haltung nichts erreicht habe. Vielleicht sogar, so vermutet Koni, habe er nicht ohne inneren Kampf gegen die „Stimme seines sukzessive austrocknenden Herzens" [golos postepenno issušaemogo serdca] eine solche Verhinderungsposition eingenommen. Schließlich endet er mit dem Statement, dass jedem, der Pobedonoscev nicht nur oberflächlich gekannt habe, bewusst gewesen sei, dass ihn eine ,innige Liebe“ zu seinem Land ausgezeichnet habe. Schon zu Beginn der Erinnerungsschrift zollt Koni ihm Respekt für seine Tätigkeit als Rechtsgelehrter und Analyst der Regierungspolitik in seinen frühen Jahren. ${ }^{404}$ Auch in den Zasulič-Erinnerungen versuchte Koni, wichtige Akteure in Relation und unter Berücksichtigung ihrer verschiedenen Seiten darzustellen. So schreibt er beispielsweise im neuen Vorwort für das sowjetische Publikum, dass gerade die Figur von Graf Pahlen (1833-1912) von ihm ganz anders beurteilt worden wäre, wenn er die Erinnerung zu einem anderen Zeitpunkt verfasst hätte. ${ }^{405}$ Tatsächlich taucht dieser im Text nicht nur als Justizminister auf, der Koni 1878 zum Rücktritt drängte. Vielmehr zeichnete Koni auch seinen weiteren Karriereverlauf nach. Und weil er selber im Nachzug zum Zasulič-Fall noch so viele ,jämmerliche und eigennützige“ Leute getroffen habe, habe er begonnen, „die guten Seiten seines Charakters" stärker zu gewichten. Pahlen habe in späteren Jahren gar „Pflichtgefühl der heimatlichen Justiz“ gegenüber gezeigt. Er habe ihm, so

\footnotetext{
402 Ebd., S. 255.

403 Ebd., S. 258.

404 Koni: Triumviry. In: GA2, S. 309-11 sowie $253 \mathrm{ff}$.

405 KonI: Vospominanija o dele Very Zasulič. In: GA2, S. 24.
} 
schreibt Koni gegen Ende der Schrift, deshalb schon lange verziehen. ${ }^{406}$ In einem Brief von 1924 führte Koni an, dass er die Erinnerungen an den Fall Vera Zasulič nicht in Druck geben könne, solange er nicht schon in der Einführung Stellung zu Graf Pahlen genommen habe. ${ }^{407}$ Sogar Katkov, der die Presse und ihre Attacken gegen Koni und den Freispruch der Revolutionärin angeführt hatte, wollte Koni "Gerechtigkeit" widerfahren lassen und in seiner Bewertung auch das "Gute in seiner Tätigkeit“ berücksichtigen ${ }^{408}$ Selbst eine Persönlichkeit vom rechten Rand wie Aleksandr Alekseevič Naryškin (1839-1916), der seit 1906 im Staatsrat saß und parallel dazu eine wichtige Figur in monarchistischen Organisationen war, stellte Koni differenziert dar. ${ }^{409}$ So verwies er in den Stichworten, die er 1924 anlegte, neben antisemitischen Ausfällen auch auf dessen liberalere Anfänge und auf sein Einsehen politischer Fehler zum Lebensende. ${ }^{410}$

Neben differenzierenden und relativierenden Aspekten ist Konis Darstellung der Politiker aus der Zarenzeit auch vom expliziten Einbringen seiner eigenen politischen Analysen gekennzeichnet. Trotz Naryškins sturer Verteidigung der Selbstherrschaft fanden sich er und Koni nämlich in einem Punkt. So sei Naryškin mit Koni bezüglich der „Samoduržavie“ einer Meinung gewesen. Es ist typisch, dass Koni in Porträts von Politikern, gerade auch wenn diese seiner Ansicht nach die falschen Strategien verfolgten, noch einmal seine eigene Einschätzung davon einbrachte, wo die Probleme im Zarenreich gelegen hätten. Mit der Wortkreation „Samoduržavie“, die an „Samoderžavie“ - Selbstherrschaft in Kombination mit „samodur“ - Dickschädel erinnert, meinte Koni wohl die Herrschaft von unfä-

406 Ebd., S. 221-22.

407 UtevskiJ: Poslednij ètap žiznennogo puti, S. 96. Es wird aus einem Brief Konis vom April 1924, in dem dieser sich entsprechend äußert, zitiert.

408 Koni: Vospominanija o dele Very Zasulič. In: GA2, S. 224. Über Trepov meinte Koni in einem separaten Erinnerungstext gar, dass in Zukunft auch bezüglich des Stadthauptmanns von St. Petersburg, der Bogoljubov hatte bestrafen lassen, ein „neutraler Historiker“ die „richtige Perspektive“ wiederherstellen werde. So müsse man auch Trepov im Vergleich sehen mit den viel „,aufgeklärteren Beamten“ seiner Zeit, die er in der damaligen Situation um Rat gebeten habe und die ihn nur noch fahrlässig bestärkt hätten, vgl. IRLI F. 134, op. 1, d. 142, l. 8ob-9. Dieser mit vielen Zusatzzettelchen und Korrekturen versehene Entwurf einer Erinnerungsschrift über Trepov wurde in Teilen in Konis Reihe in „Russische Altertümer" [Russkaja Starina] integriert und erschien folglich auch in „Auf dem Lebensweg“ I, vgl. Koni: Prokuratura i Administracija. In: ders. (Hrsg.): Na žiznennom puti, Bd.1, S. $205 \mathrm{ff}$ und in der erneuten Auflage dieses Bandes 1922.

409 Vgl. zu Naryškin und den verschiedenen Organisationen von Unterstützern der Autokratie, die sich im Zuge der Revolution von 1905 in Russland bildeten Don C. Rawson: Russian Rightists and the Revolution of 1905. Cambridge u. a. 1995, S. 109 ff.

410 IRLI F. 134, op. 1, d. 147, 1. 3ob-4. Vgl. zu der von Koni sehr häufig verwendeten Erzählfigur des Menschen, der sich zum Lebensende hin wandelt, auch unten, S. 328. 
higen Beratern und Beamten mit einem seine Rolle nicht zu seiner Zufriedenheit ausfüllenden Zaren an der Spitze. Persönlichkeiten im autokratischen Umfeld, die in den Augen Konis nicht wie Witte "Staatsmänner" gewesen seien, bildeten wie im Kapitel Konis „Wahrheit" für den Zaren ausgeführt einen Hauptpfeiler in seinen politischen Analysen. Wenn er nun Stichworte und Texte zu einem Pleve, Murav'ev oder Šuvalov verfasste, sparte er nicht mit Hinweisen darauf, was diese und deswegen auch der Zar alles falsch verstanden hätten. So verweist er im 1919 veröffentlichten Artikel über Šuvalov gleich zu Beginn auf das Attentat von Karakozov, das Alexander II. eingeschüchtert habe, so dass dieser anstatt sich auf die doch durchaus vorhandene „Liebe und Ergebenheit“ der Mehrheit zu stützen, erste Schritte geprägt von „Misstrauen gegen die Gesellschaft“ eingeleitet habe. ${ }^{411}$ Das „Lehrstück“ aus dem Fall Zasulič dringt hier durch, der für Koni das Paradebeispiel kontraproduktiver Wirkung von Repression darstellte. Es folgt erneut das Narrativ von den schlechten Beratern: Solche seien nun wie Šuvalov auf wichtige Posten gesetzt worden. ${ }^{412}$ Nach einer Aufzählung der persönlichen Begegnungen zwischen Koni und dem Beamten endet er mit dem Bild des betrunkenen, längst in Ungnade gefallenen Šuvalov. Er schlussfolgert:

Scheinbar suchte er Vergessen vor der vor ihm auftauchenden Erscheinung [videnie] der lange vorbeigegangenen Herrschaft über das Schicksal der russischen Innenpolitik und über die Seele des vom Attentat Karakozovs eingeschüchterten Zaren. ${ }^{413}$

Besonders schön zeigen sich die inhaltlichen Konstanten in Konis Interpretation der Zarenzeit auch bei seinem Mitte 1917 verfassten Porträt des letzten Zaren. In seiner Analyse der Regierungszeit von Nikolaus II. macht Koni als entscheidenden Punkt des Versagens das „Fehlen des Herzens“ [otsutstvie serdca] bei diesem aus. Seitenlang zählt er die Entscheidungen des Zaren auf, die seiner Ansicht nach herzlos gewesen seien und Russland an den „Rand des Untergangs“ [na kraj gibeli] geführt hätten. ${ }^{414}$ In der Auflistung finden sich neben neuen Punkten wie dem Krieg gegen Japan oder Judenpogromen auch altbekannte, von Koni schon über ein Jahrzehnt früher bei Alexander III. kritisierte politische Entscheidungen, wie die Einschränkung der landschaftlichen Selbstverwaltung oder das System der Landhauptleute. ${ }^{415}$ Folgerichtig erwähnt Koni nun Alexander III. und bemängelt einmal mehr dessen Verhalten nach der Errettung aus dem 1888 verunfallten Za-

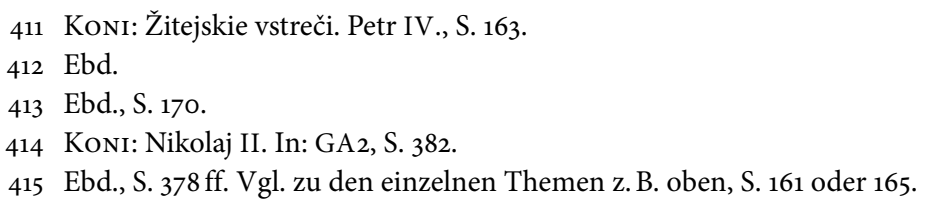


renzug. Obwohl alle froh über sein Überleben gewesen seien, habe er gleich als Nächstes Maßnahmen gegen die Selbstverwaltung ergriffen. ${ }^{416}$ Im Porträt fährt Koni damit fort, auch auf Nikolaus II. bezogen die Stimmung des „Volkes“ zu evaluieren. Auch ihm gegenüber habe es sich nicht nur einmal mit „Liebe und Vertrauen“ verhalten. Aber der Zar habe die „Interessen der Heimat“ der „schändlichen Unzucht des Rasputin-tums “ [Rasputinstva] geopfert. ${ }^{417}$ Erneut wird betont, was Koni schon im Rückblick auf seine Berufslaufbahn nach der Jahrhundertwende deutlich gemacht hatte. Der Zar sei von den falschen Leuten umgeben und habe immer wieder "unwürdige" [ničtožnye] Personen auf die wichtigen Stellen geholt. ${ }^{418}$ Die schlechten Berater müssen erneut einen Großteil der Schuld am „herzlosen“ Verhalten des Zaren übernehmen. Doch schließlich urteilt Koni auch über den Zaren selber vernichtend, wenn er ihm das „Fehlen von Würde“ vorwirft. ${ }^{419}$ Noch 1906 bei der Eröffnung der ersten Duma hatte Koni sich in seiner Niederschrift der Ereignisse erfreut darüber gezeigt, dass der Zar die Beschneidung seiner Macht mit Fassung getragen habe. ${ }^{420}$ Diese für Koni so wichtige korrekte Erfüllung des Zarenamtes gelingt Nikolaus II. gute zehn Jahre später in der Optik des Juristen nicht mehr. So kritisiert er hart, dass die fehlende Würde des Zaren sich daran zeige, dass dieser nach seinem Rücktritt ein erbärmliches Dasein friste, weil er nicht imstande sei, mit Ehre für den Schutz seiner historischen Rechte zu sterben oder wenigstens angesichts der Forderungen der Bevölkerung würdevoll zurückzutreten. ${ }^{421}$ Neben diesen harten Worten finden sich im Porträt aber auch wieder Momente der Faszination für das mächtige Zarenamt und seinen Inhaber. Literarische Ausschmückungen der beruflichen Zusammentreffen von Koni und Nikolaus II. in den 189oer-Jahren zeugen hiervon. So spricht er im Kontext der persönlichen Begegnungen von „Liebenswürdigkeit“ und dem „liebevollen Blick einer Gazelle“ [laskovyj vzgljad gazeli] ${ }^{422}$ Oder meint: „[...] Die Augen der Gazelle schauten mich liebevoll an, die Hand, von deren Unterschrift Glück und Trauer von Millionen abhingen, streichelte automatisch über den Bart [...].“423 Sogar „liebevolle Fragen“ zu Konis Gesundheit habe der Zar gestellt. ${ }^{424}$

\footnotetext{
416 Koni: Nikolaj II. In: GA2, S. 378.

417 Ebd., S. 382.

418 Ebd., S. 381.

419 Ebd., S. 382.

420 Vgl. oben, S. 204.

421 Koni: Nikolaj II. In: GA2, S. 382.

422 Ebd., S. 382.

423 Ebd., S. 383.

424 Ebd., S. 383-84.
} 
Konis Analyse der Vergangenheit und ihrer politischen Akteure zeigt deutlich auf, dass sich an seinen Beurteilungen durch die Ereignisse vom Februar, aber auch vom Oktober 1917 nichts Wesentliches geändert hatte. Für sich spricht dabei die Tatsache, dass Koni die Inhalte seiner Erinnerungsschriften aus früheren Jahren nicht grundlegend überarbeitete, und die neuen Politikerporträts nicht selten auf Notizen oder Vorformulierungen älterer Texte beruhten oder in einigen Fällen bereits veröffentlicht worden waren. Dass dies für das sowjetische Publikum schwer vorstellbar beziehungsweise für Verleger schwer vermittelbar war, zeigt sich an einem Detail. Datiert von 1923 findet sich ein publikationsreifes, maschinengetipptes Manuskript von Konis Erinnerungen an die Entgleisung des Zarenzugs in seinem Nachlass. Eine kurze Anmerkung sollte auf die Textentstehung verweisen. Darin heißt es, A. F. Koni habe diese Erinnerungen 1923 auf der Basis von Tagebüchern und offiziellen Dokumenten verfasst. ${ }^{425} \mathrm{Ganz}$ offensichtlich nimmt es der für die Überarbeitung Zuständige hier nicht so genau, denn die Schrift stimmt zum größten Teil mit dem Entwurf überein, den Koni 1904 verfasst hatte. ${ }^{426}$ Fast scheint es, dass das Zeugnis in der Optik zukünftiger Herausgeber an Bedeutung verlieren oder sogar kompromittiert werden könnte, wenn klar würde, dass Koni schon vor 20 Jahren die gleichen Schlussfolgerungen zum Unfall und zum Verhalten von Zar, Politiker und Beamtenschaft gezogen hatte. Auch sein Plädoyer für Kontextualisierung und die „Gerechtigkeit“, die er sogar Persönlichkeiten wie Trepov, Pobedonoscev oder Katkov widerfahren lassen will, lässt sich schon zu Beginn des 20. Jahrhunderts in den entsprechenden Manuskripten ausmachen. Selbst seine Überlegungen zu Erinnerung und Biografik macht Koni, zumindest was das Porträt von Loris-Melikov anbelangt, schon einige Jahre vor dem oftmals als „Epochenbruch“ interpretierten Jahr 1917 publik. Diese Erinnerungsschrift zeigt besonders eindrücklich auf, wie Koni die Zäsuren nach seinen eigenen Empfindungen legte. In der Zeitschrift „Stimme der Vergangenheit" [Golos Minuvščego] beginnt das Porträt 1914 mit den Worten:

Am 12. Dezember des vergangenen Jahres waren es 25 Jahre seit dem Tod von Graf Michail Tarielovič Loris-Melikov. Leute, die mit der lebhaften [kipučej] Tätigkeit dieses herausragenden [vydajuščegosja] Menschen Ende der 7oer- und Anfang der 8oer-Jahre gut bekannt waren, hatten keine Möglichkeit, ihre Erinnerungen über ihn mit der russischen Öffentlichkeit zu teilen [...]. Der schnelle und drastische Wandel im Leben

425 GARF F. 564, op. 1, d. 204, 1. 83.

426 Einige Streichungen und Umformulierungen gibt es allerdings, die der Zensur geschuldet scheinen, darauf wird in der Folge noch eingegangen. 
der russischen Gesellschaft in den letzten zehn Jahren hat das Bild des Menschen, der einmal allen im Ohr war, etwas neblig werden lassen. ${ }^{427}$

$\mathrm{Zu}$ Beginn der 1920er-Jahre änderte Koni lediglich den 12. Dezember in den 25. und passte sich so der Kalenderreform der Bolschewiki an. ${ }^{428}$ Er machte aus 25 Jahren, die seit dem Tod von Loris-Melikov verstrichen waren, neu 33. Er änderte aber weder die inhaltliche Bewertung des Politikers als „herausragend“ noch seinen Hinweis auf den drastischen „Wandel“. Nun sprach er einfach nicht länger von „zehn Jahren“, womit unmittelbar auf die Revolution von 1905 verwiesen wurde, sondern erweiterte die Zeit des Wandels auf die „ersten Jahrzehnte des 20. Jahrhunderts" [pervye desjatiletija XX veka] und dachte so das Revolutionsjahr 1917 mit. ${ }^{429}$ Dem Leser bleibt es überlassen, worauf genau er den Wandel beziehen möchte. Für Koni scheint die entscheidende Veränderung in der Entwicklung Russlands ein Prozess zu sein, der schon um die Jahrhundertwende begonnen hatte. Dies verdeutlicht er nochmals mit der 1922 erfolgten erneuten Veröffentlichung seiner Rede zu den „Zeugen vor Gericht“, mit der er schon 1904 vor der Juristischen Gesellschaft aufgetreten war. Nun publizierte er den Fachtext über den Umgang mit unzuverlässigen Zeugenaussagen bezeichnenderweise unter dem neuen Titel „Erinnerung und Aufmerksamkeit“ [Pamjat' i Vnimanie]. Genau wie vor fast 20 Jahren beginnt Koni wieder mit seinem Nietzschezitat. Er spricht warnend von „unserer Zeit“ als Zeit der „Umwertung aller Werte“, ohne dass dem Leser klar würde, dass Koni damit ursprünglich nicht etwa die Ideen des sozialistischen Sowjetstaates, sondern die gesellschaftliche Entwicklung im Vorfeld der ersten Russischen Revolution und all die wissenschaftlichen und sonstigen Experimente dieser Zeit gemeint hatte. ${ }^{430}$

427 Koni: Graf M. P. Loris-Melikov. In: GM 1 (1914), S. 181.

428 Erst im Februar 1918 wechselte Russland vom julianischen auf den gregorianischen Kalender, was zu diesem Zeitpunkt einen Unterschied von 13 Tagen ausmachte. Aufgrund eines Dekrets der Bolschewiki folgte auf den 31. Januar 1918 der 14. Februar, vgl. Douglas Sмiтн: Der letzte Tanz. Der Untergang der russischen Aristokratie. Frankfurt am Main 2014, S. 11. Dass Koni vom 25. Dezember spricht, beruht wohl auf einem Umrechnungsfehler, da das Todesjahr von Loris-Melikov im 19. Jahrhundert liegt, als sich die Differenz zwischen den beiden Kalendern erst auf 12 Tage belief. Loris-Melikov starb nach gregorianischem Kalender am 24. Dezember 1888.

429 Koni: Graf M. T. Loris-Melikov. In: GA5, S. 184. Im Weiteren ergänzt Koni die Skizze um einige Seiten mit neuem Material. So zum Beispiel ein Brief, den er selber Loris-Melikov geschickt hatte, vgl. ebd., S. $212 \mathrm{ff}$.

430 Anatolij F. KonI: Pamjat' i vnimanie. Iz vospominanij sudebnogo dejatelja. In: GA4, S. $70-71$. 
Konis Fokus auf die Zeit um 1905 macht klar, dass für ihn damals schon wesentliche Veränderungen stattgefunden hatten, die differenzierte Einordnungen nötig machten. Sein Versuch, nicht polarisierend, sondern seiner Ansicht nach ausgewogen zu urteilen und die historischen Umstände entsprechend zu gewichten, nahm in dieser Zeit ihren Ursprung und erschien angesichts der radikalen ideologischen Neuausrichtung nach der Oktoberrevolution von bisher ungekannter Relevanz. Indem er in seinen Schriften oder neu verfassten Vorworten immer wieder explizit auf notwendige Relativierung und Differenzierung hinwies, bat er insbesondere seine sowjetischen Leser um einen unvoreingenommenen Zugang zu den Exponenten der zarischen Politik. Das Plädoyer für einen vertieften Blick in die Vergangenheit mit ihren politischen Entscheidungen und Entscheidungsträgern war gleichzeitig eines für seine eigenen Einsichten in die Gründe des Scheiterns der Zarenherrschaft. Die „Mission der Geschichte“ - so erklärt Koni in seinem neuen Vorwort zur Zasulič-Erinnerung - bestehe schließlich darin, „die Früchte der jahrhundertealten Erfahrung“ zu sammeln und die „Errungenschaften der Nachwelt von Generation zu Generation“ weiterzugeben. Koni orientiert sich hier am kantischen Idealismus, in dem das Eingestehen von historischen Fehlentwicklungen keine Gefahr für Fortschritt und zukünftige Ziele darstellt. Aus Fehlern sollte gelernt werden, anstatt sie zu verleugnen. ${ }^{431}$ So machte Koni denn nach dem Revolutionsjahr 1917 diese „Mission der Geschichte“ zu seiner persönlichen „Erinnerungsmission“, mit der er seine eigenen Einsichten in die vergangenen Ereignisse und politischen Entwicklungen anbringen wollte. Eigentlich - so resümiert er im Vorwort abschließend - habe er die Erinnerungen an den Zasulič-Fall der Akademie der Wissenschaften übergeben wollen, damit diese die Schrift nach seinem Tod publiziere. Aber die "Schritte der Geschichte“ seien schneller vorangegangen als er dies habe voraussehen können. Und angesichts des „leichtsinnigen Bestrebens, das Alte zu zerstören“, seien diese Erinnerungsschrift und die darin enthaltene Erfahrung vielleicht schneller von Bedarf, als er dies habe vorhersehen können. ${ }^{432}$

431 Jane Burbank: Intelligentsia and Revolution. Russian Views of Bolshevism, 1917-1922. New York, Oxford 1986, S. 166-67. Burbank führt am Beispiel der beiden vorrevolutionären Politiker der Konstitutionellen Demokraten Petr Berngardovič Struve (1870-1944) und Pavel Miljukov aus, wie unterschiedliche philosophische Prämissen die individuellen Reaktionen auf den Untergang des Zarenreichs und das Entstehen der Sowjetunion beeinflussten. Sie sieht Miljukov als Positivisten und Struve als „kantischen Idealisten“, der sich über die Ungenügsamkeit des Positivismus als Quelle moralischer Prinzipien im Klaren war. Vgl. zu Koni und Kant insb. TEIL DREI der Dissertation.

432 Koni: Vospominanija o dele Very Zasulič. In: GA2, S. 25. 
„Pro“ und „Contra“: Konis Entscheid für die Erinnerungsmission

Konis Entscheid, sich der „Mission der Geschichte“ zu widmen und die (justiz-)politischen Erfahrungen aus seiner Vergangenheit im sowjetischen Russland zu vertreten, war keineswegs selbstverständlich. Viele Gesinnungsgenossen aus Konis Umfeld verließen Russland im Gegensatz zu ihm - freiwillig oder unfreiwillig - für immer. ${ }^{433}$ Tatsächlich war es die Mehrheit der liberalen Intelligencija, die die neue Ausrichtung nicht mittrug. ${ }^{434}$ Gerade für die Juristen darunter hätte die ideologische Diskrepanz zwischen der kurzen Zeitspanne unter der Provisorischen Regierung im Sommerhalbjahr 1917 und der nachfolgenden Führung des Landes durch die Partei der Bolschewiki kaum größer sein können. Nach der Februarrevolution hatten sich zahlreiche Anwälte und Juristen in verschiedenen Behörden, Kommissionen und im Parlament für die Bestrebungen der Provisorischen Regierung engagiert, den liberalen Rechtsstaat weiterzuentwickeln. ${ }^{435}$ Auch Koni war kurzfristig wieder an das Kriminalkassationsdepartement berufen worden und nahm an Sitzungen zur Reformierung des Rechtswesens teil, das nun endlich jene liberalen Grundsätze realisieren sollte, die schon 1864 die Reformbemühungen geprägt hatten. Mit der Machtübernahme der Bolschewiki brach das Justizsystem aber vollständig in sich zusammen ${ }^{436}$ Neue Ideen gewannen die Oberhand und veränderten den Blick auf Recht und Gesellschaft grundlegend. Während sich die Geschichtswissenschaft der 1920er-Jahre zu einer Sozialwissenschaft wandelte, die sich um die Geschichte der Arbeit, um den Klassenkampf und die sozialistische Doktrin drehte, wurde nun auch die Rechtswissenschaft von einem marxistischen Standpunkt aus betrachtet. ${ }^{437}$ Das Recht wurde als Waffe jener gesehen, die die wirt-

433 Kappeler: Russische Geschichte, S. 36. Zwischen zwei und drei Millionen Menschen emigrierten ins Ausland, vgl. Manfred Hildermeier: Geschichte der Sowjetunion, 1917-1991. Entstehung und Niedergang des ersten sozialistischen Staates. München 1998, S. 265.

434 Haumann: Geschichte Russlands, S. 382.

435 Eugene Huskey: Russian Lawyers and the Soviet State. The Origins and Development of the Soviet Bar, 1917-1939. Princeton New Jersey 1986, S. 27-29.

436 Baberowski: Autokratie und Justiz, S. 1. Zu Konis Posten vgl. Nikolaj P. KarabČevskij: Čto glaza moi videli. II. Revoljucija i Rossija. Berlin 1921, S. $124 \mathrm{ff}$ und SMOLJARČUK: Anatolij Fëdorovič Koni (1844-1927), S. 135. Smoljarčuk verweist auf die entsprechenden Erlasse der Provisorischen Regierung vom 5. und 30. Mai 1917, in denen Koni zuerst zum Vorsitzenden des Kriminalkassationsdepartements des Senats und danach zusätzlich zum Vorsitzenden in der Allgemeinen Versammlung der Kassationsdepartemente ernannt wurde.

437 Korine Amacher: En guise d'introduction. L'histoire dans la Russie contemporaine. In: dies./Wladimir Berelowitch (Hrsg.): Histoire et mémoire dans l'espace postsoviétique. Le passé qui encombre. Louvain-la-Neuve 2013, S. 18. 
schaftliche Vormachtstellung besaßen. Die Gerichtsreform von 1864 und das gesamte an europäischen Vorbildern orientierte Rechtswesen im Zarenreich, insbesondere der Beruf des Anwalts, erschienen nun als Instrumente des Klassenkampfes. In den ersten Jahren nach der Revolution entstand gar die Idee, den Beruf des Verteidigers völlig abzuschaffen, der als typischer Exponent der herrschenden Klasse gesehen wurde. Anwälte wurden nur noch selten überhaupt vor Gericht zugelassen. Die Anwalt-Klient-Beziehung sollte nicht mehr in freier Form möglich sein und Entlohnung gänzlich aufgehoben werden. ${ }^{438}$ Das „Klassenprinzip“ sollte in der Rechtsprechung nach der Oktoberrevolution zugunsten des "Staats der Arbeitenden“ und zuungunsten von „Verbrechern und den sozial-gefährlichen Elementen“ zur Anwendung kommen. ${ }^{439}$ Die Richter, die solches Recht zu sprechen hatten, waren eine völlig neue Kohorte von Juristen. Die meisten hatten keine entsprechende Ausbildung, viele waren aber Mitglied der Kommunistischen Partei. Sie wurden angehalten, sich bei der Rechtsprechung nach ihrem „revolutionären Bewusstsein“ zu richten. ${ }^{440}$ Angestellt waren sie in einem dualen, im Vergleich zu vorher stark vereinfachten Gerichtssystem, das aus „Revolutionstribunalen“ und „Volksgerichten“ bestand. ${ }^{441}$ Auch dieses Rechtssystem sollte aber nur eine Übergangslösung darstellen. Das marxistische Konzept des „Absterbens des Rechts“ versprach, dass in naher Zukunft, wenn die „Diktatur des Proletariates“ nicht mehr nötig sein würde, eine neue Gesellschaft ihre Dispute ohne jegliche komplizierten Gesetze, Prozessvorschriften und Beweisführungen regeln können würde. ${ }^{442}$ Führende Theoretiker wie Evgenij Bronislavovič Pašukanis (1891-1937) waren überzeugt, dass mit der Weiterentwicklung des sozialistischen Gemeinwesens jegliches Recht überflüssig werden würde. ${ }^{43}$ Diese neue Konzeption von Recht und Rechtsstaat führte dazu, dass

438 Huskey: Russian Lawyers and the Soviet State, S. 35-37, 48-49 und 72-73.

439 A. Maklezow u.a. (Hrsg.): Das Recht Sowjetrusslands. Tübingen 1925, S. 370. Zitiert nach einem Lehrbuch zum Sowjetstrafrecht.

440 Sharlet: Pashukanis and the Withering Away of Law in the USSR, S. 169. Vgl. auch Maklezow u.a. (Hrsg.): Das Recht Sowjetrusslands., S. 424ff und Huskey: Russian Lawyers and the Soviet State, S. 67 mit Zahlen zur Ausbildung und Parteimitgliedschaft der Richter.

441 Sharlet: Pashukanis and the Withering Away of Law in the USSR, S. 169.

442 Ebd., S. 169-70.

443 Stefan Plaggenborg: Die Organisation des Sowjetstaates. In: Gottfried Schramm (Hrsg.): Handbuch der Geschichte Russlands. Bd. 3, II: 1856-1945. Von den autokratischen Reformen zum Sowjetstaat. Stuttgart 1992, S. 1420. Vgl. auch ShArLet: Pashukanis and the Withering Away of Law in the USSR, S. 170. Sharlets Aufsatz erläutert die „commodity exchange theory of law“, die Pašukanis als Weg zur Umsetzung der marxistischen Prämisse des „Absterbens“ von Staat und Recht entwickelte. 
die im Zarenreich ausgebildete Juristenschaft kaum mehr in ihren angestammten Positionen weiterarbeiten konnte. So schätzt man beispielweise, dass zwischen 1500 und 2000 Mitglieder der Anwaltsräte emigrierten, was etwa $15 \%$ entsprach. Oftmals gründeten sie neue Anwaltsräte in Westeuropa oder Amerika, die als eine Art soziale Klubs funktionierten. Die im Land Verbliebenen fanden sich in neuen Stellungen wieder, so bei privaten Firmen, Justizinstitutionen oder Staatsbetrieben. ${ }^{444}$ Besonders jene Juristen, die sich vor der Oktoberrevolution in den Bolschewiki feindlich gesinnten Parteien exponiert hatten, blieb gar keine andere Wahl, als das Land zu verlassen. So hat mit Aleksandr Fëdorovič Kerenskij (1881-1970) ein Anwalt zeitweise gar die Provisorische Regierung angeführt, der nach der Oktoberrevolution sogleich untertauchen und schließlich nach Frankreich und später in die USA emigrieren musste. ${ }^{445}$ Auch ein Anwalt wie Nikolaj Platonovič Karabčevskij (1851-1925), der im Verlaufe des Jahres 1917 auf einer Versammlung der Petrograder Anwälte eine Brandrede über die „Gefahren des Bolschewismus“ gehalten hatte, suchte sein Glück in der Emigration. ${ }^{446}$ Die liberale Partei der Konstitutionellen Demokraten, die die Revolution von 1905 sowie die Februarrevolution von 1917 stark geprägt hatte, zog sich völlig in den Untergrund zurück. Aus diesen Reihen stammten auch besonders viele Juristen, die die Kadetten im Parlament vertreten hatten. Da in den Zentren des Landes die größte Gefahr für Leib und Leben der Parteimitglieder bestand, zogen sich viele von ihnen zuerst in die Außenregionen zurück, um sich danach früher oder später ins Ausland abzusetzen. ${ }^{447}$ Einen solchen Weg legte beispielsweise der bekannte russisch-jüdische Anwalt Oskar Gruzenberg zurück, der an der Seite Konis unter der Provisorischen Regierung an das Kriminalkassationsdepartement berufen worden war. Gruzenberg war im Gegensatz zu Koni schon seit 1905 Mitglied der Konstitutionellen Demokraten und verteidigte prominente politische Angeklagte, die auch in der Sowjetunion noch eine wichtige Rolle spielen sollten, wie zum Beispiel den Schriftsteller Maksim Gor'kij (1868-1936) oder den zukünftigen Volkskommissar und Organisator der Roten Armee Leo Trotzki (1879-1940). ${ }^{448}$ Als Kritiker des Zarismus begrüßte er die Februarrevolu-

444 Huskey: Russian Lawyers and the Soviet State, S. 77-79.

445 ŠIKMAN: Kto est kto v rossijskoj istorii, S. 266-68.

446 Huskey: Russian Lawyers and the Soviet State, S. 33 zur Rede von Karabčevskij. Vgl. auch die Erwähnung in Karabčevskijs eigenen Memoiren Nikolaj P. KARABČEvsкIJ: Čto glaza moi videli. II. Revoljucija i Rossija. Berlin 1921, S. 154-55. Hier berichtet er von dieser Rede und den Warnungen, die er danach erhielt. Die Rede wurde veröffentlicht in: P 16 (1917), S. 898-902.

447 Burbank: Intelligentsia and Revolution, S. 113-15.

448 Gruzenberg: Yesterday, S. XXIV (Einleitung von Don C. Rawson). Gruzenberg veröffentlichte in Paris 1938 einen Memoirenband mit dem Titel „Včera“ - „Gestern“. Eine 
tion. ${ }^{449}$ Die durch die Bolschewiki einige Monate später vollzogene vollständige Liquidation des bisherigen Verwaltungs- und Justizwesens hielt er zuerst nur für eine vorübergehende Entwicklung. ${ }^{450}$ Davon zeugt ein Brief von Gruzenberg an Koni als den „Herrn Vorsitzenden des Kriminalkassationsdepartements“, datiert vom 13. Juni 1918. Darin informiert er, dass er aus Krankheitsgründen nach Odessa fahre. ${ }^{451}$ Gruzenberg hatte sich schon seit einigen Monaten fern der Zentren in Tiflis und Kiew aufgehalten. ${ }^{452} \mathrm{Im}$ Brief fügt er aber optimistisch hinzu, er plane nach dem Aufenthalt in Odessa im September zurückzukehren. Falls man vorher die Beschäftigung wieder aufnehme, solle man ihn per Telegramm informieren. ${ }^{453} \mathrm{Zu}$ einer solchen Wiederaufnahme der Tätigkeit des Kriminalkassationsdepartements kam es aber genauso wenig wie zu einer Rückkehr Gruzenbergs in die Zentren des Landes. Im Frühling 1921 entschloss er sich, endgültig den Weg in die Emigration weiterzugehen und zog via Berlin und Riga nach Nizza, wo er bis zu seinem Lebensende bleiben sollte. ${ }^{454}$

Andere Weggefährten von Koni wie Arsen'ev oder Andreevskij, die mit ihm zusammen in den Anfangszeiten der reformierten Gerichte gewirkt hatten, zogen sich im Revolutionsjahr und der Zeit danach vollständig aus der Öffentlichkeit zurück. Die Oktoberrevolution - von Jochen Hellbeck eine „lebenskreierende Kraft“ genannt - konfrontierte gerade jene, die ihr oppositionell gegenüberstanden, mit der Frage von Leben oder Tod. Wer nicht mit dem Kollektiv mitmarschieren wollte oder konnte, fühlte sich oftmals unnütz und depressiv. ${ }^{455}$ So schreibt Koni selber in seinem Porträt über den Kollegen, dass es in Andreevskijs letzten Jahren um

Übersetzung ins Englische erschien 1981 in Amerika unter dem Titel „Yesterday: Memoirs of a Russian-Jewish Lawyer“. Zu den darin gemachten Kürzungen und Hinzufügungen vgl. ebd., S. IX (Einleitung von Don C. Rawson). Die russische Version enthält auch ein kurzes Kapitel über Koni, vgl. O. O. Gruzenberg: Ob A. F. Koni. In: ders. (Hrsg.): Včera. Vospominanija. Paris 1938, S. 197-203.

449 Gruzenberg: Yesterday, S. XXIV (Einleitung von Don C. Rawson).

450 Ebd., S. XXIV-XXIV.

451 GARF F. 564, op. 1, d. 1668, 1. 8.

452 Gruzenberg: Yesterday, S. XXV (Einleitung von Don C. Rawson).

453 GARF F. 564, op. 1, d. 1668, l. 8. Dieser Brief ist unterzeichnet mit „Senator O. Gruzenberg“. Auf l. 9 folgt datiert vom gleichen Tag ein weniger formeller Brief, in dem Gruzenberg Koni wissen lässt, dass er eine Lungenentzündung habe und zu seiner Tochter nach Odessa fahre. Gruzenberg und Koni blieben auch später in Kontakt, vgl. dazu die nachfolgenden Ausführungen.

454 Gruzenberg: Yesterday, S. XXV (Einleitung von Don C. Rawson). In der nach thematischen Kapiteln geordneten Erinnerungsschrift werden die Emigration selber und die Zeit danach nicht thematisiert.

455 Jochen Hellbeck: Revolution on My Mind. Writing a Diary Under Stalin. Cambridge Massachusetts u. a. 2009, S. 55. 
ihn immer leerer geworden sei. Nach der Revolution sei es schwierig gewesen, als Anwalt zu arbeiten, und Andreevskij sei gezwungen gewesen, seine Bücher und Kunstgegenstände zu verkaufen. Am 9. November 1918 schließlich verstarb er. ${ }^{456}$ Arsen'ev seinerseits, der im Zuge der Revolution von 1905 noch eine eigene Partei gegründet hatte, bekam schon die Februarrevolution kaum mehr mit. In seinem Tagebuch, das er seit vielen Jahrzehnten führte, tauchen die entsprechenden Ereignisse nur auszugsweise und verworren auf. Am 8. Mai 1917 notierte er gar, dass er daran denke, das Tagebuchschreiben ganz aufzugeben, da sein Leben so „eintönig und monoton“ sei. ${ }^{47}$ Isoliert von den tagesaktuellen Entwicklungen verbrachte Arsen'ev die letzten Lebensjahre zurückgezogen auf seinem Landgut und starb schließlich im März 1919. ${ }^{458}$

Im Gegensatz zu so manchen Berufskollegen und Gesinnungsgenossen entschloss sich Koni also dazu, nicht nur im sowjetischen Russland zu verbleiben, sondern auch vorhandene Spielräume zu nutzen.

Mit dem Ende des Bürgerkrieges und der Einführung der sogenannten Neuen Ökonomischen Politik 1921 kam es sukzessive zu einer Veränderung in der Haltung gegenüber den in Russland verbliebenen juristischen und sonstigen vorrevolutionären Experten. Die „Neue Ökonomische Politik“ setzte auf eine Art Staatskapitalismus mit großem Bedarf an Fachwissen. Dies führte zu einer „Phase der Versöhnung“ mit den „bürgerlichen“Spezialisten. ${ }^{459}$ Gerade was die Anwaltschaft anbelangte, wurde mit der Zeit immer klarer, dass es nach wie vor eine irgendwie geregelte Profession brauchte. ${ }^{460} \mathrm{Zu}$ den 1922/23 neu eingerichteten „Anwaltskollegien“" [Kollegii zaščitnikov] gehörten zahlreiche Mitglieder, die schon in der Zarenzeit aktiv gewesen waren. Darunter befanden sich auch Juristen, die früher nicht unbedingt als Anwälte gearbeitet hatten. ${ }^{461}$ Auch bei der Ausgestaltung eines neuen Kriminalstrafprozessrechts 1922 und weiteren Entwürfen für Rechtskodizes wurden nun wieder Exponenten des juristischen Establishments aus der Zarenzeit zur Mitarbeit eingeladen. Und in Rechtsjournalen fanden sich plötzlich dezent maskierte bürgerliche Rechtstheorien. ${ }^{462}$ Der Grund für die überdurchschnittlich hohe Zahl alter Kader gerade unter den Anwälten hatte nicht zuletzt damit zu

456 Koni: S. A. Andreevskij. In: Koni (Hrsg.): Na žiznennom puti, Bd. 5, S. 196.

457 Zitiert nach: ŠLemin: Dnevnik K. K. Arsen'eva, S. 322. Vgl. grundsätzlich zu Arsen'evs Tagebuch, dass er schon im April 1855 begann, ebd., S. 313.

458 Simutenko: K. K. Arsen’ev i rossijskoe liberal'noe dviženie konca XIX-načala XX veka, S. $83-85$.

459 Haumann: Geschichte Russlands, S. 366 und Hildermeier: Geschichte der Sowjetunion, 1917-1991, S. 300.

460 Huskey: Russian Lawyers and the Soviet State, S. 81.

461 Ebd., S. 93 und 95.

462 Ebd., S. 87. 
tun, dass für die Bolschewiki weder die Reformation der Anwaltschaft noch die Neukodifizierung von Rechtsgrundsätzen zuoberst auf der Prioritätenliste stand. Gerade während der Zeit der „Neuen Ökonomischen Politik“ verließ man sich immer stärker auf administrative Maßnahmen, um die öffentliche Ordnung aufrechtzuerhalten. ${ }^{463}$ Wegen der grundsätzlichen Überlegungen, ob die Anwaltschaft und die Justiz als Ganzes nicht bald wie ein „schlechter Traum“ der Vergangenheit angehören würde, bestand unter den neuen kommunistischen Kadern auch wenig Begeisterung, selber eine Karriere in diesem Feld einzuschlagen. ${ }^{464}$ Anders sah dies in Gebieten aus, die viel unmittelbarer mit den großen Projekten der 1920er-Jahre verbunden waren, von denen Überleben und weitere Entwicklung des Sowjetstaates abhingen. Die Ingenieure beispielsweise profitierten zwar auch von der versöhnlichen Haltung gegenüber Spezialisten. Weil ihre Arbeit aber einen unmittelbaren Beitrag zur ideologischen Leitlinie der Bolschewiki „Sowjetmacht plus Elektrifizierung gleich Kommunismus" beinhaltete, standen sie viel mehr im Fokus. ${ }^{465}$ Entsprechend hart wurden sie nach dem Ende der „Neuen Ökonomischen Politik" schließlich auch von der sogenannten Kulturrevolution erfasst, die zwischen 1928 und 1931 die Strukturen der alten technischen Intelligencija vollständig vernichtete. ${ }^{466} \mathrm{Im}$ Sommer 1929 kam es allerdings auch zu einer deutlichen

463 Ebd., S. 104 und 144.

464 Ebd., S. 105-06 ff. Huskey verfolgt die Kontroverse, die sich bezogen auf die Anwaltschaft unter den Kommunisten entwickelte. Während einige der Ansicht waren, dass sich ein Parteimitglied gar verdächtig mache, wenn es in eine solche als „bourgeois“ angesehene Berufsgattung einsteige, sahen andere die Notwendigkeit, dass Mitglieder der Kommunistischen Partei in die Anwaltschaft eintraten, um darin eine interne Kontrolle auszuüben.

465 Schattenberg schreibt, dass viele Ingenieure mit diesem Slogan überzeugt wurden, ihre Expertise in den Dienst der Bolschewiki zu stellen. Sie sahen darin ihre Vorstellungen von einem hochindustrialisierten Russland wahr werden. Die Regierung erfasste schon früh die besondere Rolle der Ingenieure und gründete noch während des Bürgerkrieges zahlreiche wissenschaftliche Einrichtungen. Gleichzeitig herrschte unter Arbeiteraktivisten und linken Bolschewiki eine offene Feindschaft gegen diese Spezialisten aus vorrevolutionärer Zeit, die als Fachleute ihre eigenen Ideen einbrachten, wie genau die Industrialisierung voranzutreiben sei. Man versuchte deshalb grundsätzlich, sie politisch zu kontrollieren und in Gewerkschaften zwangszuintegrieren, vgl. Susanne Schat tenberg: Stalins Ingenieure. Lebenswelten zwischen Technik und Terror in den 1930er Jahren. München 2002, S. 71-78. Huskey: Russian Lawyers and the Soviet State, S. 104 merkt an, dass die Aufsicht über die Juristen auch viel weniger streng war, als z. B. jene über die Schriftsteller.

466 Schattenberg: Stalins Ingenieure, S. 90-91 und 95-96. Schattenberg führt am Beispiel der Ingenieure aus, wie die herausragendsten Vertreter zu Beginn der 1930er-Jahre verurteilt wurden. Während ein kleinerer Teil hingerichtet wurde, gelangte die Mehrheit in Erziehungslager, wo sie oftmals in Konstruktionsbüros arbeiten durften und meist recht schnell wieder entlassen wurden. In einer zweiten Welle wurden viele aber schon 1937/38 wieder verhaftet. Die Kulturrevolution brachte so nicht allein einen Elitenwechsel 
Verschärfung der Gangart gegenüber den Anwälten, die nun komplett kollektiviert wurden und keiner privaten Berufstätigkeit mehr nachgehen durften. ${ }^{467}$ Dies hing unmittelbar damit zusammen, dass in Stalins Plänen zur Kollektivierung und Industrialisierung des Landes das Recht nun nicht länger eine vernachlässigbare Größe blieb, sondern eine wichtige Funktion für die Stabilisierung und Regelung der neuen Politik einnehmen sollte. Gesellschaftspolitisch stand dies im Zusammenhang mit dem politisch geförderten Wiedererstarken klassischer gesellschaftlicher Werte und Praktiken wie Familie, Steigerung der Geburtenrate oder Arbeitsdisziplin. ${ }^{468}$ Das „Absterben“ von Staat und Justiz wurde zwar mit dem Slogan „Revoljucija prava“ - „Revolution des Rechts“ - nach wie vor von gewissen marxistischen Denkern hochgehalten, bald aber mit der Festnahme und Ermordung von Evgenij Pašukanis endgültig verworfen. ${ }^{469}$ Ende der 193oer-Jahre, deutlich später als im Fall der Schriftsteller, Ingenieure oder Agrarfachleute, war die Dominanz der vorrevolutionären Spezialisten in allen Justizbereichen endgültig gebrochen. ${ }^{470}$

mit sich, sondern eine Kriminalisierung des Bilds vom „alten Ingenieur“, der sich durch Fachwissen anstelle politischer Überzeugungen ausgezeichnet hatte. Fitzpatrick definiert die „Kulturrevolution“ grundsätzlich als politische Konfrontation von "proletarischen“ Kommunisten und der „bourgeoisen“ Intelligencija. Endgültig sollten die Autoritäten aus dem Zarenreich mittels „Klassenkampf “ von einer neuen „proletarischen Intelligencija“ abgelöst werden, vgl. Sheila Fitzpatrick: Cultural Revolution as Class War. In: dies. (Hrsg.): Cultural Revolution in Russia 1928-1931. Bloomington Indiana 1978, S. 8. Vgl. auch Bruischs Studie zu den Agrarfachleuten, die in der Sowjetunion zuerst ebenfalls als Experten begehrt waren und dann Ende der 1920er-Jahre der Repression zum Opfer fielen: BRUisch: Als das Dorf noch Zukunft war.

467 Huskey: Russian Lawyers and the Soviet State, S. 152-53. Allerdings hatten die Säuberungen gegen jene, die der Klassenlinie nicht folgen wollten, keinen durchschlagenden Effekt. Noch 1932 hatte mehr als die Hälfte der Moskauer Anwälte eine Ausbildung aus dem Zarenreich und nur wenige davon waren Mitglieder der Kommunistischen Partei. Die Gerichte aber lagen nun fest in kommunistischer Hand. 1931 waren 92 \% der Richter an den Volksgerichten Parteimitglieder, vgl. ebd., S. 160-64.

468 Peter H. Solomon: Legal Journals and Soviet Social History. In: Russian History 1 (1985), S. $265-66$.

469 Schultz: Russische Rechtsgeschichte, S. 270 ff zu Pašukanis, der seine plötzlich als antikommunistisch und schädlich verunglimpfte Rechtslehre im Jahre 1936 widerrief, aber den Säuberungen trotzdem nicht entkommen konnte. Huskey: Russian Lawyers and the Soviet State, S. $184 \mathrm{ff}$ führt aus, wie gegen Ende der 193oer-Jahre klare Regeln und Einheitlichkeit anstelle von „Revolutionärem Bewusstsein“ an den Gerichten in den Vordergrund traten. Immer mehr Fälle wurden von den Volksgerichten an das „Oberste Gericht“ der UdSSR gegeben, dessen Personal von acht Richtern 1929 auf 45 ein Jahrzehnt später anstieg.

470 Huskey: Russian Lawyers and the Soviet State, S. 215-25. Im August 1939 wurden erstmals seit 1922 neue Statuten für die Profession erlassen. Parallel zu den Säuberungen von 
Die Entfaltungsräume, die sich die Juristen relativ lange erhalten konnten, versuchten sich in den 1920er-Jahren einige der im Lande verbliebenen vorrevolutionären Rechtswissenschaftler aktiv zunutze zu machen, um sich in die Entwicklungen im Rechtswesen einzubringen. So gab zum Beispiel eine Gruppe um den renommierten Rechtsprofessor Michail Nikolaevič Gernet (1874-1953) das kleine Journal „Recht und Leben“ [Pravo i Žizn'] heraus, das immerhin bis zum Beginn der „Kulturrevolution“ erscheinen konnte. ${ }^{471}$ Auch Koni nutzte unter anderem diese Zeitschrift, die auch als Verlag fungierte, um Fach- und Erinnerungstexte zum Justizwesen und einige seiner Politikerporträts abzudrucken. ${ }^{472} \mathrm{Er}$

1938/39 wurden nun auch in großem Stil neue Kräfte aus der Arbeiterschaft in den Beruf hineingebracht, so dass die Anwaltschaft wieder massiv anwuchs. Ende der 1950er-Jahre waren dann schon 70 \% aller Anwälte Parteimitglieder. Trotz dieser nun deutlich systemtreuen Institution erhielten sich gewisse Autonomien. So wurden die Anwaltskollegs nie in die bürokratische Staatshierarchie eingegliedert und blieben formell selbstverwaltet. Alte Vorstellungen von Legalität [zakonnost'] und Einsatz für die Interessen der Klienten hielten sich somit hartnäckig, nicht selten zum persönlichen Nachteil der Berufsleute. Solomon: Legal Journals and Soviet Social History, S. 282 und Huskey: Russian Lawyers and the Soviet State, S. 87 und S. 168. Solomon führt am Schluss seines Artikels eine Übersicht über alle sowjetischen Rechtszeitschriften in den 1920er- und 1930er-Jahren an, vgl. Solomon: Legal Journals and Soviet Social History, S. 277-82. Darin führt er aus, dass neben „Recht und Leben“ [Pravo i Žizn'] nur noch ein weiteres nicht marxistisches akademisches Rechtsjournal in den 1920er-Jahren erschien. Im Katalog von Butler wird vermerkt, dass die Zeitschrift zwischen 1922 und 1928 in Moskau publiziert wurde und in der Regel zehn Ausgaben pro Jahr umfasste, vgl. William Elliott ButLer: Russian and Soviet Law. An Annotated Catalogue of Reference Works, Legislation, Court Reports, Serials, and Monographs on Russian and Soviet Law (including International Law). London u. a. 1976 , S. 45 .

472 So erschien z. B. Konis Abhandlung zu rechtlichen und sonstigen Aspekten von Selbsttötung sowohl in der Zeitschrift als auch in Form einer Broschüre bei Pravo i Žizn', vgl. Anatolij F. KonI: Juridičeskij i bytovoj charakter samoubijstv. In: PŽ (1) 1923, S. 63-77; Anatolij F. Koni: Samoubijstvo v zakone i žizni. Moskva 1923. 1922 war auch das Porträt des Juristen und Staatsrats Manuchin in dieser Zeitschrift erschienen, und 1925 gab der Verlag Pravo i Žizn’ die Skizze über Sergei Witte heraus. Fachtexte zum Justizwesen und einzelne Ausgaben aus seinen „Erinnerungen eines Gerichtstätigen“ veröffentlichte Koni zudem im Verlag Majak: Vgl. Anatolij F. Koni: Sušče-glupye i umom priskorbnye. Iz vospominanij sudebnogo dejatelja, Petrograd 1922. Dieser Text stellt eine erweiterte Fassung der Erinnerungsschrift „Osvidetel'stvovanie duševno-bol’nych (1870-1895)“ dar, die erstmals 1907 in Konis Reihe in „Russische Altertümer“ [Russkaja Starina] erschienen war und in der es um die rechtliche Abklärung von psychisch Kranken geht. In einer Erklärung des Verlags Majak zur Publikation von 1922 heißt es, dass dies die Eröffnung einer ganzen Reihe von einzelnen Skizzen Konis aus den „Erinnerungen eines Gerichtstätigen“ sei, die dem nicht mehr erhältlichen ersten Band von „Auf dem Lebensweg“ entnommen und ergänzt worden seien. Davon scheint aber nichts verwirklicht worden zu sein. Eine weitere der Skizzen aus „Russische Altertümer“ [Russkaja Starina] erschien dafür beim 
beteiligte sich zudem an den Aktivitäten von „Recht und Leben“ [Pravo i Žizn’] in Zusammenhang mit der Neuausrichtung im Strafrecht, die sich in diesen Jahren abzuzeichnen begann. In der Strafprozessordnung der RSFSR von 1923 und den „Grundsätzen der Strafgesetzgebung der UdSSR und der Unionsrepubliken“ von 1924 wurde das Strafprozessrecht neu kodifiziert. Daran waren bürgerliche Spezialisten noch intensiv beteiligt, so klagte der marxistische Jurist und Bolschewik Nikolaj Vasil'evič Krylenko (1885-1938) 1922 gar, dass er sich bei der Ausarbeitung der neuen Strafprozessordnung gegen zwei bürgerliche Spezialisten habe durchsetzen müssen, die die Reformen von 1864 hätten wiederholen wollten. ${ }^{473}$ Im gleichen Jahr schrieb Koni in einem Brief, dass er nun einen Artikel mit dem Titel „Einführung in die Kommentare zum Strafprozesskodex 1922“ beendet habe. "Großen Kummer" habe ihm dies allerdings bereitet, da es einer „Totenmesse für die Gerichtsstatuten“ gleichgekommen sei, denen er „sein ganzes Leben lang gedient" habe. Aber er habe versucht, „Objektivität“ beizubehalten. ${ }^{474}$ Es war im Zuge dieser „Phase der Versöhnung“, als Koni auch von einem Gericht in Leningrad angefragt wurde, als „Konsultant" unter anderem bei schwierigen Gerichtsfällen mitzuhelfen. ${ }^{475}$ Das 1925 eröffnete „Kriminologische Kabinett“, das sich der Psychologie des Verbrechens widmete und dabei auch dringende Fragen der Zeit wie die steigende Kriminalität unter Kindern anging, lud Koni ebenfalls zur Teilnahme ein. ${ }^{476}$ Über einige Juristen, die in diesen Jahren verstarben, publizierte

Verlag Poljarnaja Zvezda, vgl. Anatolij F. Konı: Sud - nauka - iskusstvo. Iz vospominanij sudebnogo dejatelja. Petrograd 1923. Dies ist eine erweiterte Form von „Svedujuščie ljudi i ekspertiza“. Poljarnaja Zvezda hatte zuvor schon das bereits erwähnte „Erinnerung und Aufmerksamkeit“ herausgegeben. Aus der Reihe „Erinnerungen eines Gerichtstätigen“ erschien schließlich beim Verlag P. P. Sojkin auch noch „Priemy i zadači obvinenija“ sowie „Iz prošlovo peterburgskoj prokuratury“ als: Anatolij F. Koni: Priemy i zadači prokuratury. Iz vospominanij sudebnogo dejatelja. Leningrad 1924. Vollständig in der ursprünglichen Version brachte Koni die Texte in der 4. Auflage von „Auf dem Lebensweg“ I 1922 nochmals heraus. In Band III von „Auf dem Lebensweg“, der ebenfalls 1922 erschien, finden sich auch einige Rezensionen zu juristischen Büchern, die Koni in den vergangenen Jahren verfasst hatte.

473 Schultz: Russische Rechtsgeschichte, S. $325 \mathrm{ff}$ und Huskey: Russian Lawyers and the Soviet State, S. 87. Vgl. zu Krylenko und dessen enge Zusammenarbeit mit Pašukanis auch Sharlet: Pashukanis and the Withering Away of Law in the USSR, S. $170 \mathrm{ff}$.

474 Zitiert nach: VysockiJ: Koni, S. 414.

475 P. V. Gurevič: Stranički vospominanij Anatolij Fëdorovič Koni. In: Pravovedenie 3 (1971), S. 143 ff. Anfang 1924 wurde Petrograd nach dem Revolutionsführer in „Leningrad“ umbenannt, vgl. für die Hintergründe und Vorgeschichte des erneuten Namenswechsels Volkov: St. Petersburg, S. 337-339.

476 I. GRIL'/A. Sokolova: K 150-letiju so dnja roždenija A. F. Koni. Druz’ja i edinomyšlenniki i Poslednie gody žizni. In: Rossijskaja justicija 2 (1994), S. 33. In Konis Nachlass finden sich Einladungen zu Vorträgen im Kabinett wie z. B. vom 15. November 1926 eine zum 
Koni kurze Nachrufe. ${ }^{477}$ Parallel dazu engagierte er sich auch an den Universitäten Petrograds, an denen er zwischen 1918 und 1922 zu juristischen Themen unterrichtete. Inhaltlich ging es bei den meisten dieser Vorlesungen aber weniger um die Justiz als um moralische Fragen in Recht und Alltag, die zusammen mit Konis literarischen Publikationen im sowjetischen Russland im nachfolgenden TEIL DREI ins Zentrum rücken werden.

Als der Verlag Pravo i Žizn' schließlich 1923 eine knapp vierzigseitige Broschüre mit einer Kommentierung der neuen Strafprozessordnung veröffentlichte, fehlte darin Konis Beitrag. ${ }^{478}$ Der Herausgeber, der Jurist und Spezialist für das Strafrecht Nikolaj Nikolaevič Poljanskij (1878-1961), hatte Koni brieflichen Dank für seinen Artikel überbracht, aber auch angemerkt, dass man nicht sicher sei, ob er durch die Zensur gehe, auch wenn seine „objektive Bewertung“ des neuen Kodex durchaus deutlich werde. ${ }^{479}$ Als die Zeitschrift Koni im Folgejahr zu seinem 8o. Geburtstag eine Würdigung widmen wollte, entschuldigte sich Gernet in einem persönlichen Schreiben an Koni, dass diese leider nicht erscheinen könne. ${ }^{480}$

Auftritt des Psychologieprofessors Alekandr Petrovič Nečaev mit dem Titel: „Um i prestuplenie“, vgl. GARF F. 564, op. 1, d. 746. 1. 51. Auch Zettel mit Honorarzahlungen für Konis eigene Vorträge sind vorhanden, vgl. GARF F. 564, op. 1, d. 246, l. 40. Vgl. für eine kurze Übersicht zur Tätigkeit des „Kriminologischen Kabinetts“, das Ende der 192oer-Jahre geschlossen wurde: Anastasija ČAjkovskajA: Psichologija zla. Kak rabotal Leningradskij Kriminologičeskij kabinet. In: Argumenty i Fakty, 01. 04. 2015, www.spb.aif.ru/society/ people/1480412, Zugriff vom 11. 09. 2015.

477 Vgl. z. B. Anatolij F. Koni: Chranitel' idealov prava i svobody. Pamjati K. K. Arsen'eva. In: VL 5 (1919), S. 2-4; Anatolij F. KonI: N. V. Davydov. Pamjati ušedšich. In: VL 1 (1922), S. 22-23. Nikolaj Vasil'evič Davydov (1848-1920) war Mitherausgeber des geplanten mehrbändigen Werks zur Gerichtsreform, dessen erster Band 1915 erschien und an dem auch Koni beteiligt war, vgl. oben, S. 124. Ebenfalls u. a. im „Boten der Literatur“ erschien zudem ein Nachruf auf Gerichtsreformer Dmitrij Vasilevič Stasov (1828-1918). Diese Nachrufe veröffentlichte Koni z. T. auch in „Auf dem Lebensweg“ III bzw. IV, wo er zusätzlich vereinzelte seiner älteren Juristenporträts erneut abdruckte, wie jenes über Kavelin oder Rovinskij. Als neue umfangreiche Arbeit über einen Juristen verfasste Koni in diesen Jahren auch das bereits im ersten Teil der Dissertation erwähnte Porträt Andreevskijs.

478 N. N. Poljanskij (Hrsg.): Ugolovno-Processual'nyj Kodeks R. S. F. S. R. Sravnitel'nyj očerk novoj i staroj redakcii Kodeksa. Moskva 1923. Bei Pravo i Žizn' erschienen in den nachfolgenden Jahren auch weitere Kommentare zu Gesetzessammlungen, ohne dass Koni darin auftauchen würde.

479 Brief von N. N. Poljanskij an Koni, GARF F. 564, op. 1, d. 2940, 1. 11-11ob. Es ist wahrscheinlich, dass Poljanskij auf den Artikel von Koni zum Strafprozesskodex von 1922 anspielt.

480 „Recht und Leben“ [Pravo i Žizn’] widmete Koni 1924 die erste Ausgabe des Jahres. In einem Brief ließ Gernet Koni wissen, dass er eigentlich einen kleinen Gratulationsartikel verfasst habe, dass dieser aber nicht ins Journal gelangt sei. Dies ändere aber nichts an der Wertschätzung der Redaktion für Koni, vgl. IRLI F. 134, op. 3, d. 397, l. 12. 
Stark eingeschränkt, aber doch verblüffend deutlich eröffneten sich für Koni und weitere vorrevolutionäre Juristen in der Zeit nach 1917 gewisse Möglichkeiten, ihr Fachwissen und ihre klassischen Überzeugungen von einem liberalen Rechtswesen wieder einzubringen. Dieser Chance, auf seinem Fachgebiet tätig sein zu können, „ohne von seinen Überzeugungen zurückzutreten“, war sich Koni bewusst, und sie mochte ihren Teil dazu beigetragen haben, dass er nicht emigrierte. Doch der entscheidende Punkt scheint ein anderer gewesen zu sein. Fein säuberlich erstellte Koni nämlich nach 1917 eine Liste mit Argumenten, die für beziehungsweise gegen seinen Verbleib im bolschewistischen Russland sprachen. Während er in dieser Pro-und-Contra-Liste die juristische Tätigkeit zwar als Verbleibgrund aufführte, drehen sich doch mehrere der Argumente direkt um seine autobiografische Praxis. So sah er es als großen Nachteil, dass er im Falle der Emigration seine Bibliothek und persönliche Unterlagen hätte zurücklassen müssen. Ganz konkret schien ihm die Herausgabe von weiteren seiner Sammelbände „Auf dem Lebensweg“ im Ausland gefährdet. Aufgrund seiner "Unparteilichkeit“ - so führt er weiter auf - sei seine Teilnahme am öffentlichen Diskurs in Zeitungen und in der Literatur im sowjetischen Russland zwar schwierig, allerdings auch nicht schwieriger als im Ausland. ${ }^{481}$ An den Diskussionen in der Öffentlichkeit teilzunehmen und seine Erinnerungsschriften zu publizieren, war für Koni offensichtlich das entscheidende Argument für den Verbleib in Russland. ${ }^{482}$ Um durch seine autobiografischen Auseinandersetzungen mit der zarischen (Justiz-)Politik nach der Oktoberrevolution Einfluss auf die Debatten über vergangene und damit auch gegenwärtige und zukünftige Politik zu nehmen, publizierte Koni kurze Porträts wie beispielsweise zu Sergei Witte, und beorderte ältere Manuskripte aus dem Archiv zurück. Dorthin hatte er einige seiner autobiografischen Schriften wie im Fall der Zasulič-Erinnerung in seinem neuen Vorwort angedeutet - ab 1917 zur Aufbewahrung gegeben. ${ }^{483}$ Intensiv bemühte sich Koni in den frühen

481 GARF F. 564, op. 1, d. 17, 1. 1-3. Das Dokument ist nicht datiert. Die Archivbeschriftung nennt 1918 als frühst möglichen Verfassungszeitpunkt. Auf der „Pro“-Verbleib-Seite finden sich zudem Punkte wie sein körperlicher Zustand als alter Mann, die lieben Menschen, die er in Russland zurücklassen müsste, oder die Verbundenheit mit der Heimat.

482 Bakuncev erwähnt die Erinnerung des russischen Schriftstellers Vasilij Ivanovič NemirovičDančenko (1844-1936) an Koni, in der dieser ebenfalls festhält, dass Koni auch wegen seiner geliebten Bücher, Tagebücher und Notizen in Petrograd geblieben sei, vgl. Anton BAKunCev: Anatolij Fëdorovič Koni, russkaja ėmigracija i sovetskaja vlast'. In: Inye Berega. Žurnal o russkoj kul'ture za rubežom 3 (2011), S. 62.

483 Zum Archiv „Puschkinhaus“ und Konis Vereinbarung hinsichtlich seines Nachlasses ausführlich in TEIL DREI. Vgl. A. B. Muratov: A. F. Koni i Puškinskij Dom. In: V. N. Baskakov (Hrsg.): Puškinskij Dom. Stat'i. Dokumenty. Bibliografija. Leningrad 1982, S. 42 zu Koni, der seine Schriften ins Archiv gibt und schnell wieder zurückwill. Für die zahlreichen 
1920er-Jahren darum, Verlage zur Veröffentlichung dieser Werke zu finden. In den Entwürfen für die Inhaltsverzeichnisse seiner drei Folgebände von „Auf dem Lebensweg“ kommen auch die Schriften über die Entgleisung des Zarenzugs und den Fall Vera Zasulič vor. ${ }^{484}$ Für Letzteren und seine weiteren, allerdings oftmals nur in Stichworten skizzierten Porträts der politischen Elite des Zarenreiches interessierten sich gleich mehrere Publikationshäuser. In einem Brief vom März 1922 kontaktierte der Verlag Šipovnik Koni und verwies darauf, dass dieser mit einem Mitarbeiter des Unternehmens über sein Buch mit Erinnerungen an Staatsräte gesprochen habe. Gerne wolle ihm der Verlag dazu einen Vertrag unterbreiten. ${ }^{485}$ Der 1922/23 gegründete Petrograder Verlag Vremja schickte ein Jahr später ebenfalls einen Vertragsentwurf zur Herausgabe von Konis Skizzen an ehemalige Minister, Senatoren und Staatsräte. Bis Ende 1924 sollte Koni das Manuskript abgeben. Vremja war ein Verlag, der unter anderem zahlreiche Erinnerungen und Briefwechsel von Literaten der älteren Generation herausgab. ${ }^{486}$ Gleichzeitig interessierte sich Vremja zusammen mit dem Verlag Poljarnaja Zvezda - der schon 1922 einen Vertragsentwurf aufgesetzt hatte - auch für Konis Zasulič-Erinnerungen. ${ }^{487}$ Die Publikationsvorbereitungen schritten teilweise sehr weit voran. Das neue Vorwort zum Freispruch der Revolutionärin oder die lektorierte Reinschrift des Zarenzug-Manuskripts aus dem Jahr 1923 zeigen dies deutlich. Noch kurz vor seinem Tod im Jahre 1927 dachte Koni in einem Brief darüber nach, wie wichtig ihm gerade seine Erinnerungen an politische Akteure des Zarenreichs erschienen: „So vieles würde ich gerne aufschreiben, was mit meinem Tod in der Ewigkeit versinkt. Damit meine ich die Erinnerung an den Senat, den Staatsrat und die

Briefe, die Koni an die Verantwortlichen des Archivs schrieb, um gewisse Manuskripte wieder zu sich holen zu dürfen, vgl.: L. D. Zarodovaja: Perepiska B. L. Modzalevskogo s A. F. Koni. In: T. G. Ivanova (Hrsg.): Boris L’vovič Modzalevskij. Materialy k naučnoj biografii. Sankt-Peterburg 2001, z. B. S. 364-66.

484 In IRLI F. 134, op. 4, d. 89, 1. 6 das provisorische Verzeichnis zu Band III inklusive der Erinnerung an die Entgleisung und in IRLI F. 134, op. 1, d. 256, 1. $388 \mathrm{zu}$ Band V, wo beide Schriften aufgeführt sind.

485 Vgl. den Brief vom 28. 03. 1922 in GARF F. 564, op. 1, d. 245, 1. 36. Im gleichen Archivgut gibt es auch zwei vorgedruckte, noch nicht ausgefüllte Vertragsschablonen des gleichen Verlags.

486 M. Ė. Malıkova: Šum vremeni. Istorija leningradskogo kooperativnogo izdatel'stva „Vremja“ (1922-1934). In: Institut russkoj literatury Rossijskoj Akademii Nauk (Hrsg.): Instituty kul'tury Leningrada na perelome ot 1920-x k 1930-m godam. Materialy proekta. Sankt-Peterburg 2011, www.pushkinskijdom.ru/Default.aspx?tabid=10460, Zugriff vom 03. 11. 2016, v. a. S. 10. Für die Vertragsentwürfe vgl. IRLI F. 134, op. 4, d. 89, l. 4 und GARF F. 564, op. 1, d. 245, Dokument 13.

487 Vgl. GARF F. 564, op. 1, d. 245, Dokumente 10 und 12. 
Minister. “488 Die Wunschform macht deutlich, dass es in den meisten Fällen bei den Vertragsentwürfen geblieben war.

\section{Mission mit Hindernissen: (Selbst-)Zensur}

Während Konis Wirken schon auf dem juristischen Feld deutlichen Einschränkungen unterlag, musste er auch bei seiner Erinnerungsmission immer wieder Rückschläge einstecken. Dabei zeigt sich, dass er seine Einflussmöglichkeiten - wie schon in seinen um die Jahrhundertwende verfassten autobiografischen Darstellungen zu seiner beruflichen Tätigkeit - in engem Zusammenhang mit persönlichem Zugang zu Entscheidungsträgern sah. Während es im Imperium der Zar war, den Koni zumindest in seiner Darstellung von seinen politischen Analysen zu überzeugen versuchte, war es in der Sowjetunion nun der Volkskommissar Anatolij Vasil'evič Lunačarskij (1875-1933). Dieser war ab 1918 für über zehn Jahre der Hauptverantwortliche für die Bildungs- und Kulturpolitik im sowjetischen Russland. ${ }^{489}$ Lunačarskij berichtet in einer autobiografischen Schrift persönlich davon, wie Koni nach der Oktoberrevolution mit ihm habe sprechen wollen. Er habe sich versichern wollen, dass die neuen Machthaber nichts dagegen hätten, wenn er in Zukunft seine Erinnerungen bekanntmachen und Vorträge zu diversen Themen halten würde. ${ }^{490}$ An Lunačarskij wandte sich Koni nicht nur, um seine Erinnerungstätigkeit absegnen zu lassen, sondern auch, um scheinbar fehlerhafte Zensurentscheide untergeordneter Gremien umzustoßen. 1923 verbot die Moskauer Zensurbehörde die Publikation von Konis Skizze über Sergei Witte. ${ }^{491}$ Schon kurz nach der Oktoberrevolution war in Russland die Freiheit von Presse und Literatur durch verschiedene Zensurinstanzen stark eingeschränkt worden. Nachdem die Provisorische Regierung im März 1917 bis auf die Militärzensur jegliche Zensur aufgehoben hatte, verboten die Bolschewiki schon wenige Tage

488 Zitiert nach: GA4, S. 487 (Anmerkungen). Brief an M. N. Gernet, aus dem persönlichen Archiv von A. V. Gernet.

489 Sheila Fitzpatrick: Education and Social Mobility in the Soviet Union, 1921-1934. Cambridge u. a. 1979, S. 10.

490 Lunačarskij veröffentlichte in der Zeitschrift „Ogonëk“ 1927 Erinnerungen an verschiedene Personen, darunter Koni. Zitiert nach: Anatolij V. LunačArskiJ: Tri vstreči. Iz vospominanij ob ušedšich. In: Anatolij F. Koni: Izbrannoe, hrsg. u. mit einer Einleitung versehen v. Georgij M. Mironov und Leonid G. Mironov. Moskva 1989, S. 445. Dies ist die Darstellung von Lunačarskij. I. GRIL'/A. Sokolova: K 150-letiju so dnja roždenija A. F. Koni. Druz’ja i edinomyšlenniki i Poslednie gody žizni. In: Rossijskaja justicija 2 (1994), S. 31-34 sehen die Initiative für dieses Treffen beim Volkskommissar. Vgl. zu Lunačarskij und seinen Tätigkeiten im Kultur- und Literaturbetrieb in den 1920er-Jahren unten, S. 361. Domanova: Perepiska A. F. Koni kak istoričeskij istočnik, S. 127. 
nach der Oktoberrevolution erste Presseorgane. In den nachfolgenden Jahren wurde die Zensur immer reglementierter und umfassender; Ende 1920 brauchte jedes Manuskript für den Druck die Erlaubnis des Staatlichen Verlagshauses [Gosizdat]. Im Sommer 1922 entschied die Regierung schließlich, die Zensur nochmals stärker zu institutionalisieren, um die politische Überwachung effektiver zu gestalten. Dazu wurde die als Glavlit bekannt gewordene „Hauptabteilung für Literatur" geschaffen, die in der Folge die literarischen Freiheiten massiv beeinträchtigte. ${ }^{492}$ Als Koni den negativen Bescheid bezüglich seiner Skizze über den zarischen Minister erhielt, verfasste er ein Schreiben an Lunačarskij. Er charakterisierte sich darin als Beobachter seiner Zeit, der eine neutrale Wahrheit vermitteln wollte: „Ich glaube nicht, dass die Wahrheit über die Vergangenheit auf irgendeine Weise der Revolution und dem Wachstum des Bewusstseins eines freien Volkes schaden könnte. “493 Weiter führt Koni aus: „Mir bleibt nur noch eine Pflicht und eine Freude - so viel Wahres wie möglich über die Vergangenheit zu sagen. “494 Gleichzeitig schrieb Koni an den Verlag Pravo i Žizn', der sein Werk herausgeben sollte, dass Lunačarskij mit dem Bescheid der Zensurbehörde überhaupt nicht einverstanden sei und sich nun persönlich mit seiner biografischen Skizze über Witte vertraut machen wolle. ${ }^{45}$ Tatsächlich gelang es Koni, den Volkskommissar für die Veröffentlichung zu gewinnen. Bald hielt er auch Vorträge zu seinen Erinnerungen an den ehemaligen Minister. ${ }^{496}$ Als das Buch schließlich erschien, lobte man ihn für seine „Objektivität“. Darauf antwortete Koni: „Ich habe danach [nach Objektivität, CC] in allen meinen Arbeiten gestrebt, indem ich nicht als Richter, sondern als Beobachter aufzutreten versuchte. ${ }^{~}{ }^{497}$ Offensiv nutzte Koni im Kontext seiner Witte-Skizze die Selbstdarstellung als Zeitgenosse, der sich durch „Unparteilichkeit“ auszeichnete und ein neutraler Analyst des „Wahren“ sein wollte. Wie schon 1905 sah Koni einen Ausweg aus der polarisierten Situation, indem er nach außen auf seine Unabhängigkeit pochte und sich als Beobachter, Analysten ja auch neutralen juristischen Experten, niemals aber als Partei und Teil der Machtriege

492 StÄDtкe (Hrsg.): Russische Literaturgeschichte, S. 291 und Ermolaev: Censorship in Soviet Literature, 1917-1991, S. 1-3.

493 LunaČARSKIJ: Tri vstreči, S. 449. Es ist Lunačarskij selber, der einen Ausschnitt von Konis Briefes in seiner Erinnerungsschrift erwähnte.

494 Ebd., S. 449. Lunačarskij beendet seine Erinnerungsschrift mit der Versicherung, dass er sofort alles unternommen habe, um das „Missverständnis“ auszuräumen, das die Publikation von Konis Witte-Skizze verhindert habe.

495 Zitiert nach: GA5, S. 464-65 (Anmerkungen). Koni schreibt den Brief auch, um darum zu bitten, im Manuskript später nochmals eine kleine Änderung vornehmen zu dürfen, vgl. dazu unten, S. 276.

496 GARF F. 564, op. 1, d. 758, 1. 12.

497 Zitiert nach: Domanova: Perepiska A. F. Koni kak istoričeskij istočnik, S. 127. 
definierte. Lunačarskij ließ sich in diesem Falle davon überzeugen. ${ }^{498}$ Doch die rhetorische Absicherung durch „Objektivität" und „Wahrheit" war nicht immer ausreichend, um Konis Mission zur Erhellung der Zustände, Bedingungen und Erfahrungen aus den Zarenzeiten und ihren politischen Behörden zu befördern.

Noch in den 196oer-Jahren fühlten sich die sowjetischen Herausgeber der achtbändigen Ausgabe von Konis Schriften genötigt, einige grundlegende Bemerkungen zu seinen politischen Ansichten und Einschätzungen zu machen. So habe Koni auch Porträts von Persönlichkeiten verfasst, deren Rolle er überschätzt und die er zu Unrecht gelobt habe. Man habe deshalb nicht alle Skizzen in die Gesamtausgabe integriert. ${ }^{499}$ Tatsächlich fehlen zum Beispiel die Porträts der beiden Juristen und Staatsräte I. Golubev und S. Manuchin. Um die in den abgedruckten Schriften vorhandenen politischen Analysen Konis zu relativieren, wurde der Gesamtausgabe ein erklärender Aufsatz beigefügt. Darin heißt es, dass Koni leider manchmal Menschen gewürdigt habe, die dieser Ehrung nicht wert gewesen seien. So würden heutige Leser erkennen, dass die Memoiren zum Teil auch ein Podest für verschiedene liberale „Heilige“ darstellten, die schon lange von der Geschichte überholt worden seien. ${ }^{500} \mathrm{Zu}$ einzelnen Porträts haben die Herausgeber gar detaillierte Korrekturen an Konis Einschätzung vorgenommen. So heißt es in den Anmerkungen zur Erinnerungsschrift über Loris-Melikov, dass Konis Sichtweise charakteristisch für den liberalen Teil der Gesellschaft im Zarenreich gewesen sei. Diese hätten die Einsetzung von Loris-Melikov durch Alexander II. als Weg zu einer Konstitution gesehen. Deshalb äußere Koni sich nun so wohlwollend dem ehemaligen Minister gegenüber. Hinzu komme, dass dieser die Fähigkeit gehabt habe, Leute in seinen Bann zu ziehen. ${ }^{501}$ Koni - so soll dies von den Lesern des Porträts wohl verstanden werden - ließ sich vom Zeitgeist und der Persönlichkeit Loris-Melikovs blenden und war deshalb zu einer wenig realistischen Einschätzung gelangt.

Während die Herausgeber der Gesamtausgabe solche indirekten Korrekturen anbrachten, wurden Konis Erinnerungstexte in den 1920er-Jahren für die geplanten Veröffentlichungen auch direkt bearbeitet. Beispielhaft lässt sich das an

498 Wie stark Koni allerdings für die schlussendlich veröffentlichte Fassung des biografischen Porträts Abstriche machen musste, ist nicht ganz klar. In einer maschinengetippten Archivversion sind einige Teilsätze und Abschnitte durchgestrichen oder leicht abgeändert, z. B. zur Aussage des Zaren Alexanders III. über den Unfallhergang, vgl. GARF F. 564, op. 1, d. 66, 1. 5 bzw. Koni: Sergej Julevič Vitte. In: GA5, S. 248. Andere durchgestrichene Elemente sind aber trotzdem abgedruckt worden. Einige der veröffentlichten Abschnitte entsprechen sogar wortwörtlich der Version von 1904.

499 S. Volk/M. Vydrja/A. Muratov: Anatolij Fëdorovič Koni. In: GA1, S. 27.

500 Čunovskij: Anatolij Fëdorovič Koni. In: GA8, S. 22.

501 GA5, S. 457-58 (Anmerkungen). 
der Erinnerung an die Entgleisung des Zarenzugs aufzeigen. Im Archiv finden sich mehrere Abschriften des Textes, die mit verschiedenen Stiften bearbeitet worden sind. Einzelne Sätze oder ganze Teile wurden durchgestrichen, an gewissen Orten finden sich Unterstreichungen oder Fragezeichen. ${ }^{502}$ Auf einem der Exemplare steht schließlich erklärend vermerkt, dass es 1923 verfasst und von M. F. Teodorovič zum Druck vorbereitet worden sei. ${ }^{503}$ Gleich auf den ersten Seiten fallen Änderungen auf, die unmittelbar Konis Einschätzung des Zaren und dessen Stellenwert für Russland und seine Bevölkerung betreffen. So fehlen die in anderen Manuskriptversionen vorhandenen Aussagen Konis zur „berührenden Beziehung“, die Menschen aus allen Schichten der Bevölkerung zum Zaren hätten. ${ }^{504}$ Eine halbe Seite, auf der Koni von der Liebe zum Zaren, die tief im Volksherzen verankert sei, spricht, wurde vollständig weggelassen. ${ }^{505}$ Auch der von Koni en passant eingestreute Hinweis auf den Rechtsunterricht, den er einem Enkel von Zar Nikolaus I. einige Zeit erteilt hatte, erscheint im bearbeiteten Manuskript nicht mehr. ${ }^{506}$ Ähnlich sieht es aus mit dem Zasulič-Manuskript, das ebenfalls geschwärzte Stellen aufweist. Insbesondere die Worte zu den eigenen Ambitionen ganz zum Schluss der Schrift werden etwas abgeschwächt. ${ }^{507} \mathrm{Ob}$ solche Konzessionen an den politischen Mainstream durch Selbstzensur entstanden oder direkt vom Verlag diktiert wurden, muss dahingestellt bleiben. Mit großer Wahrschein-

502 Vgl. die Manuskripte in: GARF F. 564, op. 1, d. 203 und 204.

503 GARF F. 564, op. 1, d. 204, 1. 83. Es ist wohl die von M. F. Teodorovič erstellte Druckvorlage, auf die sich auch die Herausgeber der Gesamtausgabe berufen. Sie schreiben, dass sich ein Teil des Textes von Teodorovič im IRLI in St. Petersburg befinde und mit einer Handschrift im GARF abgeglichen worden sei. Leider werden keine genaueren Angaben gemacht, vgl. GA1, S. 527 (Anmerkung).

504 GARF F. 564, op. 1, d. 203, 1. 1-2.

505 Ebd. Hier sind die entsprechenden Stellen durchgestrichen worden. In der Version von Teodorovič in d. 204, 1. $82 \mathrm{ff}$ fehlen sie dann ganz. Vgl. zum Inhalt von Konis Aussagen deren Besprechung oben, S. 158.

506 GARF F. 564, op. 1, d. 203, 1. 87ob. Hier ist der Satz durchgestrichen worden. In der Version von Teodorovič in d. 204, l. $82 \mathrm{ff}$ (hier: 1. 152) fehlt er dann vollständig. Vgl. zu Konis Lehrtätigkeit für den Sohn des Großfürsten auch oben, S. 153.

507 Vgl. z. B. GARF F. 564, op. 1, d. 199, 1. 29-29ob. Von wann diese Schwärzungen stammen, kann nicht mit Sicherheit rekonstruiert werden. Es scheint aber sehr wahrscheinlich, dass sie im Zuge der Überarbeitung des Manuskriptes für eine mögliche Veröffentlichung in der Sowjetunion entstanden. Vgl. zum Schluss der autobiografischen Schrift und den verschiedenen Versionen davon auch oben, Fußnote 21 und 298 in TEIL ZWEI. Ähnliche kleinere Änderungen finden sich auch in einem Exemplar von „Triumvirn“, wo mit blauer Tinte einzelne Satzteile unkenntlich gemacht wurden. So z. B. Konis Beschreibung von Nikolaus II., der sich ,in kleinmütiger Angst“ beeilt habe, Russland die Freiheiten zu geben, gegen die sich Pobedonoscev so gewehrt habe, vgl. GA2, S. 310 bzw. die Durchstreichung in GARF F. 564, op. 1, d. 207, 1. 43ob. 
lichkeit änderte Koni selbst seine Einstellungen kaum grundsätzlich. Gerade Aspekte seiner Überzeugungen von der Figur des Herrschers, seinen Beratern und der Beziehung zur Bevölkerung tauchen sowohl in der Zarenzug-Erinnerung als auch in diversen anderen Texten immer noch auf. Wahrscheinlich ist sogar, dass Koni auch diese Aspekte hätte anpassen müssen und dazu nicht bereit war. Die Zensurvorgaben der Bolschewiki griffen sehr weit. Ziel der entsprechenden Behörden war es explizit, die Literatur von unangebrachten Erwähnungen und Beschreibungen vom zarischen Russland zu säubern. Auf Unmut der Zensoren stießen beispielsweise Parallelen zwischen der Kommunistischen Partei und Führungsfiguren aus dem vorrevolutionären Russland oder Erzählungen, die nicht in das neue historische Narrativ passten, wie beispielsweise anfänglicher Enthusiasmus der Bevölkerung für den Weltkrieg. Auch lobende Beschreibungen technologischer Errungenschaften aus der Zarenzeit wurden weggekürzt oder aller positiven Adjektive wie „außerordentlich“ oder ,erstklassig“ beraubt. ${ }^{508}$ In einem Nachruf auf Koni heißt es denn in Bezug auf die Erinnerungsschrift über die Entgleisung des Zarenzuges auch kryptisch, dass er sie zwar in den Jahren vor seinem Tod 1927 mehrfach zu veröffentlichen versucht habe. Einmal sei das Manuskript auch schon in die Typografie gegeben worden. Die Notwendigkeit, im Text einige erklärende Überarbeitungen vorzunehmen, habe aber den Druck verhindert. Für diese Überarbeitungen habe Koni weder die Kraft noch die Zeit gehabt. Dazu wird aus einem Brief Konis vom Juni 1925 zitiert, in dem Koni schreibt, dass er zu viel zu tun habe, um sich um den Text kümmern zu können. ${ }^{509}$ Neben Konis Unwille, seine Erinnerungen zu sehr zu beschneiden, dürften aber auch eigene Ansprüche an die Texte eine Rolle gespielt haben. Bezeichnend ist hierfür Konis Aussage, dass die Zasulič-Erinnerungen ohne eine Stellungnahme zum Graf Pahlen der späteren Jahre nicht publizierbar seien. Für die Verschrifflichung eines solchen Abschnittes fühle er sich aber zu krank. ${ }^{510}$ Angesichts der Tatsache, dass Koni

508 Ermolaev: Censorship in Soviet Literature, 1917-1991, S. 36-37 mit konkreten Beispielen hierzu aus der zeitgenössischen Literatur. Vgl. auch den Brief von Koni vom Dezember 1926, als er sich darüber lustig macht, dass man ihm fast verboten hätte, von „Peter dem Großen“ zu schreiben, GA8, S. 341 (Brief an S. F. Platonov vom 27.12.1926), vgl. zu Platonov unten, S. 354 .

509 UtevsкiJ: Poslednij ètap žiznennogo puti, S. 97-98. Ohne nähere Ausführungen schreibt auch Domanova: Perepiska A. F. Koni kak istoričeskij istočnik, S. 128, dass Koni einer ganzen Reihe von Einrichtungen seine Zusammenarbeit absagte, weil er seine Erinnerungsschriften und Lektionen nicht zu sehr zensieren wollte.

510 Vgl. S. 96 in der Erinnerungsschrift an Koni von Utevskij: Poslednij ètap žiznennogo puti. Es ist gut möglich, dass Koni in dieser geplanten Einführung noch von einem Treffen zwischen sich und Graf Pahlen kurz vor dessen Tod 1912, also einige Jahre nach der Fertigstellung des Manuskripts der Erinnerungsschrift, hätte erzählen wollen. Die Herausgeber 
nun schon über 80 Jahre alt war, ist es gut vorstellbar, dass ihm für die weiterführende Arbeit an seinen Erinnerungstexten und für die Ausformulierung seiner zahlreichen Stichwortsammlungen tatsächlich die Kraft fehlte. Wenn sich Konis Erinnerungsmission in der politischen Sphäre also nur eingeschränkt entfaltete, genügten die publizierten Texte und seine aktive Teilnahme an der öffentlichen Diskussion trotzdem, um ihn in eine schwierige Lage zu bringen.

\subsubsection{Erinnerte politische Haltungen}

in einer unklaren Kommunikationssituation

Wann immer Koni auf Kontextualisierung und Differenzierung beharrte und um Verständnis für die Handlungsbedingungen der politischen Akteure im Zarenreich bat, forderte er dies implizit auch für seine eigene Person. Die neuen Akten, Briefe und Selbstzeugnisse über die imperialen Machtspiele, die in der russischen Sowjetrepublik aus den Archiven geholt und öffentlich präsentiert wurden, bildeten dabei eine Grundlage, auf die Koni sich verlassen zu können glaubte. Wer immer wollte, konnte im sozialistischen Russland in den veröffentlichten Dokumenten nachlesen, in welcher politischen Großwetterlage sich Koni zu seiner Zeit am St. Petersburger Bezirksgericht und am Kriminalkassationsdepartement befunden hatte und was für eine Rolle er in den Augen der konservativen politischen Elite dort gespielt hatte. Der Einspruch Pobedonoscevs gegen seine Ernennung zum Oberstaatsanwalt war nur einer der entsprechenden Hinweise. In einem anderen Schreiben, das ebenfalls 1923 im Rahmen der Publikation der Korrespondenz Pobedonoscevs an die Öffentlichkeit gelangte, wurde explizit auf den ZasuličFall verwiesen und Koni als Verräter betitelt. Dabei handelte es sich um ein sehr emotionales Pamphlet, das kurz nach der Ermordung von Alexander II. von unbekannter Hand an den mächtigen Berater des neuen Zaren gesendet worden war. Wütend schimpft der Autor über die zu große Milde, die zum Attentat auf den Selbstherrscher geführt habe, und spricht sich gegen jegliche liberalen Zugeständnisse aus. Er regt sich darüber auf, dass die Richter überhaupt mehrere Stunden über das Schicksal der Zarenmörder beraten hätten. Alles „Verräter“ seien Leute wie Koni, der über Zasulič gerichtet habe. Nach langen Ausführungen von zwölf Punkten, wie man in Zukunft härter vorgehen solle, wird noch einmal versichert, dass Sozialisten „Bestien“ [zveri] und keine Menschen seien und deshalb außer-

der Gesamtausgabe haben eine Fußnote mit Aufzeichnungen eines mündlichen Berichts von Koni zu so einem Treffen eingefügt, vgl. dazu unten, S. 280 und 327 . Weiter schrieb Koni, dass für den Druck neben der Geschichte mit Graf Pahlen auch ein zusätzliches Kapitel zum Gang des Prozesses unabdingbar sei. 
halb des Gesetzes ständen. ${ }^{511}$ Narrativ und Niveau der Auseinandersetzung um den Umgang mit den oppositionellen, bisweilen terroristischen Kräften im späten Zarenreich werden durch diese Schmähschrift beispielhaft aufgezeigt. Mit seinen neu verfassten oder bearbeiteten Erinnerungsschriften versuchte Koni im sowjetischen Russland an diesem Vorwissen anzuknüpfen. Als „Verräter“ der zarischen Elite vermeintlich vor Kompromittierung sicher, verwies er in den 1920er-Jahren plötzlich offensiv auf konkrete Aktionen seinerseits, mit denen er vor Jahrzehnten die Regierungspolitik zu beeinflussen versucht hatte. Koni knüpfte damit bei Bemühungen an, die sich schon in seiner Schreibphase nach der Jahrhundertwende gezeigt hatten. Damals verwies er in verschiedenen seiner ausführlichen Memoiren auf die „Wahrheit", die er zeitlebens in den höchsten Regierungskreisen einzubringen versucht hatte. In „Triumvirn“ hatte er 1907 gar explizit vermerkt, dass er einen Zeitungsartikel und ein Memorandum, welche er zwischen 1878 und 1881 zuhanden der Zarenfamilie verfasst hatte, in seinen Memoirentext integrieren wolle. Da „Triumvirn“ aber damals noch nicht „ans Licht“ konnte, nahm Koni im sowjetischen Russland einen neuen Anlauf. Während er über Jahrzehnte hinweg die Öffentlichkeit im Glauben gelassen hatte, dass 1881 Arsen’ev den anonymen Artikel zur Ermordung des Zaren in Stasjulevičs Zeitung „Ordnung" verfasst habe, wollte er seine Autorschaft nun bekannt machen. ${ }^{512}$ Für die geplante Neuauflage des zweiten Bandes von „Auf dem Lebensweg“" verfasste Koni eine Ergänzung seiner autobiografischen Schrift über den „Boten Europas“ und seine Mitstreiter. In zahlreichen früheren Publikationen dieser Erinnerung hatte Koni Stasjulevičs „Ordnung“ jeweils nur knapp erwähnt. Nun führte er auf zusätzlichen Seiten detailliert aus, wie er im März 1881 einen Artikel in der Zeitung platziert hatte, der den Thronfolger von einer reformorientierten Haltung überzeugen sollte. ${ }^{513}$

511 Pobedonoscev: K. P. Pobedonoscev i ego korrespondenty, Bd. 1, S, 213-21, hier v.a. S. 214 und 220. Im Nachlass Konis ist auch dieser Ausschnitt aus dem Korrespondenzband von Pobedonoscev abnotiert festgehalten. GARF F. 564, op. 1, d. 221, 1. $56 \mathrm{ff}$ mit diversen handschriftlichen, wohl für Koni angefertigten Abschriften.

512 Vgl. für Konis Erwähnung des Artikels im nie publizierten „Triumvirn“ und den Inhalt des Textes oben, S. 155.

513 Dieser Einschub ist heute als solcher nicht mehr zu erkennen, vgl. KonI: „Vestnik Evropy“. In: GA7, S. 226-28. Die Autoren der Gesamtausgabe, in der die Skizze „Der Bote Europas“ abgedruckt ist, weisen darauf hin, dass der zweite Band von „Auf dem Lebensweg“" nach der dritten Auflage von 1916 noch für eine vierte Herausgabe bearbeitet worden war. In der Gesamtausgabe wurde die Version von „Auf dem Lebensweg“ II in der Auflage von 1916 abgedruckt und ergänzt um die Zusätze, die Koni für diese 4. Auflage vorbereitet hatte, vgl. GA7, S. 472 (Anmerkungen). Verwirrenderweise ist aber die Skizze von 1911 datiert. Nur wer den Text mit jenem in dem Sammelband „Auf dem Lebensweg“ von 1912 vergleicht, stellt fest, dass zwei Seiten dort noch fehlen. Fehlen tun sie auch in allen weiteren Veröffentlichungen aus der Zarenzeit. So verweist Koni z. B. im „Moskovskij 
Er beginnt mit der Vorgeschichte, so sei er am 1. März auf der Redaktion der Zeitung vorbeigegangen und habe da von der Ermordung des Zaren erfahren. Sofort habe er insistiert, dass man sich in so einem "historischen Moment" unbedingt „entschieden“ äußern müsse. Der Artikel, den das Blatt dann aber publizierte, habe aufgrund seiner "Unbestimmtheit" und gar "zweideutigen Interpretation“ von allen Seiten zu Befremden geführt. ${ }^{514}$ Noch am Tag des Erscheinens dieser Ausgabe habe Stajulevič ihn deshalb „hartnäckig und nachdrücklich“ dazu aufgefordert, sofort einen neuen Text zu verfassen, der am 3. März erscheinen sollte. Wortwörtlich führt Koni an, was er an den Thronfolger gerichtet damals genau geschrieben hatte. ${ }^{515}$ Nur die gescheiterte Wiederauflage von „Auf dem Lebensweg" II verhinderte, dass Konis Plädoyer an den Zaren für die Wiederaufnahme eines Reformkurses in Sowjetrussland zur Kenntnis genommen werden konnte. Erfolgreich gelang ihm dies dafür hinsichtlich des „Memorandums“. 1920 erschien in der historischen Zeitschrift „Taten und Tage“ [Dela i dni] das Schreiben, das Koni 1878 verfasst hatte und mit dem er den Thronfolger von den negativen Auswirkungen zu repressiver juristischer Verfolgung Andersdenkender hatte überzeugen wollen. ${ }^{516}$ Für die Publikation sah Koni den Titel „Politisches Memorandum des Jahres 1878. Erinnerungen um der Geschichte meiner Zeit zu dienen“ vor. ${ }^{517}$ Diese neue Titelwahl versinnbildlicht in zweierlei Hinsicht Konis Intentionen. Das „Memorandum“ ist nun „politisch“. Auf der semantischen Ebene wird dadurch ein starkes Zeichen gesetzt, dass nachfolgender Text mehr sei als „nur“ ein historisches Dokument über den repressiven juristischen Umgang mit Oppositionellen im im-

eženedel'nik“ 47 (1908), S. 23 auf die Zeitung „Ordnung“, ohne aber weiter ins Detail zu gehen. In Konis Nachlass findet man das gedruckte Buch von „Auf dem Lebensweg“ II, das er mit entsprechenden Einschüben für die 4. Auflage versehen hat, vgl. IRLI F. 134, op. 1, d. 88.

514 Koni: „Vestnik Evropy“. In: GA7, S. 226. Tatsächlich erschien die Zeitung am Montag, 2. März mit einem schwarzen Trauerrahmen und enthielt auf der ersten Seite neben der amtlichen Mitteilung vom Tod des Zaren auch einen kurzen Text, in dem die Rede ist von der schweren Stunde, unklaren Auswirkungen und der Zukunft des Volkes. Eine höhere Macht würde dieses Volk auf den Weg der Wahrheit, des Friedens und der Freiheit führen. Der Wille „des Höchsten“ [Vsevyšnjego] habe sich erfüllt und dies gelte es nun zu akzeptieren, vgl. Porjadok 60 (02.03.1881), S. 1. Gut möglich, dass es solche wenig pietätsvollen Aussagen waren, die den Unmut Konis und weiterer Kreise auf sich zogen.

515 Koni: „Vestnik Evropy“. In: GA7, S. 226-28.

516 Vgl. zum „Memorandum“, das in „Triumvirn“ erwähnt wird und dessen Inhalt auch oben, S. 154 .

517 Der Haupttitel ist russisch, der Untertitel französisch gehalten, also: Političeskaja zapiska 1878 goda. Mémoires pour servir à l'histoire de mon temps, vgl. GARF F. 564, op. 1, d. 157, 1. 1. 
perialen Russland der 1870 er-Jahre. ${ }^{518}$ Das „Politische“ impliziert - um sich einer Definition von Walter Sperling zu bedienen - eine angestrebte Breitenwirkung, Nachhaltigkeit und Verbindlichkeit. Elementare Themen wie Machtverhältnisse und Regeln des Zusammenlebens werden angesprochen. ${ }^{519}$ Mit dem neuen Titel definiert Koni sein „Memorandum“ als Analyse, mit der er Einfluss auf die Justizpolitik im Zarenreich hatte nehmen wollen. Er wird zum Akteur mit eigenen Visionen und Vorschlägen. Gleichzeitig zitiert er im zweiten Titelteil eine weitere Komponente der Funktion dieser Schrift. Sie soll der „Geschichte seiner Zeit“ dienen, also den Sowjetbürgern einen Eindruck von den Bedingungen im zarischen Russland geben. ${ }^{520}$ Politische Absichten seiner Person und historische Bedeutung des Dokuments unterstrich Koni 1920 neben dem Titel auch mit einer kurzen Einführung zum Text. Er erklärte darin, dass nun zwar über 40 Jahre vergangen seien, dass das „Memorandum“ aber für einen „Erforscher unseres vergangenen staatlichen und öffentlichen Lebens" doch nicht ohne Interesse sein möge. Mit diesem Schreiben habe er 1878 direkt an höchster Stelle gegen die Missstände bei der Bestrafung sogenannter aufrührerischer Propaganda zu protestieren versucht. ${ }^{521}$ Wenn so suggeriert wird, in der Folge habe es der Leser mit einem historischen

518 Vgl. zu den Möglichkeiten, etwas „politisch“ werden zu lassen, auch STEInMEtz/Haupt: The Political as Communicative Space in History, S. 25 bzw. die Überlegungen oben, S. 156.

519 Sperling: Jenseits von Autokratie und Gesellschaft, S. 32-33.

520 Koni zitiert hier wohl François Guizot (1787-1874), von dem ab 1858 mehrbändige Memoiren mit dem identischen Titel „Mémoires pour servir à l'histoire de mon temps“erschienen waren. Es entbehrt nicht einer gewissen Ironie, dass Guizots Vater ein französischer Advokat war, der im Nachgang der Französischen Revolution 1794 hingerichtet worden war. Sein Sohn spielte unter König Louis-Philippe I. (1773-1850) eine wichtige Rolle in der französischen Politik, vgl. Marguerite MAIRE: Guizot et ses cousins genevois d'après des lettres inédites. In: Mémoires et documents publiés par la Société d'histoire et d'archéologie de Genève, Bd. 40. Genève 1961, S. 581-82. François Guizot gehörte der „Partei der Doktrinäre“ an, die sich zum „Juste-Milieu“ zählte und sich für eine konstitutionelle Monarchie einsetzte. Das „Juste-Milieu“ (ungefähr: Beibehalten des Mittelmaßes) wurde als Begriff nach der französischen Julirevolution 1830 geläufig. Mit dem Schlagwort waren die gemäßigten Kräfte gemeint, die sich zwischen Liberalismus bzw. Radikalismus und Konservatismus sahen, vgl. Christian Koller: Juste-Milieu. In: Historisches Lexikon der Schweiz, zuletzt angepasst 2008, elektronisch verfügbar unter www.hls-dhs-dss.ch/ textes/d/D43197.php, Zugriff vom 20.11. 2015.

521 Koni: Iz vospominanij sudebnogo dejatelja. Zakon 19 maja 1871 g, S. 175-76. Diese Beschreibung gleicht ein Stück weit jener aus „Die Triumvirn“, vgl. Koni: Triumviry. In: GA2, S. 261. Die Unterschiede sind aber bezeichnend. Während Koni in „Triumvirn“ noch nacherzählt, wie er Pobedonoscev gegenüber von den Missständen bei der Verfolgung von der Verbreitung von „Propaganda“ berichtet habe und betont habe, dass der Zar leider umgeben von Lüge und Schmeichelei darüber nicht die Wahrheit wisse, fehlt Letzteres 1920 vollständig. 
Dokument zu tun, entspricht dies allerdings nicht den Tatsachen. Die Zeitschrift "Taten und Tage" [Dela i dni] oder Koni selbst zollten den neuen politischen Bedingungen Tribut und nahmen einige Justierungen am Quellentext vor. So wurden alle Formen des Wortes „Sozialismus“ weggelassen, beispielsweise spricht Koni im Original von 1878 von der „groben und sinnlosen Theorie der Anarchie, die das letzte Wort der Rädelsführer der russischen Sozialisten bildet [...] “. ${ }^{522}$ In der Zeitschrift wurde dieser Satz verkürzt auf: „Die grobe und grundlose Theorie der Anarchie [...] ${ }^{“ 523}$ Sogar die Analogie ganz zum Schluss der Schrift wurde bis zur Unkenntlichkeit verkürzt. Eigentlich sprach Koni davon, dass man mit der harten Vorgehensweise gegen die jungen Oppositionellen durch den Wunsch, „tatsächlich faule Früchte“ zu zerstören, auch solche traf, die „nur unreif“ gewesen seien und schließlich mit groben Händen ganze Äste des heimischen Baumes abgebrochen habe. ${ }^{524}$ In „Taten und Tage“ [Dela i dni] beschränkte sich das Bild auf die abgebrochenen Äste, keine Rede ist mehr von den „tatsächlich faulen Früchten“. 525

Diese Zensurierungen und die einleitenden Worte, die den Entstehungszusammenhang und die Adressierung der Schrift erläutern, sollten offensichtlich sicherstellen, dass das Dokument in seiner Bedeutung für Konis Rolle und Engagement in seinem Sinne von den sowjetischen Lesern wahrgenommen wurde. Dabei scheint er aber gespürt zu haben, dass die Offenlegung dieses Einflussversuchs ihm möglicherweise Missbilligung einbringen könnte. In seine einleitenden Worte wollte Koni deshalb ursprünglich noch einen zusätzlichen Abschnitt einfügen, der allfälliger Ablehnung zuvorkommen sollte. Darin schreibt er, dass sich vielleicht Kritiker finden könnten, die vergessen, dass man nun 42 Jahre von der damaligen Zeit entfernt sei, und die folglich bemängeln würden, dass die Skizze nicht auf die Ursachen der damaligen „politischen Gärung“ verweise. ${ }^{526}$

522 GARF F. 564, op. 1, d. 158, l. 29. Es handelt sich hier um ein Exemplar des „Memorandums“ (1. 28-530b), das zusammen mit vielen weiteren bearbeiteten Versionen in einem Archivgut liegt. Selber stellt es eine Reinschrift ohne jegliche Korrekturen dar. Es ist deshalb davon auszugehen, dass es sich um ein Original von 1878 handelt, das der Adaption von 1920 zugrunde gelegt wurde.

523 Koni: Iz vospominanij sudebnogo dejatelja. Zakon 19 maja 1871 g., S. 176. In der Gesamtausgabe von Konis Werken wurde zudem aus „Theorie der Anarchie“ neu nur noch „Anarchie“, vgl. KonI: Političeskaja zapiska 1878 goda. In: GA2, S. 331. Dies ist aber eine der ganz wenigen und inhaltlich nicht bedeutenden Änderungen zwischen der Version in „Taten und Tage“ [Dela i dni] 1920 und der Gesamtausgabe aus den 196oern. Die Herausgeber haben wissentlich oder unwissentlich die überarbeitete Fassung abgedruckt, ohne dass dies für die Leser ersichtlich wäre.

524 GARF F. 564, op. 1, d. 158, 1. 53-53ob.

525 Koni: Iz vospominanij sudebnogo dejatelja. Zakon 19 maja 1871 g., S. 188.

526 Ebd., S. 175-76. 
Doch solch grundlegende Kritik zu üben - rechtfertigt sich Koni selber -, hätte zur völligen Ablehnung des Textes geführt. Er habe aber gewollt, dass dieser ,reale Folgen" haben könne und nicht nur den „nüchternen Verstand“, sondern auch „das Herz ihres Lesers“ berühre. ${ }^{527}$ Dass dies auch durchaus der Fall gewesen sei, unterstreicht er in seinen einleitenden Worten - dieser Absatz ist in der Zeitschrift wieder abgedruckt - mit dem Verweis auf zahlreiche positive Rückmeldungen, die er schon zum Schreibzeitpunkt von diversen Politikern und Professoren erhalten habe, denen er das Dokument ebenfalls zugeschickt habe, und dass er gedenke, Auszüge aus diesen Briefen bald in seinen weiteren Bänden von „Auf dem Lebensweg“ zu veröffentlichen. ${ }^{528}$

Gestützt von unzähligen Publikationen von Quellen aus der imperialen Machtriege, die deren geradezu bösartige Einstellung oder faktische Unfähigkeit offenlegten, sah Koni den Boden bereitet, in den 1920er-Jahren eigene politische Aktionen und Haltungen aus dem 19. Jahrhundert publik zu machen. Mit Titelwahl, Einleitung und Verweis auf die gesammelten Rückmeldungen wichtiger Persönlichkeiten verdeutlichte Koni den Lesern von „Taten und Tage“ [Dela i dni], dass er das „Politische Memorandum“ als Zeugnis seiner Analysefähigkeit und seiner engagierten und hartnäckigen Haltung im Berufsleben verstanden haben wollte. Es scheint außer Frage, dass er mit der Veröffentlichung auch - ohne dies explizit zu machen - nochmals auf der Richtigkeit seiner damaligen Einschätzung beharrte und dadurch einmal mehr dem nachrevolutionären Publikum seine eigene Interpretation der politischen (Fehl-)Entwicklungen zu vermitteln versuchte. Gleichzeitig versprach er sich wohl auch, mit solch offensiver Kommunikation das Subversiv-Oppositionelle der eigenen Haltung zu Zarenzeiten öffentlich betonen

527 GARF F. 564, op. 1, d. 157, 1. 41.

528 Konkret schreibt Koni, dass er das Dokument 1878 und 1879 an verschiedene Minister und Mitglieder des Staatsrates geschickt habe und an seinen Professoren Boris Čičerin sowie an Stasjulevič und einige Landschaftsabgeordnete, vgl. KonI: Iz vospominanij sudebnogo dejatelja. Zakon 19 maja 1871 g., S. 175-76. Tatsächlich finden sich diverse Spuren von dieser Verbreitung seines Memorandums. Čičerin schrieb in einem Brief an Koni vom Januar 1879: „Vergeblich ist es, dort zu überreden und zu überzeugen, wo nichts gesehen und getan wird. " Zitiert nach: Leonov: Obščestvenno-političeskie vzgljady A. F. Koni v 6o-70 gody XIX veke, S. 154. Aleksej Michajlovič Žemčužnikov (1821-1908), dem früheren Verwaltungsbeamten und Revisor verschiedener Gouvernements, schickte Koni das „Memorandum“ im Jahre 1884 und betonte, dass er es für seine Bürgerpflicht gehalten habe, auf den „Irrweg“ [ložnyj put'] hinzuweisen, den die Regierung beschritten habe und immer noch beschreite, vgl. den Brief in GA8, S. 77-78 (Brief an A. M. Žemčužnikov vom 07. 12. 1884). Vgl. auch GARF F. 564, op. 1, d. 157, l. 650 ob für einen Brief Konis ebenfalls von 1884, wo er das „Memorandum“ erwähnt und andeutet, dass er sich zu einem späteren Zeitpunkt eine Publikation des Memorandums vielleicht sogar inklusive der Rückmeldungen von Čičerin und weiteren Persönlichkeiten vorstellen könnte. 
zu können. Dass er sich hier auf eine Gratwanderung begab, zeigen die Abschwächungen, die er im „Memorandum“ vornahm. Auch der Untertitel „Mémoires pour servir à l'histoire de mon temps" und die Einleitung, die das Dokument dem Bereich der wissenschaftlich interessierten, von „Objektivität“ geprägten Vergangenheitsforschung zuweisen sollten, zeugen hiervon. Koni ist sich wohl bewusst gewesen, dass seine Einstellungen und Überzeugungen im Russland der Bolschewiki keineswegs so progressiv erscheinen mussten, wie er sie selber gerne gesehen hätte. Ob die Leser wirklich sein eigenes Plädoyer für Relativierung und Differenzierung, das er all seinen Erinnerungstexten und Porträts beifügte, verinnerlicht hatten und ihn folglich nur im Vergleich zu den bösartigsten und unfähigsten der konservativen Elite beurteilten, muss ihm selber unklar gewesen sein. Sein prophylaktisches Aufgreifen möglicher Kritikpunkte macht das deutlich. Warum gerade seine einleitenden Worte von den "realen Folgen“, die er sich von einem gemäßigten Tonfall im Memorandum erhofft habe, in "Taten und Tage“ [Dela i dni] nicht abgedruckt wurden, kann nicht eruiert werden. Möglich, dass die Zeitschrift Platz sparen wollte, oder aber, dass Koni selber seine Rechtfertigungen, warum er nicht deutlicher auf die Ursachen für die „politische Gärung“ verwiesen hatte, schlussendlich für zu defensiv hielt. Ironischerweise trat jedoch genau das ein, was er offensichtlich befürchtet hatte. Die Veröffentlichung traf auf ein wenig wohlwollendes Publikum. Sie war aber nicht der einzige Anlass, der zu Kritik an Koni führte.

\section{Zwischen Emigranten und Bolschewiki}

Konis "Memorandum" wurde 1920 in zweierlei Hinsicht nicht so veröffentlicht wie geplant. Neben dem Absatz, in dem Koni die zurückhaltende Art des Textes mit dem zarischen Adressaten rechtfertigte, wurde auch der Titel weggelassen beziehungsweise verändert. Anstatt „Politisches Memorandum aus dem Jahre 1878. Mémoires pour servir à l'histoire de mon temps" erschienen Einleitung und Schrift in der Rubrik „Erinnerungen, Memoiren, Tagebücher und Briefwechsel“ unter dem Titel „Aus den Erinnerungen eines Gerichtstätigen. Das Gesetz vom 19. Mai $1871{ }^{\text {“ }}{ }^{229}$ Der Titel lehnte sich nun an die vielen anderen autobiografischen Kurzberichte Konis an, die er seit über einem Jahrzehnt zu seiner juristischen Tätigkeit in verschiedenen Zeitschriften publiziert hatte. Das Zeugnis wird so aus der „Sphäre“ des Politischen verdrängt, neu geht es lediglich noch um die Reaktion

529 Koni: Iz vospominanij sudebnogo dejatelja. Zakon 19 maja 1871 g., S. 175. Es kann nicht geklärt werden, ob Koni selber diesen Titel schlussendlich bevorzugte oder der Verlag dies eigenmächtig so entschied. 
auf ein Gesetz, das vor knapp 50 Jahren Willkür und Repression vorangetrieben hatte. Diese Verschiebung in der von Koni anvisierten Erinnerungsfunktion änderte aber nichts daran, dass die Publikation auf wenig Begeisterung stieß. Das Journal „Buch und Revolution“ [Kniga i Revoljucija] veröffentlichte Anfang 1921 eine Rezension zu „Das Gesetz vom 19. Mai 1871“. „Buch und Revolution“ [Kniga i Revoljucija] war eine Zeitschrift, die ab 1920 in großem Umfang Rezensionen zu Publikationen aus allen erdenklichen Themenbereichen veröffentlichte. Das erklärte Ziel war - wie die Herausgeber sich in der ersten Ausgabe ausdrückten -, Werke zu begutachten, die zwischen 1917 und 1920 in der Zeit des „neuen, freien, sozialistischen Russlands“ erschienen waren. ${ }^{530} \mathrm{Zu}$ Konis Text heißt es mit überheblichem Unterton: „Der unermüdliche Erinnerer der ,gerichtlichen Vergangenheit ${ }^{\prime}[\ldots]$ hat sein ziemlich naives Memorandum angeführt [...]." Man könne nicht anders - so die Rezension weiter - als anzumerken, dass solche „Memoranden“ sehr viel gewinnen würden, wenn sie irgendwo in einem Archiv gefunden und der Redaktion nicht vom Autor selber zugestellt würden. ${ }^{531}$ Dass Koni Naivität vorgeworfen wurde, dürfte ihn weniger getroffen haben als die Darstellung als Mann der Vergangenheit, der dem sozialistischen Russland seine fernen Erinnerungen aufzuzwängen versuchte.

Seine Vorahnung hinsichtlich möglicher Kritik am „Memorandum“ und seiner Person weist schon darauf hin, dass Koni nach der Oktoberrevolution nicht völlig den Rückzug in seine Vergangenheit angetreten hatte. Im Gegensatz zu Weggefährten wie Arsenev oder Andreevskij verharrte Koni nicht in Isolation. An zahlreichen Orten finden sich in seinem Nachlass gesammelte oder abnotierte Informationen zu Ereignissen im nachrevolutionären Russland. So beispielsweise Zeitungsartikel über die Hinrichtung des letzten Zaren, Listen mit Opfern des Weltkrieges zwischen 1914 und 1918 oder ein Artikel mit den offiziellen Freitagen des Jahres 1927.532 Alle drei Beispiele entstammen einer Sammlung von über einem Dutzend Notizbüchlein, die Koni ab 1918 anlegte und in denen er unter anderem Stichworte und Materialien zu Themen aufbewahrte, die ihn umtrieben. Die Übertitel darin lauten beispielsweise „Zum Verfassungsrecht“, „Zur Ethik“, „Über Selbstmorde“, „Aus dem Bereich Religion“, „Aus dem Bereich Geschichte“, „Für Puschkin“. 533 Alte Sammlungen, wie jene zum Fall Zasulič beziehungsweise seiner Erinnerungsschrift hierzu oder zum Themenbereich der Moral, setzte Koni fort. So bewahrt er zum Beispiel den langen Nachruf von Zasuličs einstigem

530 Kniga i Revoljucija: Ot redakcii. In: KR 1 (1920), S. 1.

531 M. MAVRIN: [Rezension über] „Dela i Dni“. Istoričeskij žurnal. Kniga pervaja. In: KR 8-9 (1921), S. 63 (Rezension zur Zeitschrift „Taten und Tage“, in der Konis Text erschien).

532 In der Reihenfolge der Erwähnung: IRLI F. 134, op. 1, d. 254, 1. 72, 1. 54, 1. 157.

533 In der Reihenfolge der Erwähnung: IRLI F. 134, op. 1, d. 254, 1. 2, 1. 8, 1. 8ob, 1. 11, 1. 14, l. 66. 
Lebensgefährten und politischem Mitstreiter Lev Dejč (1855-1941) auf, der 1919 nach Vera Zasuličs Tod in „Stimme der Vergangenheit" [Golos Minuvščego] erschienen war. ${ }^{534}$ Weiter finden sich Artikel zum Umgang der Sowjetbehörden mit Alkoholismus und mangelnder Arbeitsmoral. ${ }^{535}$ Die Wiedereinführung der Todesstrafe, gegen die Koni schon im Zuge der Niederschlagung der Revolution von 1905 angeschrieben hatte, ist ebenfalls ein präsentes Thema. ${ }^{536}$

Auch wenn Konis Erinnerungspraxis also durchaus in einer Wechselwirkung mit aktuellen Schreibanlässen und Entwicklungen von außen stand, deutete die Kritik der Redakteure von „Buch und Revolution“ [Kniga i Revoljucija] an, wie schwierig es nach der Oktoberrevolution war, „Kommunikationssituationen“ richtig einzuschätzen. Wenn Julia Herzberg von Autobiografik als „Ergebnis einer komplexen Kommunikationssituation“ spricht, meint sie damit die „Anrufungen“, die Institutionen, Publikationsorgane, aber auch Familie und Umfeld liefern können und aus denen oftmals Erinnerungen hervorgehen. ${ }^{537}$ Nach 1917 kam es zu einer Spaltung der russischen Gesellschaft, die die „Kommunikationssituation“ für Koni in einem völlig neuen Ausmaß verkomplizierte. „Buch und Revolution“ [Kniga i Revoljucija] machte sich scheinbar über den „unermüdlichen Erinnerer" Koni lustig, gleichzeitig war für Emigrantenkreise bereits die Tatsache, dass er sich noch in Russland aufhielt, skandalös. Nichts von dem war neu, sowohl Zensur wie auch Emigration waren bereits zur Zarenzeit ein russisches Charakteristikum. Neu war aber neben der Unberechenbarkeit, mit der sich die ideologischen Direktiven in Sowjetrussland entwickelten, vor allem die Breite des Kreises an Personen, die durch ihre politischen und gesellschaftlichen Überzeugungen ihr Leben nicht länger im Land verbringen wollten beziehungsweise konnten. Mit der Machtübernahme der Bolschewiki waren auch Menschen ins

534 IRLI F. 134, op. 15, d. 41. Vgl. zu Dejč auch Rindlisbacher: Leben für die Sache, S. 31. Weitere von Koni gesammelte Nachrufe auf Zasulič gibt es in GARF F. 564, op. 1, d. 523.

535 Vysockij hat sich die Packen mit Zeitungsartikeln in Konis Nachlass genau angeschaut und erwähnt diese in seinem Buch, vgl. Vysockij: Koni, S. 414-16. Er merkt dazu an, dass Koni das sowjetische Strafrecht gut gekannt und somit gewusst habe, dass dort keine Bestrafung von Betrunkenheit und Blaumacherei mehr vorgesehen war. Sicherlich habe er sich nun gefragt, wie die fehlende Arbeitsmoral anderweitig verbessert werden könne und dabei auf die Familie als Garant für eine moralische Grundlage gesetzt.

536 Vysockij: Koni, S. 417-18. Sogar der Entscheid einer Kommission rund um Lunačarskij, Rimski-Korsakows Oper „Die Legende der unsichtbaren Stadt Kitesch und der Jungfrau Fewronia“ nur eingeschränkt zur Aufführung zu erlauben, da in dieser „veraltete orthodoxe Philosophie“ vorkomme, bewahrte er auf. Die Oper, so Vysockij, sei eines der Lieblingswerke von Koni gewesen.

537 Julia Herzberg: Gegenarchive. Bäuerliche Autobiographik zwischen Zarenreich und Sowjetunion. Bielefeld 2013, S. 8-9. 
Exil gewandert, die in ihren Überzeugungen einige Übereinstimmungen mit Koni hatten und die deshalb umso schärfer über ihn urteilten. Besondere Reichweite erhielt ein Auszug aus dem Tagebuch der berühmten Kunstschaffenden aus dem „Silbernen Zeitalter“ Sinaida Hippius [Gippius] (1869-1945). ${ }^{538}$ Die literarischen Petersburger Kreise, in denen sich Hippius und ihr Ehemann Dmitrij Merežkovskij um die Jahrhundertwende aufhielten, wurden auch von Koni besucht. So traf er Merežkovskij beispielsweise im Salon der Baronessa Varvara Ivanovna Iskul' fon Gil'denbrandt (1850-1928), seines Zeichen einer der populärsten Petersburger literarisch-philosophischen Treffpunkte. ${ }^{539}$ Die Blütezeit von Symbolismus, Akmeismus und weiteren ästhetischen Neukonzeptionen der „Dekadenz" wurde von Koni allerdings inhaltlich skeptisch beurteilt. Er sah sie wohl als eine jener „Umwertungen“, die das Alte zu schnell verwarfen. ${ }^{540}$ Hippius fing zu Beginn des Ersten Weltkrieges, dessen Gewaltpotenzial sie tief erschütterte, mit dem Schreiben eines gesellschaftspolitischen Tagebuches an, das sie bis 1919 führte. ${ }^{541}$ Als die Provisorische Regierung die Macht in Russland übernahm, unterstützte Hippius den linken Flügel innerhalb der Regierung und setzte sich für einen sofortigen Friedensschluss ein. Als die Bolschewiki jedoch die Führung an sich rissen, mobilisierte sie alle Kräfte und schrieb gegen das neue Regime an. Doch ihre Möglichkeiten wurden immer stärker eingeschränkt, so dass sich Hippius und ihr Mann schließlich für die Emigration entschieden. ${ }^{542}$ Während ein großer

538 Sinaida Hippius bildete mit ihrem Mann Dmitrij Merežkovskij (1865-1941) im „Silbernen Zeitalter" der russischen Literatur und Kunst an der Wende vom 19. zum 20. Jahrhundert eine Schaffenssymbiose. Merežkovskij war durch historische Romane und kulturphilosophische Traktate über Tolstoi und Dostojewski bekannt geworden und profitierte von den originellen Ideen seiner Frau, die auch für weitere Poeten dieser Zeit als Inspiration diente und selber zahlreiche Erzählungen, Gedichtbände, drei Romane und drei Theaterstücke sowie eine Unzahl von Zeitungsartikeln und Literaturkritiken verfasste. Vgl. HippIus: Petersburger Tagebücher, 1914-1919, S. 447-50 ff (Nachwort von Christa Ebert) für eine kurze Übersicht zu Hippius' Schaffen, ihrer Beziehung zu Dmitrij Filosofov (1872-1940), ihrem Salon in St. Peterburg und der Presse- und Verlagstätigkeit des Ehepaars mit eigener Zeitschrift, wo sie ihre religiösen und philosophischen Vorstellungen verbreiteten.

539 SAšonko: A. F. Koni v Peterburge - Petrograde - Leningrade, S. 243-44.

540 Vgl. oben, S. 199. Koni, der mit der Literatur des 19. Jahrhunderts aufgewachsen war, konnte mit Hippius' wie Merežkovskijs Werken wenig anfangen, vgl. SAšonko: A. F. Koni v Peterburge - Petrograde - Leningrade, S. 249 und Sergej A. Vysockij: Sud'ja i prokuror. Istoričeskij roman. Moskva 1994, S. 350. Ausführlich zu Koni und Literatur in TEIL DREI.

541 Hippius: Petersburger Tagebücher, 1914-1919, S. 457-58 (Nachwort von Christa Ebert). Schon 1905 zeigte sich Hippius vom gewaltsamen Vorgehen der zarischen Truppen am „Blutsonntag“ schockiert und widmete sich fortan intensiv dem Kampf gegen die Autokratie, vgl. ebd., S. 453-54.

542 Ebd., S. 463-67. 
Teil ihrer Aufzeichnungen vorerst in Russland verblieb, schmuggelte Hippius ihr Tagebuch zum Zeitraum Juni bis Dezember 1919 - dem Moment ihrer sorgfältig geplanten Flucht - aus dem Lande. Das schwarze Heftchen schaffte es in ihrem Mantel eingenäht über die Grenze und wurde sogleich veröffentlicht. 1921 versah sie es mit einer Einleitung und publizierte es im Band „Das Reich des Antichrist“. Auch in der ins bulgarische Exil nach Sofia ausgewichenen russischen literarischpolitischen Zeitschrift „Russischer Gedanke“ [Russkaja Mysl'] erschienen im Januar/Februar 1921 die Tagebuchaufzeichnungen. ${ }^{543}$ Im Eintrag „St. Petersburg, Juni 1919 " heißt es unter anderem:

Ich muss wieder einen auf die „Totenliste“ setzen: A. F. Koni ist zu den Bolschewiki übergegangen! Der in ganz Petersburg bekannte Senator Koni, Schriftsteller und Lektor, der lahme, fünfundsiebzigjährige Greis, entschloss sich, für einen Wagen und eine erhöhte Ration Graupen „dem Proletariat zu dienen“. In diesem Sinne schrieb er an Lunačarskij. Jener zeigte den Brief überall herum: „Genossen, A. F. Koni ist unser! Da ist sein Brief." Es sind schon Vorträge angezeigt, die Koni für die Rotgardisten halten wird. Das jämmerlichste ist, dass er anscheinend keine besondere Not leidet. [...] Warum tut Koni das auf seine alten Tage? Er wird mehr Graupen haben, man wird ihn mit einem Wagen zu den Vorträgen abholen - aber es ist doch eine Schande $!^{544}$

Die „Totenliste“, von der Hippius hier schreibt, entsprach einer Liste mit Namen von Personen, die sie als „intellektuelle Überläufer“ taxierte. Darunter befanden sich zahlreiche ehemalige Freunde und einstmals nahestehende Personen, wie die

543 Hippius: Petersburger Tagebücher, 1914-1919, S. 471-72 (Nachwort von Christa Ebert) und Christa EвеRт: Sinaida Hippius, seltsame Nähe. Ein Porträt. Berlin u. a. 2004, S. 239. Zum Band „Das Reich des Antichrist“: Dmitrij S. MerežkovskiJ u. a.: Carstvo antichrista. München 1921. Das Buch stellt, wie der Titel schon deutlich macht, eine Auseinandersetzung mit den gesellschaftspolitischen Entwicklungen und persönlichen Erfahrungen der Autoren in Russland nach 1917 dar und enthielt neben Hippius' Tagebuch Texte wie z. B. von V. Sobin: Das Geheimnis der Bolschwisten; D. Filosofov: Unsere Flucht oder D. Merežkovskij: Das Reich des Antichrist. Der Bolschewismus, Europa und Russland.

Zitiert nach: Sinaida Hippius: Petersburger Tagebuch, hrsg. u. mit einem Nachwort versehen v. Christa Ebert. Berlin u. a. 1993, S. 42. Der hier erwähnte Brief von Koni an Lunačarskij wird auch zitiert in Kornej ČuкоvsкıJ: Anatolij Fëdorovič Koni. In: GA8, S. 6. Die Zitate aus dem Brief entsprechen dabei genau jenen, die Lunačarskij selber in seiner nach Konis Tod erschienenen kurzen Erzählung über das Treffen zwischen ihm und dem ehemaligen Staatsrat und Senatoren aufführte. An dieser Stelle allerdings nicht in Form von Briefzitaten, sondern als habe sich Koni im persönlichen Gespräch so ausgedrückt, vgl. LunAČARSKIJ: Tri vstreči, S.444-49. 
berühmten Poeten Aleksandr Block (188o-1921) und Andrej Belyj (188o-1934). ${ }^{545}$ Die Emigrantenszene erhielt über Hippius' Tagebuchauszug, in dem sie auch Koni auf dieser Liste platzierte, Kenntnis von dessen Erinnerungsmission im sowjetischen Russland. Seine Erinnerungspraktiken und Vortragstätigkeiten wirken in Hippius' Darstellung wie Akte des Verrates, die er um finanzieller Besserstellung wegen eingegangen war. Diese Auffassung blieb nicht unwidersprochen, nur wenig später erschien gleich in mehreren Emigrantenzeitschriften eine andere Einschätzung von Konis Verhalten. „Für die Sache des Volkes“, ein Organ der Sozialrevolutionäre, druckte 1921 in Revel' in Estland eine Verteidigung gegen den „Brandanschlag auf die Ehre“ Konis ab. ${ }^{546}$ Im Mai nahm die einflussreichste und populärste Emigrantenzeitung „Letzte Neuigkeiten“ [Poslednie Novosti] in Paris die Geschichte auf. Die Zeitung verwies auf den in Estland erschienenen Brief einer Dame und zitierte daraus: „Persönlich bekannt mit A. F. Koni und Besucherin seiner Lektionen und Vorträge im dritten Jahr, halte ich es für meine Pflicht zu erklären, dass diese Informationen [aus dem Tagebuch von S. Hippius, CC] nicht der Wahrheit entsprechen." Niemals habe sich Koni den Bolschewiki „ergeben“ und auch keine Lektionen vor Rotarmisten gelesen. Die Lektionen hätten vielmehr an der Universität stattgefunden. Pferd und Wagen hätten ihn tatsächlich eine Zeitlang von zuhause abgeholt, da er aufgrund seiner körperlichen Verfassung den Weg nicht ohne Hilfe geschafft habe. Er schätze sein Wissen und seine Erfahrungen aber höher als eine Droschke. Hätte er sich nämlich ,ergeben“, würde er jetzt „im Automobil“ zu den Lektionen fahren. ${ }^{547}$

Die Worte zu seiner Verteidigung bewahrte Koni ebenso in seinem persönlichen Archiv auf wie die Vorwürfe von Sinaida Hippius. ${ }^{548}$ Dies legt nahe, dass die Auseinandersetzung um seine Person nicht spurlos an Koni vorbeiging. Ein befreundeter Schriftsteller erinnert sich, dass er Koni „krank“ und „wie betäubt“ angetroffen habe, nachdem 1921 die Nachricht von Hippius’ Aussagen den Weg nach Petrograd gefunden hatte. ${ }^{549}$ Die Härte des Urteils der Künstlerin des „Silbernen Zeitalters" war dabei symptomatisch für die Verschärfung im Umgang mit

545 Hippius begann in jenem Teil ihrer „Petersburger Tagebücher“, der erst später veröffentlicht werden konnte, im Eintrag vom 11. Januar 1918 eine solche Liste, vgl. Hippius: Petersburger Tagebücher, 1914-1919, S. 292-96. Vgl. zur Aufbewahrungs- und Veröffentlichungsgeschichte der Tagebücher das Nachwort von Christa Ebert, ebd., insb. S. 471-74.

546 Vgl. zur Zeitung Sergej G. IsA Kov: Russkie v Ėstonii, 1918-1940. Istoriko-kul'turnye očerki. Tartu 1996, S. 156-57.

547 [Unbekannte Autorin]: „Podžog česti“ A. F. Koni. In: PN, 04. 05.1921, S. 3.

548 GARF F. 564, op. 1, d. 4216 und GARF F. 564, op. 1, d. 4217.

549 Bakuncev bezieht sich erneut auf Nemirovič-Dančenko, vgl. BAKuncev: Anatolij Fëdorovič Koni, russkaja èmigracija i sovetskaja vlast', S. 59. Vgl. auch Domanova: Perepiska A. F. Koni kak istoričeskij istočnik, S. 127. 
der Heimat durch die Exilrussen. Für Hippius stellte das sowjetische Russland ein „Reich des Bösen“ schlechthin dar. Eine unsichtbare Linie trennt für sie fortan Kulturbewahrer und Kulturzerstörer. Jegliche Kooperation mit den Bolschewiki beantwortete sie mit totaler Verdammung. Wenn sie Koni nun ebenfalls öffentlichkeitswirksam auf ihre „Totenliste“ setzte, passte das zu „dem ihr eigenen radikalen Maximalismus ${ }^{\text {“ }}{ }^{550}$ Das Führen von solchen Listen fungierte offensichtlich als Möglichkeit zur Orientierung in den sich so elementar verändernden äußeren Bedingungen. Es erstaunt nicht, dass Koni - allerdings im Gegensatz zu Hippius nicht öffentlich - auch selber solche Listen anlegte. Im gleichen Heft, in dem sich Koni Stichworte für seine Erinnerungen an den Staatsrat aufnotierte, gibt es auch eine Auflistung von Dutzenden von Namen. Koni scheint seine Bekanntschaften der letzten Jahre und Jahrzehnte Mitte der 1920er-Jahre in ein Bewertungssystem eingeordnet zu haben. Während Hippius eine unmissverständliche Schwarz-WeißAufteilung wählte, war Konis Raster feinmaschiger. Es gibt die Rubrik „Freunde“, mit Graf Gejden, und jene der „langjährigen Kollegen“ [sotrudniki žizni], in der zum Beispiel Arsen'ev zu finden ist. Weiter gibt es Namen unter den „Guten Erinnerungen“ und gar „Herzlichen Erinnerungen“, worunter zum Beispiel jene treuen Frauen fallen, die Koni im Alter begleitet und unzählige Seiten seiner Texte aufgesetzt haben. Daneben stehen die „Zwiespältigen Erinnerungen“ mit Tagancev oder Andreevskij und die „Schlechten Erinnerungen“ mit ca. 20 Namen. ${ }^{551}$ Ähnliches Einordnen der Menschen aus Gegenwart und Vergangenheit zeigt sich auch in der Organisation seines Nachlasses, wo Koni Rubriken aufstellte mit Titeln wie „Feinde“, „Liebe Verstorbene“ oder „Zu Lebzeiten Gestorbene“. Korrespondenz beschriftet er mit "moralisch Dahingegangene “ ${ }^{553}$ Zeugen dieser Versuche der Orientierung sind weiter auch Listen mit Informationen zu „Russen im Ausland“, die Koni in seinen Notizbüchern anlegte. Darin zählte er auf, welche russischen Publikationsorgane von welchen Exilgruppierungen wo betrieben wurden, zum Beispiel der „Sozialistische Bote“ von den „linken Menschewiki“

550 HippiUs: Petersburger Tagebücher, 1914-1919, S. 467-68 (Nachwort von Christa Ebert). Von diesem Radikalismus distanzierte sich die Redaktion von „Russischer Gedanke“ [Russkaja Mysl'] ein Stück weit. Sie druckte vor dem Tagebuch eine kurze Erklärung. Darin heißt es, dass das Tagebuch als „menschliches Dokument“ von großer historischer Bedeutung abgedruckt werde und nicht als rein literarisches Werk. Gleichzeitig betont die Redaktion, dass sie mit den Meinungen von Hippius vielfach überhaupt nicht einverstanden sei, aber auch keine Zensur habe ausüben wollen, vgl. Russkaja Mysl': Ot redakcii. In: RM, Januar-Februar (1921), S. 139.

551 IRLI F. 134, op. 1, d. 147, 1. 30-31.

552 IRLI F. 134, Op. 4, d. 385, l. 19.

553 Svetlana A. Domanova: Perepiska A. F. Koni kak istoričeskij istočnik. Avtoreferat dissertacii na soiskanie učenoj stepeni kandidata istoričeskich nauk. Moskva 1999, S. 14. 
und „Morgenröte“ von den „rechten Menschewiki“ und in Paris natürlich die Zeitung „Letzte Neuigkeiten“" [Poslednie Novosti]. ${ }^{554}$ Weiter notierte er die Anzahl Russen, die sich in Berlin einfanden und welche Profession sie ausübten. Viele von ihnen seien Ärzte oder Advokaten, oftmals jüdischer Abstammung. Auch Anhänger der Weißen Armee, wie zum Beispiel die „Markovcy“, fänden sich dort. ${ }^{555}$ Vor dem Hintergrund dieser komplexen und oftmals rigoros urteilenden Emigrantenszene versuchte Koni nun wohl gerade aufgrund der erfahrenen Kritik proaktiv zu agieren. Er stellte seine Vortragstätigkeit und seine Erinnerungsversuche im bolschewistischen Russland nicht ein, aber er bemühte sich, die Signale ins Ausland zu kontrollieren. ${ }^{556}$ In Briefen tauschte er sich mit ausgewanderten Bekannten aus und brachte dabei die Sprache immer wieder auf seine Texte. Besonders stark auf das Thema Erinnerungen und Veröffentlichungen fokussiert der Briefwechsel zwischen Koni und dem emigrierten Anwalt Gruzenberg. So schreibt dieser zwischen 1925 und 1926 mehrfach aus dem Exil in Nizza an Koni, welche Artikel dort in welchen Zeitungen und Zeitschriften erscheinen würden. Zudem nimmt Gruzenberg Bezug auf Erinnerungsschriften Konis und betont, er habe dessen Bände und Texte gelesen. ${ }^{557} 1926$ wandte sich Koni ganz konkret an einen befreundeten emigrierten Juristen, um diesen zu bitten, dafür zu sorgen, dass die Emigrantenpresse der staatlichen Pension, die er erhielt, keine größere Bedeutung beimesse. Konis Mittelsmann nahm dazu mit P. N. Miljukov, dem ehemaligen Kadettenführer und Chefedaktor von „Letzte Neuigkeiten“ [Poslednie Novosti], Kontakt auf. 558

554 IRLI F. 134, op. 1, d. 254, 1. 362ob-363.

555 Ebd., 1. 363. Die Weiße Armee, bestehend aus Gegnern der Bolschewiki mit sehr verschiedenen politischen Vorstellungen, formierte sich in Süd- und Nordrussland sowie in Sibirien und brachte mit Unterstützung der Westmächte im Verlaufe des Bürgerkrieges Sowjetrussland in große Bedrängnis. Erst im November 1920 entschied die Rote Armee die Kämpfe endgültig für sich, vgl. Haumann: Geschichte Russlands, S. 346-47. Sergej Leonidovič Markov (1878-1918) war ein hoher Militär in der Weißen Armee. Vgl. Karl SCHLÖGEL: Das russische Berlin. Ostbahnhof Europas. München 2007, S. 113-26 mit einer Übersicht zu den verschiedenen russischen Emigrantengruppen gerade in Berlin und ihren Publikationsorganen.

556 Solche Signale konnten sich tatsächlich sehr schnell verbreiten. Die russische Emigrantenszene mit ihren vielen verschiedenen Zentren war eng miteinander verbunden. Dank dem dichten Netz von Zeitungen, Verlagen und Buchhandlungen gerade im „russischen Berlin“ war man mit der Diaspora auf der ganzen Welt und natürlich auch mit der Sowjetunion in Kontakt, vgl. SCHLÖGEL: Das russische Berlin, S. 107 und 139.

557 GARF F. 564, op. 1, d. 1668, insb. 1.13 und 15.

558 Domanova: Perepiska A. F. Koni kak istoričeskij istočnik, S. 126-27. Für eine Pension hatte sich die Akademie der Wissenschaften eingesetzt, der Koni seit Jahrzehnten angehörte, vgl. dazu TEIL DREI. In einem Brief vom August 1926 erwähnt Koni die Pension. 
Während Koni im Blick zu behalten versuchte, wie liberale Gesinnungsgenossen im Ausland auf seine Erinnerungspraktiken und damit verbundene Kooperation mit den offiziellen Behörden in der Sowjetunion reagierten, musste er sich auch im Inland dauernd neu orientieren. In einem Brief an Aleksandr Ivanovič Sadov (1850-1930), ehemaliger Professor der klassischen Philologie an der „Geistlichen Akademie Sankt Petersburg“, äußerte er sich am 24. Oktober $1923 \mathrm{zu}$ einem Kritiker. Dieser fand, so wird im Brief rekapituliert, dass Koni in seinen Bemühungen, dem Volk Rechtssinn und moralische Gerechtigkeit beizubringen, nicht die ehrenvolle Rolle eines Terroristen eingenommen habe. Spöttisch schreibt Koni Sadov: „Wer ist heute schon nicht Professor - abgesehen von den echten? ${ }^{\text {“ }} 559$ Und fügt trotzig an, wenn der Kritiker erst den in Vorbereitung begriffenen fünften Band von „Auf dem Lebensweg“ lese, habe er noch mehr Gründe, ihn der „Verweigerung der Verherrlichung von politischen Morden und der Anstiftung dazu“ zu beschuldigen. ${ }^{560}$ Während Koni sich hier unbeeindruckt gab, nahm er in anderen Fällen eine defensivere Rolle ein. Insbesondere wenn er zum Gegenstand von Erinnerungen von Zeitgenossen wurde, mit deren Darstellung er nicht einverstanden war. Vor dem Hintergrund der politischen und gesellschaftlichen Prämissen im nachrevolutionären Russland achtete Koni mit besonderer Aufmerksamkeit auf die Art und Weise, wie er und sein Tun von anderen in der Öffentlichkeit präsentiert wurden. In regelrechten „Erinnerungsduellen“ berichtigte er, was er an Darstellungen seiner Person für nicht korrekt hielt oder was einen ungünstigen Eindruck hinterlassen könnte. Sidonie Smith und Julia Watson prägten den Begriff des „Writing back“ [Zurückschreiben] für die Möglichkeit von Individuen, auf die „kulturellen Geschichten“ zu reagieren, mit denen sie konfrontiert werden, und so Handlungsfähigkeit zu gewinnen ${ }^{561} \mathrm{Im}$ Moment, in dem im In- und Ausland in großem Ausmaß Erinnerungen über das zarische Russland und seine Exponenten veröffentlicht wurden und in dem sich gleichzeitig in der Sowjetunion ein völlig neues Wertesystem entwickelte, schien die Kontrolle über die Wahrnehmung der eigenen Person besonders elementar.

Diese gebe ihm ein ungutes Gefühl, da so viele andere würdige Persönlichkeiten darauf verzichten müssten. Aber er schreibt auch, dass die Zahlung ihm nun die finanzielle Sicherheit verschaffe, sich noch intensiver seinen Memoiren zu widmen und nur mehr in Extremfällen Vorträge zu halten, vgl. Vysockij: Koni, S. 418-19 bzw. GA8, S. 338 (Brief an Vladimir F. Džunkovskij vom 12. 08.1926). Vgl. zu Džunkovskij unten, Fußnote 443 in TEIL DREI.

559 Kursivsetzung im Original, zitiert nach: GA8, S. 317 (Brief an A. I. Sadov vom 24. 10. 1923). Vgl. zu Sadov GA8, S. 502 (Namensverzeichnis).

560 GA8, S. 317 (Brief an A. I. Sadov vom 24.10.1923).

561 Smith/Watson: Reading Autobiography, S. 235. Smith und Watson erstellen ein „tool kit“ zur Interpretation von Lebensnarrativen. Dabei sprechen sie von „writing back“. 
„Writing back“" wurde von Koni deshalb wörtlich umgesetzt, indem er nicht nur die Übersicht über Erinnertes zu behalten versuchte, sondern auch „zurückschrieb“, wo er es für nötig hielt. So forderte Koni beispielsweise seine Skizze über Sergei Witte nochmals vom Verleger zurück, weil „gestern“ der dritte Band von Wittes Memoiren in Russland erschienen sei und er darin falsche Angaben des Politikers zu seiner und Konis Rollen nach der Entgleisung des Zarenzuges 1888 gefunden habe, die es im Porträt noch richtigzustellen gelte. ${ }^{562}$ Eine Ausgabe von Wittes Aufzeichnungen war posthum 1922/23 in Berlin auf Russisch erschienen und sogleich in der Sowjetunion als Kopie herausgegeben worden. ${ }^{563}$ Angeblich über Nacht hat Koni diese autobiografischen Verlautbarungen also studiert und sich sogleich um Korrekturen bemüht. Von seinem Interesse an Wittes Darstellungen zeugen auch seitenweise Abschriften aus dessen Memoirenbänden, die sich in Konis Nachlass befinden. ${ }^{564}$ Während Koni hier Wittes Aussagen über seine und Konis Rollen und Ansichten bei der Untersuchung der Entgleisung des Zarenzugs korrigierte, ist es an anderer Stelle der Zasulič-Fall, den Koni auf seine Weise er-

562 Vgl. den oben, S. 257 bereits erwähnten Brief, GA5, S. 464-65 (Anmerkungen). Diese Berichtigungen Konis wurden tatsächlich noch in den Text aufgenommen. Das mit der gedruckten Version beinahe identische Manuskript der Ergänzung findet sich hinten in einer Aktenmappe mit einer maschinengetippten Version der Skizze über Witte, die stark bearbeitet wurde, vgl. GARF F. 564, op. 1, d. 66, 1. 18-19. Die Herausgeber der Gesamtausgabe entschieden sich, die handschriftlichen Ergänzungen zur Erinnerung an den Unfall des Zarenzugs hinzuzufügen, vgl. KonI: Krušenie carskogo poezda v 1888 godu. In: GA1, S. 493-95. Konkret schreibt Koni, dass einige Stellen im 3. Band von Wittes Memoiren nur mit völligem Gedächtnisschwund zu erklären seien. So bezeichne sich Witte als Experte im Rahmen der Unfalluntersuchung, während er doch als Zeuge vorgeladen worden sei, was unmöglich zusammengehen könne. Zudem behaupte Witte in seiner Erinnerung, dass Koni im Gegensatz zu ihm keinesfalls die zuständigen Minister habe zur Verantwortung ziehen wollen. Dem widerspricht Koni in seiner Berichtigung mit Verweis auf seine Aussagen zur Rolle von z. B. dem Verkehrsminister Konstantin Nikolaevič Poset (1819-1899). Tatsächlich entschied der Staatsrat entgegen Konis Empfehlungen, den Verkehrsminister, der nach dem Unfall von seinem Amt zurückgetreten war, nicht noch gerichtlich zu belangen, vgl. Schenk: Russlands Fahrt in die Moderne, S. 315.

563 Francis W. Wcislo: Tales of Imperial Russia. The Life and Times of Sergei Witte 1849-1915. Oxford 2011, S. 4. Vgl. zu den Erinnerungen Wittes und deren Publikation ebd., S. 4-6. Witte schrieb zwischen 1907 und 1912 ein 3500 Seiten starkes Manuskript mit „Notizen“ [Zapisi]. Daneben begann er 1911 mit einem „Erinnerungen“ genannten autobiografischen Werk. Die Berliner Herausgabe wurde vom liberalen Rechtsgelehrten und Freund der Familie Iosif Vladimirovič Gessen (1865-1943) konzipiert und um ein Vorwort der Witwe ergänzt. Für die Ausgabe in Russland verfasste wie schon bei der Korrespondenz von Pobedonoscev der marxistische Historiker Pokrovskij ein Vorwort. Zuvor war 1921 schon eine englische Übersetzung der „Zapisi Grafa Vitte“ in New York erschienen.

564 GARF F. 564, op. 1, d. 424. 
innert haben möchte. Das vom emigrierten Juristen Karabčevskij 1921 in Berlin veröffentlichte autobiografische Werk „Was meine Augen gesehen haben“ bietet Koni Anlass zu einem eigenen kurzen Erinnerungstext. ${ }^{565}$ In dem knapp siebenseitigen handschriftlichen und wohl nicht publizierten Dokument heißt es, dass $\mathrm{ihm}$ „Was meine Augen gesehen haben“ zufällig in die Hände geraten sei. ${ }^{566} \mathrm{Ohne}$ viel Umschweife kommt Koni schon auf der ersten Seite auf eine konkrete Stelle in Karabčevskijs Autobiografie zu sprechen: den Zasulič-Fall. Er zitiert Karabčevskijs Charakterisierung seiner Person: Koni habe mit seinen „listigen Methoden“ versucht, die Geschworenen zumindest zu einem milden Schuldspruch zu bringen. Ein solches Urteil - so Koni - sei für ihn ,ziemlich unerwartet und eigenartig“.567 Auf den nachfolgenden Seiten geht er dazu über, seine eigenen Erinnerungen an den Fall aufzurollen und insbesondere die Unannehmlichkeiten, die dieser für ihn zur Folge hatte. ${ }^{568}$ In einem stichwortartigen Entwurf am Schluss des Dokuments liest sich dies so: „8 Jahre Ächtung. Folgen für das Gericht. Erzwungener Abgang aus der Kaiserlichen Rechtsschule. Geschichte mit dem Zivilen Departement der Gerichtskammer. [...] ${ }^{\text {다 }}{ }^{569}$ Es ist sinnbildlich, dass Koni gerade auf seine Darstellung im Zasulič-Fall starken Wert legte beziehungsweise darum bemüht war, hier seine eigenen Erinnerungen zu betonen. Das „Zasulič-Narrativ“, das sich schon seit längerer Zeit in Konis autobiografischen Texten finden ließ und das ihn weit weg von den einflussreichen Machtzirkeln positionierte, wurde von ihm in der Sowjetunion verstärkt benutzt und ganz konkret angeführt, um „zurückzuschreiben“. In seiner Bezugnahme auf Karabčevskijs Erinnerung führte Koni denn auch an, dass er dem Schicksal danke für die ganzen Erfahrungen und Folgen rund um sein „persönliches Epos des Falls Vera Zasulič “ ${ }^{570}$ Er macht deutlich, dass er für jene Zeit, in der er „,nicht Lakai, sondern Diener der Rechtsprechung" gewesen sei, nicht zu erröten habe. Wenn nun Karabčevskij meine, dass er nicht neutral gewesen sei und mit den Geschworenen ein „listiges Spiel“ getrieben habe, dann sei das seine Meinung. ${ }^{571}$ Allerdings - so fügt Koni mit leicht

565 Nikolaj P. KARA BČEvsKiJ: Čto glaza moi videli, 2 Bände. Berlin 1921. Karabčevskij verfasste seine zweibändigen Memoiren 1918. Den ersten Band widmete er seiner Kindheit, den zweiten Band den revolutionären Geschehnissen in Russland. Darin geht es insbesondere um die Russische Revolution von 1905, die Involvierung von Karabčevskij und weiteren Anwälten und schließlich um die Februarrevolution von 1917 und die Tätigkeit der Provisorischen Regierung.

566 IRLI F. 134, op. 1, d. 160, l. 1.

567 Ebd., 1. 1.

568 Ebd., 1. 1-4.

569 Ebd., 1. 5 .

570 Ebd., 1. 6.

571 Ebd., 1. 6-7. 
spöttischem Unterton hinzu - hätte Karabčevskij ihm dann auch nicht seine Bücher mit der persönlichen Widmung „vom wertschätzenden und dankbaren Autor" $z u$ schenken brauchen. ${ }^{572}$ Ganz ähnlich reagierte Koni einige Jahre später, als in der Zeitschrift „Vergangenes“ [Byloe] sein Name in Zusammenhang mit Zar und Großfürsten erwähnt wurde. Sofort schrieb er „zurück“ und betonte, dass es sich um einen Irrtum handeln müsse. ${ }^{573}$ Erneut bildet der Zasulič-Fall das Argumentarium, mit dem Koni sich verteidigte. So sei seine Nähe zu solchen Kreisen aufgrund der Ächtung nach dem Freispruch völlig undenkbar gewesen. Tatsächlich publizierte die Zeitschrift in der Folge eine Berichtigung. ${ }^{574}$ Während Koni in unveröffentlichten Erinnerungsschriften aus früheren Jahren mehrfach erwähnt, dass er einen Großfürsten getroffen habe, auf einem Ball zugegen gewesen sei oder den Sohn des Großfürsten Nikolaj Nikolajevič gar unterrichtet habe, ist er nun bemüht darum, dass diese Erlebnisse nicht länger vor einem größeren Publikum ausgebreitet werden.

Die Oktoberrevolution und die weltanschaulichen Veränderungen, die sie mit sich brachte, verkomplizierten die Landschaft, in der Koni sich orientieren musste. Die ideologischen Prämissen eines wieder mehr und mehr der Zensur unterworfenen Pressewesens wurden ergänzt durch eine Gesellschaft, die in ihrem Blick zurück manche der vergangenen Lebens- und Handlungsbedingungen nicht so einschätzte, wie Koni sie erfahren hatte. Immer wieder musste er korrigierend in die Darstellung seiner Person in der Sowjetunion eingreifen. Während er versuchte, seine Erinnerungsmission auf die Leser im sowjetischen Russland auszurichten, wurde seine Tätigkeit gleichzeitig auch von ehemaligen Gesinnungsge-

572 Ebd., 1. 7.

$573 \mathrm{Zu}$ Beginn des Jahres 1925 druckte die Zeitschrift einen Artikel ab, in dem auf die Persönlichkeit von Zar Alexander III. anhand seiner Tagebücher eingegangen wird. Dabei wird ein Tagebucheintrag von 1880 erwähnt, in dem die Rede von einem Essen bei Großfürst Nikolaj Nikolaevič dem Älteren ist. Bei der Aufzählung der Gäste wird auch Koni genannt. In einem Brief an die Redaktion, der in der Zeitschrift abgedruckt wurde, schreibt Koni, dass er dies mit großer Verwunderung gelesen habe. Er möchte festhalten, dass er nie bei einem derartigen Empfang gewesen sei, diese Gäste nicht kenne und persönlich Alexander III. erst fünf Jahre später getroffen habe, A. Konı: Pis'mo v redakciju. In: B 3 (1925), S. 250, Abschrift in: IRLI F. 134, op. 1, d. 169, 1. 2-2ob.

574 Seine Teilnahme an diesem Essen - so Koni weiter - wäre schon deshalb unmöglich gewesen, weil er nur wenig Jahre davor den Zasulič-Fall geführt habe, der die ganze Regierung gegen ihn aufgebracht habe. IRLI F. 134, op. 1, d. 169, 1. 2-2ob. Wieder beschreibt er die Unannehmlichkeiten der nachfolgenden Jahre und betont die brüske Haltung des Zaren ihm gegenüber. All dies würde sicherlich ausreichen, um zu belegen, dass seine Teilnahme an diesem Essen ein Druckfehler oder eine falsche Lesart sein müsse. Die Zeitschrift fügte dem Abdruck von Konis Brief die Bemerkung hinzu, dass es sich tatsächlich um einen Druckfehler gehandelt habe, vgl. B 3 (1925), S. 250. 
nossen in der Emigration wahrgenommen. Koni sah sich mit Kritik konfrontiert und bemühte sich in der Folge, potentielle Vorwürfe aus Emigrantenkreisen im Westen abzufedern.

Wenn er in Briefen von der Notwendigkeit sprach, weitere Erklärungen und Ergänzungen in seine Erinnerungsschriften zu integrieren, lässt sich dies nicht zuletzt auch mit der Vielfalt möglicher Leserkreise erklären, die Koni alle irgendwie zu berücksichtigen versuchte.

\section{Fazit}

Während 1917 oftmals als Moment des totalen Bruchs interpretiert wird, zeigt sich im Falle von Koni, dass die Auseinandersetzung mit seiner eigenen Rolle im politischen Gefüge schon längst stattgefunden hatte und durch die Bolschewiki nicht nochmals von Grund auf erschüttert wurde. Schon um die Jahrhundertwende tarierte Koni in seinen autobiografischen Schriften vor dem Hintergrund der sich radikalisierenden gesellschaftspolitischen Verhältnisse seine Position zum Regierungsapparat aus. Versinnbildlicht im „Fall Zasulič“ erschrieb er sich ein Stück Freiheit, indem er auf seine Ächtung von offizieller Stelle als Beweis für seine Unabhängigkeit und Machtferne verwies. So konnte er an den inhaltlichen Hauptachsen seiner Erinnerungsschriften über die (Justiz-)Politik des Zarenreiches festhalten, die er nach dem Zerfall des Imperiums intensiviert an die Öffentlichkeit zu bringen versuchte. Indem er zudem auch seine eigenen, Jahrzehnte zurückliegenden Einflussversuche in solchen Erinnerungstexten einem Publikum präsentieren wollte, betonte er seine Fähigkeit zur politischen Analyse und seine aktive Haltung im justizpolitischen Umfeld des Zarenreichs. Damit erklärte und rechtfertigte er nicht nur seine eigene Position, sondern hielt auch für die Gegenwart an seinem Anspruch auf Einflussnahme fest. Diese war selbst auf dem juristischen Feld durchaus größer als oftmals angenommen wird. Schließlich konnte Anfang der 1920er-Jahre - wie Krylenko ärgerlich beklagte - noch versucht werden, die Reform von 1864 zu wiederholen.

Der Hauptfokus von Koni lag aber zweifelsohne auf seiner Erinnerungsmission, die er sich ausgelöst durch die umfangreiche und oftmals pauschal abwertende Beschäftigung von Presse und Öffentlichkeit mit der zarischen Vergangenheit selber gab. Ebenso „unermüdlich“ - wie seine Betätigung abschätzig beurteilt wurde versuchte er, neben der Veröffentlichung bereits entworfener Erinnerungsschriften auch an neuen (auto-)biografischen Porträts wichtiger politischer Figuren aus der Zarenzeit zu arbeiten. Durch die Betonung seiner angeblich neutralen Position, durch konkrete Leseanweisungen und explizite Ausführungen zu Sinn und Funk- 
tion des Erinnerns sollten die potentiellen Rezipienten dazu gebracht werden, im Sinne Konis Erfahrungen und „Errungenschaften von Generation zu Generation“ zu transportieren. Darunter verstand er insbesondere, die politischen Akteure aus dem zarischen Russland differenziert zu beurteilen und auf seine eigene Interpretation der Fehler aufmerksam zu machen, die Zar und Entourage in ihrem Verhältnis zur Bevölkerung und ihren Begehren begangen hatten.

Es mag charakteristisch sein, dass Koni nach 1917 erneut den direkten Kontakt zur starken Macht im Staate suchte, als es darum ging, seine Erinnerungs- und Unterrichtstätigkeit zu sanktionieren und Hindernisse, zum Beispiel bei der Publikation der Witte-Skizze, zu überwinden. Anstatt den Zaren um Begnadigungen und Berichtigungen juristischer Fehlentscheide zu bitten, sollte nun der Volkskommissar Lunačarskij als klassischer „Patron mit Staatsnähe“ die scheinbar außer Kontrolle geratene Zensurbehörde in die Schranken weisen. ${ }^{575}$ Gleichzeitig wurde Koni genötigt, als Teilnehmer an einer komplexen Kommunikationssituation sowohl gegenüber der offiziellen Sowjetunion als auch mit Blick auf die oftmals rigoros urteilenden Emigrantenkreise die Signale, die er aussandte, abzuwägen und die Darstellungen, die andere von ihm verbreiteten, zu erfassen und nötigenfalls mit seinen eigenen Erinnerungen korrigierend „zurückzuschreiben“. Im Gegensatz zu zahlreichen seiner Gesinnungs- und Professionsgenossen sah er aber insgesamt die Bedingungen gegeben, im Land zu verbleiben und seine Erinnerungsmission voranzutreiben. Mit dieser versuchte er, so scheint es, „seinem eigenen Denken und Handeln einen Sinn " zuzuweisen. ${ }^{576}$ Das fieberhafte Skizzieren weiterer Erinnerungsschriften, die Ansage, „nur noch eine Pflicht und eine Freude“ zu haben: „so viel Wahres wie möglich über die Vergangenheit zu sagen“, sprechen für sich. Die enorme Relevanz, die dies für Koni hatte, zeigt sich schließlich daran, wie er die Legitimation für seine autobiografischen Praktiken gegen Lebensende immer unmittelbarer mit dem "Zasulič-Narrativ“ verband. So wurde am Abend des 15. Mais 1927 eine mündliche Überlieferung Konis festgehalten. Darin berichtet er von einem Gespräch mit Graf Pahlen über den Zasulič-Fall. Einmal mehr erklärt Koni, dass er dankbar sei für den folgenschweren Prozess. Ohne die Ächtung seiner Person, die diesem nachgefolgt sei, wäre er die „hierarchische Leiter" hinaufgestiegen und wohl eines Tages Minister geworden. Dabei wäre er entweder sofort gescheitert oder aber er wäre „einen Kompromiss“ mit

575 Walker: On Reading Soviet Memoirs, S. 344-45 betont, dass in der Sowjetunion solche Patrone besonders wichtig waren. Diese wählten ihre Protégés wie im 18. Jahrhundert relativ willkürlich aus, konnten ihnen so aber gewisse Handlungsspielräume eröffnen.

576 Haumann: Geschichte, Lebenswelt, Sinn, S. 87 spricht davon, dass gerade dort, wo die Hoffnung auf eine Fortschrittsgeschichte der Menschheit sich zerschlägt, der Versuch umso zentraler ist, wenigstens der individuellen eigenen Geschichte einen Sinn zu geben. 
seinem "Gewissen“ eingegangen. So aber sei alles viel besser gekommen; er habe viel mehr "freie Zeit" gehabt und „eine ganze Reihe an Büchern" geschrieben. ${ }^{577}$ In dieser Darstellung haben die karrieremäßigen Beeinträchtigungen aufgrund des „persönlichen Epos des Falls Vera Zasulič“ den „unermüdlichen Erinnerer“ unmittelbar hervorgebracht.

Das von ihm mit scheinbarer Dankbarkeit ertragene Leiden nach dem Prozess bildet das Hauptargument in Konis autobiografischer Verwendung des Falles. Niemals geht er dazu über, seine eigene Rolle im Prozess neu zu interpretieren und sich politisch opportun in der Sowjetunion als Richter zu präsentieren, der maßgeblich und aus Überzeugung für den terroristischen Kampf gegen die Autokratie zum Freispruch der Revolutionärin beigetragen habe. Nicht verwunderlich sind deshalb die Schwierigkeiten, die Koni in der Sowjetunion mit der Zensur hatte. Die Position des früher wie heute unparteilichen, neutralen Beobachters, der nur „objektiv“ die „wahren“ Begebenheiten nacherzählte, vermochte nicht durchgängig zu überzeugen. Trotz einiger Anpassungen enthielten seine Erinnerungsschriften eine Vielzahl an Elementen, die auch durch Konis auf Distanz zum Regierungsapparat bedachtes „Zasulič-Narrativ“ nicht genügend relativiert wurden oder als „objektiv“ verstanden werden konnten. Man denke an die Momente voller Faszination für den Zaren und seine Macht über das „hundertmillionen Volk" in den Erinnerungen an den Entgleisungsfall sowie Konis Bemühen, diesen in der direkten Begegnung von seinen Argumenten zu überzeugen. Gerade das politisch Relevante an seinen Erinnerungstexten konnte Koni deshalb trotz vieler anderslautender Absichtserklärungen wegen der Komplexität von Ausgangslage und „Anrufungen“, wegen Zensurbestimmungen und Altersmüdigkeit nur sehr unvollständig publizieren. Seine Erinnerungsmission scheiterte aber nicht vollständig, sondern verschob sich leicht in Funktion und Mittel. Schlussendlich waren es seine Erinnerungen an die großen Schriftsteller des 19. Jahrhunderts, die öffentlich stark nachgefragt und von Koni in den frühen 1920er-Jahren in großem Stil mittels Publikationen und Vorträgen präsentiert wurden.

577 GARF F. 564, op. 1, d. 212. Abgedruckt auch als Fußnote der Redaktion in Koni: Vospominanija o dele Very Zasulič. In: GA2, S. 222-23. Vgl. zu diesem Dokument auch unten, S. 327 . 

TEIL DREI 



\section{Der Fall Vera Zasulič - ein Schlaglicht auf die Gesellschaft des späten Zarenreichs}

Der Zasulič-Fall funktioniert in Konis Erinnerungsschrift an die Ereignisse von 1878 und die nachfolgenden Jahre wie ein Fixpunkt, von dem aus sich das imperiale Russland und seine Gesellschaftsstruktur mit besonderer Klarheit auffächerte. Viele Seiten widmet Koni in seiner Beschreibung des Falles den Schichten und Gruppen von Menschen, die in irgendeiner Art und Weise Stellung zum Geschehen nahmen. Im vierten Teil der Erinnerungsschrift äußert er sich zur Reaktion der „gebildeten Gesellschaft“ [obrazovannoe obščestvo] St. Petersburgs. Diese habe den Freispruch größtenteils begrüßt und ihn als Ausdruck des Unmuts gegen die Behörden gesehen. So sei das Gericht mit „politischem Kolorit“ angestrichen worden. Auch die Petersburger Presse habe geschrieben, dass es sich bei der Angelegenheit um einen Protest des „öffentlichen Gewissens“ handle. ${ }^{1}$ Allerdings seien einige ob des Ausgangs des Prozesses auch erschrocken. Während man, so Koni spöttisch, „in den Regierungssphären“ ja gerne beim Zigarrenrauchen „liberalisiere“ [poliberal'ničat'] oder Witze über den Zaren mache, sei die öffentliche Unmutsäußerung vielen Mitgliedern dieses Kreises nun doch zu weit gegangen. Plötzlich seien Stimmen aufgetaucht, die Trepov verteidigt hätten, sogar der „Englische Klub“ habe sich solidarisch mit ihm gezeigt. Dabei seien völlig verschiedene und widersprüchliche Ansichten zum Fall kursiert. Von innerer Disziplin könne in diesen gebildeten Kreisen schlicht nicht die Rede sein. Insbesondere im liberalen Milieu herrschten große Diskrepanzen. Einen Gegensatz dazu hätten, so fährt Koni ironisch fort, die „Retrogrady“ gebildet. Diese hätten sich diszipliniert auf eine Interpretation geeinigt: Bereits wenige Tage nach dem Freispruch sei für sie Koni als Schuldiger festgestanden. ${ }^{2}$

Nach diesem Panorama der hauptstädtischen Reaktion auf den Zasulič-Prozess widmet sich Koni einige Seiten später der Haltung der Charkower Bevölkerung. Diese Stadt kannte Koni aus den Jahren 1868/69, in denen er dorthin versetzt worden war, um die Umsetzung der Gerichtsreform zu begleiten. ${ }^{3}$ Koni verbindet in der Erinnerungsschrift die Gedanken zurück an seine beruflichen Anfänge abseits der beiden Zentren des Imperiums mit dem Moment der verschärften Kritik an ihm durch den hauptstädtischen Justizminister. Parallel zu Graf Pah-

1 KonI: Vospominanija o dele Very Zasulič. In: GA2, S. 180.

2 Ebd., S. 182-84.

3 VysockiJ: Koni, S. 427. 
lens Aufforderung zum freiwilligen Rücktritt schreibt Koni von den „glücklichen Jahren der Gerichtsreform " in Charkow und Kasan. Diese seien von beharrlicher Arbeit und Glaube an das neue Gericht geprägt gewesen. ${ }^{4}$ Den Gedanken an diese Zeit lässt Koni sogleich Taten folgen. Er berichtet, wie er aufgrund der seelischen Erschöpfung durch den Zasulič-Fall und Graf Pahlens Drängen zum Rücktritt selber weg aus St. Petersburg gefahren und nach Charkow gereist sei. Doch habe er vergebens Erholung im Kreise seiner Freunde gesucht. Er sei mit Fragen und endlosen Gesprächen über den Fall konfrontiert worden, und ab und zu habe er erste Anzeichen für das „Abflauen von guten und innigen Beziehungen“ gespürt, das sich später noch verstärken sollte. ${ }^{5}$

Dem Zasulič-Fall, dieser Eindruck drängt sich den Lesern auf, kann Koni nicht entfliehen. Auch die Suche nach der euphorischen Anfangszeit der Gerichtsreform, versinnbildlicht in der Rückkehr nach Charkow, bringt keine Linderung. $\mathrm{Ob}$ „Englischer Klub“, Petersburger Zeitungen, liberale und retrograde hauptstädtische Kreise oder die Charkower Provinzelite, sie alle setzen sich in Konis Optik in der einen oder anderen Form zum Zasulič-Ereignis, und damit auch zu ihm, in Beziehung. ${ }^{6}$ Und keine dieser Bezugnahmen scheint Koni besonders glücklich gemacht zu haben. Das „Lehrstück Zasulič“ wirft für ihn ein schonungsloses Licht auf das russische Imperium und seine ,gebildete Gesellschaft“.

Das Kontrastprogramm dazu schafft Koni in seiner Erinnerungsschrift durch die Integration zahlreicher Erlebnisse, die ihn nicht mit der „gebildeten Gesellschaft", sondern mit der einfachen Bevölkerung oder Menschen, die in schwierigste Situationen geraten waren, verbinden. Dabei ist er nicht länger der von allen Seiten beurteilte und kritisierte Gerichtsvorsitzende, sondern der dringend benötigte Freund und Helfer in Not. In einer typischen Episode berichtet Koni zu Beginn seiner Zasulič-Erinnerungen von den großen Prozessen der 1870erJahre, im Zuge derer auch Bogoljubov verurteilt worden war. Eines Tages sei ein offensichtlich schwangeres „Mädchen kalmykischen Typs“ zu ihm gekommen, das um die Erlaubnis gebeten habe, einen der Verurteilten heiraten und in die Verbannung nach Sibirien begleiten zu dürfen. Ausführlich berichtet Koni, wie er mit großer Mühe den Justizminister habe überreden können, diesem mit vielen Tränen vorgebrachten Anliegen schlussendlich doch noch zuzustimmen. Wenige Jahre später habe das Mädchen Koni dann einen Brief aus Sibirien geschickt. Darin habe sie von der Geburt ihres Sohnes berichtet, den sie „Anatolij“" genannt habe.

4 KonI: Vospominanija o dele Very Zasulič. In: GA2, S. 202-o6.

5 Ebd., S. 213.

6 Gegen Ende der Erinnerungsschrift verweist Koni darauf, dass sogar im italienischen Neapel eine Theateraufführung der Zasulič-Geschichte stattgefunden habe, vgl. ebd., S. 229. 
Sie betont, dass sie mit ihrem Mann glücklich und ohne Not lebe. Dieser habe nämlich ein einträgliches Geschäft mit dem Schnitzen von Zarenbüsten, die er aus dem Gedächtnis anfertige, aufgebaut. ${ }^{7}$ Eine ähnliche Geschichte führt Koni auch ganz gegen Ende seiner Schrift nochmals an. Wieder ist die Rede von einem Revolutionär, der in die Verbannung geschickt wurde. Da er der Sohn einer Charkower Familie war, mit der Koni in freundschaftlichem Verhältnis stand, setzte er sich für diesen ein. Er habe die Mutter, die nun mit dem üblichen „Abflauen von Sympathien" konfrontiert worden sei, unterstützt und an die Gerichtsbehörden am Verbannungsort geschrieben. Dies habe ihm Vorwürfe sowohl vom Justizminister als auch vom Zaren persönlich eingebracht. Aber die gute Betreuung des Jungen habe schlussendlich dazu geführt, dass dieser die Universität besucht habe und in ihm „keinerlei Spuren eines für den Staat gefährlichen Menschen“ mehr zu finden gewesen seien. ${ }^{8}$

Gleich zweimal demonstrierte Koni in den Zasulič-Erinnerungen auf solch anschauliche Weise, wie viel mit menschlichem Verhalten anstelle harter Repression erreicht werden konnte. Er generierte so Argumente für seine eigenen politischen und gerichtsethischen Überzeugungen. Der einstige Revolutionär, der seinen Lebensunterhalt dank Konis Milde nun als glücklicher Familienvater mit dem Schnitzen von Büsten des eben noch gehassten Zaren verdient, wirkt wie der Kronzeuge in Konis Plädoyer gegen die gewaltsame Unterdrückung politisch Andersdenkender. ${ }^{9}$ Gleichzeitig spiegelt sich darin sein Rechtsverständnis, das eng gekoppelt scheint an moralische Grundsätze im Handeln von Juristen und im Recht stets eine gewisse Erziehungsmission mitdachte. Vor dem Hintergrund der Reaktionen und Verhaltensweisen der "gebildeten Gesellschaft" erhalten diese Textstellen aber noch eine weitere Bedeutung. Sie sind Zeugnis für die wechselseitige Kontaktaufnahme zwischen Koni und jenen Menschen, die nicht zu den Meinungsmachern gehörten und die gerade deshalb seinem Handeln als Richter und als Mensch ein Stück weit Legitimation erteilen sollten. So schreibt er denn in der Zasulič-Erinnerung auch stolz, dass er das „Gefühl großer moralischer Zufriedenheit", das sich bei ihm durch seine Taten eingestellt habe, in Form der Rückmeldungen der Betroffenen konserviert habe. Deren Dankesbriefe ließen ihn „ruhig auf die Rubrik der Vorstrafen in seinem moralischen Formular blicken“. ${ }^{10}$

Der Zasulič-Fall schärfte Konis Blick auf das Russische Reich und seine gesellschaftlichen Gruppierungen. Die wenig erbauliche Verhaltensweise der „Gebildeten" machte den Kontakt mit jenen Menschen umso nötiger, die auf Hilfe

7 Ebd., S. 33.

8 Ebd., S. 242-44.

9 Vgl. dazu ausführlich TEIL ZWEI.

10 Koni: Vospominanija o dele Very Zasulič. In: GA2, S. 226. 
angewiesen waren und deren positive Rückmeldungen sein Handeln sanktionieren sollten. Das nachfolgende Kapitel zeigt auf, wie Koni zeitlebens versuchte, sich über autobiografisches Schreiben in engen Kontakt mit der einfachen Bevölkerung des Landes zu setzen, um gleichzeitig der ,gebildeten Gesellschaft“ Anerkennung für sein eigenes Tun abzuringen. Dabei erhielt Konis Schreiben immer stärker eine literarische Komponente, die ihn selber in die Nähe der in Russland so populären großen Schriftsteller rückte, deren Einfluss auf das einfache „Volk“ unerreichbar schien. Diese Literaten wurden denn folgerichtig immer wieder selber zum Gegenstand von Erinnerungsschriften Konis. In diesen Porträts gelang es ihm, eigene rechtliche Überzeugungen mit dem moralisch begründeten gesellschaftlichen Führungsanspruch eines Dostojewskis oder Tolstois zu verbinden und so seinen direkten Zugang zu den Menschen im Russischen Reich nochmals zu bekräftigen. Diese Textsorte bot ihm schließlich auch die Möglichkeit - ausgeführt im zweiten Kapitel -, in der Sowjetunion mit seinem Schreiben in einem Bereich öffentlich sichtbar zu bleiben, der stärker nachgefragt und weniger eingeschränkt wurde als seine politischen autobiografischen Darstellungen. Implizit transportierte Koni so für ihn zentrale moralische Grundlagen der Gesellschaft über das Jahr 1917 hinaus.

\subsection{Puschkins Ehrung 1880: Legitimationssuche in Gesellschaft und Literatur}

Im Juni 1880 versammelte sich in Moskau Russlands schreibende Elite. Die Autoren des Landes fanden zusammen, um dem wichtigsten Literaten des "Goldenen Zeitalters" - Alexander Puschkin (1799-1837) - die Ehre zu erweisen. ${ }^{11}$ Seit Jahren schon hatte das Alexanderlyzeum Geld gesammelt, um seinem berühmtesten Absolventen ein Denkmal in seiner Geburtsstadt zu widmen. ${ }^{12}$ An der mehrtägigen Feier, die Puschkin endgültig zum „Kulturellen Mythos ${ }^{“ 13}$ machen sollte, nahm auch Koni als Vertreter der Juristischen Gesellschaft von St. Petersburg teil. ${ }^{14}$ Am dritten Tag der Festlichkeiten trat Fjodor Dostojewski mit einer Rede

11 Kenneth Lantz: The Dostoevsky Encyclopedia. Westport Connecticut u. a. 2004, S. 341.

12 Ebd.

13 Vgl. den Aufsatz mit dem Titel „Pushkin as a Cultural Myth“ von Alexandra Sмiтн: Pushkin as a Cultural Myth. Dostoevskii's Pushkin Speech and Its Legacy in Russian Modernism. In: Joe Andrew/Robert Reid (Hrsg.): Dostoevskii’s Overcoat. Amsterdam 2013, S. 123-47.

14 In seinem Porträt des Gerichtsreformers Nikolaj Stojanovskij (vgl. Angaben oben, Fußnote 27 in TEIL EINS) berichtet Koni, wie anlässlich der Eröffnung des Denkmals auf Stojanovskijs Initiative hin eine Delegation von Juristen aus St. Petersburg nach Moskau geschickt wurde, hier zitiert nach: Anatolij F. KonI: Nikolaj Ivanovič Stojanovskij. In: ders. 
über Puschkin auf, die einen enormen Eindruck bei den Zuhörern hinterließ. Die Zeitgenossen sahen in den Worten Dostojewskis die Kreation einer neuen Form synthetisierter nationaler Identität. ${ }^{15}$ Tatsächlich war das ganze Fest schon mit der Idee organisiert worden, über die Figur von Puschkin - der trotz einiger radikaler Kritiker von allen literarischen Gruppierungen im Land bewundert wurde - eine Annäherung zwischen verschiedenen literarischen und politischen Strömungen zu erreichen. ${ }^{16}$ Dostojewski, von vielen als konservativer, slavophiler „Reaktionär“ gesehen, stand dabei als herausragender Schriftsteller neben seinem alten Rivalen Ivan Turgenev, der als liberaler Westler verstanden wurde. ${ }^{17}$ In Dostojewskis Rede wurde Puschkins Leben und Werk nun vor den versammelten Literaten Russlands zum Ausgangspunkt einer nationalen Einheit gemacht, die - wie Dostojewski es in Puschkin versinnbildlicht sah - in kreativer Auseinandersetzung mit den europäischen Traditionen stehen sollte. ${ }^{18}$ Der Effekt dieser mündlich vorgetragenen Interpretation war überwältigend und sollte noch viele Jahre nachhallen. Unzählige Memoiren von anwesenden Persönlichkeiten bezeugen die fast schon hysterischen Emotionen, die die $\mathrm{Zu}-$ hörer überkamen. Sofort wurde erklärt, dass diese Rede eine neue Entwicklung in Russlands sozialem und kulturellem Leben bedeute. Die Spaltung zwischen „Westlern“ und "Slavophilen“ sei überwunden. ${ }^{19}$

Nur wenige Monate später hielt auch Koni eine sogleich und auch noch Jahrzehnte später in verschiedensten Ausführungen publizierte Rede, diesmal über den bald nach seiner berühmten Hommage an Puschkin verstorbenen Fjodor Dostojewski. Mit dieser Ansprache, deren Titel „Dostojewski als Kriminalist“ lautete,

(Hrsg.): Očerki i vospominanija. Publičnye čtenija, reči, stat'i i zametki. Sankt-Peterburg 1906, S. 672.

15 Smith: Pushkin as a Cultural Myth, S. 126.

16 Lantz: The Dostoevsky Encyclopedia, S. 341.

17 Joseph Frank: Dostoevsky, Bd. 5. The Mantle of the Prophet, 1871-1881. Princeton u. a. 2002, S. 509 und Lantz: The Dostoevsky Encyclopedia, S. 341. Tolstoi hatte einer Teilnahme nicht zugestimmt. Frank beschreibt in seiner Dostojewski-Biografie, wie der Schriftsteller in Gegenwart seiner Kollegen das bedrückende Gefühl hatte, dass alle denken würden: „Du bist ein Reaktionär, während wir Liberale sind.“ Vgl. zur Slavophilie Stephen Lukashevich: Ivan Aksakov, 1823-1886. A Study in Russian Thought and Politics. Cambridge Massachusetts 1965, S. 1-14. Die Slavophilie war eine Geistesströmung, die gegen die Europäisierung Russlands, die seit Ende des 17. Jahrhunderts ihren Lauf nahm, ankämpfte. Dem rational-aufgeklärten Westlertum wurde eine religiös-spirituelle Rückbesinnung auf eine Lebensweise entgegengehalten, von der man fand, dass sie spezifisch russisch sei.

18 Sмith: Pushkin as a Cultural Myth, S. 126.

19 Frank: Dostoevsky, S. 527 und Smith: Pushkin as a Cultural Myth, S. 126. 
trat er vor der Juristischen Gesellschaft von St. Petersburg auf. ${ }^{20}$ Die Beerdigung des Schriftstellers hatte wenige Tage zuvor die Massen in der Stadt bewegt. Wie Puschkin war auch Dostojewski zu einem für die russische Literatur, Kultur und das intellektuelle Leben nicht mehr wegzudenkende Figur geworden. Seine Beerdigung in St. Petersburg wurde zu einer riesigen Trauerveranstaltung, an der zwischen 30.000 und 40.000 Menschen teilnahmen, die aus Dostojewskis Tod ein historisch bedeutsames Ereignis machten. ${ }^{21}$ Indem Koni Dostojewski in seiner Rede vor den versammelten Petersburger Juristen einen „Kriminalisten“ nannte, schuf er 1881 zum ersten Mal eine direkte Verbindung zwischen dem berühmten Literaten und dem Rechtswesen. Diese Zusammenführung von Literatur und Justiz bildete das erste Glied in einer Kette von weiteren Reden und Publikationen Konis, die Ähnliches versuchten. Eigentlich Oberstaatsanwalt und Senator, erarbeitete sich Koni je länger je mehr den Ruf, auch ein Literaturkritiker zu sein, und krönte dieses Engagement 1899 zu den Feierlichkeiten des 100. Geburtstags von Puschkin mit einer viel beachteten Rede über den in Russland längst zum „Pan-Human ${ }^{\text {"22 }}$ gewordenen Poeten. ${ }^{23}$ Seine Karriere als Literaturkritiker und „Puschkingelehrter“ hatte Koni im sogenannten Shakespeare-Zirkel begonnen, in dem ab 1874 für mehrere Jahrzehnte zahlreiche Anwälte und Juristen - darunter auch Urusov oder Andreevskij - regelmäßig über Literatur und Gesellschaft diskutierten. Als Koni 1899 mit seinen Analysen von Puschkins Werken an die Öffentlichkeit gelangte, verfügte er also bereits über eine gewisse Reputation. ${ }^{24}$

20 Erstveröffentlichung: Anatolij F. Konı: Dostoevskij kak kriminalist. In: Nedelja (6) 1881, S. 208-18. Koni nahm die Rede unter dem Titel „Fëdor Michajlovič Dostoevskij“ auch auf in „Im Laufe der letzten Jahre“, „Skizzen und Erinnerungen“ und „Auf dem Lebensweg“. Vgl. GA6, S. $624 \mathrm{ff}$ (Anmerkungen) ausführlicher zur Veröffentlichungsgeschichte. In der Folge wird die Version aus „Im Laufe der letzten Jahre“ von 1896 zitiert.

21 Yanina V. ARnold: Writing Justice. Fiction and Literary Lawyers in Late Imperial Russia, 1864-1900. University of Michigan 2014 (Dissertation in Open Access), S. 203.

22 Ebd., S. 63.

23 Vgl. zu den Feierlichkeiten zu Puschkins 10o. Geburtstag auch Sмıтн: Pushkin as a Cultural Myth, S. 128. Das Jubiläum wurde nun nicht mehr ausschließlich von der russischen Intelligencija begangen, wie die Denkmaleröffnung 1880. Nun war es der Staat, der eine regelrechte „Romanze mit Puschkin“ einging und so die Reputation des Schriftstellers nochmals signifikant erhöhte.

24 Arnold: Writing Justice, S. 27 und 63-64 sowie Andreevskij: Kniga o smerti, 2005, S. 489 (Nachwort von I. I. Podol'skaja). Erstveröffentlichung der Rede: Anatolij F. KonI: Nravstvennyj oblik Puškina. In: VE 10 (1899), S. 491-525. Sowie leicht angepasst: Anatolij F. Koni: Obščestvennye vzgljady Puškina. In: Čestvovanie pamjati A. S. Puškina imp. Akademiej Nauk v sotuju godovščinu dnja ego roždenija Maj 1899. Sankt-Peterburg 1900, S. 34-70. Koni nahm die Rede unter dem ursprünglichen Titel 1906 auch in „Skizzen und Erinnerungen“ sowie später in „Auf dem Lebensweg“ IV auf. Vgl. auch GA6, S. 519 ff (An- 
Während Koni Dostojewski schon im Titel zum „Kriminalisten“ machte, nähert er sich Puschkin über dessen „moralische Gestalt“ [nravstvennyj oblik]. Auf der Basis diverser Werke des Schriftstellers kommt Koni in seiner Ansprache zum Schluss, dass auch Puschkin, der Jahrzehnte vor der Gerichtsreform und den Anfängen einer Konstitution gelebt hatte, Verfechter eines rechtsstaatlichen Russlands gewesen sei. ${ }^{25}$ Koni hielt diese Rede vor der Akademie der Wissenschaften. Nach dem Vorbild der Royal Society in London, der Académie des Sciences in Paris und der Akademie der Wissenschaften in Berlin war diese prestigereiche Institution 1725 auf Initiative von Zar Peter dem Großen in St. Petersburg gegründet worden. ${ }^{26} \mathrm{Im}$ Dezember 1896 war Koni zum Ehrenmitglied ernannt worden, nachdem er zuvor mehrfach mit juristischen Abhandlungen vor der Akademie aufgetreten war und schon 1895 zum Tod des Gerichtsreformers und Senators Rovinskij vor der allgemeinen Versammlung eine Laudatio gehalten hatte. ${ }^{27}$ Der Rede über Puschkin und seine moralisch-rechtlichen Überzeugungen folgte sogleich die Einladung, einer neu gegründeten Abteilung der Akademie beizutreten, die sich im Gedenken an Puschkin den Werken russischer Schriftsteller widmen sollte. Gemeinsam mit ihm wurde auch eine so berühmte Literaten-Persönlichkeit wie Tolstoi ernannt. ${ }^{28}$ Konis nun folgende Redetätigkeit in dieser „Abteilung für Belletristik“ [razrjad izjaščnoj slovesnosti] bewegte sich immer irgendwie im Feld zwischen Literatur und Justiz. In den Reden über Dostojewski und Puschkin hatte Koni

merkungen) ausführlicher zur Veröffentlichungsgeschichte. In der Folge wird die Version aus „Skizzen und Erinnerungen“ zitiert. Koni hielt 1904 auch noch einen weiteren Vortrag vor der Akademie zu Puschkin. Erstveröffentlicht als: Anatolij F. KonI: Pis’mo A. S. Puschkina. In: Žurnal dlja vsech 12 (1904). Auch dieser Text wurde in „Skizzen und Erinnerungen" und in "Auf dem Lebensweg" IV integriert.

25 Arnold: Writing Justice, S. 63-64 ff. In ihrer Dissertation „Writing Justice. Fiction and Literary Lawyers in Late Imperial Russia" untersucht Yanina Arnold Konis Puschkinrede en détail.

26 Wolfgang KaSACK: Die Akademie der Wissenschaften der UdSSR. Überblick über Geschichte und Struktur: Verzeichnis der Institute. Boppard 1978, S. 16.

27 Smoljarčuk: Anatolij Fëdorovič Koni (1844-1927), S. 139 ff. Vgl. zur Rede über Rovinskij auch oben, S. 58.

28 Ebd., S. 141. Zuerst wollte die Akademie zu Ehren des 10o. Geburtstags von Puschkin eine eigene „Puschkin-Akademie“ gründen. Man entschied sich dann aber für eine Unterabteilung innerhalb der existierenden Strukturen. Vgl. Muratov: A. F. Koni i Puškinskij Dom, S. 41 mit einem Abdruck des Diploms, das Konis Aufnahme in die „Abteilung für Belletristik“ bezeugt, datiert vom Januar 1900. Vgl. KASACK: Die Akademie der Wissenschaften der UdSSR, S. 16 zur Struktur der Akademie, die seit 1841 eine Gliederung in drei Klassen aufwies (russische Sprache und Literatur: hierzu gehörte auch die „Abteilung für Belletristik“ sowie historisch-philologische und physikalisch-mathematische Wissenschaften). 
diese Verbindung noch über Interpretationen der Werke der Autoren hergestellt, und auch bei anderen Literaten beschränkte sich Koni auf eine unpersönliche, werkbezogene Analyse ihres Schaffens. ${ }^{29}$ Der stark wissenschaftlich-historische Charakter, den diese Texte hatten, machte sie oftmals zu Vorlagen für biografische Nachschlagewerke. In diesem Stil porträtierte Koni auch seine eigenen Eltern und deren künstlerisches Schaffen. ${ }^{30}$ Gegen Ende der 189oer-Jahre und im 20. Jahrhundert ging Koni dann immer stärker dazu über, die enge Beziehung von Recht und Literatur anhand eigener autobiografischer Erinnerungen an die berühmten Autoren darzulegen. So trat er in der Akademie und andernorts mit Vorträgen über Schriftsteller auf, mit denen er privat in Kontakt gewesen war, oder publi-

29 Reden in diesem Stil hielt Koni vor der Akademie zu: Vladimir Sergeevič Solov’ëv (1901); Knjaz' Vladimir Fëdorovič Odoevskij (1903); Početnyj akademik K. R. (Reč’ v pamjat' Velikogo Knjazja Konstantin Konstantinoviča [Romanov]) (1915) sowie bereits 1898 eine Rede über Ivan Fëdorovič Gorbunov vor dem „Haus der Justiz“. Nicht immer fiel sein Fokus auf die Verbindung von Recht und Literatur dabei so eindeutig aus wie bei den Reden zu Puschkin und Dostojewski. Von den genannten ist aber z. B. der Vortrag über Gorbunov auch unter dem Titel „Das alte und das neue Gericht in der Darstellung von I. F. Gorbunov" erschienen, was Konis Schwerpunkt besonders deutlich macht. Alle genannten Reden wurden sofort veröffentlicht und von Koni in seine Sammelbände aufgenommen. Insbesondere „Skizzen und Erinnerungen“ von 1906 enthält neben zahlreichen Juristenporträts auch viele der umfangreichen Reden und Analysen zu Schriftstellern und einige kürzere Nachrufe auf Literaten. Solovèv, u. a. in: VE 2 (1903), S. 651-89; Odoevskij, in: Izvestija otdelenija russkogo jazyka i slovesnosti Akademii Nauk na 1903 g.t. VIII, Buch 4, 1904, S. 270-303. Beide auch in „Skizzen und Erinnerungen“ 1906 und später in „Auf dem Lebensweg“ IV. Für beide wird in der Folge die Version aus „Skizzen und Erinnerungen“ zitiert. Konstantin Konstantinovič, u. a. in: $\mathrm{PkN} 12$ (1916), S. 433-6o und später in „Auf dem Lebensweg“ IV; Gorbunov, u. a. in: VE 11 (1898), S. 5-63 bzw. 12 (1898), S. 437-81 und in "Skizzen und Erinnerungen“ sowie posthum in „Auf dem Lebensweg“ V. Vgl. auch die Anmerkungen zu den einzelnen Arbeiten in GA6 und GA7 (mit Ausnahme der Rede über den Großfürsten Konstantin Konstantinovič, die nicht in die Gesamtausgabe aufgenommen wurde) und zu den Veröffentlichungen nach 1917 auch das Kapitel Öffentliche Literatenporträts und private Überlegungen $z u$ „Volk“ und Intelligencija vor dem Lebensende.

30 Vgl. z. B. die Arbeit zu Odovevskij. Konis Rede vor der Akademie beruht auf einem Lexikoneintrag, den er schon 1897 verfasste: ĖSBE 28A/42, 1897, S. 748-52. Die Arbeit über Gorbunov wurde aufgenommen in: NĖS 14, 1913, Sp. 189-91. Über seine Eltern verfasste Koni Beiträge für das „Russische Biografische Wörterbuch“ von A. A. Polovcov, vgl.: Anatolij F. KonI: Koni, Fëdor Alekseevič. In: RBS 9, 1903, S. 104-08 sowie Anatolij F. KonI: Koni, Irina Semënovna. In: RBS 9, 1903, S. 103-04. Vgl. zum Nachschlagewerk: Nora Mengel: Biografische Lexika-Projekte des 19. Jahrhunderts als „Werkstätten imperialer Narrative“. In: Martin Aust/Frithjof Benjamin Schenk (Hrsg.): Imperial Subjects. Autobiographische Praxis in den Vielvölkerreichen der Habsburger, Romanovs und Osmanen im 19. und frühen 20. Jahrhundert. Köln 2015, S. 61-93. Auch einige von Konis Juristenporträts und die Darstellungen von Akteuren der Bauernbefreiung dienten als Basis für Nachschlagewerke, vgl. oben, S. 65 bzw. 229. 
zierte Nachrufe und persönliche Erinnerungsporträts. Dostojewski, Turgenev, der lyrisch-realistische Dichter Nikolaj Aleksejevič Nekrasov (1821-1878), der Naturalist Aleksej Feofilaktovič Pisemskij (1820-1881) und der Dichter Aleksej Nikolaevič Apuchtin (1840-1893) wurden Gegenstand eines Zyklus „Auszüge aus Erinnerungen“, mit dem Koni 1908 im „Boten Europas“ seine persönliche Beziehung zu diesen fünf Literaten näher ausführte. Darin erinnerte sich Koni auch ausführlich an die legendäre Eröffnung des Denkmals für Puschkin in Moskau zurück, an der sowohl Turgenev als auch Dostojewski zu so viel beachteten Auftritten gekommen waren. ${ }^{31}$ Zum 100. Geburtstag des realistischen Romanautoren Ivan Aleksandrovič Gončarov (1812-1891) hielt er 1912 einen Gedenkvortrag vor der Akademie der Wissenschaften, in dem er schon zu Beginn deutlich machte, dass er nicht - wie er es in anderen Reden getan hatte - nur über das Werk, sondern auch über die Persönlichkeit des Schriftstellers sprechen möchte. Dazu habe er das Recht, da er ihn persönlich gekannt habe. ${ }^{32} \mathrm{Zu}$ Tolstoi veröffentlichte Koni ein umfangreiches Porträt in der „monatlichen literarischen und populärwissenschaftlichen Beilage“ der Zeitschrift „Saatfeld“ [Niva], in dem er minuziös seine Besuche auf dem Landgut des Schriftstellers nacherzählte und dabei besonders gerne ihre Gespräche über Recht und Moral rekapitulierte. ${ }^{33}$ Mehrfach machte

31 Anatolij F. Koni: Otryvki iz vospominanij. I-V. In: VE 5 (1908), S. 5-57. Wie auch einige weitere der persönlicheren Erinnerungen an Literaten nahm Koni diesen Text in „Auf dem Lebensweg“ II auf, nun unter dem Titel: Anatolij F. Koni: Turgenev - Dostoevskij - Nekrasov - Apuchtin - Pisemskjj. In: ders. (Hrsg.): Na žiznennom puti, Bd. 2. Iz vospominanij, publičnye čtenija, v verchnej palate. Sankt-Peterburg 1912, S. 77-137, zur Denkmaleröffnung vgl. ebd., S. 88 ff. Vgl. auch die Anmerkungen in GA6 und zu den entsprechenden Veröffentlichungen nach 1917 das Kapitel Öffentliche Literatenporträts und private Überlegungen $z u$,Volk“ und Intelligencija vor dem Lebensende.

32 Veröffentlicht u. a. in: $\mathrm{PkN}_{12}$ (1912), S. 321-48 sowie: Anatolij F. Koni: Ivan Aleksandrovič Gončarov. In: ders. (Hrsg.): Na žiznennom puti, Bd. 2. Iz vospominanij, publičnye čtenija, $v$ verchnej palate. Sankt-Peterburg 1912, S. 381-405, die Aussage, dass Koni Gončarov schließlich persönlich gekannt habe, auf S. 381-82. Der Rede lag eine kürzere Skizze zugrunde, die Koni schon 1911 publiziert hatte. Auch zu Turgenev hielt Koni vor der Akademie einen Vortrag, in dem er nach ausführlichen Werkanalysen lange persönliche Briefzitate des Literaten einbrachte sowie Erlebnisse nochmals stellenweise identisch aufnahm, die er schon in der Publikation von 1908 beschrieben hatte. Veröffentlicht u. a. in: PkN 11 (1909), S. 375-96 bzw. 12 (1909), S. 561-86 sowie in „Auf dem Lebensweg“ II.

33 Anatolij F. Koni: Vospominanija o L’ve Nikolaeviče Tolstom. In: PkN 9 (1908), S. 5-76. Als „Lev Nikolaevič Tolstoi“ dann auch in „Auf dem Lebensweg“ II. In der 3. Auflage von 1916, Moskau leicht überarbeitet, vgl. dazu und zu noch ausführlicheren handschriftlichen Entwürfen für den Text GA6, S. 633 ff (Anmerkungen). In der Folge wird der Abdruck aus GA6 zitiert. 
Koni Tolstoi auf interessanten literarischen Stoff aus den juristischen Gefilden aufmerksam. ${ }^{34}$

Der Hype um die russischen Literaten, der sich besonders deutlich zur Denkmaleröffnung für Puschkin 188o, bei der Beerdigung Dostojewskis wenig später und schließlich beim Jubiläum zum 100. Geburtstag von Puschkin 1899 manifestierte, brachte Koni dazu, in den nachfolgenden Jahrzehnten sowohl über Literaturkritik als auch über Erinnerungen an Literaten einen Zugang zur Welt der populären Romanautoren zu finden. So inszenierte er nicht nur öffentlichkeitswirksam seine eigene Person, sondern machte die Literaten in einer Art „Aneignung" auch für Grundsätze von Rechtsstaat und Rechtsprofession nutzbar.

Parallel hierzu ging Koni mehr und mehr dazu über, selber literarische Texte $\mathrm{zu}$ publizieren. So gut wie immer enthielten diese autobiografische Elemente, die von Koni thematisch passend zusammengestellt und zu unterhaltsamen Anekdoten zugespitzt an ein breites Publikum vermittelt wurden. Unter dem Sammeltitel „Alltagstreffen“ [Žitejskie vstreči] veröffentlichte Koni ab 1908 in „Russische Altertümer“ [Russkaja Starina] und in der Literaturbeilage von „Saatfeld“ [Niva] verschiedene solcher Schriften, zum Teil als Fortsetzungsgeschichten. Die Titel lassen schon erahnen, worum es darin geht: „Hausangehörige“, „Gymnasiumserinnerungen“, „Aus den Studentenjahren“, „Unterwegs“, „Signore Beljaev“ oder „Ostende 1869-73“ lauten die Überschriften. Auch in die verschiedenen Bände und Ausgaben seiner Sammelbände „Auf dem Lebensweg“ integrierte Koni diese Geschichten. Kombinationen und Titel variierten dabei und änderten sich nochmals von Ausgabe zu Ausgabe; so fasste Koni einige der Textteile später unter neuen Überschriften wie „Im Ausland und in der Heimat“ oder „Aus Jugend- und Altersjahren" zusammen. ${ }^{35}$

34 Vgl. dazu insbesondere Tolstois Werk „Auferstehung“, das auf Berichten Konis aus dem Rechtswesen beruht. Ebenfalls auf einem Gerichtsfall baut Tolstois Drama „Der lebende Leichnam“ auf, zu beidem ausführlicher im nachfolgenden Unterkapitel. Anatolij F. Koni: „Živoj trup“v dejstvitel'nosti. In: Ežegodnik Imp. Teatrov Vyp. VI, 1911, S. 13-23. Erweitert als: „Po povodu dramatičeskich proizvedenij Tolstogo“ in „Auf dem Lebensweg“ II, in der 3. Auflage 1916, Moskau leicht überarbeitet. Vgl. auch Anatolij F. Koni: Iz vospominanij. In: Ežegodnik Imp. Teatrov Vyp. I, 1911, S. 1-12, wo u. a. Tolstoi und die Aufführungen von „Auferstehung“ thematisiert werden.

35 Anatolij F. Koni: Žitejskie vstreči. Otryvki iz vospominanij, Sin’or Beljaev. In: RS 1 (1908), S. 19-32 sowie Anatolij F. Koni: Sinor Beljaev. In: ders. (Hrsg.): Na žiznennom puti, Bd. 1. Iz zapisok sudebnogo dejatelja, žitejskie vstreči. Sankt-Peterburg 1912, S. 593-609. Zudem Teil von Anatolij F. KonI: Za-granicej i na rodine. In: ders. (Hrsg.): Na žiznennom puti, Bd. 3. Vospominanija, žitejskie dramy, žitejskie vstreči, pamjati ušedšich, kritičeskie očerki. Revel', Berlin 1922, S. 288-305. Anatolij F. KonI: Žitejskie vstreči (Iz vospominanij sudebnogo dejatelja). III. In: RS 1 (1910), S. 3-21 sowie Anatolij F. KonI: V doroge Gimnasičeskie vospominanija. In: ders. (Hrsg.): Na žiznennom puti, Bd. 1. Iz zapisok 
Die neuartige Qualität seines Schaffens fiel dem professionellen Blick des Literaturkritikers und Schriftstellers Kornej Čukovskij sofort auf. So schreibt Čukovskij - der ein halbes Jahrhundert später auch an der Gesamtausgabe von Konis Werken mitarbeiten sollte - 1915 in einem Gratulationsartikel zu Konis 50. Dienstjubiläum, dass dieser auf sein Alter hin ein neues Talent entwickelt habe. Während in seinen früheren Sammelbänden ein offizieller Ton und strenges Programm vorgeherrscht habe, so fielen nun Humor und Farbe auf. Die Texte über die Hausangehörigen oder den „Signore Beljaev“ seien intimer, voller Lachen und Trauer, fast wie bei Dickens und auf jeden Fall ein Genuss für den Leser. ${ }^{36}$

sudebnogo dejatelja, žitejskie vstreči. Sankt-Peterburg 1912, S. 628-36 bzw. 636-50. Der Abschnitt zu den Gymnasiumserinnerungen mit geringfügigen Änderungen zudem Teil von Anatolij F. KonI: Iz let junosti i starosti. In: ders. (Hrsg.): Na žiznennom puti, Bd. 3. Vospominanija, žitejskie dramy, žitejskie vstreči, pamjati ušedšich, kritičeskie očerki. Revel', Berlin 1922, S. 151-65.

Anatolij F. Konı: Žitejskie vstreči. Domočadcy. In: PkN (11) 1910, S. 321-40 und PkN 12 (1910), S. 513-32, sowie Anatolij F. Koni: Domočadcy. In: ders. (Hrsg.): Na žiznennom puti, Bd. 1. Iz zapisok sudebnogo dejatelja, žitejskie vstreči. Sankt-Peterburg 1912, S. 651-79 und und später auch nochmals in „Auf dem Lebensweg“ III. Anatolij F. KoNI: Žitejskie vstreči. IV. In: RS 12 (1910), S. 469-83 sowie Anatolij F. KonI: Ostende (1869-1873 gg.). In: ders. (Hrsg.): $\mathrm{Na}$ žiznennom puti, Bd. 1. Iz zapisok sudebnogo dejatelja, žitejskie vstreči. Sankt-Peterburg 1912, S. 610-24. Zudem Teil von Koni: Za-granicej i na rodine. In: ders. (Hrsg.): Na žiznennom puti, Bd. 3, S. 259-76. Alle diese Schriften erschienen auch z. T. leicht angepasst in der 3. Auflage von „Auf dem Lebensweg“ II 1916. Dies, weil Koni sie in der 2. Auflage von „Auf dem Lebensweg" I wegließ. Zudem: Anatolij F. Koni: Zitejskie vstreci. Očerk A. F. Koni (Iz vospominanij molodosti i starosti). In: $\mathrm{PkN} 10$ (1912), S. 161-92, PkN 11 (1912), S. 321-48, PkN 12 (1912), S. 513-46 sowie Anatolij F. Koni: Iz studenčeskich godov. In: Na žiznennom puti, Bd. 2. Iz vospominanij, publičnye čtenija, v verchnej palate. Sankt-Peterburg 1913, S. 290-370 (2. Auflage) und mit geringfügigen Änderungen sowie einem zusätzlichen Abschnitt zudem Teil von Koni: Iz let junosti i starosti. In: ders. (Hrsg.): Na žiznennom puti, Bd. 3, S. 165-73. Wenn nicht anders angemerkt, wird für die Studiumserinnerungen in der Folge die in der Gesamtausgabe abgedruckte Version von „Aus Jugend- und Altersjahren“ zitiert. Die Beschreibung „Alltagstreffen“ nutzte Koni auch für einige weitere Erzählungen zu einzelnen Personen, darunter zu einer Reihe an Frauen, die ihm wichtig waren, wie z. B. die Charkowerin Aleksandra Gavrilovna Charina († 1916), Witwe eines reichen Gutsbesitzers, die sich für die Reformen der 186oer-Jahre eingesetzt hatte, vgl. Anatolij F. Koni: Žitejskie vstreči. V. In: RS (IV-VI) 1917, S. 1-9 und als „A. G. Charina“ in „Auf dem Lebensweg“ III. Auch das Porträt des Kriegsministers Dmitrij Miljutin trägt diesen Übertitel, vgl. Fußnote 368 in TEIL ZWEI. Zur weiteren Verwendung der "Alltagstreffen“ nach 1917 vgl. das Kapitel Öffentliche Literatenporträts und private Überlegungen $z u$ „Volk“ und Intelligencija vor dem Lebensende.

36 Kornej Čuкov KsıJ: Anatolij Fëdorovič Koni. K 50-letiju ego obščestvennoj dejatel’nosti, 30 sentjabrja 1865-1915. In: N 39 (1915), S. 717-18. Čukovskij nennt in diesem Zusammenhang auch die Erinnerungsschriften an die verschiedensten Fälle, die Koni als „Gerichtstätiger“ verfasste und ungefähr zeitgleich veröffentlichte, vgl. dazu TEIL EINS. Auf diese scheint mir Čukovksijs Beschreibung aber weniger zu passen als auf die thematisch persönliche- 
Während Čukovskij den großen englischen Autor Charles Dickens (1812-1870) mit seinem blumigen und humorvollen Stil als literarisches Vorbild für Konis Texte ins Spiel brachte, führte dieser selber sein Schaffen zumindest für den Fall der Fortsetzungsgeschichte zu den „Hausangehörigen“ auf die Inspiration durch den russischen Literaten Ivan Gončarov zurück, mit dem er eng bekannt war. ${ }^{37}$ Gončarov hatte mit „Diener der alten Zeit“ ebenfalls seine Hausangestellten zum Sujet einer Skizze gemacht. ${ }^{38}$

Ähnlich wie die genannten Literaten verhandelte auch Koni in seinen autobiografisch inspirierten Erzählungen von Dienerschaft, Reisen und Studienzeit immer wieder seine Beziehung zu den Bewohnern des Russischen Reiches. Diese tauchen in den Schriften in mannigfaltiger Form auf. In seinen Erinnerungen an die „Hausangehörigen“ geht es, wie der Titel schon deutlich macht, um die „engsten Begleiter und Zeugen“ des „häuslichen und privaten Leben ${ }^{\text {““ }}{ }^{39} \mathrm{Nach}$ allgemeinen Bemerkungen über das Wesen von Dienern nimmt Koni nacheinander seine Hausangestellten und Sekretäre in Charkow und vor allem in St. Petersburg in den Blick. Koni erzählt von den verschiedenen Persönlichkeiten und den guten und schlechten Erfahrungen, die er mit diesen Menschen gemacht hat. In den „Gymnasiumserinnerungen" sind es die Lehrpersonen und Mitschüler, denen sich Koni oft auch weit über die gemeinsame Schulzeit hinaus widmet. In den „Jugend- und Altersjahren“ liegt sein Fokus auf den Professoren, die seine Studien zuerst in St. Petersburg und danach aufgrund der politischen Unruhen an der Juristischen Fakultät in Moskau prägten. Mit vielen Exkursen und porträtartigen Einschüben versehen, charakterisiert er seine Lehrmeister und Vorbilder wie Boris Čičerin und Nikita Krylov. Behördliche und politische Akteure kommen ins Spiel, wenn Koni beschreibt, wie er zum Ende seines Studiums hin damit liebäugelte, eine akademische Karriere einzuschlagen. Er berichtet von seinen Versuchen, eine Dissertation zu schreiben, um schließlich dazu überzugehen, vom Beginn

ren und deutlich als unterhaltsame literarische Kunstwerke aufgebauten Erinnerungen an Konis Schul- und Studienzeit, seine Hausangehörigen und seine Reisen im In- und Ausland.

37 Bischitzky bezeichnet Koni als einen „Wahl- und Geistesverwandten“ Gončarovs, vgl. Ivan Gončarov: Briefe an Anatolij F. Koni und andere Materialien, hrsg. u. kommentiert v. Vera Bischitzky. Köln u. a. 2016, S. 20 (Vorwort von Vera Bischitzky).

38 Reinhard Lauer: Kleine Geschichte der russischen Literatur. München 2005, S. 112-13. Gončarov: Slugi starogo veka, 1885-87. Balakin macht zudem darauf aufmerksam, dass Koni die „Hausangehörigen“ sogar im gleichen Journal veröffentlichte wie seinerzeit Gončarov. Auch „Im Ausland und in der Heimat" lehnte Koni laut Balakin an Gončarov an, vgl. BALAKIN: Neizvestnye stranicy vospominanij A. F. Koni o Gončarove. In: Russkaja Literatura 2 (2012), S. 12.

39 Koni: Domočadcy. In: ders. (Hrsg.): Na žiznennom puti, Bd. 1, S. 651. 
seiner juristischen Karriere in den reformierten Gerichten zu erzählen. Davor macht er aber einen langen Exkurs zu den Unannehmlichkeiten, die ihm seine Dissertation aufgrund politischer heikler Aussagen im Nachgang noch verschafft habe. In den Texten „Ostende“, „Unterwegs“ und „Signore Beljaev“ spielen Konis Studien und das Bildungswesen im Zarenreich keine Rolle mehr, und ganz andere Persönlichkeiten rücken ins Zentrum. Seine Berichte über die Badeaufenthalte im belgischen Ostende in den 1860/7oer-Jahren schmückt Koni mit zahlreichen Einschüben zu den russischen Zeitgenossen aus, die er auf seinen Urlaubsreisen in Europa kennengelernt hatte. In „Unterwegs“ schreibt Koni von seiner Zugfahrt nach Charkow, die er 1878 nach dem Zasulič-Fall angetreten hatte und auf der er unter anderem Bekanntschaft mit einem berühmten russischen Denker machte, mit dem er über den Gerichtsprozess diskutierte. Unter dem Titel „Signore Beljaev" berichtet Koni schließlich auch von einer Reise nach Italien im September 1873, als er auf einem Fährschiff einen Russen traf, der ihm seine Lebensgeschichte erzählte. Signore Beljaevs Schicksalsweg vom schlecht behandelten Leibeigenen zum unabhängigen Neoitaliener mit Familie nimmt den Hauptteil von Konis Erzählung ein. In dieses Schema der Auseinandersetzung mit gesellschaftlichen Gruppen und Personen passen auch die Manuskripte in Konis Nachlass, die sich seinen Bekanntschaften mit Kirchenoberen und mit Personen „die dem Herrscherhaus angehören", widmen. ${ }^{40}$

Konis anekdoten- und exkursreichen literarischen Erzählungen fungierten als Mittel, die Loyalität dieser verschiedenen sozialen Kreise seiner Person gegenüber zu prüfen. Ob über solche stilisierten Berichte von seinen persönlichen Treffen mit all diesen Menschen oder aber Literatenporträts und Literaturkritik, immer diente Konis Schreiben dabei auch einer Suche nach Legitimation und Selbstvergewisserung. Getreu der Begeisterung der Intelligencija für die russischen Literaten und ihre Beziehung zum „Volk“ schien auch Koni solche Bestätigung für sich und seine moralisch-rechtlichen Überzeugungen und Handlungsweisen im Feld von

40 Vgl. GARF F. 564, op. 1, d. 216, 1. 5-13ob mit Erlebnissen Konis im Kontakt mit verschiedenen orthodoxen Würdenträgern; bzw. l. 13ob-1. 24ob, wo Koni gleich im ersten Satz erklärt, dass er in seinem Leben immer wieder Personen aus dem Umfeld des Imperators angetroffen habe. In der Folge führt Koni einige Gelegenheiten an, wo er beispielsweise in wohltätigen Organisationen, bei seinen juristischen Lehraufgaben oder im Rahmen von Gerichtsfällen mit dem Adel in Kontakt gekommen sei. Ein Exemplar dieses Textes gibt es auch in IRLI F. 134, op. 1, d. 148. Vgl. auch TEIL ZWEI (im Speziellen Fußnote 140 in TEIL ZWEI), wo Konis Auseinandersetzung mit diesem Personenkreis betrachtet wird. Verfassungszeitpunkt und Publikationsgeschichte der beiden Manuskripte ist unklar. Gut möglich, dass Koni diese Erinnerungen ebenfalls in den 1910er-Jahren zu Papier gebracht hat, ohne sie je in dieser vollständigen Variante zu publizieren. 
Literatur und literarisch verarbeiteter persönlicher Auseinandersetzung mit der Gesellschaft zu finden.

\subsubsection{Aneignung der Literaten für die Sache der Justiz}

In seiner langen Rede über die „moralische Gestalt Puschkins“ bemühte sich Koni zu belegen, dass dem Poeten „,echte Gerechtigkeit“ sehr wichtig gewesen sei. ${ }^{41}$ Die "Liebe zur Wahrheit" sei in seinem gesamten Werk das beherrschende Moment. ${ }^{42}$ Konkret habe sich Puschkin ein Gericht gewünscht, das in „lebendiger Beziehung zur Persönlichkeit des Menschen“ stehe. ${ }^{43}$ Puschkins „,intellektuelle Beschäftigung mit der Idee von Recht und Rechtlosigkeit" war aber - wie Arnold anmerkt - nicht die einzige Behauptung mit juristischem Hintergrund, die Koni in Bezug auf den berühmten Dichter aufstellte. Ebenfalls sehr wichtig war ihm die Auseinandersetzung mit der Natur des Verbrechens und der Auswirkung von Schuld auf die menschliche Psyche, die er in Puschkins Literatur ausmachen wollte und die auch für gestandene Juristen höchst spannend sei. ${ }^{44}$ Diese Argumentation findet sich genauso in Konis Rede vor der Juristischen Gesellschaft von St. Petersburg über den „Kriminalisten“ Dostojewski. Darin spricht Koni gleich zu Beginn davon, dass man ihn wohl fragen könnte, welche Bedeutung denn dieser Schriftsteller für eine Versammlung von Juristen haben sollte. Tatsächlich sei Dostojewski aber die Fragen des juristischen Spezialgebiets von einer „künstlerisch-psychologischen Seite" aus angegangen, und deshalb hätten die Juristen die Pflicht, seiner zu gedenken und sich daran zu erinnern, wie genau er diese Sachen denn nun gesehen habe. ${ }^{45}$ In der nachfolgenden Rede führt Koni auf der Basis von Dostojewskis Romanen aus, über welche für Juristen relevante Fragen der Schriftsteller nachgedacht habe. Es ist die Rede vom Wesen des Verbrechens und dem „inneren Kampf " des Verbrechers: Wie kann es dazu kommen, dass jemand eine Straftat begeht? ${ }^{26}$ Aus den Büchern Dostojewskis könne man zudem als Jurist auch lernen, was es heiße, die Sanktionen der Gesetzgebung zu erleben. So zeichne er die Strafen und ihre Organisationsformen wie Gefängnis und Verbannung nach.

41 Anatolij F. Koni: Nravstvennyj oblik Puškina. In: ders. (Hrsg.): Očerki i vospominanija. Publičnye čtenija, reči, stat'i i zametki. Sankt-Peterburg 1906, S. 24.

42 Ebd., S. 12.

43 Ebd., S. 24-25.

44 Arnold: Writing Justice, S. 67.

45 Anatolij F. Koni: Fëdor Michailovič Dostoevskij. In: ders. (Hrsg.): Za poslednie gody. Sudebnye reči (1888-1896), Vospominanija i soobščenija, Juridičeskie zametki. SanktPeterburg 1896, S. 385-86.

46 Ebd., S. 386. 
Was hätten die Juristen schon gewusst über Sibirien? In Werken Dostojewskis wie „Aufzeichnungen aus einem Totenhaus“ oder „Verbrechen und Strafe“ finde man nun Antworten auf all diese Fragen. ${ }^{47}$

Mit seiner wachsenden Reputation als Jurist und Literaturkritiker bekam Koni immer öfter die Gelegenheit, seine auf das Rechtswesen ausgerichtete Interpretation kanonischer literarischer Werke vor Publikum zu verkünden. So schrieb er 1910 an den Vorsitzenden der „Gesellschaft der Liebhaber russischer Literatur“, dass er sich entschuldige, der Einladung nach Moskau an die Eröffnung eines Denkmals für den Schriftsteller und Zeitgenossen von Puschkin Nikolai Gogol (1809-1852) nicht nachkommen zu können. Er kann es aber nicht bleiben lassen, im Brief zu betonen, dass ja Gogol bekanntermaßen in seinem Werk besonders viel Aufmerksamkeit auf die Notwendigkeit einer Gerichtsreform gelegt habe, zu der er mit seinen Erzählungen schließlich gar beigetragen habe. Er sei betrübt, diese Überlegungen nicht selber in Moskau vortragen zu können. ${ }^{48}$

In den Erinnerungsporträts an jene Schriftsteller, die im Gegensatz zu Gogol oder Puschkin zeitgleich mit Koni lebten, zeigt sich die Kontaktzone von literarisch-philosophischen Themen und der Justiz in der persönlichen Begegnung. So schreibt Koni in seinem Porträt über Tolstoi beispielhaft, wie er mit dem berühmten Schriftsteller während der langen Spaziergänge auf dem Landgut „Jasnaja Poljana“ über Fragen wie jene der „Feindesliebe“ diskutiert habe. Dieses Verbot jeglicher Vergeltung von Unrecht habe Tolstoi stark beschäftigt. ${ }^{49}$ Er selber habe diesem Konzept daraufhin juristische Argumente entgegengehalten, wie beispielsweise das Recht auf Selbstverteidigung. So hätten sie zwar unterschiedliche Ansichten gehabt, aber dies sei für sie beide kein Problem gewesen. ${ }^{50}$

Dass Koni in der Erinnerungsschrift unterschiedliche Ansichten proaktiv anspricht, geschieht nicht ohne Grund. Sowohl Dostojewski als auch Tolstoi galten als Gegner des angeblich „kalten legalistischen Geistes des Westens s“. ${ }^{51}$ Tolstois Hetzreden gegen Recht und Justiz waren weitherum bekannt. Seine Ansichten kamen einem radikalen christlichen Anarchismus gleich. Jede Form von staatlicher Organisation, Gerichtswesen und Strafsystemen sah er als Verstoß gegen das biblische Gebot, nicht zu richten. ${ }^{52}$ Diese Haltung ist als Teil von Tolstois eigenen religiösen Überzeugungen zu verstehen, die er nach der oftmals als „religiöse Wende“ betitelte Phase der Niederschrift seines großen Romans „Anna Kare-

47 Ebd., S. 388.

48 GARF F. 564, op. 1, d. 153, 1. 1-1ob.

49 Anatolij F. KonI: Lev Nikolaevič Tolstoj. In: GA6, S. 467.

50 Ebd., S. 467-68.

51 Walicki: Legal Philosophies of Russian Liberalism, S. 73.

52 Ebd., S. 73 und 79. 
nina" entwickelte. Während Tolstoi schon seit jeher ausgesprochen gläubig und für Mystik sehr empfänglich war, intensivierte sich dies ab Ende der 187oer-Jahre und wurde von einer immer stärkeren Ablehnung der Staatskirche mit all ihren Regeln, Riten und Dogmen begleitet. ${ }^{53}$ Dostojewskis Überzeugungen lassen sich von Tolstois Ideen zwar deutlich unterscheiden, das ändert aber nichts daran, dass auch er in seinen Romanen scharfe Kritik an bestimmten Elementen des Rechtswesens äußerte. So war Dostojewski zwar der Ansicht, dass es die Kontrollmacht des Staates und entsprechender Gesetze brauche, aber er sah keinen Sinn in der Rolle der Verteidiger, denen er Zynismus vorwarf, da sie für Geld moralische Prinzipien relativieren würden. ${ }^{54}$ Besonders augenfällig lässt sich Dostojewskis Kritik im Roman „Die Brüder Karamasow“ nachlesen, in dem er mit der Figur des Anwalts Fetjukovič den berühmten Strafverteidiger Vladimir Spasovič parodierte. Dieser hatte sich den öffentlichen Unmut des Schriftstellers zugezogen, als er einen gewalttätigen Vater vor Gericht erfolgreich verteidigte. ${ }^{55}$

Die negativen Einstellungen dieser beiden Literaten fanden dabei durchaus Anknüpfungspunkte in breiten Kreisen der gebildeten Gesellschaft. So wurden die juristischen Verfahren von einem großen Teil der Intelligencija geringgeschätzt. Die Darstellung der Gerichtsbeamten durch die Schriftsteller, die sie als „kalte“ Offizielle mit einem als „unrussisch“ identifizierten rationalen Zug charakterisierten, verfing ausgezeichnet. Die Intelligencija sah die „wahre Gerechtigkeit“ lieber in einer gerechten politischen, sozialen oder ethischen Ordnung, die ein guter Gesetzgeber erstellen sollte, weniger aber im konkreten rechtlichen Prozess, der juristischen Prinzipien folgte. ${ }^{56}$ Der "Spirit of Law“ wurde generell als etwas Westliches, Kapitalistisches gesehen, das den romantischen Vorstellungen von der „russischen Seele " gegenüberstand.$^{57}$ Besonders deutlich wurde diese Haltung vom Juristen Bogdan Aleksandrovič Kistjakovskij (1868-1920) auf den Punkt gebracht und problematisiert. Im Rahmen des Sammelbandes „Wegzeichen“ [vechi], in dem 1909 eine Gruppe von Intellektuellen ihresgleichen kritisierte, geißelte er

53 Ulrich Schmid: Lew Tolstoi. München 2010, S. 70-72. Die Auseinandersetzung zwischen Tolstoi und seinen religiösen Ansichten und der Orthodoxen Kirche gipfelte schließlich in der Exkommunikation des Schriftstellers im Jahre 1901. Tolstois religiöse Ansichten lassen sich in drei Grundsätzen zusammenfassen. Er wollte den Glauben auf die Basis der Vernunft stellen und lehnte alle Geschichten von biblischen Wundern ab. Zentral erschien ihm eine strenge moralische Grundlage, die zu predigen sei, und drittens sollte das Fernziel die Verbrüderung aller Menschen auf der Welt sein. WALICKi: Legal Philosophies of Russian Liberalism, S. 76

55 Gary Rosenshield: Western Law, Russian Justice. Dostoevsky, the Jury Trial, and the Law. Madison Wisconsin 2005, S. 35-37.

56 Wortman: The Development of a Russian Legal Consciousness, S. 288.

57 Walicki: Legal Philosophies of Russian Liberalism, S. 10-11. 
das äußerst niedrige Rechtsbewusstsein in weiten Teilen der Intelligencija. Recht an sich werde nicht verstanden als eigener Wert, Rechte wolle man jeweils nur für die eigene Klientel in Anspruch nehmen. Ein völliges Unverständnis von Prozessen der Gesetzgebung und von rechtlichen Grundregeln sei weit verbreitet. ${ }^{58}$

Konis Reden und Erinnerungen an berühmte Literaten verfolgten unmittelbar den Zweck, diese verbreitete Skepsis gegenüber der Justiz in Intelligencija-Kreisen aufzugreifen und abzuwenden, indem ein enger Zusammenhang von Koni und Literat beziehungsweise von Justiz und Literatur behauptet wurde. So konnten die konkreten gegen Gesetzgebung und Rechtsstaat gerichteten Aussagen der Schriftsteller relativiert werden. Die elementare Bedeutung, die dies für Koni zu haben schien, erklärt sich aus dem Stellenwert, den diese Literaten im russischen Imperium des 19. Jahrhunderts hatten. Sie galten als Führer und Verteidiger gegen die Autokratie, ihre Werke wurden als einzige Orte der Forwärtsbewegung angesehen. Nach dem großen „Vorkämpfer des Realismus“ Vissarion Grigorevič Belinskij (1811-1848) - so bringt es Isaiah Berlin auf den Punkt - war kein Russe mehr frei vom Glauben, dass Schreiben zuerst einmal heiße, Zeuge der „Wahrheit" zu sein. Ein Schriftsteller hatte sich mit den Themen seiner Zeit und seiner Gesellschaft auseinanderzusetzen. ${ }^{59}$ Literatur war in Russland ein „Schlachtfeld“ für soziale und politische Lebensfragen. Es erstaunt deshalb nicht, dass die Regierung sogar durch die Begräbnisfeier für Turgenev, den man oftmals lediglich als „Geschichtenerzähler" interpretierte, in größte Nervosität versetzt wurde. ${ }^{60}$ Die Intelligencija stellte Literatur in das Zentrum ihrer Selbstidentifikation. ${ }^{61}$ So war man überzeugt, Träger und Vermittler kultureller Werte zu sein und damit in einer einflussreicheren Position, als es Wissenschaft und Professionsgruppen waren. Literaturkritik und die Auseinandersetzung mit Persönlichkeiten wie Puschkin wurden geradezu als Königsweg gesehen, soziale und politische Probleme anzugehen und gesellschaftlich aktiv zu sein. Die mächtigste Verdammung gegen die Todesstrafe, so musste der ehemalige Justizminister Dmitrij Nabokov feststellen, waren nicht wissenschaftlich fundierte Manifeste professioneller Juristen, die sich jahrzehntelang dagegen eingesetzt hatten, sondern literarische Schriften von Tols-

58 Bogdan Kistja Kovskij: Zur Verteidigung des Rechts. Die Intelligencija und das Rechtsbewusstsein. In: Nikolaj A. Berdjaev u. a. (Hrsg.): Vechi. Wegzeichen: zur Krise der russischen Intelligenz, hrsg. u. mit einer Einleitung versehen v. Karl Schlögel, Original Moskau 1909. Frankfurt am Main 1990, S. 213-50, v. a. 213, 232-33.

59 Berlin: Fathers and Children, S. 3 und 1o. Vgl. zu Belinskij Stender-Petersen: Geschichte der russischen Literatur, S. 202-03 ff. Die Worte von der Vorwärtsbewegung, die in Russland angesichts von harter Repression einzig in der Literatur auszumachen sei, stammen aus einem offenen Brief von Belinskij an Gogol vom Juli 1847.

6o Berlin: Fathers and Children, S. 4-5 und 9.

61 SDvižkov: Das Zeitalter der Intelligenz, S. 173. 
toi, Dostojewski oder Turgenev. ${ }^{62}$ Eine „Aneignung“ dieser Literaten war deshalb zentral, um ihre Popularität und Einfluss auf das „Volk“ für sich mit zu beanspruchen und so eigene berufliche Anliegen zu forcieren. Das juristische Berufsethos sprach zwar von der Verbreitung von Rechtsbewusstsein in der Bevölkerung des Russischen Reiches beispielsweise über die Geschworenengerichte mit ihrer Fähigkeit, die Involvierten zu schulen und für Fragen von Recht und Unrecht zu sensibilisieren. ${ }^{63}$ Doch die Literatur schien eine noch direktere Verbindung zur Gesellschaft und deren zukünftiger Entwicklung im Lande zu versprechen. Dabei beließ Koni nie Zweifel daran, welche Art von Literatur und Kunst er im Blickfeld hatte. Eine „aufklärerische Aufgabe“ hätte jeder Schriftsteller, der auf den Leser wirken solle, mit seinen Gedanken, die immer wesentlicher zu sein hätten als die Form der Darstellung. Letztere veralte bisweilen, der Inhalt des Werks aber habe sich auf die großen, nie an Relevanz einbüßenden Fragen der Menschheit zu beziehen. So drückte sich Koni 1903 in seiner Rede über den von der deutschen Romantik tief beeinflussten Philosophen und Verfasser gesellschaftskritischer Novellen, den Fürsten Vladimir Fëdorovič Odoevskij (1803-1869), vor der Akademie der Wissenschaften aus. ${ }^{64}$ „Mit besonderer Zuneigung“ - so konstatiert Michael Ginsburg in seiner Analyse von Konis Rede zu Recht - habe er sich diesem Schriftsteller gewidmet, der über 30 Jahre nach seinem Tod in Russland kaum noch bekannt war. Besonders hat es Koni Odoevskijs Kurzgeschichte über einen Militär angetan, der nach 60 Jahren kurz vor seinem Tod plötzlich beginnt darüber nachzudenken, wie sinnentleert sein Leben gewesen ist. ${ }^{65}$ Sinn sieht Koni, so könnte man schlussfolgern, in Odoevskijs eigenen Aktivitäten als Philanthrop und Unterstützer der „Großen Reformen“.66

Nur konsequent fokussiert Koni also in seinen „Aneignungen“ auf die klassischen Autoren wie neben Odoevskij die international renommierten Exponenten Puschkin, Dostojewski oder Tolstoi, die mit ihren moralischen Konzepten diesen aufklärerischen Impetus am deutlichsten demonstrierten. Neue literarische Akteure wie die Symbolisten, die in der Zeit der „Kulturkrise“ um die Jahrhundertwende einflussreich wurden und „Subjektivismus“, „Amoralismus“, „Aso-

62 Nethercott: Russian Legal Culture Before and After Communism, S. 128 und Arnold: Writing Justice, S. 61.

63 Vgl. dazu TEIL EINS.

64 Anatolij F. KonI: Knjaz’ Vladimir Fëdorovič Odoevskij. In: ders. (Hrsg.): Očerki i vospominanija. Publičnye čtenija, reči, stat'i i zametki. Sankt-Peterburg 1906, S. 49-50. Vgl. zu Odoevskij Stender-Petersen: Geschichte der russischen Literatur, S. 160-61 (T. II).

65 Michael Ginsburg: Koni and his Contemporaries. Authors. Indiana Slavic Studies 1 (1956), S. 55-56.

66 Ebd., S. 57. 
zialismus" und "grenzenlosen Pessimismus" predigten, entsprachen hingegen so gar nicht seinen Vorstellungen von Literaten und ihren Aufgaben ${ }^{67}$ Viel lieber griff Koni in seinen Literatenporträts und -kritiken Begriffe wie Wahrheit, Gerechtigkeit, Moral, Menschlichkeit und Lebendigkeit auf und verwendete sie im Zusammenhang mit der Justiz. In Puschkins, Dostojewskis oder Tolstois Gedanken, Gesprächen und Werken sah Koni diese Themen behandelt und behauptete öffentlich die Relevanz dieser Auseinandersetzung für das Rechtswesen, das er so in eine „spirituelle Vereinigung“ mit diesen ethischen Grundsätzen bringen konnte. $^{68}$ Trotz der augenfälligen Differenzen gelang es Koni so, gar zu einer Figur wie Tolstoi eine gewisse Nähe aufzubauen. Wie überraschend das von ihm in seinem Erinnerungsporträt gezeichnete Bild des Moralphilosophen und des Juristen sein musste, die gemeinsam in Diskussionen über Recht und Gerechtigkeit vertieft auf „Jasnaja Poljana“ spazieren gehen, spricht Koni im Text selber an. Er könne sich Tolstois gute Beziehung zu ihm nur so erklären, dass dieser in seinen Ansichten und Handlungen all das nicht gefunden habe, was ihn sonst so negativ über das russische Gerichtswesen und seine Akteure sprechen ließ ${ }^{69}$ Und sogleich versichert Koni, dass er schließlich in seinem gesamten Dienst als Richter, Staatsanwalt und Gerichtsvorsitzender nicht „eine der grundlegenden Regeln der kantschen Ethik“ verletzt habe, also nie den Menschen „als Mittel zum Erreichen irgendwelcher [...] Ziele" missbraucht habe. ${ }^{70}$ Die Überzeugungen des deutschen

67 Stender-Petersen: Geschichte der russischen Literatur, S. 508-09. Entsprechend hart drückte Koni sich in seiner privaten Korrespondenz gegenüber diesen Schriftstellern aus, vgl. zum Beispiel seinen Brief vom April 1908, in dem er Merežkovskijs Werken jeglichen Anspruch darauf abspricht, Literatur zu sein, GA8, S. 250 (Brief an Nikolaj Vladimirovič Sultanov vom 18.04.1908). In einem Entwurf des Porträts von Tolstoi hatte Koni auch noch viel deutlicher sowohl Merežkovskij als auch seine Ehefrau Hippius kritisiert in Zusammenhang mit deren Ansichten zu Tolstoi, vgl. GA6, S. 641-42 (Anmerkungen). Diese Ablehnung relativierte Koni ein Stück weit, als er im März 1917 in einem Brief von Merežkovskij als Schriftsteller spricht, der trotz gewisser Defizite wenigstens ,europäisch“ sei, vgl. GA8, S. 301 (Brief an A. A. Šachmatov vom 22. 03.1917). Vgl. auch oben, S. 198 und speziell zu Hippius und Merežkovskij oben, S. 270.

68 Arnold spricht davon, dass Juristen die Literatur benutzten, um „die spirituelle Verbindung zwischen den zeitlosen ethischen Prinzipien von Wahrheit und Gerechtigkeit und dem lebendigen sozialen Organismus der post-reformerischen Justiz" zu betonen, vgl. ARNOLD: Writing Justice, S. 71. Weiter führt sie aus, dass es Koni und weiteren juristischen Literaturkritikern gar gelang, beispielsweise die Dostojewskirezeption wesentlich zu beeinflussen, so dass gewisse seiner Werke nicht mehr nur mit dem Fokus auf seine feindliche Einstellung gegenüber den Gerichten gelesen wurden, sondern vielmehr als ein Ort, an dem der Autor über die Gesellschaft, das Strafrecht und menschliche Werte nachdachte, vgl. ebd., S. 223.

69 Koni: Lev Nikolaevič Tolstoj. In: GA6, S. 482.

70 Ebd., S. 482. 
Aufklärungsphilosophen Immanuel Kant (1724-1804) und insbesondere seine Maxime vom „kategorischen Imperativ“ bildeten eine wesentliche Grundlage von Tolstois Ansichten zu Recht und Moral. ${ }^{71}$ Koni maß so also sein eigenes Verhalten als Jurist an Tolstois Maßstäben und sonnte sich in der Absolution, die ihm die Zuneigung des Schriftstellers - in Konis Erinnerungsschrift vielfach öffentlich reproduziert - zuteilwerden ließ. In einer verblüffenden Wechselwirkung nutzte Koni dabei einerseits die moralische Autorität der Literaten, um an deren engen Verbindung zum „Volk“ teilzuhaben, die eigene Person positiv darzustellen und Kritik vom Rechtswesen abzuwenden, während er andererseits die rechtlichmoralischen Überzeugungen und Werke der Schriftsteller verwendete, um seine eigene Berufsgruppe zu disziplinieren, die aus den literarischen Darstellungen lernen sollte.

Der Frage, wie sich Juristen vor Gericht zu verhalten hatten, widmete Koni nach der Jahrhundertwende viel Arbeit und Energie. ${ }^{72}$ In seinen Reden und Arbeiten zur "Gerichtsethik“ finden sich dabei große Übereinstimmungen mit den moralischen Forderungen insbesondere Tolstois. Mit diesen Gedankengängen beteiligte sich Koni an der seit Ende des 19. Jahrhunderts verstärkt geführten Debatte zu rechtsphilosophischen Grundsätzen. Die Frage nach der Definition von Recht und dessen Abgrenzung von Gerechtigkeit und Moral beschäftigte zahlreiche juristische und philosophische russische Denker. ${ }^{73}$ Nach wie vor be-

71 Inessa Medzhibovskaja: Punishment and the Human Condition. Hannah Arendt, Leo Tolstoy, and Lessons from Life, Philosophy, and Literature. In: Julie Hansen/Andrei Rogachevskii (Hrsg.): Punishment as a Crime? Perspectives on Prison Experience in Russian Culture. Ödeshög 2014, S. 151. Medzhibovskaja schreibt, dass Tolstoi zwar Konis Prinzip von „forschender Gerechtigkeit und nicht sanfter Güte“ [pytlivaia spravedlivost', a ne laskovaia dobrota] geteilt habe, aber nur unter der Voraussetzung, dass „,forschende Gerechtigkeit" die Anwendung von Kants kategorischem Imperativ meine, der moralisches Verhalten fordere und so die Rolle des Richters von jenem, der die Macht zur Bestrafung ausübe, trenne. Vgl. zur sich entwickelnden Begeisterung Tolstois für Kant auch Ekaterina Polja kova: Differente Plausibilitäten. Kant und Nietzsche, Tolstoi und Dostojewski über Vernunft, Moral und Kunst. Berlin u. a. 2013, S. 233 ff. Poljakova führt aus, wie Tolstoi sowohl von Kants Philosophie als auch von seiner Persönlichkeit fasziniert war. Er sah ihn als „Vorbild eines Lehrers vom Sinn des Lebens“ (ebd., S. 234). Der kantisch-abendländische Ansatz, Moral aus Vernunft zu gewinnen, scheint Tolstois „religiöse Wende" stark mitgeprägt zu haben (ebd., S. 235).

72 Vgl. oben, S. 90 zu den Publikationen Konis hierzu um 1902. Diese Überlegungen Konis stehen im Zusammenhang mit seinen Juristenporträts, mit denen er auf einer abstrakteren Ebene ebenfalls an der Kreation eines generationenübergreifenden moralisch basierten Berufsethos arbeitete.

73 Anita SchlüChter: Recht und Moral. Argumente und Debatten „zur Verteidigung des Rechts" an der Wende vom 19. zum 20. Jahrhundert in Russland. Zürich 2008, S. 11-13 und 17. Schlüchter zeigt in ihrer Untersuchung auf, dass die gängige westeuropäische 
herrschten jene das Feld, die sich wie beispielsweise Nikolaj Tagancev für die klassische Vorstellung vom „Recht um des Rechts Willens“ stark machten und nicht bereit waren, juristische Prinzipien durch sozialwissenschaftliche Erkenntnisse über Verbrechen und Strafe in Frage zu stellen. Gleichzeitig wurden aber nach der Jahrhundertwende die psychologischen und soziologischen Theorien des Verbrechens immer einflussreicher. ${ }^{74}$ Diese positivistischen Vorstellungen sahen eine faire Justiz unmittelbar verbunden mit dem Studium sozialer und individueller Faktoren des Verbrechens. Strafe wurde so zum Mittel der sozialen Reintegration des Angeklagten, und Kriminalität an sich konnte nur als soziales Phänomen bekämpft werden. ${ }^{75}$ Die Strömung im Kriminalrecht, die sozioökonomische Bedingungen so stark gewichtete, war von verschiedenen Ideen beeinflusst wie dem Revival des Naturrechts und den psychologischen Rechtstheorien des St. Petersburger Rechtsprofessoren Lev Iosifovič Petražickij (1867-1931). Gleichzeitig spielten aber auch rechtsphilosophische Ideen von der moralischen Begründung des Rechts mit hinein, wie sie der Dichter und Philosoph Vladimir Sergeevič Solovëv (1853-1900) betonte. ${ }^{76}$ Solovëvv gehörte wie Koni zum Kreis um die liberale Zeitschrift des „Boten Europas“, und nach seinem Tod 1900 widmete er dem Denker einen seiner großen Auftritte vor der Akademie der Wissenschaften. Während Koni oder Čičerin Solověvs Ideen von einem moralbasierten Recht grundsätzlich als rückwärtsgewandt zurückwiesen und auf der Trennung von Recht und Moral beharrten, eröffnete gerade das Feld der Gerichtsethik die Möglichkeit, moralische Aspekte im Justizprozess zu betonen. ${ }^{77}$ Immer wieder verwies Koni in seinen theoretischen Ausführungen zum Strafprozess und zur Gerichtsethik auf die moralischen Komponenten des Gerichtswesens. Er betonte den kategorischen Imperativ von Kant mit seinem Fokus auf dem Respekt vor der

Vorstellung, dass in Russland eine totale Ablehnung des Rechts im Namen der Moral stattgefunden habe, verkürzt ist.

Nethercotт: Russian Legal Culture Before and After Communism, S. 94-95.

75 Ebd., S. 97.

76 SchlÜchter: Recht und Moral, S. 17 und Nethercott: Russian Legal Culture Before and After Communism, S. 94-95.

77 Nethercott: Russian Legal Culture Before and After Communism, S. 91-92. Vgl. zu Konis Skepsis gegenüber Solov’ëvs Rechtsverständnis auch die Rede Konis vor der Akademie. Darin macht Koni deutlich, wie umstritten die Ansichten des Philosophen in diesem Bereich waren, und geht auch auf die Auseinandersetzung mit Boris Čičerin ein, vgl. Anatolij F. Koni: Vladimir Sergeevič Solovëv. In: ders. (Hrsg.): Očerki i vospominanija. Publičnye čtenija, reči, stat'i i zametki. Sankt-Peterburg 1906, S. 224-25. Konis Wertschätzung für Solovëv als Person wird in der Rede aber sehr wohl deutlich und zeigt sich noch mehr im Abschnitt zu Solov"ëv, den Koni in seine Erinnerungen an den „Boten Europas“ integriert, vgl. KonI: „Vestnik Evropy“. In: ders. (Hrsg.): Na žiznennom puti, Bd. 2, S. $217 \mathrm{ff}$. 
menschlichen Würde und verband dies mit dem christlichen Prinzip der Nächstenliebe. ${ }^{78}$ Das ehrliche, sittliche Verhältnis zum Angeklagten wurde als moralische Pflicht jedes Juristen ins Zentrum gestellt. ${ }^{79}$ Recht und Gerechtigkeit, so führte Koni aus, seien nicht voneinander zu trennen. Gerechtigkeit bestehe nicht nur in der rechtlichen Anwendung der gesetzlichen Strafnormen, sondern auch in der Pflicht des Gerichtsakteurs, bei all seinem Handeln dem Angeklagten gegenüber die moralischen Gesetze einzuhalten. ${ }^{80}$ Um diese Empathie zum Mitmenschen wiederum zu entwickeln und die menschliche Psychologie besser zu begreifen, empfahl Koni seinen Kollegen die Lektüre der großen russischen Romanautoren. Der Kreis schließt sich und wird nur dadurch ins Ungleichgewicht gebracht, dass sich gerade Tolstoi mit Konis Bemühungen um die ethischen Prinzipien für Juristen nicht vollständig einverstanden zeigte. So schrieb er 1904 in einem Brief, dass er Konis Text über die „Allgemeinen Züge der Gerichtsethik“ gelesen habe ${ }^{81}$ Er versichert, dass solche Grundsätze, gerade wenn eine Autorität wie Koni sie vermittle, für junge Gerichtsbeamte sicher von großem Nutzen seien. Doch könne er die Hoffnung nicht aufgeben, dass mit der Umsetzung des „höchsten moralischen und religiösen Gesetzes, Kants kategorischem Imperativ“, jede Art von Gerichten überflüssig werde. ${ }^{82}$ Indem Koni in seinem Erinnerungsporträt von Tolstoi aus diesem Schreiben zitierte, verheimlichte er die ohnehin offensichtlichen Diskrepanzen zwischen dem Justizsystem und Tolstois Idealen nicht, unterstrich aber gleichzeitig die Gewogenheit des berühmten Mannes ihm und seinen Prinzipien gegenüber. Die „Gerichtsethik“ war für Koni eine ausgezeichnete Möglichkeit, zumindest gewisse moralische Kategorien in das Rechtswesen zu integrieren und dadurch Anknüpfungspunkte an Überzeugungen der Literaten und der Intelligencija zu finden. ${ }^{83}$

78 Nethercott: Russian Legal Culture Before and After Communism, S. 91-92.

79 Spalinger-Bichsel: A. F. Koni und die russische Gerichtsrhetorik, S. 63.

80 Vgl. die Zusammenfassung von Konis Rede „Moralische Grundlagen im Strafprozess“ durch Perlov: Pravovye vozzrenija A. F. Koni, S. $6 \mathrm{ff}$.

81 Koni selber spricht in seinem Porträt von einem Text zur Gerichtsethik („Obščie osnovanija sudebnoj ètiki“), den er Tolstoi geschickt habe, vgl. Koni: Lev Nikolaevič Tolstoj. In: GA6, S. 482.

82 Lev Nikolaevič TolstoJ: Tolstoy's letters, 2 Bände, Bd. 2, hrsg. v. Reginald Frank Christian. London 1978, S. 641.

83 Die Juristen waren keineswegs die einzige Berufsgruppe, die ihre Interessen, ihre Bedeutung und ihre Popularität so zu befördern versuchte. Die russischen Anthropologen beispielsweise benutzten die Verwandtschaftsverhältnisse des verehrten Puschkin als Mittel, öffentliche Aufmerksamkeit für ihre sich herausbildende Wissenschaft zu erzeugen, vgl. Arnold: Writing Justice, S. 63 bzw. Marina Mogilner: Homo Imperii. A History of Physical Anthropology in Russia. Lincoln u. a. 2013, S. $151 \mathrm{ff}$. 


\section{Transfers zwischen Justiz und Literatur}

Konis biografischer Hintergrund prädestinierte ihn für die Aufgabe, die Literaten dem Justizwesen „anzueignen“. Nicht nur sein Vater, sondern auch sein Pate Ivan Ivanovič Lažečnikov (1792-1869) waren bekannte Schriftsteller und empfingen zuhause zahlreiche Künstler und Literaten, darunter auch die Bekanntschaften von Konis Mutter aus dem Schauspielmilieu. ${ }^{84} \mathrm{Zu}$ seiner Studienzeit in Moskau blieb Koni mit dem literarisch-künstlerischen Netzwerk seiner Eltern eng verbunden. So verkehrte er regelmäßig im Haus des Schriftstellers Aleksandr Fomič Vel'tman (1800-1870), der für seine phantastisch-historischen Romane bekannt war, und besuchte Literaturabende, an denen Autoren wie Nekrasov, Dostojewski oder Apuchtin auftraten. ${ }^{85}$ Auch zahlreiche andere Juristen bewegten sich im Milieu der künstlerischen Intelligencija. Bereits erwähnt wurde der „Shakespeare-Zirkel“, in dem sich Koni seine Reputation als Puschkinkenner erwarb. Gegründet vom Anwalt Spasovič in den 187oer-Jahren, versammelte er über Jahrzehnte dreimal pro Monat Petersburger Juristen wie Koni, Arsenev, Andreevskij oder Urusov zu Gesprächen zuerst über Shakespeare, aber bald auch über aktuelle Literatur oder soziale Themen. Persönlichkeiten aus der literarischen und intellektuellen Elite der Hauptstadt wurden eingeladen, wie beispielsweise Dmitrij Merežkovskij oder Vladimir Solovëv, und tauschten sich mit den literarisch interessierten Juristen aus. ${ }^{86}$ Literatur sei zentral für die Juristen, befand ähnlich wie Koni auch Spasovič, denn nur so könnten diese einen hohen moralischen, professionellen und gesellschaftlichen Standard wahren. ${ }^{87}$ Die Darstellung einer engen Verbindung zwischen den moralisierenden Literaten und der Justiz stieß allerdings nicht in jedem Fall auf ein positives Echo. Es gab auch Stimmen, die nicht verstehen konnten, dass sich Koni ausgerechnet Personen wie einem Fjodor Dostojewski, der „die neuen und reformierten Gerichte besudelte", so gewogen zeigte. ${ }^{88}$ Zahlreiche Juristen nahmen sich die russische Autorenschaft aber ganz konkret zum Vorbild und veröffentlichten selber literarische Werke. Andreevskij publizierte erstmals auf Anraten von

84 Smoljarčuk: Anatolij Fëdorovič Koni (1844-1927), S. 10-11. Lažečnikov verfasste nach einer bürokratischen Laufbahn mehrere historische Romane, die aufgrund von spannenden Handlungen, pathetischer Sprache und einem „billigen Patriotismus“ einen großen Leserkreis begeisterten, vgl. die Einschätzung von STEnder-Petersen: Geschichte der russischen Literatur, S. 162-63.

85 Smoljarčuk: Anatolij Fëdorovič Koni (1844-1927), S. 25.

86 Simutenko: K. K. Arsen'ev i rossijskoe liberal'noe dviženie konca XIX-načala XX veka, S. 47-48 und Šlemin: Dnevnik K. K. Arseneva, S. 316 sowie Arnold: Writing Justice, S. 28.

87 Arnold: Writing Justice, S. 29.

88 Ebd., S. 210. 
Koni, Stasjulevič und Turgenev 1886 drei Gedichte in einem Sammelband. Er trat zudem in verschiedenen Gesellschaften und Zirkeln mit literaturkritischen Reden auf und veröffentlichte die entsprechenden Arbeiten. ${ }^{89}$ In den 189oern begann er schließlich an seinem Lebenswerk, dem „Buch vom Tode“ zu arbeiten, in dem sich memoiristische Prosa mit tagebuchähnlichen Aufzeichnungen zusammenfand. Daraus verteilte er Auszüge an seine Anwaltskollegen zur Lektüre oder las sie in den literarischen Zirkeln selber vor. ${ }^{90}$ Es gab auch Juristen wie Nikolaj Karabčevskij, die zuerst eine Karriere als Schriftsteller versuchten, um schließlich in den Anwaltsstand zu wechseln. ${ }^{91}$ Die überdurchschnittliche Begeisterung für Literatur und Literaturtheorie in den Kreisen der berühmteren Exponenten der Anwälte hatte sicherlich mit der Tatsache zu tun, dass dieser Beruf zu den unabhängigsten im Zarenreich des späten 19. Jahrhunderts gehörte und somit begabte und vielseitig interessierte Persönlichkeiten anzog. ${ }^{92}$ Der Zusammenhang zwischen Literatur und Justiz war gerade in der mündlich vorgetragenen Gerichtsrede, die ab 1864 in Russland eingeführt wurde, aber auch offenkundig. Schriftsteller wie beispielsweise Petr Dmitrievič Boborykin (1836-1921) betätigten sich deshalb gerne als Lehrmeister der Rhetorik für Juristen. ${ }^{93}$ Die Fragen, ob und wie stark die Rede eines Anwalts, Gerichtsvorsitzenden oder Richters von literarischen Prinzipien geleitet sein sollte und inwiefern das Gericht auch ein "Theater" sein durfte, waren denn auch viel diskutierte. ${ }^{94}$

89 RJazanova: S. A. Andreevskij, S. 106-09.

90 Andreevskij: Kniga o smerti, 2005, S. 530 und 552 (Nachwort von I. I. Podol'skaja). Vgl. zum Inhalt des Buches bzw. zur Publikation unter Konis Verantwortung in den 1920erJahren oben, S. 68.

91 Dar'ja N. Kovaleva: Nikolaj Platonovič Karabčevskij (1851-1925). Žizn', tvorčestvo, ličnost'. Avtoreferat dissertacii na soiskanie učenoj stepeni kandidata istoričeskich nauk. Saratov 2010, S. 17.

92 Marina V. Nemytina: Sud v Rossii. Vtoraja polovina XIX-načalo XX vv. Saratov 1999, S. 11.

93 BRANG: Das Land der sprachlosen Ebenen zum Sprechen bringen, S. 434-35.

94 Vgl. dazu auch die Anspielungen in den Juristenporträts, oben, S. 79 bzw. Harriet Murav: Russia’s Legal Fictions. Ann Arbor Michigan 1998, S. 1 mit einer Übersicht zur allgemeinen Forschungsliteratur über „die Beziehung zwischen Recht und der Sphäre von Fiktion, Erzählung und Rhetorik“ bzw. ebd., S. $77 \mathrm{ff}$ spezifisch zu „Law and Literature“ und „Theater in the Courtroom“ in Russland und u. a. Konis Vorstellung von der richtigen Gerichtsrede. Dies führt er insbesondere in einer Rezension mit dem Titel „Die Kunst des Redens vor Gericht“ (Anatolij F. Koni: Iskusstvo reči na sude [O knige P. S. Porochovščikova]. In: VE 11 [1911], S. 91-111 sowie in „Auf dem Lebensweg“ III) und im Text „Die Geschworenen“ aus der Reihe der „Erinnerungen eines Gerichtstätigen“ (KonI: Iz zametok i vospominanij sudebnogo dejatelja. Prisjažnye zasedateli. In: GA1, S. 331-91) aus. So sieht er, wie Murav zusammenfasst, gleichzeitig eine große Gemeinsamkeit zwischen Künstler und Gerichtsredner, da beide für die Kommunikation mit dem Publikum in Bildern sprechen. 
Während so der Einfluss der Literatur auf das Schaffen der Juristen offensichtlich scheint, bedienten sich umgekehrt auch die Literaten am juristischen Vokabular. Ein Anzeichen dafür sind all die rechtlichen Interventionen, die Koni sowie weitere Staatsanwälte und Anwälte auf Bitten von Schriftstellern vornahmen. So gelangten sowohl Dostojewski als auch Tolstoi mehrfach an Koni, um von ihm juristische Hilfe für Personen zu erbitten, die in Schwierigkeiten geraten waren. ${ }^{95}$ In einem Brief vom Oktober 1905 schrieb der Pazifist Tolstoi beispielsweise an den Kunstkritiker Vladimir Vasil'evič Stasov (1824-1906), dass er an verschiedenen Orten versucht habe, Unterstützung für eine Person zu finden, die den Militärdienst verweigert habe. Koni war es schlussendlich, der durchsetzen konnte, dass die Akte dieses Dienstverweigerers nochmals angeschaut wurde. ${ }^{96}$ Für großes öffentliches Aufsehen sorgte der Fall, in dem Koni und der Schriftsteller Vladimir Galaktionovič Korolenko (1853-1921) gemeinsam die zweifache Kassierung und anschließende Aufhebung eines Schuldspruchs wegen angeblichen Ritualmords durchsetzten. Korolenkos Novellen - so beschreibt es Stender-Petersen in seiner "Geschichte der russischen Literatur" - waren durchdrungen „von tiefem Mitgefühl mit den Unglücklichen“.97 Solchen „Unglücklichen“ wollte der Schriftsteller in den 189oer-Jahren auch ganz konkret helfen, als eine Gruppe von udmurtischen Bauern eines Ritualmordes für schuldig befunden wurde. Beispielhaft konnte der bekannte Schriftsteller dank seines Netzwerks und Einflusses zusammen mit der juristischen Autorität Konis in der Gesellschaft ein Umdenken erzielen. Waren zuerst noch weite Kreise überzeugt, dass die angeschuldigten Bauern den Mord tatsächlich begangen hätten, stimmte Korolenko mit einer öffentlichen Kampagne und Koni mit seinen Reden als Oberstaatsanwalt nicht nur Senat und Geschworene um, sondern wurden auch mit zahlreichen Glückwunschtelegrammen aus der Bevölkerung überhäuft. ${ }^{98}$ Seine Erinnerungen dazu hielt Koni - allerdings erst 1922 - für die Öffentlichkeit fest. ${ }^{99}$

Er spricht sich aber dezidiert gegen das Gericht als Ort von theatralischem Spektakel aus. Hier spielt wieder Konis Plädoyer für ein respektvolles Verhältnis zum Angeklagten und allen am Prozess Beteiligten hinein. Vgl. zu Konis Redestil auch die Analyse von SPAlinger-BIChSEL: A. F. Koni und die russische Gerichtsrhetorik, S. $58 \mathrm{ff}$.

95 SAšonko: A. F. Koni v Peterburge - Petrograde - Leningrade, S. 95-96 und 196-97.

96 Tolstoj: Tolstoy's letters, Bd. 2, S. 652 (Anmerkungen von Reginald Frank Christian).

97 Stender-Petersen: Geschichte der russischen Literatur, S. 454.

98 Michail I. Bunja: V. G. Korolenko v Udmurtii. Iževsk 1982, S. 137 und 189 ff sowie $207 \mathrm{zu}$ den Telegrammen.

99 Vgl. dazu unten, S. 343. 1900 war Korolenko gemeinsam mit Koni in die „Abteilung für Belletristik“ der Akademie der Wissenschaften ernannt worden, vgl. SMOLJARČUK: Anatolij Fëdorovič Koni (1844-1927), S. 141. 
Noch deutlicher wird die Symbiose zwischen Literatur und Justiz aber bei der Vermittlung literarischer Sujets aus dem Gerichtsalltag an zeitgenössische Autoren. Gerade Koni berichtete über solche erfolgreichen Transferleistungen dann wiederum in seinen Erinnerungen an die entsprechenden Schriftsteller. Besonders berühmt ist die Geschichte hinter Tolstois Roman „Auferstehung“ [Voskresenie]. Dieses dritte und letzte große Romanwerk von Tolstoi wurde 1899 veröffentlicht und erzählt von einem Mann, der nach einem Leben geprägt von Lastern und Genüssen als Geschworener vor Gericht eine angeklagte Prostituierte wiedererkennt als jenes Mädchen, das er vor vielen Jahren verführt hatte. In der Folge behandelt der Roman die moralische Läuterung des Mannes, der sich fortan um die Frau kümmert und ihr gar in Zwangsarbeit und Verbannung folgt. In der Geschichte werden der Formalismus des Rechtssystems, die Geschworenengerichte und das ganze Gefangenenwesen von Tolstoi mit inbrünstiger Entrüstung angegriffen. ${ }^{100}$ Dies sorgte damals unter den Juristen für großen Unmut. Mehrere Artikel wurden veröffentlicht, um die Darstellung der Gerichte und ihrer Akteure durch Tolstoi zurückzuweisen. Urusov seinerseits veröffentlichte in „Neuigkeiten des Tages“ eine Zusammenfassung dieser „Proteste“ und plädierte dafür, sich weniger aufzuregen. Ein Romanautor habe nicht die Pflicht, Typen zu beschreiben, sondern lediglich, gut zu schreiben..$^{101}$ Auch wenn Tolstoi selber der Ansicht sei, mit seinen Romanen Anweisungen an die Gesellschaft zu vermitteln, sei er in seinem Schreiben von einem „künstlerischen Instinkt“ gelenkt, den nur Poeten, nicht aber reine Prediger und Moralisten besäßen. ${ }^{102}$ Urusov fügt auch hinzu, dass Tolstoi, wie seine Kritiker zu Recht angemerkt hätten, die reale „gerichtliche Sphäre“ offensichtlich nicht allzu gut kenne. ${ }^{103}$ Tolstoi schrieb seinen Roman aber durchaus basierend auf einer realen Geschichte, und diese hatte ihm niemand anderes als Koni vermittelt. In seinem Porträt des berühmten Schriftstellers beschreibt Koni selber auf mehreren Seiten, wie er Tolstoi bei einem Besuch auf dessen Landgut Ende der 188oer-Jahre vom Fall der Rozalija Onni berichtet habe. Er habe Tolstoi mit der Geschichte dieses Mädchens und ihres Verführers beweisen wollen, wie oft er Zeuge davon gewesen sei, dass Menschen schon zu Lebzeiten Buße für getanes

100 Vgl. zur Beschreibung des Romans Stender-Petersen: Geschichte der russischen Literatur, S. 372-74.

101 Aleksandr I. Unusov: Sudejskie protesty protiv „Voskresenija“. In: ders./A. A. Andreeva/O. B. Gol'dovskij (Hrsg.): Knjaz’ Aleksandr Ivanovič Urusov (1843-19oo). Stat’i ego, pis’ma ego, vospominanija o nem, Bd. 2 und 3. Moskva 1907, S. 65. Das Original erschien 1900 in „Novosti Dnja“.

102 URUSOv: Sudejskie protesty protiv „Voskresenija“, S. 66.

103 Ebd., S. 68. 
moralisches Unrecht leisteten. ${ }^{104}$ Tolstoi sei von der Erzählung sehr beeindruckt gewesen und habe schließlich elf Jahre später den Roman „Auferstehung“ veröffentlicht. Diplomatisch meint Koni in seinem Tolstoi-Porträt über dessen Inhalt, dass dieser wohl aus verschiedenen Quellen zusammengesetzt sei und „stärksten Eindruck auf die Seelen vieler junger Leute" und deren moralische Werte haben dürfte. ${ }^{105}$ Kein Wort verliert er über die Darstellung des Rechtswesens, obwohl ihm die korrekte Wiedergabe der Details, die er Tolstoi vermittelt hatte, durchaus ein Anliegen war. So schrieb er ihm kurz vor Erscheinen des Romans noch einen Brief, in dem er juristisch seiner Ansicht nach unlogische Elemente in der Geschichte, deren Inhalt bereits in Auszügen an die Öffentlichkeit gedrungen war, zu korrigieren versuchte. ${ }^{106}$

Die Vermittlung des Sujets des reuigen Verführers an Tolstoi wird von Koni in seiner Erinnerungsschrift als ultimativer Beweis der Nähe zwischen dem Schriftsteller und dem Juristen und ihren moralischen Überzeugungen dargestellt. Dies schien für ihn mehr zu wiegen als die Munition zur erneuten Verurteilung des Rechtssystems, die er Tolstoi mit dieser Geschichte verschafft hatte. ${ }^{107}$

104 Koni: Lev Nikolaevič Tolstoj. In: GA6, S. 474 ff.

105 Ebd., S. 479-80.

106 GA8, S. 153-54 (Brief an L. N. Tolstoi vom 17. 09.1899).

107 Vgl. auch als weiteres Beispiel einer Sujetvermittlung Tolstois Drama „Der lebende Leichnam“ [Živoj trup]. Kurz zusammengefasst handelte es sich um den Fall einer Frau, der nicht erlaubt wurde, sich von ihrem Ehemann zu trennen und neu zu heiraten. In ihrer Verzweiflung konnte sie den Gatten zur Vortäuschung eines Selbstmordes überreden. Als dies aufflog, wurden beide zu harten Strafen verurteilt, vgl. SAšonko: A. F. Koni v Peterburge - Petrograde - Leningrade, S. 196-98. Koni beschreibt den „Fall Gimerov“ und das Interesse Tolstois daran ausführlich, vgl. Anatolij F. Konı: Po povodu dramatičeskich proizvedenij Tolstogo. In: ders. (Hrsg.): Na žiznennom puti, Bd. 2. Iz vospominanij, publičnye čtenija, v verchnej palate. Sankt-Peterburg 1912, S. S. 57 ff. In diesem Fall war es nicht Koni persönlich, der Tolstoi auf die Geschichte aufmerksam gemacht hatte. Er war aber selber an der Besprechung der Urteile im Stafkassationsdepartement zugegen. Im Artikel zu den Dramawerken Tolstois kommt Koni zum Schluss, dass er „vom streng juristischen Standpunkt her" mit dem Entscheid des Senats, in der Sache nichts weiter zu unternehmen, einverstanden gewesen sei. Aber trotzdem habe er gefunden, dass die formale Anwendung des Rechts äußerst hart gewesen sei, weshalb er sich für eine Milderung der Strafe eingesetzt habe, vgl. ebd., S. 62-65. Vgl. zu Tolstois Umsetzung des Stoffes in ein Dramawerk, das er aber wohl nie für beendet hielt und das trotzdem posthum mit viel Erfolg veröffentlicht bzw. aufgeführt wurde, Stender-Petersen: Geschichte der russischen Literatur, S. $376 \mathrm{ff}$. Koni selber macht in seiner Erinnerung an die Dramawerke Tolstois sehr deutlich, dass er das Werk für unvollendet halte, vgl. Koni: Po povodu dramatičeskich proizvedenij Tolstogo. In: ders. (Hrsg.): Na žiznennom puti, Bd. 2, S. 66. In einem Brief schrieb er offen, dass ihm das Stück gar nicht gefalle, vgl. GA8, S. 275 (Brief an Rašel' Mironovna Gol'dovskaja vom 19. 01.1912). 


\subsubsection{Dörfliche „Eigenart“ als Spiegel für die „sogenannte ,Gesellschaft“}

Die Glückwunschtelegramme, die neben Korolenko auch Koni aufgrund seines Engagements für die des Ritualmords angeklagten Bauern erhalten hatte, mussten ihn mit großer Genugtuung erfüllt haben. Die Suche nach Anerkennung für seinen Einsatz und das Bedürfnis nach Legitimation für seine Haltungen ist denn auch einer der auffälligsten Züge in Konis eigenen autobiografisch inspirierten literarischen Erzählungen über sein häusliches Leben, seine Ferienreisen oder die Schul- und Studienzeit. Die autobiografischen Fortsetzungsgeschichten, die Koni ab 1908 in unterschiedlichen Zeitschriften veröffentlichte, zeichnen sich alle durch die stilisiert-unterhaltsame Weise aus, in der sie mit ihren Leserinnen und Lesern spielen. Das literarische Element nimmt nun im Gegensatz zu den biografischen Porträts, der Rückschau auf sein Berufsleben oder den stark auf die einzelnen Gerichtsfälle fokussierten „Erinnerungen eines Gerichtstätigen“ eine dominantere Rolle ein. Als Erzählform wählt Koni fast durchwegs die Anekdote, die ihrerseits ein typisches Element des Genres der „Erinnerungen der Zeitgenossen“ darstellte, dessen sich die Intelligencija so häufig bediente. ${ }^{108}$ Aus dem Mündlichen kommend entwickelte sich diese Erzählfigur zu einer kleinen in sich abgeschlossenen Geschichte mit eigener Moral. Personen, Netzwerke und darin gehandelte Gerüchte und Tratschereien wurden so auf eine unterhaltsame Art und Weise dargestellt. In einer solchen „würzigen kleinen Story“ über Persönlichkeiten und ihre Beziehungen zueinander sollte den Lesern eine moralische Schlussfolgerung zu den „sozialen Charakteristiken“ der betroffenen Individuen präsentiert werden ${ }^{109} \mathrm{Die}$ sehr persönlichen Themen, die Koni für seine Veröffentlichungen wählte, wurden durch die literarische Form der Anekdote deutlich relativiert. Während die Titel autobiografische Verarbeitungen von Reiseabenteuern im In- und Ausland oder Erfahrungen des jungen Koni in seiner Studienzeit versprechen, stellen die Texte in Tat und Wahrheit relativ willkürliche und thematisch nur lose miteinander verbundene Aneinanderreihungen von unterhaltsamen Kurzgeschichten dar. In deren Zentrum steht nur zum Teil Konis persönliche Befindlichkeit und

108 Vgl. dazu auch die Bemerkungen zur Nähe der juristischen Porträtpraxis und den „Erinnerungen der Zeitgenossen“, die ein charakteristisches Merkmal der Intelligencija-Zirkel bildeten, oben, S. 85.

109 Walker: On Reading Soviet Memoirs, S. 336-37. Walker spricht von einem „particular type of gossipy tale called the anekdot" und merkt an, dass diese Art der (mündlichen) Erzählung schon im späten 18. Jahrhundert am Hofe beliebt war, als Geschichten über den Autokraten und seine Nächsten kursierten. Auch zu Puschkin galt es, alle nur möglichen Informationen zu sammeln, deren anekdotischer, gerüchtebasierter Inhalt oftmals als gesicherte Fakten weitervermittelt wurde. 
sein Erleben von Studium, Reisen oder Dienerschaft. Wichtiger scheinen gelungene Spannungsbögen der einzelnen Anekdoten, die oftmals in dramatischen Zuspitzungen gipfeln. Autobiografisches Zeugnis und literarische Stilisierung gehen nahtlos ineinander über, der Realitätsgehalt tritt vor dem Anspruch der Unterhaltsamkeit zurück. Den „bewussten Umgang mit der Sprache“, den Koni dabei pflegt, zeigt sich - so findet auch Spalinger-Bichsel in ihrer Analyse zu Konis Rhetorik - an der „Sicherheit, mit der jedes Wort gesetzt scheint ${ }^{\text {“ }}{ }^{110}$ Konis schriftstellerische Qualitäten manifestieren sich nicht zuletzt an den atmosphärischen Beschreibungen seiner Erlebnisse, in denen er Details wie die Sprechart von Begleitern und Freunden schriftlich nachzuahmen versuchte. So färbte er beispielsweise seine Erzählung über "Signore Beljaev“ stark umgangssprachlich und fügte neben dem „Signore“ im Titel noch weitere italienische Ausdrücke in den Text ein, die die neue Heimat des ehemaligen russischen Leibeigenen charakterisieren sollten, den Koni auf einer Italienreise antraf. ${ }^{111}$ In der Beschreibung seines Kuraufenthalts in „Ostende“ an der Nordseeküste nutzte Koni lautmalerische Elemente, um die Moral seiner Geschichte zu unterstreichen. Ein Badegast habe sich ungeachtet seiner Warnungen viel zu lang im Meer aufgehalten. Dies mit dem Verweis, das mache er auch "bei sich auf dem Dorfe“ so. Die Anekdote endet mit einem Zeitsprung von sechs Wochen. Dann habe Koni den Badegast nämlich per Zufall mittlerweile in Paris wieder angetroffen. Hinkend sei er auf ihn zugekommen: „A---a---a---v---y...menja ne ---e uznaete?“ - „Erkennen Sie mich nicht?" Der Mann aus Ostende, so wird dem Leser mittels Schriftbild eingänglich vermittelt, hat seine Taubheit den Ratschlägen Konis gegenüber mit dem Verlust seiner Sprech- und Gehfähigkeit bezahlt. ${ }^{112}$

Wenn man nun aber mehr über die Gründe wissen möchte, warum Koni sich überhaupt zum Kuraufenthalt nach Ostende begeben hat, wo er in diesen Jahren beruflich stand, was diese Aufenthalte für ihn bedeuteten, wie seine persönliche Befindlichkeiten aussahen, so wird man enttäuscht. Er spricht lediglich davon, dass die beiden Badeaufenthalte am Meer in Ostende Ende der 186oer-/Anfang der $1870 e r-J a h r e$ bei ihm „einige lebendige Erinnerungen“ hinterlassen hätten. ${ }^{113}$ Nebenbei heißt es einmal in einem nacherzählten Gespräch, dass Koni in Ostende „heilen und lernen“" wollte. ${ }^{114}$

110 Spalinger-Bichsel: A. F. Koni und die russische Gerichtsrhetorik, S. 11.

111 KonI: Sin’or Beljaev. In: ders. (Hrsg.): Na žiznennom puti, Bd. 1, z. B. S. 601, „rigolamento“ [Reglement].

112 KoNI: Ostende (1869-1873 gg.). In: ders. (Hrsg.): Na žiznennom puti, Bd. 1, S. 613-14.

113 Ebd., S. 610.

114 Ebd., S. 613. 
Die moralischen Anekdoten über die angetroffenen Personen stehen deutlich im Zentrum dieser Erzählungen. Und die Moral, die sie vermitteln sollen, dreht sich - der Badegast vom „Dorfe“ lässt es schon erahnen - immer wieder um das Verhältnis zwischen gebildeter, städtischer Gesellschaft und dörflichem, bäuerlichem „Volk“. Am deutlichsten wird dies in „Signore Belaev“. Der gesamte etwa fünfzehnseitige Erinnerungstext stellt eine einzige große Anekdote dar. Die wenigen Momente, in denen wirklich deutlich wird, dass es sich hier um die persönliche Erinnerung von Koni handelt, fallen umso mehr auf. So schreibt er zu Beginn, dass er im September 1873 in Neapel zwei Kollegen aus dem Gerichtsdienst getroffen habe, mit denen er eine Exkursion in die Umgebung unternommen habe. ${ }^{115}$ Was es mit diesem Gerichtsdienst auf sich hatte, wer diese Kollegen waren, wohin die Reise ging und was für Eindrücke Koni mitnahm, wird alles nur wenig bis gar nicht besprochen. Im Zentrum der Geschichte steht fortan Belaev, den die drei Reisenden auf einem Schiff antreffen und der als in Italien lebender Russe seine Dienste als Reiseführer anbietet. Koni und seine Begleiter begeben sich auch zu Beljaev nach Hause, wo sie dessen italienische Ehefrau treffen. Für einen kurzen Moment nimmt der Text einen anderen Tonfall an, Koni erzählt von einem schrecklichen italienischen Tanz, den sie sich zusammen anschauten, und einer Rauchpause, bei der sie auf der Terrasse den wunderschönen Abend genossen. ${ }^{116}$ Die Silhouette des genussvoll rauchenden Koni vor dem Sonnenuntergang über dem Mittelmeer wird aber sofort vom eigentlichen Schreibanlass beiseitegeschoben. Der Rest des Textes widmet sich nun der Lebensgeschichte von „Signore Beljaev“. Diese zeichne laut Koni „so ausdrucksstark die Natur des russischen Menschen und unserer Leibeigenschaft“, dass er sie sich „fast wörtlich“ gemerkt habe. ${ }^{117}$ Der Leibeigene Beljaev, so berichtet Koni, sei mit seinem Herrn durch Europa gereist und von diesem gewalttätig und unfair behandelt worden. Gegen die Schläge habe er sich erst gewehrt, als die Metropole der Zivilisation ins Blickfeld gekommen sei: „Hören Sie auf zu prügeln - Paris ist zu sehen!“ - habe Beljaev dem verdutzten Fürsten erklärt. ${ }^{118}$ Koni und seine Begleiter stellen die Zwischenfrage, warum er sich all dies überhaupt habe gefallen lassen. Daraufhin zeigt sich auf den die Geschichte abschließenden fünf Seiten die angebliche „Natur des russischen Menschen“. Beljaev, so berichtet Koni weiter, habe sie verwundert angeschaut und lediglich gemeint, dass der Fürst schließlich sein Herr gewesen sei. ${ }^{119}$ Für ihn, der nun schon lange in Italien lebe, sei klar, dass er nicht mehr

115 Koni: Sin’or Beljaev. In: ders. (Hrsg.): Na žiznennom puti, Bd. 1, S. 593.

116 Ebd., S. 595-96.

117 Ebd., S. 596-97.

118 Ebd., S. 60o. Kursivsetzung im Original.

119 Ebd., S. 605. 
zurück nach Russland könne. Nicht nur wegen seiner Familie und der dortigen Kälte, sondern - so habe Beljaev den verblüfften Zuhörern erklärt - auch wegen den neuen Regelungen im Lande. Es gebe in Russland nun keine Leibeigenschaft mehr. So seien die Menschen zwar frei, aber wer kümmere sich nun um sie, wenn keine Herren mehr existierten? ${ }^{120}$

Aus Konis Nacherzählung von Lebensgeschichte und Lebensweisheiten des „Signore Beljaev“ spricht gleichsam ungläubiges Staunen und stille Bewunderung für den grundehrlichen einfachen Mann, als der Beljaev in der Erinnerungsschrift dargestellt wird. Seine Welt- und Gesellschaftsordnung, in der Herren und Zaren fürsorglich für die ihnen auf ewig treu ergebenen Bauern sorgen, scheint durch die reale Verletzung dieser Übereinkunft durch den groben Fürsten nicht erschüttert worden zu sein. So viel Loyalität und stures Festhalten an alten Abhängigkeitsstrukturen beeindruckten Koni offenbar derart, dass er sich die gesamte Geschichte in sein Tagebuch aufnotierte, um sie dann Jahrzehnte später an die Öffentlichkeit zu bringen. ${ }^{121} \mathrm{Er}$ schließt die Erzählung mit den Worten, dass viel Zeit vergangen und Beljaev wohl längst gestorben sei, er aber diese Erinnerung an einen Vertreter einer „abgelebten Welt und unbewussten Helden des gesamten Leibeigenschafts-Epos" trotzdem festhalten wolle. ${ }^{122}$ Was er seinen Lesern mit dieser Geschichte zeigen wollte, spricht er zu Beginn der Erinnerungen an die „Hausangehörigen“ noch unmittelbarer an: Sehr häufig würden sich nämlich unter den Hausbewohnern ,interessante Persönlichkeiten“ befinden, die „,ernsthafte Aufmerksamkeit und sogar Studium " verdienten. ${ }^{123}$ Welche Eigenschaften Koni für diese Menschen als charakteristisch ansieht, haben die Beispiele von Beljaev und dem Badegast aus Ostende schon angedeutet. Beide verfügen über ein Weltverständnis, das durch ihren Erfahrungshorizont eng abgesteckt ist. Der Badegast besteht darauf, sich auch am Meer so zu verhalten wie „bei sich auf dem Dorfe“. Beljaev argumentiert auch nach der Abschaffung der Leibeigenschaft noch mit Loyalität zu Herr und Zar, die er als Hüter über das Wohlergehen der ihnen anscheinend seit jeher anvertrauten Subjekte sieht. Das anekdotische Potential ergibt sich quasi von selbst durch die Diskrepanz zwischen den realen Verhältnissen, die Koni selber als gebildeter Zeitgenosse zu kennen vermeint, und dem bisweilen erstaunlich eigentümlichen und sturen, immer aber grundehrlichen und naiven Weltverständnis der Vertreter der ungebildeten Dorfbewohner. Die

\footnotetext{
120 Ebd., S. 608.

121 Vgl. zur Textentstehung genauer unten, Fußnote 190 in TEIL DREI. Entgegen seinen eigenen Aussagen in der Publikation hat Koni sich die Geschichte nämlich keineswegs „fast wörtlich“ gemerkt, sondern stützte sich auf Tagebuchnotizen.

122 Koni: Sin’or Beljaev. In: ders. (Hrsg.): Na žiznennom puti, Bd. 1, S. 609.

123 Koni: Domočadcy. In: ders. (Hrsg.): Na žiznennom puti, Bd. 1, S. 651.
} 
Erinnerung an die „Hausangehörigen“ ist denn auch eine Abfolge von zahlreichen Anekdoten aus dem Zusammenleben von Koni und seinen Bediensteten, in denen diese immer wieder aufgrund ihres Halbwissens und ihres eingeschränkten Erfahrungshorizontes für lustige Begebenheiten sorgen. Wieder und wieder wird dabei deutlich, dass ihre wahren Qualitäten in Treue, Ergebenheit und echter Güte zu finden sind, die sie im Gegensatz zu manchen anderen auszeichnen. Koni beginnt mit einigen Überlegungen zu den „Njanjas“, den Kinderfrauen, die oftmals „nicht das materielle, sondern das moralische Interesse in den Vordergrund“ stellen würden. ${ }^{124}$ Auf einigen Seiten beschreibt Koni seine eigene Njanja, die ihm in der Kindheit Märchen über Werwölfe erzählt habe, an die sie selber absolut geglaubt habe. Auch noch Jahre später, als sie längst wieder in ihrer Heimat fernab von St. Petersburg gewohnt habe, habe sie sich für Konis Tätigkeit interessiert. Immer wieder habe sie ihn in St. Petersburg besucht und mit großer Begeisterung auf die Herausgabe seiner „Gerichtsreden“ reagiert. ${ }^{125}$ Etwas weniger hingerissen zeigt sich Koni von einem seiner Diener namens Pavel. Dieser sei ein kleinlicher Mensch gewesen, der schon „unter schlechtem Einfluss des Stadtlebens" gestanden habe. ${ }^{126}$ Pavels Weltsicht macht Koni an einer Anekdote über die Weihnachtsfeierlichkeiten fest. Von Freunden habe er zwei Truthennen geschenkt bekommen, die Pavel und seine Frau zusammen mit Gästen ohne sein Wissen einfach verspeist hätten. Auf Konis empörte Nachfrage hin habe Pavel gemeint, das seien doch nur Truthennen gewesen, keine Truthähne. ${ }^{127}$ Bei einer derart eigentümlichen Argumentation kommt Koni gleich die nächste Anekdote in den Sinn: Er führt an, wie die Kinderfrau einer Bekannter aus ihrem fernen Dorfe die Überzeugung mitgebracht habe, dass die Menschen gemeinhin in „einfache“, solche mit Hirn und "chemische“ [chimičeskie] aufgeteilt seien. Wobei sie mit Letzterem wohl „hinterhältige“ [chitrye] gemeint habe. ${ }^{128}$ Als Koni auf den Vorgänger von Pavel zu sprechen kommt, gerät er regelrecht ins Schwärmen. „Mein armer, alter und treuer Freund!" nennt er Varfolomej Tadeušev Gelgut. ${ }^{129}$ Dieser sei $1871 \mathrm{zu}$ ihm gekommen, als er sich wieder in St. Petersburg installiert habe. Auf acht Seiten beschreibt Koni das Wesen des polnischen Matrosen Varfolomej und zahlreiche lustige Begebenheiten, die er mit diesem durchlebt habe. Dieser Varfolomej sei „Ergebenheit und Delikatheit in Person“ gewesen. Wann immer Varfolomej den Eindruck gehabt habe, dass Koni von seinen Gästen schlecht be-

\footnotetext{
124 Ebd., S. 652.

125 Ebd., S. 652-53.

126 Ebd., S. 666.

127 Ebd., S. 669-70.

128 Ebd., S. 670.

129 Ebd., S. 665.
} 
handelt werde, habe er ihnen böse Blicke zugeworfen. In einem Büchlein habe er sich gar Notizen über den Gemütszustand seines Herrn gemacht. Da habe es dann geheißen: „Heute ist mein ,Konëk' etwas traurig. “" ${ }^{130}$ Jahre später, so Koni abschließend, habe er die Hinterlassenschaften des mittlerweile verstorbenen Dieners erhalten. Darunter ein Arbeitszeugnis, das er ihm vor langer Zeit ausgestellt hatte. Mit einer verzitterten Unterstreichung seien die Worte „immer tiefe Ehrlichkeit und Ergebenheit" hervorgehoben gewesen. ${ }^{131}$

Die von Halb- und Unwissen gekennzeichnete Naivität und Sturheit der Hausbewohner, die wesentlich für den amüsanten und unterhaltsamen Charakter der Erinnerungen verantwortlich sind, werden in Konis Erzählungen zum großen Plus. Sie werden als Eigenständigkeit, Loyalität und Ehrlichkeit interpretiert und konterkarieren so mehr oder weniger direkt jene Gesellschaftsschicht, die sehr viel gebildeter ist, aber solche Grundwerte anscheinend nicht mehr besitzt. In Konis Anekdoten zeichnen sich die „Weltsichten, Ansichten auf die gesellschaftlichen Beziehungen, Bewertungen [...] von Personen und Ereignissen und schließlich die Sprache“ eines Varfolomej und seinesgleichen durch „Eigenart" [svoeobrazie] aus. Eine Eigenart, die Koni - dies macht er gleich zu Beginn der Erinnerungen an die Hausbewohner klar - viel besser gefalle als die Art der "farblosen Vertreter der sogenannten ,Gesellschaft “'. Diese seien nämlich in ihren Ansichten und in ihrem „seelischen Raum“ nichts anderes als „eintönig und frei von jeglicher Originalität “' ${ }^{132}$ Dass ihnen ganz wesentliche Qualitäten fehlen, bringt Koni in seinem Fazit zum Diener Varfolomej auf den Punkt:

Mein armer, alter und treuer Freund! Mit welchem Recht kann ich dich bei diesem guten Namen nennen, so oft wie ich im Leben den Wert der Freundschaft jener erlebt habe, die von der Höhe ihrer Entwicklung und ihrer gesellschaftlichen Stellung auf dich mit milder Geringschätzung heruntergeblickt hätten, ohne auch nur einen Zehntel von deinem uneigennützigen goldenen Herzen zu haben. ${ }^{133}$

Die Bilder, die Koni hier erzeugt, erinnern ein Stück weit an die Visionen der idealisierten Bauernwelt, die gerade die Narodniki nach der Bauernbefreiung mit ihrem Glauben an das Landleben als Ort der Erneuerung und Wiederauferstehung für Russland verbreiteten. Längst waren diese Idealvorstellungen in den gebildeten Schichten allerdings von Enttäuschung und Pessimismus abgelöst worden. Frustration über die „Widerständigkeit“ der Dorfkultur ließ die Bauern

\footnotetext{
130 Ebd., S. 658-60.

131 Ebd., S. 665.

132 Ebd., S. 651.

133 Ebd., S. 665-66.
} 
als das „Andere“ erscheinen. Wenn auch der Glaube an die „Bildbarkeit“ des „Volkes“ noch da war, so oftmals gekoppelt mit der Überzeugung, dass einzig von der gebildeten Intelligencija eine solche Modernisierungsinitiative ausgehen könne. ${ }^{134}$ Die Desillusionierung über die Bauernschaft ging in den 188oer-Jahren und danach aber mit einer Romantisierung und Idealisierung in den literarischen Darstellungen einher. Die Literatur entfernte sich mit der Zeit immer mehr vom totalen Realismus in der Bauernbeschreibung und stellte das Land vielmehr als nostalgisch betrachteten, romantischen Ort der Vergangenheit dar, der als Gegenpol zum industriellen Stadtleben skizziert wurde. ${ }^{135}$ Diese Art der literarischen Darstellung des einfachen Menschen, der aus seiner Lebenswelt Werte einer unverbrauchten Originalität und Ehrlichkeit mitbringt, die in der modernen Stadt zwar anachronistisch und naiv, aber dafür umso erstrebenswerter wirken, spricht deutlich aus Konis Schreiben. So steht denn Pavel, der von Koni nicht allzu geschätzte Diener, bereits „unter schlechtem Einfluss des Stadtlebens“. Tatsächlich finden sich auch in anderen Texten und in zahlreichen Briefen Konis immer wieder Urteile über Moskau oder St. Petersburg als „verlogen“ und „kalt“ ${ }^{136} \mathrm{Im}$ Gegenzug schreibt Koni von seinen Reisen in die russische Provinz, wo er in den 188oer- und 189oer-Jahren Revisionen an den lokalen Gerichten durchzuführen hatte, oftmals mit Begeisterung. 1882 meldet er aus Nowgorod in einem Brief, dass die Provinz gut auf ihn wirke, dass man hier die „Liebe zur Heimat“ stärker fühle und dem hiesigen Volk mehr Glauben schenke, als dem Volk, das von den Petersburger Literaten konstruiert werde ${ }^{137}$ In einem anderen Brief schreibt er, dass er die "alte Rus“ gesehen habe auf seiner Revisionsreise und die Leute in den Provinzstädtchen hier eine „reine Seele“ hätten. Dies steht im Kontrast zum „künstlichen Petersburger Leben“. Sein Streben nach der Provinz wachse an: „Vive

134 Cathy A. Frierson: Peasant Icons. Representations of Rural People in Late NineteenthCentury Russia. New York u. a. 1993, S. 182-83 und 193-94.

135 Ebd., S. 190-92.

136 Z. B. Koni: Krušenie carskogo poezda v 1888 godu. In: GA1, S. 448 über St. Petersburg. Vgl. auch VysockiJ: Koni, S. 87 ff mit zahlreichen negativen Urteilen über die Stadt in Briefen von Koni.

137 GARF f. 564, op. 1, d. 865, 1. 53-54. Zitiert nach: Svetlana A. Domanova: „Dva blaga večny na zemle: priroda i iskusstvo“. Obrazy rossijskoj provincii i Evropy na stranicach pisem A. F. Koni. In: Istoričeskij istočnik, čelovek i prostranstvo. Tezisy dokladov i soobščenij naučnoj konferencii (3-5 fevralja 1997 g.; konferencija posvjaščena pamjati A. I. Andreeva i V. K. Jacunskogo). Moskva 1997, S. 116-18. In diesem kurzen Aufsatz geht Domanova einigen von Konis Briefen nach, die er über Jahrzehnte hinweg auf seinen zahlreichen Reisen im In- und Ausland verfasste und in denen er oftmals Land und Leute beschrieb und allgemeine Gedanken zu Russland äußerte. 
la province! “138 Als Koni aber ab 1908 seine Erinnerungen zu den „Alltagstreffen“ publizierte und dabei über Reisekameraden an der Nordsee und in Italien oder dörfliche Hausangestellte in St. Petersburg berichtete, war seine Absicht wohl eine komplexere als nur die immer wieder betonte Gegenüberstellung von der so typisch als „künstlich“ und „verlogen“ beschriebenen Stadt und dem Dorf mit seinen „reinen“ Bewohnern. ${ }^{139}$ Tatsächlich finden sich in seinen Erinnerungsschriften und Briefen nämlich ebenso viele Stellen, an denen er sich positiv über die Metropolen äußert und ein wenig begeisterndes Bild von der Dorflandschaft zeichnet. In „Aus den Studentenjahren“ berichtet er beispielsweise im Rahmen eines Exkurses über seinen Professoren Krylov, wie er Anfang der 1870er-Jahre in der Gegend von Kasan die Fortschritte der Gerichte habe beurteilen müssen. Dort sei er in einem "großen aber dumpfen tatarischen oder tschuvaschischen Dorf“ auf Menschen getroffen, die „von der Umwelt übermannt, durch das Fehlen von geistigen Interessen versunken“ gewesen seien. ${ }^{140}$ Immer wieder schreibt Koni in Briefen auch davon, dass das russische Volk den moralischen Aspekt des Christentums nicht verstehe. Es sei nicht so, wie Dostojewski denke, sondern unter der Oberfläche heidnisch. Ganz ähnlich äußert er sich in seinem autobiografischen Manuskript „Die Triumvirn“, wo Koni auf die mangelhafte moralische Fähigkeit und religiöse Toleranz der russischen Bauern verweist. ${ }^{141}$ So deutliche Worte findet Koni in seinen veröffentlichten Schriften nicht. Es scheint, als habe er in Erinnerungstexten wie jenem über die „Hausangehörigen“ diese juristischrealistische Haltung gegenüber Dorf und Bauernschaft zur Seite geschoben, um in gelungener Anekdotenform jenem Personenkreis den Spiegel vorzuhalten, um den es ihm eigentlich geht: die gebildete Gesellschaft. Die moralischen Lektionen, die Koni vermitteln will, bedienen sich Vorstellungen vom „Volk“, um damit Kritik an den „Gebildeten“ zu üben. Der Realitätsgehalt dieser Vorstellungen spielte nur eine untergeordnete Rolle. Genauso wie die eigentlichen Orte im In- und Ausland, die in den Reiseerzählungen vorkommen, kaum von Bedeutung sind und für den Leser wenig fassbar bleiben. Dostojewski sprach von der russischen „Zivilisierungsmission“ in Asien als Weg, Russland selber zu „zivilisieren“. Analog dazu scheinen auch Konis moralische Anekdoten der vermeintlichen Zivilisation selber zu gelten, die ihren eigenen Ansprüchen in seinen Augen nicht genügend

138 GA8, S. 55 (Brief an Sergej Fëdorovič Moroškin vom 21.11.1882).

139 SDvižkov: Das Zeitalter der Intelligenz, S. 165 betont, dass die Ideologie der Narodniki mit ihrer Entgegensetzung von „unverderbtem Dorf und kapitalistischer, der Jagd nach dem Geld erlegener Stadt" seit den 1870er-Jahren und bis in die 1920er-Jahre hinein die vorherrschende Strömung innerhalb der Intelligencija blieb.

140 Anatolij F. Koni: Iz let junosti i starosti. In: GA7, S. 94.

141 Domanova: Perepiska A. F. Koni kak istoričeskij istočnik, S. 175 und oben, S. 177. 
gerecht wird. ${ }^{142}$ Wenn Koni von seinen treuen Dienern, vom loyalen und ehrlichen ehemaligen Leibeigenen Beljaev oder von seiner liebevollen Njanja berichtet, die sogar seine Gerichtsreden gelesen habe, dann schreibt er damit gegen jene Bildungsbürger an, die in seinen Augen nicht einmal „ein Zehntel“ von der Uneigennützigkeit Varfolomejs besitzen und durch ihr Verhalten Koni gegenüber „den Wert der Freundschaft" diskreditiert haben.

\subsubsection{Fremdversicherung auf Reisen}

Koni nutzte in seinen Erinnerungsschriften die Idealbilder des „Volkes“ noch unmittelbarer, um für seine eigene Person und sein Tun Absolution zu erhalten. Wie der Titel der Erinnerungsschrift „Unterwegs" schon andeutet, bediente sich Koni mehrfach eines verbreiteten literarischen Stilmittels, indem er Reisesituationen nutzte, um sich in persönlicher Beziehung mit Menschen aus der „Province“ abzubilden und dabei deren Urteile über ihn anzusprechen. ${ }^{143}$ Koni beginnt „Unterwegs" mit dem Zasulič-Fall. So sei er 1878 nach dem folgenschweren Freispruch mit der Eisenbahn nach Charkow gefahren, auf der Suche nach Erholung im Kreise alter Freunde aus den Anfängen seiner Dienstzeit. ${ }^{144}$ Kurz vor Moskau habe ein Fahrgast in seiner Nähe ihn angesprochen. In Dialogform führt Koni aus, wie das Gespräch sich entwickelte und sein Gegenüber schließlich auf die Stadt St. Petersburg zu sprechen gekommen sei.

Und eine gute Stadt. Ich habe 20 Jahre auf dem Dorfe gelebt, nachdem ich in Pension gegangen bin, und jetzt habe ich zwei Monate in St. Petersburg verbracht. Viel Neues habe ich entdeckt. [...] Eine interessante Stadt! Gott weiß, wann es mich wieder einmal dorthin verschlägt. Ich wollte alles anschauen. Nur ins Gericht habe ich es nicht geschafft, zum Fall Zasulič. Sie haben davon wohl gehört? [...] Und kennen Sie jemanden, der da war? ${ }^{145}$

142 Vgl. Mark Bassin: Geographies of Imperial Identity. In: Dominic Lieven (Hrsg.): The Cambridge History of Russia. Volume II: Imperial Russia, 1689-1917. Cambridge u. a. 2006, S. 50 und 54 der Dostojewski zitiert: „Our civilising mission there will give us spirit [...]!“

143 Einige der nachfolgenden Beispiele und Argumentationen wurden bereits thematisiert in Cordin: Von Schreibanlässen und Erinnerungsfunktionen, S. 195-200.

144 Koni: V doroge - Gimnasičeskie vospominanija. In: ders. (Hrsg.): Na žiznennom puti, Bd. 1, S. 628-29. Diese Darstellung lässt die Desillusionierung weg, mit der Koni von dieser Reise laut seiner Darstellung im Manuskript der Zasulič-Erinnerung zurückkehrte, vgl. dazu S. 286.

145 Koni: V doroge - Gimnasičeskie vospominanija. In: ders. (Hrsg.): Na žiznennom puti, Bd. 1, S. 629-630. 
Mit der bejahenden Antwort auf diese Frage weckte Koni die Neugier seines Gegenübers, und dieser - so die Fortsetzung der Erzählung - bringt denn auch schnell in Erfahrung, dass ihm der Gerichtsvorsitzende persönlich gegenübersitzt. Ironisch fügt Koni hinzu, dass der Reisegefährte ihm zuerst nicht geglaubt habe, aber dann eingesehen habe, dass wohl kaum jemand sich den Titel des Gerichtsvorsitzenden aneignen würde. ${ }^{146}$ Der Mitreisende habe sich plötzlich äußerst liebenswürdig, ja „zuckersüß“ [ljubezen do pritornosti] ihm gegenüber verhalten, ihm mit dem Gepäck geholfen und ihm gar eine Unterkunft in Moskau angeboten. Die Anpreisung dieser Unterkunft zitiert Koni als Schlusspunkt der Anekdote erneut in direkter Rede: „Sehr billig, ruhig - und Wanzen - fügte er vieldeutig hinzu - nicht eine einzige! " 147

Fast identisch nimmt sich ein weiteres solches "Treffen von unterwegs“ aus. ${ }^{148}$ Diesmal blickt Koni zurück ins Jahr 1890, als er auf der Halbinsel Krim in der Umgebung von Jalta eine Kutschenfahrt unternommen habe. In dieser Kutsche hätten außer ihm noch gesessen:

Ein stellvertretender Staatsanwalt von einem der nordwestlichen Bezirksgerichte mit Ehefrau, ein einheimischer reicher Tatare in geschmücktem Kostüm, eine französische Gouvernante und ein außerordentlich redseliger Gutsbesitzer aus dem Umland von Saratow, der über die Krim staunte, wohin es ihn verschlagen hatte, nachdem er 20 Jahre ohne Unterbruch auf seinem Hof verbracht hatte. ${ }^{149}$

Die Mitreisenden bringen das Gespräch auf das Rechtswesen und bald auch konkret auf den Zasulič-Fall. Erneut gibt sich Koni nicht sofort zu erkennen und nimmt so quasi anonym die lobenden Worte des Gutsbesitzers entgegen, der über ihn und seine Handhabung des Falls gesagt habe: „Völlig richtig! Wenn ich Koni damals getroffen hätte, hätte ich ihn ohne Zeremonie geküsst. “150 Einige Sätze weiter fallen aber kritische Worte über ein Urteil Konis in einem anderen Fall. Koni verschafft den Lesern seines Artikels den nötigen Kontext, indem er die Hintergründe auf einer ganzen Seite erläutert. Seine Rechtfertigung übernimmt in der Erinnerungsgeschichte dann aber ein anderer Fahrgast

\footnotetext{
146 Ebd., S. 630.

147 Ebd.

148 Koni: Za-granicej i na rodine. In: ders. (Hrsg.): Na žiznennom puti, Bd. 3, S. 285. Diese Episode wurde von Koni erst für die 1922 erfolgte Neuzusammenstellung von „Unterwegs“ als Teil von „Im Ausland und in der Heimat“ in „Auf dem Lebensweg“ III integriert, findet sich aber bereits in den früheren Manuskripten, vgl. unten, Fußnote 191 in TEIL DREI.

149 Ebd.

150 Ebd., S. 285-86.
} 
in der Kutsche, der stellvertretende Staatsanwalt von einem der nordwestlichen Bezirksgerichte.

„[...] Was hätte der Oberstaatsanwalt schon tun können [...]? Dieses Gesetz zu umgehen ist unmöglich [...].“ - „Was sagen Sie da!“ - hat unser Gefährte beinahe geschrien. - „Niemals werde ich glauben, dass eine solche gescheite Bestie wie er nicht das Gesetz umdrehen könnte, wie es gerade passt!!“

In diesem Moment tritt Koni in der Erzählung einen Schritt zurück, indem er seine eigenen Gedanken angesichts des Gehörten offenlegt. Es sei offensichtlich „das Schicksal“, das ihn hier mit den verschiedensten Ansichten über ihn konfrontiere. „Hören wir, was noch kommt, das ist wohl noch nicht das Ende. “151 Tatsächlich provoziert die holprige Kutschenfahrt auch noch ein Gespräch über den Unfall des Zarenzugs. So habe der Gutsbesitzer verächtlich zu seinen Reisegefährten gemeint, dass bei einem Unfall des Gefährts niemand zur Rechenschaft gezogen werden würd, schließlich sei auch die Entgleisung des Zarenzuges ohne Konsequenzen geblieben. Nach seiner Meinung gefragt, erwidert Koni, dass die Motive hierfür nach Aussagen des abschließenden Berichts in der „himmlischen Barmherzigkeit“ liegen würden. Diese sei der Zarenfamilie gegenüber gezeigt worden und diese zeige sie nun gegenüber den Schuldigen. Daraufhin der erzürnte Gutsbesitzer:

Also ich würde euch mal auf die Position von Koni setzen, der die Untersuchung geführt hat vor Ort: Zwei Monate lang hat er auf dem Damm gelebt; man sagt, dass es seiner Gesundheit geschadet hat; er hat eine riesige Arbeit erledigt und das alles für nichts $[\ldots]$. Da würden Sie wohl anders reden ... ${ }^{152}$

Während Koni in dieser Episode die ihm im Großen und Ganzen zugetane Haltung des Mannes aus Saratow ausführlich darlegt und als Höhepunkt schließlich dem verdutzten, aber erfreuten Gutsbesitzer seine Identität eröffnet, funktioniert dieses Setting in einer weiteren „Reiseerzählung“ genau umgekehrt. Die Zugfahrt nach Charkow 1878 hielt für Koni neben der Begegnung mit dem „zuckersüßen“ Herrn vom Dorfe auch noch eine weitere Bekanntschaft bereit. So beschreibt Koni gleich im Anschluss, dass ein ihm unbekannter Mann seinem Abteil zugestiegen sei. Im Gegensatz zu den Akteuren der anderen Episoden weiß dieser sofort, dass ihm der Gerichtsvorsitzende des Zasulič-Prozesses gegenübersitzt. Koni selber ist es diesmal, der seinen Mitfahrer erst zum Schluss als den berühmten Slavo-

151 Ebd., S. 287 .

152 Ebd., S. 287-88. 
philen Ivan Sergeevič Aksakov (1823-1886) erkennt. Schon vorher wurde ihm, so erzählt Koni die Anekdote, aber aufgrund ihrer Gesprächsthemen klar, dass sein Gegenüber „offensichtlich zum hochgebildeten Kreis der Moskauer Gesellschaft" gehören musste. ${ }^{153}$ Schließlich sei die Rede erneut auf den Zasulič-Fall gekommen und der Mitreisende habe Koni geradeheraus gesagt, dass er in dieser Frage nicht auf seiner Seite sei. Die Ausfälle der Presse gegen Koni, die würde er aber nicht unterstützen. Trotzdem meint er anklagend: „Wie konnten Sie den Geschworenen einen Freispruch erlauben?" ${ }^{154}$ Daraufhin erklärt Koni, woraus die „gesetzliche Rolle“ [zakonnaja rol'] des Gerichtsvorsitzenden an Geschworenenprozessen bestehe. Als er geendet habe, da sei einige Minuten Stille gewesen. Danach habe der Mitreisende gesagt: „Ja, ich sehe, Sie haben Recht [...] ich nehme meinen Vorwurf zurück [...]. “"155 Ähnlich überzeugend im Kontakt mit kritischen Zeitgenossen wirkt Koni auch auf einer weiteren Zugfahrt, die er diesmal in den „Gymnasiumserinnerungen“ publizierte. Im Rahmen eines Exkurses über seine frühen Studienjahre erinnert sich Koni an eine Reise ins Ausland im Sommer 1881. In einem Zugabteil habe er eine „Dame mittleren Alters“ getroffen. An ihren Manieren und ihrer Ausdrucksweise habe er sofort gemerkt, dass sie „nicht nur zur höchsten Gesellschaft, sondern auch zum Kreis der hochgebildeten Personen" gehören müsse. Im Verlauf des Gesprächs sei klargeworden, dass die Russin schon lange in England lebe und dort Russland in „zu rosiger Farbe“ darstelle. Sie unterstützte nämlich die Ansichten Katkovs und seiner Zeitung „Moskauer Nachrichten “ [Moskovskij Vedomosti] zur russischen Politik. ${ }^{156}$ Den Höhepunkt der Anekdote bildet erneut der Moment, in dem die Dame, mit der Koni trotz mancher unterschiedlicher Ansichten gut auszukommen scheint, seine Identität erfährt. Trocken merkt er an:

Sie war nicht wenig erstaunt, als sie erfuhr, dass ihr Gefährte, den sie sich nach den Worten der „Moskauer Nachrichten“ als „Erschütterer von Grundlagen“ vorstellte, bei näherem Kennenlernen ganz anders und jeglicher Parteifärbung fremd war. ${ }^{157}$

In einer Manuskriptversion benutzt Koni gar noch etwas stärkere Ausdrücke, indem er schreibt, dass die Dame über seine „gemäßigten politischen Ansichten“ erstaunt gewesen sei, da sie offensichtlich gedacht habe, er sei „mindestens ein

153 KonI: V doroge - Gimnasičeskie vospominanija. In: ders. (Hrsg.): Na žiznennom puti, Bd. 1, S. 631. Vgl. Zur Slavophilie vgl. Fußnote 17 in TEIL DREI.

154 Ebd., S. 632.

155 Ebd., S. 632-33.

156 Ebd., S. 645-46.

157 Ebd., S. 646. 
Anarchist “ ${ }^{158}$ In dieser Handschrift wird auch der Name der Frau offengelegt, es handelt sich um niemand Geringeres als Ol'ga Alekseevna Novikova (1840-1925). ${ }^{159}$ Novikova war eine russische Publizistin, die mit einem hohen Petersburger Beamten verheiratet war und regelmäßig die Winterzeit in London verbrachte. Dort machte sie sich schnell einen Namen als eine "russische Agentin“, die in den höchsten Kreisen der englischen Politik verkehrte, um die Interessen Russlands zu vertreten. Ihr Londoner Salon entwickelte sich in den 187oer-Jahren zum Zentrum der liberalen englischen Opposition. Im Zuge des Russisch-Osmanischen Krieges nahm Novikova die auch von Katkov vertretene nationalistische Haltung an und verteidigte in der britischen Öffentlichkeit Russlands kriegerisches Engagement als Pflicht gegenüber den Slaven auf dem Balkan. ${ }^{160}$

Die verschiedenen Reiseanekdoten, die Koni in seine Erzählungen einbaute, weisen verblüffende Parallelen auf. Aus dem Eisenbahncoupé oder der Pferdekutsche wird in seiner Darstellung immer wieder ein geschützter Begegnungsort, der ihn mit den unterschiedlichsten Menschen des Russischen Reiches zusammenführt. Das Erzählmotiv vom Eisenbahnwaggon als „Ort der Begegnung“ erfreute sich in der russischen Literatur des 19. Jahrhunderts großer Beliebtheit. Gerade das Zusammentreffen von Personen unterschiedlichen Standes oder Ethnie im eng abgesteckten Raum des Zuges diente immer wieder als Schauplatz von Erzählungen. ${ }^{161}$ In Konis Geschichten bietet diese Kontaktzone jeweils die Gelegenheit, Haltungen und Meinungen der Bevölkerung zu ihm und dem Rechtswesen zu erfahren beziehungsweise seinen Leserinnen und Lesern zu präsentieren. Indem Koni in den verschiedenen Episoden geschickt mit dem angeblichen NichtErkennen des Gegenübers oder seiner eigenen Person spielt, kann er über sich selber sprechen, ohne überheblich zu wirken. Er verlässt sich auf die „autobiografische Lücke“, die eintritt, wenn der Leser über die Ineinssetzung von Autor-

158 In den Anmerkungen der Herausgeber von Konis Gesamtausgabe wird unter Verweis auf IRLI F. 134, op. 1, d. 56, 1. 1730b auf diese unterschiedlichen Fassungen verwiesen, vgl. GA7, S. 444 (Anmerkungen) bzw. das nachfolgende Unterkapitel.

159 GA7, S. 443-44 (Anmerkungen).

160 V. D. Dmitriev; O. E. Majorova: Novikova, Ol'ga Alekseevna. In: Russkie pisateli 1800-1917. Biografičeskij slovar', Bd. 4, 1999, S. 232-40. Der Lexikoneintrag erwähnt auch Konis Beschreibung von Novikova in seiner Erinnerung.

161 Schenk: Russlands Fahrt in die Moderne, S. $237 \mathrm{ff}$. Als Beispiele nennt Schenk die Eingangsszene von Dostojewskis Roman „Der Idiot“ oder Tolstois Novelle „Die Kreutzersonate“. Vgl. auch ebd., S. 245 ff zum Reisebericht „Čto takoe Rossija“ [Was ist (eigentlich) Russland?] von Pavel A. Kruševan (1860-1909), in dessen Erzählung in den Wartesälen der Bahnhöfe und Coupés der Züge ebenfalls verschiedene Ethnien bzw. „nationale Typen" aufeinandertreffen. 
schaft und Erzähler hinwegsieht. ${ }^{162}$ Glaubwürdig kann er so eine ganze Reihe an Punkten ansprechen, die ihm wichtig zu sein scheinen. Ungefähr 50 Jahre nach der Gerichtsreform und über 30 Jahre nach dem Zasulič-Prozess führt Koni Grundprinzipien der Rechtsprechung nochmal aus - vom Funktionieren des Geschworenengerichtes bis zu den Handlungsmöglichkeiten des Oberstaatsanwaltes, der sich auch an das Gesetz zu halten hat. In einer Manuskriptversion von „Unterwegs" verzichtet Koni noch auf solche Ausführungen, für die Publikationen scheinen sie ihm aber unerlässlich. ${ }^{163} \mathrm{Er}$ antwortet indirekt auf Kritik, die gegen ihn und das reformierte Recht generell immer wieder angebracht wurde, und lässt sich mit Vorliebe durch die verständnisvollen Worte Mitreisender rechtfertigen. Wie sehr aus deren Aussagen in den Erinnerungen jeweils Konis eigene Befindlichkeiten sprechen, zeigt die Diskussion über Alexander III. und dessen Entscheidung zur Einstellung weiterer Untersuchungen im Entgleisungsfall. „Eine riesige Arbeit" habe der Oberstaatsanwalt erledigt, so wirft der Gutsbesitzer ein, während Koni selber zurückhaltend die offizielle Argumentation von Zar und Pobedonoscev nacherzählt. Die Diskrepanz zu seinem Ärger über die Haltung von Alexander III. und dessen Entourage, den er im Erinnerungsmanuskript zur Entgleisung ausführlich zum Thema machte, könnte nicht größer sein. ${ }^{164}$ Ungerechtigkeit und Undank Konis und seinem Engagement gegenüber kommen aber durch die Worte des Mitreisenden viel stärker zur Geltung, als wenn er selber dies offenlegen würde. Genauso verhält es sich mit überschwänglichem Lob. So unterstreicht er die Aksakov-Episode sogar noch, indem er nicht nur die positiven Worte des bekannten Denkers zitiert, sondern auch einen Brief, in dem dieser von der Begegnung mit Koni schreibt. Bescheiden schickt er voraus, dass Aksakovs Urteil für ihn „schmeichelhaft [...] aber auch völlig unverdient" sei. Im angefügten Briefzitat charakterisiert Aksakov Koni als "gescheit, begabt und einen sehr guten Menschen “. ${ }^{165}$ Das positive Urteil des Slavophilen Aksakovs aber auch der reichs-patriotischen Novikova war für Koni von besonderem Wert. Aksakov war für seine zwiespältige Haltung gegenüber der Gerichtsreform weithin bekannt und hatte sich insbesondere über den Ausgang des Zasulič-Prozesses - dessen Urteil er

162 ADAK: Identifying the „Internal Tumors“ of World War I, S. 153 ff bzw. oben, S. 114.

163 Vgl. das Manuskript in IRLI F. 134, op. 1, d. 56, auf das im nachfolgenden Unterkapitel noch eingegangen wird. Darin heißt es auf 1. 1580b nach Aksakovs Frage, warum Koni den Freispruch zugelassen habe, lediglich „Ich erzählte ihm in Kürze die ganze Geschichte dieses Falles“. In der publizierten Version führt Koni Gedanken zur „gesetzlichen Rolle“ des Gerichtsvorsitzenden an.

164 Vgl. oben, S. 158.

165 Koni: V doroge - Gimnasičeskie vospominanija. In: ders. (Hrsg.): Na žiznennom puti, Bd. 1, S. 635 . 
als viel zu nachsichtig empfand - empört. ${ }^{166}$ Novikova galt gemeinhin als Sprachrohr Katkovs, der den Freispruch der Attentäterin in schärfsten Tönen verurteilte. Umso bemerkenswerter müssen den informierten Lesern die im Erinnerungstext vollzogenen, öffentlichkeitswirksamen Kehrtwendungen erschienen sein.

Solche Einsichten zelebrierte Koni in seinen Erinnerungstexten manchmal auch noch ausführlicher und scheute sich dabei nicht, die Pointen in deutlich zugespitzter Art darzustellen. Einstmals mächtige Persönlichkeiten wie der Innenminister Petr Aleksandrovič Valuev (1815-189o) oder der Justizminister Graf Pahlen werden so zu reuigen Sündern, die sich bei Koni für ihre ungerechte Haltung entschuldigen. In „Aus den Studentenjahren“ führt Konis Doktorarbeit zu einem Exkurs über Petr Valuev, der zusammen mit weiteren Behörden und Ministerien in die Beanstandungen an der Schrift involviert gewesen war. Konis Arbeit „Über das Recht auf notwendige Verteidigung“, die die Gesetzeslagen zur Selbstverteidigung in verschiedenen Ländern miteinander verglich, erschien der Zensurinstanz als Aufruf dazu, das Recht selber in die Hand zu nehmen. Besonders störte man sich an der Aussage, dass die Staatsmacht keine Gesetzestreue verlangen könne, wenn sie selber dieser nicht nachkomme ${ }^{167}$ Nachdem Koni in der Erinnerung ausführt, wie diese Geschichte dank der geringen Auflagenzahl seiner Dissertation ohne weitreichende Konsequenzen bereinigt werden konnte, widmet er gleich anschließend fünf Seiten dem weiteren Leben des Politikers. ${ }^{168}$ Er verweilt bei den Vorwürfen, die Valuev nach dem Zasulič-Freispruch an Koni gerichtet habe. Danach führt er aus, wie Valuev beim Zaren in Ungnade gefallen sei und fortan in einer „bescheidenen Wohnung“ in St. Petersburg gehaust habe, zufälligerweise im gleichen Haus wie die Redaktion des „Boten Europas“. ${ }^{169}$ Dort habe er ihn wieder getroffen, und dieser habe „bereut“, dass er nicht früher

166 Lukashevich: Ivan Aksakov, 1823-1886, S. 70-73 bzw. Walicki: Legal Philosophies of Russian Liberalism, S. 47-48 zu Katkovs Ausbrüchen gegen das Justizsystem.

167 Vgl. zu den Problemen, die Koni aufgrund der Dissertation hatte, ausführlich Smolja RČUk: Anatolij Fëdorovič Koni (1844-1927), S. 29-36, hier v. a. S. 31 mit entsprechenden Zitaten aus den behördlichen Beanstandungen. Diese wurden interessanterweise in einem Jubiläumsband für Koni in der frühen Sowjetunion publiziert, vgl. Angabe in Fußnote 362 in TEIL DREI. Vgl. auch oben, S. 137, wo Borisovas Argumentation zum Zusammenhang zwischen dem Inhalt dieser Arbeit und Konis Verhalten im Zasulič-Prozess dargelegt wird. Pomar: Anatoly Fedorovich Koni, S. 15 ff erläutert und kontextualisiert Konis Ausführungen zum „Recht auf notwendige Verteidigung“.

168 Anatolij F. Kons: O prave neobchodimoj oborony, hrsg. u. mit einer Einleitung versehen v. A. Coriev. Moskva 1996. Coriev verweist in seiner Einleitung ebenfalls darauf, dass Koni nur deshalb keine Probleme aufgrund der Dissertation erhalten hat, weil die Arbeit lediglich in einer sehr kleinen Auflage gedruckt wurde.

169 Koni: Iz let junosti i starosti. In: GA7, S. 119-20. 
Menschen mit liberaler Gesinnung gekannt habe. Der ehemalige Minister habe ihn auch zuhause besucht und sich „beim Abschied entschuldigt, dass er mich falsch eingeschätzt“ habe. Sogleich führt Koni bekräftigend weiter aus: „Das war ehrlich, denn nach seinem Tod zeigte mir sein Sohn eine Tagebuchstelle, wo er sich ebenfalls bedauernd äußerte. ${ }^{\text {"170 }}$ Dies unterstreicht Koni noch, indem er aus einem Brief von Valuev zitiert, den dieser ihm kurz vor seinem Tod geschrieben habe. Darin betont Valuev, dass er Konis Meinung sehr schätze. ${ }^{171}$ Koni beschreibt den Beamten, der ihm und seinen Gesinnungsgenossen einst Steine in den Weg gelegt hatte, als „völlig neu und moralisch predigend“ ${ }^{172}$ Dabei nimmt er einen Gedanken auf, den Valuev vor seinem Tod geäußert habe: „Kann die Sicht auf einen Staatsmann völlig getrennt werden von der Sicht auf diese Person als einfachen Menschen und Christen?" Valuev habe erkannt, dass dies nicht möglich sei. ${ }^{173}$ Zum Abschluss des Exkurses beschreibt Koni das Begräbnis Valuevs, an dem zahlreiche höher Beamte St. Petersburgs zugegen gewesen seien. Mit verächtlichen Worten berichtet er von den „Amtsträgern neuesten Typs“, die über den in Ungnade gefallenen Valuev jahrelang ungerechte Anschuldigungen verbreitet hätten und nun zu seiner Abdankung erscheinen würden. Angewidert habe er die Kirche verlassen. ${ }^{174}$

Ein fast identisches Bild ergibt sich, wenn Koni über das Schicksal von Graf Pahlen spricht, der nach dem Zasulič-Fall als Justizminister zurücktreten musste und später gemeinsam mit Koni im Staatsrat saß, bevor er 1912 starb. Im Gegensatz zur Geschichte von Valuev ist Koni nicht mehr dazu gekommen, seinen Bericht über Pahlen zu veröffentlichen. ${ }^{175}$ In der Aufzeichnung wird Pahlen zitiert, der Koni bei einem Treffen viele Jahrzehnte nach dem verhängnisvollen Zasulič-Fall gefragt habe: „Haben Sie mir verziehen?“ Er habe vieles damals nicht verstanden

\footnotetext{
170 Ebd., S. 120-21.

171 Ebd., S. 122.

172 Ebd., S. 123.

173 Ebd., S. 123-24. Konis Einschätzung von Valuevs Veränderung und die Gedanken zur Trennung von Staatsmann und Mensch werden auch von Holquist in seiner Analyse zu „Bürokratentagebüchern“ aufgegriffen, vgl. Peter Holquist: Bureaucratic Diaries and Imperial Experts. Autobiographical Writing in Tsarist Russia in the late Nineteenth Century: Fëdor Martens, Dmitrii Miliutin, Pëtr Valuev. In: Martin Aust/Frithjof Benjamin Schenk (Hrsg.): Imperial Subjects. Autobiographische Praxis in den Vielvölkerreichen der Habsburger, Romanovs und Osmanen im 19. und frühen 20. Jahrhundert. Köln 2015, S. $217-18$.

174 Koni: Iz let junosti i starosti. In: GA7, S. 124.

175 Vgl. oben, S. 28o. Der Bericht wurde nach einer mündlichen Aussage Konis datiert vom Mai 1927 aufgezeichnet und von den Herausgebern von Konis Gesamtausgabe als Fußnote in die Zasulič-Erinnerungen integriert.
} 
und Koni so viel Kummer gemacht. Erst jetzt, wo es zu spät sei, verstehe er. Dramatisch endet die Erzählung mit dem Tod Pahlens. Diesem sei nämlich nach Konis versöhnlicher Antwort auf sein Bereuen ein Stein vom Herzen gefallen, und „am nächsten Tag" sei er gestorben. ${ }^{176}$ Der unmittelbare Zusammenhang zwischen der erleichternden Beichte und dem Ableben des ehemaligen Justizministers wird im Nachhinein etwas abgeschwächt. Jemand hat das „am nächsten Tag“ korrigierend ergänzt zu „innerhalb einiger Tage“.177

Sowohl Valuev als auch Pahlen erteilen Koni in solchen Bekehrungserzählungen ihre Absolution. Von Konis Doktorarbeit über sein Verhalten im Zasulič-Fall bis zur liberalen Zeitschrift „Bote Europas“ [Vestnik Evropy] - alles wird von den ehemaligen Ministern im Alter gutgeheißen. In seiner Präsentation dieser Bitten um Vergebung unterstreicht Koni die Tragweite dieser Kehrtwenden durch den kurz danach folgenden Tod der reuigen Sünder. Das Dahinscheiden und dessen Umstände sind für Koni aber nicht nur ein stilistisches Mittel, um die Bedeutung der Vergebung zu erhöhen. Vielmehr stellte für ihn der Tod den Moment der Abrechnung dar, in dem das vergangene Leben endgültig beurteilt werden kann. In seinen Überlegungen zum Verfassen von Biografien über Zeitgenossen betonte Koni immer wieder, wie wichtig es sei, diesen Zeitpunkt abzuwarten, bevor Leben und Taten der entsprechenden Akteure analysiert werden dürfen. ${ }^{178}$ Die Beerdigung gibt dabei ihrerseits Hinweise darauf, wie die verstorbene Person ihr Leben verbracht hat. Nikolaj Nekljudov, dessen Biografie Koni als eine Art Schreckensversion seines eigenen Werdegangs zeichnete, erhielt eine Totenfeier in der Hauskirche des Chefs des Gendarmeriecorps. Die Erwähnung dieses Umstandes in Konis Erinnerungen an den Juristen macht dessen Verrat an seinen ursprünglichen Idealen überdeutlich. ${ }^{179}$ Die Beerdigung als Moment der Wahrheit findet sich auch in Konis Porträt des letzten Zaren. Darin schreibt Koni von Stolypin, der im Nachgang der ersten Russischen Revolution „tausende von Todesurteilen auf sein Gewissen geladen“ habe. Trotzdem habe es Nikolaus II. nicht für nötig gefunden, an seine Beerdigung zu kommen. ${ }^{180}$ Dass Koni in diesen Todes-Erzählungen oft auch mit Pointierungen arbeitete, zeigt die Zuspitzung zum Ableben von Graf Pahlen. ${ }^{181}$

176 GARF F. 564, op. 1, d. 212.

177 In der korrigierten Version ging die Erzählung auch in die Gesamtausgabe ein.

178 Vgl. zu diesen Überlegungen Konis oben, S. $235 \mathrm{ff}$.

179 Koni: Triumviry. In: GA2, S. 315. Vgl. zu Nekjudov und Konis Probelauf oben, S. 216.

180 Koni: Nikolaj II. In: GA2, S. 379.

181 Das Kontrastprogramm zu einem derart negativen Lebensende zeichnet Koni im Fall von Personen, die ihm als Vorbild dienten. In seinen Erinnerungen an die Studienzeit schreibt er in den höchsten Tönen über Nikita Krylov, der Professor für Römisches Recht war. Er 
Während Koni durch solche Bekehrungsmomente wichtiger Persönlichkeiten eine Art „Fremdversicherung" für sein Tun erschuf, tat er dies noch lieber durch das inszenierte Lob von zentrums- und bildungsfernen Persönlichkeiten. Bei der Lektüre von Konis Berichten über seine Begegnungen mit der Bevölkerung entsteht zwangsläufig ein Bild des imperialen Russlands, in dem rechtliche Themen auf der Krim genauso präsent sind wie in Moskau oder Charkow und in Zug wie Kutsche von allen Bevölkerungsschichten voller Emotionen sogar mit Wildfremden diskutiert werden. So unterstreicht beispielsweise die Erwähnung des „Tataren in geschmücktem Kostüm“, der während der Kutschenfahrt im Süden des Reiches zugegen ist, die örtliche Abgelegenheit des Gesprächs über die hauptstädtischen Prozesse. Selber erhält der Einheimische während der Fahrt - genau wie die anwesenden Frauen - keinen aktiven Part zugewiesen. Auch wenn das „Volk“ also nicht in jeder Szene mitdiskutiert, sind es doch immer wieder die Personen, die „20 Jahre auf dem Dorfe“ oder „20 Jahre ohne Unterbruch“ auf einem Hof fern der Metropolen gelebt haben, deren Anerkennung Koni besonders betont. So wird seine Verhandlungsführung im Zasulič-Fall unmittelbar sanktioniert durch die liebenswürdig-naive Art, mit der der Zugpassagier aus der Provinz dem Gerichtsvorsitzenden ein Zimmer empfiehlt, das „nicht eine einzige!“ Wanze habe. Der Gegensatz zu den Kritiken und Beschimpfungen der gebildeten Gesellschaft der Hauptstädte, die in der Presse gegen Koni und Justiz wettern, schwingt implizit mit. Schließlich macht sich Koni eben deshalb auf zur Zugfahrt nach Moskau und weiter nach Charkow, weil er sich von diesen Vorwürfen erholen möchte. Auch während der Kutschenfahrt auf der Krim wird die Diskrepanz zwischen den Eliten, die Konis Arbeit im Fall der Entgleisung des Zarenzuges mit Nichtbeachtung strafen, und den warmen Worten der einfachen Passagiere deutlich. In „Die Entgleisung des Zarenzugs“ machte Koni das sogar noch offensichtlicher. So notiert er, dass er während seiner Zeit in der Nähe der Unfallstelle immer wieder „anonyme Schmähschriften in Prosa und Versen“ erhalten habe. Dieser literarisch hochstehenden Kritik setzt er eine Ikone gegenüber, die er einmal auf seinem Tisch vorgefunden habe. In ungelenker Art sei dazu geschrieben gewesen: „Beschütze und hilf dem gerechten Verfolger der Unrechten. “"182

sei „der herausragendste Professor der juristischen Fakultät“ gewesen, vgl. KonI: Iz let junosti i starosti. In: GA7, S. 94. Einige Seiten weiter beschreibt Koni, wie er zufällig in Moskau gewesen sei, als ihn die Nachricht vom Tod Krylovs erreicht habe. Er sei sogleich zur Kirche geeilt, habe sich am Trauerzug beteiligt und einige Worte am Grab des ehemaligen Rechtsprofessors gesprochen. Noch heute, nach so vielen Jahren, wo er selbst dem Tod nicht mehr fern sei, denke er mit „,innigem, dankbarem Gefühl“ an Krylov zurück, vgl. ebd., S. 99. Vgl. zu dieser Trauerrede auch oben, S. 60.

182 Koni: Krušenie carskogo poezda v 1888 godu. In: GA1, S. 466. 
Der Wert, den die lobenden Worte der Provinzbevölkerung für Koni und auch für das Lesepublikum haben, versteht sich - davon scheint er auszugehen - von selbst. Die einfachen Menschen mit ihrer naiven „Eigenart“ waren schließlich das Zielpublikum, für das die Intelligencija aus Literaten wie Juristen Führungsverantwortung und Fürsorge übernehmen wollte. Ihre Zuneigung entsprach folglich der höchstmöglichen Auszeichnung.

\section{Horizont Schriftsteller: von Tagebüchern und frühen Entwürfen}

Die Zeitschrift, in deren Literaturbeilage ein Teil von Konis anekdotischen Schriften erschien, steht sinnbildlich für die erfolgreiche Vermittlung von literarischen Werken an vielfältige Leserkreise und den omnipräsenten Bildungsauftrag, der damit verbunden war. Die Wochenzeitschrift „Niva“ - „Saatfeld. Illustrierte Zeitschrift für Literatur und modernes Leben“ erschien schon seit 1869/70 regelmäßig, so dass ganze Generationen mit dem „Saatfeld“ [niva] groß geworden waren. Eine möglichst breite Bevölkerungsschicht in Russland zu adressieren und für Bildung zu begeistern, war das erklärte Ziel des Organs. ${ }^{183}$ So wurden in der Literaturbeilage von „Saatfeld“ [niva] regelmäßig die Werke von populären Schriftstellern wie Fjodor Dostojewski, Nikolai Gogol, Heinrich Heine oder Oscar Wilde publiziert. Deren äußerst beliebte Romane führten zu einer enormen Auflagensteigerung. Während 1870 noch 9000 Exemplare gedruckt wurden, hatte die Zeitschrift um die Jahrhundertwende schon eine Auflage von 200.000. ${ }^{184}$ Koni dürfte es ein zweifaches Anliegen gewesen sein, in diesem Publikationsorgan veröffentlicht zu werden. „Saatfeld“ [niva] verkörperte aufgrund von Anspruch und hoher Auflagenzahl nicht nur exemplarisch die erzieherische Mission der Intelligencija und ihre Suche nach Nähe zum „Volk“. Gleichzeitig bot der Reigen an Texten berühmter Schriftsteller, der in der Zeitschrift veröffentlicht wurde, wohl genau das Ambiente, in dem Koni seinen eigenen Namen gerne sah. ${ }^{185}$ Literarische Ambitionen werden allein schon durch die Entstehungsgeschichte der Erinnerungen an die Studienzeit, die Reiseerlebnisse oder die Hausangestellten deutlich. Dieser „Horizont

183 Irina Cernova Burger: „Alle lesen sie, alle kennen sie ...“. In: Libernensis. Zeitschrift der Universitätsbibliothek Bern 2 (2007), S. 16. Das symbolische Bild des Bauern, der sät und erntet, sollte die Landbevölkerung ansprechen, und unzählige künstlerische Illustrationen in der Zeitschrift bildeten lesende und sich bildende Individuen ab.

184 Ebd., S. 18-19 und SDvižkov: Das Zeitalter der Intelligenz, S. 173.

185 In einem Brief schrieb Koni 1909, dass er unbedingt in „Saatfeld“ [niva] veröffentlichen wolle, um ein möglichst großes Publikum ansprechen zu können. Konkret bezieht er sich da auf seine Erinnerungen an Turgenev und Tolstoi, vgl. GA8, S. 262 (Brief an A. A. Šachmatov vom 02. 09.1909). 
Schriftsteller" lässt sich, wie die Studiumserinnerungen exemplarisch zeigen, schon seit den 186oer-Jahren im Schaffen Konis ausmachen. Das familiäre Umfeld mit dem schreibenden Vater und der schauspielenden Mutter dürfte dabei entscheidende Impulse gesetzt haben. Konis frühes Liebäugeln mit dem Verfassen literarischer Werke erklärt nicht nur die enorme Detailtreue, sondern auch die anekdotische und von unzähligen Exkursen und abrupten Übergängen geprägte Form der Schriften. So hat Koni schon 1864, in der Schlussphase seines Studiums Versatzstücke für seine späteren Darstellungen dieser Lebensphase angelegt. In einem Manuskript von ungefähr 14 Seiten hielt er handschriftlich Erlebnisse aus seiner Studienzeit seit 1861 fest. Gleich zu Beginn äußerte er sich zu seinen Beweggründen. So kämen ihm nicht selten Erlebnisse aus dem Unileben in den Sinn. Gerne wolle er hier in der Folge aufschreiben, was ihm im Gedächtnis geblieben sei. Dabei bemühe er sich, die Aufmerksamkeit ganz auf das universitäre Treiben zu lenken und die „öffentliche Sphäre“ [obščestvennaja sreda] außen vor zu lassen. Seine Notizen in diesem Heft könnten ihn dann später daran erinnern, was er in vergangenen Zeiten erlebt habe. Vor ihm stehe nun das gesamte universitäre Leben mit seinen „lustigen “ und seinen „traurigen“ Attributen. ${ }^{186}$ Bereits dieser erste Entwurf basierte auf Tagebucheinträgen, die Koni zeitnah in den frühen 186oer-Jahren angelegt hatte. ${ }^{187}$ Die gesammelten Tagebuchauszüge sind auf zahlreiche Blätter aufnotiert, die aber wohl nicht dem eigentlichen Tagebuch entsprechen, da die Daten nicht immer chronologisch sind. Vielmehr scheint es, dass Koni aus seinem Tagebuch als Vorbereitung für den Entwurf gewisse Einträge abnotiert und neu angeordnet hat, um darauf aufbauend seine Erinnerungen zu formen. Auf diese Technik griff Koni auch fast ein halbes Jahrhundert später zurück, als es darum ging, „Aus den Studentenjahren“ für die Publikation bereit zu machen. Er notierte jeweils zu den entsprechenden Stellen in den Tagebuchauszügen, wo inhaltlich spannendes Material für eine spezifische Episode zu finden war. In der Handschrift des „alten“ Anatolij Koni finden sich auf den Blättern immer wieder entsprechende Zwischentitel wie „Dva sumašedšich matematika“ [Zwei verrückte Mathematiker] oder „Istorija [?] Beringera“ [Die Geschichte von Beringer] ${ }^{188}$ Gewisse „Geschichten“ ergänzte Koni über die Jahrzehnte hinweg mit neuen Materialien, so bewahrte er in den Kuverts mit dem frühen Entwurf und den Tagebuchauszügen beispielsweise auch einen Zeitungsausschnitt aus der „Neuen Zeit“ vom November 1881 mit einem abgedruckten Glückwunschtelegramm eines Staatssekretärs an Sergej Ivanovič Baršev (1808-1882) oder eine

\footnotetext{
186 GARF F. 564, op. 1, d. 194, l. 21-22.

187 Braune Kuverts in seinem Nachlass sind beschriftet mit: „Aus dem Tagebuch des Jahres ...", vgl. GARF F. 564, op. 1, d. 194, 1. 44-45.

188 Ebd., l. $110 b$ und 1. 15.
} 
1903 in den „Russischen Nachrichten“ veröffentlichte Erinnerungsschrift eines L. Panteleev, in der von Nikolaj Ivanovič Kostomarov (1817-1885) die Rede ist, auf. ${ }^{189}$ Sowohl über Baršev - seines Zeichens Rechtswissenschaftler und Rektor der Moskauer Universität - als auch über Kostomarov - Professor an der Petersburger Universität - schrieb Koni später ausführlich in seinen publizierten Studiumserinnerungen. Neben solchen allgemeinen Informationen sammelte Koni thematisch passend auch persönliches Material, in dem Aussagen über ihn und seine Themen enthalten waren. Exemplarisch dafür steht der Brief von Valuev an Koni selber oder jener von Ivan Aksakov, den Koni zitiert, um den Wahrheitsgehalt des guten Eindrucks, den der slavophile Denker von ihm hatte, zu unterstreichen.

Die Anzahl an Geschichten und Geschichtchen, zu denen Koni im Verlauf seines Lebens Unterlagen sammelte, Tagebuchauszüge aufbewahrte und Entwürfe verschriftlichte, ist umfangreicher als die von ihm schließlich veröffentlichten „Alltagstreffen ${ }^{\text {“ }}{ }^{190}$ Nicht für alle Anekdoten gab es Platz. Selbst die von Koni mit 1912 datierten Manuskripte für die in diesem Jahr publizierten Studiumserinnerungen gelangten nur in Auszügen in „Saatfeld“ [niva]. Später ergänzte Koni für

189 Ebd., 1. 16 und 1. 31-31ob.

190 Im Fall von „Signore Belaev“verzichtete Koni beispielsweise auf die Nutzung umfangreicher Entwürfe. Schon in den 188oer-Jahren hatte Koni eine Erzählung in Briefform über die Reise nach Italien angelegt. Minuziös beschreibt er darin die Landschaften, die er auf dem Weg aus der Schweiz über den Gotthard hinunter Richtung Neapel angetroffen hatte. Koni hat den Text mit diversen, z. T. wieder durchgestrichenen Titeln versehen, „Dlja novoj knigi“ [Für das neue Buch], „Iz vospominanij turista“ [Aus den Erinnerungen eines Touristen], „Iz starogo pis'ma“ [Aus einem alten Brief] und schließlich „Iz žitejskich vstreč“ [Aus Alltagstreffen] und „Sin’or Beljaev“. Über diesen schrieb Koni in der briefartigen Erzählung allerdings lediglich: „Wenn sie in Neapel sind, gehen sie zu einem interessanten Menschen und lernen sie ihn kennen. Es ist Sinor Beljaev. Ich erzähle ihnen über ihn nach meinen persönlichen Erinnerungen und nach den Anmerkungen in meinem alten Tagebuch“, vgl. IRLI F. 134, op. 1, d. 7, 1. 7ob. Darauf wird auch verwiesen in GA7, S. 462 (Anmerkungen). Vgl. zudem die Stichworte für einen sehr ähnlichen Text, möglicherweise sogar eine Vorbereitung für die Brieferzählung in einer umfangreichen Mappe mit losen Notizen Konis zu diversen Themen in IRLI F. 134, op. 1, d. 255, 1. 103-04. Ob es sich bei dieser briefartigen Erzählung tatsächlich um einen sehr ausführlichen Brief Konis handelt, den er verschickt und vorher für sich selber abnotiert hatte, oder ob er die Briefform als literarische Variation wählte, muss dahingestellt bleiben. Im Nachlass befindet sich datiert von 1882 auch eine weitere Reiseerinnerung „Vospominanie o Valdae“ [Erinnerung an Waldai], die Koni scheinbar nie veröffentlicht hat, vgl. IRLI F. 134, op. 1, d. 96.1882 erwähnt Koni die Revision der Gerichtsbehörden in der Gegend von Waldai, der er sich zu widmen hatte, vgl. GA8, S. 55 (Brief an Sergej Fëdorovič Moroškin vom 21.11. 1882). Im Archiv finden sich auch Stichworte und Teilentwürfe für einen Erinnerungstext über weitere Revisionen, die Koni im Verlauf seiner Amtszeit durchführte, vgl. „Revizii“, in: GARF F. 564, op. 1, d. 52. 
die verschiedenen Auflagen seiner Sammelbände "Auf dem Lebensweg" einige der Episoden mit zusätzlichem Material aus diesen Entwürfen. Der Aufzählungscharakter seiner aneinandergereihten Anekdoten verstärkt sich dadurch nochmals. ${ }^{191}$

Während die verschiedenen Entwürfe und Manuskripte in Konis Nachlass einsehbar sind, fehlt von den Originalen seiner Tagebücher jede Spur. Einzig einige der Abschriften und Zusammenstellungen als Grundlagen für seine Erinnerungsschriften sind erhalten geblieben. ${ }^{192}$ Vysockij schreibt ohne weitere Quellenangaben in seiner Koni-Biografie, dass es „nicht ohne Feuer“ gegangen sei und Koni zum Lebensende sein Tagebuch sowie einige Briefe verbrannt habe, weil er nicht gewollt habe, „dass die Leute ihn so sehen, wie er sich selbst sah“.93 Der enorme Umfang dieses Tagebuchs lässt sich erahnen, ebenso die Gründe für seine Vernichtung. Arsen'ev, der ebenfalls zeitlebens Tagebuch geführt hat, meinte dazu in einem Brief an seinen Juristenkollegen Dmitrij Stasov im Januar 1914:

Meine Tagebücher [...] gäben einem anderen absolut gar nichts, weil in ihnen nur kurze, nackte Aufzeichnungen von Fakten zu finden sind. [...] In mir weckt manchmal ein einzelnes Wort viele Erinnerungen. ${ }^{194}$

Tatsächlich lässt sich aus den erhaltenen Tagebuchabschriften von Koni nur wenig herauslesen. Die Schrift ist schwer lesbar, viele Abkürzungen und unklare

191 So integrierte Koni beispielsweise 1922 in den 3. Band vom „Auf dem Lebensweg“, als er verschiedene seiner „Alltagstreffen“ zum Text „Aus Jugend- und Altersjahren“ zusammenfasste, eine Anekdote über eine Schülerin namens Liza, vgl. KonI: Iz let junosti i starosti. In: ders. (Hrsg.): Na žiznennom puti, Bd. 3, S. 250-58. Diese Geschichte befindet sich bereits in den Manuskripten in IRLI F. 134, op. 1, Nr. 56, die an einer Stelle mit dem Datum 1912 versehen sind, vgl. 1. 106-13. Vgl. auch die oben, S. 321 erwähnte Episode einer Reisebegegnung, die Koni erst in „Auf dem Lebensweg“ III, als Teil von „Im Ausland und in der Heimat" einfügte. Die Herausgeber der Gesamtausgabe haben gerade die beiden umfangreichen Zusammenstellungen „Aus Jugend- und Altersjahren“ und „Im Ausland und in der Heimat" ausführlich kommentiert bzw. die Manuskriptversionen mit den Veröffentlichungen abgeglichen. Sie merken an, dass der Entwurf oftmals noch lakonischer und knapper als die Publikation sei. Meist sind die Unterschiede inhaltlich nicht wesentlich, so heißt es z. B. vom Gutsbesitzer in der Kutsche in der veröffentlichten Version, dass er Koni „geküsst“ habe, und im Manuskript ist die Rede davon, dass er bereit gewesen sei, ihm „die Hand“ zu küssen, vgl. GA7, S. 462 (Anmerkungen).

192 Neben den bereits erwähnten Zusammenstellungen in GARF F. 564, op. 1, d. 194, 1. 44-45 hat Koni auch Tagebuchabschriften aus den 188oer-Jahren erstellt, vgl. IRLI F. 134, op. 4, d. 93, 1. 47-53 oder etwa 35 Seiten mit Einträgen aus den Jahren 1901-1905 aufbewahrt. Dieses Heft ist mit der unmissverständlichen Anweisung: „Abschriften. Aufbewahren“ und „Aus den Tagebüchern“ versehen, vgl. IRLI F. 134, op. 15, d. 50, 1. 1.

193 VysockiJ: Koni, S. 420.

194 RO IRLI F. 294, op. 4, d. 57, l. 11. Zitiert nach LegkiJ: Dmitrij Vasil’evič Stasov, S. 32. 
Zusammenhänge erschweren es, inhaltlich etwas zu verstehen. Genauso wie für Arsenev waren aber auch für Koni diese „kurzen, nackten Aufzeichnungen von Fakten" eine wichtige Voraussetzung für das Erinnerungsschreiben. Ab und zu macht er dies in seinen Texten auch transparent, zum Beispiel wenn er schreibt, dass etwas sich dann und dann oder so und so zugetragen habe, und dabei auf sein Tagebuch verweist. ${ }^{195}$ Das Tagebuch als Erinnerungsstütze für autobiografische Texte war nicht nur im Fall von Koni oder Arsenev zentral, tatsächlich werden wohl die meisten autobiografischen Schriften mit Hilfe von Tagebüchern erstellt, auch wenn dies nicht immer transparent gemacht wird. ${ }^{196}$ Dass die entsprechenden Notizen nicht für die Allgemeinheit gedacht waren, machte Koni indirekt mehrfach klar. So schreibt er zu Beginn seiner Skizze über Sergei Witte, dass sowohl Briefwechsel als auch Tagebücher „von flüchtigen Eindrücken“ beeinflusst seien. Schmerzhafte Momente würden Aussagen hervorrufen, die den Schreibenden, „nach weiterer Bekanntschaft mit dem Leben“, oftmals zur Vernichtung seiner Tagebücher führen würden. ${ }^{197}$ Es ist augenfällig, dass Koni hier auch für sich selber spricht. Nicht nur Knappheit und Unverständlichkeit der aufgeführten Aussagen, sondern vor allem deren „flüchtiger“ Charakter ließen ihn zum Gegner von Publikationen von Tagebüchern werden. Offensichtlich war ihm klar, dass auch sein eigenes Tagebuch Urteile, Emotionen oder Informationen enthielt, die er so nicht vor einer interessierten Öffentlichkeit vertreten konnte. Die zu intimen Momentaufnahmen stellte er zurück zugunsten von Gesamtinterpretationen in zahlreichen ausgereiften Erinnerungstexten und autobiografisch unterlegten literarischen Erzählungen. Dass Koni sich genötigt sah, die Aufzeichnungen gleich vollständig zu vernichten, dürfte auf die mangelnden Garantien für die Respektierung der Privatsphäre öffentlicher Personen in Russland zurückzuführen sein. Die große Verehrung gerade für die Schriftsteller des Landes sorgte für ein enormes Interesse an deren Leben. Gleichzeitig dominierte die Überzeugung, dass diese Menschen aufgrund ihrer Tätigkeit das Recht auf eine Privatsphäre verwirkt hätten. ${ }^{198}$ Ivan Gončarov hatte mit einem offenen Brief 1889 eine Kontroverse zu diesem Thema initiiert. Der Schriftsteller klagte all jene angeblichen Freunde an, die nach dem Tod berühmter Literaten

195 Z. B. Koni: Triumviry. In: GA2, S. 300.

196 Vgl. z. B. die Memoiren des polnischen Adeligen Tadeusz Bobrowski, die 1900 erschienen. Dieser hat sein Werk ebenfalls auf Grundlage eines Tagebuchs verfasst und dies sogar offen angesprochen. Trotzdem ist das Tagebuch nicht erhalten, vgl. HeRLTH: „Verengung des Handlungsfelds", S. 393-94.

197 Koni: Sergej Jul'evič Vitte. In: GA5, S. 239.

198 E. A. Pravilova: A Public Empire. Property and the Quest for the Common Good in Imperial Russia. Princeton 2014, S. 249. 
wie Puschkin nichts anderes zu tun hätten, als sofort die Briefe zu veröffentlichen, die sie von diesem im Verlauf der Jahre erhalten hatten. ${ }^{199}$ Sein Plädoyer fand aber nur wenig Gehör. Gončarov sorgte deshalb vor und nahm seine Korrespondenten in die Pflicht, Briefe von ihm nicht ohne sein Einverständnis zu veröffentlichen. Auch verbrannte er zahlreiche Briefe. ${ }^{200}$ Dies dürfte schlussendlich die einzige sichere Option gewesen sein, die Veröffentlichung von Privatem zu verhindern. John Randolph stellt in seiner Biografie des Familienarchivs des russischen Anarchisten Michail Aleksandrovič Bakunin (1814-1876) fest, dass auch ein Brief mit dem in der Handschrift Bakunins notierten eindeutigen Vermerk „zum Verbrennen“ heute weitherum erhältlich ist. ${ }^{201}$ Im Zuge der Ausarbeitung eines neuen Gesetzes zur Frage von Schutzfristen, das in der dritten Duma und im Staatsrat diskutiert wurde und schließlich 1911 in Kraft trat, setzte sich Koni persönlich für einen größeren Schutz der Privatsphäre von Autoren und ihren Erben ein, während er allerdings gleichzeitig für eine sehr großzügige Auslegung des öffentlichen Eigentums an literarischen Werken eintrat. ${ }^{202}$ Dies steht wohl sinnbildlich für seinen eigenen Umgang mit seinen autobiografischen und literarischen Werken. Er stellte sicher, dass in der Regel nur seine ausgereiften Interpretationen und Schriften, nicht aber die „flüchtigen Eindrücke“ in seinen täglichen Notizen erhalten blieben. Gleichzeitig tat er alles, um möglichst große Teile seiner Geschichten der Öffentlichkeit zugänglich zu machen. Seine schriftstellerischen Ambitionen zeigen sich nicht nur am frühzeitigen Sammeln von möglichen Sujets, sondern auch ganz konkret an seiner Hoffnung, für „Die

199 Ebd., S. 245. Vgl. für die deutsche Übersetzung des Schreibens und diverse weitere Informationen dazu Gončarov: Briefe an Anatolij F. Koni und andere Materialien.

200 Pravilova: A Public Empire, S. 246.

201 John Randolph: On the Biography of the Bakunin Family Archive. In: Antoinette M. Burton (Hrsg.): Archive Stories. Facts, Fictions and the Writing of History. Durham 2005, S. 226.

202 Tatsächlich wurden Korrespondenzen, Tagebücher und sonstige private Papiere schließlich mit einer fünfzigjährigen Schutzfrist versehen, in der nur die Erben über sie verfügen durften, vgl. Pravilova: A Public Empire, S. 253 ff zu diesen Debatten. Vgl. zu Konis Haltung speziell und den Details bezüglich des neuen Gesetzes und der Schutzfristen, ebd., S. 255 und Anmerkungen, S. 385-87. Koni verfasste zur neuen Gesetzgebung und deren Regelung der Rechte von Autoren und Erben an den literarischen Werken und an den persönlichen Korrespondenzen auch den Eintrag im Lexikon „Neue Enzyklopädie Brockhaus-Efron“, vgl.: Anatolij F. KonI: Avtorskoe pravo. In: NĖS 1, 1911, Sp. 327-65 und veröffentlichte seinen Beitrag, den er bei der Diskussion im Staatsrat im Herbst 1910 vorgestellt hatte, vgl. Anatolij F. Koni: Po zakonoproektu ob avtorskom prave. In: ders. (Hrsg.): Na žiznennom puti, Bd. 2. Iz vospominanij, publičnye čtenija, v verchnej palate. Sankt-Peterburg 1912, S. 595-618. 
Hausangehörigen“ die prestigereiche Auszeichnung für russische Literatur, den „Puschkinpreis“, zu gewinnen. ${ }^{203}$

\section{Fazit}

Indem sich Koni mit seinen Erzählungen über Signore Belaev, Kutschenfahrten auf der Krim und Badeurlaub in Ostende an schriftstellerische Vorbilder wie Gončarov anlehnte, machte er unmissverständlich deutlich, dass hier aus seinem Schreiben das Bedürfnis sprach, selbst ein Literat zu sein. Erlebnisse wie die Denkmaleröffnung für Puschkin 1880 hatten Koni schon früh davon überzeugt, dass die Künstler und Poeten einen unerreichten Einfluss auf das „Volk“ besaßen. Die „Aneignung“ dieser Schriftsteller durch biografische Porträtierungen und Literaturkritik scheint deshalb nur konsequent. So konnte Koni für sich und die Justiz behaupten, an diesem direkten Zugang zu Land und Leuten teilzuhaben. Dass er über das Bindeglied der Gerichtsethik dem Rechtswesen gar eine moralischabsolute Komponente zuschrieb, förderte nochmals die Anschlussfähigkeit von Justiz und Literatur. Inwiefern Koni und all die anderen Rechtsgelehrten und Anwälte, die so begierig die Nähe zum Kunstschaffen suchten, ihrem Beruf einen Dienst erwiesen, ist dabei durchaus eine berechtigte Frage. Anna Schur kritisiert in ihrer Arbeit „Wages of evil. Dostoevsky and punishment“ ausführlich Konis Rede über den Schriftsteller „als Kriminalisten“. Wenn ein so anerkannter Jurist wie Koni seinen Kollegen Romane wie „Schuld und Sühne“ als Lehrbücher anpreise, um das Seelenleben der Angeklagten und somit deren Schuld besser einzuschätzen und damit zu treffenderen Strafen $\mathrm{zu}$ finden, dann sei dies wenig hilfreich im rechtlichen Alltag. Im Gegenteil, in Dostojewskis Werken sei doch gerade die „Undurchsichtigkeit“ des menschlichen Innenlebens zentral, so dass diese für Staatsanwälte und Verteidiger denkbar schlecht als Anleitungen fungieren würden. ${ }^{204}$ Dieser Einwand hat sicherlich seine Berechtigung. Gleichzeitig scheint klar, dass für Koni jegliche potentielle Verbindungslinie recht war, um eine Angliederung der Juristen an Dostojewski, Tolstoi, Gogol oder Puschkin zu forcieren. Dabei stand nicht unbedingt der konkrete Nutzen von Romanliteratur im Gerichtssaal im Fokus, sondern die Legitimation der Profession und die Steigerung ihrer Bedeutung. Diese sollte - wie im Falle der Schriftsteller - eben

203 Vgl. die Äußerungen Konis in einem Brief an den Literaturkritiker Aleksandr A. Izmajlov vom November 1910, GA8, S. 267-68 (Brief an A. A. Izmajlov vom 09.11.1910).

204 SChur: Wages of Evil, S. 16. 
nicht auf die eigentliche Kerntätigkeit beschränkt sein, sondern als Leitfigur auf dem „Schlachtfeld“ für soziale und politische Lebensfragen dienen.

Auf seine eigene Person und seine Biografie bezogen suchte Koni solche Legitimation mit der Veröffentlichung von Geschichten über reuige Minister und belehrte Wortführer kritischer Art wie Ivan Aksakov. Anerkennung generierte er auch besonders gerne aus dem Wohlwollen der Menschen vom "Dorfe" und der Loyalität und naiven Zuneigung von Dienern und Reisebekanntschaften, die der gebildeten Öffentlichkeit der großen Städte in seinen Erzählungen den Spiegel vorhalten sollten. Wie Konis Kontaktaufnahme mit diesen Menschen in den Augen jener gewirkt haben könnte, deren Loyalität und Zuneigung er zelebriert, lässt sich nur erahnen. Das Urteil eines bäuerlichen Autodidakten, der selber Erinnerungsschriften über sein Leben verfasst hatte, mag einen Eindruck geben. ${ }^{205}$ Matvej I. Ožegov verglich 1912 in einem Brief die Memoiren von Bauern mit jenen von privilegierteren Bürgern, die so gerne von ihren Kontakten mit dem „Volk“ berichteten:

Man solle ihnen [den bäuerlichen Schriften, CC] einen würdigen Platz in den Gazetten und Zeitschriften einräumen, und zwar anstelle jener „Glückspilze“, die auf der Sonnenseite des Lebens stehen und gewöhnlich über Kleinigkeiten schreiben: Darüber wie sie gereist sind, mit einigen humoristischen Abenteuern, was sie in den Hotels und den Gaststuben getrunken und gegessen haben, ihre Gespräche mit dem Dienstmädchen, den Kutschern und Lastenträgern, die sie geführt haben, um das „Leben“ zu erfahren. ${ }^{206}$

Unbeirrt von solchem Spott scheint Koni der festen Überzeugung gewesen zu sein, über Nähe und Wohlwollen von Eisenbahnpassagieren und Badegästen aus allen Ecken und Enden des Imperiums Legitimation für sich und sein berufliches Tun zu generieren. Konis persönliche Beweggründe, seinem eigenen Schaffen in seinen Erinnerungen öffentliche Absolution zuteilwerden zu lassen, schimmern in seinen Berichten immer wieder durch. Bestätigung für seine Arbeit am Gericht, die er in seiner Wahrnehmung von den eigenen Vorgesetzten und den staatstragenden Kräften im Russischen Imperium nicht zur Genüge erhielt, sollte so kompensiert werden. Das „Ereignis Zasulič“, das Koni über Jahrzehnte

205 Julia Herzberg legt in ihrer Untersuchung zu bäuerlicher Autobiografik im Russischen Reich einen Schwerpunkt auf die Bildungswege und Erinnerungsschriften sogenannter Autodidakten, vgl. Herzberg: Gegenarchive, v. a. S. 120 ff.

206 Julia Herzberg: „Selbstbildung“ und Gemeinwohl. Das Aushandeln eines besseren Russlands in bäuerlichen Briefen und Autobiographien. In: Walter Sperling (Hrsg.): Jenseits der Zarenmacht. Dimensionen des Politischen im Russischen Reich 1800-1917. Frankfurt am Main u. a. 2008, S. 272. 
hinweg begleitete, spielt hier ungenannt mit hinein. Die Berufskollegen, die sich im entscheidenden Moment von Koni distanzierten und ihre eigenen Haltungen verrieten, bilden den Hintergrund für seine Erzählungen von bekehrten Ministern und treuen Bauernsöhnen. Zahlreich sind in Konis Erinnerungen „Aus Jugendund Altersjahren“ denn auch Geschichten über andere illoyale Wendehälse, deren Symbolwirkung nicht zuletzt darin besteht, Konis eigene Charakterfestigkeit zu unterstreichen. Typischerweise schildert er zum Beispiel zu Beginn der „Gymnasiumserinnerungen“ einen Mitschüler und dessen Bruder, deren Bekanntschaft für ihn „verbunden mit einem jener Lebenswechsel im Menschen“ gewesen sei, wo aus dem Freund ein Feind werde. ${ }^{207}$ Die Episode beschreibt, wie aus einem jungen Mann, der die Exiljournale der russischen Sozialisten gelesen und von der jungen Generation einen Aufstand verlangt habe, schließlich ein Agent geworden sei, der ebendiese Jugend ausspioniert habe. ${ }^{208}$

\section{2 Öffentliche Literatenporträts und private Überlegungen $\mathrm{zu}$ „Volk“ und Intelligencija vor dem Lebensende}

Zur Zeit des Ersten Weltkrieges wurde der Jugend in den russischen Schulstuben immer noch mit Vorliebe patriotische und religiös-moralische Literatur verordnet. Viele der im Lehrplan von 1903/05 eben erst eingeführten Werke von Autoren wie Turgenev, Gončarov, Tolstoi, Dostojewski, Ostrovskij oder Nekrasov wurden wieder verboten. ${ }^{209} \mathrm{Nach}$ den Revolutionen von 1917 aber fanden die Bücher dieser Schriftsteller erneut den Weg in den Schulunterricht. 1921 nannte ein Lehrplan Griboedov, Puschkin, Lermontov, Gogol, Turgenev, Gončarov, Ostrovskij, Tolstoi, Čechov und Gor'kij als „die größten Dichter" des 19. beziehungsweise 20. Jahrhunderts. ${ }^{210}$ Während nun der literarische Kanon nicht länger von zarischen Behörden eingeschränkt wurde, spielten allerdings die bolschewistischen Vorstellungen von guter Literatur immer deutlicher eine entscheidende Rolle. 1923/24 wurden unter anderem auf Anweisung der Vorsitzenden der „Zentralen Bibliothekskommission" Listen von Autoren und Buchtiteln erstellt, die es aus den Bibliotheken des Landes zu entfernen galt. Alles, was ,tierische und antisoziale

207 Koni: V doroge - Gimnasičeskie vospominanija. In: ders. (Hrsg.): Na žiznennom puti, Bd. 1, S. 636.

208 Ebd., S. 636-43.

209 Erna Malygin: Literatur als Fach in der sowjetischen Schule der $1920 e r$ und 1930er Jahre. Zur Bildung eines literarischen Kanons. Bamberg 2012, S. 72.

210 Ebd., S. 113-14. Dieser Lehrplan beruhte allerdings noch auf einer Absprache der Russischlehrer aus vorrevolutionärer Zeit. 
Gefühle“ auszulösen im Verdacht stand, sollte aus den Regalen verschwinden. Daneben gehörten Militarismus, Nationalismus oder Aberglaube zu den heiklen Themen. Die russischen Klassiker allerdings gelangten nicht auf diese schwarze Liste. ${ }^{211}$ Es mag auf den ersten Blick erstaunen, dass einem Lew Tolstoi, der sich so intensiv Fragen von Moral und Glauben gewidmet hatte, in den 1920er-Jahren ein Platz in Lehrplan, Bibliotheken und in der Literaturgeschichte gelassen wurde. Tatsächlich war es aber Lenin persönlich, der mit mehreren Essays schon im Jahrzehnt vor der Oktoberrevolution entscheidend zur Integration des äußerst populären und international renommierten Autors in die sozialistische Wertewelt beigetragen hatte. „Leo Tolstoi als Spiegel der russischen Revolution“ lautete einer der Aufsätze, mit denen Lenin die „Ehrrettung“ Tolstois vorantrieb. Argumentiert wurde dabei mit dem „künstlerischen Realismus“, der stärker sei als die explizite Weltanschauung des Autors. ${ }^{212}$ Während Tolstoi also auch in den 1920er-Jahren zum literarischen Kanon gehörte, verhielt sich das bei Dostojewski etwas anders. Die „Apologie des Duldens“ und antirevolutionäre Aussagen in den späten Romanen erschwerten seinen Werken für viele Jahre die öffentliche Anerkennung in der Sowjetunion. Nichtsdestoweniger behielt er eine gewisse Bedeutung als "Autor der Erniedrigten und Beleidigten“ ${ }^{213}$ Mit der neuen Literaturpolitik unter Stalin wurde in den 1930er-Jahren neben Tolstoi - dessen Werke als Vorbilder für die sozialistisch-realistischen Langromane dienen sollten - sogar Alexander Puschkin wieder Teil des literarischen Kanons. An seinem 10o. Todestag 1937 wurde er als Puzzleteil in Stalins Neufokussierung auf die Größe Russlands als „nationales Genie“ hochgejubelt. Keine Rede war mehr vom Puschkin als Repräsentant des Adels. ${ }^{214}$

Dass Russland ohne seine großen Autoren nicht denkbar war, schien auch Konis feste Überzeugung gewesen zu sein. Wie bereits im Kapitel Politische Erinnerung an das Zarenreich in der Sowjetunion angedeutet, bestand ein großer Teil von Konis publizierten Erinnerungsschriften in den 1920er-Jahren aus Porträts von Literaten des 19. Jahrhunderts. Während seine autobiografischen Texte über Politiker und seine eigenen beruflichen Tätigkeiten nicht zuletzt auch wegen

211 Ermolaev: Censorship in Soviet Literature, 1917-1991, S. 6.

212 Anne Hartmann/Wolfram Eggeling: Sowjetische Präsenz im kulturellen Leben der SBZ und frühen DDR 1945-1953. Berlin 1998, S. 305-06.

213 Ebd., S. 306. Noch in den 1970er-Jahren wurde nur mit Vorsicht auf Dostojewski verwiesen.

214 Amacher: En guise d'introduction, S. 18-19 und Hartmann/Eggeling: Sowjetische Präsenz im kulturellen Leben der SBZ und frühen DDR 1945-1953, S. 305. Vgl. zur „Inthronisation eines Klassikers" auch Karl Schlögel: Terror und Traum. Moskau 1937. München 2008, S. $202 \mathrm{ff}$. 
Zensurbestimmungen oftmals im Manuskriptstadium verblieben, war der Spielraum für die Publikation von Schriften über Literaten größer. Tatsächlich gelang es Koni im frühen Sowjetrussland, beinahe den gesamten klassischen Kanon der großen Autoren aus dem 19. Jahrhundert zu bedienen. Dabei deutet sich an, dass er seine Literaturanalysen und Erinnerungsschriften an diese Autoren als eine Art Brücke verwendete, über die Werthaltungen des „alten“ Russlands in die 1920er-Jahre und darüber hinaus transportiert werden sollten. Bereits 1919 verhandelte Koni mit dem Petrograder Verlag Z. I. Gržebin über die Herausgabe von zwei umfangreichen Bänden mit dem Titel „Erinnerungen und literarische Skizzen“'215 Ein provisorisches Inhaltsverzeichnis, das vermutlich für diese $\mathrm{Pu}$ blikation gedacht war, führt 30 Texte auf, von „Tolstoi“ über „Dostojewski“ zu „Pisemskij“ und „Gorbunov“. ${ }^{216} 1923$ nahm er mit einem anderen Verlag Kontakt auf, um die Herausgabe eines Buches mit dem Titel „Russische Schriftsteller nach persönlichen Erinnerungen“ "zu diskutieren. ${ }^{217}$ Schlussendlich waren es aber die in Tallinn und Berlin publizierten Bände „Auf dem Lebensweg“ III und IV und der erst 1929 posthum in Russland erschienene V. Band, mit denen Koni erfolgreich einen großen Teil seiner Erinnerungen an Literaten und (literatur-)wissenschaftliche Arbeiten aus dem Umfeld der Akademie der Wissenschaften nicht nur im Ausland, sondern auch in der Sowjetunion in Buchform wiederveröffentlichen konnte. Das Ausweichen auf ausländische Verlage und Druckereien war in der frühen Sowjetunion eine gängige Praxis. Während des Bürgerkrieges, der nach der Oktoberrevolution bis Ende 1920 um die Vorherrschaft in Russland geführt wurde, hatten die inländische Papierindustrie und das Druckwesen fast gänzlich den politischen und militärischen Bedürfnissen zu dienen. ${ }^{218}$ Der im Zarenreich so erfolgreiche Verleger Ivan Sytin wollte 1920 auf der Suche nach Papier und Maschinen, die in Russland allesamt große Mangelware waren, nach Finnland ausweichen, um von dort aus den Druck von Publikationen zu organisieren. ${ }^{219}$

215 GARF F. 564, op. 1, d. 245, 5. Vertrag.

216 Ebd., d. 150, 1. 5-5ob. Vgl. zum Verleger Zinovij Isaevič Gržebin (1877-1929) bzw. dessen Zusammenarbeit mit dem Verlag Vsemirnaja Literatura auch die nachfolgenden Ausführungen und L. M. Chle Bnikov: Iz istorii Gor'kovskich izdatel'stv. „Vsemirnaja literatura“ i „Izdatel'stvo Z. I. Gržebina“. In: V. R. Ščerbina u. a. (Hrsg.): V. I. Lenin i A. V. Lunačarskij. Perepiska, doklady, dokumenty. Moskva 1971, S. 668-703.

217 GARF F. 564, op. 1, d. 246, 1. 38.

218 SтÄрtкe (Hrsg.): Russische Literaturgeschichte, S. 291. Vgl. zum Bürgerkrieg, in dem die äußerst heterogen zusammengesetzte „Weiße Armee“ eine Gegenrevolution versuchte und dabei von Truppen der Westmächte, die sich aufgrund des Weltkrieges noch in der Region befanden, unterstützt wurde, Haumann: Geschichte Russlands, S. $346 \mathrm{ff}$.

219 RuUd: Russian Entrepreneur Publisher Ivan Sytin of Moscow, 1851-1934, S. 179. Vgl. zu Sytin auch oben, S. 116. 
Diese Nutzung ausländischer Ressourcen und Geschäftsbedingungen wurde auch in den nachfolgenden Jahren, als sich in Russland die Macht der Bolschewiki stabilisiert hatte und längst wieder zahlreiche Verlage gegründet worden waren, beibehalten. Gerade Berlin, das nach dem Ersten Weltkrieg unter starker Inflation litt, lockte mit seinen außerordentlich tiefen Produktionskosten. Die deutsche Hauptstadt entwickelte sich schnell zu einem Zentrum des russischsprachigen Buchdrucks. ${ }^{220}$ Dabei waren es keineswegs nur die politischen Emigranten, die diese Verlage nutzten. ${ }^{221}$ Zahlreiche sowjetische Häuser hatten Zweigniederlassungen in Berlin, und es gab durchaus Verlage, die sowohl Sowjetautoren als auch emigrierte Schriftsteller in ihrem Programm führten. Die Beziehungen zwischen „Sowjet-, Emigranten- und ,Zwischen'schriftstellern“ sollten nie mehr so eng sein wie in den frühen 1920er-Jahren. ${ }^{222}$ Der Verlag Bibliofil, in dessen Obhut Koni seinen III. und IV. Band "Auf dem Lebensweg" gab, war in Estland beheimatet. In diesem Land, das seit 1918 unabhängig von Russland war, hatte sich eine kleine Zahl an Verlagen auf die Herausgabe russischsprachiger Bücher spezialisiert. Bibliofil, 1921 gegründet, war der bedeutendste davon und publizierte in erster Linie Bücher der „hungernden Petrograder [...] Schriftsteller“ ${ }^{223}$ Auch dieser Verlag nutzte Berlin als günstiges Geschäftsumfeld. So heißt es denn im Impressum von Konis Bänden entsprechend: „Revel' [Tallinn, CC] - Berlin“.224 In einem Nachruf auf Koni wird berichtet, warum er sich dazu entschlossen habe, die Manuskripte der Bände III und IV nach Estland zu geben. Schon lange zum Druck bereit, seien diese viele Hundert Seiten umfassenden Bücher in Russland nicht zu publizieren gewesen. Nicht zuletzt aus materiellen Gründen sei Koni aber auf die

220 John Glad (Hrsg.): Conversations in Exile. Russian Writers Abroad. Durham u.a. 1993, S. 3 .

221 Irina Paperno: Intimacy and History. The Gercen Family Drama Reconsidered. In: Russian Literature 1-2 (2007), S. 32. Paperno beschreibt, wie beispielsweise die Tochter von Alexander Herzen überredet wurde, die Memoiren ihres Vaters „Byloe i dumy“ auch außerhalb der Sowjetunion herauszugeben. Dies, damit sie nicht nur im „bolschewistischen Stil“ - also in neuer Rechtschreibung und auf schlechtem Papier - gedruckt würden.

222 Gleb Struve: Geschichte der Sowjetliteratur. München 1958, S 48. Mit „Zwischenschriftstellern“ sind solche gemeint, die zwar nach Berlin emigriert waren, aber später in die Sowjetunion zurückkehrten, oder solche, die zwar als "Sowjetbürger“ in Deutschland lebten, sich aber später entschlossen, der Heimat für immer den Rücken zu kehren. Vgl. zur Vielfalt der Verlagshäuser auch SCHLÖGEL: Das russische Berlin, S. 135-39 mit einer Übersicht. Schlögel spricht von 86 Verlagen, die weltweit die russische Diaspora mit Zeitungen und Büchern belieferten und auch nach Sowjetrussland exportierten.

223 IsA KOv: Russkie v Ėstonii, 1918-1940, S. 42-43 und 67.

224 Revel', zu Deutsch Reval war offiziell bis 1918 und teilweise auch noch länger die Bezeichnung für Tallinn. 
baldige Veröffentlichung dieser Bände angewiesen gewesen. ${ }^{225}$ Im dritten dieser Bände veröffentlichte Koni seine eigenen literarisch-memoiristischen Versuche „Im Ausland und in der Heimat", „Hausangehörige“ und „Aus Jugend- und Altersjahren“ erneut. ${ }^{226}$ Der IV. Band, so schrieb Koni in der Vorbemerkung, sollte zugänglich machen, was er 1906 im längst vergriffenen Sammelband „Skizzen und Erinnerungen" veröffentlicht hatte. Es sind dies fast ausschließlich Literatenporträts und -analysen, so beispielsweise zu Puschkin, Odoevskij, Solovëv, Turgenev oder Dostojewski. ${ }^{27}$ Im fünften Band, der für das sowjetische Publikum besser erhältlich war als die von Bibliofil herausgegebenen, integrierte Koni schließlich zahlreiche Literatenporträts, die er erst in seinen letzten Lebensjahren geschrieben oder ergänzt hatte. Sie verweisen auf seine umfangreichen Aktivitäten in Bezug

225 Utevskij: Poslednij ètap žiznennogo puti, S. 91-92. Neben den beiden Fortsetzungsbänden legte Bibliofil auch den ersten Band von „Auf dem Lebensweg“ nochmals auf, vgl. Angaben in Fußnote 369 in TEIL ZWEI. Es ist klar, dass Publikationen und Lektionen für Koni immer auch eine Möglichkeit waren, sein Einkommen aufzubessern, das insbesondere in den Jahren des Bürgerkrieges gleich nach der Oktoberrevolution sehr niedrig war. Vgl. z. B. Domanova: Perepiska A. F. Koni kak istoričeskij istočnik, S. 121: Koni musste 1918 aus Geldnot einem Sammler einige Stücke aus seinem Archiv verkaufen, darunter Notizen seiner Mutter. Auf S. 124 zitiert Domanova zudem aus einem Brief, in dem Koni von der schwierigen Lebenslage berichtet. Vgl. zum allerdings auch sehr bescheidenen Einkommen Konis aus Vorträgen VysockiJ: Koni, S. 397-98. Vgl. auch nochmals Utevskij: Poslednij ètap žiznennogo puti, S. 92, der weiter beschreibt, wie Koni für die Veröffentlichung seiner beiden „Auf dem Lebensweg“-Bände nur einen kleinen Teil der Summe erhielt, die ihm zugestanden hätte. Dies habe aber doch für „einige Jahre ruhigen Alters“ gereicht. In einem Brief verweist Koni auch selber darauf, dass die Bände ihm eine finanzielle Grundsicherheit verschafften, vgl. Michail N. Gernet: Anatolij Fëdorovič Koni na ischode ego „žiznennogo puti“. In: PŽ 6-7 (1927), S. III.

226 Anatolij F. Koni (Hrsg.): Na žiznennom puti, Bd. 3. Vospominanija, žitejskie dramy, žitejskie vstreči, pamjati ušedšich, kritičeskie očerki. Revel', Berlin 1922. Daneben integrierte Koni in diesem Buch die Porträts von Loris-Melikov und M. M. Kovalevskij, dem er den Band auch widmete, sowie mehrere Rezensionen von vornehmlich juristischen Büchern, vgl. oben, Fußnote 472 in TEIL ZWEI und einige Nachrufe und Kurzporträts, beispielsweise seine Reihe über weibliche Persönlichkeiten wie Aleksandra Charina, vgl. oben, Fußnote 35 in TEIL DREI.

227 Anatolij F. Koni (Hrsg.): Na žiznennom puti, Bd. 4. Publičnye čtenija i reči. Revel', Berlin 1923. Vgl. auch: Anatolij F. Koni (Hrsg.): Očerki i vospominanija. Publičnye čtenija, reči, stat'i i zametki. Sankt-Peterburg 1906. Daneben integrierte Koni in den Band auch einige Juristenporträts, so beispielsweise die Rede über den Gerichtsreformer Rovinskij, die er vor der Akademie der Wissenschaften 1895 gehalten hatte, vgl. oben, S. 59. Koni widmete den vierten Band dem verdienten Wissenschaftler A. A. Šachmatov, mit dem er in der Akademie der Wissenschaften über Jahre hinweg eng zu tun gehabt hatte. $\mathrm{Zu}$ ihm finden sich einige einleitende Worte im Band. 
auf Erinnerungen an und Analysen von diesen Schriftstellern und ihren Werken in der frühen Sowjetunion. ${ }^{228}$

Tatsächlich schien Koni in den 1920er-Jahren keine Gelegenheit auszulassen, an „seine“ Literaten zu erinnern. Wer verstarb, wurde von ihm beispielsweise in der Zeitschrift „Bote der Literatur“ [Vestnik Literatury] mit einigen Gedenkworten geehrt. Als 1922 mit Vladimir Korolenko eine der Größen des vergangenen Jahrhunderts den Tod fand, schrieb Koni eine ausführliche Erinnerungsschrift über „Korolenko und das Gericht“. Darin berichtete er über seine Zusammenarbeit mit dem Schriftsteller anlässlich der Anklage wegen Ritualmordes gegen die udmurtischen Bauern in den 189oer-Jahren. ${ }^{229}$ Wer schon vor längerer Zeit verschieden war, dem widmete Koni zur Feier des runden Geburts- oder Todestages eine Gedenkschrift oder konstruierte aus Versatzstücken seiner älteren Porträts neu Würdigungen. So publizierte er 1921 über Dostojewski zu dessen 40. Todestag sowohl die Jahrzehnte alte Rede zum Schriftsteller als „Kriminalisten“ als auch neue Schriften mit bezeichnenden Titeln wie „Nochmals“ über Dostojewski. Zu Nekrasov, Tolstoi und erstmals auch zum russischen Novellisten Anton Pavlovič Čechov (1860-1904) und dem Dramatiker Aleksandr Nikolaevič Ostrovskij (1823-1886) veröffentlichte Koni jeweils anlässlich ihrer 10o. Geburtstage entsprechende Würdigungen. ${ }^{230}$ Im Rahmen der „Puschkintage“, die 1921 zur 84.

228 Neben den Literatenporträts erschienen darin auch die Porträts der Politiker Witte und Manuchin, vgl. zu diesen oben, S. 228. Leseexemplare der Bände aus Estland gelangten zwar nach Russland, aber die Reichweite war doch eingeschränkt, vgl. die Aussage von Utevskij: Poslednij ètap žiznennogo puti, S. 92 sowie die Dokumentation der Zollformalitäten zum Erhalt von zwei der Bände aus dem Ausland, IRLI F. 134, op. 4, d. 136.

229 Anatolij F. Koni: V. G. Korolenko i sud. In: Žurnal' obščestvenno-kooperativnoj mysli „Proizvodsojuz“ Nr. 1-4 (1922) sowie Anatolij F. Koni: V. G. Korolenko i sud. In: ders. (Hrsg.): Na žiznennom puti, Bd. 5. Leningrad 1929, S. 291-97. Vgl. zum Gerichtsfall und Konis Zusammenarbeit mit Korolenko oben, S. 309.

230 Für den 40. Jahrestag von Dostojewskis Tod, der mit dem 100. Geburtstag von Nekrasov zusammenfiel, publizierte er 1921 ein Büchlein mit dem Titel „1821-1921. Nekrasov. Dostojewski. Nach persönlichen Erinnerungen“, vgl. Anatolij F. Koni: Nekrasov, Dostoevskij. Po ličnym vospominanijam: 1821-1921. Petrograd 1921. Seine beiden Skizzen beruhten auf den schon 1908 veröffentlichten „Auszüge aus Erinnerungen“. In „Auf dem Lebensweg“V wurden beide Skizzen in der Version von 1921 nochmals abgedruckt. Vgl. für genauere Angaben die Anmerkungen in KonI (Hrsg.): Na žiznennom puti, Bd. 5, S. 343-44. Ebenfalls 1921 publizierte Koni auch seine berühmte Rede zu „Dostojewski als Kriminalist“ erneut: Anatolij F. Koni: O F. M. Dostoevskom. In: Žurnal’ obščestvenno-kooperativnoj mysli „Proizvodsojuz“ 2O-24 (1921), S. 4-11. Ebenfalls abgedruckt in „Auf dem Lebensweg“IV und V. Koni stützt sich hier auf seine Rede von 1881, vgl. KonI (Hrsg.): Na žiznennom puti, Bd. 5, S. 361 (Anmerkungen). Vgl. zudem als Sinnbild für die Unerschöpflichkeit des Materials, mit dem Koni hantierte, den Aufsatz „Nochmals über Dostojewski“: Anatolij F. KonI: Ešče o Dostoevskom. In: Utrenniki 1 (1922), S. 72-76 sowie in „Auf dem 
Jährung des Todestages des verehrten Poeten veranstaltet wurden, fungierte Koni als Mitherausgeber des Bandes „Puschkin und Dostojewski“ und druckte unter anderem seine Rede von 1899 zu Puschkins ,moralischer Gestalt“ erneut ab. ${ }^{231}$ Für Turgenev konzipierte Koni ebenfalls einen ganzen Sammelband inklusive eines eigenen Erinnerungstextes an dessen Beerdigung im Jahre $1883^{232}$ und schließlich bündelte er all dies in „St. Petersburg. Erinnerungen eines Alteingesessenen“. Sinn-

Lebensweg“ V. In Zukunft wird der Abdruck aus der Gesamtausgabe zitiert, die sich auf die Veröffentlichung in „Utrenniki“ bezieht. Vgl. ferner weitere Artikel zu Dostojewski, die Versatzstücken alter Texte in neuem Rahmen entsprechen: Anatolij F. Konı: Vstreči s F. M. Dostoevskim. In: VL 2 (1921), S. 6-8; Anatolij F. Koni: Pamjati Dostoevskogo. In: AD (1-4) 1922, S. 2-3. Zu Nekrasov zudem auch: Anatolij F. Koni: Motivy i priemy tvorčestva Nekrasova. Beglye zamteki. In: Nekrasov. Pamjatka ko dnju stoletija roždenija. 22 nojabrja 1821 g. - 22 nojabrja (5 dekabrja) 1921 g. Petrograd 1921, S. 15-17 sowie in „Auf dem Lebensweg“ V. Im Folgenden wird der Abdruck aus der Gesamtausgabe zitiert, der sich auf die Erstpublikation beruft.

Zu Tolstoi der erneute Abdruck von „Über die Dramawerke Tolstois“, vgl. Anatolij F. KonI: Po povodu dramatičeskich proizvedenij Tolstogo. In: N. N. Gusev (Hrsg.): L. N.Tolstoi. Jubilejnyj sbornik. Leningrad u. a. 1928. Zu seiner Freundschaft mit Čechov verfasste Anatolij F. Koni: A. P. Čechov. Otryvočnye vospominanija. In: M. D. Beljaev/A. S. Dolinin: A. P. Čechov. Zaterjannye porizvedenija, neizdannye pis’ma, vospominanii, bibliografija. Leningrad 1925, S. 199-216 sowie in "Auf dem Lebensweg" V. Und schließlich zu Ostrovskij: Anatolij F. Koni: A. N. Ostrovskij. Otryvočnye vospominanija. In: A. A. Bachrušin/N. L. Brodskij/N. A. Popov (Hrsg.): Ostrovskij. 1823-1923. K stoletiju so dnja roždenija. Moskva 1923, S. 19-23. Im Folgenden wird die Version aus der Gesamtausgabe zitiert, die sich auf die Publikation im Jubiläumsband von 1923 bezieht.

Vgl. für die zahlreichen Vorlagen und Erstpublikationen das Kapitel Öffentliche Literatenporträts und private Überlegungen $z u$ „Volk“ und Intelligencija vor dem Lebensende.

231 Anatolij F. Koni: Obščestvennye vzgljady Puškina. In: Dom Literatorov (Hrsg.): Puškin. Dostoevskij. Petrograd 1921, S. 46-75. Dies, so wird auf S. 4-5 des Sammelbandes, den Koni selber mit herausgegeben hat, vermerkt, sei eine Zusammenfassung von Konis Vortrag „Die moralische Gestalt Puschkins“, den er im Februar 1921 zu den Feierlichkeiten gehalten habe. Ebenfalls mündlich vorgetragene einführende Worte von Koni zur Ehrung des Dichters sind zudem abgedruckt als: Anatolij F. Koni: [A. S. Puškin]. In: VL 3 (1921), S. 18-19. Für diesen Text wird in der Folge die Version aus der Gesamtausgabe zitiert, die sich auf die Publikation im „Boten der Literatur“ bezieht. Konis Rede zur „moralischen Gestalt“"wurde in ihrer Originalversion von 1899 auch in „Auf dem Lebensweg“ IV integriert.

232 Anatolij F. Konı: Pochorony Turgeneva. In: ders. (Hrsg.): Turgenevskij sbornik. Petrograd 1921, S. 7-85 sowie in „Auf dem Lebensweg“ IV. In der Folge wird die in der Gesamtausgabe abgedruckte Variante zitiert, die sich am Abdruck im Sammelband 1923 orientiert, der einige kleine stilistische Veränderungen zur Erstausgabe aufweist. Vgl. auch Anatolij F. Konı: K stoletiju roždenija I. S. Turgeneva. In: RS 10-12 (1918), S. 53-63. Sowie die Erinnerungsschrift „Savina i Turgenev“, die als Vorwort des von Koni herausgegebenen Sammelbandes „Turgenev i Savina“ 1918 in Petrograd erschien (S. V-XXXVIII), sowie in „Auf dem Lebensweg“ III. Darin sind zahlreiche Elemente aus anderen Erinnerungsschriften enthalten. Vgl. dazu detaillierter GA6, S. 608 ff (Anmerkungen). 
bildlich für die Bedeutung, die Koni den Literaten zumaß, ließ er zahlreiche von ihnen in diesem 1922 veröffentlichten Buch als zentralen Bestandteil der „alten Stadt des heiligen Peters" [staryj gorod Svjatogo Petra] zu Wort kommen. ${ }^{233} \mathrm{Er}$ nimmt seine Leser auf einen virtuellen Rundgang durch das St. Petersburg des 19. Jahrhunderts mit und beschreibt die Stadt dabei als Heldin, deren integraler Bestandteil die Wohnhäuser berühmter Literaten waren. ${ }^{234}$ Immer wieder dienen Zitate und Gedichtzeilen aus den Werken von Nekrasov und weiteren Autoren als Mittel, um die Stadt und ihre damaligen Bewohner zu beschreiben. Diese Charakterisierungen standen in direktem Zusammenhang mit der „Gesellschaft für das alte St. Petersburg“, für die Koni beispielsweise im Rahmen der Lektionenreihe „Lebendige Erinnerungen“ [Živaja pamjat'] auch mündlich von seiner Heimatstadt berichtete. ${ }^{235}$

Aus der Gesamtschau von Konis publizistisch-literarischem Engagement in dieser Zeit wird deutlich, dass oftmals Versammlungen literarischer Zusammenschlüsse, die sich dem Studium der Schriftsteller und ihrer Wirkungsorte widmeten oder Jubiläen und Todesfälle von Autoren feierlich begingen, den Anlass für Konis Schaffen bildeten. Mit Vorträgen und Lektionen trat er bei diesen Gelegenheiten auf und verschriftlichte später das Gesagte. Dieser Entstehungskontext verweist nicht nur auf das Netzwerk, in dem Koni sich nach 1917 vornehmlich bewegte. Die starke Orientierung am öffentlichen Auftritt deutet bereits auf die Rolle hin, die Koni mit seinen Erinnerungen nun einnehmen wollte. Er positionierte sich immer deutlicher als Schriftsteller und Lehrer, der in möglichst intensiven Kontakt zu seinen Lesern und Schülern treten wollte, um ihnen jene Persönlichkeiten nahezubringen, die ihm selber so wichtig waren.

Die Publikation all dieser Erinnerungen und Analysen von Literaten war aber nur ein Aspekt von Konis autobiografischer Praxis im sowjetischen Russland. Ein anderer Aspekt gelangte nie an die Öffentlichkeit. In mehreren Versuchen bemühte sich Koni im Revolutionsjahr 1917 und in den Jahren danach, sein eigenes Leben auf Papier zu bannen. Bis dahin waren seine autobiografischen Texte immer thematisch beschränkt gewesen. Nun aber, nicht zuletzt auch angesichts seines fortschreitenden Alters, nahm er mehrere Anläufe, eine „klassische“ Autobiografie zu

233 Anatolij F. Koni: Peterburg. Vospominanija starožila. Petrograd 1922 sowie in „Auf dem Lebensweg" V. Für das Zitat vgl. S. 23. Hier und in der Folge wird die Publikation aus der Gesamtausgabe zitiert, die sich auf die Erstausgabe von 1922 beruft.

234 Spalinger-Bichsel: A. F. Koni und die russische Gerichtsrhetorik, S. 9-10. Spalinger spricht in Bezug auf diesen Text von der „besonderen Porträtkunst“ Konis, der die Stadt als Heldin eingänglich beschreibt.

235 Vgl. für Notizen zur Lektionenreihe IRLI F. 134, op. 1, d. 222. Ausführlicher zur Gesellschaft und dem Kontext der Heimatkunde im nachfolgenden Abschnitt. 
verfassen, die sein Leben „von der Wiege bis zur Bahre“ abbilden sollte. Auffällig ist dabei die enge Verbindung zwischen historischer Entwicklung von Land und Gesellschaft und dem eigenen Lebensweg. Der Moment des verschärften historischen Wandels nach den Revolutionen von 1917 forderte von Koni eine neue Einordnung seiner persönlichen Geschichte anlässlich grundsätzlicher Fragen zur Entwicklung Russlands. Am deutlichsten zeigt sich diese historische Dimension im Titel des ersten dieser Entwürfe: „Die Geschichte der Heimat im Laufe

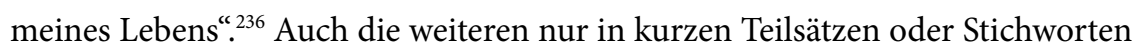
und Jahreszahlen skizzierten Versuche weisen schon in den Überschriften darauf hin, dass Koni hier im Moment der fundamentalen Veränderungen Erklärungen für die Geschehnisse in seinem Leben und der ihn umgebenden Welt anstrebte. Eine halbe Seite mit Stichworten ist überschrieben mit: „Die Gegenwart und die Zukunft unseres Landes “.237 Auch hier beginnt Koni die Aufzählung mit seinen Studentenjahren und verfolgt die Entwicklungen in Russland nach. Dabei tauchen diverse Ereignisse auf, die aus seinem eigenen Erfahrungshorizont stammen, wie der Gerichtsprozess gegen Vera Zasulič. Am deutlichsten den Charakter einer klassischen Autobiografie haben die Stichworte, die Koni datiert von 1923 in ein Heft notierte. Diese heißen denn auch „Biografische Notizen“ und beginnen mit der „Kindheit 1844-1851“, gefolgt von den „Knabenjahren 1852-1858“ und der „Jugend 1858-1861“. Hier brechen die Halbsätze, die Koni zu den entsprechenden Jahren jeweils festgehalten hat, abrupt ab. ${ }^{238}$ Diese mehrfach angefangenen Versuche rekapitulieren beziehungsweise festigen Konis Interpretation der Geschichte Russlands zu seinen Lebzeiten. Während er den Grundzügen seiner politischen Analyse, wie bereits im Kapitel „Politische Erinnerung an das Zarenreich“ gesehen, im Wesentlichen treu blieb, sind nun aber verschärfte Töne in Bezug auf Rolle und Verhaltensweise der verschiedenen gesellschaftlichen Akteure zu hören. Dies zeigt sich besonders deutlich auch in weiteren ähnlichen Stichwortsammlungen von jeweils zwei bis drei Seiten, in denen er den Fokus auf die historische Rolle von „Volk“ und Intelligencija legte. Seine ambivalente Haltung zur Neugestaltung des Landes im Sinne der Bolschewiki steht dabei in engem Zusammenhang mit der Suche nach den Ursachen für diese Entwicklung. In „Traurige Erfahrung mit alltäglichen Beobachtungen“ oder „Analyse der seelischen Unruhe“ hielt er solche Überlegungen in den Jahren vor seinem Tod schriftlich fest. ${ }^{239}$

236 GARF F. 564, op. 1, d. 171 [Istorija rodini za moju žizni].

237 GARF F. 564, op. 1, d. 192 [Nastojaščee i buduščee rodiny]. Dieser Text ist undatiert.

238 IRLI F. 134, op. 4, d. 93, 1. 38-41 [Biografičeskie zametki].

239 GARF F. 564, op. 1, d. 174 [Gor'kij opyt žitejskich nabljudenij] bzw. GARF F. 564, op. 1, d. 38 [Analiz duševnoj trevogi]. Während der erste Text von 1926 datiert, fehlt beim zweiten eine Jahresangabe. 


\subsubsection{Verherrlichte Literaten der vorrevolutionären Welt}

Die Schriftstellerporträts, die Koni schon im Zarenreich veröffentlicht hatte, hatten auf vielfältige Art und Weise dazu beigetragen, eine „Aneignung“ der Literaten für die Sache der reformierten Justiz voranzutreiben. Moralische Komponenten, die Koni im schriftstellerischen Schaffen eines Tolstois, Dostojewskis oder Fürst Odoevskijs gegeben sah, wurden betont und als Element der vorbildhaften Führungshaltung in Bezug auf die Bevölkerung präsentiert, an der auch Koni und seine Kollegen teilhaben wollten. In der sowjetischen Umgebung spielte die Verbindung von Literatur und Justiz zwar immer noch eine Rolle, Koni schien mit dem exzessiven Werben für „seine“ Literaten nun aber viel allgemeiner und umfassender die Gesellschaft direkt erreichen zu wollen. Es war nicht mehr nur die Justiz, die mit Hilfe der Literaten in ihrer Relevanz bestärkt werden wollte. Die sowjetischen Menschen an sich sollten dank der Kenntnisse über Literatur und Literaten, die Koni als Träger einer vorbildhaften moralischen Wertehaltung charakterisierte, belehrt werden. Durch diesen Impetus erhielten seine Darstellungen der verschiedenen Autoren und ihrer Werke aus dem 19. Jahrhundert fast einen subversiven Charakter - blieben aber im Gegensatz zu manchen anderen seiner Porträts vielgestaltig publizierbar. So versuchte Koni beispielsweise seine im Zarenreich schon unzählige Male veröffentlichte biografische Studie über den Gefängnisarzt Doktor Friederich Joseph Haas in Sowjetrussland nochmals zu publizieren. An der Schnittstelle von Justiz und Philanthropie war „Doktor Gaaz“, der 1853 verstorbene Chefarzt der Gefängnishospitäler und Mitglied im Gefängnisschutzkomittee, von Koni seit den 189oer-Jahren als Idealfigur im vorreformierten Rechtswesen beschrieben worden. An seiner Person konnten rechtlichmoralische Werthaltungen wie der Kampf für menschliche Haftbedingungen und die humanitäre Behandlung von Verurteilten exemplifiziert werden. ${ }^{240}$ Doch diese

240 Vgl. die kurze Erwähnung im Rahmen von Konis Juristenporträts in Fußnote 34 in TEIL EINS. Vgl. zu Haas: Johannes BECKMANN: „Die ganze Bewegung war die Bewegung aufsteigender Elemente“. Neue Forschungen zur Familie und Jugend von Friedrich Joseph Haas (1780-1853). In: Dominik Groß/Axel Karenberg/Stephanie Kaiser/Wolfgang Antweiler (Hrsg.): Medizingeschichte in Schlaglichtern. Beiträge des „Rheinischen Kreises der Medizinhistoriker". Kassel 2011, S. 145-78. Koni publizierte erstmals 1897 in St. Petersburg das Büchlein „Fëdor Petrovič Gaaz“, das in den Folgejahren ergänzt und mehrfach neu aufgelegt wurde, vgl. z. B.: Anatolij F. Koni: Fëdor Petrovič Gaaz. Biografičeskij očerk. Sankt-Peterburg 1904 (3. erweiterte Auflage). Bereits 1899 erschien gar eine deutsche Übersetzung: Anatolij F. KonI: Doktor Friedrich Haas. Lebensskizze eines deutschen Philanthropen in Russland. Leipzig 1899. Weitere Veröffentlichungen von Koni zu Haas erschienen im „Boten Europas“ (VE I [1897], S. 8-62 und VE II [1897], S. 461-520 sowie VE XII [1903], S. 646-702) sowie 1906 in Konis Sammelband „Skizzen und Erinnerungen“. 
Veröffentlichung misslang. ${ }^{241}$ Im Gegensatz dazu fanden Konis Analysen und Erinnerungsschriften an die Literaten aufgrund des weder explizit politischen noch liberal-rechtlichen Inhaltes auch nach der Oktoberrevolution Platz.

Ohne noch speziell kommentiert werden zu müssen, sprachen die erneuten Veröffentlichungen von Konis Reden über Puschkins „moralische Gestalt“ oder Dostojewski als „Kriminalisten“ deutlich aus, welche Inhalte zu transportieren waren. Die „Liebe zur Wahrheit“ eines Alexander Puschkins oder die Empathiefähigkeit eines Fjodor Dostojewskis mit den Verbrechern und ihrem „inneren Kampf" dienten als Sinnbild für große Ideen von Gerechtigkeit und Menschlichkeit. Daran knüpfen auch die nach 1917 neu von Koni verfassten Texte an, die er explizit an das sowjetische Publikum richtete. Geschickt positionierte er mit entsprechenden Geleitworten seine autobiografischen Erinnerungen an die großen Schriftsteller. In den einführenden Worten zum Büchlein „Dostojewski und Nekrasov" schreibt Koni, dass das Lesen der Werke dieser Literaten oftmals nur ungenügend Auskunft gebe über die "moralischen und gesellschaftlichen Ideale“ dieser Menschen. Noch besser sei es deshalb, sich auf die Erinnerung von Zeitgenossen zu verlassen. Dass damit insbesondere Koni selber gemeint war, wird deutlich in der gleich nachfolgenden Aufzählung von zehn Schriftstellern, die er auf seinem „Lebensweg“ getroffen habe. ${ }^{242}$ Immer wieder machte Koni die Deutungshoheit, die er über die „moralischen Ideale“ der Literaten und ihre Werke zu haben behauptete, mit eingestreuten Verweisen auf diese persönliche Komponente deutlich. So schreibt Koni über Ostrovskij, dass er ihn noch „leibhaftig“ vor sich sehe. In der Schrift über Turgenevs Beerdigung betont er, dass er an den Trauerfeierlichkeiten selber zugegen gewesen sei. ${ }^{243}$ Durch den persönlichen Faktor in seiner Glaubwürdigkeit gestärkt, kritisierte Koni in der Folge jeweils zuerst das mangelhafte Interesse der Zeitgenossen für die Figuren aus ihrer Vergangenheit.

Dieses Werk brachte Koni 1902 eine Nomminierung für den Nobelpreis ein, vgl. www. nobelprize.org/nomination/archive/show.php?id=993, Zugriff vom 02. 08. 2018.

241 Vergeblich plante ein Verlag 1919 ein entsprechendes Büchlein, vgl. GARF F. 564, op. 1, d. 246, 1. 35. Auch ein angedachtes Projekt, zusätzlich nach dem Vorbild von Victor Hugo ein Buch über die Herausgabe des Buches zum Gefängnisarzt zu verfassen, konnte nicht realisiert werden. Beides wird in einem Nachruf auf Koni erwähnt, ohne dass näher auf die Gründe für die misslungene Publikation eingegangen würde, vgl. UtevskiJ: Poslednij ètap žiznennogo puti, S. 92-93.

242 Vgl. die einführenden Worte in: KonI: Nekrasov, Dostoevskij.

243 Anatolij F. Koni: A. N. Ostrovskij. Otryvočnye vospominanija. In: GA6, S. 251. Anatolij F. Koni: Pochorony Turgeneva. In: GA6, S. 389. Im Text zu Puschkin, der vor Konis Zeit lebte, spricht er stellvertretend von einem Erinnerungsmedaillon an den berühmten Schriftsteller, das er von einem anderen bekannten Mitglied der Zunft, Gončarov, erhalten habe, vgl. Anatolij F. KonI: [A. S. Puškin]. In: GA6, S. 73. 
$\mathrm{Zu}$ solcher Schelte hatte Koni schon in früheren Porträts beispielsweise über den Literaten Odoevskij gegriffen. ${ }^{244}$ Nun tat er dies exzessiv und mit besonderem Nachdruck. Gleich in mehreren Artikeln nutzt er den Ausspruch von Puschkin „Wir sind faul und nicht neugierig“" als Auftakt, um die schlechte Eigenschaft der Russen zu geißeln, für die „der gestrige Tag nicht existiert“. Deshalb sei der "morgige Tag so unklar“. ${ }^{245}$ Der „Nebel“, der den "gestrigen Tag“ umgebe, habe die ungenügende Beschäftigung mit diesen wichtigen Autoren zur Folge. ${ }^{246}$ In den Erinnerungen an St. Petersburg spricht Koni von der in Russland „typischen [...] Gleichgültigkeit“.247 „Undankbar“ ${ }^{\text {“248 }}$ sei man den Autoren gegenüber, was sich auch in der Art und Weise zeige, wie über deren Privatleben und ihre schlechten Eigenschaften geredet werde. Während sie „für den Dienst an der Gesellschaft“ gelitten hätten, seien sowohl Nekrasov als auch Dostojewski oder Turgenev mit schlechter Nachrede bestraft worden. ${ }^{249}$ Wie Koni sich - als Kontrastprogramm zu diesen Verunglimpfungen - die Beziehung zu den Schriftstellern des 19. Jahrhunderts wünschen würde, machte er unmissverständlich klar. „Ernsthafte [...] Neugier" sei angebracht, und diese zeige sich in der Auseinandersetzung mit den "Idealen“ und dem "gesellschaftlichen Einfluss" der einzelnen Schriftsteller. ${ }^{250}$ Welche Ideale ein Schriftsteller genau haben sollte - zumindest damit Koni über ihn als moralisches Vorbild berichtete -, machte er 1923 im Rahmen eines Vortrages einmal mehr deutlich. Ein Literat solle sich zum Ziel setzen, einen positiven Einfluss auf den Leser auszuüben. Deshalb sollte er entweder über Gutes berichten oder über Schlechtes mit entsprechendem Vorbehalt schreiben, da der Autor ansonsten kulturellen Rückschritt befördere. Mit dem Wort - so zitiert er Gogol - solle man ehrlich umgehen. ${ }^{251}$ In Bezug auf das Theater fügte er dem bei anderer Gelegenheit noch unmissverständlicher hinzu:

Sie [die Aufgabe des Theaters, CC] ist in erster Linie erzieherischer Natur [...]. Eine echte erzieherische Aufgabe - das echte Leben darstellen, die Realität darstellen, ihr

244 Vgl. z. B. Koni: Knjaz’ Vladimir Fëdorovič Odoevskij. In: ders. (Hrsg.): Očerki i vospominanija, S. 47-48.

245 Koni: [A. S. Puškin]. In: GA6, S. 73 und Koni: Pochorony Turgeneva. In: GA6, S. 400-02.

246 Koni: Pochorony Turgeneva. In: GA6, S. 400-02. Konkret nennt Koni die Tatsache, dass die beste Biografie über Gončarov auf Französisch und nicht auf Russisch geschrieben worden sei und dass für Turgenev nicht einmal ein Denkmal gebaut worden sei.

247 Anatolij F. Koni: Peterburg. Vospominanija starožila. In: GA7, S. 58.

248 Koni: [A. S. Puškin]. In: GA6, S. 73.

249 Koni: Pochorony Turgeneva. In: GA6, S. 400-02 sowie Anatolij F. Koni: Motivy i priemy tvorčestva Nekrasova. Beglye zamteki. In: GA6, S. 275.

250 Koni: Pochorony Turgeneva. In: GA6, S. 400-02.

251 IRLI F. 134, op. 1, d. 232, 1. 8-8ob. 
Licht und ihre Schatten, wie in einem Gemälde von Rembrandt. [...] Das Theater soll die Zuschauer zu sich emporheben und nicht sich hinabbegeben zu den groben Vorlieben der Masse [....$^{252}$

Um dieser „erzieherischen Natur“ und den „moralischen und gesellschaftlichen Idealen“ der Schauspieler und Schriftsteller volle Entfaltungsmöglichkeit zu verschaffen, betonte Koni denn beispielsweise in seiner Analyse von Nekrasovs literarischen Motiven, dass er Autor und Werk nur nach den „besten Seiten“ beurteilen wolle. ${ }^{253}$ Nichts brachte ihn so sehr in Rage wie öffentliche Diskussionen über persönliche Unzulänglichkeiten der verherrlichten Literaten - so geschehen beispielsweise 1924 zum belasteten Verhältnis von Gončarov und Turgenev. ${ }^{254}$ Vielmehr bemühte sich Koni, anhand dieser Schriftsteller jene „besten Seiten“ und moralischen Grundhaltungen, die ihm nach wie vor relevant erschienen, im nachrevolutionären Russland präsent zu machen. Unterschiedlich ausgeprägt enthalten die Literatenporträts aus den frühen 1920er-Jahren eine Fülle an mehr oder weniger beiläufigen Bezügen zum Russland des 19. Jahrhunderts. Immer wieder werden die Reformen von 1864 und die persönlichen Qualitäten ihrer Akteure beschworen. So schreibt Koni im Zusammenhang mit der „Beerdigung Turgenevs“ von den juristischen Gesellschaften, die 1883 um den Tod des Autors trauerten, und erwähnt die „humanistischen Persönlichkeiten“, die sich im

252 GARF F. 564, op. 1, d. 213, l. 16. Dieser ausführliche Erinnerungstext Konis ist übertitelt mit „Theatererinnerungen“ [Teatral'nye vospominanija]. Das Manuskript trägt kein Datum und es ist unklar, ob und wann es publiziert wurde. Weiter führt Koni aus: „[...] wie dies in Westeuropa geschieht, und auch bei uns, in Zusammenhang mit den Erfolgen der Zivilisation. Ich glaube der Hauptgrund für diese bedauerliche Entwicklung liegt darin, dass die Begriffe ,Kultur' und ,Zivilisation' vermischt werden. Oft sagt man: ,Jetzt sind solche Errungenschaften erreicht, dass alles neu sein muss, keinerlei Traditionen, keinerlei Aufgaben, keinerlei Ratschläge sollen mehr existieren. Alles nach vorne, zur Eroberung der Natur.' Dies bezieht sich auf die Zivilisation [...]. Auf die Kultur bezogen stimmt das nicht. Wenn die heutige Zivilisation mit schnellem Schritt vorangeht, so bleibt die Kultur stehen oder bewegt sich rückwärts." Koni machte mit solchen Aussagen einmal mehr deutlich, dass die Entwicklungen, die auch in Kunst und Kultur von neuen Strömungen geprägt waren, ihm mit ihrer radikalen Abwertung des eben noch Gültigen Mühe bereiteten. Vgl. dazu im Zusammenhang mit den politischen Radikalisierungen nach der Jahrhundertwende auch TEIL ZWEI, z. B. S. 199.

253 Koni: Motivy i priemy tvorčestva Nekrasova. In: GA6, S. 275.

2541924 hatte die Leningrader Bibliothek ein Manuskript von Gončarov veröffentlicht, in dem er ungerechtfertigte Anschuldigungen gegen den Schriftstellerkollegen Turgenev erhob. Koni hielt diese Veröffentlichung für völlig unverantwortlich, vgl. die Darstellung in: ČukovsкiJ: Anatolij Fëdorovič Koni. In: GA8, S. 12-13. Es fällt auf, wie Koni mit dieser Argumentation von den „besten Seiten“ an seinen Erinnerungsskizzen über Juristen anknüpfte. 
Rahmen der Gerichtsreform hervorgetan hätten. ${ }^{255}$ In „Nochmals über Dostojewski“ hält er fest, dass er sich eben „nochmals an Dostojewski erinnern“ wolle, und streicht dabei dessen Beziehung zu seinen Mitmenschen hervor, indem er ihn sogleich als Vertreter von Kants „kategorischem Imperativ“ charakterisierte. ${ }^{256}$ Neben Dostojewski sei zudem auch Tolstoi im psychologischen Bereich von höchstem Interesse. ${ }^{257}$ In Bezug auf Puschkin schreibt Koni von den Geschworenengerichten, für welche dieser sich eingesetzt habe, und auch das Porträt der Stadt St. Petersburg kommt nicht ohne einige lobende Sätze zur Bauernbefreiung und den neuen Gerichten aus. ${ }^{258}$

Dabei unterließ Koni es in diesen Texten fast vollständig, Bezug zur Tagesaktualität und dem veränderten sowjetischen Russland zu nehmen. Einzig in den Erinnerungen an die Stadt St. Petersburg spielt naheliegenderweise der Vergleich von damals und heute eine wichtige Rolle. So erwähnt Koni zu Beginn, dass ihm als „Alteingesessenem“ die Stadt noch in „originaler Gestalt“ bekannt sei. ${ }^{259}$ Der Vergleich funktioniert dann aber oftmals zwischen dem St. Petersburg der 1850/6oer-Jahre und der Stadt in den ersten beiden Jahrzehnten nach der Jahrhundertwende. Die vor dem Hintergrund des Ersten Weltkrieges erfolgte kurzfristige Umbenennung von St. Petersburg in das weniger deutsch klingende „Petrograd“ wird von Koni im Text denn auch missbilligend erwähnt. ${ }^{260}$ Eine spezifische Zäsur durch die Machtübernahme der Bolschewiki findet in der Schrift hingegen kaum einen Niederschlag. Das einzige, was als Replik auf die aktuelle Politik gelesen werden könnte, ist die Erwähnung von Zensur, der die Schriftsteller des "alten“ St. Petersburgs zu Zarenzeiten ausgesetzt gewesen waren. ${ }^{261}$ An sich nicht weiter erstaunlich, ist es doch einigermaßen verblüffend, dass Koni nicht nur in seiner Erinnerung an die Stadt und ihre Bewohner, sondern auch in weiteren der neu verfassten Artikel den administrativen Einschränkungen des freien Schreibens einiges an Platz einräumte. So beschreibt er, mit welchen Hindernissen Puschkin in der ersten Hälfte des 19. Jahrhunderts konfrontiert gewesen war. ${ }^{262}$ Auch Ostrovskijs Probleme mit der Zensur und die Nervosität der zarischen Behörden bei der Beerdigung von Turgenev werden zum Thema. ${ }^{263}$ Zensur und Pressefreiheit

\footnotetext{
255 KonI: Pochorony Turgeneva. In: GA6, S. 391-92.

256 Anatolij F. Koni: Ešče o Dostoevskom. In: GA6, S. 448.

257 Ebd., S. 452-53.

258 Koni: [A. S. Puškin]. In: GA6, S. 74 und Koni: Peterburg. In: GA7, S. 35 und 56-57.

259 Koni: Peterburg. In: GA7, S. 23.

260 Ebd.

261 Einzig im ersten Satz der „Erinnerungen eines Alteingesessenen“ erwähnt Koni zudem das heutige St. Petersburg, das leer und leblos sei, vgl. Koni: Peterburg. In: GA7, S. 23.

262 Koni: [A. S. Puškin]. In: GA6, S. 73.

263 Koni: A. N. Ostrovskij. In: GA6, S. 255 und Koni: Pochorony Turgeneva. In: GA6, S. 394.
} 
waren für Koni schon im Zuge der politischen und rechtlichen Veränderungen vor und während der Revolution von 1905 ein wichtiges Thema gewesen. ${ }^{264}$ Trotzdem kommt unweigerlich der Gedanke auf, dass er angesichts der sich nach dem Oktober 1917 stetig verschärfenden Zensurvorgaben den Verweis auf das identische Vorgehen unter dem nun gemeinhin verurteilten autokratischen Zarentum nicht ohne Hintergedanken aufrief. Nicht nur war er selber schon auf Hindernisse durch die Zensurbehörden der Bolschewiki gestoßen, in seinen autobiografischhistorischen Überlegungen zum Lebensende taucht auch explizit die Unfreiheit der Presse als negativer Aspekt der neuen Herrschaft auf. ${ }^{265}$

Der indirekte und zurückhaltende Bezug auf die Lebenswirklichkeit der 1920er-Jahre wird von Koni nur in einem durchaus programmatischen Falle regelmäßig aufgebrochen. Viele der kurzen Artikel und Erinnerungstexte aus dieser Zeit enthalten ein explizites Plädoyer für die Beschäftigung breiter Bevölkerungskreise mit den entsprechenden Literaten und deren moralischer Vorbildwirkung. Im Falle von Ostrovskij betont er, dass zukünftige Wissenschaftler dessen Werke nutzen könnten, um „wertvolles [...] Material“ zum früheren Alltagsleben zu finden. ${ }^{266}$ Über Puschkin schreibt er zu dessen 84. Todestag gleich zu Beginn, dass das Gedenken an ihn im heutigen Russland zu einem "moralischen Gesetz“ werden solle. ${ }^{267}$ Er beendet die Skizze, indem er der Hoffnung Ausdruck verleiht, dass der 29. Januar in Russland für alle Zeiten ein Feiertag sein möge. ${ }^{268}$ Konkret nennt er im Artikel das neu gegründete „Haus der Literaten“, das Puschkin fördern wolle. ${ }^{269}$ In „Nochmals über Dostojewski“ beginnt er gar mit einem herzhaften Ausspruch für die Gründung einer Dostojewski-Gesellschaft, die sich dem Werk des berühmten Mannes widmen solle. ${ }^{270}$ Und „Die Beerdigung Turgenevs“ ist der „Turgenev-Gesellschaft“ gewidmet, die mit ihren Arbeiten in den Jahren nach dem Bürgerkrieg „das Verständnis und das Studium des Werks Turgenevs“ vertiefen und erweitern wollte. ${ }^{271}$

Anstelle der bemängelten Undankbarkeit sollten die Bewohner des sowjetischen Russlands nun also die Literaten der vorrevolutionären Welt in Literaturzirkeln erforschen und zu ihren Ehren Festlichkeiten organisieren. Solange Russland Puschkins Jubiläum feiert - könnte man überspitzt formulieren -, solange sah

264 Vgl. oben, S. 199 zur Kommission für Pressefragen und Konis Einsitz darin.

265 Darauf wird im Kapitel „Volk“ und Intelligencija: Notizen der Enttäuschung eingegangen.

266 Koni: A. N. Ostrovskij. In: GA6, S. 256.

267 Koni: [A. S. Puškin]. In: GA6, S. 72.

268 Ebd., S. 75.

269 Ebd., S. 74.

270 Koni: Ešče o Dostoevskom. In: GA6, S. 446.

271 Koni: Pochorony Turgeneva. In: GA6, S. 404-05. 
Koni auch "moralische und gesellschaftliche Ideale" und „humanistische"Wertehaltungen, die seiner Ansicht nach vor vielen Jahrzehnten zu Bewegungen wie der Bauernbefreiung oder der Gerichtsreform geführt hatten, weitertransportiert. In den Dienst dieser Zielsetzung stellte Koni nun in der frühen Sowjetunion einen großen Teil seiner öffentlichen Erinnerungspraktiken. Dabei sprach er sich nicht nur im Rahmen seiner autobiografischen Schriften für das Puschkinjubiläum oder eine Dostojewski-Gesellschaft aus, sondern entfaltete auch selber umfangreiche Aktivitäten in einem Netzwerk aus Wissenschaftlern und Literaten.

\section{Künstlerische und wissenschaftliche Vereinigungen in der frühen Sowjetunion}

Nicht umsonst tauchen in Konis Texten Plädoyers für Schriftstellerjubiläen und wissenschaftliche Gesellschaften zum Studium der literarischen Werke der alten Meister auf. Koni war selber Gründer und Mitglied von verschiedensten $\mathrm{Zu}$ sammenschlüssen von Literaten, Künstlern und Wissenschaftlern im nachrevolutionären Petrograd und Leningrad. Die entsprechenden Versammlungen und (Jubiläums-)Aktivitäten boten oftmals die Bühne für mündliche Auftritte mit seinen Erinnerungen und Analysen, die dann später verschriftlicht wurden. Insgesamt trat Koni in dem Jahrzehnt nach der Oktoberrevolution über 9oo Mal mit Vorträgen vor einer Zuhörerschar auf. ${ }^{272}$ In Form unzähliger Auflistungen, Anfragen und Vereinbarungen finden sich in seinem Nachlass die detaillierten Themen für diese Auftritte. Hin und wieder tauchen Referate über politische oder juristische Persönlichkeiten aus Konis Bekanntenkreis oder Erinnerungen an seine Vergangenheit im Gerichtswesen auf. ${ }^{273}$ Aber am präsentesten sind Themen wie „Fürst Odoevskij“, „Turgenev“, „Nekrasov“, „Gončarov“, „Tolstoi“ oder „Das Lebensdrama von Puschkin“. ${ }^{274}$ Die moralischen Botschaften, die Koni schon in seinen publizierten Artikeln zu diesen Schriftstellern platzierte, wurden so im mündlichen Format wieder und wieder reproduziert. Ein genauerer Blick auf diese Vereinigungen und Konis Rolle darin zeigt auf, wie er sich nach der Oktoberre-

272 Die konkrete Zahl hielt Koni selber fest, auf diese Form der Selbstdarstellung wird noch eingegangen.

273 Vgl. z. B. GARF F. 564, op. 1, d. 758, 1. 11 Gedenksitzung für D. Rovinskij im November 1925, zu der eine Rede von Koni angekündigt wird oder l. 12: Werbung für einen Vortrag von Koni über Graf Witte sowie SAšonko: A. F. Koni v Peterburge - Petrograde - Leningrade, S. 267, der Vorträge zu „Doktor Gaaz“ erwähnt.

274 Vgl. Konis eigene Aufzählung: Anatolij F. Konı: [Avtobiografčeskij očerk]. In: VL 9 (1921), S. 15-16. Auf diesen Artikel wird nachfolgend noch eingegangen. Vgl. auch GARF F. 564, op. 1, d. 249 und d. 758 , z. B. l. 13 und 16. 
volution erfolgreich Nischen schuf, und dabei auch in seiner Selbstpositionierung der erzieherische Aspekt des Dozierens immer mehr in den Vordergrund rückte.

Schon seit dem Ende des 19. Jahrhunderts war Koni Ehrenakademiker der „Abteilung für Belletristik“ im Bereich für russische Sprache und Literatur der Akademie der Wissenschaften. Als mit der Machtübernahme der Bolschewiki Konis Tätigkeit in Senat und Staatsrat ein abruptes Ende nahm, wurde die Akademie zur wichtigsten institutionellen Bindung, die Koni noch besaß. Sie war es, die sich dafür einsetzte, dass Koni als „Akademik" eine staatliche Pension zugesprochen bekam. ${ }^{275}$ Sie war es, die ihn in großem Stil feierte und ehrte. So beging die Akademie 1924 Konis 8o. Geburtstag mit einer Festversammlung. Der bekannte Historiker Sergej Fëdorovič Platonov (1860-1933) eröffnete als Vorsitzender des Jubiläumskomitees den Reigen der Lobpreisungen für den Gefeierten. ${ }^{276}$ Die Festgemeinschaft veröffentlichte wenig später Grußadressen, biografische Darstellungen sowie wissenschaftliche Artikel in einem Sammelband zu Konis Ehren. ${ }^{277}$ Ein fast identisches Autorenkollektiv taucht in einer Broschüre auf, die ein halbes Jahr nach Konis Tod mit einer Auflage von 600 Exemplaren für Vorträge im Rahmen einer „Feierlichen Sitzung“ zum Gedenken an das „Ehrenmitglied“ A. F. Koni warb. Erneut sprachen bedeutende Wissenschaftler wie neben Platonov auch der langjährige ständige Sekretär der Akademie, der Orientalist Sergej Fëdorovič Ol'denburg (1863-1934) zu „Persönlichkeit“ und „Einigen Charakteristika der Arbeit“ Konis. ${ }^{278}$ Auch diese Reden wurden wenig später in einem Sammelband veröffentlicht. ${ }^{279}$ Die Intensität, mit der sich die Akademie Koni widmete, wurde von ihm voll und ganz erwidert. So dozierte er zu wichtigen Gedenktagen, wie beispielsweise dem 125. Geburtstag von Puschkin 1924, vor der Akademie über die entsprechenden Literaten. ${ }^{280}$ Gewisse Autoren lagen ihm

275 Gernet: Anatolij Fëdorovič Koni na ischode ego „žiznennogo puti“, S. II-III zitiert in seinem Nachruf auf Koni einen Brief vom Sommer 1926, wo Koni betont, dass sich die Akademie ohne sein Zutun für eine Pension eingesetzt habe. Vgl. zur Pension auch oben, S. 274.

276 SAšonko: A. F. Koni v Peterburge - Petrograde - Leningrade, S. 290.

277 Sergej F. Platonov/Sergej F. Ol’denburg u.a. (Hrsg.): Anatolij Fëdorovič Koni 1844-1924. Jubilejnyj sbornik. Leningrad 1925.

278 GARF F. 564, op. 1, d. 4328, 1. 1-2. Ol'denburg war die zentrale Persönlichkeit der Akademie in den ersten Jahrzehnten des 20. Jahrhunderts, da er von 1904 bis 1929 als permanenter Sekretär amtierte. Er war seit 1895 Professor für Indische Sprachen und Literatur an der Universität St. Petersburg, vgl. Loren R. Graham: The Soviet Academy of Sciences and the Communist Party, 1927-1932. Princeton 1967, S. 29.

279 Trudy Puškinskogo Doma Akademii Nauk SSSR (Hrsg.): Pamjati Anatolija Fëdoroviča Koni. Leningrad u. a. 1929.

28 o GARF F. 564, op. 1, d. 758, 1. 16. 
dabei besonders am Herzen. In seiner biografischen Skizze zu Konis Tod erinnert sich der Turgenev-Forscher und Übersetzer Lev Samojlovič Utevskij (1897-1960), dass er 1919 dem viele Jahre älteren Ehrenakademiker Koni die Gründung einer „Turgenev-Gesellschaft" vorgeschlagen hatte. „Wer anderes als Koni hätte ihr vorsitzen können?" - fragt er in einer Gedenkschrift rhetorisch. ${ }^{281}$ Utevskij führt aus, wie begeistert sich Koni für die Gesellschaft engagiert habe und wie viele Vorträge er selber über Turgenev vor dem Kreis interessierter Zuhörer gehalten habe. Die Jahre bis 1921, als die Gesellschaft „zu kränkeln begann“, bezeichnet Utevskij als Konis „Turgenev-Gesellschafts-Epoche“ “282 Tatsächlich sprach Koni in dieser Zeit an zehn von 15 Versammlungen selber über Turgenev und seine Kritiker, über Turgenev und die russische Sprache, über Turgenev und die Liebe in seinen Werken, um eine Auswahl der Vortragstitel zu nennen. ${ }^{283}$ Besonders bemerkenswert ist die Publikation des Sammelbandes mit Artikeln, Erinnerungen und Briefen von und über Turgenev, die unter Anleitung Konis zusammengestellt worden waren und in dem auch sein eigener Erinnerungstext über die „Beerdigung Turgenevs“ erschien. ${ }^{284}$ Im Vorwort erwähnt die Gesellschaft die schwierigen Bedingungen für den Druck von Büchern, spricht aber trotzdem davon, im Verlauf der nächsten Zeit ganze acht Bände mit Briefen des berühmten Schriftstellers herausgeben zu wollen. ${ }^{285}$ Solche Editionstätigkeiten brachte die "Turgenev-Gesellschaft“ in engen Kontakt mit einer weiteren Einrichtung im Umfeld der Akademie - dem „Puschkinhaus“. Das heutige „Institut für russische Literatur - Puschkinhaus“ gehört der Abteilung für Literatur und Sprache der Akademie der Wissenschaften an und beinhaltet unter anderem eine Handschriftenabteilung, in der sich auch eine Sammlung von persönlichen Briefen Turgenevs befindet. ${ }^{286}$ Parallel zu seinem Engagement in der „Turgenev-Gesellschaft" und insbesondere nach deren Auflösung wurde das „Puschkinhaus“ zu einer wichtigen Wirkungsstätte Konis. Schon bei dessen Gründung 1905 im Nachgang der Jubiläumsfeierlichkeiten der Akademie für Alexander Puschkins 10o. Geburtstag war Koni involviert gewesen. Das „Puschkinhaus“ war als eine Art ständiges Lager für Handschriften, Bücher und Erinnerungen an den großen russischen Schriftsteller und weitere ihm nach-

281 Utevskij: Poslednij ètap žiznennogo puti, S. 80-81.

282 Ebd., S. 8o-83. Vgl. zur Schließung der Gesellschaft gleich nachfolgend.

283 SAšonko: A. F. Koni v Peterburge - Petrograde - Leningrade, S. 286 mit einer Aufzählung der Titel. Vgl. für die Ankündigung des Vortrags zur aktuellen russischen Sprache, vgl. GARF F. 564, op. 1, d. 758, 1. 13 .

284 Dies war der einzige von Konis Vorträgen über Turgenev, der publiziert wurde, vgl. UtevskiJ: Poslednij ètap žiznennogo puti, S. 83.

285 Anatolij F. Koni (Hrsg.): Turgenevskij sbornik. Petrograd 1921, S. 11-12.

286 KASACK: Die Akademie der Wissenschaften der UdSSR, S. 108-09 und www.pushkinskijdom.ru/, Zugriff vom 08.11.16. 
folgende Literaten gedacht. ${ }^{287}$ Während Koni also schon vor 1917 an den Aktivitäten des „Puschkinhauses“ teilnahm, krönte er dieses Engagement in den Jahren nach der Oktoberrevolution mit der schrittweisen Übergabe seines eigenen Nachlasses an ebendiese Institution. Mit Stolz streicht dies der Puschkinspezialist und Mitbegründer des Instituts Boris L’vovič Modzalevskij (1874-1928) in seiner Gedenkrede zum Tod Konis hervor. ${ }^{288}$ Inwiefern die Schaffung dieses Nachlassarchivs einer autobiografischen Praxis gleichkam, und was für Implikationen diese Vorgehensweise hatte, wird in den nachfolgenden Ausführungen noch thematisiert.

Das Netzwerk, das Koni mit der Akademie der Wissenschaften und den damit verbundenen literarischen Organisationen und Gesellschaften besaß, verband Zarenreich und Sowjetunion nicht nur auf institutioneller Ebene. Zahlreiche der beteiligten Persönlichkeiten wie Ol'denburg, Modzalevskij oder Platonov waren sowohl vor als auch nach der Oktoberrevolution gleichsam Teil der Akademie wie auch Teil von Konis Bekanntenkreis. Modzalevskij, der schon zu Beginn des 20. Jahrhunderts für die Erörterung literaturgeschichtlicher Fragen in persönlichen Austausch mit Koni getreten war, führte in der Sowjetunion zusammen mit Utevskij den Verlag „Atenej“. Die beiden Literaturwissenschaftler publizierten in dem 1921 gegründeten Verlagshaus insbesondere Werke der „Puschkinovedenie“der Puschkinforschung. Doch Koni konnte darin auch seine „Erinnerungen eines Alteingesessenen“" an die Stadt St. Petersburg veröffentlichen. Und 1925 erschien bei „Atenej“ der Jubiläumsband zu Ehren von Konis 80. Geburtstag. ${ }^{289}$ Die Be-

287 Muratov: A. F. Koni i Puškinskij Dom, S. 37-38, Koni gehörte der Kommission aus Mitgliedern der Akademie an, die die Feierlichkeiten zum 100. Geburtstag Puschkins 1899 organisierten. In diesem Zusammenhang wurde auch eine Ausstellung veranstaltet, zu der Koni diverse Porträtbilder wichtiger Schriftsteller beisteuerte, die im Nachlass seines Vaters gelagert hatten. Diese Ausstellung war der Ausgangspunkt für die Errichtung der stetigen Sammlung - dem „Puschkinhaus“. Vgl. für Konis Rede zur Eröffnung des Literaturarchivs: GARF F. 564, op. 1, d. 151.

288 Boris L. Modzalevskij: Krug literaturnych otnošenij A. F. Koni. In: Trudy Puškinskogo Doma Akademii Nauk SSSR (Hrsg.): Pamjati Anatolija Fëdoroviča Koni. Leningrad u. a. 1929, S. 54. Modzalevskij konnte seine Gedenkrede nicht mehr persönlich halten, da er schon schwer krank war und kurz nach der Feier für Koni verstarb, vgl. ebd., S. 30-31. In der Gedenkrede verweist er auch auf die Gratulationsadresse des „Puschkinhauses“ zu Konis 8o. Geburtstag 1924, die ebenfalls mit Stolz Konis Nachlass erwähnt, vgl. für die veröffentlichte Adresse Platonov/Ol'denburg (Hrsg.): Anatolij Fëdorovič Koni 1844-1924, S. 18.

289 Informationen zum Verlag von: https://fantlab.ru/publisher3542, Zugriff vom o8. 11. 2016; Modzalevskij war zwischen 1922 und 1924 Direktor des „Puschkinhauses“, bevor er wegen einer haltlosen Anschuldigung verhaftet und kurze Zeit eingesperrt wurde, vgl. dazu Zarodovaja: Perepiska B. L. Modzalevskogo s A. F. Koni, S. 362 und Fußnote auf S. 373-74. Modzalevskij schreibt in seiner Gedenkrede für Koni, dass er nach der Jahr- 
ständigkeit solcher Beziehungen aus vorrevolutionärer Zeit erleichterte Koni in der frühen Sowjetunion ganz unmittelbar den Zugang zu Plattformen für mündliche wie schriftliche öffentliche Aktionen. Zu den alten Bekanntschaften gesellten sich aber auch neue. Tatsächlich entwickelte sich in den frühen 1920er-Jahren in der Sowjetunion ein ,ausgeprägter Pluralismus des literarischen Lebens", in dem eine Vielzahl an verschiedensten literarischen und wissenschaftlichen Gesellschaften, Verlagen oder Zeitschriften aufblühten. ${ }^{290}$ Nach den Jahren von Bürgerkrieg und Papiermangel, in denen „praktisch kein einziger Roman“ gedruckt werden konnte, lebten Verlagswesen und Buchhandel ab 1921/22 langsam wieder auf. ${ }^{291}$ Das faktische Monopol des Staatsverlages Gosizdat wurde durch die Stärkung privater Verlagsunternehmen konkurrenziert, die Druck- und Verkaufsmöglichkeiten mehrten sich. ${ }^{292}$ Die typischen Literaturzeitschriften, in denen belletristische Werke erstveröffentlicht wurden, formierten sich erneut. ${ }^{293}$ Dies änderte aber nichts daran, dass die politische Überwachung und Zensur gleichzeitig immer effizienter organisiert wurde. ${ }^{294}$ Zahlreiche literarische und wissenschaftliche Initiativen wurden in ihrer Arbeit behindert oder verboten. So beispielweise auch Konis „Turgenev-Gesellschaft“ oder der Verlag Atenej..$^{295}$ Dass in den frühen 1920er-Jahren trotzdem ein verhältnismäßig liberales und weltoffenes Klima herrschte, stand in direktem Zusammenhang mit der Devise der „Neuen Ökonomischen Politik“, die den Umgang der Sowjetregierung mit vorrevolutionären Experten, Wissenschaftlern aber eben auch Literaten in dieser Zeit prägte. ${ }^{296}$

hundertwende an den Juristen gelangt sei, um von ihm Informationen über einen Schriftsteller zu erhalten, der Zeitgenosse Puschkins gewesen war und ihn, Modzalevskij, stark interessiert habe, vgl. Modzalevskij: Krug literaturnych otnošenij A. F. Koni, S. 36-37.

290 SтÄDTKE (Hrsg.): Russische Literaturgeschichte, S. 296.

291 Dmitrij S. Mirskij: Geschichte der russischen Literatur. München 1964, S. 477-78.

292 Struve: Geschichte der Sowjetliteratur, S. 48.

293 SтÄDtKe (Hrsg.): Russische Literaturgeschichte, S. 296.

294 Vgl. zur Zensur ebd., S. 291 und Ermolaev: Censorship in Soviet Literature, 1917-1991, S. 1-3 bzw. oben, S. 260.

295 SAšonko: A. F. Koni v Peterburge - Petrograde - Leningrade, S. 286-87 bringt das Ende der „Turgenev-Gesellschaft" in direkten Zusammenhang mit dem Ausnahmezustand nach dem Kronstädter Matrosenaufstand im März 1921. In diesem Monat kam es zu einer Revolte der Matrosen, die in der Seefestung Kronstadt vor Petrograd stationiert waren. Zusammen mit Demonstranten in der Hauptstadt stellten sie ökonomische Forderungen nach freiem Handel zwischen Stadt und Land. Die Revolte wurde von den Bolschewiki blutig niedergeschlagen, vgl. Haumann: Geschichte Russlands, S. 365. Tatsächlich schrieb Koni selber in dieser Zeit an Utevskij, ob man nun für die Sitzungen der Gesellschaft schon eine Bewilligung des Kriegssowjets benötige, vgl. UtevskiJ: Poslednij ètap žiznennogo puti, S. 82.

296 Vgl. zur „Neuen Ökonomischen Politik“ auch oben, S. 248. 
Den „Pluralismus“ von Gruppierungen und Organisationen verschiedenster künstlerischer und ideologischer Überzeugungen machte sich Koni zunutze, um sein Engagement auf eine Vielzahl an Institutionen zu verteilen. Aktiv wurde er beispielsweise im „Haus der Literaten“ [Dom Literatorov]. Dieses bot den von Hunger, Kälte und fehlenden Verdienstmöglichkeiten geplagten Schriftstellern und Journalisten Petrograds in den Jahren 1919-1922 einen Zufluchtsort mit warmen Mahlzeiten. ${ }^{297}$ Durch das Verbot der freien Presse und die Einschränkung der Publikationsmöglichkeiten befanden sich gerade die Schreibenden der oftmals liberal eingestellten „alten Intelligenz" in den Jahren des Bürgerkrieges in einer prekären Situation. ${ }^{298}$ Initiiert von der „Kasse zur gegenseitigen Unterstützung von Literaten und Wissenschaftlern“ [Obščestvo Vzaimopomošči Literatorov i Učenych] wurde das „Haus der Literaten“ zu einem wichtigen Treffpunkt für Hunderte von diesen Literaturschaffenden. Darunter befanden sich bekannte Künstler wie Kornej Čukovskij oder die Dichter des Symbolismus und Akmeismus, Aleksandr Aleksandrovič Blok (1880-1921) und Anna Andreevna Achmatova (1889-1966). ${ }^{299}$ Koni selber war Teil des Führungskomitees und gehörte mit seinen Gerichts- und Literaturerinnerungen zu den beliebten Gästen an den Literaturabenden, Diskussionen und Vorlesungen, die das Haus veranstaltete. ${ }^{300}$ Der Verwalter der Hilflosenkasse, der langjährige Zeitungskorrespondent und Publizist Abram Evgen’evič Kaufman (1855-1921), veröffentlichte im Januar/Februar 1919 eine erste Nummer der Zeitschrift „Bote der Literatur“ [Vestnik Literatury], in der später unter der Rubrik „Chronik“ [Letopis'] auch einzelne Vorlesungen aus dem „Haus der Literaten“ publiziert wurden. ${ }^{301}$ Der „Bote der Literatur“ [Vestnik

297 SCHLÖGEL: Petersburg, S. 593-95.

298 Struve: Geschichte der Sowjetliteratur, S. 48-49.

299 SChlögel: Petersburg, S. 593-607, hier insb. S. 594, 600-01 und 604.

300 Ebd., S. 6oo. Der Schriftsteller und Journalist Aleksandr Valentionvič Amfiteatrov (1862-1938) erinnert sich in seinen Memoiren, die er nach dem Schritt in die Emigration veröffentlichte, an die zahlreichen Sitzungen des „Hauses der Literaten“, an denen er zusammen mit Koni und weiteren Persönlichkeiten aus der Führungsequipe der Organisation teilgenommen hatte, vgl. Aleksandr V. Amfiteatrov: Sobranie sočinenij v 10 tomach, Bd. 10:2. Memuary, hrsg. u. mit einer Einleitung versehen v. Timofej F. Prokopov. Moskva 2003, S. 594. Vgl. zu Amfiteatrov ebd., Bd. 1, S. 5-14 (Einleitung von Timofej Prokopov). In Konis Nachlass finden sich Plakate und Einladungen. Vgl. beispielsweise ein Werbeposter, auf dem unter anderem auch ein Vortrag Konis über Odoevskij angekündigt wird, GARF F. 564, op. 1, d. 781, Dokument 1.

301 Aleksandr Ju. GalušKın: Predislovie. In: ders. u. a. (Hrsg.): Žurnaly „Vestnik literatury“ (1919-1922), „Letopis’ Doma Literatorov“ (1921-1922), „Literaturnye zapiski“ (1922). Annotirovannyj ukazatel'. Moskva 1996, S. 5 und 8. Seit der Ausgabe Nummer 3 des Jahres 1921 erschien die Rubrik „Letopis’ Doma Literatorov“ mit den „interessantesten Werken“, die an den Literaturabenden des „Hauses“ vorgelesen wurden. Ab November 1921 erschien die 
Literatury] war im ersten Jahr seines Bestehens beinahe das einzige größere kritisch-bibliografische Journal, das sich dem aktuellen Literaturbetrieb widmete und dabei die politischen Entwicklungen lediglich äußerst zurückhaltend, „wie durch ein Fernglas" kommentierte. ${ }^{302}$ Der Kreis der Autoren blieb über die Jahre fast identisch und war dadurch gekennzeichnet, dass neben Koni auch Kaufman und Persönlichkeiten wie der Schriftsteller und Journalist Vasilij Ivanovič Nemirovič-Dančenko (1845-1936) dazu zählten, die ihre Laufbahn lange vor der Revolution begonnen hatten und meist liberal-demokratischer Orientierung waren oder mit den Narodniki sympathisierten. ${ }^{303}$ Das Interesse an der Zeitschrift war sehr groß, auch wenn gezwungenermaßen eine starke Tendenz zur neutralbeschreibenden ,énciklopedičnost" "vorherrschte. ${ }^{304}$ Inhaltlich sah sich das Journal in der Tradition der russischen vorrevolutionären Kultur. Kein einziges Werk der neuen Strömungen des Proletku'lt erschien darin. Auch aus futuristischer Feder stammte kein einziger Beitrag. Dafür fanden sich die unterschiedlichsten Lager der vorrevolutionären Literatur vereint. ${ }^{305} \mathrm{Im}$ „Boten der Literatur“ und in den Publikationen des „Hauses der Schriftsteller" veröffentlichte Koni mehrere seiner Literaturskizzen und zahlreiche Nachrufe auf Persönlichkeiten, die in den Jahren 1919 und nachfolgend verstarben. ${ }^{306}$ Auch der Sammelband zu „Puschkin und

„Chronik des Hauses der Schriftsteller“ sogar als eigenständige Ausgabe. Diese widmete sich im Unterschied zum „Boten“ fast ausschließlich dem aktuellen literarischen Geschehen. So finden sich beispielsweise in der ersten Ausgabe Artikel über die Symbolisten Blok und Belyj, vgl. ebd., S. 8.

302 SChlögel: Petersburg, S. 606 zum „Fernglas“ und GalušKin: Predislovie, S. 6.

303 GalušKin: Predislovie, S. 6.

304 Ebd., S. 5-6. Auch Amfiteatrov hält in seinen Erinnerungen fest, dass das Journal damals das einzige "nichtsowjetische“ Journal im sowjetischen Petrograd gewesen sei. Allerdings - so fügt er kritisch hinzu - habe man dafür inhaltlich auch einen gewissen Preis zahlen müssen, vgl. Amfiteatrov: Sobranie sočinenij v 10 tomach, Bd. 10:2. Memuary, S. 599-600.

305 GalušKin: Predislovie, S. 7. Vgl. zum Futurismus als Bewegung in der Kunst, die schon in den 1910er-Jahren entstand, sich sowohl gegen den Realismus als auch gegen den Symbolismus wandte und schließlich in den Jahren nach der Revolution zur vollen Entfaltung fand, Stender-Petersen: Geschichte der russischen Literatur, S 537-539. Die Form und nicht der Inhalt - stand für die Futuristen wie Vladimir Vladimirovič Majakovskij (1893-1930) im Zentrum ihres Schaffens. Vgl. zur Bewegung des Proletkul't, der nach der Oktoberrevolution eine unabhängige proletarische Kultur schaffen wollte, an der schließlich Tausende von Arbeiterinnen und Arbeitern teilnahmen, die so Kenntnisse beispielsweise in Poesie, Schauspiel oder Tanz erwarben, SтÄDTKE (Hrsg.): Russische Literaturgeschichte, S. $294 \mathrm{ff}$ oder ausführlich Lynn MALly: Culture of the Future. The Proletkult Movement in Revolutionary Russia. Berkeley 1990, S. 1-3 ff.

306 Koni gedachte in kurzen Texten einer Reihe an Schriftstellern, vgl. Anatolij F. Koni: [O P. D. Boborykine]. In: VL 7 (1919), S. 4-5 sowie Anatolij F. KonI: Pamjati P. D. Boborykina. 
Dostojewski“, für den Koni nicht nur als Autor, sondern auch als Mitherausgeber fungierte, entstand in diesem Umfeld. Der Band, an dem sich große Namen wie der Schriftsteller Aleksej Michajlovič Remizov (1877-1957) oder Aleksandr Blok beteiligten, entsprach einer Zusammenstellung aus Publikationen insbesondere des „Boten der Literatur" und erhielt große Aufmerksamkeit in der Literaturszene Petrograds. ${ }^{307}$ Koni gehörte so eng zum Kreis der Autoren rund um den „Boten“ dass er, als die treibende Kraft der Zeitschrift, Abram Kaufman 1921 starb, für das Publikationsorgan einen Nachruf auf den Chefredaktor verfasste. Darin betonte er, wie groß das Engagement Kaufmans für die Literaten der Stadt gewesen sei. Er endet mit dem Verweis auf die „Turgenev-Gesellschaft“, für die Kaufman noch kurz vor seinem Tod einen Vortrag vorbereitet habe. ${ }^{308}$ Genau wie die von Koni hier einmal mehr ins Spiel gebrachte Turgenev-Gesellschaft stellte aber auch der „Bote der Literatur“ [Vestnik Literatury] im Jahr nach Kaufmans Tod den Betrieb ein. Eine entsprechende Anordnung der Geheimpolizei spielte dabei die entscheidende Rolle. Kritik wurde geübt an der „Rückständigkeit“ und der apolitischen Haltung der Autoren. ${ }^{309}$ Dessen ungeachtet entwickelten sich im Umfeld der geschlossenen Zeitschriften sehr schnell neue, allerdings äußerst kurzlebige Produkte wie beispielsweise der Almanach „Utrenniki“. Darin erschienen gar Artikel, die

In: ders. (Hrsg.): Na žiznennom puti. Leningrad 1929, S. 337-40. Dieser Nachruf wurde aufgrund einer irrtümlichen Todesnachricht zu früh verfasst, vgl. ebd., S. 362 (Anmerkungen). Vgl. weiter: Anatolij F. Koni: Pamjati Ž. A. Polonskoj. In: VL 1 (1920), S. 16; Anatolij F. Koni: Pamjati A. E. Molčanova. In: VL 6-7 (1921) S. 16-17. Zudem veröffentlichte er darin Nachrufe auf den Arzt L. L. Giršman (1839-1921) und den Philosophen, Juristen und zeitweiligen Staatsrat E. N. Trubeckoj (1863-1920), vgl. Anatolij F. KonI: Pamjati L. L. Giršmana. In: VL 3 (1921), S. 13-14 und Anatolij F. Koni: [O E. N. Trubeckom]. In: VL 4-5 (1920), S. 23. Ursprünglich hatte er vorgehabt, einen Teil dieser Nachrufe in seine Sammelbände „Auf dem Lebensweg“ III und IV zu integrieren, vgl. den Vertrag mit dem Verlag Bibliofil vom Mai 1921, IRLI F. 134, op. 4, d. 89, 1. 6. Neben den Nachrufen publizierte Koni wie bereits erwähnt im „Boten der Literatur“ auch „Vstreči s F. M. Dostoevskim“ und „A. S. Puškin“. Vgl. oben, Fußnote 477 in TEIL ZWEI zu Nachrufen auf einige wenige Juristen, die Koni ebenfalls in dieser Zeitschrift platzieren konnte.

307 GalušKin: Predislovie, S. 9. Vgl. die zahlreichen Rezensionen.

308 Anatolij F. Koni: Pamjati A. E. Kaufmana. In: Letopis' Doma Literatorov 1-2 (1922), S. 5. Die Seite enthält auch weitere Nachrufe über Kaufman sowie eine allgemeine Meldung zum Tod des Chefredaktors und der Beerdigung, die bei der Synagogenwand auf dem Preobraženskoe-Friedhof in Petrograd stattfinden sollte.

309 GalušKin: Predislovie, S. 8-9. Hinzu kam, dass in der Zwischenzeit auch neue literarische Journale entstanden waren, die sich auf spezifischere Lesergruppen fokussierten und so eine ernsthafte Konkurrenz für den „Boten“ darstellten. Auch die „Chronik“ stellte im Februar 1922 ihr Erscheinen ein. Nur sieben Nummern waren von diesem Blatt erschienen. Da das Autorenkollektiv der beiden Zeitschriften in weiten Teilen identisch war, traf die Kritik der offiziellen Presse die beiden Produkte gleichermaßen. 
sich unmittelbar den politischen Geschehnissen der Zeit widmeten und auf großen Widerspruch in der sowjetischen Presse stießen. ${ }^{310} \mathrm{Koni}$, von dem in „Utrenniki“ der Artikel „Nochmals über Dostojewski“ veröffentlicht worden war, musste sich, nachdem auch das „Haus der Literaten“ Ende 1922 geschlossen worden war, andere Publikationsmöglichkeiten und Plattformen für seine öffentlichen Auftritte suchen. ${ }^{311}$ Dabei boten sich jene Institutionen an, die von Unterstützung aus den Reihen der Kommunistischen Partei und ihren Sympathisanten profitierten. Insbesondere der Schriftsteller Maksim Gor'kij betätigte sich in den Jahren nach der Oktoberrevolution als Schutzherr der gebildeten Intelligencija. ${ }^{312}$ Gor'kij gehörte seit der Revolution von 1905 zum Kreis der Sozialdemokraten und stand seit diesem Zeitpunkt auch in persönlichem Kontakt mit Lenin. Auch wenn er im Revolutionsjahr 1917 der Vorgehensweise der Bolschewiki nicht von Anfang an positiv gegenüberstand, entwickelte er bald eine Art „wohlwollende Neutralität", die es ihm erlaubte, sich effektiv für die russischen Kulturschaffenden einzusetzen. ${ }^{313}$ Wichtig waren dabei seine Beziehungen zum Volkskommissariat für Bildungs- und Kulturpolitik und dessen Vorsteher Lunačarskij. ${ }^{314}$ Lunačarskij selber und sein Volkskommissariat waren bekannt für ihre ausgeprägte Sympathie, die sie der vorrevolutionären literarischen- und künstlerischen Elite entgegenbrachten - so setzten sie sich zeitweise auch für das „Haus der Literaten“ ein. ${ }^{315}$ Dieses Engagement stieß zwar immer wieder auf harsche Kritik aus den eigenen Reihen von Partei und Regierung, innerhalb derer das Volkskommissariat für Bildungs- und Kulturpolitik und Lunačarskij selber lediglich ein „politisches Leichtgewicht" darstellten. Trotzdem blieb er bis 1929 Volkskommissar. ${ }^{316}$ Mit Gor'kij verband ihn eine intensive Zusammenarbeit nach der ersten Russischen Revolution, als beide sich im Exil für die theoretische Auseinandersetzung mit

310 Dolmat A. Lutochin: Sovetskaja Cenzura. Po ličnym vospominanijam [1923]. In: Aleksandr Ju. Galuškin u. a. (Hrsg.): Žurnaly „Vestnik literatury“ (1919-1922), „Letopis’ Doma Literatorov“ (1921-1922), „Literaturnye zapiski“ (1922). Annotirovannyj ukazatel’. Moskva 1996, S. 261-62. Dolmat Aleksandrovič Lutochin (1885-1942), ein Mitarbeiter von Kaufman, erinnert sich in diesem Artikel an die Vorgehensweise und unklaren Haltungen der Zensurbehörden sowie an die Kritik, die einzelne Artikel im „Boten der Literatur“ und im Almanach „Untrenniki“ hervorriefen.

311 Galuškin: Predislovie, S. 10 zur Schließung.

312 A. D. Nozdračev/V. A. Petrickij: Pervyj v Rossii Dom Učenych. In: Vestnik Rossijskoj Akademi Nauk 10 (1995), S. 922.

313 Cecilia von Studnitz: Mit Tränen löschst du das Feuer nicht. Maxim Gorki und sein Leben. Düsseldorf 1993, S. 323 und 327 und ST RUve: Geschichte der Sowjetliteratur, S. 75-76.

314 Vgl. oben, S. 256, auch zu Lunačarskij und seinem Verhältnis zu Koni.

315 SChlögel: Petersburg, S. 595-96.

316 Fitzpatrick: Education and Social Mobility in the Soviet Union, 1921-1934, S. 10-11. 
dem Marxismus engagiert hatten. ${ }^{317}$ Gor'kij führte mit Einwilligung Lenins schon im Sommer 1918 mit Lunačarskij Verhandlungen über die Einrichtung eines Verlages, der - finanziert vom Volkskommissariat - Übersetzungen ausländischer Literatur ins Russische drucken und so als Einnahmequelle für verarmte Schriftsteller dienen sollte. ${ }^{318}$ Weitere Projekte folgten schnell nach. Koni selber beteiligte sich insbesondere am „Haus der Künste“, das von Gor'kij ein Stück weit als Gegengewicht zum „Haus der Literaten“ konstruiert worden war. ${ }^{319}$ Kornej Čukovksij, sogenannter Weggefährte der Revolution, der sich der Sowjetunion gegenüber loyal verhielt, ohne aber der Parteilinie strikt zu folgen, hatte im „Haus der Künste“ eine Führungsposition inne. ${ }^{320}$ Er erinnert sich, dass Koni ihm deswegen ein ganzes Programm mit möglichen Redethemen geschickt habe. Darunter seien Erinnerungen an „Alltagstreffen“, Gerichtsredner oder Schriftsteller wie Fürst Odoevskij gewesen. Letzterer, so habe Koni betont, verdiene momentan besondere Aufmerksamkeit. ${ }^{321}$ Eine weitere von Gor'kij initiierte Vereinigung war schließlich das „Haus der Wissenschaftler“ [Dom Učennych]. Im Gegensatz zum „Haus der Künste“, das 1923 geschlossen wurde, existiert diese Organisation - mittlerweile als Teil der Akademie der Wissenschaften - bis heute. ${ }^{322}$ Die Stadt Petrograd stellte dem „Haus der Wissenschaftler" ein Gebäude zur Verfügung, in dem sich Wissenschaftler aller Fachbereiche austauschen, arbeiten und Vorträge halten konnten. Im November 1921 wurden bereits 700 Mitglieder gezählt, und 2000 wissenschaftliche Mitarbeiter erhielten Unterstützung in Form von Kleidern, Schuhen oder

317 Struve: Geschichte der Sowjetliteratur, S. 65 und STudnitz: Mit Tränen löschst du das Feuer nicht, S. 325.

318 Chlebnikov: Iz istorii Gor'kovskich izdatel'stv, S. 669. und Struve: Geschichte der Sowjetliteratur, S. 76. Das Verlagshaus „Weltliteratur“ [Vsemirnaja Literatura] wurde nach seiner Gründung in den Jahren des Bürgerkrieges tatsächlich zu einer wichtigen Einnahmequelle für Schriftsteller. Das Projekt war allerdings nicht unumstritten. Die Anschuldigungen von Literaten, die nach einigen Jahren Sowjetmacht emigrierten, gegen Gor'kij und weitere Exponenten aus dem russischen Verlagswesen in den Jahren nach der Oktoberrevolution werden dargestellt in: E. DinneršTEjn: K voprosu o reputacii izdatelja Z. Gržebina. In: Novoe Literaturnoe Obozrenie 106 (2010), magazines.russ.ru/ nlo/2010/106/di41.html, Zugriff vom 08.11. 2016.

319 Struve: Geschichte der Sowjetliteratur, S. 65 spricht davon, dass das „Haus der Künste“ weniger bürgerlich sein sollte. SCHLÖGEL: Petersburg, S. 613 führt an, dass es eine strengere Auswahl traf und nur die Besten ihres Faches Eingang fanden.

320 STÄDt Ke (Hrsg.): Russische Literaturgeschichte, S. 298 und SCHLÖgEL: Petersburg, S. 613.

321 Čunovskij: Anatolij Fëdorovič Koni. In: GA8, S. 9.

322 Struve: Geschichte der Sowjetliteratur, S. 75-76 und für die langjährige Geschichte des „Hauses der Wissenschaftler“ Nozdračev/Petrickij: Pervyj v Rossii Dom Učenych, S. $922-30$. 
Ähnlichem. ${ }^{323}$ Auch wenn im Zusammenhang mit der Ausweisung vieler Wissenschaftler und Schriftsteller und der zeitweiligen Auslandsabsenz Gor'kijs 1921/22 das „Haus der Wissenschaftler“ in seiner Tätigkeit beschnitten wurde, blieb das Gebäude an der Dvorcovaja Naberežnaja doch weiterhin ein beliebter Treffpunkt. ${ }^{324}$ Koni wurde im Februar 1924 nicht nur von der Akademie der Wissenschaften, sondern auch vom „Haus der Wissenschaftler" mit einem Jubiläumsabend zu seinem 8o. Geburtstag geehrt. Noch im Jahr seines Todes hielt er im „Haus der Wissenschaftler" Vorträge. ${ }^{325}$ In den repressiven 193oer-Jahren bot die Organisation auch unter Druck geratenen literarisch-kulturellen Gruppierungen Unterschlupf. So fanden beispielsweise die Versammlungen der „Gesellschaft zu Studium, Popularisierung und Erhalt des alten St. Petersburg" im Wissenschaftler-Haus statt. ${ }^{326}$ Diese Gesellschaft gehörte zu einer der zahlenmäßig stärksten Verbindungen der Intelligencija Petrograds, und auch Koni spielte darin seit der Gründung nach dem Bürgerkrieg 1921 eine wesentliche Rolle. Ziel der Gesellschaft waren sowohl der Erhalt von Denkmälern und Gebäuden des „alten St. Petersburgs" als auch die Beschäftigung mit der Stadtgeschichte, über die man nun zahlreiche Vorträge und Publikationen herausgab. Bis in die 1930er-Jahre blieb die Gesellschaft ein „Hort kulturellen Lebens ““ ${ }^{327}$ Diese intensive Beschäftigung mit der Stadt ist auf das Erstarken der Heimat- beziehungsweise Stadtkunde [kraevedenie/gradovedenie] im ersten Jahrzehnt nach der Oktoberrevolution zurückzuführen. Angesichts der enormen Veränderungen nach den revolutionären Umwälzungen, der Entvölkerung und des völligen Stillstands, der sich in den Jahren von Revolution und Bürgerkrieg für einen Moment in der industriellen Metropole ausbreitete, schien die Beschäftigung mit der Lebenswelt, die im Verschwinden begriffen war, besonders wichtig. Die 1920er-Jahre gelten als das „Goldene Zeit-

323 Nozdračev/Petrickij: Pervyj v Rossii Dom Učenych, S. 922-23.

324 Ebd., S. 924. Gor'kij verließ Russland, da Lenin den kritischen Schriftsteller - wie Studnitz es formuliert - „auf Dauer in Russland nicht mehr decken“ konnte oder wollte. Ab Ende 1921 lebte Gor'kij, der an akuter Tuberkulose litt, in Deutschland und später in Italien. 1928 kehrt er unter großem Jubel von offizieller Seite in die Sowjetunion zurück, vgl. StudnitZ: Mit Tränen löschst du das Feuer nicht, S. 330-33. In den Jahren im Ausland hatte er die Verbindung mit der Sowjetunion immer aufrechterhalten, aber auch Kritik an der politischen Vorgehensweise gegen Andersdenkende im Inland geübt, vgl. STRUVE: Geschichte der Sowjetliteratur, S. 76-77.

325 SAšonko: A. F. Koni v Peterburge - Petrograde - Leningrade, S. 296. Das ungeheizte „Haus der Wissenschaftler“ soll Koni gar die Erkältung beschert haben, der er schließlich erlag.

326 Gustav Boguslavskij: 100 očerkov o Peterburge. Severnaja stolica glazami moskviča. Moskva 2011, S. 545.

327 Ebd., 544-45 und 542-43, Zitat S. 542. 
alter der Landeskunde" in ganz Russland. ${ }^{328}$ Koni las als Mitglied seit der Gründungszeit zahlreiche Lektionen für Schulkinder oder Arbeitergemeinschaften und berichtete darin von seinen Erinnerungen als ,alteingesessener" Petersburger, bevor er diese dann auch in Buchform herausgab. ${ }^{329}$ Mit diesem Werk und seiner Zelebrierung der heimischen Schriftsteller setzte er sich in enge Beziehung zu einem anderen Mitglied der „Gesellschaft des alten St. Petersburg“. Nikolaj Pavlovič Anciferov (1889-1958) hatte als wichtiger Stadtforscher und einer der Begründer der historischen Landeskunde ebenfalls 1922 das Buch „Die Seele Petersburgs“ veröffentlicht, in dem er unzählige Literaten zu Wort kommen lässt. ${ }^{330}$

Zwischen 1918/19 und 1922/23 kamen zu den wissenschaftlichen und literarischen Institutionen, bei denen Koni auftrat, noch akademische hinzu. Anstatt einzig seine Erinnerungen an die vorrevolutionären großen Literaten als Vehikel zu nutzen, konnte Koni hier seinen erzieherischen Fokus ganz unmittelbar umsetzen. So dozierte er an den Universitäten in Petrograd und an weiteren Bildungsinstitutionen zur „Strafgerichtsordnung“, zur „Redekunst“ und zur „Gerichtsethik“.331

328 Nikolaj P. AnCiferov: Duša Peterburga, hrgs. u. mit einem Nachwort versehen v. A. Margolis. Leningrad 199o, S. 233-34 (Nachwort von A. Margolis) und Nikolaj P. AnCiferov: Die Seele Petersburgs, hrsg. u. mit einer Einleitung versehen v. Karl Schlögel. München 2003, S. 12-15 und 41-42 (Einleitung von Karl Schlögel).

329 Vgl. zur Aufnahme GARF F. 564, op. 1, d. 752, 1. 44: 12.12.1921, Brief an Koni, dass er zum Mitglied der Gesellschaft gewählt worden sei. In seinem Nachlass finden sich auch ein Durchschlag der Statuten der Gesellschaft sowie ein 148 Titel umfassender Seminarplan mit Vortragsthemen zu St. Petersburg in den verschiedenen historischen Epochen, vgl. GARF F. 564, op. 1, d. 775. Boguslavskij erwähnt Konis Auftritte vor der Gesellschaft, vgl. Boguslavskij: 100 očerkov o Peterburge, S. 543. Für sein Engagement bedankte sich die Gesellschaft anlässlich von Konis Tod mit einem Kondolenztelegramm an Ponomareva, vgl. GARF F. 564, op. 1, d. 4235, 1. 8. Darin trat die Organisation bereits mit neuem Namen auf und nannte sich „Altes Petersburg - neues Leningrad“. Seit 1925 hieß die Gesellschaft so. Trotz der Unterstützung der Stadtregierung wurden die Tätigkeiten zum Erhalt alter Gebäude oder die öffentlichen Versammlungen der Gesellschaft in den Jahren nach Konis Tod immer stärker eingeschränkt. Die Unterstützung des „Hauses der Wissenschaftler“ oder der „Akademie der Künste“ ließ die Gesellschaft weiterbestehen, im Februar 1938 fand aber endgültig die letzte Versammlung statt, vgl. BogusLAvsKiJ: 100 očerkov o Peterburge, S. 542 und 544-45.

330 Anciferov: Die Seele Petersburgs, S. 12 und 34 (Einleitung von Karl Schlögel) und Anciferov: Duša Peterburga, S. 233-34 (Nachwort von A. Margolis).

331 Vgl. zu Konis Ernennung zum Professor VysockiJ: Koni, S. 397-98. Vysockij zitiert mehrere Briefe an Koni, die ihm 1918/19 von der ersten Petrograder Universität zugeschickt wurden. Vgl. zu den Kursen auch Smoljarčuk: Anatolij Fëdorovič Koni (1844-1927), S. 197. Vgl. auch GA4, S. 486 (Anmerkungen). Koni las bis Sommer 1922 an der ersten Petrograder Universität einen Kurs zur Strafgerichtsordnung sowie an der zweiten Petrograder Universität bis 1921 Kurse zur Gerichtsethik und zur „Ethik des Gemeinschaftslebens“, worauf sogleich noch näher eingangen wird. Am 1918 gegründeten „Institut des 
Thematisch bildeten diese Vorlesungen die Fortsetzung von Konis Bemühungen um eine Berufsethik für Juristen, der er sich schon seit der Jahrhundertwende intensiv gewidmet hatte. ${ }^{332}$ Während er mit diesen Überlegungen noch einen klar definierten Personenkreis ansprach, weitete er im sowjetischen Russland nun seine potentielle Zuhörerschaft aus. Er konzipierte für die Petrograder Universität auch einen Vorlesungszyklus zur „Ethik des Gemeinschaftslebens“ [ėtika obščežitija]. Darin bemühte sich Koni um die Kommunikation von - so beschrieb er es selber - „allgemeinen Grundlagen der Ethik“ für eine Vielzahl an Berufsgruppen wie Ärzte, Ökonomen oder Politiker und sprach grundlegend über Erziehung und persönliche Umgangsformen. ${ }^{333}$ Ein veröffentlichtes Kursprogramm, das Konis Vorlesung am „Institut des lebendigen Wortes“ ankündigte, führt in neun Abschnitten knapp aus, was Inhalt der Lektionen sein werde. Ausgehend von der philosophischen Verortung von Ethik in der Antike arbeitet sich Koni vor zu Fragen von Eltern-Kind-Beziehung und Pflichtbewusstsein, um schließlich die moralischen Grundforderungen von Kant zu wiederholen, die ihm im Gerichtswesen so wichtig waren. Er leuchtet das Arztgeheimnis aus, die Problematik der Sterbehilfe, die Gewissensfreiheit oder die Trennung von Kirche und Staat. Auch Kunst und Literatur mit Fragen von Plagiaten, Autorenrechten oder Missbrauch der freien Presse werden angesprochen. Und schließlich endet Koni mit der Beziehung der Menschen untereinander. Themen wie Höflichkeit, Kompromissfähigkeit, Egoismus und Strenge zu sich selber will er in seinem Kurs angehen. ${ }^{334}$ Zwei weitere Themen in Konis Programm werden in Zeitschriftenartikeln sogar etwas ausführlicher vorgestellt. Dabei geht es einerseits um Entwicklungen wie Voyeurismus und Zurschaustellung von Brutalität im Rahmen von Sportveranstaltungen, öffentlichen Hinrichtungen oder Kinofilmen. Koni sieht eine generelle

lebendigen Wortes“ [Institut živogo slova] las er gleichzeitig zur Theorie der Redekunst und der Geschichte der Rhetorik in Russland, vgl. GA4, S. 486-87 (Anmerkungen). Dieses Institut existierte zwischen 1918 und 1924 und widmete sich den verschiedenen Formen poetischer Deklamationskunst. Die populären Namen, die am Institut unterrichteten, trugen zusammen mit seinem experimentellen Charakter zur Beliebtheit der Bildungseinrichtung bei, in der schon Mitte 1919 um die 8oo Personen eingeschrieben waren. Neben Koni waren dies Dozenten aus den unterschiedlichsten Bereichen wie Literatur, Musik, Philosophie oder Sprachwissenschaft, vgl. Raffaèla VAssena: K rekonstrukcii istorii dejatel'nosti Instituta živogo slova (1918-1924). In: Novoe Literaturnoe Obozrenie 86 (2007), http://magazines.russ.ru/nlo/2007/86/va5.html, Zugriff vom 09.11. 2016.

Vgl. oben, S. $90 \mathrm{zu}$ Konis Unterricht am Alexanderlyzeum und seinem Wunsch, diese Grundlagen der Gerichtsethik auch vor einem breiteren Publikum vorzutragen.

333 Vgl. eine kurze Inhaltsübersich von Koni selber zu diesem Kurs in: KoNı: [Avtobiografčeskij očerk]. In: VL 9 (1921), S. 15-16.

334 Anatolij F. Koni: Ėtika obščežitija. In: Zapiski Instituta Živogo Slova 1919 (1), S. 56-58. 
Enthemmung und Entsolidarisierung Einzug halten. Andererseits spricht Koni die Ethik des Staates an, der Geld eintreibt für wichtige Aufgaben im Bereich Sicherheit oder Kultur, aber dabei selber moralische Grundsätze verletzt. Insbesondere in der Besteuerung von Alkohol oder Glücksspiel sieht Koni ein Hindernis im Kampf gegen die entsprechenden Problematiken. ${ }^{335}$ Die Bandbreite an Themen scheint unerschöpflich und fast sieht es danach aus, als habe Koni in diesen Kursen Antworten auf alle erdenklichen Fragen der Lebensführung vermitteln wollen. Die Vorlesungen zur "Gemeinschaftsethik“ lagen ihm mit ihrer breiten Adressierung denn auch ganz besonders am Herzen. ${ }^{336}$ Koni musste solche unmittelbar der "Ethik" gewidmeten Lektionen allerdings bald wieder aufgeben. 1920/21 wurde der Kurs zur Gerichts- und Lebensethik an der Universität abgesetzt, weil das Fach im Zuge der grundlegenden Umstrukturierungen im Gerichtswesen abgeschafft wurde.$^{337}$ An einem anderen Institut wurde der Ethikkurs gar explizit mit der Begründung eingestellt, dass Koni in seinen Lektionen zu sehr „moralisieren“ würde. ${ }^{338}$ Eine umfassende Veröffentlichung seiner Ansichten zu den richtigen Verhaltensweisen in Kindererziehung, Beruf oder Staatsfinanzierung gelang Koni trotz entsprechender Bemühungen nicht. ${ }^{339}$ Die sowjetische Kritik an den von Koni betonten ethischen Grundlagen lässt sich für den juristischen Bereich beispielhaft am Kommentar ablesen, der seinem schon 1902 publizierten Artikel „Moralische Grundlagen im Strafprozess" in der Gesamtausgabe seiner Werke in den 196oer-Jahren beigefügt ist. Die mangelnde Fähigkeit, den „Klas-

335 Anatolij F. KonI: Nravstvennost' i obščestvennaja žestokost'. Iz kursa „Ėtiki obščežitija“. In: AD 5-8 (1922), S. 5-11 und Anatolij F. KonI: Nravstvennosti i gosudarstvennye dochody. Iz kursa „Ėtiki obščežitija“. In: AD 1-4 (1922), S. 15-18.

336 Vgl. auch den Brief in RGALI F. 122, op. 1, d. 713, 1. 24-25ob, zitiert nach Domanova: Perepiska A. F. Koni kak istoričeskij istočnik, S. 125, in dem Koni schreibt, wie sehr er die Lektionen über die „Ethik des Gemeinschaftslebens“ liebe.

337 Tat’jana L. ŠČepkina-Kupernik: Iz vospominanij, hrsg. v. A. O. Boguslavskij. Moskva 1959, S. 391. Diese Erinnerungsschrift der Literatin Tat'jana L'vovna Ščepkina-Kupernik (1874-1952) wurde einige Jahre nach ihrem Tod auf Basis eines unveröffentlichten Manuskripts in ihrem Archiv publiziert, vgl. ebd., S. 388-95. Darin schreibt sie über Koni, dass seine Gerichtsethik-Lektionen gestoppt worden seien, weil man das Fach nicht länger unterrichtet habe. Vgl. zur Textgeschichte ebd., S. 458 (Anmerkungen). Koni selber spricht davon, dass er von Herbst 1918 bis 1920 diese Lektionen gehalten habe und danach die Universität aufgelöst worden sei, vgl. Konı: [Avtobiografčeskij očerk]. In: VL 9 (1921). Den Kurs zur Strafgerichtsordnung las Koni noch bis zum Sommer 1922, vgl. GA4, S. 486 (Anmerkungen).

338 Domanova: Perepiska A. F. Koni kak istoričeskij istočnik, S. 125.

339 Vgl. den Entwurf eines Inhaltsverzeichnisses für den Sammelband „Auf dem Lebensweg“ V in IRLI F. 134, op. 1, d. 256, 1. 388. Vgl. zur misslungenen Publikation auch Utevskij: Poslednij ètap žiznennogo puti, S. 98. 
sencharakter der vorrevolutionären Justiz" und die Gründe für die Reform von 1864 zu verstehen, habe dazu geführt, dass Konis Lektionen und Publikationen zu diesem Themenbereich niemandem viel gebracht hätten. ${ }^{340}$

Die Einschränkung dieser Vorlesungstätigkeit und die dabei geäußerte Kritik stehen sinnbildlich für die zahlreichen Hindernisse, auf die Koni bei seinen Aktivitäten in den verschiedenen künstlerischen und wissenschaftlichen Organisationen und Gesellschaften nach 1917 traf. Die Kurzlebigkeit vieler dieser Einrichtungen spricht dabei für sich. Bereits 1919 hatte die „Außerordentliche Kommission zum Kampf gegen die Konterrevolution und Spekulation“ zudem Koni persönlich ins Visier genommen und bei einer Durchsuchung seiner Wohnung Geld, Medaillen und sonstige Gegenstände beschlagnahmt und - wie er bitterlich beklagte - unter seinen ordentlich sortierten „Notizen, Manuskripten, Tagebüchern“ ein großes Durcheinander angerichtet. ${ }^{341}$ Beschwerden Konis an die offiziellen Stellen hatten zwar die Einstellung des Falles zur Folge, einige der beschlagnahmten Materialien blieben aber unumgänglich verloren. ${ }^{342}$ Wenige Jahre später verschärfte die Kommunistische Partei die Gangart gegen die „bourgeoise Ideologie“, die sie aufgrund der Lockerungen durch die „Neue Ökonomische Politik“ gestärkt sah, mit einer Reihe an Maßnahmen. Darunter fiel auch das Verbot des Almanachs „Utrenniki“ sowie die Verhaftung und Ausweisung einer ganzen Reihe an Autoren aus diesem Umfeld. ${ }^{343}$ Lutochin, der exilierte Redaktor des Almanachs, schreibt in seinen Erinnerungen an die Verhaftung und Ausweisung, dass er nie genau begriffen habe, was ihm vorgeworfen worden sei. „Antisowjetische“ Tätigkeit schien als Begründung für den erzwungenen Gang ins Exil zu genügen, während andere lediglich innerhalb des Landes verbannt wurden. ${ }^{344}$ Bei dieser großflächigen Strafaktion

340 GA4, S. 490 (Anmerkungen). Vgl. zum Artikel Angaben in Fußnote 151 in TEIL EINS.

341 Bakuncev zitiert aus den Erinnerungen von Vasilij Nemirovič-Dančenko, der beschreibt, wie Koni sich über die „barbarische Durchsuchung“ und insbesondere über das zurückgelassene Durcheinander beklagt habe, vgl. BAKUnCEv: Anatolij Fëdorovič Koni, russkaja ėmigracija i sovetskaja vlast', S. 61. SAšonko: A. F. Koni v Peterburge - Petrograde - Leningrade, S. $271 \mathrm{ff}$ mit dem Protokoll zur Untersuchung. Vgl. auch Smoljarčuk: A. F. Koni i ego okruženie, S. 11 u. a. mit einer kürzeren Aufzählung der beschlagnahmten Materialien.

342 Smoljarčuk: A. F. Koni i ego okruženie, S. 11 und Sašonko: A. F. Koni v Peterburge Petrograde - Leningrade, S. 273-78 mit einer genauen Nachverfolgung der Briefwechsel zwischen Koni und offiziellen Stellen, die aber trotz mancher anderslautenden Versprechen einen Teil der Materialien nie zurückgaben.

343 GalušKin: Predislovie, S. 10-11. Die Listen der Personen, die unter dem Stichwort der „administrativen Ausweisung " das Land verlassen sollten, umfassten neben Politikern linker, nicht kommunistischer Gruppierungen auch Exponenten der „,angeblich-unparteilichen, bourgeois-demokratischen Intelligencija“.

344 Lutochin: Sovetskaja Cenzura, S. 268. 
gegen liberale Kräfte wurden im Herbst 1922 weit über 100 „anti-sowjetische Juristen, Literaten und Professoren" ausgewiesen. Die zufällig anmutende Auswahl der Verbannten und Ausgewiesenen sollte nicht zuletzt eine Warnung für alle Zurückgebliebenen sein. ${ }^{345}$ Koni gehörte nicht zu den Betroffenen, obwohl auch er unter anderem in der ins Visier geratenen Zeitschrift publiziert hatte. Allerdings scheint ihm ebenfalls die Ausreise - und sei es aus gesundheitlichen Gründen - nahegelegt worden zu sein. ${ }^{346}$ Lunačarskij wurde schon 1921 in einem Schreiben von höchster Stelle gebeten, zu Koni und zahlreichen weiteren Fachleuten Stellung zu beziehen. Seine Darstellung von Koni schien die Parteioberen beruhigt zu haben. Er sagte aus, dass Koni sich ,außerordentlich freundschaftlich gegenüber dem neuen Regime“ ausgedrückt habe, da er der Überzeugung sei, dass es in Russland eine starke Macht brauche. Der vorrevolutionäre Jurist lese nun Lektionen an diversen Bildungsinstituten und trete mit verschiedenen Erinnerungen auf, die mehr oder weniger in einem der Sowjetmacht sympathischen Ton ausgestaltet seien. ${ }^{347}$

Konis Vorlesungs- und Vortragspraxis im Jahrzehnt nach der Oktoberrevolution blieb so trotz einiger Einschränkungen unangefochten. Auch nach der Absetzung der Lektionen zu Gerichts- und Lebensethik an den akademischen Institutionen blieben ihm bis zu seinem Tode genug andere Möglichkeiten, zu „moralisieren“. Die Nachfrage nach den Erinnerungen und Vorträgen Konis schien unerschöpflich zu sein, wovon die zahlreichen Bittbriefe von verschiedenen Organisationen zeugen, die in Konis Nachlass lagern. ${ }^{348}$ Mit welchen Gruppierungen, Organisationen oder Verlagsgemeinschaften Koni dabei im Detail zusammenarbeitete, schien sekundär gewesen zu sein. Von der Akademie der Wissenschaften mit dem „Puschkinhaus“ hin zum „Haus der Literaten“ und schließlich zum „Haus der Künste“ und der „Wissenschaftler“ boten diese Orte Koni in ihrer ganzen Vielfalt die Möglichkeit, über unzählige Vorträge seine Erinnerungen und Berichte von den Menschen und insbesondere den Literaten der vorrevolutionären Welt an ein Publikum zu richten.

345 FitzPatrick: Education and Social Mobility in the Soviet Union, 1921-1934, S. 76-77 und SCHLÖGEL: Petersburg, S. 623 ff ausführlich zu den Exilierungsmaßnahmen.

346 Ščepkina-Kupernik erinnert sich, dass es 1922 Gerüchte gegeben habe, dass Koni ausreisen dürfe, aber dies nicht tue, vgl. ŠčEPKINA-KuPERnIK: Iz vospominanij, S. 391. Bakuncev schlussfolgert aus diesen und ähnlichen Aussagen, die auch erwähnen, dass Koni zur Kur ins Ausland hätte gehen dürfen, dass man Koni hatte loswerden wollen, vgl. BAKUNCEv: Anatolij Fëdorovič Koni, russkaja ėmigracija i sovetskaja vlast', S. 62.

347 Michail E. GlavackiJ (Hrsg.): V žernovach revoljucii. Rossijskaja intelligencija meždu belymi i krasnymi v porevoljucionnye gody. Sbornik dokumentov i materialov. Moskva 2008, S. 90.

348 Vgl. zum Beispiel die Briefe in GARF F. 564, op. 1, d. 249. 
Die „Zuhörer“ erreichen: Koni als Schriftsteller und Vortragender

Immer deutlicher machte Koni das Vortragen und Dozieren auch explizit zu seinem Lebenssinn. Offensichtlich wird dies in einer Art „öffentlichem Curriculum“, das Koni im Herbst 1921 im „Boten der Literatur“ publizierte. Auf zwei Seiten legt er Zeugnis ab über seine Tätigkeiten im sowjetischen Russland. Er führt aus, dass er nach der Oktoberrevolution ein neues Betätigungsfeld habe suchen müssen, wo er die "seelischen Stärken, Kenntnisse und Erfahrungen eines langen Lebens“ habe einbringen können. ${ }^{349}$ Er habe deshalb mit großer Bereitschaft das Angebot der Petrograder Universität angenommen, Kurse zum Strafrecht und zur Redekunst zu halten. In einer Rückblende erklärt Koni den Lesern ausführlich, dass er in den 1860-er Jahren bereits an eine universitäre Laufbahn gedacht habe, dies sich aber nicht realisiert habe. Er wiederholt dabei in einer gerafften Form, was er 1912 schon in "Saatfeld“ [niva] als Erinnerung an die „Studentenjahre“ veröffentlicht hatte. ${ }^{350}$ Seine Dissertation, die bei Innenminister Valuev auf Unmut stieß, wird nicht ausgelassen. Leicht zugespitzt läuft das Narrativ gar darauf hinaus, dass politische Gründe ihm anno 1865 eine akademische Karriere verunmöglicht hätten. ${ }^{351}$ Indem Koni schon 1912 und noch deutlicher 1921 diese Probleme mit den Behörden betonte, distanzierte er sich vom zarischen Regierungs- und Verwaltungsapparat, in dem er über Jahrzehnte hinweg gearbeitet hatte. Nachdem er weiter kurz das "Glück“ erwähnt, an der Umsetzung der Gerichtsreform habe teilnehmen zu dürfen, zählt er die Institute auf, an denen er parallel zu seiner Juristenkarriere $\mathrm{ab}$ und an unterrichtet hatte. Dank diesen Betätigungen habe er auch weiterhin von einem Lehrstuhl an der Universität geträumt. Mit der Feststellung: „Dieser Traum hat mich nicht betrogen ${ }^{\text {“352 }}$ leitet Koni denn auch über in die zweite Texthälfte, in der er nun zu einer langen Zusammenfassung seiner Tätigkeiten im frühen Sowjetrussland ansetzt. Diese gehen vom Unterricht an den Petrograder Universitäten aus - der Erfüllung des „Traums“ von der akademischen Lehrtätigkeit. Er führt insbesondere den Inhalt seines Ethikkurses näher aus, erwähnt seine Vorträge zur Geschichte des Gerichtes und zu Themen aus dem Justizwesen und zählt verschiedene Literaturverbindungen auf, in denen er zur

349 Vgl. den bereits erwähnten Artikel: Konı: [Avtobiografčeskij očerk]. In: VL 9 (1921), S. 15-16. Wenn nicht anders angemerkt, wird in der Folge der Wiederabdruck in einem Sammelband von 1989 zitiert, Anatolij F. KonI: [Avtobiografičeskij fragment]. In: ders.: Izbrannoe, hrsg. u. mit einer Einleitung versehen v. Georgij M. Mironov und Leonid G. Mironov. Moskva 1989, S. 420-24.

350 Vgl. oben, S. 296.

351 Koni: [Avtobiografičeskij fragment]. In: ders.: Izbrannoe, S. 420-21.

352 Ebd., S. 421. 
russischen Literaturgeschichte gelesen habe oder persönliche Erinnerungen an „Tolstoi, Nekrasov, Dostojewski, Gončarov, Pisemskij, Apuchtin, Solovëvv, Kavelin und Turgenev" vorgetragen habe. Ein Abschnitt, in dem Koni unter anderem auch sein Engagement für die „Turgenev-Gesellschaft“ ausführlicher darstellt, wurde in der Veröffentlichung weggekürzt. ${ }^{353}$ Zum Schluss kommt er noch kurz auf seinen schriftlichen Leistungsausweis der letzten Jahre zu sprechen und berichtet von seinen weiteren Publikationsplänen. ${ }^{354}$

Koni tritt in dieser Darstellung seiner Tätigkeit nach der Oktoberrevolution als Mann der Lehre in Erscheinung, der die sowjetische Bevölkerung mit seinen Lektionen und Erinnerungsvorträgen beehrte, genau dies schon immer hatte tun wollen und damit erfolgreich den direkten Zugang zu den Menschen seiner Zeit fand. So betont er schon zu Beginn des veröffentlichten Curriculums explizit, dass er trotz der schwierigen Umstände bei der „lernenden Jugend“ „Wissensbegierde und Interesse“ festgestellt habe und des Öfteren das „erfreuliche Gefühl der geistigen Verbindung zwischen Vortragendem und Zuhörer" verspürt habe. ${ }^{355}$ Er berichtet von der Kutsche, die seine Studierenden ihm, dem alten Mann, über die offiziellen Stellen besorgten, um nicht auf seine Lektionen verzichten zu müssen. Stolz benennt er die „berührende Ungewöhnlichkeit dieses Schrittes“ und kommt zum Schluss, dass er vor diesem Hintergrund wohl eine „möglicherweise fälschliche Meinung“ gehabt habe über den mangelnden „Nutzen“, den er mit den Lesungen erreichen könne. ${ }^{356}$ Wie sehr Koni sich selber nun als Teil der Gemeinschaft der Literaturschaffenden verstand, wird durch den Titel greifbar, mit dem er seinen Entwurf für den öffentlichen Lebenslauf überschrieb: „Wie die russischen Schriftsteller leben und arbeiten" [Kak živut i rabotajut russkie pisateli]. ${ }^{357}$ Wie die Literaten, über die Koni so gerne schrieb und sprach, war auch er selber nun ein "Schriftsteller“, dem zugehört wurde und der wie Tolstoi, Dostojewski oder Turgenev Leser und Zuhörer „emporheben“ wollte und in enger „geistiger Verbindung" zu ihnen stand.

353 Vgl. das Manuskript des Textes, GARF F. 564, op. 1, d. 3, 1. 3.

354 Koni: [Avtobiografičeskij fragment]. In: ders.: Izbrannoe, S. 424. Koni erwähnt die Nachrufe, die er publiziert hatte und die veröffentlichten Auszüge aus seinen Erinnerungen über P. A. Šuvalov und über „das Gesetz vom 19. Mai 1871“, womit das „Politische Memorandum“ gemeint ist, vgl. oben, S. 263. Zudem versichert er, dass er für die zukünftigen Ausgaben von „Auf dem Lebensweg“ III und IV Material vorbereite, darunter auch die Erinnerungen an den Fall Vera Zasulič und die Entgleisung des Zarenzuges.

355 Ebd., S. 421.

356 Ebd., S. 422. Vgl. oben, S. 271 zu dieser Geschichte, die auch von Sinaida Hippius in ihrer Kritik an Koni angesprochen wurde.

357 Vgl. das Manuskript des Textes, GARF F. 564, op. 1, d. 3, 1. 1. Vgl. auch gleich nachfolgend. 
Dieses Selbstbild auch nach außen wirkungsvoll zu entfalten, war für Koni im Moment der Neuorientierung von Staat und Gesellschaft nach 1917 zentral. Im Staatsgebilde, das die Bolschewiki aufbauten, waren Rang, Ausbildungszertifikate oder Pensionsansprüche, die in den letzten Jahrzehnten gegolten hatten, auf einen Schlag in Frage gestellt. Koni versuchte zwar, seine zarischen Errungenschaften auch in der Sowjetunion geltend zu machen. So ließ er sich in einem Zeugnis vom März 1918 offiziell beglaubigen, welchen Rang er im Zarenreich erreicht hatte, welche Schule und Ausbildungsinstitute er durchlaufen hatte, in welche Ämter er befördert worden war und was für ein Honorar daraus resultiert hatte. ${ }^{358}$ Und als bei der Hausdurchsuchung zahlreiche Beweise für seine „literarischen“, „wissenschaftlichen“ und „gesellschaftlichen“ Tätigkeiten beschlagnahmt wurden, schrieb er empörte Briefe und bat um die Rückgabe von Medaillen und Amtskleidung, die für ihn wohl nicht nur Erinnerung, sondern auch physischer Beweis für die eigenen Leistungen in diesen Gebieten waren. ${ }^{359}$ Mit dem Tätigkeitsbericht „Wie die russischen Schriftsteller leben und arbeiten“ verfasste Koni schließlich eine gänzlich auf das Leben nach 1917 fokussierte Zusammenfassung seiner selbst. Die vorrevolutionären Errungenschaften werden nur noch insofern erwähnt, als sie die aktuelle Tätigkeit als Vortragender vorgespurt haben sollen. Auch in mehreren tabellenartigen "Curricula Vitae“, die jene ergänzen, die Koni schon früher verfasst hatte, wird nun ein neuer Schwerpunkt auf die Anstellung als Professor an der Petrograder Universität oder die zahlreichen Mitgliedschaften und Lektionsreihen im literarischen Feld gelegt. ${ }^{360}$ Quantitativ fasste Koni den „Nutzen“, den er noch zu bringen behauptete, in der Zahl der öffentlichen Auftritte in den Jahren nach der Machtübernahme durch die Bolschewiki. So steht in einem Notizbuch aus Konis Nachlass in der Rubrik „Anzahl Lektionen“ die Zahl „832“, die durchgestrichen und mit „958“ aktualisiert worden war. ${ }^{361}$

Faktisch kam diese Selbstpositionierung als Vortragender mit enger Verbindung zur Bevölkerung einer Konzentration auf die einzige Nische gleich, die Koni mit der Einschränkung seiner beruflichen Möglichkeiten geblieben war. Eine

358 IRLI F. 134, op. 15, d. 17, 1. 72. Es handelt sich um eine Abschrift des Dokuments und nicht um das Original.

359 SAšonko: A. F. Koni v Peterburge - Petrograde - Leningrade, S. 274 zitiert aus einem Schreiben Konis an die zuständigen Behörden.

360 IRLI F. 134, op. 4, d. 93, 1. 33, 33ob, 34, von 1918; IRLI F. 134, Op. 4, d. 391, Seite 3-4, der letzte Eintrag stammt von 1923, es handelt sich wohl um eine Abschrift des Dokuments, die hier als Teil eines Albums aufgenommen wurde. Auf dieses Dokument wird gleich noch eingegangen. Vgl. zu den Curricula aus früheren Jahren oben, S. 103.

361 IRLI F. 134, op. 1, d. 254, l. 132 ob. 
Nische allerdings, der er seit jeher großes Potenzial beimaß. Auch von außen wurde dieser Fokus mitgetragen und mitgeprägt. In den beiden Bänden zu seinen Ehren, die 1925 und 1929 von der Akademie der Wissenschaften und dem „Puschkinhaus" herausgegeben wurden, spielen Konis publizistische, literarische und akademische Errungenschaften eine zentrale Rolle. ${ }^{362}$ Der Jurist Gernet zitiert in seinem Nachruf gar prominent einen Brief, in dem Koni selber kurz vor seinem Tod erwähnte, Schritt für Schritt in das „künstlerische Feld“ überzugehen. ${ }^{363}$ Und auch das Curriculum „Wie die russischen Schriftsteller leben und arbeiten“ lässt sich auf eine Anfrage der Zeitschrift an Koni zurückführen, die seinen Rechenschaftsbericht in vorgesetzte Bahnen leitete. So handelte es sich bei dem Titel nämlich nicht um Konis eigene Wahl, sondern um die Überschrift einer Rubrik, die der „Bote der Literatur“ [Vestnik Literatury] mit dem Ziel führte, die Aktivitäten der „russischen Schriftsteller“ in den 1920er-Jahren abzubilden. Mehrfach wurden dazu ausformulierte Curricula von verschiedenen Literaten publiziert. ${ }^{364}$ Im Manuskript für den Artikel nimmt denn Koni im ersten Satz auch unmittelbar Bezug auf die Zeitschrift, die ihm „schon vor langer Zeit die Frage zu seinen Beschäftigungen“ gestellt habe, auf die er nun im „Sommerloch“ endlich antworten könne. ${ }^{365}$ Der „Bote der Literatur“ [Vestnik Literatury] ordnete Koni also seiner Schriftstellerrubrik zu und trug so mit dazu bei, ihn in seinem neuen Selbstbild zu stärken und seine Glaubwürdigkeit öffentlich zu bezeugen.

362 Im Jubiläumsband 1924 wird ausführlich die Geschichte um Konis Dissertation und die Probleme, die sich daraus ergaben, ausgeführt, vgl. den Beitrag von Lev S. UTEVsKIJ: Iz rannich let A. F. Koni. Po neizdannym materialam. In: Sergej F. Platonov/Sergej F. Ol'denburg u. a. (Hrsg.): Anatolij Fëdorovič Koni 1844-1924. Jubilejnyj sbornik. Leningrad 1925, S. $70-88$.

363 Gernet: Anatolij Fëdorovič Koni na ischode ego „žiznennogo puti“, S. IV. Treffend hält Gernet auch fest, dass Koni in seinen verschiedenen Rollen immer in erster Linie ein Lehrer gewesen sei, ebd., S. V.

364 Vgl. für eine Übersicht zu den verschiedenen Nummern der Zeitschrift, in die jeweils die Rubrik „Kak živut i rabotajut russkie pisateli“ integriert wurde: Aleksandr Ju. GALUšKıN u. a. (Hrsg.): Žurnaly „Vestnik literatury“ (1919-1922), „Letopis’ Doma Literatorov“ (1921-1922), „Literaturnye zapiski“ (1922). Annotirovannyj ukazatel'. Moskva 1996.

365 GARF F. 564, op. 1, d. 3, 1. 1. Dieser einleitende Satz wurde nicht abgedruckt. Konis Artikel erschien ohne eigenen Titel in der entsprechenden Rubrik. Während Koni noch meinte, dass diese „Wie die russischen Schriftsteller leben und arbeiten“ hieß, hatte die Zeitschrift den Rubriktitel bis zur Publikation des Textes umgewandelt, der nun lautete: „Womit unsere Schriftsteller beschäftigt sind“, vgl. GalušKın u. a. (Hrsg.): Žurnaly „Vestnik literatury“ (1919-1922), „Letopis’ Doma Literatorov“ (1921-1922), „Literaturnye zapiski“ (1922), S. 142. 


\section{Das Archiv „Puschkinhaus“: Fokus auf die Nachwelt}

Die Sinngebung als Schriftsteller und Vortragender kann nicht darüber hinwegtäuschen, dass Koni sowohl im Zarenreich wie auch in der Sowjetunion noch viel mehr zu berichten und erinnern gehabt hätte, was aufgrund mangelnder Publikationsmöglichkeiten oder Zensur die Öffentlichkeit nicht erreichen konnte oder von ihm selber aus verschiedenen Gründen nicht veröffentlicht wurde. Schon seit vielen Jahren richtete Koni seine autobiografische Praxis deshalb auf einen Zukunftshorizont aus, der weit über sein eigenes Leben hinauswies. Die Archivierung seiner Erinnerungsmanuskripte erbot sich ihm als Möglichkeit, seine Interpretationen der Vergangenheit bis zu einem Zeitpunkt zu erhalten, an dem sie auf ein ihnen gewogeneres Umfeld treffen mögen.

Seit seiner Studienzeit hatte Koni kistenweise Material gesammelt, aus dem sich mit den Jahrzehnten ein umfangreiches und vielfältiges persönliches Archiv gebildet hatte. ${ }^{366}$ Schon ganz zu Beginn dieser Sammeltätigkeit machten die eigenen Texte einen wichtigen Teil des Korpus aus. Doch daneben hatte dieser immer auch den Charakter einer historischen Sammlung mit Dokumenten bedeutender russischer Persönlichkeiten - insbesondere Schriftsteller. Archivalien aus der Sammlung und dem Nachlass von Konis Vater machten hier den Anfang und wurden bald ergänzt um Bücher, Porträtfotos, Briefe und weitere Andenken an verschiedene Autoren. ${ }^{367} \mathrm{Da}$ es sich dabei um Schriftstücke und Gegenstände handelte, denen Koni großen historischen Wert beimaß, zeigte er sich schon in den 1880er-Jahren um deren Sicherheit besorgt. ${ }^{368}$ Diese Dokumente wurden von ihm denn auch als Erste dem „Puschkinhaus“ übergeben, das ihm als der perfekte Ort für die Aufbewahrung dieser Schätze erscheinen musste. 1917 ging Koni dazu über, auch Teile seiner eigenen Schriften und Briefe als Vorlass an das Archiv zu übergeben. In einem Vertrag von 1920 wurde schließlich vereinbart, dass Koni Schritt für Schritt alle seine Unterlagen in das Literaturarchiv transferieren sollte. ${ }^{369}$ Koni hielt fest, dass seine Sammlung von „historischer Bedeutung" sei und „gedruckte und handschriftliche Notizen, Vorträge, Dokumente, Memoiren, seltene unpublizierte Ausgaben von Büchern, Zeichnungen, Porträts und Briefe von Schriftstellern, Gelehrten, Ärzten und politischen und staatlichen Akteuren“ enthalte sowie Zeugnis sei für seine eigene Arbeit ,in den Gefilden der Wissenschaft,

366 Diese Aussagen zu Konis jahrzehntelanger Sammeltätigkeit macht u. a. Ponomareva in einem kurzen Übersichtsdokument zu Konis Nachlass, das nach seinem Tod verfasst wurde, vgl. GARF F. 564, op. 1, d. 4208, 1. 1.

367 Muratov: A. F. Koni i Puškinskij Dom, S. 39 und 46-47.

368 Vgl. Domanova: Perepiska A. F. Koni kak istoričeskij istočnik, S. $56 \mathrm{f}$.

369 Muratov: A. F. Koni i Puškinskij Dom, S. 42-43. 
der Literatur und dem Rechtswesen““.370 Diese zuletzt genannten persönlichen Unterlagen enthielten als größte Einheit eine Sammlung von ca. 20.000 Briefen von und insbesondere an Koni. Hinzu kamen die Entwürfe und Handschriften seiner publizierten oder unpublizierten Schriften, Reden, Artikel, Erinnerungen und Vorlesungen. Aber auch Gerichtsmaterialien zu diversen Fällen und sonstige dienstliche Dokumente, Unterlagen zu Konis Tätigkeit in Kommissionen und im Staatsrat, biografische Materialien wie Zeugnisse oder Urkunden über Mitgliedschaften in diversen Organisationen sowie Verträge und Rechnungsbücher wurden dem „Puschkinhaus“ vermacht. ${ }^{371}$

Seit dem 19. Jahrhundert gewannen Archive als Orte „historisch und kulturell wertvoller und aussagekräftiger Quellen“ an Bedeutung. ${ }^{372}$ Hatte früher ein Archiv als Aufbewahrungsstätte von Urkunden und Rechtstiteln vor allem juristische Funktion gehabt, wuchs nun das auf die Vergangenheit bezogene Interesse an den aufbewahrten Dokumenten. Diese sollten insbesondere das „historische Erbe der Nation“ näher beleuchten. Diese „gesellschaftliche Neupositionierung“ der Archive ging Hand in Hand mit der Professionalisierung von Quellenkritik und Archivkunde. ${ }^{373}$ Immer deutlicher drang im 20. Jahrhundert ins Bewusstsein, dass im Zusammenhang mit Archiven auch über „Auswahl“ und das Gestalten von „bewusster Überlieferung“ gesprochen werden musste. ${ }^{374}$ Die Macht, die von einem Archiv und dem ihm eigenen Deutungsangebot ausging, wurde zu einer rege diskutierten Erkenntnis. ${ }^{375}$ Das Archiv wird so zu einem Untersuchungsgegenstand - es besitzt eine „Geschichte“ und verfügt über eine „Biografie ${ }^{\text {“ }}{ }^{376} \mathrm{Ganz}$ im Sinne dieser Einsichten widmete Koni sich in den Jahren vor

370 GARF F. 564, op. 1, d. 4208, 1. 2. Ponomarevas Übersichtsdokument umfasst auch nochmals die Vereinbarung zwischen Koni und dem Archiv.

371 Trudy Puškinskogo Doma Akademii Nauk SSSR (Hrsg.): Pamjati Anatolija Fëdoroviča Koni, S. 117-43. Das „Puschkinhaus“ selber veröffentlichte 1929 im Gedenkband für Koni einen ersten Beschrieb des Nachlasses; darauf wird gleich noch eingegangen.

372 Rainer Hering: Rezension über Markus Friedrich, Die Geburt des Archivs (München 2013). In: H-Soz-Kult, 10. 06. 2014, www.hsozkult.de/publicationreview/id/rezbuecher21351, Zugriff vom 09.11. 2016.

373 Markus Friedrich: Die Geburt des Archivs. Eine Wissensgeschichte. München 2013, S. $27-78$.

374 Dietmar Schenk: „Aufheben, was nicht vergessen werden darf“. Archive vom alten Europa bis zur digitalen Welt. Stuttgart 2013, S. 214.

375 Dietmar Schenk führt in seinem Aufsatz „,Archivmacht' und geschichtliche Wahrheit“ aus, wie diese Diskussionen unter anderem mit Inputs von Jacques Derrida in den 199oerJahren und weiteren Denkern der Postmoderne zusammenhängen, vgl. Dietmar SCHEnK: „Archivmacht" und geschichtliche Wahrheit. In: Rainer Hering/Dietmar Schenk (Hrsg.): Wie mächtig sind Archive? Perspektiven der Archivwissenschaft. Hamburg 2013, S. 21-43.

376 Randolph: On the Biography of the Bakunin Family Archive, S. 209-10. 
seinem Tod der Strukturierung seines persönlichen Nachlasses. Immer präsent war dabei der Gedanke, dass gewisse Erinnerungen zu einem späteren Zeitpunkt an die Öffentlichkeit gebracht werden könnten oder sollten. Dieser Fokus auf Publikation und öffentliche Verwendung seiner autobiografischen Texte nach seinem Ableben zeigte sich am deutlichsten in Bezug auf die Erinnerungsschrift zum Fall Vera Zasulič. Im neu verfassten Vorwort in der Sowjetunion schrieb Koni explizit, dass er die autobiografische Schrift eigentlich zur Publikation nach seinem Tode vorgesehen habe. ${ }^{377}$ Dass Koni sich eine intensive Beschäftigung mit seiner Hinterlassenschaft wünschte und dabei immer auch die posthume Veröffentlichung seiner unpublizierten autobiografischen Manuskripte im Hinterkopf gehabt haben musste, zeigt sich nicht zuletzt daran, dass er vernichtete, was er nicht für zukünftige Generationen erhalten wollte. Bewusst grenzte er so die Interpretationen ein, die die Benutzer des Archivs von seiner Person in $\mathrm{Zu}$ kunft machen konnten. An Sergej Platonov schrieb er: „Ich sammle alle meine Dokumente für die Übergabe ins ,Puschkinhaus', die ich nicht der Zerstörung überlassen möchte (Briefwechsel, historische Notizen, Grußbotschaften etc.). “378 Jenen Erinnerungsschriften, die er nicht der „Zerstörung “ ̈̈berließ oder zuführte, stellte Koni in seinem Nachlass weitere Informationen zur Seite. Der von ihm so häufig in seinen Schriften bemühte „zukünftige Historiker“ sollte nicht nur in den autobiografischen Versatzstücken Konis wühlen können, sondern auch ein durch zusätzliche Materialien geformtes, sehr deutliches Bild vom Autor dieser Werke erhalten - und weitertransportieren. Ähnlich wie viele Persönlichkeiten öffentlichen Interesses sorgte Koni dafür, dass seine „Rolle in der Geschichte“ sichtbar und zumindest für die Nachwelt in seinem Sinne fassbar wurde. ${ }^{379}$ Koni ließ deshalb seine Texte nicht einfach für sich selber sprechen, sondern bewahrte auch auf, was die Zeitgenossen von seinem Schreiben, aber auch von seinen Leistungen und Erfolgen hielten. Geschickt steuerte er so die Interpretation seiner selbst. Neben den biografischen Unterlagen wie Zeugnissen oder Auszeichnungen finden sich in seinem Nachlass auch zahlreiche Koni lobend porträtierende Zeitungsartikel, unzählige Gratulationen in Brief- oder Telegrammform und verschiedene herz-

377 Koni: Vospominanija o dele Very Zasulič. In: GA2, S. 25. Dabei sollte es bekanntlich auch bleiben, da Konis Publikationsbemühungen in den 1920er-Jahren nicht von Erfolg gekrönt wurden, vgl. das Kapitel Politische Erinnerung an das Zarenreich in der Sowjetuion.

378 Zitiert nach: Domanova: Perepiska A. F. Koni kak istoričeskij istočnik, S. 56. Vgl. oben, S. 333 mit Überlegungen zur Vernichtung gewisser Dokumente durch Koni.

379 Holquist: Bureaucratic Diaries and Imperial Experts, S. 214. Holquist spricht von Bürokratentagebüchern, aber auch persönlichen Archiven und Memoiren von Staatsmännern, die so ihre Erfolge beispielsweise im Russisch-Osmanischen Krieg 1877/78 festhalten wollten. 
liche Grußadressen zu seinen Dienstjubiläen und Geburtstagen. ${ }^{380}$ Ein dickes Aktenbündel enthält verschiedene, oft von einem professionellen „Sammler von Zeitungsausschnitten“ [Kollekcioner gazetnych vyrezok] zusammengetragene Erwähnungen Konis in der Tagespresse vornehmlich in den 1910er-Jahren. ${ }^{381}$ Signierte Titelblätter von Büchern, die Koni von den Autoren persönlich gewidmet wurden, verweisen auf seine Bekanntschaft mit den Schriftstellern und Denkern seiner Zeit. ${ }^{382}$ Gigantisch erscheint die Sammlung von Visitenkarten, die Koni dem „Puschkinhaus“ vermachte. Mehr als 1000 Stück erinnern an die vielen Besucher, die Koni zuhause eine Visite abstatteten. Kurze Anmerkungen wie Daten, zusätzliche Namen oder gestellte Fragen geben kryptische Hinweise auf die Bedürfnisse der Gäste. ${ }^{383}$ Dieser eindrückliche Beleg für Konis breite Vernetzung und seinen enormen Bekanntenkreis wird noch übertroffen von seiner Briefsammlung. Die Abertausende von Briefen veranlassten Modzalevskij dazu, bei Koni eine gewisse „Gier“ nach Bekanntschaften zu diagnostizieren. Der ehemalige Direktor des „Puschkinhauses“ merkte 1929 in seinem Nachruf auf Koni an, dass keine einzige Person, die in den letzten Jahren ihren Nachlass in das Archiv gegeben habe, nicht auch Briefe von Koni mitgeliefert habe. ${ }^{384}$ Sowohl der spezifische Inhalt als auch der hohe Grad an Bewusstheit, mit der Koni seine Hinterlassenschaft zusammenstellte und sortierte, lassen das Archiv zu einer Spielart seiner autobiografischen Praxis werden. Zweifelsohne diente auch diese Sammel- und Ordnungstätigkeit einer "Darstellung des Selbsts“ - um noch einmal Jochen Hellbeck zu zitieren.

Dabei zeigt sich allerdings einmal mehr, dass die Grenzen zwischen Selbstdarstellung und Außenwahrnehmung nicht eindeutig zu ziehen sind. Die Entstehungs- und Verwendungsgeschichte der Dokumentensammlung lässt erahnen, dass ein eigentümliches Wechselspiel zwischen Konis eigenen Intentionen sowie Interessen und Interpretationen von Außenstehenden gegeben war. So fallen überall Spuren von Menschen und Institutionen auf, die beim Ordnen und teilweise auch schon beim Verfassen der Materialien beteiligt gewesen waren. Bereits 1924 heißt es in der Grußadresse des „Puschkinhauses“ zu Konis 8o. Geburtstag, dass sich das Archiv als „ewiger Bewahrer“ [večnyj chranitel'] von Konis Nachlass

\footnotetext{
380 Vgl. z. B. IRLI F. 134, op. 4, d. 22 ff oder 45.

381 GARF F. 564, op. 1, d. 4222.

382 GARF F. 564, op. 1, d. 4194. Ähnlich nehmen sich auch die Kurzlebensläufe aus, die Koni im Verlauf seiner Karriere immer wieder verfasste und in denen er die zahlreichen Institutionen und Organisationen nannte, an denen er beteiligt war, vgl. oben, S. 103.

383 Smoljarčuk: Anatolij Fëdorovič Koni (1844-1927), S. 203-04 und IRLI op. 4, d. 386.

384 Modzalevskij: Krug literaturnych otnošenij A. F. Koni, S. 51.
} 
verstehe. ${ }^{385} \mathrm{Im}$ „Jubiläumssammelband“ findet sich denn auch bereits eine erste Ordnungsleistung der Archivare. So wurde eine nach Jahren geordnete Bibliografie der Werke Konis erstellt. ${ }^{386}$ Eine Übersicht über Konis publizistische und archivalische Hinterlassenschaft zu erhalten, war auch das Ziel weiterer Dokumentationsversuche Dritter. Im Gedenkband für Koni, den das „Puschkinhaus“ 1929 veröffentlichte, beschreiben die Archivare Konis Hinterlassenschaft und rekapitulieren den Zustand der Archivalien vor der Übergabe und den Prozess des Transfers ins Literaturarchiv. ${ }^{387}$ Auch wenn Koni zahlreiche Dokumente schon $\mathrm{zu}$ Lebzeiten in das Archiv brachte, befand sich ein großer Teil der Sammlung $\mathrm{zu}$ seinem Todeszeitpunkt noch bei ihm zuhause. 130 Schachteln seien in seiner Wohnung verteilt gewesen. In den Schränken seines Arbeitszimmers und seiner Bibliothek oder einfach auf dem Boden hätten diese gestanden und allesamt seien sie thematisch beschriftet gewesen. „Puschkin“, „Turgenev“, „Tolstoi“, „Akademie der Wissenschaften“, „Theater“, „Materialien zur Gesetzgebung“, „Geschichte“, „Jubiläen“, „Ethik und Psychologie“ oder „Erinnerungen“ hätten diese Beschriftungen geheißen. ${ }^{388}$ Noch bevor all dies in die Räumlichkeiten des „Puschkinhauses“ transportiert worden sei, sei durch ,die Hände einiger engen und ihm ergebenen Freunde" ein Protokoll erstellt worden, in dem alle Unterlagen von Koni genau in der Reihenfolge und Anordnung festgehalten worden seien, in der er selber sie hinterlassen hatte. Dies, damit später, wenn es zu einer nötigen Systematisierung und Überarbeitung von Konis Ablageprinzip gekommen sei, immer noch der Originalzustand rekonstruierbar sei. So könne man den Prozess seines Arbeitens am besten nachverfolgen. ${ }^{389}$ Tatsächlich befinden sich zusätzlich zur Auflistung, die im Gedenkband abgedruckt wurde, auch verschiedene Übersichtsdarstellungen

385 Ebd., S. 54 oder die veröffentlichte Adresse in Platonov/Ol'Denburg (Hrsg.): Anatolij Fëdorovič Koni 1844-1924, S. 18.

386 R. L. Gol'darbejter/E. A. Šachmatova/S. A. Šachmatova-Koplan/B. I. Koplan: Bibliografija sočinenii A. F. Koni. In: Sergej F. Platonov/Sergej F. Ol'denburg u. a. (Hrsg.): Anatolij Fëdorovič Koni 1844-1924. Jubilejnyj sbornik. Leningrad 1925, S. 207-26. Diese Liste beruhte auf einer Vorlage, die in einem anderen Band zu Konis Geburtstag abgedruckt wurde, vgl. N. JuRskij/R. Gol'darbejter: A. F. Koni v istorii Russkoj obščestvennosti. Petrograd 1924, S. 19-46. Hier ist die Ordnung noch alphabetisch und es sind auch Artikel über Koni integriert. Es wird vermerkt, dass sich die Bibliografie auf eine Ausstellung beziehe, die für Koni 1921 in der „Zentralbibliothek Genosse Lunačarskij“ organisiert wurde. Bücher von und über Koni seien damals zu besichtigen gewesen und auch ein erster kurzer Katalog der Werke. Koni selber habe diesen dann weiter ergänzt, vgl. ebd., S. 21.

387 Trudy Puškinskogo Doma Akademii Nauk SSSR (Hrsg.): Pamjati Anatolija Fëdoroviča Koni, S. 117-43.

388 Ebd., S. 117-18.

389 Ebd., S. 119. 
im Nachlass. Diese listen Büchertitel oder thematische Dossiers auf und vermerken zudem immer wieder, dass dies und jenes im „Schrank II, Regal 1“ oder „auf dem obersten Regal im Wohnzimmer" oder im „historischen Schrank" in einer „graugrünen Mappe ohne Beschriftung“ zu finden gewesen sei. ${ }^{390}$

Wenn hier also der Anschein größtmöglicher Zurückhaltung und vorausschauender Arbeit vermittelt wird, lässt die Sichtung von Konis Nachlass doch keinen Zweifel daran, dass die „engen und ihm ergebenen Freunde“ auch ihren eigenen Teil zur Darstellung von Koni mit beigetragen haben. Ein kunstvoll gestaltetes Album, das aus den 1920er-Jahren zu stammen scheint, stellt Koni, seine Geschichte und sein Umfeld vor. Unter den Albumseiten befinden sich auch solche, auf die in verschiedenen Farben Bücherrücken aufgemalt wurden. Darauf prangen die Titel der Publikationsorgane, die Beiträge über Koni veröffentlicht haben. ${ }^{391}$ Die Zeichnung kreiert mit ihrer Farbenpracht und der großen Anzahl an aufgelisteten Titeln eingänglicher als all die Bibliografien und Zeitungsausschnitte das Bild von einem Mann, der zeitlebens in aller Munde gewesen sein musste. Gleichzeitig macht die Darstellungsform deutlich, dass unmöglich Koni selber diese und die anderen Albumseiten verfasst haben konnte, da sein Gesundheitszustand solcherlei nicht zugelassen hätte. Vermutlich hat Elena Ponomareva diese schmuckvolle Zusammenfassung von Konis Leben und Werk kurz vor seinem Tod gestaltet. ${ }^{392}$ Ein ähnliches Beispiel stellt ein Schriftenbündel dar, das als „Konvolut“ in den Nachlass gegeben wurde und eine umfangreiche Abschrift von einzelnen Dokumenten aus Konis Hinterlassenschaft darstellt. Auch hier wird von unbekannter Hand ein Schwerpunkt auf Konis Erfolge gelegt. Eine Gratulationsadresse der Akademie der Wissenschaften findet sich ebenso wie Abschriften aus Ehrungen, die Zeitungen zu Konis Dienstjubiläen abgedruckt hatten. Verschiedene Briefe sind abnotiert worden, und dabei steht immer fein säuberlich vermerkt, aus welchem „Korb“ ihn der Verfasser oder die Verfasserin dieses Konvoluts in der Wohnung Konis entnommen habe. ${ }^{393}$ Inwiefern auch die ursprünglichen Dokumente - insbesondere die vielen Zeitungsartikel mit Lobpreisungen zu Konis Geburtstagen oder Dienstjubiläen im Zarenreich - von Drittpersonen in Konis

390 In der Reihenfolge der Zitate: der Bibliothekskatalog in GARF F. 564, op. 1, d. 4224, hier 1. 1, das Notizbuch „Archivalphabet“, IRLI F. 134, Op. 4, d. 385, hier 1. 29 ob und ein Heft mit einer Auflistung in GARF F. 564, op. 1, d. 4223, hier 1. 1.

391 IRLI F. 134, op. 4, d. 391, S. 34.

392 Smoljarčuk: Anatolij Fëdorovič Koni (1844-1927), S. 208 schreibt ohne weitere Angaben, dass sie dies zusammen mit Koni in dessen letzten Lebensjahren zusammengetragen habe.

393 IRLI F. 134, op. 15, d. 17. Das Archiv datiert das „Konvoljut“ auf die 1920er-Jahre und vermerkt, dass es von unbekannter Schrift verfasst sei. Vgl. z. B. 1. 56ob: Brief aus dem Korb „Tolstoi“. 
Umfeld gesammelt wurden, lässt sich nicht mit Bestimmtheit sagen. Während diese Dokumentationen aber grundsätzlich sicherlich im Sinne von Koni waren, überhöhte sich das Bild von ihm durch die Ehrfurcht dieser Gehilfen nochmals beträchtlich. Wie bedeutend gerade für Ponomareva nicht nur Konis Lebenswerk, sondern auch seine Hinterlassenschaft war, wird in der bereits zitierten von ihr verfassten Notiz zu Konis Nachlass deutlich:

An uns, seinen [Konis, CC] Zeitgenossen, liegt es, alles zu erhalten, was den zukünftigen Generationen das Geheimnis der Ausstrahlung und der enormen Leistungsfähigkeit dieser facettenreichen Persönlichkeit zu Gunsten der Menschheit eröffnen kann. ${ }^{394}$

Nach Konis Tod veranstaltete Ponomareva Führungen durch die Wohnung ihres verstorbenen Freundes und zeigte den interessierten Zeitgenossen die Bücher und Gegenstände, die noch darin verblieben waren. Konis Wohnung wurde so für kurze Zeit zu einer Art Außenstelle des „Puschkinhauses“ und fungierte gleichzeitig als Gedenkstätte und als Ort, an dem die Vorbereitungen zur endgültigen Archivierung seiner Hinterlassenschaft getroffen wurden. ${ }^{395}$ Schon in den Jahrzehnten vor seinem Tod hat Koni sich in seinen schriftlichen Aktivitäten auf die Hilfe von befreundeten Frauen gestützt, die als Sekretärinnen und Schreibhilfen agierten. Seit Ende der 188oer-Jahre litt Koni unter Herzproblemen, die ihm das Schreiben stark erschwerten. In den ersten beiden Jahrzehnten des 20. Jahrhunderts übernahm die Russischlehrerin Nadežda Pavlovna Lanser (1879/80-1920) die Reinschrift zahlreicher Texte oder Briefe, nach ihrem Tod Ponomareva und weitere Freundinnen des Hauses. ${ }^{396}$ Ponomareva, so erinnert sich Čukovskij, sei einige Jahre vor Konis Tod zu ihm gezogen und habe sich völlig der Umsorgung des alten Mannes gewidmet. Dabei habe sie sogar den Namen "Anatolij Fëdorovič“ mit besonderer Betonung ausgesprochen, weil darin für sie „alles Edle, Menschliche, was es nur gibt auf dieser Erde" innezuwohnen schien. ${ }^{397}$ Während diese Helferinnen zuerst lediglich die Worte Konis verschriftlichten, zeigt das Beispiel von Ponomareva, dass daraus immer mehr auch die Zusammenfassung, Gestal-

394 GARF F. 564, op. 1, d. 4208, 1. 1.

395 Muratov: A. F. Koni i Puškinskij Dom, S. 52.

396 Domanova: Perepiska A. F. Koni kak istoričeskij istočnik, S. 73-74 und SAšonko: A. F. Koni v Peterburge - Petrograde - Leningrade, S. 280-82. Lanser, so Koni in einem Brief, den Sašonko zitiert, habe einen großen Teil der Bände „Auf dem Lebensweg“ unter seiner Diktion verfasst. Vgl. zum Kreis der Frauen auch SMoljarčuK: A. F. Koni i ego okruženie, S. 357-6o. Smoljarčuk nennt 1879 als Geburtsjahr, in den Anmerkungen zu GA8, S. 488 ist von 1880 die Rede.

397 Čukovskij: Anatolij Fëdorovič Koni. In: GA8, S. 8-9. 
tung und Hervorhebung spezifischer Leistungen des bewunderten Mannes wurde. Nach seinem Tod ging sie gar dazu über, angefangene Texte von Koni selber zu beenden. Ein mit Schreibmaschine getipptes Manuskript, das auf Ponomareva zurückzuführen ist, enthält die Angabe, dass es "nach den Werken von A. F. Koni“ und anhand vom ihm zitierter Autoren verfasst worden sei. Es beinhaltet eine Zusammenfassung von Konis Gedanken zu Moral und Erziehung. ${ }^{398}$

Gemeinsam mit seinen engsten Freunden und Helfern sorgte Koni also dafür, dass der Zugang zu ihm und seinen Gedanken auch nach seinem Tod gewährleistet blieb, und versuchte dabei, sein Wesen und sein Schaffen in einer ihm genehmen Form zu konservieren. Wie stark er dabei in der Logik seines eigenen Biografen dachte, zeigen schließlich auch die letzten Anweisungen, die er für den Fall seines Todes erließ. ${ }^{399}$ Im Oktober 1926 schickte er eine Liste mit seinen seit 1918 gehaltenen Vorträge an Gernet. Diese „Liste der Kurse und öffentlichen Vorlesungen des Ehrenakademikers A. F. Koni zwischen 1918 und Juni 1926“ sollte dem befreundeten Juristen als Material für den vom ihm zu erwartenden Nachruf auf Koni dienen. ${ }^{400}$ Im Sommer des gleichen Jahres hielt er zudem auf einem gefalteten Blatt fest, was „,im Falle meines Todes“ zu tun sei. Neben Anweisungen zum Friedhof, der Beerdigung und den Meldungen an die Zeitungen enthält der Zettel gleich an erster Stelle die Bitte, sofort dem „Puschkinhaus“ Bescheid zu geben. Modzalevskij wird als Vertrauensperson genannt. ${ }^{401}$ Damit die Übergabe an das Archiv sicher nicht schiefgehen konnte, schrieb Koni diesem einige Monate danach auch noch einen persönlichen Brief, der sofort nach sei-

398 IRLI F. 134, op. 12, d. 8, 1. 7-15, Zitat 1. 7.

399 Leben werden offensichtlich manchmal schon als Autobiografien gelebt, oder als Biografien. So drückte es Volker Depkat an der Abschlusstagung des Projektes „Imperial Subjects" im Februar 2016 bezogen auf Koni aus.

400 Gernet selber benutzt dann nicht nur die Liste in seinem Nachruf auf Koni, sondern erwähnt auch, wie diese an ihn gelangte, vgl. Gernet: Anatolij Fëdorovič Koni na ischode ego „žiznennogo puti“, S. I-II.

401 IRLI F. 134, op. 4, d. 377. Koni hat neben dem Wunsch, auf dem Aleksandr-NevskijFriedhof beerdigt zu werden, auch bereits die Grabaufschrift bestimmt. Es scheint allerdings mehrere Varianten gegeben zu haben. Diese letzte aller Selbstbeschreibungen lautet bis heute: „Er dachte nach, fühlte, arbeitete“ - ein Zitat aus dem Werk von Konis Vater, vgl. Domanova: Perepiska A. F. Koni kak istoričeskij istočnik, S. 86. Ein wohl verworfener, früherer Vorschlag findet sich in IRLI F. 134, op. 15, d. 17, 1. 72. Nach einer Verlegung in den 1930er-Jahren befindet sich Konis Grab heute auf dem Volkovo-Friedhof umgeben von zahlreichen berühmten Literaten und Künstler im Abschnitt „Literatorskie mostki“, vgl. VysockiJ: Koni, S. 426 sowie ein bebilderter Artikel zur Einweihung des im September 2017 frisch restaurierten Grabsteins, http://mitropolia.spb.ru/news/culture/?id=121545, Zugriff vom 01. 08. 2018. Die Initiative zur Restaurierung sei vom Justizministerium ausgegangen und über den privaten Fonds „Grachya Pogosyan“ finanziert worden. 
nem Tod übergeben werden sollte. Darin rekapituliert Koni einmal mehr, dass er 1920 vereinbart habe, alle seine Unterlagen dem „Puschkinhaus“ zu übergeben, dass aber einiges noch bis zu seinem Tod in der Wohnung verbleiben werde. Er brauche diese Sachen für seine Vorträge und zur „Verzierung meiner Wohnstätte“. Sobald nun also Modzalevskij diesen Brief erhalte, solle er Leute losschicken, um die Materialien aus dem Haus des Verstorbenen zu holen. Explizit erwähnt Koni seinen Schreibtisch, der doch recht schwer sei und für den es wohl besondere Transportvorkehrungen zu treffen gelte. Schließlich beendet er den Brief mit einem innigen Dank an Modzalevskij. ${ }^{402}$

Die letzten Worte Konis an den Freund widmeten sich also ganz und gar der eigenen artefaktischen und schriftlichen Hinterlassenschaft. Nach seinem Tod konnte das Erinnerungsmaterial nicht länger als Basis für seine Vorträge dienen, aber Konis Botschaft sollte nicht vergessen gehen. Sie harrte nun im Literaturarchiv ihrer möglichen Entfaltung in naher oder ferner Zukunft.

\subsection{2 „Volk“ und Intelligencija: Notizen der Enttäuschung}

Warum kam es im Februar 1917 zu einer Revolution, die den Zaren für immer seines Thrones entledigen sollte? Wie hatte es passieren können, dass dieser Umsturz von Gewalt begleitet wurde? Was bedeutete es für Russland und seine Bewohner, als nicht einmal ein Jahr später die Bolschewiki die Macht übernahmen? Die in ihrer Finalität und Radikalität außerordentlichen Veränderungen, mit denen Koni 1917 und in den Jahren danach konfrontiert war, weckten in ihm das Bedürfnis, eine Geschichte seiner Heimat zu schreiben. Eine Geschichte, in der er selber als Akteur und Beteiligter mannigfaltig auftauchte und die dem Ziel zu dienen schien, über die Suche in der Vergangenheit Antwort auf die Frage nach der eigenen und Russlands Gegenwart und Zukunft zu geben.

Autobiografien - so Volker Depkat - sind immer auch ein Akt der „Selbsthistorisierung einer jeweiligen Gegenwart". Vorstellungen vom geschichtlich Relevanten am eigenen Erfahrungsschatz kristallisieren sich heraus. Gleichzeitig wird die Zeit, in der der Autor lebt, in der Geschichte positioniert. Autobiografien der Neuzeit kommen ohne dieses „zeitpunktspezifische Epochenbewusstsein“ nicht aus. Indem aus einer jeweiligen Gegenwart in die Vergangenheit und in die $\mathrm{Zu}$ kunft geschaut wird, wird der "historische Ort“ definiert, an dem man selber

402 Zarodovaja: Perepiska B. L. Modzalevskogo s A. F. Koni, S. 385-86. Zarodovaja gibt an, dass hinten auf dem Brief eine Bemerkung von E. Ponomareva stehe, dass der Brief schon offen gewesen sei, als sie ihn gefunden habe, und sie ihn deshalb nicht sofort weitergegeben habe. 
steht. ${ }^{403}$ Gerade im russischen Kontext war diese „Reflexion über Subjekt und Geschichte" außerordentlich stark. Seit der Wende vom 18. zum 19. Jahrhundert betonte der "Imperativ der Zeitgenossenschaft" diesen Zusammenhang. ${ }^{404}$ Der Autobiograf verstand sich selber geradezu als Katalysator historischer Prozesse und gestaltete seine Erinnerungen in diesem Sinne. ${ }^{405}$ Eine regelrechte „Besessenheit mit Geschichte" findet man in der russischen literarischen Elite. ${ }^{406}$ Die gesamte Intelligencija lässt sich unmittelbar als Netzwerk von Personen beschreiben, die alle von der sozialen und historischen Bedeutung ihrer eigenen Leben tief überzeugt waren. ${ }^{407}$ Umso notwendiger müssen angesichts des historischen Wandels im Jahre 1917 die „Ordnungsleistung“ und „Sinnbildung“ erscheinen, die autobiografisches Schreiben zu leisten vermag. ${ }^{408}$

Die Entwürfe, die Koni schon im Moment der Februarrevolution und dann im ganzen nachfolgenden Jahrzehnt verfasste, tragen unverkennbar die Spuren dieses Bedürfnisses nach Einordnung und Erklärung des Geschehenen. Ein halbes Dutzend Versuche, über sich und die Geschichte Russlands nachzudenken, verpacken ähnliche Gedanken in verschiedene Formen. Mehrfach legte Koni Stichwortsammlungen von ein bis vier Seiten an oder notierte in Halbsätzen seine Ideen, vereinzelt schrieb er auch zwei bis drei Seiten Fließtext. Meistens teilt er dabei seine Entwürfe in Abschnitte ein. Diese folgen manchmal den Zäsuren seines eigenen Lebens, manchmal aber auch den Ereigniszusammenhängen der historischen Entwicklung zu seinen Lebzeiten. Die "große Geschichte“ taucht mal mehr, mal weniger dominant auf. Gemeinsam ist den verschiedenen Schriften, dass sie in ihrem Anspruch immer ein Gesamtbild von Entwicklungen und Geschehnissen abgeben möchten. Den frühesten dieser Textentwürfe scheint Koni noch während der Februarrevolution verfasst zu haben. Die „Geschichte der Heimat während meines Lebens" beginnt im Jahre 1850 und orientiert sich an den Regierungsperioden der verschiedenen Zaren. Auf der letzten Seite schreibt Koni vom 26. Februar 1917, als sich die Truppen mit den Arbeitern verbündeten. ${ }^{409}$ Bezeichnenderweise ist dieser letzte Abschnitt der Stichwortsammlung zu den

403 DepкAт: Nicht die Materialien sind das Problem, sondern die Fragen, die man stellt, S. 114-15.

404 Herlth: „Verengung des Handlungsfelds“, S. 414.

405 Hellbeck, zitiert in Nathans: Talking Fish, S. 585.

406 Wachtel untersucht russische Schriftsteller und ihre, wie er sagt „obsession with history“ in seiner Monografie, vgl. Andrew B. Wachtel: An Obsession with History. Russian Writers Confront the Past. Stanford California 1994.

407 PAPerno: Intimacy and History, S. 2-3.

408 Haumann: Geschichte, Lebenswelt, Sinn, S. 86 und Depкat: Nicht die Materialien sind das Problem, sondern die Fragen, die man stellt, S. 109.

409 GARF F. 564, op. 1, d. 171, l. 3. 
Ereignissen in den vergangenen Jahrzehnten nicht abgeschlossen. Auf Seite zwei heißt der Zwischentitel nämlich „1894-?“. Das Fragezeichen verdeutlicht, dass zum Schreibzeitpunkt das Schicksal von Zar Nikolaus II., der 1894 den Thron bestiegen hatte, noch völlig offen war. Trotzdem verfasste Koni bereits in den Wirren des Umsturzes seine „Geschichte der Heimat“. Darin gibt er auf die implizite Frage nach dem Warum genau die gleichen Antworten, die er schon seit Jahrzehnten in seinen politischen Analysen betont hatte. Erneut vermischen sich biografische und historische Ereignisse zu einer Kette von Fehlentwicklungen, an deren Ende nun das Revolutionsjahr von $1917 \mathrm{zu}$ stehen kommt. Die Gerichtsreform wird ebenso genannt wie das Attentat von Karakozov 1866. ${ }^{410}$ Der Gerichtsfall Vera Zasulič und die Reformen von Loris-Melikov tauchen auf, die von Koni als „erster Schritt zur Rettung Russlands vor der Revolution“ gedeutet werden. ${ }^{411}$ Der „neue Weg der Reaktion“, der nach der Ermordung des Zaren eingeschlagen wird, bildet schließlich den Auftakt für den Anfang vom Ende. ${ }^{412}$ Anhand von Beispielen aus seiner beruflichen Tätigkeit - insbesondere bezogen auf den Umgang mit religiösen Minderheiten - führt Koni vor Augen, wie ungeschickt die politische Führung seiner Ansicht nach handelte, und kritisiert die Art und Weise, wie Nikolaus II. im entscheidenden Moment 1905 agierte. ${ }^{413}$ Fast wortwörtlich finden sich diese Elemente auch auf einer 1920 verfassten Seite mit Stichworten zur Geschichte Russlands, die diesmal allerdings schon beim Zasulič-Fall endet. ${ }^{414}$ Das gleiche Bild ergibt sich aus dem Text „Die Gegenwart und die Zukunft der Heimat“. Undatiert, aber augenfällig gut zu den anderen biografisch-historischen Gesamtbeurteilungen passend, zählt Koni auch hier die genannten Stichworte auf. Er bricht ab nach der Aufzählung einiger „zwielichtiger Gestalten rund um den Thron“. Weitere Ausführungen, insbesondere Prognosen für die Zukunft, fehlen entgegen der Versprechung im Titel. Oder war mit dem Verweis auf diese „Zwielichtigen Gestalten“ schon alles gesagt und der Niedergang des Zarenreiches selbsterklärend und unausweichlich? ${ }^{415}$

\footnotetext{
410 Ebd., 1. 1-10b.

411 Ebd., l. 1ob.

412 Ebd., 1. $10 \mathrm{obf}$.

413 Ebd., 1. 2.

414 GARF F. 564, op. 1, d. 199, 1. 66. Das Konzept entstammt einer Sammlung mit Materialien zum Fall Vera Zasulič. Möglicherweise verfasste Koni diese Stichworte also auch als historischen Abriss für die Einleitung zu seiner Erinnerungsschrift über diesen Fall.

415 GARF F. 564, op. 1, d. 192. Im Stil ebenfalls ähnlich sind die wohl um die Mitte der 1920erJahre verfassten Gedanken zum Jahre 1881. Anhand der Geschehnisse in diesem einen Jahr kann Koni die meisten der genannten Punkte verdichtet darstellen. Er erwähnt hierbei auch seine eigenen publizistischen Beiträge zum Tod des Zaren, vgl. GARF F. 134, op. 1, d. $147,1.22-220 b$.
} 
Ebenfalls unvollendet scheint ein weiteres Konzept zu sein, das Koni 1923 anfertigte. Die „biografischen Notizen“ legen aber einen deutlich anderen Schwerpunkt. Seine eigene Person bildet den Mittelpunkt, während die historischen Ereignisse in den Hintergrund treten. Die Stichworte und Halbsätze sind nach Lebensphasen geordnet und geben vielleicht insgesamt mehr Persönliches preis, als es in irgendeinem anderen von Konis autobiografischen Texten der Fall ist. Hin und wieder erwähnt Koni zwar durchaus gesellschaftliche und politische Entwicklungen, wie beispielsweise den Krimkrieg und den Tod von Zar Nikolaus I. im Jahre 1855 und den Eindruck, den dies auf die Schriftsteller und Künstler gemacht habe. ${ }^{416}$ Oft aber bewegt sich Koni im privaten Bereich. Im Abschnitt „Kindheit 1844-1851“ werden Stichworte zur Mutter oder dem Bruder aufgelistet. ${ }^{417}$ Unter „Knabenjahre 1852-1858“ kommen die Erfolge des Vaters und dessen Bekanntenkreis vor. ${ }^{48}$ Und nach dem Zwischentitel „Jugend 1858-1861“ findet man nicht nur die Aufzählung von Konis ersten Professoren an der Universität, sondern auch Stichworte zum „Sommer in Petergof. Panafidiny. Katja. Erste Liebe“. ${ }^{419}$ Trotz dieses deutlich persönlicheren Charakters scheint es nicht verfehlt, dieses Schriftstück in Zusammenhang zu bringen mit den zeitgleich entstandenen Entwürfen für die Geschichte der „Heimat“. Auch in den „biografischen Notizen“ geht es Koni erstmals darum, eine ganzheitliche Erklärung über die Ereignisse in der Vergangenheit, insbesondere nun seiner eigenen, abzulegen. Die Frage nach dem „Warum“ steht nicht ganz so deutlich als Ziel der Analyse im Fokus. Trotzdem ist es bezeichnend, dass Koni, der immer nur thematische Erinnerungsschriften verfasst hatte und eine Biografie über sich nicht wünschte, nun doch noch eine Gesamtschau seines Lebensweges abgeben wollte. Da dieser Ansatz zu einer klassischen Autobiografie allerdings weder ausformuliert wurde noch über die Beschreibung der Studienzeit hinausgelangte, lässt sich kaum eine Bezugnahme zum Schreibzeitpunkt in der frühen Sowjetunion ausmachen. Wie Koni den weiteren Verlauf seines Lebens in dieser Autobiografie beschrieben hätte und wie stark dabei wieder die Analyse der Ursachen für die revolutionären Veränderungen eine Rolle gespielt hätte, bleibt offen.

In die bekannten Analysemuster Konis mischen sich in den 1920er-Jahren verstärkt neue Töne. Die Frage nach dem „Warum“ und die Schlüsse, die Koni aus den historischen Neuordnungen für den Sinn und die Bedeutung seines eigenen Lebens zieht, erhalten eine zusätzliche Komponente. Intelligencija und „Volk“ ge-

416 IRLI F. 134, op. 4, d. 93, 1. 39.

417 Ebd., l. 38-38ob. Vgl. auch Vysockis: Koni, S. 17-18. Vysockij zitiert ohne Angabe des genauen Archivgutes einen Großteil der Stichworte aus den „Biografischen Notizen“.

418 IRLI F. 134, op. 4, d. 93, 1. 28ob-39ob. Vgl. auch VysockiJ: Koni, S. 25-26.

419 IRLI F. 134, op. 4, d. 93, l. 39ob-41. Vgl. auch VysockiJ: Koni, S. 36 und 47. 
sellen sich plötzlich immer dominanter zu Konis Überlegungen zu „Subjekt und Geschichte" hinzu, und eine tiefe Enttäuschung von beiden ist unübersehbar. Eine Sammlung von über einem Dutzend Notizbüchlein, die mit Daten zwischen 1918 und 1923 versehen sind, enthält Gedanken Konis zu den verschiedensten Themen, über die er in diesen Jahren referierte. In einem der Heftchen finden sich auch Überlegungen zu den „Übeln des Tages“.${ }^{420}$ Darin hält Koni fest:

Die Regierung hat alles unternommen, um die Intelligencija aufzuwühlen, unbefriedigt zu lassen, zu reizen und in ihr die Begierde zu wecken, die Ordnung zu stürzen, anstatt das Volk vernünftig, laut den Ideen der gerechten Ordnung, zu erziehen. ${ }^{421}$

Dem „Volk“ [narod] aber sei alles fremd, mit Ausnahme „der Gedanken an das Land“. Es habe keinerlei Verständnis für intellektuelle Berufe ohne Kontakt zur Landwirtschaft. ${ }^{422}$

Daraus folgt das Fehlen des Verständnisses für die Lebensumstände (Sünde der Intelligencija), für die Moral (Sünde der Popen) und das Gefühl von Hass und Neid gegenüber dem „Herrn“, bestärkt durch Armut und Faulheit. ${ }^{423}$

Dieses Urteil wird von Koni weiter vertieft in einer undatierten, aber wohl gegen Ende des Ersten Weltkrieges verfassten Schrift. In dieser „Analyse der Seelenunruhen“ führt Koni explizit Biografisches und Historisches zusammen. Er stellt nämlich zuerst einige allgemeine Überlegungen zum Verhältnis zwischen der "gemeinen Sache der Menschheit und der Heimat“ und der „bedauerlichen persönlichen" Sache an. ${ }^{424}$ So sei das, was nun mit den Ländern Europas und Russland passiere, wahrscheinlich insgesamt gesehen etwas Gutes. Die Demokratie sei auf dem Vormarsch. Das „alte Russland“, das sich seinen verschiedenen Völkern gegenüber so schlecht verhalten habe, zerfalle wohl in kleine föderative Republiken oder parlamentarische Monarchien. Jetzt sei das alles hart für das Land, aber in einigen Jahrzehnten werde das „föderative Russland“, das auf „gutnachbarschaftlichen Beziehungen" aufbaue, sich in einer so guten Lage wie Schweden, Holland oder die Schweiz befinden. ${ }^{425}$ Diese großen Linien kontrastiert Koni

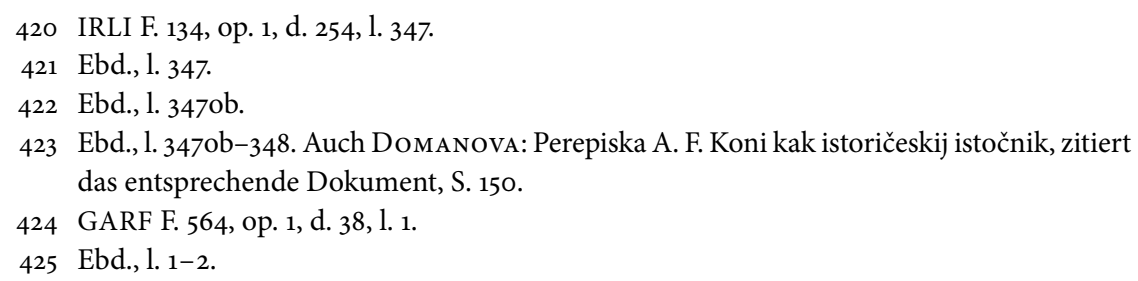


nun mit der individuellen Situation. Er zählt auf, wie der Zerfall der öffentlichen Ordnung, die internationale Situation Russlands, die physische und moralische Gewalt auf die Menschen wirkten. Erneut gibt er der „Samoduržavie“ der Zarendynastie die Hauptschuld für diese Entwicklung. Eine Entwicklung, die ihn und seinesgleichen mit der drängenden Frage nach dem grundlegenden Sinn zurücklässt: „Unwillkürlich regt sich bei jedem, der ehrlich seine Pflicht gegenüber der Heimat erfüllt hat, die Frage: Wofür? [Za čto?] Wofür diese moralischen, und für viele auch physischen Leiden?" ${ }^{426}$ Gerade für jene, die schon zu alt seien, um noch auf die Zukunft zu hoffen, sei dies hart. Zwar gebe es dort, „wo es keine Hoffnung gibt“, wenigstens noch „Erinnerungen“. Aber die Erinnerungen jener, die „im Namen des Volkes“ gegen Russlands „dunkle Seiten“ gekämpft hätten, seien „voller Bitterkeit““427 Denn das „Dienen für das Volk war eine Illusion“. Der „russische Mensch“, den man sich als voll von brüderlicher Liebe vorgestellt habe, als ein „Gottesträger“ [bogonosec], sei in Wirklichkeit „verlogen und diebisch“, „ohne jegliches Pflichtgefühl und ohne einen Sinn für das Vaterland“, „Voll von tierischen Instinkten und Abscheu gegen die Arbeit“ ${ }^{428}$ Gleichermaßen bitter geht Koni mit der Intelligencija ins Gericht: „Die Intelligencija hat sich als nur zur Kritik und Zerstörung fähig herausgestellt, ohne jegliche schöpferischen Kräfte und Handlungsformen. “429 Ähnliche Gedanken rekapitulierte Koni im März 1917 in verschiedenen Briefen an Freunde, die allesamt unmittelbar unter dem Eindruck der Revolution verfasst wurden. Er knüpft dabei an die vielfach wiederholten Vorwürfe gegen die Intelligencija an, die am prominentesten 1909 im selbstkritischen Sammelband "Wegzeichen“ ausgedrückt worden waren. Als Antwort auf die mangelnde Gestaltungskraft der Intelligencija wurde damals offen aus den eigenen Reihen Kritik an der „Opposition aus Prinzip“ und der zu ideologischen Denkweise geäußert, die nicht zu echten Lösungen beitragen würde. ${ }^{430}$ Ganz ähnlich laute nun Konis Fazit: „Über die ,Intelligencija', die nichts anderes kann als zu schwatzen und verschiedene Götzen anzubeten, muss man gar nicht erst sprechen. “" ${ }^{431}$ In diesen Briefen bezieht Koni die in der „Analyse der Seelenunruhe" in unpersönlicher Form geäußerte Bitterkeit direkter auf seine Person. So hält er fest, dass er sein ganzes Leben lang „diesem Volk gedient“ habe. Das

\footnotetext{
426 Ebd., 1. 2.

427 Ebd.

428 Ebd., 1. 2-2ob.

429 Ebd., 1. $20 b$.

430 Berdjaev u.a. (Hrsg.): Vechi, S. 7-8 ff (Einleitung von Karl Schlögel). Vgl. oben, S. 300 zur Kritik am mangelnden Rechtsbewusstsein.

431 GARF F. 564, op. 1, d. 882, 1. 29-31. Zitiert nach: Domanova: Perepiska A. F. Koni kak istoričeskij istočnik, S. 120.
} 
nun, wie es scheint, zur Anarchie übergehe. ${ }^{432}$ Die „historische Rolle Russlands“ sei zu Ende, weil nichts die Wunden heilen könne, die dem Land sein eigenes Volk beigebracht habe. „Moralischen Selbstmord“ habe dieses Volk begangen, dem er „die Idee der Rechtsprechung“versucht habe beizubringen und um dessen „moralische Entwicklung“ er sich bemüht habe. „Umsonst“ sei all dies gewesen. ${ }^{433}$

Noch immer kommt in Konis Analyse den Regierungskreisen eine Hauptverantwortung zu, aber diese funktionieren nicht mehr losgelöst von den gesellschaftlichen Gruppen, die das Russische Reich bevölkerten. Schon in Bezug auf die Revolution von 1905 hatte sich Koni entsetzt gezeigt über die „Umwertung aller Werte" und insbesondere das in seiner Optik zu überhastete und zu gewaltsame Vorgehen der Aufständischen. Diese Warnung vor der „Anarchie“ und die vernichtende Beurteilung der moralischen Qualitäten des „Volkes“ erklangen aber 1917 so deutlich wie noch nie. Die allgemeine Frage nach dem „Warum“ wird dabei ergänzt um die auf das eigene Leben bezogene Frage nach dem „Wofür?“. Das Objekt, dem der „Dienst“ seiner Person gewidmet war, hatte sich als unwürdig herausgestellt. Gleichzeitig kritisiert Koni aber auch die Art und Weise der Bemühungen um das „Volk“: Die Intelligencija habe viel geredet, aber nichts bewirkt.

Diese totale Desillusionierung von „Volk“, Intelligencija und den eigenen Bemühungen und die überharte Verurteilung der Menschen in Russland als „tierisch“ und „verlogen“ stellten offensichtlich eine Momentaufnahme dar, die unter dem Einfluss des Revolutionsjahres 1917 entstanden war. 1926, in der wohl letzten von Koni skizzenhaft erstellten Gesamtdarstellung Russlands und seiner Geschichte, finden sich die gleichen Schlüsse aber ebenso wieder. In dem zweiseitigen, dicht beschriebenen Papier hält Koni seine „Traurigen Erfahrungen der Lebensbeobachtungen“ in Halbsätzen fest. Mit bemerkenswerter Wachheit analysiert Koni die Entwicklungen, die der Machtübernahme der Bolschewiki nachfolgten. Er schreibt von den „,ersten friedlichen Schritten“ nach der Oktoberrevolution, vom dann aber folgenden „Mord an den Romanovs; Terror; Tätigkeit der Tschekka“. Er erwähnt die „Raserei der Weißen; Judenpogrome; verstärkte Emigration und sinnlose Träumereien“. ${ }^{434}$ Schließlich zählt er die „guten Seiten“ und die „düsteren Seiten“ der momentanen Situation auf. Bei Ersteren heißt es: „Auflösung der Stände; Trennung von Kirche und Staat; Emanzipation der Frauen“. Bei Letzteren: „vollständiges faktisches Fehlen von Presse- und Versammlungsfreiheit; Beleidi-

432 IRLI F. 134, op. 1, d. 27, 1. 137. Zitiert nach: Domanova: Perepiska A. F. Koni kak istoričeskij istočnik, S. 119.

433 GARF F. 564, op. 1, d. 882, 1. 29-31. Zitiert nach: Domanova: Perepiska A. F. Koni kak istoričeskij istočnik, S. 120. „Umsonst“ wird besonders betont, indem Koni es auf Deutsch schreibt.

434 GARF F. 564, op. 1, d. 174, 1. 1 ob. 
gung des religiösen Gefühls und Entweihung von Heiligtümern der Volksverehrung; unordentliche und unkontrollierte Gesetzgebung “. ${ }^{435}$ Während Koni in dieser abwägenden Darstellung keineswegs wie im Titel angekündigt nur „Traurige Erfahrungen“ aufführt, scheint seine Desillusionierung vom „Volk“ trotzdem zu einem Faktum geworden zu sein. Seine Wortwahl ist nun aber im Gegensatz zu den Momentaufnahmen im Revolutionsjahr frei von Bitterkeit und Emotion. So schreibt er im Papier zu den Ursachen für die entsprechende Entwicklung Russlands von den „ersten Anzeichen der Krankheit“ und zählt neben Kritik an den Kriegen der Zaren, der ökonomischen Situation oder der Nationalitätenpolitik das „Fehlen echter Religiosität im Volk“ als Tatsache auf. ${ }^{436} \mathrm{Im}$ nachfolgenden Abschnitt „Krankheit“ werden neben dem „Unverständnis von der Aufgabe einer harmonischen Beendigung der Selbstherrschaft“ trocken auch die „trügerischen Hoffnungen auf den Konservatismus des russischen Volkes, begleitet vom Unverständnis für dessen Anarchismus und nichtvorhandenen Sinn für das Vaterland" konstatiert. ${ }^{437}$

Während Koni in der Öffentlichkeit der frühen 1920er-Jahre durchaus auf seiner politischen Analyse beharrte - es sei an die Veröffentlichung des „politischen Memorandums“ erinnert -, fehlen jegliche Aussagen über die gesellschaftliche Dimension. Es liegt auf der Hand, dass Koni weder die harschen Verurteilungen des „verlogenen“ Volkes voller „tierischer Instinkte“ noch die gemilderte Version eines Volkes voller „Anarchismus und nichtvorhandenen Sinn für das Vaterland“ hätte veröffentlichen können. Doch Zensur dürfte kaum der alleinige Grund gewesen sein, dass diese Aussagen nie an die Öffentlichkeit gelangten. Konis Notizen der Enttäuschung und der private Charakter, der sie auszeichnet, können nur unter Berücksichtigung der Tatsache interpretiert werden, dass Koni mit seinen öffentlich sichtbaren Taten in den letzten Lebensjahren genau das Gegenteil eines desillusionierten, vom „Volk“ enttäuschten Menschen verkörperte.

\section{Fazit}

Konis Pessimismus bezüglich Land und Bevölkerung kann schwerlich so total gewesen sein, wenn man die unermüdlichen Aktivitäten als Vortragender und Schriftsteller vor eben diesem so gescholtenen "Volk“ in seinen letzten Lebensjahren bedenkt. Ein Widerspruch tut sich auf zwischen seinem öffentlichen Er-

435 Ebd., 1. 1ob-2.

436 Ebd., 1. 1.

437 Ebd., 1. 1-1ob. 
innern und Lehren in Form von Artikeln und Vorträgen über gelobte Literaten oder moralische Grundlagen der Rechtsprechung und des Gemeinschaftslebens auf der einen, und nur in privaten Briefen oder skizzenhaften Archivalien festgehaltenen Enttäuschungen von „Volk“ und Intelligencija auf der anderen Seite. Tatsächlich schien Koni daran zu scheitern, sich selber die Frage nach dem „Wofür?" in einer Art und Weise zu beantworten, die den Erwartungen an die eigene Biografie als Katalysator historischer Prozesse gerecht wurde. Eine „historische Rolle" konnte Koni weder für sich noch für Russland im Moment der enormen Umwälzung nach 1917 mehr ausmachen. Dies zeigt sich nicht zuletzt daran, dass es ihm in den meisten seiner Versuche trotz eindeutiger Absicht nicht gelang, die eigene Geschichte tatsächlich - und sei es auch nur in einigen Stichworten - bis ins hohe Alter nachzuverfolgen und gesamthaft zu interpretieren. Zwar gab sich Koni durchaus Mühe, seine Gegenwart mit ihren „guten“ und „düsteren“ Aspekten zu analysieren, aber einen wirklichen Sinn schien das alles für ihn nicht mehr zu ergeben. Er verlagerte vielmehr die großen Linien in die Zukunft, sprach von einigen Jahrzehnten, die es dauern dürfte, bis Russland sich zu neuer Stärke entwickelt haben würde. Dass Koni den Glauben an diese Zukunft aber keineswegs verloren hatte und dass seine Enttäuschung vom Weg des „Dienens für das Volk“, ja vom „Volk“ selber in seiner Gesamtheit nicht für die einzelnen Individuen in seiner Gegenwart galt, davon zeugt sein öffentliches Engagement in den letzten Lebensjahren. Koni beging eine Art Sinnproduktion en miniature, indem er so intensiv wie nie zuvor den direkten Bezug zu möglichst vielen Menschen seiner Zeit suchte. Im Zarenreich war das Erinnern an persönliche Bekanntschaften mit berühmten Autoren oder das Verfassen eigener literaturwissenschaftlicher Arbeiten noch eine Möglichkeit für Koni gewesen, sich und sein juristisches Kerngeschäft in eine Reihe mit den Wortführern der Intelligencija zu stellen. Öffentlich versicherte er sich so der Legitimation und Zuneigung eines abstrakten „Volkes“ und konnte gleichzeitig moralische Komponenten in das Rechtssystem integrieren. In der Sowjetunion nun boten ihm seine Erinnerungen an die Literaten des 19. Jahrhunderts die beste verbliebene Möglichkeit, direkt und persönlich auf die einzelnen Menschen einzuwirken. Wieder und wieder vor möglichst breitem Leserkreis und Zuhörerschaft seine Erinnerungen an jene Autoren zu rekapitulieren, deren Schreiben in seinen Augen die Gesellschaft „emporheben“ sollte, war unverfänglicher und einfacher möglich, als Erinnerungen an Berufsleben und Politiker aus der Zarenzeit oder juristische Grundsatztexte zu publizieren, geschweige denn aktiven Anteil am juristischen oder politischen Leben der frühen Sowjetzeit zu nehmen. Koni nutze diese ihm verbliebene Chance zur aktiven Teilnahme intensiv aus und ging völlig auf in der neuen Rolle des Schriftstellers und Akademikers, die er sich nun gab und in der er auch von außen bestärkt 
wurde. Mit dem gleichen Pflichtbewusstsein und der gleichen Menschenliebe, die er in seinen Ethiklektionen von anderen forderte, betätigte er sich unermüdlich als Lehrer moralischer Grundlagen und führte fleißig Buch über die stetig wachsende Anzahl seiner Lektionen und Vorträge. Diese waren Beweis für seine unmittelbaren Kontaktaufnahmen mit den individuellen Vertretern des „Volkes“, die an die Stelle der Überhöhung dieser abstrakten Größe getreten waren.

Vorerst war Koni nicht der Einzige, der daran festhielt, dass die Literaten der Vergangenheit ihren Nutzen als vereinende Kraft und Rückbesinnung auf gesellschaftliche Grundwerte immer noch entfalten konnten. Aleksandr Blok, nach anfänglicher Euphorie längst desillusioniert angesichts der Folgen der Oktoberrevolution, hielt an den Feierlichkeiten für Puschkins 84. Geburtstag 1921 im „Haus der Literaten“ eine Rede über den großen Poeten. Er schien sich von diesem als „Sohn der Harmonie“ eine versöhnende Wirkung auf die vom Bürgerkrieg zerrissene postrevolutionäre Gesellschaft zu erhoffen. ${ }^{438}$ Ironischerweise maßen auch die Bolschewiki den Poeten eine außerordentliche Kraft zu. So wurde wenig später Bloks Ausreiseantrag nach Finnland, wo der kranke Literat medizinische Hilfe in Anspruch nehmen wollte, mit der Begründung abgelehnt, dass Blok ,a poet by nature" sei. Er werde nicht anders können, als seine Poesie auch gegen die Bolschewiki zu nutzen. ${ }^{439}$ Kurz darauf verstarb der Dichter. Bloks Beerdigung wurde von vielen seiner Dichterkollegen als „das Ende“ gesehen. ${ }^{440} \mathrm{Im}$ Jahr 1921, insbesondere auch in den Jubiläumsfeierlichkeiten für Puschkin im „Haus der Literaten“, vermeinten viele Mitglieder der vorrevolutionären Intelligencija-Kreise das „Ende der alten Zeit“ zu sehen und konstatierten in der Stabilisierung und weiteren Entfaltung des bolschewistischen Russlands einen totalen Epochenwechsel. ${ }^{41}$ Für Koni aber, der sich an vorderster Front für dieses Fest engagiert hatte, schien es nur ein weiteres Glied in der langen Kette an Gelegenheiten gewesen zu sein, in das „neue“ Russland jene Ideale des „alten“ zu integrieren, für die er sich zeitlebens eingesetzt hatte.

438 Bloks Rede erschien ebenfalls im von Koni mit herausgegebenen Sammelband, vgl. Aleksandr A. Blok: O naznačenii poèta. In: Dom literatorov (Hrsg.): Puškin. Dostoevskij. Petrograd 1921, S. 15-28. Der symbolistische Dichter begrüßte die Revolution zuerst als eine Art anarchische, lang ersehnte Befreiung des russischen Volkes von einer seelenlosen, ihm fremden Kultur. Daraus entstand 1918 das berühmte Gedicht „Die Zwölf“ [Dvenadcat'], vgl. Stender-Petersen: Geschichte der russischen Literatur, S. 531. Schon wenig später verlor Blok aber den Glauben an die Bolschewiki. Er hörte auf zu dichten, vgl. Orlando Figes: A People's Tragedy. The Russian Revolution 1891-1924. London 1997, S. 784-85.

Donald Loewen: The Most Dangerous Art. Poetry, Politics and Autobiography after the Russian Revolution. Lanham Maryland 2008, S. 4-5.

440 Figes: A People's Tragedy, S. 785.

441 SCHLÖgEL: Petersburg, S.561. 
Wohl nicht zuletzt das hohe Alter Konis und sein Tod 1927 bewahrten ihn schlussendlich davor, für seinen Verbleib im Land einen hohen Preis zu bezahlen. Andere Persönlichkeiten, die sich in den 1920er-Jahren im akademischen und literarischen Feld engagierten, wurden gegen Ende des Jahrzehnts Opfer der stalinistischen Repressionsmaschinerie. Nikolaj Anciferov beispielsweise, der zusammen mit Koni Mitglied in der "Gesellschaft für das alte St. Petersburg" war und wie er 1922 ein Buch über die Heimatstadt und ihre Literaten verfasst hatte, wurde im Zuge der Repressionen, die auch die Akademie der Wissenschaften und die Lokalforschung trafen, verhaftet und zu Lagerhaft verurteilt. Nach einer mehrjährigen Strafe wurde er 1937 erneut festgenommen. Erst Ende 1939 kam er endgültig frei und konnte sich nach dem Zweiten Weltkrieg im Staatlichen Literaturmuseum in Moskau eine Existenz aufbauen, wo er bis zu seinem Tod 1958 Ausstellungen zur russischen Literatur gestaltete. ${ }^{442}$ Andere, wie Sergej Platonov, der als international hoch angesehener Historiker zu den prominentesten Opfern der Säuberungen in der Akademie der Wissenschaften gehörte, überlebten Verhaftung und Verbannung nicht. ${ }^{443}$

Die unbeirrbare Zuversicht, die Koni auszeichnete, lässt sich vielleicht damit erklären, dass seine Biografie unzählige Momente der vergeblichen Arbeit und des folgenlosen Engagements kennt. Schon früh hatte ihn die Arbeit in den politischen und juristischen Gremien des Zarenreiches eine außerordentliche Frustrationstoleranz gelehrt. Beispielhaft lässt sich das an der endlosen Reihe an juristischen Kommentaren aufzeigen, die Koni im Verlauf seiner Karriere für immer neue Kommissionen und Gesetzeseditionen im Rechtswesen verfasst hatte. Wieder und wieder waren diese in kürzester Zeit überholt, wurden verworfen

442 Anciferov: Duša Peterburga, S. 235 (Nachwort von A. Margolis) und Anciferov: Die Seele Petersburgs, S. 31 ff (Einleitung von Karl Schlögel).

443 Lange war die Akademie jene Institution, die sich politischer Infiltration am erfolgreichsten widersetzen konnte, vgl. Huskey: Russian Lawyers and the Soviet State, S. 164. Doch 1929 wurde Platonov als Direktor des „Puschkinhauses“ beschuldigt, zarische Dokumente im Archiv zu verheimlichen. Er musste von allen seinen Posten zurücktreten und wurde wenig später in einen größeren Prozess wegen angeblicher monarchistischer Verschwörungspläne hineingezogen, dem zahlreiche Akademiker zum Opfer fielen. 1933 starb Platonov in der Verbannung in Samara, vgl. A. A. Č́nnobaev u. a. (Hrsg.): Istoriki Rossii. Biografii. Moskva 2001, S. 152-6o und Anciferov: Die Seele Petersburgs, S. 32 (Einleitung von Karl Schlögel). Ironischerweise war unter den Dokumenten, deren Lagerung im „Puschkinhaus" auf solchen Unmut stieß, auch das Tagebuch des ehemaligen Gouverneurs aus dem Zarenreich Vladimir Fëdorovič Džunkovskij (1865-1938). Dieser hatte die Aufzeichnungen auf Vermittlung Konis an das „Puschkinhaus“ übergeben, vgl. Vladimir F. DžunkovksıJ: Vospominanija, 2 Bände, hrsg. v. A. L. Panina, mit einer Einleitung versehen v. I. Puškareva und Z. Peregudova, Bd. 1. Moskva 1997, S. $23-24$ (Einleitung von I. Puškareva und Z. Peregudova). 
oder standhaft ignoriert und nie umgesetzt. Die Vorschläge der Arbeitsgruppe von Justizminister Murav'ev wurden im Zuge der revolutionären Umgestaltungen 1905 nicht weiter verfolgt, nachdem Koni und die anderen Beteiligten sich zu über 500 Sitzungen getroffen hatten. ${ }^{444}$ Genauso wurde die Arbeit für eine neue Presserechtsgesetzgebung von den Übergangsregelungen in Zusammenhang mit dem Oktobermanifest überholt. ${ }^{445} \mathrm{Ab} 1914$ erschienen mehrere Bände mit Kommentaren und Übersichtsdarstellungen zur Entwicklung des Strafprozessrechtes in den vergangenen 50 Jahren, für die Koni eine umfangreiche Einführung verfasste. Was er zusammen mit vielen anderen Rechtspraktikern und -theoretikern hier zusammenstellte, war nur wenig später mit der Februarrevolution erneuter Überarbeitung ausgesetzt. ${ }^{46}$ Angeblich praktisch am Tag nach der Einsetzung der Provisorischen Regierung verfasste Koni einen Artikel mit dem Titel „Die nächsten Aufgaben der Gesetzgebung im Bereich Strafrecht ${ }^{“ 4}{ }^{447}$ Nur wenige Monate später wurde auch dies von den historischen Entwicklungen überrollt. Mit einer Mischung aus Ernüchterung und Galgenhumor schrieb Koni wohl schon in den Jahren nach der Jahrhundertwende Stichworte auf zu all den vielen Kommissionen und Komitees, denen er im Verlauf seines Berufslebens angehört hatte. Darin finden sich auch einige grundsätzliche Gedanken zur „Fruchtlosigkeit vieler Arbeit “ ${ }^{448}$ Ungeachtet all dieser Rückschläge nahm er aber selbst nach der Oktoberrevolution nochmals einen Anlauf, mit wissenschaftlichen Kommentaren seine Ansichten zu den neuen sowjetischen Rechtsgrundsätzen einzubringen. ${ }^{449}$

444 Baberowski: Autokratie und Justiz, S. 479 und „Ob’jasnenija Ministra Justicii, Stats Sekretarja N. V. Murav'eva v pervom zasedanii Soedinennych Departamentov Gosudarstvennago Soveta po delu o peresmotre sudebnych zakonopoloženij, 16 Dekabrja 1902 goda“, in: GARF F. 564, op. 1, d. 4133, 1. 9.

445 Lichomanov: A. F. Koni v osobom soveščanii po sostavleniju novogo Ustava o pečati, S. 137-38. Vgl. auch S. 202.

446 Die Bände sollten laut Herausgeber den praktizierenden Juristen Einordnungen und wissenschaftliche Erklärungen zum aktuellen Stand der Rechtsprechung verschaffen, vgl. Michail N. Gernet (Hrsg.): Ustav ugolovnago sudoproizvodstva, 3 Bände, Bd.1. Moskva 1914-1915, S. IIII. Koni schrieb in seiner Einführung von den Entwicklungen im Rechtsverständnis, der Entstehung der Gerichtsreform und auch von einigen Problemen, die in der Praxis im vergangenen halben Jahrhundert aufgetaucht waren, vgl. Koni: Vvedenie k Sistematičeskomu Kommentariju U. U. S., S. 1-30.

447 Poljanskij: A. F. Koni, S. 24-25.

448 GARF F. 564, op. 1, d. 220, 1. 4. Die Stichworte sind nicht datiert. In einem Brief an Konstantin Arsen'ev schreibt Koni 1909 davon, dass er einen Artikel über Kommissionen und Komitees vorbereite, der aber weder für die März- noch für die Aprilnummer des „Boten Europas“ fertig werden würde, vgl. GA8, S. 257-59 (Brief an K. K. Arsen’ev vom 16. 02.1909).

449 Vgl. oben, S. 252. 
Bis zu seinem 8o. Geburtstag verfügte Koni schließlich über Jahrzehnte an Erfahrung mit einer politischen Umgebung, die er als den Ideen der Gerichtsreform und dem Rechtsstaat feindlich gegenüber eingestellt empfand. Eine Umgebung, die geradezu systematisch Scheitern beförderte.

Die Geduld, die ihn das gelehrt haben musste, dürfte gleichzeitig von einem tiefen Glauben an die eigene Wirksamkeit malgré tout begleitet gewesen sein. Nur so lässt sich wohl die Hartnäckigkeit erklären, mit der Koni zeitlebens seine eigenen Analysen, Visionen und Vergangenheitsinterpretationen festhielt und in die öffentliche Diskussion einzubringen versuchte. Tatsächlich kann kaum daran gezweifelt werden, dass Koni die „geistige Verbindung zwischen Vortragendem und Zuhörer" gerade auch in der frühen Sowjetunion immer wieder erfolgreich etablierte. Nach seinem Tod erschien kaum ein Nachruf, in dem nicht mit Bewunderung über seine exzessive Vortragstätigkeit in den letzten Jahren berichtet wurde. Keineswegs nur die alten Bekanntschaften seiner Generation, sondern auch junge Personen erinnerten sich an ihre Erlebnisse im Hörsaal zurück. So hielt eine begeisterte Studentin ihre Erinnerungen an Koni fest, die ihm im „Institut des lebendigen Wortes" zugehört hatte. ${ }^{450}$ In Konis eigenem Nachlass liegt ein von 1928 datierter maschinengetippter Nachruf eines Mannes, der in den Jahren zuvor Konis Vorträgen über die russischen Literaten gelauscht hatte und nun die Begeisterung der Zuhörer beschreibt. Er merkt an, dass Koni die Jugend oftmals als egoistisch, auf das Materielle fokussiert und ohne moralische Prinzipien bewertet habe. Aber gleichzeitig habe man im persönlichen Gespräch sofort gemerkt, dass in ihm noch eine Kerze brannte, die er in seinen Vorträgen in eine Flamme zu verwandeln versucht habe ${ }^{451}$ Erst viele Jahrzehnte später erschienen in juristischen Zeitschriften Erinnerungen von Personen, die als Studenten Konis Vorträge besucht, ihn persönlich um seinen Rat für ihren Lebensweg gebeten und schließlich in der Sowjetunion Karriere gemacht hatten. Professor Gurevič berichtete 1971 davon, wie er nach der Oktoberrevolution Konis Rat gesucht habe und dieser ihn darin bestärkt habe, sich auch unter den neuen Machthabern als Lehrer in die Gesellschaft einzubringen. ${ }^{42}$ Die Juristin A. P. Andreeva erzählte 1978 in einem

450 Zarodovaja: Perepiska B. L. Modzalevskogo s A. F. Koni, S. 361 mit Verweis auf IRLI F. 474, Nr. 659, 1. 7-8: „Vospominanija o A. F. Koni byvšej studentki Instituta živogo slova Niny Valerianovny Galaninoj“.

451 GARF F. 564, op. 1, d. 4201, S. 1 und 6. Text von N. V. Zelenin.

452 Gurevič: Stranički vospominanij Anatolij Fëdorovič Koni, S. 140-42. Professor P. V. Gurevič berichtet in seiner Erinnerungsschrift auch, wie er Koni schon zu seiner Studienzeit nach 1907 kennengelernt habe. Er berichtet von den Vorträgen Konis zu Tolstoi vor Arbeitern (ebd., S. 141) und davon, wie Koni ihm auch über sein eigenes Leben erzählt habe. 
Artikel von den Vorträgen Konis, denen sie als junge Studentin des Rechts 1921 gelauscht habe. Der geringe Stellenwert der Justiz in diesen Jahren habe sie stark verunsichert, so dass sie den alten Mann um Rat gebeten habe. Koni habe richtig prophezeit, dass jeder Staat, auch der aktuelle, ein Rechtssystem und auch eine Advokatur brauche, und habe sie in ihrer Berufswahl bestärkt. ${ }^{453}$ Wie bedeutsam für Konis Selbstverständnis diese Beratung der Jugend gewesen sein muss, lässt sich erahnen anlässlich der Sorgfalt, mit der er in seinem Nachlass die Beweise für seine Vernetzung mit der Bevölkerung aufbewahrte. Die über 1000 Visitenkarten von Menschen, die bei ihm anklopften, sind ein eindrückliches Zeugnis. Eine Tafel mit den Worten „Nicht zuhause“ habe Koni in seinen letzten Lebensjahren an die Türe gehängt, wann immer er das Haus verlassen habe. Wer seinen Rat suchte und ihn nicht antraf, habe in einem Buch seine Anliegen eintragen können. ${ }^{454}$

Die euphorischen Erinnerungsberichte zu Konis Vorträgen vor der sowjetischen Jugend werden in den ersten Biografien über den Juristen in den 1980erJahren gerne zitiert. Erst nach dem Zerfall der Sowjetunion wird in manchen Darstellungen versucht, einen schwermütigen Koni zu zeichnen, der sich bei seinen Freunden über das Publikum der Vorträge beklagte, in dem irgendwelche Matrosen sitzen würden, die Tolstois Werke - ohne sie je gelesen zu haben - in Bausch und Bogen verwerfen würden. ${ }^{455}$ Offensichtlich haben solche negativen Erlebnisse Koni aber - trotz mehrfacher Ankündigung - nicht dazu bewogen, die Zahl seiner Auftritte maßgeblich zu reduzieren. Die sich hier andeutende, der Sowjetunion kritisch gegenüberstehende Auslegung von Konis letzter Lebensphase ist in erster Linie ein Zeichen für die Interpretation des Juristen als liberaler Held und moralische Instanz aus dem Zarenreich, wie sie seit den 199oer-Jahren betont wird.

453 A. P. Andreeva: Pamjati Anatolija Fëdoroviča Koni. In: Anatolij F. Koni: Izbrannoe. Moskva 1989, S. 425 und 427-29. Original in der Zeitschrift „Pravovedenie“ 1978.

454 Smoljarčuk: Anatolij Fëdorovič Koni (1844-1927), S. 203.

455 BAKuncev: Anatolij Fëdorovič Koni, russkaja ėmigracija i sovetskaja vlast', S. 60 unter Berufung auf Nemirovič-Dančenko. 


\section{Anatolij Konis autobiografische Praktiken: Zusammenfassung und Ausblick}

Zweifelsohne zeichnete sich Anatolij Koni durch die vielfältigen Kontexte aus, in denen er sein Leben verortete. „Zwischen Recht, Macht und Volk“ oszillierten seine Zugehörigkeiten hin und her und ermöglichten ihm ein Selbstverständnis, das sowohl im imperialen Russland als auch in der Sowjetunion "funktionierte“ und ihm erlaubte, eine sinnerfüllte Rolle einzunehmen. Diese Einordnungen passierten ganz wesentlich im Rahmen der Auseinandersetzung mit seinem eigenen Leben in Form autobiografischen Schreibens, das so wahlweise zu einem „Einschreiben“ und „Erschreiben“ wurde. Die Relevanz autobiografischer Praktiken und ihre Wirkungsmächtigkeit scheint offenkundig, zeigt sich aber in ganz verschiedenen Spielarten. Intentionalität, externe Einflüsse und Bedeutung der „Momente" des Selbstverortens hatten dabei nicht immer den gleichen Stellenwert.

Besonders deutlich lässt sich ein Zusammenhang zwischen Selbstreflexion und historischen Entwicklungen im Fall der ersten Russischen Revolution ausmachen, die effektiv gleich mehrere autobiografische Texte aus Koni „hervortreibt“.' Dieser „Moment" manifestiert sich folglich in Form seiner zeitnah niedergeschriebenen kurzen Erinnerungen an die Ministeranfrage - „Nacht Gethsemane“ - , die Eröffnung der ersten Duma und den Besuch beim Zarenpaar in Gatčina. Die Engführung von spektakulärem Zeitgeschehen und autobiografischem Schreiben mag oftmals auf das Bewusstsein des Zeitzeugen zurückzuführen sein, der die Geschehnisse bereits als historisch erkennt und in Anbetracht dessen Erwartungen zukünftiger Analysten entsprechen will und deshalb festhält, was passiert. ${ }^{2}$ In Konis Fall lässt der Inhalt dieser Reflexionen aber noch weitere Schlüsse zu. Im Kontext der gewaltsamen Zusammenstöße von Regierungstruppen und Revolutionären und der zumindest im Ansatz erkennbaren Neuverteilung von Macht und Kompetenzen erinnerte er sich nicht nur an die unmittelbaren Ereignisse, sondern stellte in seinen Assoziationen Themen wie berufliche Ambitionen oder das Verhältnis zur zarischen Elite in den Mittelpunkt, die ihn im Rahmen der persönlichen Auseinandersetzung mit seiner Rolle im Machtgefüge beschäftigten.

In ausführlichen Memoiren blickte Koni fast zeitgleich auf sein Berufsleben der letzten Jahrzehnte und dessen wichtigste Stationen zurück und lässt auch darin

1 DepкAT: Autobiographie und die soziale Konstruktion von Wirklichkeit, S. 476.

2 Überlegung von Viktoria Frede an der ersten internationalen Tagung des Projektes „Imperial Subjects“ im Juni 2013 in Basel. 
ganz verschiedene Nuancen seines Selbstverständnisses durchschimmern, das in den Jahren nach der Jahrhundertwende Gegenstand eines Aushandlungsprozesses $\mathrm{zu}$ sein schien. Augenfällig ist Konis Faszination von der Machtfülle des Zarenamtes, die sich in den poetisch klingenden Beschreibungen seiner Begegnungen mit dem Monarchen ausmachen lässt. Ob in den Erinnerungen an den Fall Vera Zasulič, seiner Darstellung zur Untersuchung der Entgleisung des Zarenzuges oder der von 1907 datierten Rückschau auf seine Arbeit am Kriminalkassationsdepartement - immer wieder lotete Koni im Schreiben seine Beziehung zum Zaren aus. Dessen Missgunst erschien ihm wie ein „Trauma“, lobende Worte wurden dafür umso mehr betont. Indem Koni sich mit besonderer Vorliebe daran erinnerte, wie er den verschiedenen Zaren jeweils ein Wort der „Wahrheit“ bringen wollte, rekapitulierte er seine politischen Überzeugungen und machte die Funktion deutlich, die er und der Zar seiner Ansicht nach im Staats- und Rechtswesen eines reformorientierten imperialen Russlands einzunehmen hätten. Zum justizpolitischen Berater des Monarchen schreibt sich Koni selber, indem er davon berichtet, wie er das liberale Gedankengut - von seinen Kollegen beim „Boten Europas“ beispielhaft vertreten - an höchster Stelle einzubringen versuchte. Eine kontrollierte, in kleinen Schritten vorangehende und durch umfassende Bildungsmaßnahmen gestützte Entwicklung hin zu mehr Freiheiten, Mitsprache und Selbstorganisation der Bürger sollte die Abkehr von Repression gegen Andersdenkende bedeuten. Dem Autokraten kam dabei die Rolle des wohlwollenden Anführers dieser Entwicklung zu, die er durch Unterstützung und Rat seiner Experten - so die Überzeugung Konis und zahlreicher Reformer seiner Zeit - auch ausgezeichnet hätte ausfüllen können. Hin- und hergerissen zwischen Bestätigung im Kontakt mit den Monarchen und tiefer Enttäuschung von der mangelnden Durchschlagkraft seiner Visionen beließ Koni die Figur des „guten Zaren“ in seinen Erinnerungen intakt, indem er - ähnlich wie die sozial-utopischen Volkslegenden seiner Zeit - große Energie darauf verwendete, die Schuld für das fehlgeleitete Handeln des Selbstherrschers bei eigensüchtigen und boshaften Kreaturen im Umfeld des Thrones auszumachen. Die eigene Hartnäckigkeit zelebrierte Koni in den Jahren um die erste Russische Revolution, indem er Einflussversuche und Inhalte seiner politischen Ideen, die vor Jahrzehnten aktuell gewesen waren, in seinen Memoiren aufleben ließ. Damit hielt er nicht nur an ihrer Richtigkeit und Relevanz fest, sondern betonte auch seine aktive, weiteren Reformen zugetane Haltung im Kontakt mit den Mächtigen. Dieser Aspekt von Konis Selbstverständnis gelangte aber kaum an die Öffentlichkeit.

Eine stark eingeschränkte parlamentarische Monarchie - seitens der Zaren lange Zeit bereits als absolutes Schreckgespenst verstanden - war 1905 plötzlich eine Realität, die von vielen Kräften nunmehr als zu bescheidener Tribut an das 
Mitspracherecht der Bevölkerung angesehen wurde. Als „Konservativer unter Liberalen" fand sich Koni in diesem polarisierten und radikalisierten Kontext wieder. Nicht nur im politischen Feld erschienen Koni die Entwicklungen, die er eigentlich begrüßte, als zu eruptiv und überhastet. Auch in manchen anderen Lebensbereichen wie der Literatur oder der Wissenschaft sah er die „Umwertung aller Werte" als Gefahr, blindlings das Neue lediglich um seiner Neuheit willen zu verfolgen. Aus dieser Dynamik versuchte Koni ein Stück weit auszusteigen, indem er im autobiografischen Schreiben seine eigene Position neu austarierte. Ambitionen auf ein Amt in der Regierung, das vielleicht doch echte Hebelwirkung versprochen hätte, wurden von ihm in einem Prozess des schriftlichen Ringens mit sich ein für alle Mal begraben. Fast schon hilflos verwies Koni auf sein Alter und seinen Gesundheitszustand, um vor sich und anderen die Zurückweisung von Verantwortung zu rechtfertigen, die er sich doch eigentlich lange gewünscht und zugetraut hätte. Seine politischen Überzeugungen schienen sich nicht in konkrete Anleitungen zur Realpolitik übertragen zu lassen. Unsicher ob des einzuschlagenden Weges entschied sich Koni deshalb für den Rückzug, was sich schließlich in seiner autobiografischen Praxis in Form des „Zasulič-Narratives“ niederschlug.

Der Prozess von 1878, der für Koni als prägendes „Ereignis“ von Anfang an symbolisch für zentrale (Fehl-)Entwicklungen im Bereich von Justiz, Politik und Gesellschaft gestanden hatte, wurde von ihm nach der Jahrhundertwende sowohl in seinen privaten autobiografischen Schriften als auch im Kontakt nach außen endgültig als schicksalhaft interpretiert. Für dieses Schicksal zeigte er sich jetzt dankbar, da es ihn vor zu großer Machtnähe, Verführungen und Kompromissen um der Karriere willen bewahrt habe. Dieses positive Narrativ seines Werdegangs fern von politischer Einflussnahme stützte Koni mit Hilfe von Negativbeispielen aus seiner Peergruppe ab und versicherte sich so selber der Richtigkeit seiner Entscheidung. Auch seine weitere autobiografische Praxis spiegelt diese Distanzierung wider. In der Öffentlichkeit wurde Koni in den Jahren nach der Revolution von 1905 mit Texten präsent, die sich einer gänzlich anderen Thematik aus seiner Vergangenheit widmeten.

Koni akzentuierte nun seine Treue zu den Idealen der Gerichtsreform, die 1864 in Russland ein modernes Rechtswesen hätte installieren sollen. Von pädagogischem Eifer angetrieben, versuchte er mit seinen Erinnerungen an die Anfangsjahre dieser neuen Gerichte ein breites Publikum von rechtsstaatlichen Grundlagen und Erfolgen der reformierten Justiz zu überzeugen. Seine „Erinnerungen eines Gerichtstätigen“, die er ab 1907 in der Zeitschrift „Russische Altertümer“ [Russkaja Starina] publizierte, vermittelten nicht nur die Ideale einer unabhängigen Rechtsprechung, sondern ließen auch seine eigene Person als Hauptfigur dieser Berichte in bestem Licht erscheinen. Der Erfolg ergab sich in den Erzäh- 
lungen dabei oftmals aus der Verurteilung von Persönlichkeiten, die aufgrund ihres Reichtums oder ihres Einflusses unter den vorreformierten Gerichten als unantastbar gegolten hatten. Die Überhöhung von Koni im Speziellen und der Justiz und den juristischen Berufen im Allgemeinen, die dadurch erfolgte, fand aber nirgends so deutlich statt wie in den biografischen Porträts, die Koni und Gesinnungsgenossen wie zum Beispiel Konstantin Arsenev über ihre Juristenkollegen verfassten und publizierten. Konis Vorlagen eigneten sich dabei auch ausgezeichnet zur Verwertung durch Dritte, die seine Berichte und Porträts aus dem Rechtswesen - manchmal gar seine Fotosammlung von den beschriebenen Juristen - aufnahmen und weiterverbreiteten. Der Zusammenhang von autobiografischer Konjunktur und dem historischen Kontext - insbesondere der Entwicklung des Rechtswesens - scheint hierbei umgekehrt proportional zu funktionieren. Je weiter die Reform zurücklag, je deutlicher es wurde, dass sich die Gesetzgebung kaum entwickelte, Ausnahmeregelungen die Kompetenzen der regulären Gerichten beschnitten und die Aura des Aufbruchs aus den 1860erJahren verloren zu gehen drohte, desto mehr intensivierte Koni diese Form der (auto-)biografischen Praxis.

Seine Intentionen wurden zum 50. Jubiläum der Reform besonders deutlich, als er Juristenporträts, die er seit den 189oer-Jahren geschrieben, in Reden vorgetragen und in juristischen und anderen Zeitschriften veröffentlicht hatte, nun auch in einem prachtvollen Sammelband zusammenfasste. Unmissverständlich bediente sich Koni an globalen Professionalisierungsstrategien, indem er seine Berufskollegen - gänzlich unabhängig vom persönlichen Verhältnis, das er zu ihnen hatte - mit einer mythischen Aura umgab und so ethische Grundregeln durch den Verweis auf eine übergeordnete „Berufung" verfestigte. Kanonische Begriffe wie jene vom ,edlen“ Juristen, der sich mit seiner außerordentlichen Begabung insbesondere in der mündlichen Gerichtsrede aus innerer Überzeugung für die „ungeheuchelte Wahrheit" und die „ewigen Forderungen [...] der Gerechtigkeit" einsetzte, wurden wieder und wieder rekapituliert. Die Gerichtsreform selber bildete dabei den Fluchtpunkt, von dem alles auszugehen schien, was die Juristen auch noch 1914 begeistern sollte. Sie war die Göttin der Liebe, der man im „Dienst“ für die Ideale des Rechtsstaates immer treu zu bleiben hatte. Durchaus typisch etablierte Koni gerade zu den runden Geburtstagen der Reform, die immer wieder als Schreibanlässe dienten, ein Generationennarrativ. Die Rede war von den „Vätern“ und „Söhnen“ und den nun nachfolgenden „Enkeln“, die auf das Vorbild ihrer Vorgänger verpflichtet werden sollten.

Die Rückbindung der autobiografischen Praxis an den Schreibkontext weist aber gerade hier darauf hin, dass externe Logiken dies begünstigten. Mit zahlreichen Abbildungen versehene und kunstvoll eingebundene Jubiläumsproduk- 
tionen fügten sich ausgezeichnet in das Verlagsschema des wichtigsten Verlegers Russlands, Ivan Sytin, der so seine sich in den Jahren vor dem Ersten Weltkrieg rasant entwickelnde technische Leistungsfähigkeit demonstrieren wollte. Koni als eine Art heldenhafter Chefbiograf passte dabei für alle Beteiligten bestens ins Bild. Zum „Historiker“ der Gerichtsreform geworden und durch unzählige Anfragen aus Presse und Verlagswesen in dieser Rolle bestärkt, schien Koni von der Relevanz seiner panegyrischen Tätigkeit überzeugt. Diese stellte auch ein Ausweichen auf eine indirekte Form der Verteidigung von Recht und Rechtsstaat dar, die wohl nicht zuletzt den mangelnden Alternativen im einer stärkeren Bedeutung der Justiz feindlich gesinnten autokratischen Umfeld geschuldet war.

Dass zumindest in der Konzeption Konis eine unabhängige und mit weitreichenden Kompetenzen ausgerüstete Justiz innerhalb der Selbstherrschaft hätte möglich sein können, zeigt sich in seinen Erinnerungsschriften durch die unzähligen Berichte über Ratschläge und Gnadengesuche, die er im Verlauf seiner Karriere dem Zaren vorlegte. Die Rolle des Autokraten lag in Konis Augen in der Milde und Güte, mit der dieser - auf Antrag seiner Juristen hin - Ungerechtigkeiten im System ausgleichen und den Vorschlägen seiner Rechtsexperten die entsprechende Durchschlagskraft verleihen sollte.

Im Kontext der Auseinandersetzung um die Entwicklung des russischen Justiz- und Staatswesens, in der von autokratisch-konservativen über konstitutionellmonarchistische bis zu radikal-marxistischen Ideen alles zu finden war, erhielt die Diskussion über die Sinnhaftigkeit des eigenen Tuns in den intellektuellen Eliten des Landes eine besondere Bedeutung. Versinnbildlicht in der Debatte um die „Wegzeichen“ 1909 drehte sich diese immer wieder um das Ausmaß an Konkretheit, mit der die eigenen Ideale vorangetrieben werden sollten. Dass Koni sich für die Juristen hier trotz aller abstrakter Überhöhung der „edlen“ Zunft in erster Linie einen aktiven Part im Alltagsleben der Menschen wünschte, zeigt das Prädikat des "gesellschaftlichen Akteurs", mit dem er seine porträtierten Kollegen so gerne versah. Auch für seine eigene Biografie betonte er in zahlreichen Kurzlebensläufen die Vernetzung in der Gesellschaft durch Berufsorganisationen, wohltätige Gremien oder wissenschaftliche Zusammenschlüsse. Die breite Verankerung und der Anspruch, als Fachkraft unmittelbar für Erziehung und Wohlergehen der Bevölkerung mitverantwortlich zu sein, schien ihm aber durch diese Rhetorik noch nicht deutlich genug zu werden. Koni griff paradoxerweise zurück auf Diskurse der klassischen literarischen Intelligencija, um die Relevanz der Justiz für das Leben der Menschen zu betonen.

Die Analyse von Konis autobiografischer Praxis in „Momenten“ nimmt hier ein Stück weit den Charakter einer Hilfskonstruktion an, denn es scheint außer Frage, dass Konis Überzeugung von der engen Verbindung zwischen Literaten 
und Bevölkerung nicht nur auf die Denkmaleröffnung für Puschkin in Moskau 1880 oder die Feierlichkeiten für den großen Poeten im Jahre 1899 zurückzuführen sind. Vielmehr trugen diese wohl zusammen mit seinem biografischen Hintergrund in der Summe dazu bei, dass Koni die Bekanntschaft mit wichtigen Künstlern und Schriftstellern suchte, die ihrerseits auch seinen Einfluss im Rechtswesen zu nutzen wussten. Durch die in seinen Literaturanalysen von Dostojewski, Puschkin oder Odoevskij betonte Verbundenheit dieser berühmten Autoren mit zentralen Elementen der Gerichtsreform wie beispielsweise dem Geschworenenprozess sah Koni die Glaubwürdigkeit der Justiz bestärkt. Diese „Aneignung“ der Literaten, deren Einfluss auf das einfache „Volk“ gemeinhin für außerordentlich groß gehalten wurde, konnte Koni dank persönlicher Erinnerungen an Treffen mit diesen Koryphäen sogar im Falle eines Lew Tolstois erfolgreich behaupten, der für seine äußerst ablehnende Haltung gegenüber jeglichen Rechtsinstanzen bekannt war. Konis Aktivitäten in der Akademie der Wissenschaften widmeten sich insbesondere nach seinem Rückzug aus dem Justizdienst immer ausführlicher diesen Persönlichkeiten, und im Rahmen seines Engagements für eine "Gerichtsethik" gelang es ihm, in Zusammenhang mit der Justiz auch von moralischen Kategorien zu sprechen und so weitere Anknüpfungspunkte an die Intelligencija zu schaffen.

Schließlich ging Koni in den Jahren vor dem Ersten Weltkrieg dazu über, selber literarische Texte zu publizieren. Ähnlich wie die genannten Schriftsteller schrieb sich Koni in diesen Erzählungen mit autobiografischer Basis in eine enge Beziehung zum „Volk“, das in den Schriften über Konis Dienerschaft, Reisen und Studienzeit immer wieder in Form von naiven provinziellen Persönlichkeiten auftauchte und bestätigte, dass Konis Tun als Jurist von größter Wichtigkeit sei. Teilweise sind es auch gewichtige Gegenspieler aus der Vergangenheit, die Koni in seinen Berichten nun plötzlich öffentlich um Vergebung für ihm angetanes Unrecht bitten. So hält er der Elite den Spiegel vor, von der er sich in seinem Berufsleben nicht genügend unterstützt gefühlt hatte. Die Wahl der Publikationsorgane zeigt dabei deutlich, dass Koni ein möglichst breites Publikum anstrebte und mit seinen Texten durchaus auch literarische Ambitionen verfolgte.

In einen politischeren Kontext rückten Konis autobiografische Praktiken erst wieder, als Ende 1917 die Bolschewiki die Macht in Russland übernahmen. Dieser „Epochenbruch“ bewirkt im Falle von Koni nun aber keineswegs die totale Umorientierung oder einen vollständigen Rückzug aus der Öffentlichkeit bis hin zur Emigration. Vielmehr schien Koni die Neukonzeption von Politik und Justiz dazu $\mathrm{zu}$ bewegen, seine eigenen Interpretationen der Vergangenheit und seine eigenen Idealvorstellungen nun endlich , ans Licht“ zu bringen. Dass er hinsichtlich seiner eigenen Position im Machtgefüge und seines Lebensnarrativs rund um den Fall 
Zasulič bereits seit Jahren eine konsistente Interpretation seiner selbst anzubieten hatte, dürfte ihm hier entgegengekommen sein.

Angeregt durch die Diskussionen um Verfehlungen der zarischen Administration, versuchte Koni nicht nur, seine umfangreichen Memoiren über die aufsehenerregenden Fälle von Zasulič und dem entgleisten Zarenzug zu veröffentlichen, sondern er begann mit dem Verschriftlichen seiner Erinnerungen an die politischen Akteure, mit denen er es im Verlauf seiner Karriere zu tun bekommen hatte. Mit umfangreichen Anweisungen versehen, bemühte er sich, die Leser seinen Erinnerungen gewogen zu stimmen und plädierte immer wieder für ein differenziertes Urteil über die Politik und die Politiker des Zarenreiches.

Diese von Koni im Kontakt mit zahlreichen Verlagen intensiv vorangetriebene Erinnerungsmission bat mit ihrem Appell an Kontextualisierung und Differenzierung immer auch um Verständnis für seine eigene Person und seine Taten im imperialen Russland. Gleichzeitig scheute er sich nicht, auf seinen Analysen der Vergangenheit zu beharren, die sich durch den Oktober 1917 nicht geändert hatten. Wenn Koni von Wandel sprach, dann bezog er ihn auf die Jahrhundertwende. Dass es ihm nur in geringem Masse gelang, seine Version der Ereignisse auch wirklich an die Öffentlichkeit zu bringen, verdeutlicht die verkomplizierte Kommunikationssituation, auf die Koni in den frühen 1920er-Jahren traf. Nicht nur Zensurbestimmungen und spöttische Urteile sozialistischer Blätter gegenüber Konis Berichten, sondern auch Verratsvorwürfe emigrierter Bekannter erschwerten die Orientierung und die Adressierung seiner Erinnerungen an eine bestimmte Leserschaft. In Form von „Erinnerungsduellen“ musste Koni immer wieder um die Wahrnehmung seiner Person im In- und Ausland kämpfen. Um seinen autobiografischen Schriften und seinen Politikerporträts doch noch ein Publikum zu verschaffen, nahm Koni gar Kontakt zu den neuen Mächtigen im sowjetischen Russland auf. Nichts schien ihm wichtiger zu sein, als die „Errungenschaften von Generation zu Generation“ weiterzutransportieren. Als er einsehen musste, dass dies mit seinen Erinnerungen an die (Justiz-)Politik des Zarenreiches nur ungenügend gelang, verlagerte Koni diesen Transfer auf eine Metaebene. Getreu seiner Überzeugung, dass die großen russischen Autoren des 19. Jahrhunderts moralische Vorbilder für Land und Leute darstellten, bemühte er sich, deren Präsenz im neuen Russland so groß wie möglich zu halten.

Konis autobiografische Praktiken entfalteten sich nun in einem Netz aus Versammlungen literarischer Zusammenschlüsse wie dem „Puschkinhaus“, der „Turgenev-Gesellschaft“, dem „Haus der Literaten“ oder den Petrograder Universitäten, die sich dem Studium der Schriftsteller und ihrer Wirkungsorte widmeten, Jubiläen und Todesfälle von Autoren feierlich begingen oder ethische Fragen in Gericht und Leben behandelten. Dass autobiografische Praxis immer 
ein Kommunikationssystem mit meint, in dem Wechselwirkungen und Austausch mit anderen Menschen, deren Erinnerungen und aktuellen Geschehnissen unausweichlich sind, trug direkt zur Verankerung Konis in der Lebensrealität der 1920er-Jahre bei. Einerseits brachten ihn seine Vorträge in unmittelbaren Kontakt nicht nur zu seinen Bekannten aus den vorrevolutionären wissenschaftlichen $\mathrm{Ge}-$ filden, sondern auch zu neuen Zuhörerkreisen, deren Annäherung er in Form von gesammelten Visitenkarten mit Stolz konservierte. Andererseits schien das autobiografische Schreiben, selbst wenn es um Erinnerungen an lange zurückliegende Ereignisse ging, vom Interesse für die Vorgänge der Gegenwart nicht trennbar zu sein. Während Arsen’ev 1917 mit dem Tagebuchschreiben aufhören wollte, weil er den Kontakt zu den aktuellen Entwicklungen völlig verloren hatte, sammelte Koni parallel zu seinem politischen und literarischen Erinnern fleißig Zeitungsartikel und Informationen zu den gesellschaftspolitischen Plänen der neuen Machthaber und machte sich gar Gedanken zum neuen Rechtssystem.

Der mündliche Auftritt vor verschiedenen wissenschaftlichen und literarischen Gruppierungen verweist auf die Rolle, auf die sich Koni in der frühen Sowjetunion fokussierte. Er machte sich immer stärker selber zum Schriftsteller und Lehrer, der in möglichst intensiven Kontakt zu seinen Lesern und Schülern treten wollte, um ihnen jene Persönlichkeiten aus der Welt der Literatur nahezubringen, die ihm selber so wichtig waren. Deren „moralische und gesellschaftliche Ideale“ und „humanistischen“ Werte, die in Konis Augen die Reformen von Justiz, Persönlichkeitsrechten und Selbstverwaltung in den 186oer-Jahre mit hervorgebracht hatten, sollten so implizit Eingang in die Gesellschaft Sowjetrusslands finden. Koni nutzte die ihm verbliebene Nische als „russischer Schriftsteller“ proaktiv und unterschied sich dadurch von so manchen Gesinnungsgenossen, die im sowjetischen Russland keinen Platz mehr für sich erkannten.

Der individuelle Aspekt scheint hier unübersehbar, so verfügte Koni nicht nur über eine in Administration und Gerichtswesen des Zarenreichs gestählte Frustrationstoleranz, sondern auch über eine ausgeprägte Anspruchshaltung an sich selber, die er getreu seiner stetig propagierten moralischen Grundsätze nur schwerlich umgehen konnte. In einem Brief an Lew Tolstoi, mit dem ihn insbesondere die Verehrung für Immanuel Kant verband, hatte er schon 1895 von der „ewigen Arbeit, die Erholung keinen Platz lässt“, geschrieben. Das Leben an sich liebe er nicht, er sei einsam und der Gedanke an den Tod erfülle ihn mit heimlicher Freude. In etwa so wie bei einem Soldaten, der an Urlaub denke. ${ }^{3}$ Gleichzeitig ist

3 Dieser Brief wird im Gedenkband für Koni von 1929 erwähnt, vgl. V. I. SREZnEvsKij: A. F. Koni i L. N. Tolstoj. In: Trudy Puškinskogo Doma Akademii Nauk SSSR (Hrsg.): Pamjati Anatolija Fëdoroviča Koni. Leningrad u. a. 1929, S. 112-13. 
Konis Bezogenheit auf seine eigenen Erinnerungen, für deren Verbreitung er wie ein nimmermüder "Soldat" kämpfte, zweifelsohne auch Ausdruck einer starken Überzeugung von seiner eigenen Wirkungsmächtigkeit und dem Interesse seiner Umwelt für die Erfahrungen des Juristen. Schon seit seiner Studienzeit hielt Koni Erlebnisse in Stichworten fest, und sehr bewusst legte er die Priorität auf die Schaffung eines Nachlasses, der sein Leben überdauern sollte. Dies lief ein Stück weit parallel mit seiner nur im privaten Bereich verbliebenen schriftlichen Auseinandersetzung mit der Enttäuschung, die die Entwicklungen in der Gegenwart nach 1917 für ihn doch auch bedeuteten. In skizzenhaften Archivalien hielt er in den Jahren vor seinem Tod fest, dass er die Frage nach dem „Wofür?" nicht mehr umfassend zu beantworten wusste. Sowohl „Volk“ als auch Intelligencija schienen ihm versagt zu haben, eine „historische Rolle“ konnte er für Russland nicht länger ausmachen. Auch deshalb verlagerte Koni die großen Linien in die Zukunft, in der sich sowohl sein Archiv als auch das Land wieder stärker entfalten können sollten.

Nicht zuletzt durch die Arbeit an seinem Nachlass zeigte sich die Involvierung zahlreicher Beteiligter in Konis Erinnerungspraxis und die Einflüsse dieser Fremdeinwirkungen auf die Wahrnehmung seiner Person. Als Koni 1927 schließlich starb, überließ er das Feld der Erinnerung diesen Menschen. Nicht nur jenen allerdings, die ihm zugetan den Nachlass in seinem Sinne und auf seine Anweisungen hin ordneten, sondern notgedrungen allen, die das Bedürfnis hatten, über ihn etwas zu sagen.

In den Monaten nach Konis Tod wurde seiner auf verschiedene Art und Weise gedacht. Von offizieller Seite weihte im März 1928 der Leningrader Sowjet eine Gedenktafel ein, die am Haus angebracht wurde, in dem Koni verstarb. ${ }^{4}$ Neben dem „Klub der Wissenschaftler“ [Klub naučnych rabotnikov] oder der Medizinischen Gesellschaft Leningrads waren es in erster Linie juristische Organisationen und die Akademie der Wissenschaften, die Koni mit Gedenkversammlungen ehrten. ${ }^{5}$ Grundsätzlich wurde in diesen Reden, die oftmals später im Rahmen von Gedenkbänden publiziert wurden, Konis lebenslanges Engagement in den Bereichen von Justiz und Literatur betont. Insbesondere seine Lektionen und Vorträge in der Sowjetunion fanden lobende Erwähnung, und der Prozess gegen Vera Zasulič wurde als Beleg genannt, dass Koni der Autokratie oppositionell gegenüberge-

4 Vgl. für die Einladung zur Eröffnung der Tafel GARF F. 564, op. 1, d. 4218. Koni wohnte vor seinem Tod in einem Haus an der damaligen Nadeždinskaja-Straße 3, die später zur Majakovskaja-Straße wurde. Auch heute noch lässt sich die Gedenktafel besichtigen, auf der vermerkt ist, dass in diesem Haus am 17.09.1927 Anatolij Koni den Tod fand.

5 Vgl. die Zusammenstellung von Einladungen zu Gedenkfeiern in GARF F. 564, op. 1, d. 4218 oder für den Gedenkvortrag eines Mediziners, S. M. Luk'Janov: Pamjati A. F. Koni. Leningrad 1927. 
standen habe. Nur einige der Juristen gingen weiter, indem sie versuchten, Koni aus den Gefilden der liberalen Politik und der zarischen Justiz wegzurücken. Auf einer gemeinsamen Feier verschiedener Leningrader Rechts- und Gerichtsvereinigungen hieß es im Vortrag von Professor Magaziner, dass Koni zwar nach Erfolg gestrebt habe, diesen aber nicht für sich, sondern zur Stärkung der von ihm für so wichtig befundenen Moral gesucht habe. Recht - so führt Magaziner im Artikel aus, der bald auch im vom Justizministerium mit herausgegebenen „Boten der Sowjetischen Justiz“ erschien - könne bekanntlich nur in einem gegebenen sozialen System wirken. Die Moral aber fördere die Güte unabhängig von den systemischen Bedingungen. ${ }^{6}$ Auf der Gedenkversammlung des Leningrader Anwaltskollegiums für Koni am 10. Oktober 1927 wurde gar eine Rede gehalten, in der explizit verneint wurde, dass Koni ein Mensch der 1860er-Jahre gewesen sei. Die damaligen Reformen seien einem Liberalismus des staatsfeindlichen Manchesterstils gleichgekommen. Koni habe in seinem Leben aber keineswegs teilnahmslos zugeschaut, wie die ökonomisch Starken die ökonomisch Schwachen ausnahmen. ${ }^{7}$ Diese Ansprache wurde später in der Zeitschrift „Recht und Leben“ [Pravo i Žizn’] publiziert, aus deren Kreis Koni als ehemaliger Beiträger auch mit weiteren Gedenkschriften geehrt wurde. Poljanskij erzählte klassisch und sehr ausführlich Konis gesamten Werdegang nach und betonte neben den juristischen auch die literarischen Aspekte wie Konis Verbundenheit mit den großen Schriftstellern. Etwas verklausuliert heißt es zum Schluss, es gebe keine Zeit, in der Koni keinen Platz habe, da er die Kultur des Geistes und des Herzens verkörpere. ${ }^{8}$ Auch Gernet gedachte seines Kollegen mit einem Nachruf, in den er die von Koni vorbereitete Übersicht über seine publizistischen und vertragsmäßigen Tätigkeiten in den letzten Lebensjahren integrierte. Noch im April 1927, so Gernet mit Bezug auf Konis unermüdliche Auftritte mit seinen Erinnerungen, habe Koni ihm geschrieben, dass er „mit der Waffe in der Hand, oder besser im Mund sterben" wolle. ${ }^{9}$

Ausgiebig und mit besonders viel Wohlwollen ehrten schließlich die Akademiker Koni. Zum Halbjahrestag seines Todes druckte die Akademie 6oo Exemplare einer kleinen Broschüre, die für eine Festversammlung für den Ehrenakademiker

6 Ja. Magaziner: Ličnost’ A. F. Koni. In: VSJ 24 (1927), S. 824-25. Vgl. für eine Einladung verschiedener Gerichtsorganisationen zum Gedenken an Koni ebenfalls GARF F. 564, op. 1, d. 4218.

7 M. Ja. Pergament: Pamjati A. F. Koni. In: PŽ 2-3 (1928), S. 98-99.

8 Poljanskij: A. F. Koni. In: ders./B. I. Syromjatnikov (Hrsg.): Na službe pravu, S. 32 . Vgl. auch das zweite Porträt Konis in diesem Band.

9 Gernet: Anatolij Fëdorovič Koni na ischode ego „žiznennogo puti“, S. I. Vgl. oben, S. 380 zu der von Koni vorbereiteten Übersicht. 
warb. Vorträge zentraler Akteure wie Sergej Platonov, Boris Modzalevskij und Sergej Ol'denburg wurden angekündigt. ${ }^{10}$ Die Reden erschienen 1929 im Gedenkband „Pamjati“, in den das „Puschkinhaus“ auch eine erste Übersicht zu Konis Nachlass integrierte. ${ }^{11}$ Dies zu einem Zeitpunkt, als die Akademie und mit ihr Persönlichkeiten wie Platonov in die Repressionsmaschinerie der „Kulturrevolution“ gerieten.

$\mathrm{Zu}$ Beginn der 1930er-Jahre wurde nun ein erstes Erinnerungsdokument Konis veröffentlicht, das er selber zu Lebzeiten trotz wiederholter Anläufe nicht publiziert hatte. Es handelte sich dabei - wie könnte es anders sein - um die Erinnerungen an den Fall Vera Zasulič. Trotz der eingeschränkten politischen Spielräume inmitten großangelegter Säuberungen erblickten Konis Aufzeichnungen zum Prozess von 1878 nun endlich das Licht der Öffentlichkeit - allerdings nicht, ohne im Kommentarapparat entsprechend ideologisch zurechtgebogen zu werden. Als Erstes erschien 1933 im Sammelband „Zven'ja“, der unter anderem von Anatolij Lunačarskij mit herausgegeben wurde, der Anfang der Erinnerungsschrift. Konis Leseanweisungen, mit denen er das Manuskript nach der Oktoberrevolution versehen hatte, wurden ersetzt durch eine Bemerkung der Redaktion. Darin hieß es, dass Koni ein gemäßigter Liberaler gewesen sei, der dank seines Opportunismus auch im Umfeld der zarischen Bürokratie haben wirken können. Die Leser werden angehalten, alle Bewertungen des Autors zu ignorieren und sich auf die Beschreibung der Zustände im Moment der Tat der ersten russischen Terroristin zu konzentrieren. Zum Schluss des Vorworts wird auf Konis vollständiges Manuskript verwiesen, das in Bälde im Verlag Academia unter Redaktion von M. F. Teodorovič erscheine. ${ }^{12}$ Tatsächlich wurde noch im gleichen Jahr die gesamte Erinnerungsschrift veröffentlicht. Auch hier fehlt Konis eigene Einführung. Statt-

10 GARF F. 564, op. 1, d. 4328.

11 Trudy Puškinskogo Doma Akademii Nauk SSSR (Hrsg.): Pamjati Anatolija Fëdoroviča Koni. Leningrad u. a. 1929.

12 Anatolij F. Koni: Vospominanija o dele Very Zasulič. In: Vladimir D. Bonč-Bruevič/ Anatolij V. Lunačarskij (Hrsg.): Zven’ja. Sbornik materialov i dokumentov po istorii literatury, iskusstva i obščestvennoj mysli XIX veka, Bd. 2. Moskva/Leningrad 1933, S. 490 (Vorbemerkung der Redaktion). Dieser umfangreiche Sammelband von fast 700 Seiten enthält Texte über Schriftsteller wie Goethe, Puschkin oder Gogol sowie diverse Briefe und wurde ebenfalls vom Verlag Academia herausgegeben. Die ausführlichen Anmerkungen zum Auszug aus Konis Zasulič-Text finden sich auf S. 485-571.

Ähnlich nimmt sich auch das Vorwort des Verlags Priboj zum 1929 posthum publizierten fünften Band von Konis „Auf dem Lebensweg“ aus. Während betont wird, dass der Jurist selber die Vorbereitungen und Auswahl der Texte noch begleitet habe, wird gleichsam deutlich gemacht, dass Koni ein Mann der weit entfernten Vergangenheit sei, der im Gegensatz zu den marxistischen Historikern die Epoche der „Großen Reformen“ völlig überschätzt habe, vgl. Koni (Hrsg.): Na žiznennom puti, Bd. 5, S. VII (Vorwort der Redaktion). Auch dieses Buch wurde mit zahlreichen Anmerkungen versehen, für die Ju. G. Oksman verantwortlich 
dessen werden im Vorwort, das ein Iv. Teodorovič verfasst hat, unmissverständliche Worte zu Koni als ,in seiner Doktrin eingeschränkter Liberaler“ angeführt, der nichts von den sozioökonomischen Prozessen seiner Zeit begriffen und sich doch erlaubt habe, über andere zu urteilen, die viel weiter gewesen seien als er. ${ }^{13}$ Die dem Text nachfolgenden Kommentare verschaffen dem Lesepublikum eine Vielzahl an Detailinformationen über die Persönlichkeiten und Kontexte, die Koni in der Erinnerungsschrift anspricht. Neben diesen Kurzbiografien gibt es ab und zu mit einem Sternchen versehene Einschübe, die, so wird vermerkt, nicht von M. F. Teodorovič verfasst worden waren. Es sind vor allem diese Abschnitte, in denen Konis Ansichten einer Korrektur zugeführt werden. ${ }^{14}$ Während M. F. Teodorovič noch zu Lebzeiten des Autors an dessen Manuskripten gearbeitet hatte und unter anderem der guten Bekannten Konis Elisaveta Aleksandrovna Sadova (1886-1970) für ihre Unterstützung bei der Kommentierung dankte, wurde zusätzlich offensichtlich von Seiten Dritter in diese Anmerkungen eingegriffen. ${ }^{15}$ Dies verweist auf die ideologische Unverträglichkeit des Erinnerungstextes, von dessen Thematik und sicher auch von dessen Gestalt aber eine so starke Anziehungskraft auszugehen schien, dass man das Manuskript trotzdem publizieren wollte.

Ähnlich sah es in den nachfolgenden Jahrzehnten aus, als Koni nie ganz von der Bildfläche verschwand. Immer wieder erschienen zu seinen runden Geburtsoder Todestagen in Zeitungen oder Zeitschriften Erinnerungen an ihn und ab 1956 schließlich auch Sammelausgaben seiner Texte im zentralen juristischen Verlag der Sowjetunion. In diesen mehrfach herausgegebenen Bänden waren

zeichnete. Es handelt sich dabei hauptsächlich um Informationen zur Textentstehung und weitere Verweise.

13 KonI: Vospominanija o dele Very Zasulič, hrsg. u. mit einer Einleitung versehen v. M. F. Teodorovič und Iv. Teodorovič. Moskva u. a. 1933, S. XXV (Einleitung von Iv. Teodorovič).

14 Vgl. Koni: Vospominanija o dele Very Zasulič, hrsg. u. mit einer Einleitung versehen v. M. F. Teodorovič und Iv. Teodorovič. Moskva u. a. 1933, S. 487 (Anmerkungen) mit dem Hinweis, dass die mit einem Sternchen versehenen Korrekturen - auf dieser Seite eine Rüge von Konis Gebrauch des Wortes „Volk“ - nicht von M. F. Teodorovič stammten.

15 Vgl. für den Dank M. F. Teodorovičs Koni: Vospominanija o dele Very Zasulič, hrsg. u. mit einer Einleitung versehen v. M. F. Teodorovič und Iv. Teodorovič. Moskva u. a. 1933, S. XXXVIII (Vorbemerkung von M. F. Teodorovič). E. A. Sadova war die Tochter des mit Koni befreundeten Philologieprofessors A. I. Sadov. Sie arbeitete als Russischlehrerin und als Bibliothekarin und unterstützte E. Ponomareva bei den Arbeiten an Konis Schriften, vgl. SAšonko: A. F. Koni v Peterburge - Petrograde - Leningrade, S. 282. In den 196oerJahren beteiligte sie sich auch an den Vorarbeiten zur Gesamtausgabe von Konis Werken, vgl. O. S. Ost roj: Sadova Elizaveta Aleksandrovna. In: Sotrudniki Rossijskoj nacional'noj biblioteki - dejateli nauki i kul'tury. Biografičeskij slovar', 4 Bände. Sankt-Peterburg 2008, elektronisch verfügbar unter www.nlr.ru/nlr_history/persons/info.php?id=1172, Zugriff vom 18.11. 2016. 
sowohl Gerichtsreden als auch Fachtexte, das Zasulič-Manuskript und eine Auswahl aus Konis „Erinnerungen eines Gerichtstätigen“ sowie beispielsweise das Porträt von Lew Tolstoi abgedruckt. ${ }^{16}$ Gegen Ende der 196oer-Jahre folgte die achtbändige Gesamtausgabe seiner Werke, die ebenfalls im Verlag Juridičeskaja literatura erschien. Umfassende Vorarbeiten waren dieser Publikation vorangegangen. Zahlreiche bislang unveröffentlichte Manuskripte hatte man für den Abdruck vorbereitet und diverse handschriftliche Briefe entziffert. Erstmals erschien nun vor der Zasulič-Erinnerung auch Konis eigenes Vorwort zum Prozessbericht. ${ }^{17}$

In den letzten Jahren der Sowjetzeit und insbesondere nach dem Zerfall der Union stieg das Interesse an Koni dann rasant an. Offiziell knüpfte das russische Justizministerium 1993 beim Juristen aus der Zarenzeit an, als man Vorbereitungen für die Feier seines 150. Geburtstages zu treffen begann. Erklärungen wurden abgedruckt, in denen es hieß, dass Koni einer der wenigen Namen sei, die in Russland nicht vergessen worden seien. Sein Einsatz für den Rechtsstaat und die Wahrung der Rechte der Individuen, die vor Gericht alle gleich seien, wurde betont. ${ }^{18}$ Die Beschäftigung mit Konis Fachtexten und Gerichtsreden nahm sprunghaft zu.

Das Bedürfnis nach der Neuetablierung eines Rechtsstaates, in dem die juristischen Instrumente wirklich den Interessen der gesamten Bevölkerung dienten, war seit der Perestroika-Zeit in Russland überwältigend groß. ${ }^{19}$ Die Neubewertung der Vergangenheit, die nach dem Zerfall der Sowjetunion begann, sah die Zeit seit 1917 oftmals als eine Art Abweichung vom normalen Gang der Geschichte. Intensiv wurde deshalb versucht, direkt aus der Zarenzeit eine Brücke in die 1990er-Jahre zu schlagen und das sowjetische Vermächtnis beiseitezulassen. Das moderne Russland sollte Erbe des Zarenreiches sein, das man mit idealisierten Zügen versah. ${ }^{20}$ In diesem Ambiente diente die Beschäftigung mit Koni unmittelbar der Bekanntmachung von Rollenmodellen aus der vorrevolutionären Vergangenheit des Justizwesens. Der Aufbau der Demokratie und die entsprechende

16 Vgl. für die erste Ausgabe 1956: Anatolij F. KonI (Hrsg.): Izbrannye proizvedenija. Stat'i i Zametki, Sudebnye reči, Vospominanija, hrsg. v. A. B. Amelin. Moskva 1956. Vgl. zum Verlag „Juristische Literatur“, dessen Geschichte bis auf 1917 zurückgeht und der zeitweise auch „Staatlicher Verlag für juristische Literatur“ hieß, die Übersicht auf der heutigen Verlagswebsite, www.jurizdat.ru/phouse/index.htm, Zugriff vom 18.11. 2016.

17 Vgl. für Artikel zu Konis Geburtstagen und die Angaben zur Gesamtausgabe auch die Einleitung der Dissertation.

18 Anatolij V. ŠA povalov: Pravovye vzgljady A. F. Koni i ich vlijanie na provodimuju v Rossii sudebno-pravovuju reformu. Kubanskij gosudarstvennyj agrarnyj universitet, Krasnodar 2005, S. 7-8 (unveröffentlichte Dissertation).

19 Burbank: Legal Culture, Citizenship, and Peasant Jurisprudence, S. 102. Vgl. für den Boom an Texten über Koni auch die Einleitung der Dissertation.

20 Amacher: En guise d'introduction, S. 15 und 23. 
Reform des Rechtssystems förderten in den 199oer-Jahre die Auseinandersetzung mit dem renommierten Juristen aus dem Zarenreich. ${ }^{21}$ Eigenschaften wie absolute Integrität und voller Einsatz für Rechtsstaatlichkeit unter den letzten Zaren, die ehemaligen Meistern des Fachs wie Anatolij Koni zugeschrieben wurden, wurden als zentrale Elemente in der Neustrukturierung des Rechtswesens nach dem Ende der Sowjetunion angesehen. ${ }^{22}$ Konis Aktivitäten in den Jahren vor seinem Tod im sowjetischen Leningrad rückten nun in den Hintergrund. Mit Vorliebe wurde und wird direkt an seinen Erinnerungsschriften, Gerichtsreden, Fachtexten und Literatenporträts angeknüpft, die bis heute in immer wieder neuen Kombinationen und Auflagen erscheinen. 1996 wurde Konis Dissertation zum „Recht auf notwendige Verteidigung" publiziert, 2000 seine Rede zu den moralischen Grundlagen des Strafprozesses erneut herausgegeben, 2003 das Porträt der Stadt St. Petersburg nochmals veröffentlicht, und 2010 erschien ein Sammelband, der sich ganz auf die Erinnerungen Konis an die großen Literaten konzentrierte. ${ }^{23}$ Sein Nachlass, um dessen Bewahrung schon zu Sowjetzeiten Rivalitäten ausgebrochen waren, befindet sich heute aufgeteilt hauptsächlich auf das „Puschkinhaus" in St. Petersburg und das Staatliche Archiv der Russischen Föderation (GARF) in Moskau. ${ }^{24}$ Wobei in Letzterem Konis Fond vor Kurzem als einer der ersten des gesamten Archivs vollständig digitalisiert worden ist. Ehrbezeugungen

21 Kantypenko verweist darauf, dass es seit 1991 in Russland Versuche gibt, ganz konkrete Elemente der vorrevolutionären Justiz wiedereinzuführen. Für die Gerichtsrhetorik wird gerne auf Lehrbücher und Memoiren von Juristen aus der Reformära des späten Zarenreichs zurückgegriffen, vgl. Elena KANTY PENKO: Klassische Plädoyers in Strafprozessen der „europäischen Ära“ russischer Rechtsentwicklung nach der Justizreform von 1864. In: Werner Krawietz (Hrsg.): Gewohnheitsrecht, Rechtsprinzipien, Rechtsbewusstsein. Transformationen der Rechtskultur in West- und Osteuropa: interdisziplinäres Symposion 2004 an der Universität Münster. Berlin 2004, S. 357.

22 Lichomanov: A. F. Koni v osobom soveščanii po sostavleniju novogo Ustava o pečati, S. 125 und Neтневсотт: Russian Legal Culture Before and After Communism, S. 2-3.

23 Vgl. in der Reihenfolge der Erwähnung: Anatolij F. Koni: O prave neobchodimoj oborony, hrsg. u. mit einer Einleitung versehen v. A. Coriev. Moskva 1996; Anatolij F. KonI: Ugolovnyj process: nravstvennye načala. Moskva 200o; Anatolij F. KonI: Peterburg. Vospominanija starožila. Moskva 2003; Anatolij F. KonI: Vospominanija o pisateljach. Literaturnye očerki, hrsg. v. Alevtina Bessonova u. a., mit Kommentaren versehen v. A. S. Stepanova. Sankt-Peterburg 2010.

24 Domanova schreibt, dass in den 1930er-Jahren ein Teil des Nachlasses aus dem „Puschkinhaus" nach Moskau gebracht wurde, wo zuerst im Staatlichen Archiv der feudalleibeigenschaftlichen Epoche (GAFKĖ) ein Findbuch v. a. von den Briefen erstellt wurde. 1941 ging dies alles wieder nach St. Petersburg an das Zentrale Staatliche Historische Archiv (CGIA), das sich dabei gegenüber dem Zentralen Staatlichen Archiv für Literatur und Kunst (CGALI) durchsetzte. Erst 1968 wurde dann der Moskauer Teil des Nachlasses endgültig und bis heute ins GARF in Moskau gegeben, das damals noch Zentrales Staat- 
für Koni gibt es auch in klassischer Manier. So finanzierte ein privater Spender 1998 ein Denkmal des Juristen, das vor der Staatlichen Universität Moskaus zu besichtigen ist. ${ }^{25}$ Wenig später wurde durch das Justizministerium eine „Medaille Anatolij Koni“" geschaffen, mit der Verdienste um das russische Rechtswesen belohnt werden. ${ }^{26}$ Niederschwelliger sind Anlehnungen an Koni im Internet. Auf verschiedenen Homepages sind Fotografien und kurze Lebensbeschreibungen zu finden. Teilweise handelt es sich bei diesen Zusammenstellungen um das Werk von Anwaltskanzleien oder sonstigen juristischen Organisationen, die sich dadurch direkt auf Koni als Vorbild berufen. ${ }^{27}$

Die Art und Weise, wie Koni bis zum heutigen Tag in Russland als juristisch äußerst versierter Kämpfer für einen die liberalen Freiheitsrechte schützenden Rechtsstaat dargestellt wird, der insbesondere aufgrund seiner persönlichen Integrität und seiner hohen moralischen Standards als Rollenmodell für zukünftige Juristen dienen soll, nimmt Aspekte auf, die Koni selber zu Lebzeiten in seinen autobiografischen Praktiken propagiert hatte. Dies gilt in zweierlei Hinsicht. Sowohl die Bedeutung von Vorbildern an sich als auch die konkreten Inhalte, die auf diese projiziert werden, lassen sich auf Konis eigene Anstrengungen zurückführen. Die idealistische Porträtierung der „edlen“ Juristen und die Etablierung eines Generationennarratives, dem sich Koni zum 50. Jubiläum der Reform so intensiv gewidmet hatte, werden wieder aufgegriffen. Die enorme Wirkungskraft der Narrative, die durch Koni und durch die Verwendung der Begrifflichkeiten in seinem Umfeld geschah, scheint bis heute ungebrochen. Gerne werden exakt jene Ausdrücke verwendet, die Koni mitgeprägt hatte. So wird er selber von einem seiner Biografien 1988 als ,treuer Ritter des Rechtswesens" bezeichnet. ${ }^{28} 1993$ heißt ein Artikel über Fëdor Plevako „Ritter des Rechtswesens“. ${ }^{29}$ Dmitrij Legkij nennt eines der Kapitel in seiner Biografie über den Juristen Dmitrij Stasov 2011 „Un-

liches Archiv der Oktoberrevolution (CGAOR) hieß, vgl. Domanova: Perepiska A. F. Koni kak istoričeskij istočnik, S. 58-59.

25 Vgl. dazu und zu weiteren Gedenkarten wie beispielsweise einer Briefmarke mit Konis Konterfei https://ru.wikipedia.org/wiki/Кони,_Анатолий_Фёдорович, Zugriff vom 16.11. 2016.

26 Für eine Fotografie der Medaille und eine Liste mit einigen der bisherigen Trägern vgl. https://ru.wikipedia.org/wiki/Медаль_Анатолия_Кони, Zugriff vom 16.11. 2016.

27 Vgl. mit juristischem Hintergrund z. B. http://cripo.com.ua/?sect_id=2\&aid=145728; http:// kozhemjakin.ru/ru/dinamika-yuridicheskoj-myisli/koni-anatolij-fyodorovich.html; Zugriffe vom 16.11. 2016.

28 VysockiJ: Koni, S. 57.

29 Fëdor N. Pleva ko: Izbrannye reči, hrsg. u. mit einem Vorwort versehen v. R. A. Markovič und G. M. Reznik. Moskva 1993, S. 5-40 (Vorwort von G. M. Reznik). 
bekannter Vater" der Gerichtsreform. ${ }^{30}$ Dass sich die Argumentation dabei bisweilen im Kreis dreht, macht ein Beispiel aus der Koni-Biografie von Smoljarčuk besonders deutlich. Er erwähnt in seiner Darstellung von 1981 ein „Plakat“ in Konis Nachlass, auf dem dieser zusammen mit den Juristen Urusov, Plevako, Arsen’ev und Spasovič als „Gigant und Zauberer des Wortes“ bezeichnet werde. Dies wird von Smoljarčuk als Beweis für die großartige Redekunst Konis und seine herausragende Bedeutung für die Juristen angeführt. ${ }^{31}$ In Tat und Wahrheit handelt es sich bei diesem Plakat aber um eine der kunstvollen Albumseiten, die wohl Elena Ponomareva zu Konis Ehren gestaltet und mit den entsprechenden lobenden Worten betitelt hatte. ${ }^{32}$

Die Tatsache, dass Koni über eine solche Vielzahl an Juristen, Politikern und Literaten seiner Zeit Erinnerungsporträts verfasste und seine Erlebnisse so ausführlich in seinen autobiografischen Schriften Revue passieren ließ, garantiert ihm bis heute eine enorme, wenn auch oftmals indirekte, Präsenz. In zahlreichen Arbeiten der Russlandforschung wird gerne und ausführlich auf Konis Porträts und Erinnerungen zurückgegriffen. Die Biografie von Stasov enthält noch vor der Einleitung einen Auszug aus der Rede Konis zum Tod des Juristen, in dem er diesen als Gerichtsreformer und prägenden Advokaten beschreibt. Und 250 Seiten später endet die Biografie auch wieder mit einem Zitat Konis. ${ }^{33}$ Aleksandr Polunovs 2010 publizierte Biografie von Konstantin Pobedonoscev enthält eine Vielzahl an Verweisen auf Konis Erinnerungsschrift „Die Triumvirn“ über seine Zeit am Kriminalkassationsdepartement. ${ }^{34}$ Francis Wcislo beendet sein Buch über das Leben von Sergei Witte mit einem halbseitigen Zitat aus Konis Skizze zum Staatsmann. ${ }^{35}$ Ana Siljak erzählt in ihrer Monografie über Vera Zasulič und Russlands „revolutionäre Welt“ streckenweise ganze Szenen aus Konis Erinnerungsschrift zum Fall nach. ${ }^{36}$ Die außerordentliche Wirkungskraft von Konis

30 LegkiJ: Dmitrij Vasilevič Stasov.

31 Smoljarčuk: Anatolij Fëdorovič Koni (1844-1927), S. 69-70. Wenig später betitelt Smoljarčuk auch seine Sammlung von Kurzbeschreibungen wichtiger Gerichtsredner und Beispiele ihrer Reden mit „Giganten und Zauberer des Wortes“, vgl. Vasilij I. SMOLJARčUK: Giganty i čarodei slova. Russkie sudebnye oratory vtoroj poloviny 19 - načala 20 veka. Moskva 1984.

32 IRLI, F. 134, Op. 4, d. 391, 1. 9. Vgl. für das Album auch oben, S. 378.

33 Legkij: Dmitrij Vasil'evič Stasov, Widmungsseite und S. 248.

34 Polunov: K. P. Pobedonoscev v obščestvenno-političeskoj i duchovnoj žizni Rossii, vgl. z. B. S. 68, 75, 94 oder 127 sowie Polunov über Konis Erinnerungstext als Quelle seiner Arbeit auf S. 6 und $33-35$.

35 WCislo: Tales of Imperial Russia, S. 253.

36 SiLjak: Angel of Vengeance, S. 171. Siljak übernimmt hier exakt Konis Nacherzählung eines Gesprächs im Büro von Graf Pahlen. 
Erinnerungen und Skizzen wurde schon 1980 von Heinz Müller-Dietz in dessen Biografie über den in Russland arbeitenden Mediziner Friedrich Joseph Haas mit Verwunderung konstatiert. Koni hatte seit Mitte der 189oer-Jahren über den Chefarzt der Gefängnishospitäler und Mitglied im Gefängnisschutzkomitee mehrfach sowohl auf Russisch als auch auf Deutsch veröffentlichte biografische Skizzen geschrieben, in denen er den Kampf Haas' für bessere Haftbedingungen und seine weitreichenden philanthropischen und humanitären Bemühungen in Russland hervorhob - Ziele, für die auch Koni selber sich einsetzte. Müller-Dietz schreibt dazu: „Der Dr. Haas, wie er seit der Jahrhundertwende gekannt und verehrt wird,

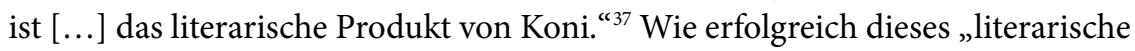
Produkt" bis heute ist, zeigt sich daran, dass erst kürzlich in Zusammenhang mit der Verhaftung der ukrainischen Kampfpilotin Nadija Savčenko in einer russischen Zeitung auf Friedrich J. Haas verwiesen wurde, der all seine Kräfte dafür gegeben habe, in Russland die Haftbedingungen zu verbessern, weshalb nun in seinem Namen um Milde für die Angeklagte gebeten werde. ${ }^{38}$

Die immer wieder dramatischen und detailreichen, oftmals in Dialogform operierenden Darstellungen Konis sind von hoher Prägnanz und Unterhaltsamkeit. Nicht zuletzt die literarische Qualität seiner Erinnerungen dürfte mit dazu beitragen, dass von seinen autobiografischen Schriften bis heute eine fast unwiderstehliche Anziehungskraft auszugehen scheint. Die Inhalte von Konis Darstellungen und seine Anliegen werden so weitergegeben - meist ohne auf deren zeitgenössischen Entstehungskontext einzugehen. Es ist klar, dass mit dieser häufigen Verwendung von Konis Werk nicht nur die Themen seiner Erinnerungsschriften und Porträts aktuell gehalten werden, sondern auch die Bedeutung seiner Person unterstrichen wird. Außerordentlich gut gelang es Koni so, die Deutungshoheit über sein Leben und seine Rolle auch posthum beizubehalten. Es sind die „hellen Seiten“ und exakt jene Themen und Meinungen, die er in seinen Erinnerungen betonte, die in Zusammenhang mit seiner Person wieder und wieder rekapituliert werden.

Svetlana Domanova konstatiert 1999 im Rahmen ihrer langjährigen Beschäftigung mit Konis Briefwechseln, dass dieser ein „in Vielem noch unverstandener Mensch" sei. ${ }^{39}$ Zweifelsohne trägt für dieses Unverstandensein Konis Art der Selbstreflexion eine gewisse Verantwortung. Es ist offensichtlich, dass Koni die Interpretation seiner Person durch seine Erinnerungsschriften ein Stück weit

37 Zitiert nach: Beckmann: „Die ganze Bewegung war die Bewegung aufsteigender Elemente“, S. 145. Heinz Müller-Dietz: Friedrich Joseph Haass als Arzt in Moskau. Biographische Skizzen. Berlin 1980. Vgl. oben, S. 411 zu Konis Skizze über Dr. Haas bzw. Haass oder Gaaz.

38 www.novayagazeta.ru/society/67393.html, Zugriff vom 17.11. 2016. Domanova: Perepiska A. F. Koni kak istoričeskij istočnik, S. 32. 
steuerte und auch seinen Nachlass in der Logik seines eigenen Biografen zu konstruieren versuchte. Die Analyse von Konis autobiografischen Praktiken bewegt sich in diesem Spannungsfeld. Die Engführung, die Koni selber in seiner Selbstdarstellung bewerkstelligte, lässt gewisse Themenbereiche außen vor. Durchaus aufsehenerregende Gerichtsfälle, in die Koni involviert war, über die er sich aber nicht schriftlich äußerte - wie beispielsweise die Untersuchungen zu einem großen Schiffsunglück 1894 - können höchstens indirekt eine Rolle spielen. ${ }^{40}$ Auch das Privatleben des nie verheirateten Koni wird von ihm nur selten und vage thematisiert. Doch hier gilt, was in der gesamten Auseinandersetzung mit dem Quellenkorpus aus Selbstzeugnissen zentral ist. Das genaue Hinhören, die Öffnung des Blicks für Unerwartetes und Vielschichtiges, das Lesen der Texte als Gesamtkompositionen in ihren verschiedenen Versionen und Kontexten des Entstehungszusammenhangs, schließlich das erneute Studium der Selbstbeschreibungen mit einiger Distanz und im Bewusstsein, dass die intensive Auseinandersetzung mit Konis Nachlass auch wieder die Interpretation seiner autobiografischen Praxis mit beeinflusst - all dies lässt auch im oftmals unpersönlichen Schreiben Konis persönliche Züge durchschimmern. So ist in seiner Suche nach Anerkennung und Bestätigung, in seinem Pflichtbewusstsein und seiner ausgeprägten Überzeugung von sich und seinem Handeln, aber auch seinen Ausfluchten vor noch mehr Verantwortung und der Konkretisierung seiner eigenen Haltungen sehr viel zutiefst Menschliches zu finden. Hierzu zählen wohl auch die schwarz verbliebenen Stellen seiner Selbstbeschreibungen, die konstitutiv zu seiner Persönlichkeit gehören.

Indem Konis autobiografische Selbstverortung in ihrer „textuellen Dimension“ als „Sinnganzes“ und als „historisches Ereignis“ interpretiert wurde, gelang es über die erneute Nacherzählung von Konis Erinnerungen hinauszugehen und Aussagen nicht nur über die Persönlichkeit des Juristen, sondern auch über sein Umfeld, seine Zeit sowie den Stellenwert und die Funktionsweise autobiografischer Praktiken im Allgemeinen zu machen. Dabei ist es gerade die Quellenlage, die die detailreiche und intensive Auseinandersetzung mit der autobiografischen Praxis eines einzelnen Individuums auf diese Art und Weise überhaupt erst möglich und besonders lohnend macht. Was an übergeordneten Fragen mithilfe von

40 Im Juli 1894 wurde Koni vom Justizminister nach Odessa geschickt, um die lokalen Behörden bei der Untersuchung eines Schiffsunglücks zu unterstützen, in das neben einem russischen auch ein italienisches Schiff involviert war und das zahlreiche Todesopfer gefordert hatte. Vgl. für die Dienstanweisung an Koni von Murav’ev GARF F. 564, op. 1, d. 588. Vgl. für eine kurze Übersicht zum Fall und die Verteidigungsrede von Nikolaj Karabčevskij für den angeklagten Kapitän des russischen Bootes, Evgenij M. VorOžEJKIN (Hrsg.): Sudebnye reči izvestnych russkich juristov. Moskva 1957, S. 333-57. 
Konis Person und ihrer Selbstverortung aufgezeigt werden kann, ist nicht auf ihn beschränkt, wird aber erst durch seine ausgeprägte, lebenslange und auch hinsichtlich des Kontextes von Seiten Dritter gut überlieferten Auseinandersetzung mit sich und seiner Zeit analysierbar.

Die Untersuchung der Inhalte von Konis autobiografischen Schriften verweist so auf die zeitgenössischen Diskurse, an die er anknüpfte und die er für seine eigenen Interessen nutzte. Professionalisierungsbestrebungen und Konzepte von generationeller Weitergabe und die dadurch erfolgte Verteidigung des Rechtsstaates auf einer indirekten Ebene werden deutlich. Die Definition von guter Prozessführung, die auch Eliten nicht verschont, steht neben Idealvorstellungen von liberalen Reformen durch einen die unabhängige Justiz respektierenden und gar befördernden ,guten“ Zaren. In der autobiografischen Praxis zeigt sich gleichsam die Hartnäckigkeit, mit der Koni an seinen Überzeugungen festhielt, als auch die tiefe Verunsicherung, mit der er angesichts der rasanten Veränderungen in Politik und Gesellschaft nach der Jahrhundertwende zu kämpfen hatte. Der Zusammenhang von historischem Wandel und autobiografischem Schreiben schlägt sich ganz konkret in der Notwendigkeit nieder, sich angesichts der erfahrenen Veränderung selber zu hinterfragen und zu behaupten - was wesentlich in Form eines schriftlichen Ringens mit sich selbst gelang. An der Sinnsuche und der Frage, wie man als Individuum einen Beitrag zur Gesellschaft leisten konnte, schien in diesem Kontext von rivalisierenden Weltanschauungen und Zukunftsvisionen für Russland kein Weg vorbeizuführen. Zeitgenössische Diskussionen um die Rolle von Intelligencija und „Volk“ spiegeln sich in Konis Legitimationsstrategien und in seiner Überhöhung der Literaten, die für ihn in der frühen Sowjetunion schließlich eine Art Vehikel wurden, um eigene moralische Überzeugungen vom Verhältnis der Menschen zueinander weiterzutransportieren. Ein zutiefst moderner, liberaler Ethos von individueller Pflicht und Verantwortung des Bürgers beziehungsweise die von Koni so oft zitierten "grundlegenden Regeln der kantschen Ethik“" scheinen für Koni sowohl im Zarenreich wie auch im frühen Sowjetrussland leitend zu sein und Platz zu haben. Das die Intelligencija prägende Selbstverständnis von der Bedeutung des eigenen Lebens und der Notwendigkeit zur Übernahme von Verantwortung für die Zukunft Russlands geht dabei einher mit Konis Engagement als "gesellschaftlicher Akteur“, der sich mit dem „Volk“ nicht nur als abstrakte Größe, sondern auch im realen (Gerichts-)alltag und in seinen Analysen der Tätigkeiten der Geschworenengerichte auseinandergesetzt hatte. Der „Epochenbruch“ 1917 bedeutete für ihn auch deshalb keine Neuorientierung, sondern - herausgefordert durch den Deutungskampf um die Vergangenheit - eine verstärkte Orientierung seiner Erinnerungspraktiken auf die Öffentlichkeit hin. Die breite Konzeption von autobiografischer Praxis erlaubt schließlich, Konis Gestaltung seines Nachlasses 
als Element derselben zu verstehen und festzuhalten, wie er „Sinn“ ein Stück weit in die Zukunft zu verlagern versuchte.

Dass Konis Erinnerungspraktiken in enge Beziehung zum Entstehungszeitpunkt gebracht werden, bereichert nicht nur deren Interpretation, sondern gibt auch Aufschluss über verschiedene Komponenten aus Konis Leben und die externen Faktoren, die die Autobiografik und die Entfaltung von Konis Selbstverständnis förderten und prägten. Haltungen und Meinungen von Persönlichkeiten aus seinem Umfeld - beispielsweise den Journalisten des „Boten Europas“ - lassen sich ebenso finden wie Interessen von Verlagen, privaten Bewunderern oder Vereinen, die in ihrer Fokussierung auf Koni dessen Wahrnehmung mitgestalten. Der genaue Blick auf Konis Erinnerungen und die Reaktionen, die sie hervorriefen, zeigt sein Netzwerk gerade in der frühen Sowjetunion auf, das in In- und Auslandsrussen zerrissen war. Die Orte, an denen Koni seine Schriften platzierte, die Verlage, mit denen er kooperierte, und die Rückgriffe auf Obrigkeiten, die er im Zarenreich wie auch in der Sowjetunion suchte, verweisen auf seine Intentionen und die Machtstrukturen. Dabei gilt, dass autobiografische Praxis nur schwerlich ohne den Bezug zur Gegenwart zu funktionieren scheint. Koni setzte sich - auch wenn dies heute in den aktuellen Darstellungen seiner Person gerne übersehen wird - auch mit dem sowjetischen Russland intensiv auseinander. Nur so konnte er die Zuhörer abholen und für seine Erinnerungen an die zarische Vergangenheit gewinnen.

Der Abgleich mit Berufskollegen und Gesinnungsgenossen, mit denen Koni manchmal gerade aufgrund seiner Erinnerungsmission in Kontakt kam, zeigt sowohl Übereinstimmungen als auch Unterschiede. Auch andere Juristen aus der vornehmlich hauptstädtischen Elite der Berufsgruppe übten sich wie er im Schreiben von kanonisierenden Porträts der Kollegen. In seiner Faszination von Zarenamt und Machtfülle der Selbstherrscher und seinem Glauben an deren Führungsaufgabe glich Koni den Reformbürokraten der 1850er- und 186oer-Jahre. Er hielt diese Vorstellungen aber auch noch viel später aufrecht, als er - im Gegensatz zu den Publizisten mit ähnlichen Haltungen - in direkten Kontakt mit den verschiedenen Zaren trat und sich in konkreter Beeinflussung derselben übte. Seine enorme Frustrationstoleranz und ein unzerstörbares Festhalten an der Überzeugung von der Wirkungsmächtigkeit seiner selbst und seiner Erinnerungen unterschieden Koni nach der Oktoberrevolution schließlich grundlegend von vielen seiner Kollegen, die sich in die innere oder äußere Emigration zurückzogen. Autobiografische Praxis als Eigenwert wird hier besonders fassbar. In ihrer Gesamtheit trugen alle Selbstreflexionen und Bezugnahmen Konis, die er ein Leben lang beging, dazu bei, ihm in verschiedenen historischen Kontexten eine selbstbewusste Position und eine aktive Rolle zu ermöglichen. 


\title{
Quellen-, Literatur- und Abkürzungsverzeichnis
}

\author{
Allgemeine Abkürzungen
}

\author{
d. Delo [Dossier] \\ ed. chr. Edinica Chranenija [Dossier] \\ F. Fond [Bestand] \\ GA Gesamtausgabe* \\ GARF Gosudarstvennyj Archiv Rossijskoj Federacii \\ IRLI Institut Russkoj Literatury \\ 1. List [einzelnes Blatt] \\ ob. Rückseite \\ op. Opis' [Serie] \\ RNB Rossijskaja Nacional'naja Biblioteka
}

\section{Periodika (Abkürzungen)}

\author{
AD Artel'noe Delo [Das Artel] \\ B Byloe [Vergangenes] \\ DD Dela i dni [Taten und Tage] \\ GM Golos Minuvščego [Stimme der Vergangenheit] \\ IV Istoričeskij Vestnik [Historischer Bote] \\ KN Knižki Nedeli [Bücher der Woche] \\ KR Kniga i Revoljucija [Buch und Revolution] \\ MV Moskovskij Vedomosti [Moskauer Nachrichten] \\ N Niva [Saatfeld] \\ P Pravo [Recht] \\ $\mathrm{PkN}$ Ežemesjačnoe literaturnoe i populjarno-naučnoe priloženie k žurnalu „Niva“ \\ [Monatliche literarische und populärwissenschaftliche Beilage zum Journal \\ „Saatfeld“] \\ PN Poslednie Novosti [Letzte Neuigkeiten] \\ $\mathrm{PŽ} \quad$ Pravo i Žizn' [Recht und Leben] \\ RM Russkaja Mysl' [Russischer Gedanke] \\ RS Russkaja Starina [Russische Altertümer] \\ RV Russkij Vestnik [Russischer Bote] \\ VE Vestnik Evropy [Bote Europas]
}

* Die acht Bände der Gesamtausgabe von Konis Werken aus den 196oer-Jahren werden in der Arbeit als GA1-8 abgekürzt. Die vollständige Literaturangabe lautet: Anatolij F. Konı: Sobranie sočinenij, 8 Bände, hrsg. v. V. G. Bazanov, L. N. Smirnov und K. I. Čukovskij. Moskva 1966-1969. 
VL Vestnik Literatury [Bote der Literatur]

VP Vestnik Prava [Bote des Rechts]

VSJ Vestnik Sovetskoj Justicii [Bote der Sowjetischen Justiz]

ŽMJ Žurnal Ministerstva Justicii [Journal des Justizministeriums]

\section{Nachschlagewerke (Abkürzungen)}

ĖSBE Ėnciklopedičeskij slovar' Brokgauza i Efrona [Enzyklopädie Brockhaus-Efron], St. Petersburg 1890-1907

NÉS Novyj ènciklopdeičeskij slovar’ [Neue Enzyklopädie Brockhaus-Efron], St. Petersburg 1911-1916

RBS Russkij biografičeskij slovar' [Russisches Biografisches Wörterbuch], St. Petersburg 1896- 1918

SČOLRS Slovar' členov Obščestva ljubitelej Rossijskoj slovesnosti pri Moskovskom Universitete 1811-1911, Moskau 1911

\section{Archivbestände}

Gosudarstvennyj Archiv Rossijskoj Federacii (GARF), Moskau

F. 564 (A. F. Koni, 4329 ed. chr.)

Institut Russkoj Literatury Rossijskoj Akademii Nauk (IRLI RAN - Puškinskij Dom), St. Petersburg

F. 134 (A. F. Koni, 4175 ed. chr.)

Rossijskaja Nacional'naja Biblioteka (RNB), St. Petersburg

F. 367 (A. F. Koni, 16 ed. chr.)

\section{Gedruckte Quellen/Quelleneditionen}

Textvarianten, auf die nur in einer Fußnote verwiesen wird, ohne dass je aus ihnen zitiert würde, sind in der Regel nicht im Literaturverzeichnis aufgeführt.

Aleksandr V. Amfiteatrov: Sobranie sočinenij v 10 tomach, Bd. 10:2. Memuary, hrsg. u. mit einer Einleitung versehen v. Timofej F. Prokopov. Moskva 2003.

Nikolaj P. Anciferov: Duša Peterburga, hrsg. u. mit einem Nachwort versehen v. A. Margolis. Leningrad 1990.

Nikolaj P. Anciferov: Die Seele Petersburgs, hrsg. u. mit einer Einleitung versehen v. Karl Schlögel. München 2003.

A. P. Andreeva: Pamjati Anatolija Fëdoroviča Koni. In: Anatolij F. Koni: Izbrannoe. Moskva 1989, S. 425-31. 
Sergej A. Andreevskij (Hrsg.): Zaščititel'nye reči. Sankt-Peterburg 1909 (3., erweiterte Auflage nach 1891 und 1898).

Sergej A. Andreevskij (Hrsg.): Dramy žizni. Petrograd 1916.

Sergej A. Andreevskij: Nad mogiloj knjazja A. I. Urusova. In: ders. (Hrsg.): Dramy žizni. Petrograd 1916, S. 621-23.

Sergej A. Andreevskij: Ob ugolovnoj zaščite. In: ders. (Hrsg.): Dramy žizni. Petrograd 1916, S. 3-38.

Sergej A. AndreevskiJ: Kniga o smerti, Bd. 1 und 2. Revel', Berlin 1922.

Sergej A. AndreevskiJ: Kniga o smerti. Leningrad 1924.

Sergej A. Andreevskij: Kniga o smerti, hrsg. u. mit einem Nachwort versehen v. I. I. Podol'skaja. Moskva 2005.

Konstantin K. Arsen'ev: Zametki o russkoj advokature. Obzor dejatel'nosti St. Peterburgskogo soveta prisjažnych poverennych za 1866-74 gg. Sankt Peterburg 1875.

Konstantin K. Arsen'ev: Novye sborniki sudebnych rečej. In: VE 6 (1891), S. 777-804.

Konstantin K. Arsen'ev: Kn. A. I. Urusov. In: VE 5 (1900), S. 433-35.

Konstantin K. Arsen'Ev (Hrsg.): Glavnye dějateli i predšestvenniki sudebnoj reformy. Sankt-Peterburg 1904.

Konstantin K. Arsen'ev: Vospominanija o V. D. Spasoviče. In: VE 11 (1906), S. 458-61.

Konstantin K. Arsen'Ev: Vospominanija o knjaze A. I. Urusove. In: Aleksandr I. Urusov/A.

A. Andreeva/O. B. Gol'dovskij (Hrsg.): Knjaz' Aleksandr Ivanovič Urusov (1843-1900). Stat'i ego, pis'ma ego, vospominanija o nem, Bd. 2 und 3. Moskva 1907, S. 237-39.

Konstantin K. Arsen'ev: Polveka tomu nazad i teper'. In: VE 2 (1911), S. 303-15.

Konstantin K. ArSEN'ev: Iz vospominanij. In: GM 2 (1915), S. 118-29.

Nikolaj A. Berdjaev u. a. (Hrsg.): Vechi. Wegzeichen: zur Krise der russischen Intelligenz, hrsg. u. mit einer Einleitung versehen v. Karl Schlögel, Original Moskau 1909. Frankfurt am Main 1990.

Aleksandr A. Blok: O naznačenii poèta. In: Dom literatorov (Hrsg.): Puškin. Dostoevskij. Petrograd 1921, S. 15-28.

Rašel' M. Chin-Gol’dovskaja: Pamjati starogo druga. In: Trudy Puškinskogo Doma Akademii Nauk SSSR (Hrsg.): Pamjati Anatolija Fëdoroviča Koni. Leningrad u. a. 1929, S. $55-78$.

I. A. Chmel'nickiJ: Sudebnaja Reforma v eë dejateljach. K 5o-letiju „Sudebnych Ustavov“. Odessa 1915.

M. P. Čubinskit: Anatolij Fëdorovič Koni. In: VE 10 (1915), S. 233-61.

Kornej Čukovksıs: Anatolij Fëdorovič Koni. K 50-letiju ego obščestvennoj dejatel'nosti, 30 sentjabrja 1865-1915. In: N 39 (1915), S. 717-18.

N. V. Davydov/N. N. Poljanskij (Hrsg.): Sudebnaja reforma, Bd. 1. Moskva 1915.

Dom Literatorov (Hrsg.): Puškin. Dostoevskij. Petrograd 1921.

Vladimir F. DžunkovksıJ: Vospominanija, 2 Bände, hrsg. v. A. L. Panina, mit einer Einleitung versehen v. I. Puškareva und Z. Peregudova. Moskva 1997.

F. A. Gallanin: Process Very Zasulič. Sud i posle suda. Sankt Peterburg 1906.

Michail N. Gernet (Hrsg.): Ustav ugolovnago sudoproizvodstva, 3 Bände. Moskva $1914-1915$. 
Michail N. Gernet: Anatolij Fëdorovič Koni na ischode ego „žiznennogo puti“. In: PŽ 6-7 (1927), S. I-VIII.

R. L. Gol'darbejter/E. A. ŠAChmatova/S. A. Šachmatova-Koplan/B. I. Koplan: Bibliografija sočinenii A. F. Koni. In: Sergej F. Platonov/Sergej F. Ol'denburg u. a. (Hrsg.): Anatolij Fëdorovič Koni 1844-1924. Jubilejnyj sbornik. Leningrad 1925, S. 207-26.

Ivan GonČArov: Briefe an Anatolij F. Koni und andere Materialien, hrsg. u. kommentiert v. Vera Bischitzky. Köln u. a. 2016.

O. O. Gruzenberg: Ob A. F. Koni. In: ders. (Hrsg.): Včera. Vospominanija. Paris 1938, S. 197-203.

O. O. Gruzenberg (Hrsg.): Včera. Vospominanija. Paris 1938.

O. O. Gruzenberg: Yesterday. Memoirs of a Russian-Jewish Lawyer, hrsg. u. mit einer Einleitung versehen v. Don C. Rawson. Berkeley u. a. 1981.

P. V. Gurevič: Stranički vospominanij Anatolij Fëdorovič Koni. In: Pravovedenie 3 (1971), S. $138-44$.

Sinaida Hippius: Petersburger Tagebuch, hrsg. u. mit einem Nachwort versehen v. Christa Ebert. Berlin u. a. 1993.

Sinaida HippIUs: Petersburger Tagebücher, 1914-1919, hrsg. u. mit einem Nachwort versehen v. Christa Ebert. Berlin 2014.

Oliver Wendell Holmes: The Essential Holmes. Selections from the Letters, Speeches, Judicial Opinions, and Other Writings of Oliver Wendell Holmes, Jr., hrsg. u. mit einer Einleitung versehen v. Richard A. Posner. Chicago 1992.

Oliver Wendell Holmes: The Path of the Law [1897]. In: ders.: The Essential Holmes. Selections from the Letters, Speeches, Judicial Opinions, and Other Writings of Oliver Wendell Holmes, Jr., hrsg. u. mit einer Einleitung versehen v. Richard A. Posner. Chicago 1992, S. 160-77.

A. Izmajlov: Rezension über Anatolij F. Koni, Na žiznennom puti, Bd. 2 (1912). In: PkN 3 September-Dezember (1912), S. 681-84.

N. Jurskij/R. Gol'Darbejter: A. F. Koni v istorii Russkoj obščestvennosti. Petrograd 1924.

Nikolaj P. KarabČEvsKiJ: Čto glaza moi videli. I. V detstve. Berlin 1921.

Nikolaj P. KARA b̌̌EvsKiJ: Čto glaza moi videli. II. Revoljucija i Rossija. Berlin 1921.

Sergej M. Kazancev (Hrsg.): Sud prisjažnych v Rossii. Gromkie ugolovnye processy 1874-1917 gg. Leningrad 1991.

Bogdan Kistja kovskis: Zur Verteidigung des Rechts. Die Intelligencija und das Rechtsbewusstsein. In: Nikolaj A. Berdjaev u. a. (Hrsg.): Vechi. Wegzeichen: zur Krise der russischen Intelligenz, hrsg. u. mit einer Einleitung versehen v. Karl Schlögel, Original Moskau 1909. Frankfurt am Main 1990, S. 213-50.

KNiga I Revoljucija: Ot redakcii. In: KR 1 (1920), S. 1.

[Anatolij F. Koni: Ohne Titel] In: Porjadok 61 (03.03.1881), S. 1.

[Anatolij F. Koni: Ohne Titel] In: Porjadok 73 (15. 03.1881), S. 1.

Anatolij F. Koni: Koni, Fëdor Alekseevič. In: RBS 9, 1903, S. 104-o8.

Anatolij F. Koni: Koni, Irina Semënovna. In: RBS 9, 1903, S. 103-04.

Anatolij F. Koni (Hrsg.): Sudebnye reči, 1868-1888. Sankt-Peterburg 1888. 
Anatolij F. Koni: Fëdor Michailovič Dostoevskij. In: ders. (Hrsg.): Za poslednie gody. Sudebnye reči (1888-1896), Vospominanija i soobščenija, Juridičeskie zametki. SanktPeterburg 1896, S. 385-400.

Anatolij F. Koni: Juridičeskie pominki i novye tečenija v ugolovnom processe Italii i Germanii. In: ders. (Hrsg.): Za poslednie gody. Sudebnye reči (1888-1896), Vospominanija i soobščenija, Juridičeskie zametki. Sankt-Peterburg 1896, S. 403-27.

Anatolij F. Koni: Novye mecha i novoe vino. Iz istorii pervych dnej sudebnoj reformy. In: ders. (Hrsg.): Za poslednie gody. Sudebnye reči (1888-1896), Vospominanija i soobščenija, Juridičeskie zametki. Sankt-Peterburg 1896, S. 461-92.

Anatolij F. Koni (Hrsg.): Za poslednie gody. Sudebnye reči (1888-1896), Vospominanija i soobščenija, Juridičeskie zametki. Sankt-Peterburg 1896 (2. Auflage 1898).

Anatolij F. Koni: Fëdor Petrovič Gaaz. Biografičeskij očerk. Sankt-Peterburg 1904 (3., erweiterte Auflage).

Anatolij F. Koni: Avtobiografija. In: P. K. Tichomirov (Hrsg.): Istoričeskaja zapiska vtoroj S.-Peterburgskoj gimnazii, Bd. 3. Sankt-Peterburg 1905, S. 378-8o.

Anatolij F. Koni: Nravstvennye načala v ugolovnom processe. Obščie čerty sudebnoj etiki. In: ders. (Hrsg.): Sudebnye reči. Sankt-Peterburg 1905, S. 3-35 (4., überarbeitete Auflage). Anatolij F. Koni (Hrsg.): Sudebnye reči. Sankt-Peterburg 1905 (4., überarbeitete Auflage nach 1888, 1890 und 1897).

Anatolij F. KonI: Svideteli na sude. Zametki i vospominanija sud'i. In: ders. (Hrsg.): Sudebnye reči. Sankt-Peterburg 1905, S. 36-79 (4., überarbeitete Auflage).

Anatolij F. Konı: Knjaz' Vladimir Fëdorovič Odoevskij. In: ders. (Hrsg.): Očerki i vospominanija. Publičnye čtenija, reči, stat'i i zametki. Sankt-Peterburg 1906, S. 47-72.

Anatolij F. Konı: Nikolaj Ivanovič Stojanovskij. In: ders. (Hrsg.): Očerki i vospominanija. Publičnye čtenija, reči, stat'i i zametki. Sankt-Peterburg 1906, S. 645-80.

Anatolij F. Koni: Nravstvennyj oblik Puškina. In: ders. (Hrsg.): Očerki i vospominanija. Publičnye čtenija, reči, stat'i i zametki. Sankt-Peterburg 1906, S. 1-34.

Anatolij F. Koni (Hrsg.): Očerki i vospominanija. Publičnye čtenija, reči, stat'i i zametki. Sankt-Peterburg 1906.

Anatolij F. Koni: Vladimir Danilovič Spasovič. In: ders. (Hrsg.): Očerki i vospominanija. Publičnye čtenija, reči, stat'i i zametki. Sankt-Peterburg 1906, S. 771-82.

Anatolij F. Koni: Vladimir Sergeevič Solov'ëv. In: ders. (Hrsg.): Očerki i vospominanija. Publičnye čtenija, reči, stat'i i zametki. Sankt-Peterburg 1906, S. 191-228.

Anatolij F. Konı: Zadači trudovoj pomišči. Pis'mo k redaktoru žurnala „Trudovaja pomošč‘“. In: ders. (Hrsg.): Očerki i vospominanija. Publičnye čtenija, reči, stat’i i zametki. SanktPeterburg 1906, S. 824-36.

Anatolij F. KonI: Iz zametok i vospominanij sudebnogo dejatelja. I. Osvidetel'stvovanie duševno-bol'nych (1870-1895). In: RS 2 (1907), S. 259-87.

Anatolij F. Koni: Vospominanie o knjaze Aleksandre Ivanoviče Urusove. In: Aleksandr I. Urusov/A. A. Andreeva/O. B. Gol'dovskij (Hrsg.): Knjaz' Aleksandr Ivanovič Urusov (1843-1900). Stat'i ego, pis'ma ego, vospominanija o nem, Bd. 2 und 3. Moskva 1907, S. $191-216$. 
Anatolij F. Koni: Konstantin Konstantinovič Arsen'ev. Po povodu 50-letija ego dejatel'nosti. In: RS 2 (1908), S. 245-55.

Anatolij F. KonI: Iz zametok i vospominanij sudebnogo dejatelja. XVI. [Iz prošlovo peterburgskoj prokuratury]. In: RS 12 (1911), S. 461-88.

Anatolij F. Koni: Delo Gulak-Artemovskoj. In: ders. (Hrsg.): Na žiznennom puti, Bd. 1. Iz zapisok sudebnogo dejatelja, žitejskie vstreči. Sankt-Peterburg 1912, S. 250-59.

Anatolij F. Koni: Delo Ovsjannikova. In: ders. (Hrsg.): Na žiznennom puti, Bd. 1. Iz zapisok sudebnogo dejatelja, žitejskie vstreči. Sankt-Peterburg 1912, S. 11-20.

Anatolij F. Koni: Domočadcy. In: ders. (Hrsg.): Na žiznennom puti, Bd. 1. Iz zapisok sudebnogo dejatelja, žitejskie vstreči. Sankt-Peterburg 1912, S. 651-79.

Anatolij F. KonI: Dva sudebnych oratora. In: ders. (Hrsg.): Na žiznennom puti, Bd. 2. Iz vospominanij, publičnye čtenija, v verchnej palate. Sankt-Peterburg 1912, S. 416-29.

Anatolij F. Konı: Graf Dmitrij Alekseevič Miljutin. In: ders. (Hrsg.): Na žiznennom puti, Bd. 2. Iz vospominanij, publičnye čtenija, v verchnej palate. Sankt-Peterburg 1912, S. $261-83$.

Anatolij F. KonI: Igornyj dom Kolemina. In: ders. (Hrsg.): Na žiznennom puti, Bd. 1. Iz zapisok sudebnogo dejatelja, žitejskie vstreči. Sankt-Peterburg 1912, S. 64-72.

Anatolij F. Koni: Igumen’ja Mitrofanija. In: ders. (Hrsg.): Na žiznennom puti, Bd. 1. Iz zapisok sudebnogo dejatelja, žitejskie vstreči. Sankt-Peterburg 1912, S. 42-52.

Anatolij F. Konı: Ivan Aleksandrovič Gončarov. In: ders. (Hrsg.): Na žiznennom puti, Bd. 2. Iz vospominanij, publičnye čtenija, v verchnej palate. Sankt-Peterburg 1912, S. 381-405.

Anatolij F. Koni: Iz char'kovskich vospominanij. In: ders. (Hrsg.): Na žiznennom puti, Bd. 1. Iz zapisok sudebnogo dejatelja, žitejskie vstreči. Sankt-Peterburg 1912, S. 26-41.

Anatolij F. Koni: Konstantin Konstantinovič Arsen'ev. Po povodu 50-letija ego dejatel'nosti. In: ders. (Hrsg.): Na žiznennom puti, Bd. 2. Iz vospominanij, publičnye čtenija, v verchnej palate. Sankt-Peterburg 1912, S. 234-6o.

Anatolij F. Koni: Landsberg. Iz predsedatel'skoj praktiki. In: ders. (Hrsg.): Na žiznennom puti, Bd. 1. Iz zapisok sudebnogo dejatelja, žitejskie vstreči. Sankt-Peterburg 1912, S. $260-78$.

Anatolij F. Koni: Margarita Žjužan. Iz predsedatel’skoj praktiki. In: ders. (Hrsg.): Na žiznennom puti, Bd. 1. Iz zapisok sudebnogo dejatelja, žitejskie vstreči. Sankt-Peterburg 1912, S. 279-305.

Anatolij F. Koni (Hrsg.): Na žiznennom puti, Bd. 1. Iz zapisok sudebnogo dejatelja, žitejskie vstreči. Sankt-Peterburg 1912 (ebenfalls herausgegeben in Moskau 1913, 2. Auflage Moskau 1914, zudem Revel', Berlin 1922).

Anatolij F. KonI (Hrsg.): Na žiznennom puti, Bd. 2. Iz vospominanij, publičnye čtenija, v verchnej palate. Sankt-Peterburg 1912 (2. Auflage St. Petersburg 1913 sowie Herausgabe in Moskau 1916).

Anatolij F. Konı: Ostende (1869-1873 gg.). In: ders. (Hrsg.): Na žiznennom puti, Bd. 1. Iz zapisok sudebnogo dejatelja, žitejskie vstreči. Sankt-Peterburg 1912, S. 610-24.

Anatolij F. KonI: Po povodu dramatičeskich proizvedenij Tolstogo. In: ders. (Hrsg.): Na žiznennom puti, Bd. 2. Iz vospominanij, publičnye čtenija, v verchnej palate. SanktPeterburg 1912, S. 57-76. 
Anatolij F. Koni: Po zakonoproektu ob avtorskom prave. In: ders. (Hrsg.): Na žiznennom puti, Bd. 2. Iz vospominanij, publičnye čtenija, v verchnej palate. Sankt-Peterburg 1912, S. $595-618$.

Anatolij F. Koni: Priemy i zadači obvinenija. In: ders. (Hrsg.): Na žiznennom puti, Bd. 1. Iz zapisok sudebnogo dejatelja, žitejskie vstreči. Sankt-Peterburg 1912, S. 94-148.

Anatolij F. Koni: Prokuratura i Administracija. In: ders. (Hrsg.): Na žiznennom puti, Bd. 1. Iz zapisok sudebnogo dejatelja, žitejskie vstreči. Sankt-Peterburg 1912, S. 183-217. Anatolij F. Konı: Sin’or Beljaev. In: ders. (Hrsg.): Na žiznennom puti, Bd. 1. Iz zapisok sudebnogo dejatelja, žitejskie vstreči. Sankt-Peterburg 1912, S. 593-609.

Anatolij F. KonI: Turgenev - Dostoevskij - Nekrasov - Apuchtin - Pisemskjj. In: ders. (Hrsg.): Na žiznennom puti, Bd. 2. Iz vospominanij, publičnye čtenija, v verchnej palate. Sankt-Peterburg 1912, S. 77-137.

Anatolij F. KonI: V doroge - Gimnasičeskie vospominanija. In: ders. (Hrsg.): Na žiznennom puti, Bd. 1. Iz zapisok sudebnogo dejatelja, žitejskie vstreči. Sankt-Peterburg 1912, S. $628-36$ bzw. $636-50$.

Anatolij F. Koni: „Vestnik Evropy“. In: ders. (Hrsg.): Na žiznennom puti, Bd. 2. Iz vospominanij, publičnye čtenija, v verchnej palate. Sankt-Peterburg 1912, S. 193-233.

Anatolij F. KonI: Graf M. P. Loris-Melikov. Otryvočnye vospominanija. In: GM 1 (1914), S. 181-202.

Anatolij F. KonI: K portretam. In: ders. (Hrsg.): Otcy i deti sudebnoj reformy. K pjatidesjatiletiju Sudebnych Ustavov, 20. nojabrja 1864-1914. Moskva 1914, S. 276-84.

Anatolij F. Koni: Mirovye sud'i. Iz vospominanij. In: ders. (Hrsg.): Otcy i deti sudebnoj reformy. K pjatidesjatiletiju Sudebnych Ustavov, 20. nojabrja 1864-1914. Moskva 1914, S. $192-215$.

Anatolij F. Koni (Hrsg.): Otcy i deti sudebnoj reformy. K pjatidesjatiletiju Sudebnych Ustavov, 20. nojabrja 1864-1914. Moskva 1914.

Anatolij F. KonI: Vladimir Danilovič Spasovič (1829-1907). In: ders. (Hrsg.): Otcy i deti sudebnoj reformy. K pjatidesjatiletiju Sudebnych Ustavov, 20. nojabrja 1864-1914. Moskva 1914, S. 227-35.

Anatolij F. Koni: Vvedenie k Sistematičeskomu Kommentariju U. U. S. In: Michail N. Gernet (Hrsg.): Ustav ugolovnago sudoproizvodstva, Bd. 1. Moskva 1914-1915, S. 1-30. Anatolij F. Koni: Pjat'desjat' let nazad. In: RS 1 (1915), S. 5-28.

Anatolij F. Konı: Ėtika obščežitija. In: Zapiski Instituta Živogo Slova 1919 (1), S. 56-58.

Anatolij F. Koni: Žitejskie vstreči. Petr IV. In: GM 5-12 (1919), S. 163-70.

Anatolij F. KonI: Iz vospominanij sudebnogo dejatelja. Zakon 19 maja 1871 g. In: DD 1 (1920), S. 175-88.

Anatolij F. Koni: [Avtobiografčeskij očerk]. In: VL 9 (1921), S. 15-16.

Anatolij F. Koni: Nekrasov, Dostoevskij. Po ličnym vospominanijam: 1821-1921. Petro$\operatorname{grad} 1921$.

Anatolij F. Koni (Hrsg.): Turgenevskij sbornik. Petrograd 1921.

Anatolij F. Koni: Graf M. T. Loris-Melikov. In: ders. (Hrsg.): Na žiznennom puti, Bd. 3. Vospominanija, žitejskie dramy, žitejskie vstreči, pamjati ušedšich, kritičeskie očerki. Revel', Berlin 1922, S. 3-40. 
Anatolij F. KonI: Graždanskie dela. In: ders. (Hrsg.): Na žiznennom puti, Bd. 1. Iz zapisok sudebnogo dejatelja. Revel', Berlin 192(2/4?) (4., überarbeitete Auflage).

Anatolij F. Koni: Iz let junosti i starosti. In: ders. (Hrsg.): Na žiznennom puti, Bd. 3. Vospominanija, žitejskie dramy, žitejskie vstreči, pamjati ušedšich, kritičeskie očerki. Revel', Berlin 1922, S. 151-258.

Anatolij F. Koni (Hrsg.): Na žiznennom puti, Bd. 3. Vospominanija, žitejskie dramy, žitejskie vstreči, pamjati ušedšich, kritičeskie očerki. Revel', Berlin 1922.

Anatolij F. Koni (Hrsg.): Na žiznennom puti, Bd. 1. Iz zapisok sudebnogo dejatelja. Revel', Berlin 192(2/4?) (4., überarbeitete Auflage).

Anatolij F. Koni: Nravstvennost' i obščestvennaja žestokost'. Iz kursa „Ėtiki obščežitija“. In: AD 5-8 (1922), S. 5-11.

Anatolij F. Koni: Nravstvennosti i gosudarstvennye dochody. Iz kursa „Ėtiki obščežitija“. In: AD 1-4 (1922), S. 15-18.

Anatolij F. Koni: Pamjat' i vnimanie. Iz vospominanij sudebnogo dejatelja. Petrograd 1922.

Anatolij F. Koni: Pamjati A. E. Kaufmana. In: Letopis’ Doma Literatorov 1-2 (1922), S. 5.

Anatolij F. KonI: Peterburg. Vospominanija starožila. Petrograd 1922.

Anatolij F. Koni: Za-granicej i na rodine. In: ders. (Hrsg.): Na žiznennom puti, Bd. 3. Vospominanija, žitejskie dramy, žitejskie vstreči, pamjati ušedšich, kritičeskie očerki. Revel', Berlin 1922, S. 259-305.

Anatolij F. Koni (Hrsg.): Na žiznennom puti, Bd. 4. Publičnye čtenija i reči. Revel', Berlin 1923.

Anatolij F. Koni: Pamjati Andreja Aleksandroviča Saburova. In: ders. (Hrsg.): Na žiznennom puti, Bd. 4. Publičnye čtenija i reči. Revel', Berlin 1923, S. 397-411.

Anatolij F. Koni: Pis'mo v redakciju. In: B 3 (1925), S. 250.

Anatolij F. Koni (Hrsg.): Na žiznennom puti, Bd. 5. Leningrad 1929.

Anatolij F. Koni: S. A. Andreevskij. Po ličnym vospominanijam. In: ders. (Hrsg.): Na žiznennom puti Bd. 5. Leningrad 1929, S. 178-96.

Anatolij F. Konı: V. G. Korolenko i sud. In: ders. (Hrsg.): Na žiznennom puti, Bd. 5. Leningrad 1929, S. 291-97.

Anatolij F. Koni: Vospominanija o dele Very Zasulič, hrsg. u. mit einer Einleitung versehen v. M. F. Teodorovič und Iv. Teodorovič. Moskva u. a. 1933.

Anatolij F. Konı: Vospominanija o dele Very Zasulič. In: Vladimir D. Bonč-Bruevič/Anatolij V. Lunačarskij (Hrsg.): Zven’ja. Sbornik materialov i dokumentov po istorii literatury, iskusstva i obščestvennoj mysli XIX veka, Bd. 2. Moskva, Leningrad 1933, S. 490-571.

Anatolij F. Koni (Hrsg.): Izbrannye proizvedenija. Stat'i i Zametki, Sudebnye reči, Vospominanija, hrsg. v. A. B. Amelin. Moskva 1956.

Anatolij F. Koni: A. N. Ostrovskij. Otryvočnye vospominanija. In: ders.: Sobranie sočinenij, Bd. 6, hrsg. v. V. G. Bazanov, L. N. Smirnov und K. I. Čukovskij. Moskva 1968, S. 248-56.

Anatolij F. Koni: [A. S. Puškin]. In: ders.: Sobranie sočinenij, Bd. 6, hrsg. v. V. G. Bazanov, L. N. Smirnov und K. I. Čukovskij. Moskva 1968, S. 72-75.

Anatolij F. Koni: Ešče o Dostoevskom. In: ders.: Sobranie sočinenij, Bd. 5, hrsg. v. V. G. Bazanov, L. N. Smirnov und K. I. Čukovskij. Moskva 1968, S. 446-53. 
Anatolij F. Koni: Graf M. T. Loris-Melikov. In: ders.: Sobranie sočinenij, Bd. 6, hrsg. v. V. G. Bazanov, L. N. Smirnov und K. I. Čukovskij. Moskva 1968, S. 184-216.

Anatolij F. Koni: Iz let junosti i starosti. In: ders.: Sobranie sočinenij, Bd. 7, hrsg. v. V. G. Bazanov, L. N. Smirnov und K. I. Čukovskij. Moskva 1969, S. 65-158.

Anatolij F. KonI: Iz zametok i vospominanij sudebnogo dejatelja. Prisjažnye zasedateli. In: ders.: Sobranie sočinenij, Bd. 1, hrsg. v. V. G. Bazanov, L. N. Smirnov und K. I. Čukovskij. Moskva 1966, S. 331-91.

Anatolij F. Koni: Krušenie carskogo poezda v 1888 godu. Borki-Taranovka. In: ders.: Sobranie sočinenij, Bd. 1, hrsg. v. V. G. Bazanov, L. N. Smirnov und K. I. Čukovskij. Moskva 1966, S. 420-95.

Anatolij F. Koni: Lev Nikolaevič Tolstoj. In: ders.: Sobranie sočinenij, Bd. 6, hrsg. v. V. G. Bazanov, L. N. Smirnov und K. I. Čukovskij. Moskva 1968, S. 454-501.

Anatolij F. Koni: Moja gefsimanskaja noč. In: ders.: Sobranie sočinenij, Bd. 2, hrsg. V. V. G. Bazanov, L. N. Smirnov und K. I. Čukovskij. Moskva 1966, S. 360-76.

Anatolij F. KonI : Motivy i priemy tvorčestva Nekrasova. Beglye zamteki. In : ders. : Sobranie sočinenij, Bd. 6, hrsg. v. V. G. Bazanov, L. N. Smirnov und K. I. Čukovskij. Moskva 1968, S. 275-78.

Anatolij F. KonI: Nikolaj II. Vospominanie. In: ders.: Sobranie sočinenij, Bd. 2, hrsg. v. V. G. Bazanov, L. N. Smirnov und K. I. Čukovskij. Moskva 1966, S. 377-88.

Anatolij F. Koni: Otkrytie I Gosudarstvennoj Dumy. In: ders.: Sobranie sočinenij, Bd. 2, hrsg. v. V. G. Bazanov, L. N. Smirnov und K. I. Čukovskij. Moskva 1966, S. 355-59.

Anatolij F. Koni: Pamjat' i vnimanie. Iz vospominanij sudebnogo dejatelja. In: ders.: Sobranie sočinenij, Bd. 4, hrsg. v. V. G. Bazanov, L. N. Smirnov und K. I. Čukovskij. Moskva 1967, S. 70-120.

Anatolij F. Koni: Peterburg. Vospominanija starožila. In: ders.: Sobranie sočinenij, Bd. 7, hrsg. v. V. G. Bazanov, L. N. Smirnov und K. I. Čukovskij. Moskva 1969, S. 23-64.

Anatolij F. Koni: Pochorony Turgeneva. In: ders.: Sobranie sočinenij, Bd. 6, hrsg. v. V. G. Bazanov, L. N. Smirnov und K. I. Čukovskij. Moskva 1968, S. 385-405.

Anatolij F. KonI: Političeskaja zapiska 1878 goda. Zakon 19 maja 1871 g. Iz vospominanij sudebnogo dejatleja. In: ders.: Sobranie sočinenij, Bd. 2, hrsg. v. V. G. Bazanov, L. N. Smirnov und K. I. Čukovskij. Moskva 1966, S. 329-47.

Anatolij F. Koni: Predstavlenie Aleksandru III. v Gatčine (v nojabre 1892 goda). In: ders.: Sobranie sočinenij, Bd. 2, hrsg. v. V. G. Bazanov, L. N. Smirnov und K. I. Čukovskij. Moskva 1966, S. 348-54.

Anatolij F. Koni: Sergej Jul'evič Vitte. Otryvočnye vospominanija. In: ders.: Sobranie sočinenij, Bd. 5, hrsg. v. V. G. Bazanov, L. N. Smirnov und K. I. Čukovskij. Moskva 1968, S. 238-77.

Anatolij F. Konı: Sobranie sočinenij, 8 Bände, hrsg. v. V. G. Bazanov, L. N. Smirnov und K. I. Čukovskij. Moskva 1966-1969.

Anatolij F. KonI: Triumviry. In: ders.: Sobranie sočinenij, Bd. 2, hrsg. v. V. G. Bazanov, L. N. Smirnov und K. I. Čukovskij. Moskva 1966, S. 253-328. 
Anatolij F. Koni: Trudy i zadači Peterburgskogo Juridičeskogo Obščestva. In: ders.: Sobranie sočinenij, Bd. 4, hrsg. v. V. G. Bazanov, L. N. Smirnov und K. I. Čukovskij. Moskva 1967, S. 293-316.

Anatolij F. Koni: „Vestnik Evropy“. In: ders.: Sobranie sočinenij, Bd. 7, hrsg. v. V. G. Bazanov, L. N. Smirnov und K. I. Čukovskij. Moskva 1969, S. 220-59.

Anatolij F. KonI: Vospominanija o dele Very Zasulič. In: ders.: Sobranie sočinenij, Bd. 2, hrsg. v. V. G. Bazanov, L. N. Smirnov und K. I. Čukovskij. Moskva 1966, S. 24-252.

Anatolij F. Koni: [Avtobiografičeskij fragment]. In: ders.: Izbrannoe, hrsg. u. mit einer Einleitung versehen v. Georgij M. Mironov und Leonid G. Mironov. Moskva 1989, S. $420-24$.

Anatolij F. Koni: Izbrannoe, hrsg. u. mit einer Einleitung versehen v. Georgij M. Mironov und Leonid G. Mironov. Moskva 1989.

Anatolij F. KonI: O prave neobchodimoj oborony, hrsg. u. mit einer Einleitung versehen v. A. Coriev. Moskva 1996.

Anatolij F. Koni: Peterburg. Vospominanija starožila. Moskva 2003.

Anatolij F. Koni: Vospominanija o pisateljach. Literaturnye očerki, hrsg. v. Alevtina Bessonova u. a., mit Kommentaren versehen v. A. S. Stepanova. Sankt-Peterburg 2010.

M. I. Kulišer: 35-letie dejatel'nosti A. F. Koni. In: VP 10 (1901), S. 172-86.

S. M. Luk'Janov: Pamjati A. F. Koni. Leningrad 1927.

Anatolij V. LunačArskiJ: Tri vstreči. Iz vospominanij ob ušedšich. In: Anatolij F. Koni: Izbrannoe, hrsg. u. mit einer Einleitung versehen v. Georgij M. Mironov und Leonid G. Mironov. Moskva 1989, S. 444-49.

Dolmat A. Lutochin: Sovetskaja Cenzura. Po ličnym vospominanijam [1923]. In: Aleksandr Ju. Galuškin u. a. (Hrsg.): Žurnaly „Vestnik literatury“ (1919-1922), „Letopis” Doma Literatorov“ (1921-1922), „Literaturnye zapiski“ (1922). Annotirovannyj ukazatel'. Moskva 1996, S. 258-71.

Ja. Magaziner: Ličnost' A. F. Koni. In: VSJ 24 (1927), S. 824-26.

M. Mavrin: [Rezension über] „Dela i Dni“. Istoričeskij žurnal. Kniga pervaja. In: KR 8-9 (1921), S. 63-65.

M. Ja. Pergament: Pamjati A. F. Koni. In: PŽ 2-3 (1928), S. 98-103.

Sergej F. Platonov/Sergej F. Ol'denburg u.a. (Hrsg.): Anatolij Fëdorovič Koni 1844-1924. Jubilejnyj sbornik. Leningrad 1925.

Fëdor N. Pleva Ko: Izbrannye reči, hrsg. u. mit einem Vorwort versehen v. R. A. Markovič und G. M. Reznik. Moskva 1993.

Konstantin P. Pobedonoscev: K. P. Pobedonoscev i ego korrespondenty. Pis'ma i zapiski, Bd. 1, mit einer Einleitung versehen v. M. N. Pokrovskij. Moskva u. a. 1923.

N. N. Poljanskij (Hrsg.): Ugolovno-Processual'nyj Kodeks R. S. F. S. R. Sravnitel'nyj očerk novoj i staroj redakcii Kodeksa. Moskva 1923.

N. N. Poljanskij: A. F. Koni. In: ders./B. I. Syromjatnikov (Hrsg.): Na službe pravu. A. F. Koni. Moskva 1928, S. 5-32.

N. N. Poljanskij/B. I. Syromjatnikov (Hrsg.): Na službe pravu. A. F. Koni. Moskva 1928. RussKajA MYsL': Ot redakcii. In: RM Januar-Februar (1921), S. 139. 
RussKaJA ŽIZN': Golodnomu na chleb. Al'bom avtografov pisatelej, chudožnikov, artistov i obščestvennych dejatelej: izd. v pol'zu golodajuščich. Sankt-Peterburg 1892.

F. S.: K pjatidesjatiletiju suda prisjažnych. Po povodu knigi A. F. Koni „Otcy i deti sudebnoj reformy“. Moskva 1915.

Michail Semevskij (Hrsg.): Znakomye. Al'bom M. I. Semevskogo. Kniga avtobiografičeskich sobstvennoručnych zametok 850 lic. Vospominanija. Stichotvorenija. Epigramy. Šutki. Podpisi. 1867-1888. Sankt-Peterburg 1888.

D. N. ŠIPov: Vospominanija i dumy o perežitom. Moskva 1918.

Vl. SL.: Koni, Anatolij Fëdorovič. In: ĖSBE 15A/30 (1895), S. 949-51.

Slovar' Členov ObšČestva ljubitelej Rossijskoj slovesnosti: Koni, Anatolij Fëdorovič. In: SČOLRS, 1911, S. 145-46.

V. I. Sreznevskij: A. F. Koni i L. N. Tolstoj. In: Trudy Puškinskogo Doma Akademii Nauk SSSR (Hrsg.): Pamjati Anatolija Fëdoroviča Koni. Leningrad u. a. 1929, S. 102-14.

Lev Nikolaevič Tolsto : Tolstoy's letters, 2 Bände, Bd. 2, hrsg. v. Reginald Frank Christian. London 1978.

Trudy Puškinskogo Doma Akademir Nauk SSSR (Hrsg.): Pamjati Anatolija Fëdoroviča Koni. Leningrad u. a. 1929.

[Unbekannte Autorin]: „Podžog česti“ A. F. Koni. In: PN, 04. 05.1921, S. 3.

Aleksandr I. Urusov: Pamjati V. I. Žukovskogo. In: ders./A. A. Andreeva/O. B. Gol'dovskij (Hrsg.): Knjaz' Aleksandr Ivanovič Urusov (1843-190o). Stat'i ego, pis’ma ego, vospominanija o nem, Bd. 2 und 3. Moskva 1907, S. 39-41.

Aleksandr I. Unusov: Sudejskie protesty protiv „Voskresenija“. In: ders./A. A. Andreeva/O. B. Gol'dovskij (Hrsg.): Knjaz' Aleksandr Ivanovič Urusov (1843-190o). Stat'i ego, pis’ma ego, vospominanija o nem, Bd. 2 und 3. Moskva 1907, S. 64-69.

Aleksandr I. Urusov/A. A. Andreeva/O. B. Gol'Dovskij (Hrsg.): Knjaz’ Aleksandr Ivanovič Urusov (1843-1900). Stat'i ego, pis'ma ego, vospominanija o nem, 3 Bände. Moskva 1907.

Lev S. Utevskij: Iz rannich let A. F. Koni. Po neizdannym materialam. In: Sergej F. Platonov/Sergej F. Ol'denburg u. a. (Hrsg.): Anatolij Fëdorovič Koni 1844-1924. Jubilejnyj sbornik. Leningrad 1925, S. 70-88.

Lev S. Utevskis: Poslednij ètap žiznennogo puti. In: Trudy Puškinskogo Doma Akademii Nauk SSSR (Hrsg.): Pamjati Anatolija Fëdoroviča Koni. Leningrad u. a. 1929, S. 79-101.

A. VITMER: Chudožnik slova i pera. Beglye zametki i otryvočnye vospominanija, vyzvannye vtorym tomom na „Žiznennom puti“ A. F. Koni. In: IV 8 (1913), S. 566-79.

L. E. Vladimirov: Russkij sudebnyj orator A. F. Koni. Char'kov 1889.

P. Voronov: Anatolij Fëdorovič Koni. K 5o-letiju ego literaturnoj i obščestvennoj dejatel'nosti, 30 sentjabrja 1865-1915 gg. Petrograd 1915.

Max Weber: Zur Russischen Revolution von 1905. Schriften und Reden 1905-1912, Gesamtausgabe, Bd. 10, hrsg. u. mit einer Einleitung versehen v. Wolfgang J. Mommsen. Tübingen 1989.

Aleksandr A. Žıžılenko: A. F. Koni, kak kriminalist. In: Sergej F. Platonov/Sergej F. Ol'denburg u. a. (Hrsg.): Anatolij Fëdorovič Koni 1844-1924. Jubilejnyj sbornik. Lenin$\operatorname{grad} 1925$, S. 24-39. 


\section{Sekundärliteratur}

Hülya ADAk: Identifying the „Internal Tumors“ of World War I. Talat Paşa’s Memoirs, or the Travels of a Unionist Apologia into „History“. In: Andreas Bähr/Peter Burschel/ Gabriele Jancke (Hrsg.): Räume des Selbst. Selbstzeugnisforschung transkulturell. Köln u. a. 2007, S. 151-69.

Helmut Altrichter: Kleine Geschichte der Sowjetunion 1917-1991. München 1993.

Korine AMACHER: En guise d'introduction. L'histoire dans la Russie contemporaine. In: dies./Wladimir Berelowitch (Hrsg.): Histoire et mémoire dans l'espace postsoviétique. Le passé qui encombre. Louvain-la-Neuve 2013, S. 15-32.

N. V. Andrianov: Graždanskoe obščestvo kak sreda institucionalizacii advokatury. Moskva 2011.

Yanina V. ARnold: Writing Justice. Fiction and Literary Lawyers in Late Imperial Russia, 1864-1900. University of Michigan 2014 (Dissertation in Open Access).

Martin Aust/Frithjof Benjamin Schenk: Einleitung. Autobiographische Praxis und Imperienforschung. In: dies. (Hrsg.): Imperial Subjects. Autobiographische Praxis in den Vielvölkerreichen der Habsburger, Romanovs und Osmanen im 19. und frühen 20. Jahrhundert. Köln 2015, S. 11-35.

Martin Aust/Frithjof Benjamin Schenk (Hrsg.): Imperial Subjects. Autobiographische Praxis in den Vielvölkerreichen der Habsburger, Romanovs und Osmanen im 19. und frühen 20. Jahrhundert. Köln 2015.

Jörg BABERowski: Rechtsanwälte in Russland, 1866-1914. In: Charles E. MacClelland/ Stephan Merl/Hannes Siegrist (Hrsg.): Professionen im modernen Osteuropa. Berlin 1995, S. 29-59.

Jörg BABerowski: Autokratie und Justiz. Zum Verhältnis von Rechtsstaatlichkeit und Rückständigkeit im ausgehenden Zarenreich 1864-1914. Frankfurt am Main 1996.

Alain BAdIou: Ethik. Versuch über das Bewusstsein des Bösen. Wien 2003.

Z. V. BAIšEvA: Vyraženie oratorskogo „Ja“v obvinitel'nych rečach A. F. Koni. In: „Černye dyry“ v Rossijskom zakonodatel'stve 1 (2004), S. 403-05.

Anton BAKUnCEv: Anatolij Fëdorovič Koni, russkaja èmigracija i sovetskaja vlast'. In: Inye Berega. Žurnal o russkoj kul'ture za rubežom 3 (2011), S. 58-62.

Ju. Balakin: Neizvestnye stranicy vospominanij A. F. Koni o Gončarove. In: Russkaja Literatura 2 (2012), S. 97-104.

Elizabeth Ballantine: Koni and the Russian Judiciary, 1864-1917. Yale University 1986 (unveröffentlichte Dissertation).

M. A. BALYŠEv/A. A. ŠAndulA: Anatolij Fëdorovič Koni i char'kovčane. O novych faktach iz žizni izvestnogo russkogo jurista. In: Universitates. Nauka i prosveščenie 3 (2007), S. $26-36$.

Harley D. Balzer: Introduction. In: ders. (Hrsg.): Russia's Missing Middle Class. The Professions in Russian History. Armonk New York u. a 1996, S. 1-38.

Harley D. Balzer (Hrsg.): Russia's Missing Middle Class. The Professions in Russian History. Armonk New York u. a 1996. 
Mark BAssin: Geographies of Imperial Identity. In: Dominic Lieven (Hrsg.): The Cambridge History of Russia. Volume II: Imperial Russia, 1689-1917. Cambridge u. a. 2006, S. 45-63.

Annegret BAUtz: Sozialpolitik statt Wohltätigkeit? Der Konzeptionswandel städtischer Fürsorge in Sankt Petersburg von 1892 bis 1914. Wiesbaden 2007.

Elisa Marielle Becker: Medicine, Law, and the State in Imperial Russia. Budapest 2011.

Rolf Becker: Grusswort. In: Patrick Bühler/Thomas Bühler/Fritz Osterwalder (Hrsg.): Zur Inszenierungsgeschichte pädagogischer Erlöserfiguren. Bern 2013, S. 13-17.

Johannes BeCKMANN: „Die ganze Bewegung war die Bewegung aufsteigender Elemente“. Neue Forschungen zur Familie und Jugend von Friedrich Joseph Haas (178o-1853). In: Dominik Groß/Axel Karenberg/Stephanie Kaiser/Wolfgang Antweiler (Hrsg.): Medizingeschichte in Schlaglichtern. Beiträge des „Rheinischen Kreises der Medizinhistoriker“. Kassel 2011, S. 145-78.

Isaiah BERLin: Fathers and Children. Oxford 1972.

Girish N. Внат: The Consensual Dimension of Late Imperial Russian Criminal Procedure. The Example of Trial by Jury. In: Peter H. Solomon (Hrsg.): Reforming Justice in Russia, 1864-1996. Power, Culture, and the Limits of Legal Order. Armonk New York 1997, S. $61-83$.

Hans Erich BöDEkER: Biographie. Annäherungen an den gegenwärtigen Forschungs- und Diskussionsstand. In: ders. (Hrsg.): Biographie schreiben. Göttingen 2003, S. 9-63.

Gustav BoguslavskiJ: 100 očerkov o Peterburge. Severnaja stolica glazami moskviča. Moskva 2011.

Kirsten BönKer: Rezension über Anton A. Fedyashin, Liberals under Autocracy (Madison 2012). In: H-Soz-Kult, 13. 06. 2014, www.hsozkult.de/publicationreview/id/rezbuecher-20583, Zugriff vom 30.10. 2016.

Tatiana Borisova: The Digest of Laws of the Russian Empire. The Phenomenon of Autocratic Legality. In: Law and History Review 3 (2012), S. 901-25.

Tat'jana J. Borisova: „Neobchodimaja oborona obščestva“. Jazyk suda nad Zasulič. In: Novoe literaturnoe obozrenie 5 (2015), S. 101-18.

Pierre Bourdiev: Praktische Vernunft. Zur Theorie des Handelns. Frankfurt am Main 1998.

Joseph Bradley: Voluntary Associations, Civic Culture, and Obshchestvennost' in Moscow. In: Edith W. Clowes/Samuel D. Kassow/James L. West (Hrsg.): Between Tsar and People. Educated Society and the Quest for Public Identity in Late Imperial Russia. Princeton 1991, S. 131-48.

Joseph BradLey: Subjects into Citizens. Societies, Civil Society, and Autocracy in Tsarist Russia. In: The American Historical Review 4 (2002), S. 1094-123.

Joseph Bradley: Voluntary Associations in Tsarist Russia. Science, Patriotism, and Civil Society. Cambridge Massachusetts 2009.

Peter BRANG: Das Land der sprachlosen Ebenen zum Sprechen bringen. Über öffentlichen und privaten Vortrag von Dichtung in Russland. In: Nada Boškovska u. a. (Hrsg.): Wege der Kommunikation in der Geschichte Osteuropas. Köln 2002, S. 423-51. 
Katja BRUisCH: Als das Dorf noch Zukunft war. Agrarismus und Expertise zwischen Zarenreich und Sowjetunion. Köln u. a. 2014.

V. G. Buchert: Pis'ma S. F. Platonova A. F. Koni. In: Archeografičeskij ežegodnik za 1995 god. Moskva 1997, S. 351-54.

Patrick BüHleR/Thomas BüHLER/Fritz Osterwalder: Vorwort. In: dies. (Hrsg.): Zur Inszenierungsgeschichte pädagogischer Erlöserfiguren. Bern 2013, S. 7-12.

Michail I. BunJA: V. G. Korolenko v Udmurtii. Iževsk 1982.

Jane Burbank: Intelligentsia and Revolution. Russian Views of Bolshevism, 1917-1922. New York, Oxford 1986.

Jane Burbank: Discipline and Punish in the Moscow Bar Association. In: Russian Review 1 (1995), S. 44-64.

Jane Burbank: Legal Culture, Citizenship, and Peasant Jurisprudence. Perspectives from the Early Twentieth Century. In: Peter H. Solomon (Hrsg.): Reforming Justice in Russia, 1864-1996. Power, Culture, and the Limits of Legal Order. Armonk New York 1997, S. $82-106$.

Jane Burbank: Russian Peasants Go to Court. Legal Culture in the Countryside, 1905-1917. Bloomington 2004.

Jane Burbank: Mercy, Punishment, and Law. The Qualities of Justice at Township Courts. In: Kritika: Explorations in Russian and Eurasian History 1 (2006), S. 23-6o.

William Elliott Butler: Russian and Soviet Law. An Annotated Catalogue of Reference Works, Legislation, Court Reports, Serials, and Monographs on Russian and Soviet Law (including International Law). London u. a. 1976.

Anastasija ČAJKovskaJA: Psichologija zla. Kak rabotal Leningradskij Kriminologičeskij kabinet. In: Argumenty i Fakty, 01. 04. 2015, www.spb.aif.ru/society/people/1480412, Zugriff vom 11. 09. 2015.

A. A. Č́nnobaev u.a. (Hrsg.): Istoriki Rossii. Biografii. Moskva 2001.

Irina Cernova Burger: „Alle lesen sie, alle kennen sie ...“. In: Libernensis. Zeitschrift der Universitätsbibliothek Bern 2 (2007), S. 16-19.

L. M. Chle Bnikov: Iz istorii Gor'kovskich izdatel'stv. „Vsemirnaja literatura“ i „Izdatel'stvo Z. I. Gržebina“. In: V. R. Ščerbina u. a. (Hrsg.): V. I. Lenin i A. V. Lunačarskij. Perepiska, doklady, dokumenty. Moskva 1971, S. 668-703.

Kirill V. Čistov: Der gute Zar und das ferne Land. Russische sozial-utopische Volkslegenden des 17.-19. Jahrhunderts, hrsg. u. mit einer Einleitung versehen v. Dagmar Burkhart. Münster u. a. 1998.

Edith W. Clowes/Samuel D. Kassow/James L. West (Hrsg.): Between Tsar and People. Educated Society and the Quest for Public Identity in Late Imperial Russia. Princeton 1991.

Carla CoRdin: Von Schreibanlässen und Erinnerungsfunktionen. Erkenntnisgewinn aus autobiographischer Praxis von Juristen im späten Zarenreich. In: Martin Aust/Frithjof Benjamin Schenk (Hrsg.): Imperial Subjects. Autobiographische Praxis in den Vielvölkerreichen der Habsburger, Romanovs und Osmanen im 19. und frühen 20. Jahrhundert. Köln 2015, S. 175-204.

Olga Crisp/Linda Edmondson (Hrsg.): Civil Rights in Imperial Russia. Oxford 1989. 
Kornej ČuкоvsкıJ: Anatolij Fëdorovič Koni. In: Anatolij F. Koni: Sobranie sočinenij, Bd. 8, hrsg. v. V. G. Bazanov, L. N. Smirnov und K. I. Čukovskij. Moskva 1969, S. 5-25. Sandra DAHLke: Old Russia in the Dock. The Trial Against Mother Superior Mitrofaniia Before the Moscow District Court (1874). In: Cahiers du monde russe et soviétique 1 (2012), S. 95-120.

Jonathan W. DALY: Emergency Legislation in Late Imperial Russia. In: Slavic Review 3 (1995), S. 602-19.

Aleksej A. DemičEv: Sudebnaja reforma 1864 g. v dorevoljucionnom anekdote. Opyt izučenija rossijskoj mental'nosti. Moskva 2012.

Volker Dеркат: Autobiographie und die soziale Konstruktion von Wirklichkeit. In: Geschichte und Gesellschaft 1 (2003), S. 441-76.

Volker Depкat: Nicht die Materialien sind das Problem, sondern die Fragen, die man stellt. Zum Quellenwert von Autobiographien für die historische Forschung. In: Thomas Rathmann/Nikolaus Wegmann (Hrsg.): Quelle. Zwischen Ursprung und Konstrukt. Ein Leitbegriff in der Diskussion. Berlin 2004, S. 102-17.

Volker Deркат: Lebenswenden und Zeitenwenden. Deutsche Politiker und die Erfahrungen des 20. Jahrhunderts. München 2007.

Volker Depкат: Zum Stand und zu den Perspektiven der Autobiographieforschung in der Geschichtswissenschaft. In: Bios: Zeitschrift für Biographieforschung, oral history und Lebensverlaufsanalysen 2 (2011), S. 170-87.

E. Dinnerštejn: K voprosu o reputacii izdatelja Z. Gržebina. In: Novoe Literaturnoe Obozrenie 106 (2010), http://magazines.russ.ru/nlo/2010/106/di41.html, Zugriff vom o8.11. 2016.

V. D. Dmitriev/O. E. Majorova: Novikova, Ol'ga Alekseevna. In: Russkie pisateli 1800-1917. Biografičeskij slovar', Bd. 4, 1999, S. 232-40.

Michail Dolbilov: The Political Mythology of Autocracy. Scenarios of Power and the Role of the Autocrat. In: Kritika: Explorations in Russian and Eurasian History 4 (2001), S. 773-95.

Svetlana A. Domanova: Epistoljarnoe nasledie A. F. Koni v CGAOR SSSR. In: Sovetskie archivy 6 (1990), S. 70-74.

Svetlana A. Domanova: Perepiska A. F. Koni. Problemy sravnitel'nogo izučenija. In: N. I. Basovskaja u. a. (Hrsg.): Istočnikovedenie i komparativnyj metod v gumanitarnom znanii. Tezicy dokladov i soobščenij naučnoj konferencii. Moskva 1996, S. 242-44.

Svetlana A. Domanova: „Dva blaga večny na zemle: priroda i iskusstvo“. Obrazy rossijskoj provincii i Evropy na stranicach pisem A. F. Koni. In: Istoričeskij istočnik, čelovek i prostranstvo. Tezisy dokladov i soobščenij naučnoj konferencii (3-5 fevralja 1997 g.; konferencija posvjaščena pamjati A. I. Andreeva i V. K. Jacunskogo). Moskva 1997, S. 116-18.

Svetlana A. Domanova: Perepiska A. F. Koni kak istoričeskij istočnik. Avtoreferat dissertacii na soiskanie učenoj stepeni kandidata istoričeskich nauk. Moskva 1999.

Svetlana A. Domanova: Perepiska A. F. Koni kak istoričeskij istočnik. Rossijskij gosudarstvennyj gumanitarnyj universitet, Moskva 1999 (unveröffentlichte Dissertation).

B. B. Dubencov u. a. (Hrsg.): Peterburgskaja gorodskaja duma, 1846-1918. Sankt-Peterburg 2005. 
Christa Ebert: Sinaida Hippius, seltsame Nähe. Ein Porträt. Berlin u. a. 2004.

Anna Echterhölter: Schattengefechte. Genealogische Praktiken in Nachrufen auf Naturwissenschaftler (1710-1860). Göttingen 2012.

Ben Eklof/John Bushnell/Larissa Zakharova (Hrsg.): Russia's Great Reforms, 1855-1881. Bloomington 1994.

Barbara Alpern Engel: Breaking the Ties That Bound. The Politics of Marital Strife in Late Imperial Russia. Ithaca 2011.

Laura Engelstein: The Dream of Civil Society in Tsarist Russia. Law, State, and Religion. In: Nancy Bermeo/Philip Nord (Hrsg.): Civil Society Before Democracy. Lessons from Nineteenth-Century Europe. Boston 2000, S. 23-42.

Herman Ermolaev: Censorship in Soviet Literature, 1917-1991. Lanham u. a. 1997.

Anton A. Fedyashin: Liberals under Autocracy. Modernization and Civil Society in Russia, 1866-1904. Madison Wisconsin 2012.

Orlando Figes: A People's Tragedy. The Russian Revolution 1891-1924. London 1997.

Orlando Figes: Hundert Jahre Revolution. Russland und das 20. Jahrhundert. München 2015.

Sheila FitzPatrick: Cultural Revolution as Class War. In: dies. (Hrsg.): Cultural Revolution in Russia 1928-1931. Bloomington Indiana 1978, S. 8-40.

Sheila FitzPatrick (Hrsg.): Cultural Revolution in Russia 1928-1931. Bloomington Indiana 1978.

Sheila FitzPATrick: Education and Social Mobility in the Soviet Union, 1921-1934. Cambridge u. a. 1979.

Joseph Frank: Dostoevsky. The Mantle of the Prophet, 1871-1881, Bd. 5. Princeton u. a. 2002.

Victoria FrEDE: Doubt, Atheism, and the Nineteenth-Century Russian Intelligentsia. Madison 2011.

Markus Friedrich: Die Geburt des Archivs. Eine Wissensgeschichte. München 2013.

Cathy A. Frierson: Peasant Icons. Representations of Rural People in Late NineteenthCentury Russia. New York u. a. 1993.

Aleksandr Ju. GalušKın: Predislovie. In: ders. u. a. (Hrsg.): Žurnaly „Vestnik literatury“ (1919-1922), „Letopis’ Doma Literatorov”“ (1921-1922), „Literaturnye zapiski“ (1922). Annotirovannyj ukazatel'. Moskva 1996, S. 5-13.

Aleksandr Ju. GALUŠKıN u. a. (Hrsg.): Žurnaly „Vestnik literatury“ (1919-1922), „Letopis’ Doma Literatorov“ (1921-1922), „Literaturnye zapiski“ (1922). Annotirovannyj ukazatel'. Moskva 1996.

Lena Gautam: Agents of Knowledge Transfer. Western Debates and Psychiatric Experts in Late Imperial Russia. In: Stefan B. Kirmse (Hrsg.): One Law for All? Western Models and Local Practices in (Post-)Imperial Contexts. Frankfurt am Main 2011, S. 93-116.

Wolfgang Geierhos: Vera Zasulič und die russische revolutionäre Bewegung. München 1977.

Ilya V. Gerasimov: Modernism and Public Reform in Late Imperial Russia. Rural Professionals and Self-Organization, 1905-30. Basingstoke 2009.

Michael Ginsburg: Koni and His Contemporaries. Authors. Indiana Slavic Studies 1 (1956). 
John Glad (Hrsg.): Conversations in Exile. Russian Writers Abroad. Durham u. a. 1993.

Michail E. Glavackij (Hrsg.): V žernovach revoljucii. Rossijskaja intelligencija meždu belymi i krasnymi v porevoljucionnye gody. Sbornik dokumentov i materialov. Moskva 2008.

Loren R. Gra ham: The Soviet Academy of Sciences and the Communist Party, 1927-1932. Princeton 1967.

I. Gril'/A. Sokolova: K 150-letiju so dnja roždenija A. F. Koni. Druz’ja i edinomyšlenniki i Poslednie gody žizni. In: Rossijskaja justicija 2 (1994), S. 31-34.

Dagmar GüNTHER: „And now for something completely different“. Prolegomena zur Autobiographie als Quelle der Geschichtswissenschaft. In: Historische Zeitschrift 272 (2001), S. 25-61.

Lutz HÄFner: Die Bombe als „Notwendigkeit“. Terrorismus und die Debatten der Staatsduma um die Legitimität politischer Gewalt. In: Walter Sperling (Hrsg.): Jenseits der Zarenmacht. Dimensionen des Politischen im Russischen Reich 1800-1917. Frankfurt am Main u. a. 2008, S. 433-61.

Gary M. Hamburg: Boris Chicherin and Human Dignity in History. In: ders./Randall A. Poole (Hrsg.): A History of Russian Philosophy 1830-1930. Faith, Reason, and the Defense of Human Dignity. Cambridge u. a. 2010, S. 111-30.

Anne Hartmann/Wolfram Eggeling: Sowjetische Präsenz im kulturellen Leben der SBZ und frühen DDR 1945-1953. Berlin 1998.

Heiko Haumann (Hrsg.): Aufbruch der Gesellschaft im verordneten Staat. Russland in der Spätphase des Zarenreiches. Frankfurt am Main, Berlin 1994.

Heiko Haumann: Geschichte Russlands. Zürich 2003.

Heiko Haumann: Die Verarbeitung von Gewalt im Stalinismus am Beispiel ausgewählter Selbstzeugnisse. Methodische Bemerkungen und ein Werkstattbericht. In: Heiko Haumann/Jörn Happel/Carmen Scheide (Hrsg.): Das Jahrhundert des Gedächtnisses. Erinnern und Vergessen in der russischen und sowjetischen Geschichte im 20. Jahrhundert. Traben-Trarbach 2010, S. 58-76.

Heiko Haumann: Geschichte, Lebenswelt, Sinn. Über die Interpretation von Selbstzeugnissen. In: ders. (Hrsg.): Lebenswelten und Geschichte. Zur Theorie und Praxis der Forschung. Wien u. a. 2012, S. 85-95.

Heiko Haumann: Lebensweltlich orientierte Geschichtsschreibung in den Jüdischen Studien. Das Basler Beispiel. In: ders. (Hrsg.): Lebenswelten und Geschichte. Zur Theorie und Praxis der Forschung. Wien u. a. 2012, S. 70-84.

Guido Hausmann: Universität und städtische Gesellschaft in Odessa, 1865-1917. Stuttgart, Köln 1998.

Jochen Hellbeck: Russian Autobiographical Practice. In: ders./Klaus Heller (Hrsg.): Autobiographical Practices in Russia. Göttingen 2004, S. 279-98.

Jochen Hellbeck: The Diary between Literature and History. A Historian's Critical Response. In: Russian Review 4 (2004), S. 621-29.

Jochen Hellbeck: Revolution on My Mind. Writing a Diary Under Stalin. Cambridge Massachusetts u. a. 2009. 
Jochen Hellbeck/Klaus Heller (Hrsg.): Autobiographical Practices in Russia. Göttingen 2004.

Rainer Hering: Rezension über Markus Friedrich, Die Geburt des Archivs (München 2013). In: H-Soz-Kult, 10. 06. 2014, www.hsozkult.de/publicationreview/id/rezbuecher-21351>, Zugriff vom 09.11. 2016.

Jens Herlth: „Verengung des Handlungsfelds“. Tadeusz Bobrowski, ein polnischer Adeliger in der ukrainischen Provinz. In: Martin Aust/Frithjof Benjamin Schenk (Hrsg.): Imperial Subjects. Autobiographische Praxis in den Vielvölkerreichen der Habsburger, Romanovs und Osmanen im 19. und frühen 20. Jahrhundert. Köln 2015, S. 389-417.

Julia Herzberg: Autobiographik als historische Quelle in „Ost“ und „West“. In: dies./ Christoph Schmidt (Hrsg.): Vom Wir zum Ich. Individuum und Autobiographik im Zarenreich. Köln u. a. 2007, S. 15-62.

Julia Herzberg: „Selbstbildung“ und Gemeinwohl. Das Aushandeln eines besseren Russlands in bäuerlichen Briefen und Autobiographien. In: Walter Sperling (Hrsg.): Jenseits der Zarenmacht. Dimensionen des Politischen im Russischen Reich 1800-1917. Frankfurt am Main u. a. 2008, S. 255-77.

Julia Herzberg: Gegenarchive. Bäuerliche Autobiographik zwischen Zarenreich und Sowjetunion. Bielefeld 2013.

Manfred Hildermeier: Geschichte der Sowjetunion, 1917-1991. Entstehung und Niedergang des ersten sozialistischen Staates. München 1998.

Peter Holquist: Bureaucratic Diaries and Imperial Experts. Autobiographical Writing in Tsarist Russia in the late Nineteenth Century: Fëdor Martens, Dmitrii Miliutin, Pëtr Valuev. In: Martin Aust/Frithjof Benjamin Schenk (Hrsg.): Imperial Subjects. Autobiographische Praxis in den Vielvölkerreichen der Habsburger, Romanovs und Osmanen im 19. und frühen 20. Jahrhundert. Köln 2015, S. 205-32.

Eugene Huskey: Russian Lawyers and the Soviet State. The Origins and Development of the Soviet Bar, 1917-1939. Princeton New Jersey 1986.

John F. Hutchinson: Late Imperial Russia, 189o-1917. London 1999.

A. V. Iljuchin: A. F. Koni o sude prisjažnych. In: Rossijskij sud’ja 8 (2001), S. 40-46. Sergej G. IsA Kov: Russkie v Ėstonii, 1918-1940. Istoriko-kul'turnye očerki. Tartu 1996.

L. JACHNiČ: Anatolij Fëdorovič Koni. K 30-letiju so dnja smerti. In: Sovetskaja justicija 7 (1957), S. 52-56.

Anatolij N. JAŠIN: Filosofskie idei russkich myslitelej sudebnoj zaščity II poloviny XIX veka. A. F. Koni, V. D. Spasovič, F. N. Plevako, K. K. Arsen'ev, S. A. Andreevskij. Murmanskij gosudarstvennyj techničeskij universitet, Murmansk 2009 (unveröffentlichte Dissertation).

Rudolf JAWORSKI: Jubiläen und Gedenktage im östlichen Europa. Versuch einer einordnenden Betrachtung. In: ders./Jan Kusber (Hrsg.): Erinnern mit Hindernissen. Osteuropäische Gedenktage und Jubiläen im 20. und zu Beginn des 21. Jahrhunderts. Münster 2011, S. 11-28.

Evgenija A. Jurtaeva: Gosudarstvennyj sovet v Rossii (1906-1917 gg.). Moskva 2001.

A. Kaloev: A. F. Koni o Kavkaze. In: Ėtnografičeskoe Obozrenie 3 (1997), S. 149-56. 
Elena Kanty penko: Klassische Plädoyers in Strafprozessen der „europäischen Ära“ russischer Rechtsentwicklung nach der Justizreform von 1864. In: Werner Krawietz (Hrsg.): Gewohnheitsrecht, Rechtsprinzipien, Rechtsbewußtsein. Transformationen der Rechtskultur in West- und Osteuropa: interdisziplinäres Symposion 2004 an der Universität Münster. Berlin 2004.

Alexander P. Kaplunovskiy: Die Politisierung der Angestellten im späten Zarenreich. In: Walter Sperling (Hrsg.): Jenseits der Zarenmacht. Dimensionen des Politischen im Russischen Reich 1800-1917. Frankfurt am Main u. a. 2008, S. 313-44.

Andreas Kappeler: Russische Geschichte. München 2014.

Wolfgang KaSACK: Die Akademie der Wissenschaften der UdSSR. Überblick über Geschichte und Struktur: Verzeichnis der Institute. Boppard 1978.

Samuel D. Kassow: Students, Professors, and the State in Tsarist Russia. Berkeley u. a. 1989.

Samuel D. Kassow/James L. West/Edith W. Clowes: Introduction. The Problem oft the Middle Class in Late Imperial Russian Society. In: dies. (Hrsg.): Between Tsar and People. Educated Society and the Quest for Public Identity in Late Imperial Russia. Princeton 1991, S. 3-14.

Monika Katz: F. A. Koni und das russische Vaudeville. Zur Geschichte des Unterhaltungstheaters in St. Petersburg 1830-1855. München 2012.

Isaak M. Kaufman: Russkie ènciklopedii. Obščie ènciklopedii. Bibliografija i kratkie očerki. Moskva 1960.

Michael Khodarkovsky: Bitter Choices. Loyalty and Betrayal in the Russian Conquest of the North Caucasus. Ithaca 2011.

Stefan B. Kirmse: Dealing with Crime in Late Tsarist Russia. Muslim Tatars and the Imperial Legal System. In: ders. (Hrsg.): One Law for All? Western Models and Local Practices in (Post-)Imperial Contexts. Frankfurt am Main 2011, S. 209-41.

Stefan B. Kirmse (Hrsg.): One Law for All? Western Models and Local Practices in (Post-) Imperial Contexts. Frankfurt am Main 2011.

Wolfgang Stephan Kissel: Der Kult des toten Dichters und die russische Moderne. Puškin, Blok, Majakovskij. Köln 2004.

Christian Klein: Einleitung: Biographik zwischen Theorie und Praxis. Versuch einer Bestandsaufnahme. In: ders. (Hrsg.): Grundlagen der Biographik. Theorie und Praxis des biographischen Schreibens. Stuttgart u. a. 2002, S. 1-22.

Christian Koller: Juste-Milieu. In: Historisches Lexikon der Schweiz, zuletzt angepasst 2008, elektronisch verfügbar unter www.hls-dhs-dss.ch/textes/d/D43197.php, Zugriff vom 20.11.2015.

Elena D. Konusova: Russkaja intelligencija. Avtobiografii i biobibliografičeskie dokumenty v sobranii S. A. Vengerova, Bd. 1. Sankt-Peterburg 2001.

Reinhart Koselleck: Vergangene Zukunft. Zur Semantik geschichtlicher Zeiten. Frankfurt am Main 1979.

Stephen Kot kin: Stalin. Vol 1: Paradoxes of Power, 1878-1928. London u. a. 2014.

Dar'ja N. Kovaleva: Rossijskaja prisjažnaja advokatura. Vzgljad iznutri (N. P. Karabčevskij o F. N. Plevako). In: Vestnik Saratovskogo gosudarstvennogo social'no-èkonomičeskogo universiteta 2 (2009), S. 147-49. 
Dar'ja N. Kovaleva: Nikolaj Platonovič Karabčevskij (1851-1925). Žizn', tvorčestvo, ličnost'. Avtoreferat dissertacii na soiskanie učenoj stepeni kandidata istoričeskich nauk. Saratov 2010.

Margret Kraul/Winfried Marotzki/Cornelia Schweppe: Biographie und Profession. Eine Einleitung. In: dies. (Hrsg.): Biographie und Profession. Bad Heilbrunn Oberbayern 2002, S. 7-26.

Benigna von Krusenstjern: Was sind Selbstzeugnisse? Begriffskritische und quellenkundliche Überlegungen anhand von Beispielen aus dem 17. Jahrhundert. In: Historische Anthropologie 2 (1994), S. 462-71.

David Lambert/Alan Lester (Hrsg.): Colonial Lives Across the British Empire. Imperial Careering in the Long Nineteenth Century. Cambridge, New York 2006.

David LAMBERT/Alan LeSTER: Introduction. Imperial Spaces, Imperial Subjects. In: dies. (Hrsg.): Colonial Lives Across the British Empire. Imperial Careering in the Long Nineteenth Century. Cambridge, New York 2006, S. 1-31.

Kenneth Lantz: The Dostoevsky Encyclopedia. Westport Connecticut u. a. 2004.

Aleksandr M. LARIN: A. F. Koni. Sudebnyj dejatel'. Moskva 1988.

Simone LÄssıg: Die historische Biographie auf neuen Wegen? In: Geschichte in Wissenschaft und Unterricht 10 (2009), S. 540-53.

Reinhard LaUER: Kleine Geschichte der russischen Literatur. München 2005.

Dmitrij M. LegkiJ: Dmitrij Vasil’evič Stasov. Sudebnaja reforma 1864 g. i formirovanie prisjažnoj advokatury v Rossijskoj Imperii. Sankt-Peterburg 2011.

N. I. Leonov: Obščestvenno-političeskie vzgljady A. F. Koni v 60-70 gody XIX veke. Moskovskij gosudarstvennyj universitet imeni M. V. Lomonosova, Moskva 1974 (unveröffentlichte Dissertation).

Brian L. Levin-Stankevich: Koni, Anatolii Fedorovich (1844-1927). In: The Modern Encyclopedia of Russian and Soviet History Bd. 3, 1980, S. 153-55.

Brian L. Levin-Stankevich: The Transfer of Legal Technology and Culture: Law Professionals in Tsarist Russia. In: Harley D. Balzer (Hrsg.): Russia’s Missing Middle Class. The Professions in Russian History. Armonk New York u. a 1996, S. 223-43.

Anton V. Lichomanov: A. F. Koni v osobom soveščanii po sostavleniju novogo Ustava o pečati. In: Cenzura v Rossii: Istorija i sovremennost'. Sankt-Peterburg 2008, S. 125-41.

Peter Liessem: Autonomie in der Autokratie? Die Juristischen Gesellschaften im späten Zarenreich. In: Heiko Haumann (Hrsg.): Aufbruch der Gesellschaft im verordneten Staat. Russland in der Spätphase des Zarenreiches. Frankfurt am Main, Berlin 1994, S. 242-71.

Peter Liessem: Verwaltungsgerichtsbarkeit im späten Zarenreich. Der Dirigierende Senat und seine Entscheidungen zur russischen Selbstverwaltung (1864-1917). Frankfurt am Main 1996.

Dominic Lieven: Russian Senior Officialdom under Nicholas II. Careers and Mentalities. In: Jahrbücher für Geschichte Osteuropas 2 (1984), S. 199-223.

Dominic Lieven: Russia’s Rulers Under the Old Regime. New Haven Connecticut 1989. Adele Lindenmeyr: The Rise of Voluntary Associations during the Great Reforms. The Case of Charity. In: Ben Eklof/John Bushnell/Larissa Zakharova (Hrsg.): Russia’s Great Reforms, 1855-1881. Bloomington 1994, S. 264-80. 
Heike Kathrin Litzinger: Juristen und die Bauernfrage. Die Diskussion um das bäuerliche Grundeigentum in Russland von 1880 bis 1914. Frankfurt am Main 2007.

Donald Loewen: The Most Dangerous Art. Poetry, Politics and Autobiography after the Russian Revolution. Lanham Maryland 2008.

Eric Lohr: The Ideal Citizen and Real Subject in Late Imperial Russia. In: Kritika: Explorations in Russian and Eurasian History 2 (2006), S. 173-94.

Stephen Lukashevich: Ivan Aksakov, 1823-1886. A Study in Russian Thought and Politics. Cambridge Massachusetts 1965.

Semion Lyandres: The Fall of Tsarism. Untold Stories of the February 1917 Revolution. Oxford 2013.

T. I. Lysenko: O perepiske A. F. Koni s A. A. Šachmatovym. In: Archeografičeskij ežegodnik za 1979 god. Moskva 1981, S. 274-83.

Amanda Mabillard: The History and Context of „Et tu, Brute?“. In: Shakespeare Online, 20. 08. 2006, www.shakespeare-online.com/ettubrute.html, Zugriff vom 02. 06. 2016.

Charles E. MacClelland/Stephan Merl/Hannes Siegrist (Hrsg.): Professionen im modernen Osteuropa. Berlin 1995.

Thomas Macho: Vorbilder. Paderborn 2011.

Marguerite MAIRE: Guizot et ses cousins genevois d’après des lettres inédites. In: Mémoires et documents publiés par la Société d'histoire et d'archéologie de Genève, Bd. 40. Genève 1961, S. 581-92.

A. Maklezow u. a. (Hrsg.): Das Recht Sowjetrusslands. Tübingen 1925.

M. É. Malikova: Šum vremeni. Istorija leningradskogo kooperativnogo izdatel'stva „Vremja“ (1922-1934). In: Institut russkoj literatury Rossijskoj Akademii Nauk (Hrsg.): Instituty kul'tury Leningrada na perelome ot 1920-x k 1930-m godam. Materialy proekta. Sankt-Peterburg 2011, www.pushkinskijdom.ru/Default.aspx?tabid=1046o, Zugriff vom 03.11. 2016.

Lynn Mally: Culture of the Future. The Proletkult Movement in Revolutionary Russia. Berkeley 1990.

Erna MALYGin: Literatur als Fach in der sowjetischen Schule der 1920er und 1930er Jahre. Zur Bildung eines literarischen Kanons. Bamberg 2012.

Laurie Manchester: Holy Fathers, Secular Sons. Clergy, Intelligentsia, and the Modern Self in Revolutionary Russia. DeKalb 2008.

Ondřej MatĚjкA: Uses of a „Generation“. The Case of the Czech „68ers“. In: Hartmut Berghoff/Bernd Weisbrod/Uffa Jensen (Hrsg.): History by Generations. Generational Dynamics in Modern History. Göttingen 2013, S. 258-78.

Trude Maurer: Hochschullehrer im Zarenreich. Ein Beitrag zur russischen Sozial- und Bildungsgeschichte. Köln 1998.

Inessa Medzhibovskaja: Punishment and the Human Condition. Hannah Arendt, Leo Tolstoy, and Lessons from Life, Philosophy, and Literature. In: Julie Hansen/Andrei Rogachevskii (Hrsg.): Punishment as a Crime? Perspectives on Prison Experience in Russian Culture. Ödeshög 2014, S. 137-61.

Nora Mengel: Biografische Lexika-Projekte des 19. Jahrhunderts als „Werkstätten imperialer Narrative“. In: Martin Aust/Frithjof Benjamin Schenk (Hrsg.): Imperial Subjects. 
Autobiographische Praxis in den Vielvölkerreichen der Habsburger, Romanovs und Osmanen im 19. und frühen 20. Jahrhundert. Köln 2015, S. 61-93.

Patrick Merziger: Rezension über Thomas Macho, Vorbilder (Paderborn 2011). In: H-SozKult, 22.10. 2013, www.hsozkult.de/publicationreview/id/rezbuecher-17121, Zugriff vom 24. 10. 2016.

Dmitrij S. MirskiJ: Geschichte der russischen Literatur. München 1964.

Georg Мisch: Begriff und Ursprung der Autobiographie [1907]. In: ders. (Hrsg.): Geschichte der Autobiographie, Bd. 1: Das Altertum. Bern 1949, S. 3-21.

Marina P. MochnaČEva/Anna KAsK (Hrsg.): Russkij illjustrirovannyj žurnal. 1703-1941. Moskva 2006.

Boris L. Modzalevskij: Krug literaturnych otnošenij A. F. Koni. In: Trudy Puškinskogo Doma Akademii Nauk SSSR (Hrsg.): Pamjati Anatolija Fëdoroviča Koni. Leningrad u. a. 1929, S. $30-54$.

Marina Mogilner: Homo Imperii. A History of Physical Anthropology in Russia. Lincoln u. a. 2013.

A. B. Muratov: Literatur'nye vzgljady A. F. Koni. In: Anatolij F. Koni: Sobranie sočinenij, Bd. 6, hrsg. v. V. G. Bazanov, L. N. Smirnov und K. I. Čukovskij. Moskva 1968, S. 5-23. A. B. Muratov: A. F. Koni i Puškinskij Dom. In: V. N. Baskakov (Hrsg.): Puškinskij Dom. Stat'i. Dokumenty. Bibliografija. Leningrad 1982, S. 37-52.

Harriet Murav: Russia's Legal Fictions. Ann Arbor Michigan 1998.

Benjamin Nathans: Talking Fish. On Soviet Dissident Memoirs. In: Journal of Modern History 87 (2015), S. 579-614.

Marina V. Nemy tina: Sud v Rossii. Vtoraja polovina XIX-načalo XX vv. Saratov 1999.

Frances Nethercotт: Russian Legal Culture Before and After Communism. Criminal Justice, Politics and the Public Sphere. London 2007.

Dietmar Neutatz: Träume und Alpträume. Eine Geschichte Russlands im 2o. Jahrhundert. München 2013.

Philip Nord: Introduction. In: Nancy Bermeo/Philip Nord (Hrsg.): Civil Society Before Democracy. Lessons from Nineteenth-Century Europe. Boston 2000, S. XIII-XXXIII.

A. D. Nozdračev/V. A. Petrickij: Pervyj v Rossii Dom Učenych. In: Vestnik Rossijskoj Akademi Nauk 10 (1995), S. 922-30.

O. S. Ostroj: Sadova Elizaveta Aleksandrovna. In: Sotrudniki Rossijskoj nacional'noj biblioteki - dejateli nauki i kul'tury. Biografičeskij slovar', 4 Bände. Sankt-Peterburg 2008, elektronisch verfügbar unter www.nlr.ru/nlr_history/persons/info.php?id=1172, Zugriff vom 18.11. 2016.

Irina Paperno: Chernyshevsky and the Age of Realism. A Study in the Semiotics of Behavior. Stanford California 1988.

Irina PAperno: Intimacy and History. The Gercen Family Drama Reconsidered. In: Russian Literature 1-2 (2007), S. 1-65.

Lynn PAтук: Dressed to Kill and Die. Russian Revolutionary Terrorism, Gender, and Dress. In: Jahrbücher für Geschichte Osteuropas 2 (2010), S. 192-209.

I. D. Perlov: Pravovye vozzrenija A. F. Koni. In: Anatolij F. Koni: Sobranie sočinenij, Bd. 4, hrsg. v. V. G. Bazanov, L. N. Smirnov und K. I. Čukovskij. Moskva 1967, S. 5-32. 
Jonas Pfister: Werkzeuge des Philosophierens. Stuttgart 2013.

Richard Pipes: Die historische Entwicklung der russischen Intelligentsia. In: ders. (Hrsg.): Die russische Intelligentsia. Stuttgart 1962, S. 65-81.

Richard Pipes (Hrsg.): Die russische Intelligentsia. Stuttgart 1962.

Richard Pipes: The Trial of Vera Z. In: Russian History 37 (2010), S. 1-82.

Stefan Plaggenborg: Die Organisation des Sowjetstaates. In: Gottfried Schramm (Hrsg.): Handbuch der Geschichte Russlands, Bd. 3, II: 1856-1945. Von den autokratischen Reformen zum Sowjetstaat. Stuttgart 1992, S. 1413-525.

Ekaterina PolJa Kova: Differente Plausibilitäten. Kant und Nietzsche, Tolstoi und Dostojewski über Vernunft, Moral und Kunst. Berlin u. a. 2013.

Aleksandr Ju. Polunov: K. P. Pobedonoscev v obščestvenno-političeskoj i duchovnoj žizni Rossii. Moskva 2010.

Alexander Polunov: Russia in the Nineteenth Century. Autocracy, Reform, and Social Change, 1814-1914. Armonk New York u. a 2005.

Mark G. Pomar: Anatoly Fedorovich Koni. Liberal Jurist as Moralist. Pittsburgh 1996.

William Pomeranz: The Practice of Law and the Promise of Rule of Law. The Advokatura and the Civil Process in Tsarist Russia. In: Kritika: Explorations in Russian and Eurasian History 2 (2015), S. 235-62.

Anna D. Popova: Femida v èpochu preobrazovanij. Sudebnye reformy 1864 g. i rubeža XX-XXI vv. v kontekste modernizacii. Moskva 2009.

I. PotapČUk: Russkie sudebnye oratory v izvestnych ugolovnych processach XIX veka. Tula 1997.

E. A. Pravilova: A Public Empire. Property and the Quest for the Common Good in Imperial Russia. Princeton 2014.

Joachim von Puttkamer: Die russische Justizreform von 1864. Eine Kontroverse. In: Jahrbücher für Geschichte Osteuropas 3 (1999), S. 405-09.

Marc Raeff: Political Ideas and Institutions in Imperial Russia. Boulder u. a. 1994.

John Randolph: On the Biography of the Bakunin Family Archive. In: Antoinette M. Burton (Hrsg.): Archive Stories. Facts, Fictions and the Writing of History. Durham 2005, S. 209-31.

Don C. Rawson: Russian Rightists and the Revolution of 1905. Cambridge u. a. 1995.

S. ReH/C. Schelle u. a.: Biographie und Professionalität. Die Reflexivität berufsbiographischer Erzählungen. In: Johannes Bastian (Hrsg.): Professionalisierung im Lehrerberuf. Von der Kritik der Lehrerrolle zur pädagogischen Professionalität. Opladen 2000, S. 107-24.

Andreas Renner: Russland und die Civil Society. Neue Wege zur Erforschung des Liberalismus im Zarenreich. In: H. G. Fleck u. a. (Hrsg.): Jahrbuch zur Liberalismus-Forschung. Baden-Baden 1996, S. 230-36.

Andreas RenNER: Russischer Nationalismus und Öffentlichkeit im Zarenreich 1855-1875. Köln 2000.

Julia Reuter: Ordnungen des Anderen. Zum Problem des Eigenen in der Soziologie des Fremden. Bielefeld 2002. 
Stephan Rindlisbacher: Leben für die Sache. Vera Figner, Vera Zasulič und das radikale Milieu im späten Zarenreich. Wiesbaden 2014.

Diana A. RJazanova: S. A. Andreevskij. Jurist i obščestvennyj dejatel' (1847-1918 gg.). Saratov 2003.

Malte RoLf: Einführung: Imperiale Biographien. Lebenswege imperialer Akteure in Großund Kolonialreichen (1850-1918). In: Geschichte und Gesellschaft 1 (2014), S. 5-21.

Gary Rosenshield: Western Law, Russian Justice. Dostoevsky, the Jury Trial, and the Law. Madison Wisconsin 2005.

Anton D. Rudokvas/Alexei S. Kartsov: Der Rechtsunterricht und die juristische Ausbildung im kaiserlichen Russland. In: Zoran Pokrovac (Hrsg.): Juristenausbildung in Osteuropa bis zum Ersten Weltkrieg. Frankfurt am Main 2007, S. 273-316.

Charles Ruud: Russian Entrepreneur Publisher Ivan Sytin of Moscow, 1851-1934. Montreal Quebec 1990.

Charles RuUd: Fighting Words. Imperial Censorship and the Russian Press, 1804-1906. Toronto 2009.

Julija SAFronova: Russkoe obščestvo v zerkale revoljucionnogo terrora. 1879-1881 gody. Moskva 2014.

Anatolij V. ŠA Povalov: Pravovye vzgljady A. F. Koni i ich vlijanie na provodimuju v Rossii sudebno-pravovuju reformu. Kubanskij gosudarstvennyj agrarnyj universitet, Krasnodar 2005 (unveröffentlichte Dissertation).

Vladimir N. SAšonko: A. F. Koni v Peterburge - Petrograde - Leningrade. Leningrad 1991.

Doris Schaeffer: Psychotherapie zwischen Mythologisierung und Entzauberung. Therapeutisches Handeln im Anfangsstadium der Professionalisierung. Opladen 1990.

Leonard SCHA PIRO: Die vorrevolutionäre Intelligentsia und die gesetzliche Ordnung. In: Richard Pipes (Hrsg.): Die russische Intelligentsia. Stuttgart 1962, S. 33-48.

Susanne Schat TEnBERG: Stalins Ingenieure. Lebenswelten zwischen Technik und Terror in den 1930er Jahren. München 2002.

Susanne Schattenberg: Die korrupte Provinz? Russische Beamte im 19. Jahrhundert. Frankfurt am Main 2008.

Dietmar Schenk: „Archivmacht“ und geschichtliche Wahrheit. In: Rainer Hering/Dietmar Schenk (Hrsg.): Wie mächtig sind Archive? Perspektiven der Archivwissenschaft. Hamburg 2013, S. 21-43.

Dietmar SCHENK: „Aufheben, was nicht vergessen werden darf“. Archive vom alten Europa bis zur digitalen Welt. Stuttgart 2013.

Frithjof Benjamin Schenk: Russlands Fahrt in die Moderne. Mobilität und sozialer Raum im Eisenbahnzeitalter. Stuttgart 2014.

Zachary Schiffman: The Birth of the Past. Baltimore 2011.

Karl SCHLÖGEL: Petersburg. Das Laboratorium der Moderne 1909-1921. München 2002.

Karl Schlögel: Das russische Berlin. Ostbahnhof Europas. München 2007.

Karl SCHLÖGEL: Terror und Traum. Moskau 1937. München 2008.

Anita SCHLÜCHTER: Recht und Moral. Argumente und Debatten „zur Verteidigung des Rechts“ an der Wende vom 19. zum 20. Jahrhundert in Russland. Zürich 2008. 
Ulrich ScH mid: Ichentwürfe. Die russische Autobiographie zwischen Avvakum und Gercen. Zürich 2000.

Ulrich ScHMID: Lew Tolstoi. München 2010.

Ulrich Schмid: Die subjektbildende Kraft des Imperiums. Autobiographien in der späten Zarenzeit. In: Martin Aust/Frithjof Benjamin Schenk (Hrsg.): Imperial Subjects. Autobiographische Praxis in den Vielvölkerreichen der Habsburger, Romanovs und Osmanen im 19. und frühen 20. Jahrhundert. Köln 2015, S. 159-74.

Thomas SснміDт: Kalender und Gedächtnis. Erinnern im Rhythmus der Zeit. Göttingen 2000 .

Gottfried Schramm (Hrsg.): Handbuch der Geschichte Russlands, Bd. 3, II: 1856-1945. Von den autokratischen Reformen zum Sowjetstaat. Stuttgart 1992.

Lothar Schultz: Russische Rechtsgeschichte. Von den Anfängen bis zur Gegenwart einschließlich des Rechts der Sowjetunion. Lahr 1951.

Winfried Schulze: Ego-Dokumente: Annäherung an den Menschen in der Geschichte? Vorüberlegungen für die Tagung „Ego-Dokumente“. In: ders. (Hrsg.): Ego-Dokumente. Annäherung an den Menschen in der Geschichte. Berlin 1996, S. 11-30.

Dirk Schumann: Youth Culture, Consumption, and Generational Dispositions in Twentieth-Century Germany. In: Hartmut Berghoff/Bernd Weisbrod/Uffa Jensen (Hrsg.): History by Generations. Generational Dynamics in Modern History. Göttingen 2013, S. $125-45$.

Anna Schur: Wages of Evil. Dostoevsky and Punishment. Evanston Illinois 2012.

Denis A. Spvižkov: Das Zeitalter der Intelligenz. Zur vergleichenden Geschichte der Gebildeten in Europa bis zum Ersten Weltkrieg. Göttingen 2006.

Ju A. Šestakov: Sudebnaja Reforma načala XX veka i frakcii III gosudarstevnnoj dumy. Šachty 2010.

Robert Sharlet: Pashukanis and the Withering Away of Law in the USSR. In: Sheila Fitzpatrick (Hrsg.): Cultural Revolution in Russia 1928-1931. Bloomington Indiana 1978, S. $169-88$.

M. ŠIfmAn: A. F. Koni vydajuščijsja jurist i sudebnyj orator. K $30-$ letiju so dnja smerti. In: Socialist. zakonnost' 9 (1957), S. 51-56.

Anatolij P. Šı IKMAN: Kto est kto v rossijskoj istorii. Biobibliografičeskij slovar'. Moskva 2003.

Ana Siljak: Angel of Vengeance. The Girl Assassin, the Governor of St. Petersburg and Russia’s Revolutionary World. New York 2008.

Aleksandr A. Simu tenko: K. K. Arsen’ev i rossijskoe liberal'noe dviženie konca XIX-načala XX veka. Severo-zapadnaja akademija gosudarstvennoj služby, Sankt-Peterburg 2006 (unveröffentlichte Dissertation).

Helmut SLAPNICKA: Juristen als Wegbereiter des aufsteigenden Bürgertums des 19. Jahrhunderts in den Böhmischen Ländern. In: Österreichische Akademie der Wissenschaften, Philosopisch-historische Klasse (Hrsg.): Anzeiger. 125. Jahrgang 1988, Nr. 1-9. Wien, S. 35-60.

P. I. ŠLemin: Dnevnik K. K. Arsen’eva. In: Archeografičeskij ežegodnik za 1977 god. Moskva 1978, S. 312-22. 
Alexandra Sмiтн: Pushkin as a Cultural Myth. Dostoevskii’s Pushkin Speech and Its Legacy in Russian Modernism. In: Joe Andrew/Robert Reid (Hrsg.): Dostoevskii’s Overcoat. Amsterdam 2013, S. 123-47.

Douglas Sмiтн: Der letzte Tanz. Der Untergang der russischen Aristokratie. Frankfurt am Main 2014.

Sidonie Smith/Julia Watson: Reading Autobiography. A Guide for Interpreting Life Narratives. Minneapolis Minnesota u. a. 2010.

Vasilij I. Smoljarčuk: Anatolij Fëdorovič Koni (1844-1927). Moskva 1981.

Vasilij I. SMOLJARČUK: Giganty i čarodei slova. Russkie sudebnye oratory vtoroj poloviny 19 - načala 20 veka. Moskva 1984.

Vasilij I. SMOLJarČuk: A. F. Koni i ego okruženie. Moskva 1990.

Peter H. Solomon: Legal Journals and Soviet Social History. In: Russian History 1 (1985), S. $265-82$.

Peter H. Solomon (Hrsg.): Reforming Justice in Russia, 1864-1996. Power, Culture, and the Limits of Legal Order. Armonk New York 1997.

Andreas Urs Sommer: Was (er-)schafft die Umwertung aller Werte? Zu Nietzsches Kreativitätsmythologemen. In: Oliver Krüger u.a. (Hrsg.): Mythen der Kreativität. Das Schöpferische zwischen Innovation und Hybris. Frankfurt am Main 2003, S. 196-206.

Regula Spalinger-Bichsel: A. F. Koni und die russische Gerichtsrhetorik. Zürich 1993 (unveröffentlichte Dissertation).

Walter Sperling (Hrsg.): Jenseits der Zarenmacht. Dimensionen des Politischen im Russischen Reich 180o-1917. Frankfurt am Main u. a. 2008.

Walter Sperling: Jenseits von Autokratie und Gesellschaft. Zur Einleitung. In: ders. (Hrsg.): Jenseits der Zarenmacht. Dimensionen des Politischen im Russischen Reich 1800-1917. Frankfurt am Main u. a. 2008, S. 7-39.

Matthias Stadelmann: Grossfürst Konstantin Nikolaevič. Der persönliche Faktor und die Kultur des Wandels in der russischen Autokratie. Wiesbaden 2012.

Klaus SтÄDTKE (Hrsg.): Russische Literaturgeschichte. Stuttgart 2011.

Nigel Starck: Life After Death. The Art of the Obituary. Carlton Victoria 2006.

Timm Starl: Im Prisma des Fortschritts. Zur Fotografie des 19. Jahrhunderts. Marburg 1991.

Martin Stein: Zur Problematik von Professionalisierungs- und Substitutionsprozessen neuer Berufsgruppen. Am Beispiel der Absolventen sozialwissenschaftlicher Studiengänge. Bochum 1993.

Willibald Steinmetz/Heinz-Gerhard Haupt: The Political as Communicative Space in History. The Bielefeld Approach. In: Willibald Steinmetz/Ingrid Gilcher-Holtey/ Heinz-Gerhard Haupt (Hrsg.): Writing Political History Today. Frankfurt, New York 2013, S. 11-33.

Adolf Stender-Petersen: Geschichte der russischen Literatur. München 1993.

Anžela V. Stepanova: A. I. Urusov. Jurist i sudebnyj orator. Saratovskij gosudarstvennyj universitet im. N. G. Černyševskogo, Saratov 2005 (unveröffentlichte Dissertation).

Anke Stephan: Erinnertes Leben. Autobiographien, Memoiren und Oral-History-Interviews als historische Quellen. In: Virtuelle Fachbibliothek Osteuropa. Digitales Hand- 
buch zur Geschichte und Kultur Russlands und Osteuropas, zuletzt angepasst 2005, elektronisch verfügbar unter www.osmikon.de/metaopac/singleHit.do?methodToCall =showHit\&curPos=2\&identifier=2dibe49b, Zugriff vom 20.10. 2018.

Christopher Stolarski: Another Way of Telling the News. The Rise of Photojournalism in Russia, 1900-1914. In: Kritika: Explorations in Russian and Eurasian History 3 (2011), S. 561-90.

Gleb Struve: Geschichte der Sowjetliteratur. München 1958.

Cecilia von Studnitz: Mit Tränen löschst du das Feuer nicht. Maxim Gorki und sein Leben. Düsseldorf 1993.

Willard Sunderland: The Baron's Cloak. A History of the Russian Empire in War and Revolution. Ithaca 2014.

Marc Szeftel: Rezension über Michael Cherniavsky, Tsar and People (1961). In: Specu$\operatorname{lum}_{3}$ (1962), S. 423-25.

Ludmila Tномаs: Georgi Tschitscherin. „Ich hatte die Revolution und Mozart“. Berlin 2012.

Michel Tissier: Malaise dans la culture juridique libérale en Russie après 1905. „Pédagogie des libertés“ et éducation au droit. In: Cahiers du monde russe et soviétique 2 (2007), S. 185-208.

Michel Tissier: Les sociétés juridiques dans l'Empire russe au tournant du XXe siècle. Professionnalisation des juristes et culture juridique. In: Cahiers du monde russe et soviétique 1 (2010), S. 5-34.

Hans Joachim Torke: Einführung in die Geschichte Russlands. München 1997.

Nikolaj A. TroickiJ: Advokatura v Rossii i političeskie processy 1866-1904 gg. Tula 2000.

Konstantin N. Tsimbaev: Jubilee Mania in Late Nineteenth- and Early Twentieth-Century Russian Society. In: Russian Studies in History 2 (2008), S. 14-30.

Claudia Ulbrich/Hans Medick/Angelika Schaser: Selbstzeugnis und Person. Transkulturelle Perspektiven. In: dies. (Hrsg.): Selbstzeugnis und Person. Transkulturelle Perspektiven. Köln u. a. 2012, S. 1-19.

Ju V. Varfolomeev: Nikolaj Konstantinovič Murav'ev. Advokat, politik, čelovek. Saratov 2007.

Raffaèla VAsSENA: K rekonstrukcii istorii dejatel'nosti Instituta živogo slova (1918-1924). In: Novoe Literaturnoe Obozrenie 86 (2007), magazines.russ.ru/nlo/2007/86/va5.html, Zugriff vom 09.11. 2016.

Claudia Verhoeven: Court Files. In: Miriam Dobson/Benjamin Ziemann (Hrsg.): Reading Primary Sources. The Interpretation of Texts from Nineteenth- and Twentieth-Century History. Milton Park 2009, S. 90-105.

Claudia Verhoeven: The Odd Man Karakozov. Imperial Russia, Modernity, and the Birth of Terrorism. Ithaca 2009.

S. Volk/M. Vydrja/A. Muratov: Anatolij Fëdorovič Koni. In: Anatolij F. Koni: Sobranie sočinenij, Bd. 1, hrsg. v. V. G. Bazanov, L. N. Smirnov und K. I. Čukovskij. Moskva 1966, S. 5-36.

Solomon Volkov: St. Petersburg. A Cultural History. New York u. a. 2010.

Evgenij M. VorožEjKIn (Hrsg.): Sudebnye reči izvestnych russkich juristov. Moskva 1957. 
M. VydrJA: A. F. Koni kak sudebnyj orator. In: Anatolij F. Koni: Sobranie sočinenij, Bd. 3, hrsg. v. V. G. Bazanov, L. N. Smirnov und K. I. Čukovskij. Moskva 1967, S. 5-19.

Sergej A. Vysockij: Koni. Moskva 1988.

Sergej A. VysockiJ: Sud'ja i prokuror. Istoričeskij roman. Moskva 1994.

Andrew B. Wachtel: An Obsession with History. Russian Writers Confront the Past. Stanford California 1994.

William G. WAgner: Marriage, Property, and Law in Late Imperial Russia. Oxford u. a. 1994. Peter WALdron: Religious Toleration in Late Imperial Russia. In: Olga Crisp/Linda Edmondson (Hrsg.): Civil Rights in Imperial Russia. Oxford 1989, S. 103-19.

Andrzej WALICKI: Legal Philosophies of Russian Liberalism. Notre Dame Indiana u. a. 1992.

Barbara WALKER: On Reading Soviet Memoirs. A History of the „Contemporaries“ Genre as an Institution of Russian Intelligentsia Culture from the 1790 s to the 1970s. In: Russian Review 3 (2000), S. 327-52.

Francis W. WCISLO: Tales of Imperial Russia. The Life and Times of Sergei Witte 1849-1915. Oxford 2011.

Richard Wortman: The Development of a Russian Legal Consciousness. Chicago 1976.

Richard Wortman: Scenarios of Power, Bd. 2. Myth and Ceremony in Russian Monarchy: from Alexander II to the Abdication of Nicholas II. Princeton 2000.

Richard Wortman: Reply to Mikhail Dolbilov. In: Kritika: Explorations in Russian and Eurasian History 4 (2001), S. 797-801.

Richard Wortman: Russian Monarchy and the Rule of Law. New Considerations of the Court Reform of 1864. In: Kritika: Explorations in Russian and Eurasian History 1 (2005), S. 145-70.

Marion Wullschleger: „Truthfulness and Sincerity“. Habsburg Civil Servants in Trieste and their Autobiographical Practices after the Fall of the Empire. München, Konferenz „Imperial Experts and Their Autobiographical Practices“ Juli 2014 (unveröffentlichter Aufsatz).

Larissa Za kharova: The Reign of Alexandr II. A Watershed? In: Dominic Lieven (Hrsg.): The Cambridge History of Russia. Volume II: Imperial Russia, 1689-1917. Cambridge u. a. 2006, S. 593-616.

L. D. Zarodovaja: Perepiska B. L. Modzalevskogo s A. F. Koni. In: T. G. Ivanova (Hrsg.): Boris L'vovič Modzalevskij. Materialy k naučnoj biografii. Sankt-Peterburg 2001, S. $360-88$.

Mary F. Zirin: Meeting the Challenge. Russian Women Reporters and the Balkan Crises of the Late 1870s. In: Barbara T. Norton/Jehanne M. Gheith (Hrsg.): An Improper Profession. Women, Gender, and Journalism in Late Imperial Russia. Durham North Carolina u. a. 2001, S. 140-66. 


\section{Register}

A

Achmatova, Anna Andreevna (1889-1966) 358

Aksakov, Ivan Sergeevič (1823-1886) 289, $322 \mathrm{ff}, 325 \mathrm{f}, 332,337$

Amfiteatrov, Aleksandr Valentionvič (1862-1938) $358 \mathrm{f}$

Anciferov, Nikolaj Pavlovič (1889-1958) 364, 391

Andreevskij, Sergej Arkad'evič (1847-1918) 16, $68 \mathrm{ff}, 72 \mathrm{ff}, 76 \mathrm{ff}, 92 \mathrm{ff}, 192,205,247 \mathrm{ff}$, 253, 268, 273, 290, $307 \mathrm{ff}$

Apuchtin, Aleksej Nikolaevič (1840-1893) 293, 307, 370

Arcimovič, Viktor Antonovič (1820-1893) $58 \mathrm{ff}, 66,120,164$

Arsen'ev, Konstantin Konstantinovič (1837-1919) $62 \mathrm{ff}, 71 \mathrm{ff}, 91 \mathrm{ff}, 113,119,155$, $164 \mathrm{ff}, 173,178,192,196,200 \mathrm{f}, 247 \mathrm{f}, 253$, 262, 268, 273, 307, 333 f, 392, 398, 402, 410

Atarščikov, Semën Semënovič (1807-1845) $32 \mathrm{f}$

B

Bachtin, Michail (1895-1975) 69

Badiou, Alain $\left({ }^{*} 1937\right) 17$

Bakunin, Michail Aleksandrovič (1814-1876) 335

Baršev, Sergej Ivanovič (18o8-1882) $331 \mathrm{f}$

Belinskij, Vissarion Grigor'evič (1811-1848) $85 \mathrm{f}, 301$

Belyj, Andrej (1880-1934) 272, 359

Blok, Aleksandr Aleksandrovič (188o-1921) $358 \mathrm{ff}, 390$

Boborykin, Petr Dmitrievič (1836-1921) 308, 359

Bobriščev-Puškin, Aleksandr Michajlovič (1851-1903) 61, 66

Bobrovskij, Pavel Osipovič (1832-1905) 61

Bogoljubov 15, 133f, 137, 156, 238, 286

Borovikovskij, Aleksandr L'vovič

(1844-1905) 62, 66
Buckovskij, Nikolaj Andreevič (1811-1873) $65 \mathrm{f}$

C

Čechov, Anton Pavlovič (1860-1904) 41, $338,343 \mathrm{f}$

Černyšev, Vasilij Il'ič (1866/67-1949) 94

Černyševskij, Nikolaj Gavrilovič (1828-1889) 128

Čičerin, Boris Nikolaevič (1828-1904) 59 ff, 9o, 110, 151, $166 \mathrm{ff}, 202,224,266,296,305$

Čičerina, Aleksandra Alekseevna (1845-1920) 90, 202

Čukovskij, Kornej Ivanovič (1882-1969) 36, 43 f, 145 f, 258, 271, 295 f, 350, 358, 362, 379

\section{D}

Davydov, Nikolaj Vasilevič (1848-1920) 124, 253

Dejč, Lev (1855-1941) 269

Deljanov, Ivan Davydovič (1818-1897) 231

Dickens, Charles (1812-1870) $295 \mathrm{f}$

Dostojewski, Fëdor (1821-1881) 41, 270, $288 \mathrm{ff}, 298 \mathrm{ff}, 319 \mathrm{f}, 324,330,336,338 \mathrm{ff}$, $347 \mathrm{ff}, 360 \mathrm{f}, 370,400$

Dril, Dmitrij Andreevič (1846-1910) 62

Džunkovskij, Vladimir Fëdorovič (1865-1938) 275, 391

$\mathrm{E}$

Efron, Il'ja Abramovič (1847-1917) 65

Esipovič, Jakov Grigor'evič (1822-1906) 62, 66

F

Figner, Vera (1852-1942) 33

Filosofov, Dmitrij (1872-1940) 27of

G

Gejden, Petr Aleksandrovič (1840-1907) 62, 188, 191, 196f, 201, 221, 228, 273

Gercen (Herzen), Aleksandr Ivanovič (1812-1870) 85 
Gernet, Michail Nikolaevič (1874-1953) 67, $251,253,256,342,354,372,380,392,404$

Gessen, Iosif Vladimirovič (1865-1943) 276

Gil'denbrandt fon, Varvara Ivanovna Iskul ${ }^{\circ}$ (1850-1928) 270

Giršman, L. L. (1839-1921) 360

Gogol, Nikolai (1809-1852) 299, 301, 330, $336,338,349,405$

Golovnin, Aleksandr Vasil'evič (1821-1886) 168,229

Golubev, Ivan Jakovlevič (1841-1918) 228, 258

Gončarov, Ivan Aleksandrovič (1812-1891) $45,293,296,334 \mathrm{ff}, 348 \mathrm{ff}, 353,370$

Gor'kij, Maksim (1868-1936) 246, 338, $361 \mathrm{ff}$

Goremykin, Ivan Logginovič (1839-1917) 237

Gruzenberg, Oskar Osipovič (1866-1940) 179, 215 f, 246 f, 274

Gržebin, Zinovij Isaevič (1877-1929) 340

Gubskij, Michail Fëdorovič (1850-1901) 59, 61,66

\section{$\mathrm{H}$}

Haas (Gaaz), Friedrich Joseph (1780-1853) $61,347,353,411$

Hippius (Gippius), Sinaida (1869-1945) 199, $270 \mathrm{ff}, 303,370$

Holmes Jr., Oliver Wendell (1841-1935) $84 \mathrm{f}$

\section{I}

Izmajlov, Aleksandr Alekseevič (1873-1921) $116,123,145,336$

\section{$\mathrm{J}$}

Juzefovič, Boris Michajlovič (1843-1911) 202

\section{K}

Kairova, Anastasija Vasilevna (1844-1888) 13

Karabčevskij, Nikolaj Platonovič (1851-1925) 39, 81, 152, 193, 244, 246, 277 f, 308, 412

Karakozov, Dmitrij Vladimirovič (1840-1866) 21f, 33, 146, 159, 183, 239, 383
Katkov, Michail Nikiforovič (1818-1887) $15 \mathrm{f}, 238,241,323 \mathrm{ff}$

Kaufman, Abram Evgen’evič (1855-1921) $358 \mathrm{ff}$

Kavelin, Konstantin Dmitrievič (1818-1885) $58 \mathrm{ff}, 68,99,164,173,253,370$

Kerenskij, Aleksandr Fëdorovič (1881-1970) 246

Kessel', Konstantin Ivanovič (1843-1918) $53 \mathrm{f}$

Kistjakovskij, Bogdan Aleksandrovič (1868-1920) $300 \mathrm{f}$

Kobeko, Dmitrij Fomič (1837-1918) $199 \mathrm{ff}$

Koni, Fëdor Alekseevič (1809-1879) 13, 292, $307,331,356,373,380$,

Koni, Irina Semënovna (geborene Jur'eva, auch Sandunova) (1811-1891) 13, 292, $307,331,342,384$

Korolenko, Vladimir Galaktionovič (1853-1921) 309, 312, 343

Kostomarov, Nikolaj Ivanovič (1817-1885) 332

Kovalevskij, Maksim Maksimovič (1851-1916) 63, 124, 228, 342

Kovalevskij, Michail Evgrafovič (1829-1884) $65 \mathrm{f}$

Kravčinskij, Sergej Michajlovič (Pseudonym Stepnjak) (1851-1895) 164

Kruševan, Pavel A. (1860-1909) 324

Krylenko, Nikolaj Vasil'evič (1885-1938) 252, 279

Krylov, Nikita Ivanovič (1807-1879) 6of, 296, 319, $328 \mathrm{f}$,

Kulišer, Michail Ignat'evič (1847-1919) 122

Kulomzin, Anatolij Nikolaevič (1838-1923) $230 \mathrm{f}$

Kuropatkin, Aleksej Nikolaevič (1848-1925) 223

L

Lanser, Nadežda Pavlovna (1879/80-1920) 379

Loris-Melikov, Michail Tarielovič (1824-1888) 155, 169, $228 \mathrm{ff}, 233,236$, 241f, 258, 342, 383

Lunačarskij, Anatolij Vasil'evič (1875-1933) $256 \mathrm{ff}, 269,271,28 \mathrm{o}, 361 \mathrm{f}, 368,377,405$ 
Lutochin, Dolmat Aleksandrovič

(1885-1942) 361,367

M

Majakovskij, Vladimir Vladimirovič

(1893-1930) 39, 359

Manuchin, Sergej Sergeevič (1856-1922) 228, 251, 258, 343

Markov, Sergej Leonidovič (1878-1918) 274

Merežkovskij, Dmitrij (1865-1941) 270f, 303, 307

Miljukov, Pavel Nikolaevič (1859-1943) 201, 243, 274

Miljutin, Dmitrij Alekseevič (1816-1912) 65, 228, 295

Miljutin, Jurij Nikolaevič (1856-1912) 196

Mitrofanija (Praskov'ja Grigor'evna Rozen, 1825-1899) $70,80,112,179 \mathrm{f}$

Mjasoedov, Nikolaj Nikolaevič (1839-1908) 62

Modzalevskij, Boris L’vovič (1874-1928) 255, $356 \mathrm{f}, 376,380 \mathrm{f}, 405$

Mordvinov, Semën Aleksandrovič (1825-1900) 52

Moroškin, Sergej Fëdorovič (1844-1900) 61, $66,319,332$

Motovilov, Georgij Nikolaevič (1834-188o) 6of, 66

Murav'ev, Nikolaj Valerianovič (1850-1908) 9o, 141, 143, 153, 175, 193, 208, $212 \mathrm{ff}, 231$, 239, 392, 412

Muromcev, Sergej Andreevič (1850-1910) 218

$\mathrm{N}$

Nabokov, Dmitrij Nikolaevič (1827-1904) 59, 61, 66, 228, 301

Naryškin, Aleksandr Alekseevič (1839-1916) 231, 238

Naryškina, Elizaveta Alekseevna (1838-1928) 197

Nekljudov, Nikolaj Adrianovič (1840-1896) 216, 328

Nekrasov, Nikolaj Aleksejevič (1821-1878) 293, 307, 338, $343 \mathrm{ff}, 348 \mathrm{ff}, 370$
Nemirovič-Dančenko, Vasilij Ivanovič (1845-1936) 254, 272, 359, 367, 394

Novikova, Ol'ga Alekseevna (1840-1925) $324 \mathrm{ff}$

O

Odoevskij, Vladimir Fëdorovič (1803-1869) 292, 302, 342, 347, 349, 353, 358, 362, 400

Ol'denburg, Sergej Fëdorovič (1863-1934) $125,354,356,372,377,405$

Ostrovskij, Aleksandr Nikolaevič (1823-1886) 338, 343f, 348, $351 \mathrm{f}$

$\mathbf{P}$

Pahlen, Konstantin Ivanovič (1833-1912) 15, $16,51 \mathrm{ff}, 74,133 \mathrm{ff}, 203,209,231,237 \mathrm{f}, 26 \mathrm{of}$, 280, 286, $326 \mathrm{ff}, 410$

Passover, Aleksandr Jakovlevič (1840-1910) 230

Pašukanis, Evgenij Bronislavovič (1891-1937) 245, 250, 252

Petražickij, Lev Iosifovič (1867-1931) 305

Pisemskij, Aleksej Feofilaktovič (1820-1881) 293, 340, 370

Platonov, Sergej Fëdorovič (186o-1933) 45, 260, 354, 356, 375, 377, 391, 405

Plevako, Fëdor Nikiforovič (1842-1908/o9) $62,66,68,71,73,76,80 \mathrm{ff}, 94,97,409 \mathrm{f}$

Pleve fon, Vjačeslav Konstantinovič (1846-1904) 141, 231, 236, 239

Pobedonoscev, Konstantin Petrovič (1827-1907) $141 \mathrm{ff}, 154 \mathrm{f}, 159 \mathrm{ff}, 169,175$, 177, 183, 208, 223f, 226, 231, 237, 241, 259, 261f, 264, 276, 325, 410

Pokrovskij, Michail Nikolaevič (1868-1932) 160, 224, 226, 276

Poljanskij, Nikolaj Nikolaevič (1878-1961) 122, 124, 253, 392, 404

Polovcov, Valerian Aleksandrovič (1843-1907) 74

Ponomareva, Elena Vasilevna 40, 119, 364, $373 \mathrm{f}, 378 \mathrm{ff}, 406,410$

Pos'et, Konstantin Nikolaevič (1819-1899) 159, 276

Puschkin, Alexander (1799-1837) 42, 81, 268, $288 \mathrm{ff}, 298 \mathrm{ff}, 301 \mathrm{ff}, 306 \mathrm{f}, 312,335 \mathrm{f}$, 
$338 \mathrm{f}, 342 \mathrm{ff}, 348 \mathrm{f}, 351 \mathrm{ff}, 359,377,390,400$, 405

Pypin, Aleksandr Nikolaevič (1833-1904) 166, 173

Rasputin, Grigorij E. (1871-1916) 223, 240

Remizov, Aleksej Michajlovič (1877-1957) 360

Rovinskij, Dmitrij Aleksandrovič (1824-1895) 59 ff, 65f, 105, 118f, 122, 253, 291, 342, 353

\section{S}

Saburov, Andrej Aleksandrovič (1837-1916) $53 \mathrm{f}, 62 \mathrm{f}, 68,82$

Šachmatov, Aleksej Aleksandrovič

(1864-1920) 45, 116, 145, 303, 330, 342, 377

Sadov, Aleksandr Ivanovič (1850-1930) 236, 275,406

Sadova, Elisaveta Aleksandrovna (1886-1970) 406

Šamšin, Ivan Ivanovič (1835-1912) 62, 66 Ščepkina-Kupernik, Tat'jana L’vovna (1874-1952) 366,368

Šipov, Dmitrij Nikolaevič (1851-1920) 188, 191

Solovëv, Vladimir Sergeevič (1853-1900) 292, 305, 307, 342, 370

Spasovič, Vladimir Danilovič (1829-1906)

$45,63,66,68,72 \mathrm{ff}, 79$ f, $95 \mathrm{ff}, 102,118,164$, $173,192,200,300,307,410$

Stasjulevič, Michail Matveevič (1826-1911) 155, $163 \mathrm{ff}, 173,201,227,262,266,308$

Stasov, Dmitrij Vasil'evič (1828-1918) 253, 333, $409 \mathrm{f}$

Stasov, Vladimir Vasilevič (1824-1906) 309 Stojanovskij, Nikolaj Ivanovič (1821-190o) 59, 61, 65f, $119 \mathrm{ff}, 288$

Stolypin, Petr Arkad'evič (1862-1911) 188, 19of, 198, 206, 210, 221, 231, 328

Struve, Petr Berngardovič (1870-1944) 243 Šuvalov, Pëtr Andreevič (1827-1889) 228, 239, 370
$\mathrm{T}$

Tagancev, Nikolaj Stepanovič (1843-1923) 141f, 153, 175, 208f, 214, 273, 305

Tarnovskij, Veniamin Michajlovič (1837-1906) 230

Tolstoi, Lew (1828-1910) 41, 109, 270, $288 \mathrm{f}$, 291, 293 f, 299 f, $302 \mathrm{ff}, 309 \mathrm{ff}, 324,330,336$, $338 \mathrm{f}, 340,343 \mathrm{f}, 347,351,353,370,377 \mathrm{f}$, $393 \mathrm{f}, 400,402,407$

Trepov, Fëdor Fëdorovič (1809/12-1889) 13, 15, 51, 136f, 238, 241, 285

Trotzki, Leo (1879-1940) 246

Trubeckoj, E. N. (1863-1920) 360

Turgenev, Ivan Sergeevič (1818-1883) 41, 69, $86,119,164,289,293,301 \mathrm{f}, 308,330,338$, $342,344,348$ f, $350 \mathrm{ff}, 355,357,360,370$, 377,401

$\mathrm{U}$

Ungern-Sternberg von, Roman Fëdorovič (1885-1921) $33 \mathrm{f}$

Urusov, Aleksandr Ivanovič (1843-1900) $62 \mathrm{f}, 66,68 \mathrm{f}, 71 \mathrm{ff}, 76 \mathrm{ff}, 81,92,94 \mathrm{ff}, 118$, 192, 290, 307, 310, 410

Utevskij, Lev Samojlovič (1897-1960) 145, $238,260,342 \mathrm{f}, 348,355 \mathrm{ff}, 366,372$

$\mathrm{V}$

Valuev, Petr Aleksandrovič (1815-189o) $326 \mathrm{ff}, 332,369$

Vel'tman, Aleksandr Fomič (180o-1870) 307

Vengerov, Semën Afanas'evič (1855-1920) 65, 106

Veselovskij, Aleksej Nikolaevič (1843-1918) 55

Vitmer, Aleksandr Nikolaevič (1839-1916) 123

W

Witte, Sergei (1849-1915) 40, 140 f, 149, 202, 228, $230 \mathrm{f}, 233,236 \mathrm{f}, 239,251,254,256 \mathrm{f}$, $276,280,334,343,353,410$ 
$\mathrm{Z}$

Zamjatin, Dmitrij Nikolaevič (1805-1881) $65 \mathrm{f}, 228$

Zarenfamilie

- Alexander II. (1818-1881) 13, 17, 20, 23, $82,121,125,142,146,151 \mathrm{f}, 155,159,163,167$, $171 \mathrm{f}, 175,188,215,224,227,230,239,258$, 261

- Alexander III. (1845-1894) 23, 38, 64, $142,146,148 \mathrm{ff}, 153 \mathrm{f}, 158,161 \mathrm{ff}, 169,174$, $186 \mathrm{f}, 191,205 \mathrm{ff}, 214,224,239,278,325$

- Alexandra Fjodorowna (1872-1918) 149, 150, 223

- Elena Pavlovna (1806-1873) 229

- Nikolaj Aleksandrovič (1843-1865) $168 \mathrm{f}$

- Nikolaj Nikolaevič (1831-1891) 208, 278

- Nikolaj Nikolaevič (1856-1929) 153

- Nikolaus I. (1796-1855) 102, 153, 168, 208, 259, 384
- Nikolaus II. (1868-1918) 38, 56, 65, 69, $117,149,150,185,187,198,203 \mathrm{f}, 223,225$, 227, 231, 236, 239f, 259, 328, 383

- Peter der Große (1672-1725) 36, 233, 291

- Sergej Aleksandrovič (1857-1905) $152 \mathrm{f}$, 213

Zasulič, Vera Ivanovna (1849-1919) $13 \mathrm{ff}$, $21 \mathrm{f}, 24,33 \mathrm{ff}, 37,39 \mathrm{f}, 47 \mathrm{f}, 51 \mathrm{ff}, 62,68,74$, $8 \mathrm{off}, 119,125,129,133 \mathrm{ff}, 136 \mathrm{ff}, 143 \mathrm{ff}, 148$, $150,152,154,156,159,163 \mathrm{ff}, 174,177,18 \mathrm{o}$, $182,189,191,206,209 \mathrm{ff}, 217,219 \mathrm{ff}, 226$, $232 \mathrm{f}, 237 \mathrm{ff}, 243,254 \mathrm{f}, 259 \mathrm{ff}, 268 \mathrm{f}, 276 \mathrm{ff}$, $285 \mathrm{ff}, 297,320 \mathrm{ff}, 325 \mathrm{ff}, 337,346,370,375$, $383,396 \mathrm{f}, 401,403,405 \mathrm{ff}, 410$

Žemčužnikov, Aleksej Michajlovič (1821-1908) 266

Žukovskij, Vladimir Ivanovič (1838-1899) 72 
